\title{
A Review of Actinide-Sediment Reactions with an Annotated Bibliography
}

February 10, 1976

Prepared for the Energy Research and Development Administration under Contract E(45-1):1830 


\section{DISCLAIMER}

This report was prepared as an account of work sponsored by an agency of the United States Government. Neither the United States Government nor any agency Thereof, nor any of their employees, makes any warranty, express or implied, or assumes any legal liability or responsibility for the accuracy, completeness, or usefulness of any information, apparatus, product, or process disclosed, or represents that its use would not infringe privately owned rights. Reference herein to any specific commercial product, process, or service by trade name, trademark, manufacturer, or otherwise does not necessarily constitute or imply its endorsement, recommendation, or favoring by the United States Government or any agency thereof. The views and opinions of authors expressed herein do not necessarily state or reflect those of the United States Government or any agency thereof. 


\section{DISCLAIMER}

Portions of this document may be illegible in electronic image products. Images are produced from the best available original document. 
NOTICE

This report was prepared as an account of work sponsored by the United States Government. Neither the United States nor the Energy Research and Development Administration, nor any of their employees, nor any of their contractors, subcontractors, or their employees, makes any warranty, express or implied, or assumes any legal liability or responsibility for the accuracy, completeness or usefulness of any imformation, apparatus, product or process disclosed, or represents that its use would not infringe privately owned rights.

PACIFIC NORTHWEST LABORATORY

operated by

BATTELLE

for the

ENERGY RESEARCH AND DEVELOPMENT ADMINISTRATION

Under Contract $E(45-1)-1830$

Printed in the United States of America

Available from

National Technical Information Service

U.S. Department of Commerce

5285 Port Royal Road

Springfield, Virginia 22151

Price: Printed Copy \$14.00; Microfiche $\$ 2.25$

12.00 
BNWL -1983

UC-70

\title{
A. REVIEW OF ACTINIDE-SEDIMENT REACTIONS \\ WITH AN ANNOTATED BIBLIOGRAPHY
}

(Reproduction. of this document by permission of authors only.)

by

\author{
L. L. Ames \\ Dhanpat Rai \\ R. J. Serne \\ BATTELLE PACIFIC NORTHWEST LABORATORIES \\ WATER AND WASTE MANAGEMENT SECTION \\ WATER AND LAND RESOURCES DEPARTMENT \\ P. O.'BOX 999 \\ RICHLAND, WASHINGTON 99352
}

February 10, 1976

This report was prepated as an account of work sponsored by the United States Government. Neither tho Unitod Gteles nor tho Unitod Stotes Enargy Research and Development Administration, nor any or subcontractors, of their employees, makes any wartanty. express or imptied, of assumes any legal ant unly cespons of infor process disclosed or sepresents inas its use would of infringe privately owned rights. 
PREFACE. ....................... 1

LIST OF ABBREVIATIONS USED FOR SCIENTIFIC REPORTS. . . . . . . 3

CHEMISTRY AND GEOCHEMISTRY OF ACTINIDES. . . . . . . . . 5

GENERAL PROPERTIES AND NATURAL DISTRIBUTIONS. . . . . . 5

SOLID PHASE AND SOIL SOLUTION EQUILIBRIA . . . . . . . . . 5

Construction of the Diagrams ........... . . 9

Interpretation of Diagrams for Mineral

Stability and Formation. . . . . . . . . . 24

Interpretation of Diagrams for Solution

Species of Actinides . . . . . . . . . . . 25

General Remarks. . . . . . . . . . . . . 26

REFERENCES. . . . . . . . . . . . . . . 27

ANNOTATED BIBLIOGRAPHY. . . . . . . . . . . . . 29

MIGRATION AND ACCUMULATION OF ACTINIDES IN SEDIMENTS ...... 101

REVIEW OF MIGRATION AND ACCUMULATION OF

INDIVIDUAL ACTINIDES. . . . . . . . . . . . . 101

Actinium ................. . . 101

Thorium. . . . . . . . . . . . . . . . 101

Protactinium . . . . . . . . . . . 103

Uranium. . . . . ............... 104

Neptunium. . . . . . . . . . . . . . . 111

Plutonium. . . . . . . . . . . . . . . . 111

Americium. . . . . . . . . . . . . 127

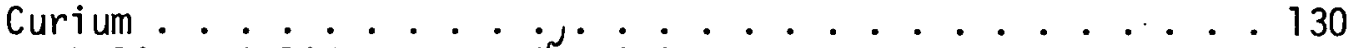

Berkelium, Californium, Eis teinium,

Fermi um, Mendelevium, Nobeli ium

and Lawrencium ................ . . 130

ANNOTATED BIBLIOGRAPHY. . . . . . . . . . . . . . . 131

CULTURAL ACTINIDE DISTRIBUTIONS IN SEDIMENTS . . . . . . . . 225

ANNOTATED BIBLIOGRAPHY. . . . . . . . . . . . . . . 227 
TABLE OF CONTENTS (CONT'D.)

Page

NATURAL ACTINIDE DISTRIBUTIONS IN SEDIMENTS. . . . . . . . 353

ANNOTATED BIBLIOGRAPHY. . . . . . . . . . . . . 355

SELECTED BIBLIOGRAPHIES AND ANNUAL REPORTS . . . . . . . . 507

ANNOTATED BIBLIOGRAPHY. . . . . . . . . . . . 509 


\section{LIST OF FIGURES}

Number

Page

THE RELATIVE STABILITY OF VARIOUS THORIUM

MINERALS IN SOILS BASED UPON THE INDICATED

ASSUMPTIONS (DCPD = DICALCIUM PHOSPHATE

DIHYDRATE; OCP = OCTACALCIUM PHOSPHATE;

$V \& G=$ VARISCITE AND GIBBSITE) $\ldots \ldots \ldots 10$

2 THE ACTIVITY OF. VARIOUS THORIUM IONS IN

SOIL SOLUTION IN EQUILIBRIUM WITH Th0 2 (s),

$\mathrm{pCl}^{-}=\mathrm{pNO}_{3}^{-}=\mathrm{pSO}_{4}^{2-}=3.0, \mathrm{pF}^{-}=3.5$,

AND $\mathrm{pH}_{2} \mathrm{PO}_{4}{ }^{-}=5.0$. . . . . . . . . . . . . . . . .

3 THE RELATIVE STABILITY OF VARIOUS URANIUM

MINERALS IN SOILS UNDER OXIDIZING ENVIRON-

MENT $\left(\mathrm{pO}_{2}(\mathrm{~g}) 0.68 \mathrm{~atm}.\right), \mathrm{pCO}_{2}$ (g) $3.52 \mathrm{~atm}$. ,

$\mathrm{pK}^{+}=\mathrm{pNa}^{+}=\mathrm{pNH}_{4}^{+}=3.0$, AND PHOSPHATE

LEVELS IN EQUILIBRIUM WITH VARISCITE AND

LEVELS IN EQUILIBRIUM WITH VARISCITE AND

4 THE RELATIVE STABILITY OF URANIUM PHOS-

PHATES AND URANIUM ARSENATES UNDER.

SIMILAR $\mathrm{PO}_{4}{ }^{3-}$ AND $\mathrm{AsO}_{4}{ }^{3-}$ LEVELS AND

$\mathrm{pK}^{+}=\mathrm{pNa}^{+}=\mathrm{pNH}_{4}^{+}=3.0 . . . . . . . . . . . .13$

5 THE RELATIVE STABILITY OF URANIUM

MINERALS UNDER EXTREMELY REDUCING

CONDITIONS $\left(\mathrm{pO}_{2}(\mathrm{~g}) 80 \mathrm{~atm}.\right), \mathrm{pCO}_{3}(\mathrm{~g})$,
$3.52, \mathrm{pF}^{-} 3.5, \mathrm{pR}^{+}=\mathrm{pNa}^{+}=\mathrm{pSO}_{4} 2 \mathrm{~g}$

3.0, AND PHOSPHATE LEVELS IN EQUILIBRIUM

WITH VARISCITE AND GIBBSITE. . . . . . . . . . . . . 14

6 THE ACTIVITY OF VARIOUS URANIUM IONS IN

EQUILIBRIUM WITII $\mathrm{Na}_{2} \mathrm{UO}_{4}, \mathrm{pO}_{2}(\mathrm{~g}) 0.68 \mathrm{~atm}$.

$\mathrm{pCO}_{2}$ (q) $3.52 \mathrm{~atm}, \mathrm{pCl}^{-}=\mathrm{pSO}_{4}^{2-}=3.0$,

$\mathrm{pF}^{-}=3.5$, AND $\mathrm{pH}_{2} \mathrm{PO}_{4}^{-}=5.0 \ldots \ldots \ldots . . . . . .$.

7 THE RELATIVE STABILITY OF VARIOUS NEPTUNIUM

MINERALS IN SOILS UNDER OXIDIZING ENVIRON-

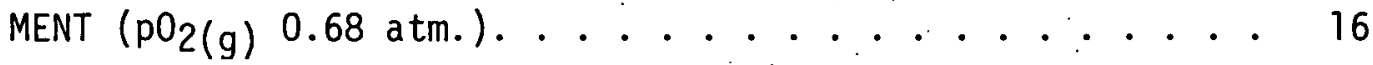

8 THE RELATIVE STABILITY OF NEPTUNIUM MINERALS

UNDER EXTREMELY REDUCING ENVIRONMENT

$\left(\mathrm{pO}_{2}(\mathrm{~g}) 80 \mathrm{~atm}.\right) \ldots \ldots \ldots \ldots$ 
Number

$\underline{\text { Page }}$

9

THE ACTIVITY OF VARIOUS NEPTUNIUM IONS

IN SOIL SOLUTION IN EQUILIBRIUM WITH

$\mathrm{NpO}_{2}(\mathrm{OH})_{2}(\mathrm{~s})$, UNDER OXIDIZING ENVIRON-

MENT $\left(\mathrm{pO}_{2}(\mathrm{~g}) 0.68\right.$ atm. $), \mathrm{pCO}_{2}(\mathrm{~g}) 3.52$,

$\mathrm{pCl}^{-}=\mathrm{pNO}_{3}=\mathrm{pSO}_{4}^{2-}=3.0 \mathrm{AND}^{2-} \mathrm{pF}^{-}=3.5 \ldots . . .$.

10 THE RELATIVE STABILITY OF VARIOUS PLUTONIUM

MINERALS UNDER OXIDIZING ENVIRONMENT $\left(\mathrm{pO}_{2}(\mathrm{~g})\right.$

$0.68 \mathrm{~atm}.), \mathrm{pCO}_{2}(\mathrm{~g}) 3.52 \mathrm{~atm}$., IN EQUILIBRIUM

WITH $\mathrm{CaCO}_{3}, \mathrm{pCa}^{2+}=3.0, \mathrm{pF}^{-}=3.5$, AND

PHOSPHATE LEVELS IN EQUILIBRIUM WITH V\&G

(VARISCITE AND GIBBSITE), DCPD (DICALCIUM

PHOSPHATE UIHYURATE), AND OCP (OCTACALCIUM

PHOSPHATE ). . . . . . . . . . . . . . . . .

11 THE RELATIVE STABILITY OF VARIOUS PLUTONIUM

MINERALS IN SOILS UNDER EXTREMELY REDUCING

CONDITIONS $\left(\mathrm{pO}_{2}(\mathrm{~g}) 80 \mathrm{~atm}.\right), \mathrm{pCO}_{2}(\mathrm{~g}) 3.52$

$\mathrm{atm}$., IN EQUILIBRTUM WITH $\left.\mathrm{CaCO}_{3}, \mathrm{PC}\right\}-=3.0$,

$\mathrm{pF}^{-}=3.5$, AND PHOSPHATE LEVELS IN EQUILIBRIUM

WITH V\&G (VARISCITE AND GIBBSITE), DCPD (DI-

CALCIUM PHOSPHATE DIHYDRATE), AND OCP (OCTACAL-

CIUM PHOSPHATE) . . . . . . . . . . . . . . . .

12 THE ACTIVITY OF VARIOUS PLUTONIUM IONS IN

SOIL SOLUTION IN EQUILIBRIUM WITH PU0 $2(s)$,

UNDER OXIDIZING ENVIRONMENT ( $\mathrm{pO} 2(\mathrm{~g}){ }^{0}, 68$

2.5, AND $\mathrm{pF}(g)=3.5$. . . . . . . ...........

13 THE RELATIVE STABILITY (LINES ARE BASED

UPON ESTIMATED THERMODYNAMIC QUANTITIES)

OF VARIOUS AMERICIUM MINERALS IN SOILS

UNDER OXIDIZING ENVIRONMENT $\left(\mathrm{pO}_{2}(\mathrm{~g}) 0.68\right.$

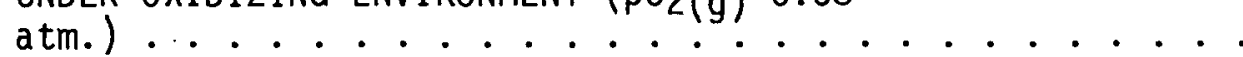

14. THE ACTIVITY OF VARIOUS AMERICIUM IONS IN

SOIL SOLUTION IN EQUILIBRIUM WITH A $1102 \mathrm{OH}_{2}(\mathrm{~s})$, UNDER OXIDIZING ENVIRONMENT $\left(\mathrm{pO}_{2} 0.68\right), \mathrm{p} \overline{\mathrm{C}} \mathrm{T}=$

$\mathrm{pNO}_{3}{ }^{-}=\mathrm{pSO}_{4}{ }^{-}=3.0, \mathrm{AND} \mathrm{pH}_{2} \mathrm{PO}_{4}^{-}=5.0 . . . . \therefore .$.

15 EFFECT OF PH AND PLUTONIUM OXIDATION STATE

ON THE ADSORPTION OF PLUTONIUM BY SOIL. . . . . . . . . 120

16 ADSORPTION OF PLUTONIUM BY SOIL AS A FUNCTION

$\mathrm{OF}$ pH. . . . . . . . . . . . 122 


\section{LIST OF TABLES}

Number

$\underline{\text { Page }}$

SOME PROPERTIES OF ACTINIDE ELEMENTS. . . . . . . . . . 6

2 AVERAGE CONTENTS OF THORIUM AND URANIUM

IN COMMON SOIL MINERALS FROM NORTH AMERICA* . . . . . . . . 7

3 OXIDATION STATES AND IONIC RADII OF

ACTINIDES*. . . . . . . . . . . . . . . . . . 8

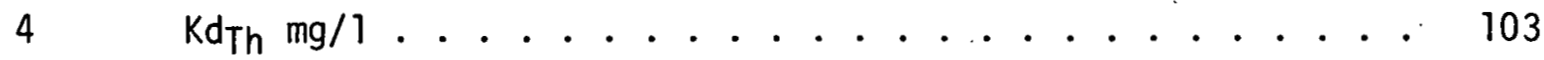

5 Kd VALUES FOR URANIUM . . . . . . . . . . . . . . 110

$6 \quad$ KdNp AS A FUNCTION OF SOIL AND SOLUTION . . . . . . . . . . 111

7 PU ADSORPTION VS PARTICLE SIZE. . . . . . . . . . . . 121

8 KdPu AS FUNCTION OF VALENCE STATE . . . . . . . . . . . . 125

9 PERCENT PU REMOVED BY EXTRACTANTS . . . . . . . . . . 126

$10 \quad K d_{A m}$ AND Kdpu VS ORGANIC SOLUTION . . . . . . . . . . . 129 
PREFACE

The purpose of this publication is to summarize the information on actinidesediment reactions and help the scientists working in this field to determine the present status and to direct the research at needed areas. This publication summarizes and gives an annotated bibliography of actinides in sediments. The bibliography is divided into sections on chemistry and geochemistry, migration and accumulation, cultural distributions, natural distributions and bibliographies and annual reviews. The material in the first two sections was extensively reviewed and summarized. The abstracts are listed in alphabetical order within sections to facilitate use.

The information for this publication was obtained from various journals, books, past bibliographies, scientific reports, and abstracting services such as Chemical Abstracts and Nuclear Science Abstracts. An effort was made to include all relevant information regarding the actinide-sediment reactions published from 1944 to December 1975. Standard abbreviations were used for technical journals. Abbreviations used for scientific reports of various governmental laboratories are listed on a following page. The abbreviations used at the end of abstracts, in annotated bibliographies, refer to abstracts prepared by the author (auth) and the publishers of Chemical Abstracts (CA) and Nuclear Science Abstracts (NSA). Other abstracts were prepared by us.

Abstracts reprinted from CHEMICAL ABSTRACTS are copyrighted by the American Chemical Society and are reproduced with permission. No further copying is permitted. 
THIS PAGE

\section{WAS INTENTIONALLY LEFT BLANK}




\section{LIST OF ABBREVIATIONS USED FOR SCIENTIFIC REPORTS}

ANL - Argonne National Laboratory, Lemont, Illinois, USA.

ARH - Atlantic Richfiel:d Hanford Company, Richland, Washington, USA.

BARC - Bhabha Atomic Research Centre, Bombay, India.

BNWL - Battelle-Northwest Laboratories, Richland, Washington, USA.

CEA - Commissariat a' 1'Energie Atomique, Paris, France.

C00 - Chicago Operations Office, Atomic Energy Commission, Chicago, Illinois, USA.

CRT - National Research Council of Canada. Atomic Energy Project, Chalk River, Ontario.

CU - Columbia University, New York, New York, USA.

DP - duPont deNemours and Company, Wilmington, Delaware, USA.

DPST - Savannah River Laboratory, Aiken, South Carolina, USA.

EUR - European Atomic Energy Community.

GJ0 - Grand Junction Office, Atomic Energy Commission, Grand Jucntion, Colorado, USA.

HASL - United States Atomic Energy Commission, Health and Safety Laboratory, New York, New York, USA.

HW - General Electric Company, Hanford Atomic Products Operations, Richland, Washington, USA.

IAEA - International Atomic Energy Agency, Vienna, Austria.

IDO - Idaho Operations Office, Atomic Energy Commission, Idaho Falls, Idaho, USA.

LADC - Los Alamos Scientific Laboratory, Los Alamos, New Mexico, USA.

LA - Los Alamos Scientific Laboratory, Los Alamos, New Mexico, USA.

LASL - - Chicago University Laboratories for Applied Sciences, Chicago, Illinois, USA.

MLM - Mound Laboratory, Miamisburg, Ohio, USA.

NAS-NS - National Academy of Sciences-National Research Council Committee on Nuclear Science. 
NIM - National Institute for Metallurgy, Johannesburg, South Africa.

NP - Division of Technical Information Extension, Atomic Energy Commission.

NVO - Nevada Operations Office, Atomic Energy Commission, Las Vegas, Nevada, USA.

NYO - New York Operations Office, Atomic Energy Commission, New York, New York, USA.

ORNL - Oak Ridge National Laboratory, Oak Ridge, Tennessee, USA.

ORO - Oak Ridge Operations Office, Alumic Eneryy Cummission, Oak Ridye, Tennessee, USA.

RFP - Rocky Flats Division, Dow Chemical, Denver, Colorado, USA.

RLO - Richland Operations Office, Atomic Energy Commission, Richland, Washington, USA.

RME - Division of Raw Materials, Atomic Energy Commission.

RMO - Division of Raw Materials, Atomic Energy Commission.

TEI - Geological Survey, Washington, D. C., USA.

TEM - Geological Survey, Washington, D. C., USA.

TID - Office of Technical Information Extension, United States Atomic Energy Commission, Oak Ridge, Tennessee, USA.

UCB - University of California, Berkley, California, USA.

UCLA - University of California, Los Angeles, California, USA.

UCRL - University of California/Lawrence Livermore Laboratory, Livermore, California, USA.

IISAES, - IInited St.at.es Atnmir, Fnergy Commission.

USERDA - United States Energy Research and Development. Administration.

USNRDL - Naval Radiological Defense Laboratory, San Francisco, California, USA.

WASH - Atomic Energy Commission, Washington, D. C., USA. 


\section{CHEMISTRY AND GEOCHEMISTRY OF ACTINIDES}

Several publications (listed under annotated bibliography) dealing with the chemistry of actinides are available. The intent here is not to discuss in detail the chemistry of individual actinide elements, for that is not the scope of this publication. Rather, it is to give in an understandable and useful manner, a brief account of those chemical aspects that govern their behavior in terrestrial and aquatic environments.

\section{GENERAL PROPERTIES AND NATURAL DISTRIBUTIONS}

The information regarding the elemental symbols, atomic numbers, atomic weights, and naturally occurring radioactive isotopes is given in Table 1. Natural occurrence of radioactive isotopes of $\mathrm{Ac}, \mathrm{Th}, \mathrm{Pa}$ and $\mathrm{U}$ are well documented. The natural distribution of Th and $U$ in soil minerals is reported in Table 2. Thorium is fairly abundant $\left(10^{-3.1}\right.$ weight percent) in the earth's crust and its concentration in high silica rocks is much higher than in low silica rocks (Ryabchikov and Gal'braikh, 1960). Protactinium is a radioactive element with extremely low natural abundance (10-10 weight percent in earth crust) (Pal'shin, Myasoedov, and Davydov, 1970). Pa231 is the most abundant of the two naturally occurring isotopes, $\mathrm{Pa}_{231}$ and $\mathrm{Pa}_{2}^{234}$. $\mathrm{Pa}_{2} 31$ is constantly produced by decaying $\mathrm{U}^{235}$ and thus the main source of this element is the wastes of uranium ore processing. Naturally occurring uranium is a mixture of three isotopes $U^{238}, U^{235}$, and U234 in a proportion of $99.28,0.71$ and 0.006 percent, respectively (Palei, 1962). Rocks high in silica contain the bulk of the uranium. Very small quantities of $\mathrm{Np}^{237}\left(\mathrm{~Np}^{237} / \mathrm{U}^{238}=10^{-12}\right.$ and $\left.\mathrm{U}^{233} / \mathrm{U}^{238}=10^{-13}\right)$ were found occurring naturally in the liquid wastes of uranium ore processing (Keller, 1971). Very small amounts of natural $\mathrm{Pu} 239\left(\mathrm{Pu} / \mathrm{U}=10^{-11}\right)$ are formed in uranium mineral pitchblend (Cleveland, 1970). However, the present distribution of transuranics (elements of atomic numbers $>92$ ) in the environment is almost entirely due to preparation and dissemination by man's activities such as nuclear bomb explosions and nuclear powered machinery.

The oxidation states and the ionic radii for actinides (Keller, 1971) are given in Table 3. In this table the most stable oxidation state is underlined. It should be pointed out that "most stable oxidation state" has relevance only when the weathering environment is specified. The weathering environment for the most stable oxidation states is not specified by Keller (1971) but is taken to represent the environment commonly found in terrestrial/aqueous systems. The values given in parenthesis have not yet been confirmed. According to Fried (1955) the oxidation states of the elements that occur in solids only are Th(II, III), $\mathrm{Pa}$ (II), U(II), Np(II), $\mathrm{Pu}$ (II), Am(II, IV), and $\mathrm{Cm}$ (IV).

SOLID PHASE AND SOIL SOLUTION EQUILIBRIA

The standard free energy of formation $\left(\Delta G_{f}^{\circ}\right)$ of a mineral depends upon its chemical composition and the nature of its chemical bonds. Thus, $\Delta G_{f}^{\circ}$ values are useful for comparing the stabilities of minerals. Rai and Lindsay (1975) have demonstrated, using $\Delta G_{f}^{\circ}$ values for common soil minerals, the usefulness 
TABLE 1

SOME PROPERTIES OF ACTINIDE ELEMENTS

\begin{tabular}{|c|c|c|c|c|}
\hline Symbol & Name & $\begin{array}{l}\text { Atomic } \\
\text { Number }\end{array}$ & $\begin{array}{l}\text { Atomic or } \\
\text { Weighta }\end{array}$ & $\begin{array}{l}\text { Naturally Occurring } \\
\text { Radioactive Isotope }\end{array}$ \\
\hline$A C$ & Actinium & 89 & (227) & 227 \\
\hline Th & Thorium & 90 & 232.05 & $\begin{array}{l}227,228,230,231, \\
232,234 b \mathrm{~b}\end{array}$ \\
\hline $\mathrm{Pa}$ & Protactinium & 91 & (231) & $231,234^{c}$ \\
\hline U & Uranium & 92 & 238.03 & $234,235,238^{d}$ \\
\hline $\mathrm{Np}$ & Neptunium & 93 & (237) & $237 \mathrm{e}$ \\
\hline $\mathrm{Pu}$ & Plutonium & 94 & (242) & $239 e, f$ \\
\hline Am & Americium & 95 & (233) & -- \\
\hline $\mathrm{Cm}$ & Curium & 96 & (247) & -- \\
\hline Bk & Berkelium & 97 & (247) & -- \\
\hline C.f & Californium & 98 & (249) & -- \\
\hline Es & Einsteinium & 99 & (254) & -- \\
\hline $\mathrm{Fm}$ & Fermium & 100 & (253) & $-=$ \\
\hline Md & Mendelevium & 101 & (256) & -- \\
\hline No & Nobelium & 102 & (254) & -- \\
\hline Lr & Lawrencium & 103 & (257) & -- \\
\hline $\begin{array}{l}\text { aAtom } \\
\text { best } \\
\text { bRyab } \\
\text { cPal' } \\
\text { dPale } \\
\text { élil } \\
\text { fClev }\end{array}$ & $\begin{array}{l}\text { weights enclo } \\
\text { nown isotopes } \\
\text { ikov, and Gol } \\
\text { in, Myasoedov, } \\
(1962) \\
(1971) \\
\text { and (1970) }\end{array}$ & $\begin{array}{l}\text { in pa } \\
\text { kh ( } 1 \\
\text { Davy }\end{array}$ & $\begin{array}{l}\text { hesis are } \\
(1970)\end{array}$ & most stable or \\
\hline
\end{tabular}


TABLE 2

AVERAGE CONTENTS OF THORIUM AND URANIUM IN COMMON SOIL MINERALS FROM NORTH AMERICA*

\begin{tabular}{|c|c|c|}
\hline Mineral & Thorium in ppm & Uranium in ppm \\
\hline \multicolumn{3}{|l|}{ Major Minerals: } \\
\hline Quartz & $0.5-10$ & $1.7(0.1-10)$ \\
\hline $\begin{array}{l}\text { Feldspar (including } \\
\text { potassium feldspar } \\
\text { and plagioclase) }\end{array}$ & $0.5-10$ & $2.7(0.1-10)$ \\
\hline Biotite & $0.5-50$ & $8.1(1-60)$ \\
\hline Muscovite & -- & $2-8$ \\
\hline Hornblende & $5-50$ & $7.9(0.2-60)$ \\
\hline Pyroxene & -- & $3.6(0.1-50)$ \\
\hline 0livine (from dunite) & 0.02 & $\sim 0.05$ \\
\hline \multicolumn{3}{|l|}{ Accessory Minerals: } \\
\hline Apatite & $70(50-250)$ & $65(10-100)$ \\
\hline Epidote & $200(50-500)$ & $43(20-200)$ \\
\hline Garnet & -- & $6-30$ \\
\hline $\begin{array}{l}\text { Magnetite (and other } \\
\text { opaque minerals) }\end{array}$ & $0.3-20$ & $1-30$ \\
\hline Sphene & $510(100-1,000)$ & $280(10-700)$ \\
\hline Zircon & $560(100-10,000)$ & $1,330(100-6,000)$ \\
\hline $\begin{array}{l}\text { Thorianite and } \\
\text { Uraninite }\end{array}$ & $\begin{array}{l}\text { Varies from } \mathrm{ThO}_{2} \text { to } \\
\text { to } \mathrm{UO}_{2}\end{array}$ & \\
\hline $\begin{array}{l}\text { Thorite and } \\
\text { Uranothorite }\end{array}$ & $\begin{array}{l}\text { Varies from } \mathrm{ThS}_{\mathrm{j}} \mathrm{O}_{4} \\
\text { and } \mathrm{US}_{j} \mathrm{O}_{4}(?) \text { : Solid } \\
\text { solution may not be } \\
\text { complete. }\end{array}$ & \\
\hline
\end{tabular}

*Data from a review article by Rogers and Adams (1969). 
TABLE 3

OXIDATION STATES AND IONIC RADII OF ACTINIDES*

\begin{tabular}{|c|c|c|c|c|c|}
\hline \multirow[b]{2}{*}{ Element } & \multirow[b]{2}{*}{ Oxidation State } & \multicolumn{4}{|c|}{ Ionic Radii (Coordination No. 6 ) in $A^{\circ}$} \\
\hline & & $M^{3+}$ & $M^{4+}$ & $\mathrm{M}^{5+}$ & $M^{6+}$ \\
\hline Ac & $(2), \underline{3}$ & 1.11 & & & \\
\hline Th & $(2), 3, \underline{4}$ & 1.08 & 0.99 & & \\
\hline $\mathrm{Pa}$ & $(3), 4, \underline{5}$ & 1.05 & 0.96 & 0.90 & \\
\hline U & $2,3,4,5, \underline{6}$ & 1.03 & 0.93 & 0.89 & 0.83 \\
\hline $\mathrm{Np}$ & $3,4, \underline{5}, 6,7$ & 1.01 & 0.92 & 0.88 & 0.82 \\
\hline $\mathrm{Pu}$ & $3, \underline{4}, 5,6,7$ & 1.00 & 0.90 & 0.87 & 0.81 \\
\hline Am & $(2), 3,4,5,6$ & 0.99 & 0.80 & 0.86 & 0.80 \\
\hline $\mathrm{Cm}$ & $(2), \underline{3}, 4$ & 0.986 & 0.88 & & \\
\hline Bk & $\underline{3}, 4$ & 0.981 & 0.87 & & \\
\hline $\mathrm{Cr}$ & $2, \underline{3}, 4,(5)$ & 0.976 & & & \\
\hline Es & $2, \underline{3}$ & 0.97 & & & \\
\hline $\mathrm{Fm}$ & 2,3 & & & . & \\
\hline Md & $2, \underline{3}$ & & & & \\
\hline No & $\underline{2}, 3$ & & & & \\
\hline Lr & 3 & & & & \\
\hline
\end{tabular}


and the method of constructing diagrams for predicting the formation, stability, and weathering of soil minerals. A similar approach was taken to depict variation in solution concentration with the changes in $\mathrm{pH}$ and the weathering, and the formation of minerals of actinides (Th, U, Np, Pu, and $\mathrm{Am})$. The details of the 1) sources of thermodynamic data; 2) chemical reactions and equilibrium constants; 3 ) method of construction of the diagrams; 4) interpretation or discussion of the diagrams; 5) limitations of the diagrams and the deficiency in the thermodynamic data; and 6) future research needs are given by Rai, et. al. (1975, unpublished data, BattelleNorthwest, P. 0. Box 999, Richland, Washington).

In order to summarize the thermodynamic data for the actinides, the diagrams from Rai, et. al., (1975) are reproduced here in Figures 1 through 14 . Following is a list of the kinds of interpretations that can be made from these diagrams:

- kinds of solid compounds of the element;

- relative stabilities of the minerals;

- predictions regarding the minerals that are most apt to form in soils under various weathering environments;

- nature and activity of the soluble species (free ions, charged with neutral ion pairs) in the soil solution in equilibrium with the known quantities of the element or the most stable solid phase;

- the relative ability of various anions to form solution complexes with the actinide ions;

- disproportionation reactions and the nature of the dominant solution species under various weathering regimes; and

- predictions regarding the degree of adsorption of actinide solution species by the soil exchange complex.

A brief discussion regarding the construction and interpretation of these diagrams is given below.

\section{Construction of the Diagrams}

The accurate values of the equilibrium constants for the reactions or the standard Gibbs free energies of formation of all the reactants and products are required to construct the diagrams. The best available values of equilibrium constants for various reactions were selected from Burney and Harbour (1974), Cleveland (1970), Garrels and Christ (1965), Keller (1971), Latimer (1952), Palei (1962), Robie and Waldbaum (1968), and Sillen and Martell (1964). In some cases the best available values are only approximate. The solubility lines for compounds or solution species (Figures 1 through 14) denoted by an asterisk (*) are based upon the concentration equilibrium constants under varying ionic strengths, whereas, all the others are based upon thermodynamic equilibrium constants at about $25^{\circ} \mathrm{C}$ and $1 \mathrm{~atm}$ pressure. In all the figures 


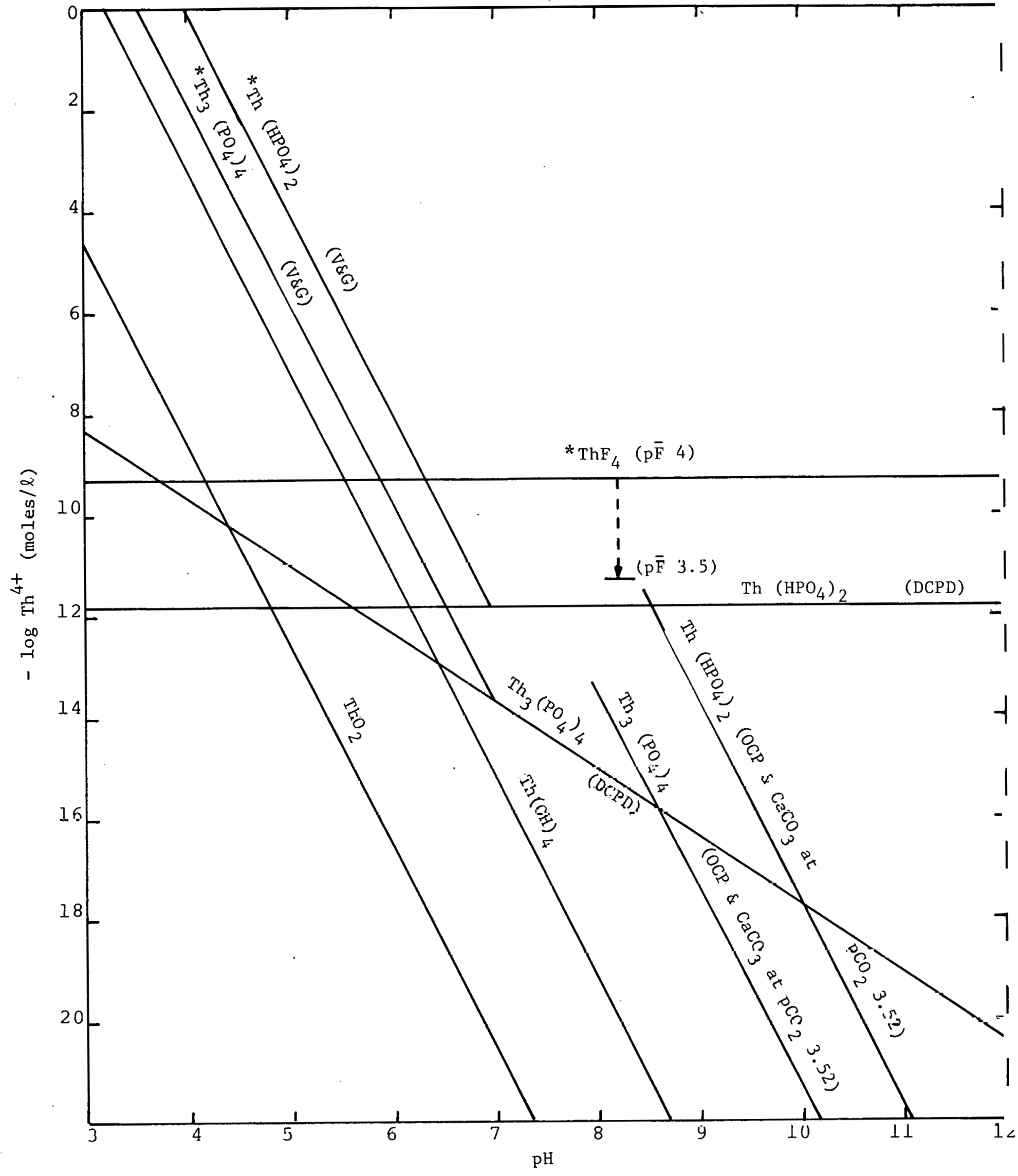

FIGURE 1. THE RELATIVE STABILITY OF VARIOUS THORIUM MINERALS IN SOILS BASED UPON THE INDICATED ASSUMPTIONS (DCPD $=$ DICALCIUM PHOSPHATE DIHYDRATE; OCP = OCTACALCIUM PHOSPHATE; - $\mathrm{V} \& G=$ VARISCITE AND GIBBSITE). 


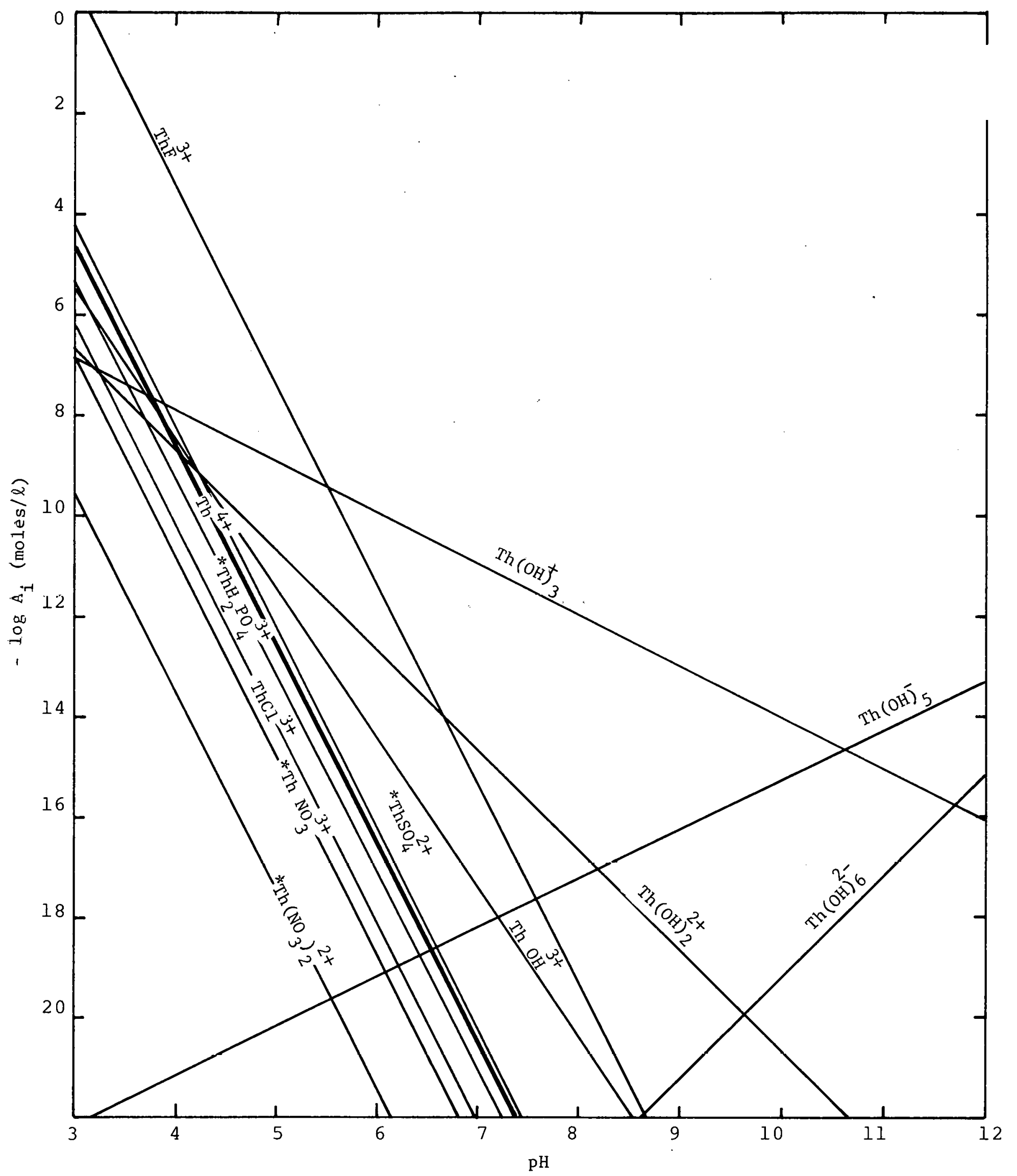

FIGURE 2. THE ACTIVITY OF VARIOUS THORIUM IOINS IN SOIL SOLUTIO IN EQUILIBRIUM WITH $\mathrm{ThO}_{2}(\mathrm{~s}), \mathrm{pC} \overline{\mathrm{l}}=\mathrm{pNO}_{3}=\mathrm{pSO}_{4}^{2-}$ $=3.0, \mathrm{PF}=3.5$, and $\mathrm{PH}_{2} \mathrm{P} \bar{O}_{4}^{\prime}=5.0$. 


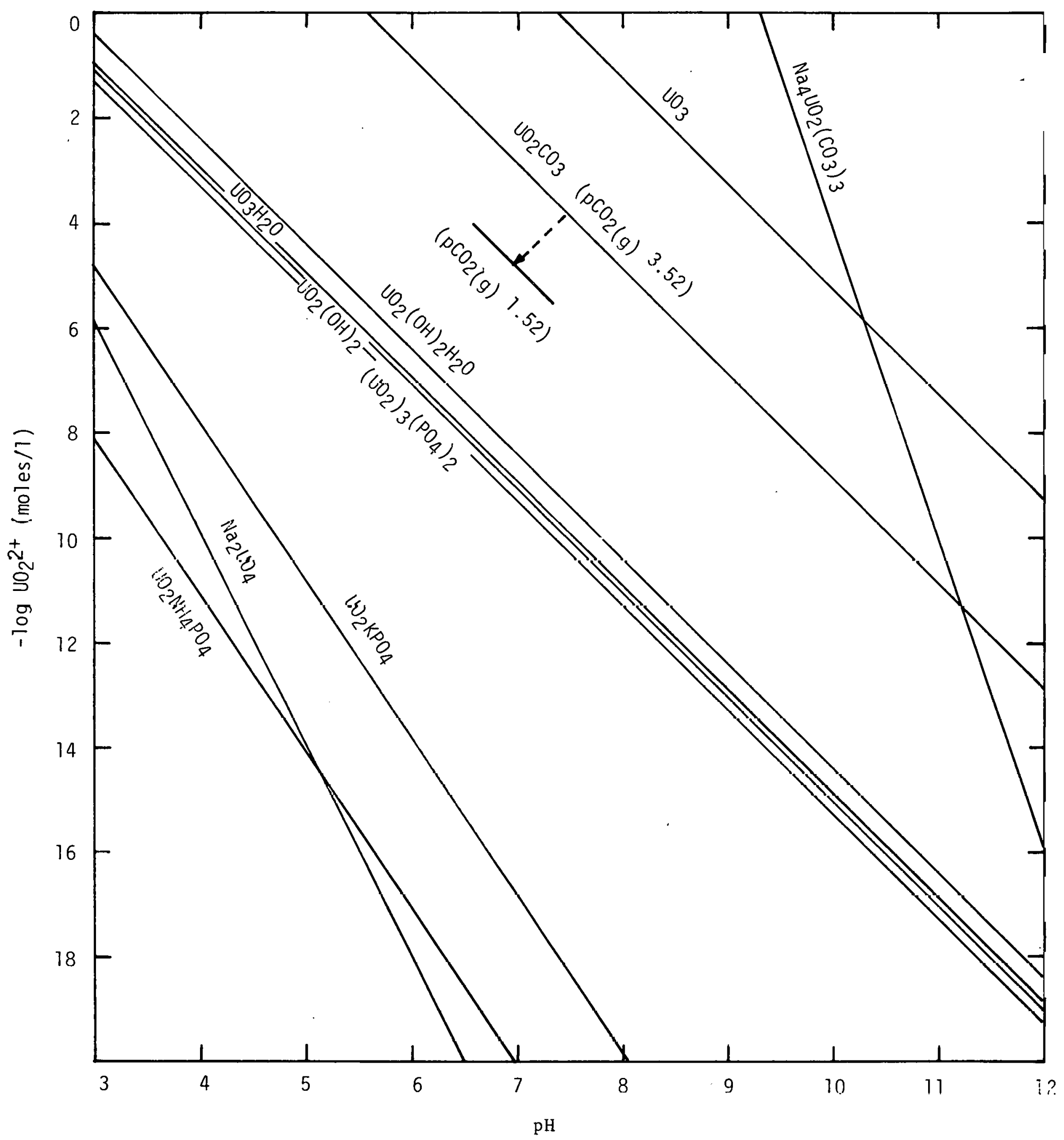

FIGURE 3. THE RELATIVE STABILITY OF VARIOUS URANIUM MINERALS IN SOILS UNDER OXIDIZING ENVIRONMENT $\left(\mathrm{pO}_{2}(\mathrm{~g}) 0.68 \mathrm{~atm}.\right)$, $\mathrm{pCO}_{2}$ (g) $3.52 \mathrm{~atm} ., \mathrm{pk}^{2}=\mathrm{pNa}^{+}=\mathrm{pNH}_{4}^{+}=3.0, \mathrm{AND}^{+}$PHOSPHA'l'E LEVELS IN EQUILIBRTUM WITH VARISCITE AND GIBBSITE. 


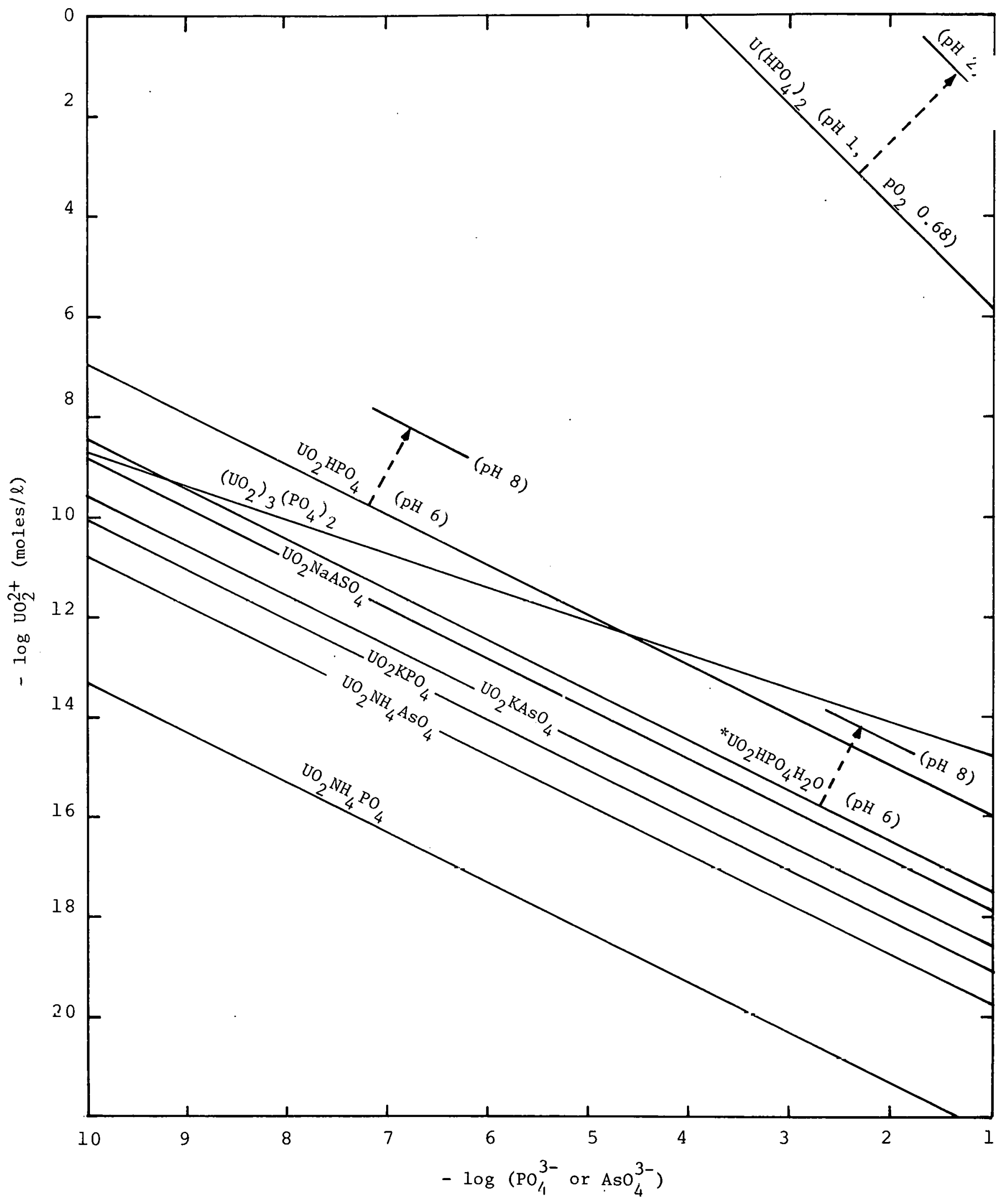

FIGURE 4. THE RELATIVE STABILITY OF URANIUM PHOSPHATES AND URANIUM ARSENATES UNDER SIMILAR PO $4^{3-}$ AND AsO $4_{4}^{3-}$ LEVELS AND $\mathrm{pK}^{+}=\mathrm{pNa}^{+}=\mathrm{pNH}_{4}^{+}=3.0$. 


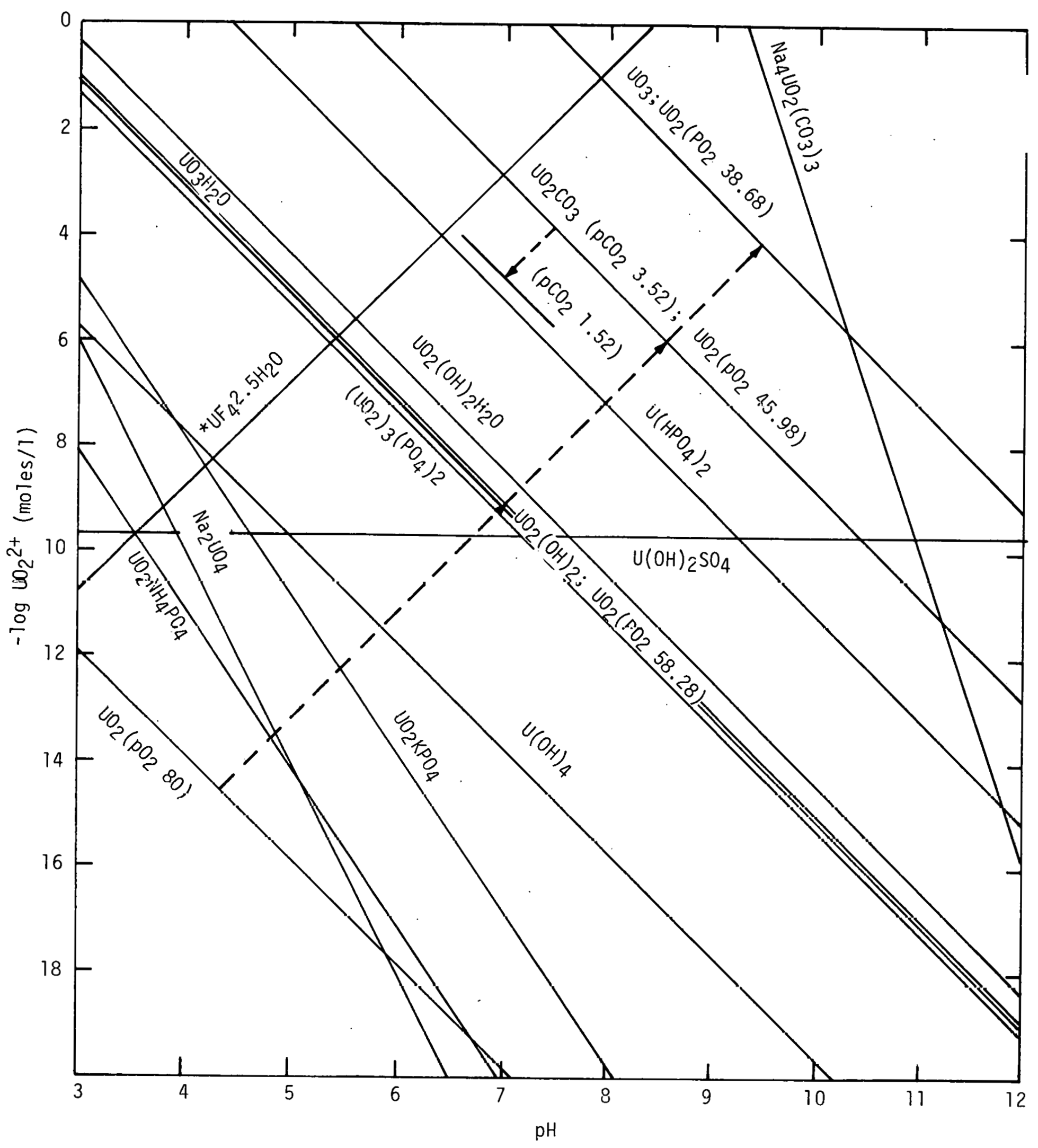

FIGURE 5. THE RELATIVE S'IABILITY OF URANIUM MINERALS UNDER EXTREMELY REDUCING CONDITIONS ( $\mathrm{pO}_{2}$ (g) 80 atm.),
$\mathrm{pCO}_{2}$ (g) 3.52, $\mathrm{p} \overline{\mathrm{F}} 3.5, \mathrm{pK}^{+}=\mathrm{pNa}^{+}=\mathrm{pSO}_{4}^{-}=3.0$, AND PHOSPHATE LEVELS IN EQUILIBRIUM VVITH VARISCI'IE AND GIBBSITE. 


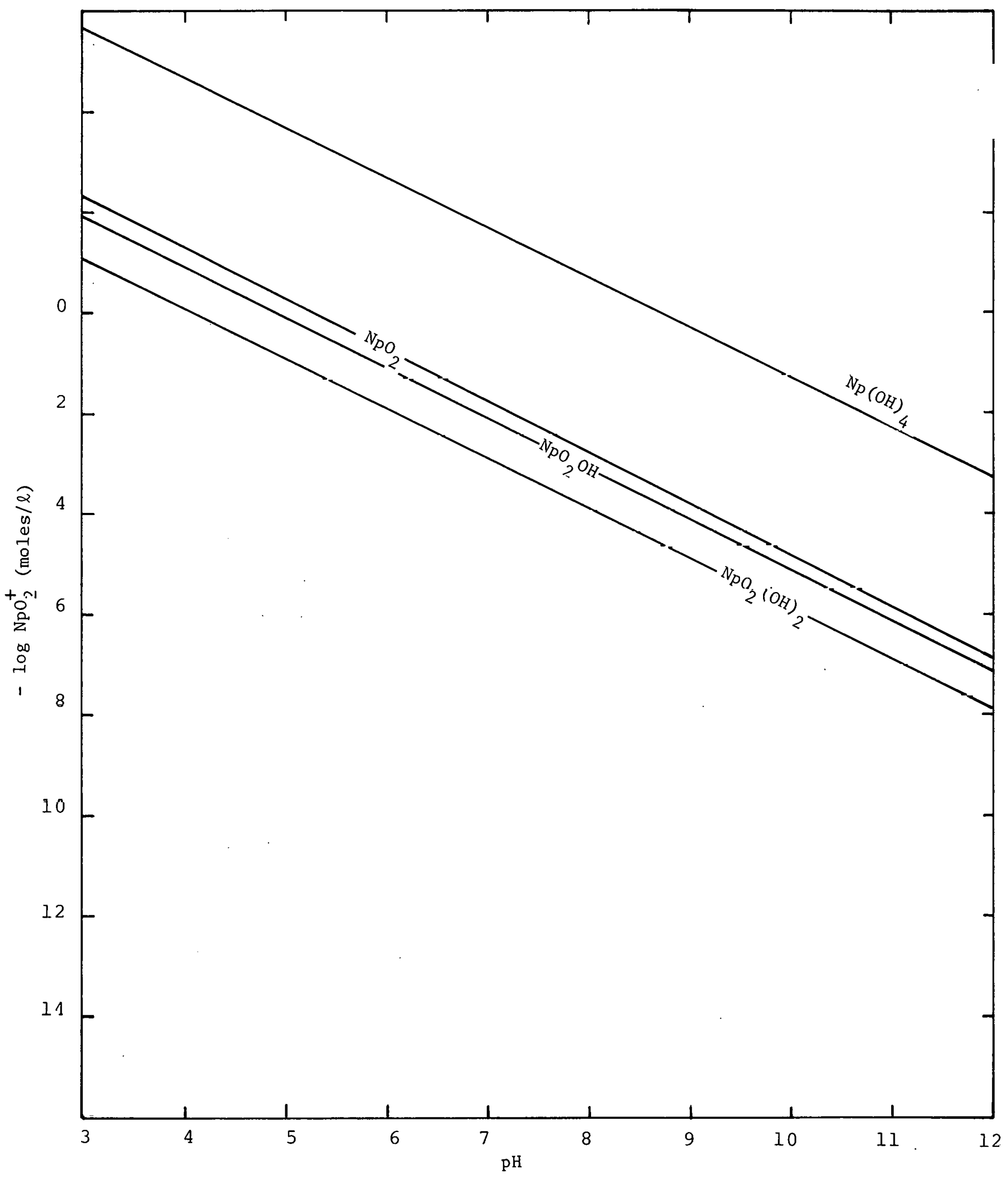

FIGURE 7. THE RELATIVE STABILITY OF VARIOUS NEPTUNIUM MINERALS IN SOILS UNDER OXIDIZING ENVIRONMENT $\left(\mathrm{pO}_{2}(\mathrm{~g}) \quad 0.68 \mathrm{~atm}.\right)$ 


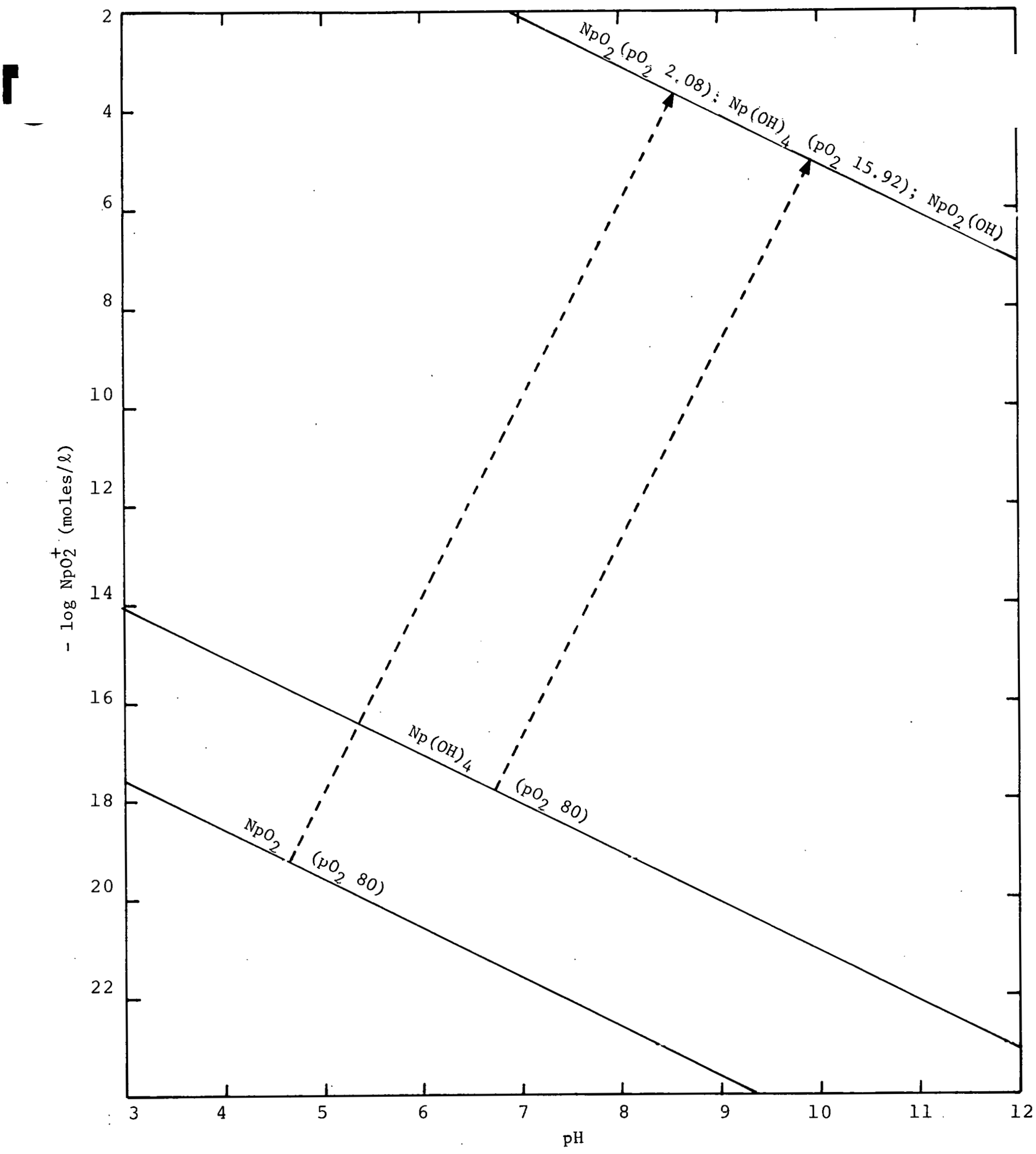

1

FIGURE 8. THE RELATIVE STABILITY OF NEPTUNIUM MINERALS UNDER EXTREMELY REDUCING ENVIRONMENT $\left(\mathrm{pO}_{2}(\mathrm{~g}) 80\right.$ atm.). 


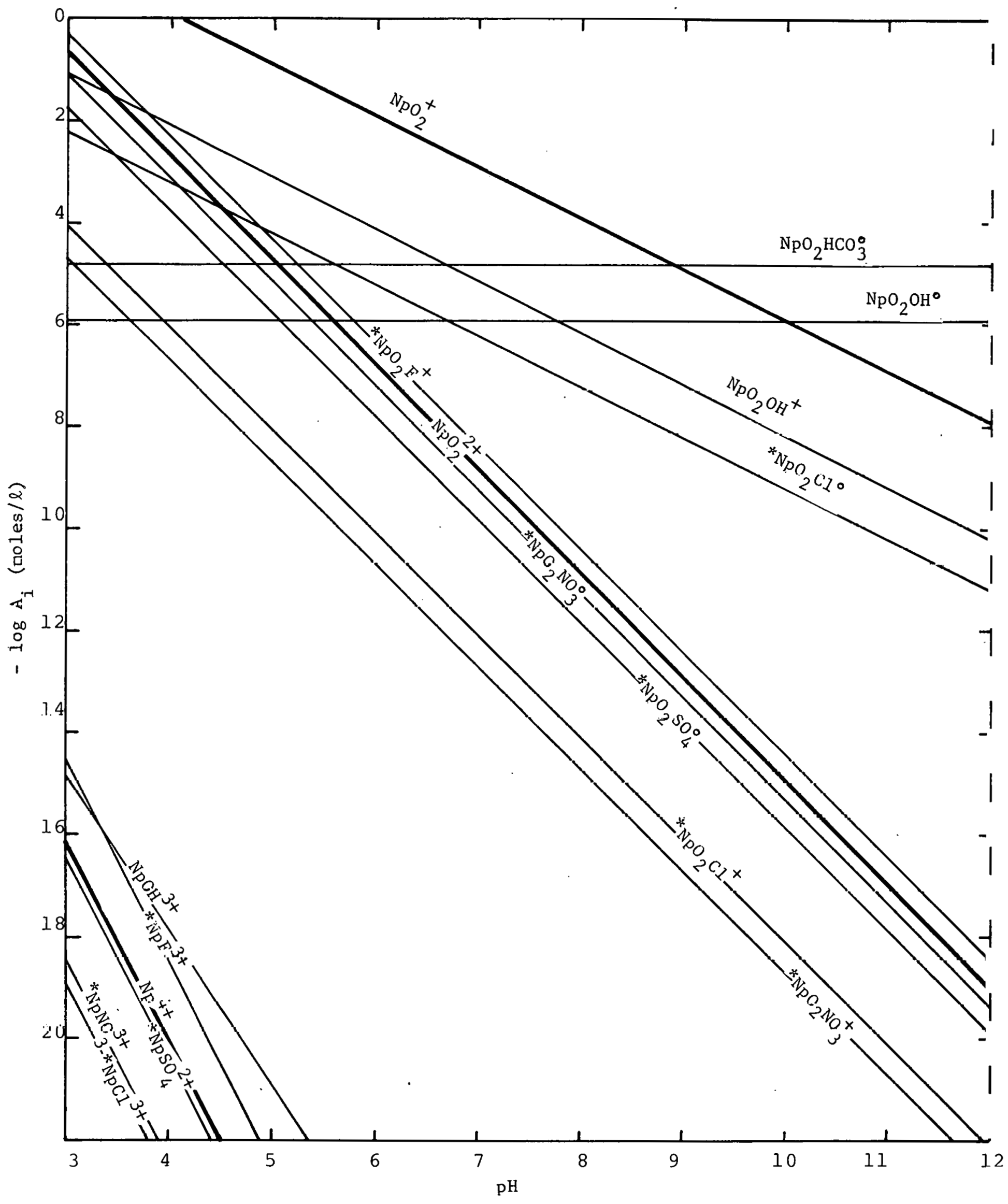

FIGURE 9. THE ACTIVITY OF VARIOUS NEPTUNIUM IONS IN SOLL SOLUTJ" IN EQUILIBRIUM WITH $\mathrm{NPO}_{2}(\mathrm{OH})_{2}(\mathrm{~s})$, UNDER OXIDIZING FIRONMENT $\left(\mathrm{pO}_{2}(\mathrm{~g}) \mathrm{0} .68\right.$ atm. $), \mathrm{pCO}_{2}(\mathrm{~g}) 3.52, \mathrm{pC} \overline{\mathrm{I}}=$
$\mathrm{pSO}_{4}^{2-}=3.0, \mathrm{ANB} \mathrm{p}=3.5$. 


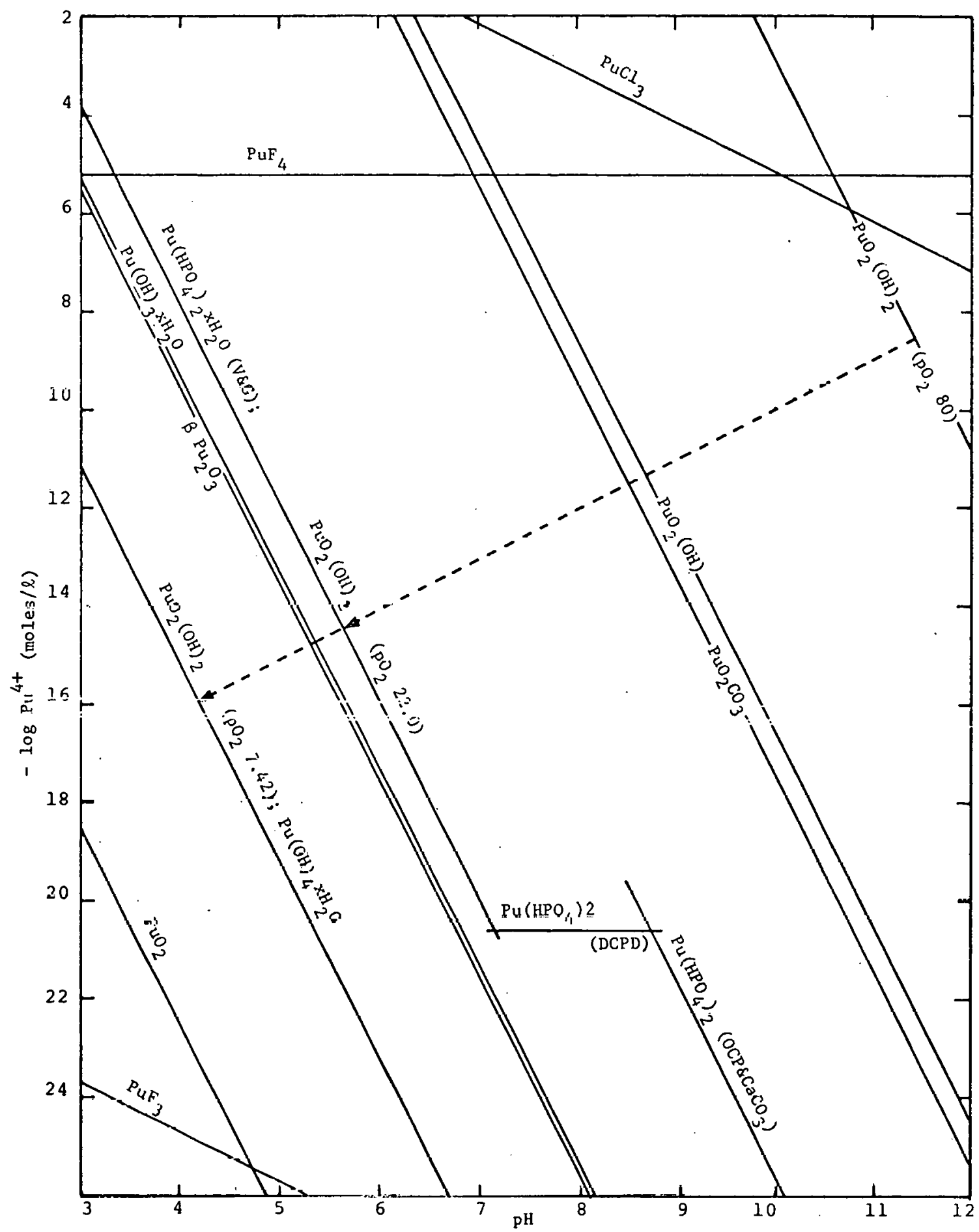

FIGURE 11. THE RELATIVE STABILITY OF VARIOUS PLUTONIUM MINERALS TN SOILS UNDER EXTREMELY REDUCING CONDITIONS ( $\mathrm{pO}_{2}(\mathrm{~g})$ 80 atm.), $\mathrm{pCO}_{2}$ (g) 3.52 atm., IN EQUILIBRIUM WITH $\mathrm{CaCO}_{3}, \mathrm{PCl}^{-}=3.6, \mathrm{pF}^{-}=3.5$, AND PHOSPHATE LEVELS IN EQUILIBRIUM WITH V\&G (VARISCITE AND GIBBSITE), DCPD (DICALCIUM PHOSPHATE DIHYDRATE),. AND OCP (OCTACALCIUM PHOSPHATE). 


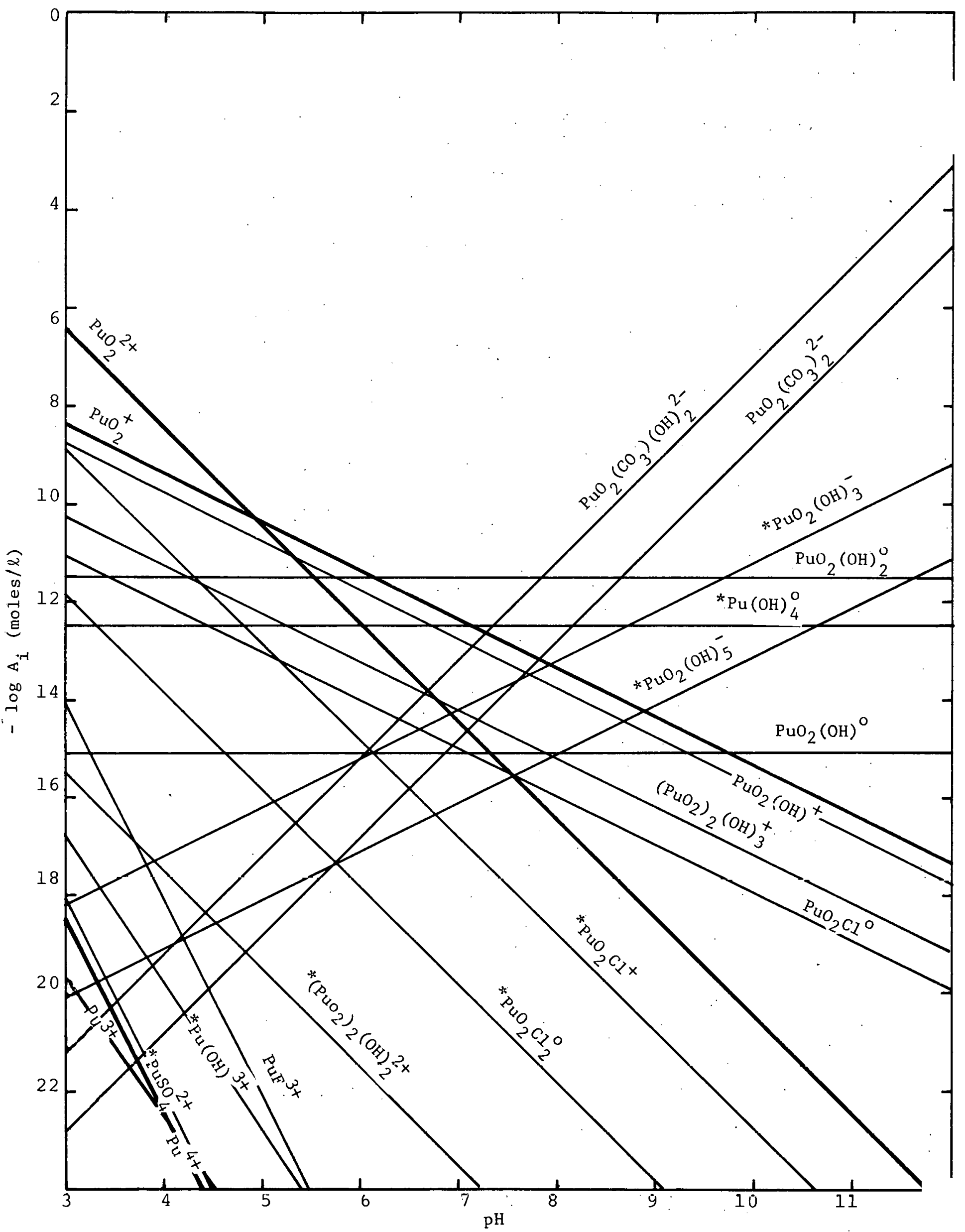

FIGURE 12. THE ACTIVITY OF VARIOUS PLUTONIUM IONS IN SOIL SOLUTION I EQUILIBRIUM WITH $\mathrm{PUO}_{2}(\mathrm{~s})$, UNDER OXIDIZING ENVIRONMENT_(pO 2 (g) 0.68 atm.), $\mathrm{pCO}_{2}(\mathrm{~g}) 3.52 \mathrm{~atm} ., \mathrm{pCI}=\mathrm{pSO}_{4}^{2-}=2.5 ; \mathrm{AND} \mathrm{pF}=3.5$. 


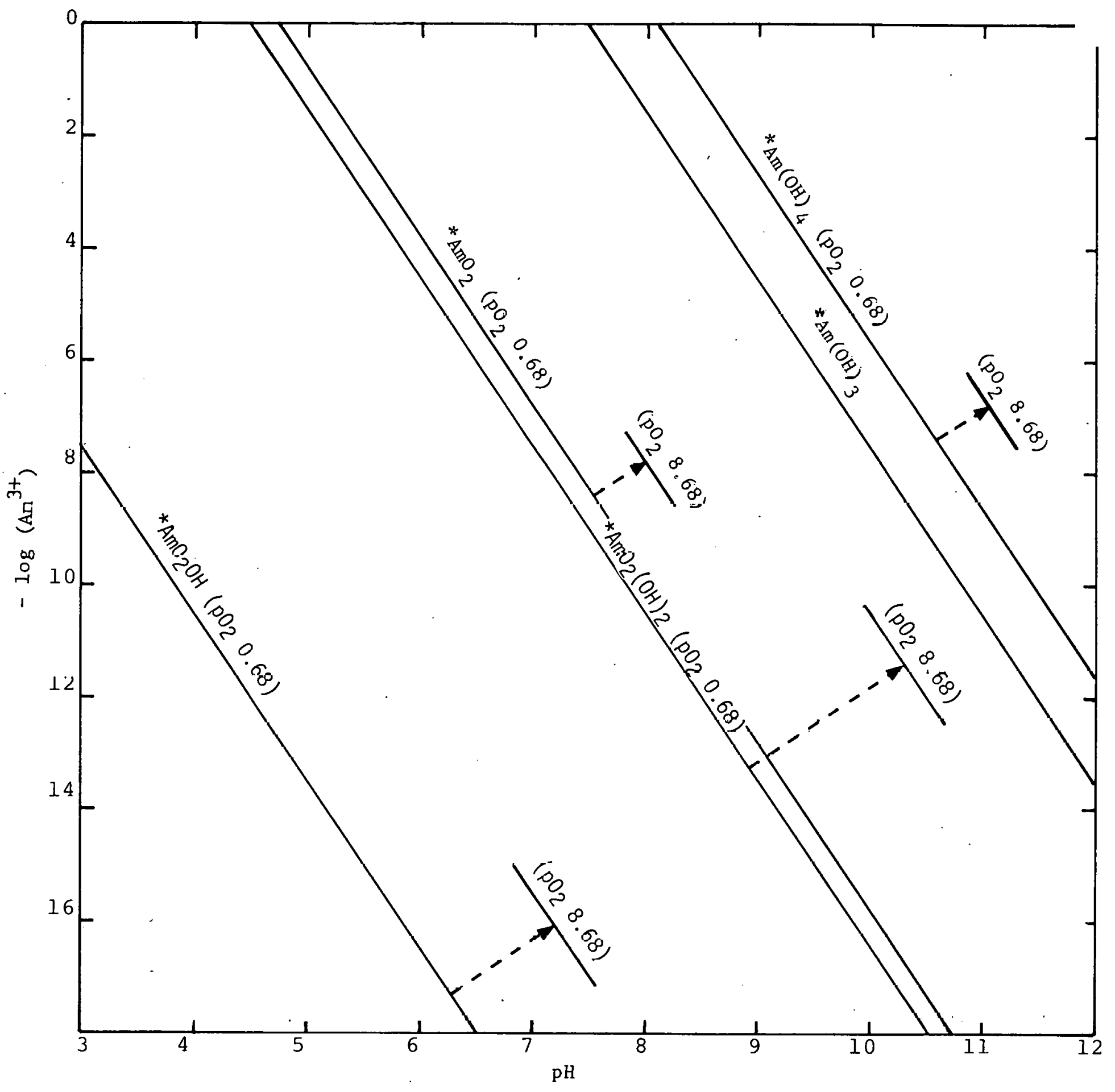

FIGURE 13. THE RELATIVE STABILITY (LINES ARE BASED UPON ESTIMATED THERMODYNAMIC QUANTITLES) UH' VARIOUS AMERICIUM MINERALS IN SOILS UNDER OXIDIZING ENVIRONMENT $\left(\mathrm{pO}_{2}(\mathrm{~g}) \quad 0.68 \mathrm{~atm}.\right)$. 


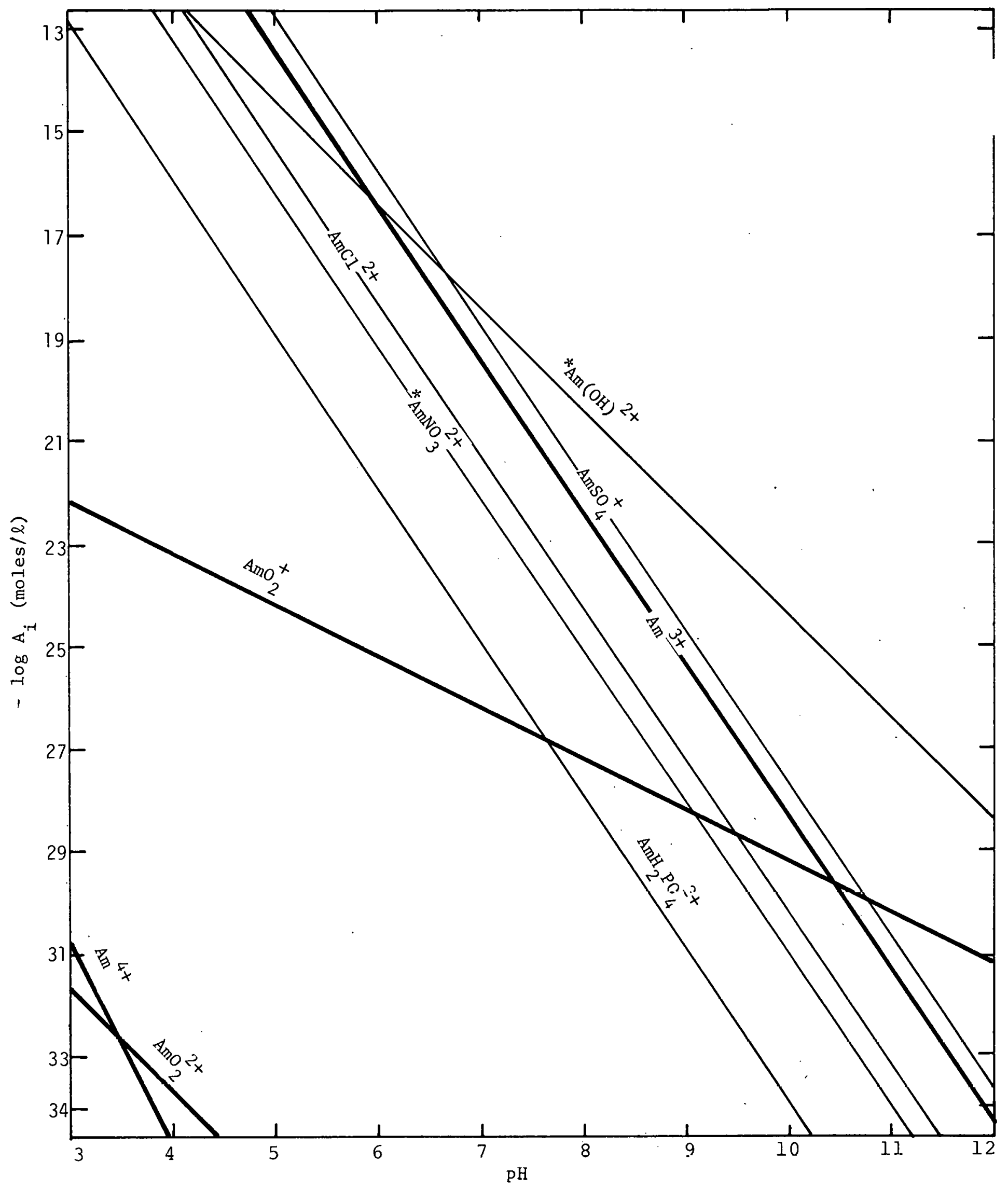

FIGURE 14. THE ACTIVITY OF VARIOUS AMERICIUM IONS IN SOIL SOLUTIOI IN EQITT.TBRIUM WITH $\mathrm{AmO}_{2} \mathrm{OH}(\underline{s})$, UNDF, $\operatorname{MENT}\left(\mathrm{pO}_{2} 0.68\right), \mathrm{pCl}^{-}=\mathrm{pNO}_{3}=\mathrm{pSO}_{4}^{2-}=3.0$, AND $\mathrm{pH}_{2} \mathrm{PO}_{4}={ }^{2} 5.0$. 
the $\mathrm{pCO}_{2}(\mathrm{~g}), \mathrm{pK}^{+}$and $\mathrm{pNa}^{+}$, etc., refer to the negative logarithm of the activity (in moles per liter for solution species and atmospheres for gases) of the chemical species mentioned. The assumptions regarding the weathering environment are given in the figure captions. For details of construction of diagrams and selected thermodynamic data for plutonium, see Rai and Serne (1976) and for other elements see Rai, et. al., (1975).

Interpretation of Diagrams for Mineral Stability and Formation

The method of interpretating the diagrams is illustrated using plutonium (Fjgures 10, 11 , and 12) as an example. Figure 10 relates the activity of $\mathrm{Pu}^{4+}$ to $\mathrm{pH}$ under an oxidizing environment $\left(\mathrm{PO}_{2}(\mathrm{~g})=0.68 \mathrm{~atm}\right)$ in equilibrium with various plutonium minerals. Any mineral in Figure 10 that 1 ies below another mineral, at a given $\mathrm{pH}$, is more stable than that nther mineral. Thus, for any two minerals at a specific $\mathrm{pH}$, the mineral that maintains lower $\mathrm{Pu}^{4+}$ activity is more stable. Under the assumptions outlined in Figure 10 and at $\mathrm{pH} 6$, the minerals in order of increasing stability are: $\mathrm{Pu}(\mathrm{OH})_{3} \times \mathrm{H}_{2} \mathrm{O}$;

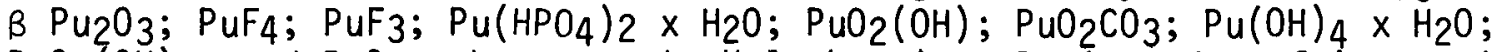
$\mathrm{PuO}_{2}(\mathrm{OH})_{2}$; and $\mathrm{PuO}_{2}$, whereas, at $\mathrm{pH} 8$ the minerals in order of increasing stability are: $\mathrm{PuF}_{4} ; \mathrm{Pu}(\mathrm{OH})_{3} ; \mathrm{B} \mathrm{Pu}_{2} \mathrm{O}_{3} ; \mathrm{PuF}_{3} ; \mathrm{Pu}\left(\mathrm{HPO}_{4}\right) \times \mathrm{H}_{2} \mathrm{O} ; \mathrm{Pu}_{1 .} \mathrm{O}_{2}(\mathrm{OH})$; $\mathrm{PuO}_{2} \mathrm{CO}_{3} ; \mathrm{Pu}(\mathrm{OH})_{4} \times \mathrm{H}_{2} \mathrm{O} ; \mathrm{PuO}_{2}(\mathrm{OH})_{2}$; and $\mathrm{PuO}_{2}$. $\mathrm{PuO}_{2}$ is the most stable mineral under oxidizing conditions at all $\mathrm{pH}$ values (Figure 10).

In addition to stability, information regarding weathering and formation can also be obtained from Figure 10. If, in a given soil, the soil solution composition is below the solid line, the soil is undersaturated with respect to the mineral represented by the line, and the mineral will dissolve or weather. On the other hand, if a soil solution point is above the solid line, then the soil is supersaturated with respect to the mineral represented by the line and the mineral can precipitate. For example, $\mathrm{PuO}_{2} \mathrm{CO}_{3}$ can dissolve to form any of the minerals occurring below its solid line $\left(\mathrm{Pu}(\mathrm{OH})_{4} \times \mathrm{H}_{2} \mathrm{O} ; \mathrm{PuO}_{2}(\mathrm{OH})_{2}\right.$; $\mathrm{PuO}_{2}$ ) providing the qualifying assumptions are met. On the other hand, none of the above minerals can dissolve to form $\mathrm{PuO}_{2} \mathrm{CO}_{3}$. These predictions concern the feasibility of formation of various minerals at $25 \mathrm{C}$ and 1 atm pressure and do not say anything regarding the rates of formation.

The stabilities of the plutonium minerals under a reducing environment $\left(0_{2}(\mathrm{~g})=\right.$ $\left.10^{-80} \mathrm{~atm}\right)$ is represented in Figure 11 . In general, the reducing environment substantially changes the stabilities of the minerals. Comparing Figures 10 and 11 , it can be seen that the Pu(IV) minerals remain unchanged, while $\mathrm{Pu}(I I I)$ minerals increase and $\mathrm{Pu}(\mathrm{V}$ and $\mathrm{VI})$ minerals decrease in their stabilities with the decrease in the oxygen pressures. The plutonium minerals under the reducing environment and at $\mathrm{pH} 6$ can be arranged in order of the ir increasing stabilities as follows: $\mathrm{PuO}_{2}(\mathrm{OH})_{2} ; \mathrm{PuO}_{2}(\mathrm{OH}) ; \mathrm{PuCl}_{3} ; \mathrm{PuO}_{2} \mathrm{CO}_{3}$; $\mathrm{PuF}_{4} ; \mathrm{Pu}\left(\mathrm{HPO}_{4}\right)_{2} \times \mathrm{H}_{2} \mathrm{O} ; \mathrm{Pu}(\mathrm{OH})_{3} \times \mathrm{H}_{2} \mathrm{O} ; \mathrm{BPu} \mathrm{O}_{3} ; \mathrm{Pu}\left(\mathrm{OH}_{4} \times \mathrm{H}_{2} \mathrm{O} ; \mathrm{PuF}_{3} ; \text { and } \mathrm{PuO}\right)_{2}$. $\mathrm{PuF}_{3}$ would be the most stable mineral below $\mathrm{pH} 4.75$ whereas above this $\mathrm{pH}$ value $\mathrm{PuO}_{2}$ would be the most stable mineral (Figure 11). Based upon the Eh-pH diagrams for plutonium oxides and hydroxides, Polzer (1971) predicted $\mathrm{PuO}_{2}(\mathrm{~s})$ to be the most stable mineral under conditions generally found in the environment. However, in making his predictions Polzer (1971) did not consider minerals other than oxides and hydroxides. 
The knowledge of the most stable compound that may be present in the soils is necessary in order to predict the behavior or fate of the element in soils. Numerous workers have studied the plutonium concentration and distribution with depth in soils. However, with the exception of one (Price and Ames, 1975), none have made any attempt to identify the solid phases of plutonium present in soils. Price and Ames (1975) reported the presence of $\mathrm{PuO}_{2}$ under oxidizing and alkaline as well acidic environments. Tamura (1974) inferred the presence of $\mathrm{PuO}_{2}$ in aridisols or entisols from Nevada Test Site. Thus, their results confirm theoretical predictions made regarding the most stable plutonium compound expected to be present in soils.

Interpretation of Diagrams for Solution Species of Actinides

The activity of the element in solution can be predicted from the information regarding the solid phases of the element present in the soils, the weathering environment, and the thermodynamic data for various ions and ion-pairs. In order to demonstrate the predictability of plutonium in soil solution, Figure 12 was constructed by assuming the weathering environment $\left(\mathrm{pO}_{2}(\mathrm{~g})=\right.$ $\left.0.68 ; \mathrm{pCO}_{2}(\mathrm{~g})=3.52 ; \mathrm{pCl}^{-}=\mathrm{pSO}_{4}^{2-}=2.5 ; \mathrm{pF}^{-}=3.5\right)$ and $\mathrm{PuO}_{2}$ the compound that may be present in the soil at equilibrium. When the diagram is constructed for a given weathering environment of a soil, all the organic and inorganic ligands present in the soil solution should be considered. Figure. 12 relates the activity of various plutonium species $(A i)$ to the solution $\mathrm{pH}$.

It can be seen (Figure 12) that the plutonium in solution exists in four oxidation states $(3,4,5,6)$ and forms complexes with $\mathrm{OH}^{-}, \mathrm{Cl}^{-}, \mathrm{SO}_{4}^{2-}$, and $\mathrm{CO}_{3}{ }^{2-}$ ions. In general, the activity of all positively charged ions and ionpairs and a few neutral ion-pairs decreases with the increase in $\mathrm{pH}$, while the activity of all negatively charged ion-pairs increases with the increase in $\mathrm{pH}$. Under an oxidizing environment, $\mathrm{Pu}^{3+}$ and $\mathrm{Pu}^{4+}$ and their ion-pairs (except $\mathrm{Pu}(\mathrm{OH}) \&$ around neutral $\left.\mathrm{pH}^{\prime} \mathrm{s}\right)$ have an insignificant effect on the total activity of plutonium in solution. At any given $\mathrm{pH}$, the total activity of plutonium in solution can be obtained by adding the appropriate activities of various plutonium species. Since the lines for plutonium species preceeded by an asterisk are based upon concentration constants, the lines may change some in their position when converted to thermodynamic equilibrium constants. However, in doing so, the total activity of plutonium in solution at any given $\mathrm{pH}$ would not change significantly because the activity of asterisked species compared to non-asterisked species is very smal1. When the concentration constants are converted to thermodynamic constants, the new lines would only shift downward or upward but still be parallel to the present lines. The activities of various species would still vary in the same direction, as reported in Figure 12, with the changes in $\mathrm{pH}$.

The most dominant species, for the conditions specified in Figure 12, of plutonium in $\mathrm{pH}$ ranges of approximately $0-5,5-6,6-8$ and $>8$ are $\mathrm{PuO}_{2}{ }^{2+}$; $\mathrm{PuO}_{2}{ }^{+} ; \mathrm{PuO}_{2}(\mathrm{OH}) 2$; and $\mathrm{PuO}_{2}\left(\mathrm{CO}_{3}\right)(\mathrm{OH})_{2}^{2-}$, respectively. The colloid complex of soils is mainly negatively charged. Therefore, only positively charged species are adsorbed by soils in cation exchange processes. Since positively charged species of $\mathrm{Plutonium}\left(\mathrm{PuO}_{2}{ }^{2+}\right.$ and $\left.\mathrm{PuO}_{2}{ }^{+}\right)$predominate only in solutions 
of $\mathrm{pH}$ values $<6$, cation exchange adsorption of plutonium by soils would be limited to acidic soils $\left(\mathrm{pH}_{2}<6\right)$. Negatively charged plutonium ions $\left[\mathrm{PuO}_{2}\right.$ $\left(\mathrm{CO}_{3}\right)(\mathrm{OH})_{2}^{2-}$ and $\left.\mathrm{PuO}_{2}\left(\mathrm{CO}_{3}\right)_{2}^{2-}\right]$, that exist in significant quantities above a pH of approximately 8 , would not be adsorbed by soils. Because of 1) little adsorption of negatively charged ions, and 2) increases in the activities of negatively charged ions with the increase in $\mathrm{pH}$, it can be predicted that the activity of plutonium in soil solutions of $\mathrm{pH}>8$ would be relatively high. Similarly under extremely low $\mathrm{pH}$ conditions the activity of plutonium in soil solutions in equilibrium with $\mathrm{PuO}_{2}$ (s) may also be high. Rhodes (1957) found low adsorption of plutonium by soils in the $\mathrm{pH}$ ranges of approximately $<2$ and $8-13$. Thus, Rhodes' (1957) results confirm part of the predictions based upon Figure 12; continuous decrease in adsorption is predicted with the increase in pH above 8 , whereas, Rhodes' (1957) data indicate first a decrease in adsorption and then continuous increase in adsorption above $\mathrm{pH}$ 12. It should be mentioned that in addition to cation exchange, the total retention of plutonium by soils from plutonium wastes percolating through soils would depend upon many other factors, such as flow rate, precipitation of solid phases, physical entrapment of particulate and colloidal plutonium, properties of soils, and the composition of waste water.

\section{General Remarks}

The diagrams were developed assuming a kind of weathering environment most commonly found in soils. These diagrams can, however, be developed for a particular soil with a particular weathering environment and can be modified or extended to other minerals as better thermodynamic data accumulates. Based upon predictions regarding the most stable mineral that would be present in soils and the thermodynamic data for all the solution species, a computer program can be developed that would predict the amount of the element present in the soil solution under any qiven weathering environment. This computer program could serve as a building block which could be modified as laboratory information regarding the solid phascs actually present in the soils and the diffusion and adsorption coefficients accumulates. A few computer models (Martin, Bloom and Yorde, 1974; Martin and B1oom, 1975; Cuddihy, et. al., 1975) that predict the dose of plutonium to man are available. Because of the lack of information regarding the dissolution, movement, and translocation of plutonium in soils through water, all these mode is have neglected the effect of water in determining the fate of plutonium in the terrestrial environments and have developed models based solely upon the effect of wind and other physical factors. These models have assumed that $\mathrm{PuO}_{2}$, a major plutonium contaminant, is highly insoluble. This assumption is questionable because the total activity of plutonium in solution in equilibrium with $\mathrm{PuO}_{2}$ (Figure 12) is many times higher in very low and very high $\mathrm{pH}$ solutions than the recomiended RCG value of 10-9.46 moles/l of plutonium-239 in drinking waters. Thus, data on the fate of plutonium and other actinides in soils is urgently needed. However, until such data become available, a computer model based upon the theoretical predictions and diagrams can be used to approximately predict the behavior of actinides in soils. 
REFERENCES

Burney, G. A. and R. M. Harbour. 1974. Radiochemistry of Neptunium. NASNS-3060. Tech. Info. Center, Office of Info. Serv. USAEC.

Cleveland, J. M. 1970. The Chemistry of Plutonium. Gordon and Breach Science Publishers, New York.

Cuddihy, R. G., R.0. MCClellan, L. D. Chapman, J. R. Wayland and V. L. Dugan. 1975. Simulation Modeling of Environmental Transport and Heal th Consequences of Radioactive Effluents from Nuclear Power Systems. IAEA-SM-199/107.

Fried, S. 1955. The Chemistry and Crystal Chemistry of Heavy Metal Compounds. A/CONF $8 / P / 730$.

Garrels, R. M. and C. L. Christ. 1965. Solutions, Minerals, and Equilibria. Harper and Row, New York.

Keller, C. 1971. The Chemistry of the Transuranium Elements. Kern Chemie in Ein Zeldarstellungen, Volume 3. Verlagchemie GmbH. Weinheim/Bergstr., Germany.

Latimer, W. M. 1952. The Oxidation States of the Elements and Their Potentials in Aqueous Solutions. Second Edition. Pretice-Hall, Inc., Englewood $\mathrm{Cl}$ iffs, $\mathrm{NJ}$.

Martin, W. E. and S. G. Bloom. 1975. Plutonium Transport and Dose Estimation Model. IAEA-SM-199/78.

Martin, W. E., S. G. Bloom and R. J. Yorde, Jr. 1974. NAEG Plutonium Study Modeling Program: Plutonium Transport and Dose Estimation Model. IN:

Dunaway, P. B. and M. G. White (eds.). The Dynamics of Plutonium in Desert Environments. NVO-142 (NVO-AEIC-74-1 or UC-2):331-360.

Palei, P. N. (comp.). 1962. Analytical Chemistry of Uranium. Trans. by N. Kaner. 1963. Israel Program for Scientific Transiations Ltd. $421 \mu$.

Pal'shin, E. S., B. F. Myasoedov and A. V. Davydov. 1970. Trans. by J. Schmorak. 1970. Israel Program for Scientific Translations Ltd. $233 \mathrm{p}$.

Polzer, W. L. 1971. Solubility of Plutonium in Soil/Water Environments. Proceedings of Rocky Flats Symposium on Safety in Plutonium Handling Facilities, CONF-710401, p. 411-430.

Price, S. M. and L. L. Ames. 1975. Characterization of Actinide-Bearing Sediments Underlying Liquid Waste Disposal Facilities at Hanford. IAEA-SM$199 / 87$.

Rai, Dhanpat and W. L. Lindsay. 1975. A Thermodynamic Model for Predicting the Formation, Stability, and Weathering of Common Soil Minerals. Soil Sci. 5oc. Amer. Proc. 39:991-996. 
Rai, Dhanpat, and R. J. Serne. 1976. Plutonium Activities in Soil Solutions and the Stability and Formation of Selected Plutonium Minerals. A paper presented at Mineral Cycling Symposium of USERDA at Agusta, GA, Apri1 1976. BNWL-SA-5767.

Rhodes, D. W. 1957. The Adsorption. of Plutonium by Soil. Soil Science $84: 465-471$.

Robie, R. A. and D. R. Waldbaum. 1968. Thermodynamic Properties of Minerals and Related Substances at $298.15^{\circ} \mathrm{K}\left(25^{\circ} \mathrm{C}\right)$ and One Atmosphere (1.013 Bars) Pressure and at Higher Temperatures. Geol. Surv. Bul1. 1259.

Rogers, J. J. W. and J. A. S. Adams. 1969. Thorium, No. 90, Uranium, No. 92. IN: Wedepoh1, K. H. (Executive Ed.). Handbook of Geochemistry, Vol. II/l. Springer-Verlag Berlin.

Ryabchikov, D. I. and E. K. Gol'braikh. 1960. Analytical Chemistry of Thorium. Trans. by A. Aladjem. 1963. Israel Program for Scientific Translations Ltd. $289 \mathrm{p}$.

Sillen, L. G. and A. E. Marte11. 1964. Stability Constants of Metal Ion Complexes. Second ed. Spec. Pub. No. 17. The Chemical Society, London.

Tamura, T. 1974. Distribution and Characterization of Plutonium in Soils From Nevada Test Site. IN: Dunaway, P. B. and M. G. White (eds.). The Dynamics of Plutonium in Desert Environments. NVO-142 (NVO-AEIC-74-1 or $U(-2): 29-42$. 
ANNOTATED BIBLIOGRAPHY

Adams, J. A. S., J. K. Osmond and J. J.W. Rogers. 1959. The Geochemistry of Thorium and Uranium. Physics and Chemistry of the Earth. Vol. 3, Pergamine Press, New York, pp. 298-348.

The natural distribution of uranium and thorium in the crustal rocks is reviewed along with the average abundance in each rock and sediment type. The separation of uranium and thorium during weathering processes is accomplished in three ways: 1) Solution processes in which the minerals holding the thorium and uranium are put into true solution, 2) physical movement of resistates containing uranium and thorium, and 3) precipitation with clays, opal and other similar minerals.

The thorium is easily removed by and concentrated in the clays. Uranium, as the uranyl ion, is usually precipitated by a low Eh environment.

Adams, J. A. S., and K. A. Richardson. 1960. Thorium, Uranium, and Zirconium Concentrations in Bauxite. Econ. Geol. 55:1653-75.

Twenty-nine samples of bauxites from different locations were analyzed for thorium and uranium by gamma spectrometric, alpha counting, and wet chemical methods. The thorium concentrations ranged from 5.0 to $131 \mathrm{ppm}$ and averaged $48.9 \mathrm{ppm}$. The uranium concentrations ranged from 2.7 to 26.7 ppm and averaged $11.4 \mathrm{ppm}$. The thorium-to-uranium ratios ranged from 1.5 to 20.9, with an average value of 5.1. Zirconium determinations on some of the bauxites gave values ranging from 0.02 to $0.65 \%$ zirconium, and averaging $0.09 \%$ zirconium. The thorium, uranium, and zirconium contents of the bauxites were related to the type of source rock. Bauxites dierived from nepheline syenites contained more thorium and uranium than bauxites derived from other rock types; bauxites derived from basic igneous rocks had the lowest thorium and uranium concentrations, and bauxites derived from carbonate rocks had the lowest thorium-to-uranium ratios. The greatest concentrations of zirconium were found in bauxites derived from nepheline syenites, and bauxites derived from carbonates contained the lowest concentrations of zirconium. A study of samples from alumina plants treating Surinam and Arkansas bauxites showed that during the process over $70 \%$ of the thorium and uranium in these two bauxites is concentrated into the red mud, and the alumina contains very small amounts of these elements. This study also indicated that much of the thorium and uranium in bauxites occurs in either primary or secondary resistate minerals. (auth) 
Adams, J. A. S. and C. E. Weaver. 1958. Thorium to Uranium Ratios as Indications of Sedimentary Processes: Example of Concept of Geochemical Facies. Bul1. Am. Assoc. Petrol. Geologists. 42:387-430.

More than 200 new analyses of Th and $U$ made with a $\gamma$-ray spectral technique and an $\alpha$-activity-fluorometric $U$ technique are reported. The over-all error is estimated to be $< \pm 20 \%$ if the $\mathrm{Th} / \mathrm{U}$ ratio is more than 0.5 and there is more than $0.3 \mathrm{ppm} U$ and Th, respectively. Ratios in many oxidized continental deposits are above 7 , whereas most marine deposits have ratios below 7; this permits recognition of deposits formed in these environments. Gamma rays from $U$, Th, and $K$ can be differentiated by a spectral logging device and useful data for interpretation of subsurface rocks are obtained. (CA)

Adams, W. H. 1971. Solubility of Plutonium-238 Labeled $\mathrm{PuO}_{2}$ in Los A1amos Tap Water. LADC- 12900.

The solubility of 238-1abeled $\mathrm{PuO}_{2}$ microspheres of various sizes was studied with time. Los Alamos tap water was used for this study.

Agamirov, S. S. 1963. Precipitation of $U$ in Black Sea. Geokhimiya. No. 1: 92-3. - (in Russian).

Hydrochemical tests of the northeast portion of the BIack Sea Basin during July 1961 indicated $2.4 \mathrm{~g} / 1 \mathrm{U}$ in the upper $500-\mathrm{m}$ layer, $1.6 \mathrm{~g} / 1 \mathrm{U}$ between 1000 and $1800 \mathrm{~m}$, and much smaller amounts at greater depths. Further studies showed the feasibility of hexavalent uranium reduction to tetravalent by hydrogen sulfide contamination, followed by a precipitation to a depth of 1700 to $2000 \mathrm{~m}$ where the e.H value is 0.15 to $0.20 \mathrm{v}$, resulting in an enrichment of Black Sea sediments. (NSA)

Alberti.G., C. Bettinali, G. Grassini, and F. Silvestro. 1959. Leaching Tests of Uranium of Canale Monterano. IN:Studie Ricerche Della Divisione Geomineraria. 2:129-53.

Short descriptions of the deposit, of the various hypotheses of its origin and of the methods of sampling are given. The results of the radiometric and chemical analyses of samples collected in the various galleries are reported. The ronnditions of solubilization of the uranium in pure water and in acidic and alkaline solutions were studied, taking in account the concentration of the solutions, the time of leaching, the temperature, the grain size of the crushed material, the presence of oxidizing compounds and of oxygen under pressure. It was found that in the case of leaching by water only, the percentage of uranium going in solution is strictly linked to the acidity of the material. Most of the examined samples shows pH-values between 2.4 and 3.2 , but also extreme values, such as 1.8 and 5.5 were observed. On the average, about $18 \%$ of the total uranium present goes in solution in pure water, while, in solutions with $20 \%$ sulfuric acid, maximally $60 \%$ of the uranium could be leached out. (auth) 
Alekseev, F. A. 1972. Use of Radioactive and Stable Isotopes in. Geological Research. Yad, Geofiz., Dok1. Uses. Nauch-Tekh. Konf IXX [Dvadtsat] let Proizvod. Primen. Izotop. Islochnikov. Yad. Izluch. Nar. Khoz. SSSR. :177-93 (in Russian).

Distribution of radioactive elements ( $U, K, T h$ ) along the cross-section and area of a sedimentation basin indicates the age subdivisions in the deposits, and the stratigraphic boundaries. By establishing the laws governing the distribution of radioactive elements in a basin, it is possible to reconstruct the conditions existing in the sedimentation region (tectonic conditions, climate, physical-chemical siuation of the basin), the composition of the rocks, and the size and configuration of the basin, relief of the sea bottom, lithological facial zones, etc. There is a large' range in the changes of $U$ content within each stratigraphic complex, varition ranges in each age complex, and a relatively regular decrease in the $U$ content upwards in the section. Paleogiographical reconstructions are possible. The maximum $U$ quantities are related to accumulations of humus type organic matter. Increased clayiness of the carbonates is accompanied by increased Th and $K$ rontent and increased Th/U ratio. (CA)

Ames, L. L., Jr. 1960. Some Cation Substitutions During the Formation of Phosphorite from Calcite. Econ. Geol. 55:354-362.

The nature of cation substitution during replacement of calcite by phosphorite allows the statistical treatment of data concerning such substitution.

Log-probability plots of data yield straight lines that allow easy and accurate extrapolations. Data are presented to show the effect of phosphate ion concentration, temperature, flow rate, and $\mathrm{Na}$ concentration on the primary inclusion of the radioisotopes of $\mathrm{Pu}$ (III), $\mathrm{Sr}$ (II), U (IV), and $\mathrm{Pu}$ (IV). (auth)

Ames, L. L. 1974. Characterization of Actinide Bearing Soils: Top Sixty Centimeters of 216-Z-9 Enclosed Trench. IJSFRDA Report. BNWL-1812.

A program to examine the soil-acitinide relationship in sediments from a disposal facility was initiated in March 1973. Initial work has been done using samples from the 216-Z-9 covered trench.

Soil mounts were made of soil recovered from a core of an uncontaminated well drilled alongside Z-9 trench. The mounts were made by plasticimpregnating smaller, l-inch diameter cores taken from the original 4-inch diameter cores. The uncontaminated mounts showed that the less than 30 mesh. soil was composed of predominately metamorphic rock fragments of the Belt Series, brought down from northern Washington and Idaho by the ancestral Columbia River. 
Two 4-inch diameter cores, 2 feet in length, were taken from the floor of Z-9 trench. Smaller contaminated mounts were made from these original cores in the same manner as with the uncontaminated samples. Overlying one of these cores (4-11), was a sludge layer of silica, alumina and water. The other core (4-5) had no sludge layer.

At least two types of plutonium were found in cores 4-11 and 4-5 by autoradiographic and microprobe examination. The plutonium particles (up to $10 \mu \mathrm{m}$ in diameter and $60 \mathrm{wt} \% \mathrm{PuO}_{2}$ ) were the most conspicuous form. These occurred near the top of the core 4-11, but extended down nearly to the bottom of core 4-5. It is probable that the sludge layer over core 4-11 acted as a filtering media to remove and concentrate the plutonium particles.

The second form of plutonium occurred in lesser concentration $(<0.4 \mathrm{wt} \%$ $\mathrm{Pu}_{2}$ ) but was found throughout the lengths of both cores associated with silicate hydrolysis. Silicate hydrolysis was investigated with microprobe chemical analysis. Loss of alkalies and alkaline earths, along with the absence of several metamorphic minerals found in the uncontaminated mounts, indicated extensive chemical attack of soil rock fragments by acidic influent solutions.

The locations of the base of the silicate hydrolysis zone, and associated plutonium deposition, are presently unknown. (auth)

Amiel, A. J., D. S. Miller, and G. M. Friedman. 1972. Uranium Distribution in Carbonate Sediments of a Hypersaline Pool, Gulf of Elat, Red Sea. Isr. J. Earth Sci. 21:187-91.

Two kinds of laminites exist interlayered between blue-green algal mat carpets of a hypersaline pool, fibrous aragonite and cryptocrystalline high magnesian calcite. Cryptocrystalline laminites contain more U (15) ppm) than fibrous laminites $(3.5 \mathrm{ppm})$. Organic $C$ in laminites is $1.1-1.4 \mathrm{wt} \%$. The organic phase ties up $35 \%$ of total $U$. Increased $U$ concentration in cryptocrystalline layers is related to organic matter present in these layers and to fine crystal size and greater specific surface area. In nonorganic matter $U$ occurs in exchangeable as well as in absorbed sites from which $U$ can be readily removed by leaching with distilled water.

(CA)

Andelman, J. B., and T. C. Rozze11. 1970. P1utonium in the Water Environment, ACS Advances in Chemistry No. 93 (Washington: American Chemical Society).

In the $\mathrm{pH}$ range of natural waters colloidal plutonium (IV) hydroxide forms from polymeric hydrolys is products and ages slowly. At least over a period of several days an increase in particle sizes is observed. At pH 7 such solutions aged for a few months showed a significant increase in size of the colloidal plutonium as the ionic strength increased from 0.002 to 0.1 . The centrifugability of the colloid, aged for three and seven days 
at $\mathrm{pH} 7$, decreased for plutonium concentrations less than $10^{-7} \mathrm{M}$. The addition of macroscopic grains of crystalline silica affected the colloidal plutonium size distribution as did the variation in $\mathrm{pH}$ over the range of 5 to 8 . The addition of $10^{-2} \mathrm{M}$ bicarbonate ions at $\cdot \mathrm{pH} 7$ also influenced the distribution but less systematically. (auth)

Anonymous. 1962. Geology of Uranium and Thorium Bibliography Series No. 4. IAEA, Vienna. $134 \mathrm{p}$.

The bibliography contains 892 references to literature published from 1940 to 1960. Information is given on age, genesis, mineralogy, geochemistry, tests, prospecting and exploration, and reserves of thorium and uranium. The bibliography also includes a guide to literature and a summary giving the present status of the well-known deposits of thorium and uranium. An author index is included. (NSA)

Anonymous. 1966. Chemistry of Transplutonium Elements. Bibliography Series No. 19. IAEA, Vienna. $238 \mathrm{p}$.

An annotated bibliography of transplutonium elements is given.

Anonymous. 1966. Physico-Chimie Du Protactium.: Colloques Internationaux Du Centre National De La Recherche Scientifique. No. 154 Orsay Institut du Radium, 2-8 July 1965. 351 p.

This publication deals with the symposium on the physical chemistry of Protactinium.

Anonymous. 1968. Geology of Uranium and Thorium, Vol. II (1961-1966) Bibliographical Series No. 31. IAEA, Vienna. 102 p.

Varinus sections of the publication deal with geology of radioactive occurrences, age of radioactive deposits, genesis of radioactive deposits, mineralogy, geochemistry and radioecology, analytical procedures and tests for radioactive ores, prospecting and exploration, and reserves, resources, and production.

Armands, G. and S. I..andergren. 1960. Geochemical Prospecting for Uranium in Northern Sweden: The Enrichment of Uranium in Peat. Intern. Geo1. Congr. Rept. 21 st. Session, Copenhagen. Pt. 15: 51-66.

Analyses of peat from Masugnsbyn showed an average content on a drymatter basis of $600 \mathrm{ppm} U(=900 \mathrm{ppm}$ in the organic component). Analyses of spring waters within the bog showed an average of $0.1 \mathrm{ppm} U$. Profiles across the bog show considerable variation of $\mathrm{pH}$ and $U$ content; similar 
variations were shown by determinations of $U$ content of plants (Betula alba, $B$. nana, Salix, and Alnus). Twigs contain much more $U$ than do leaves. Leaching experiments on $\mathrm{Fe}$ ore from the region that contained $0.05 \% \mathrm{U}$ showed that $12-26 \%$ of the $U$ could be leached by $\mathrm{NaHCO}_{2}$ solutions in 4 days; the $U$ in the bog probably came from leaching the Fe ore by ground-water bicarbonate solutions. (CA)

Bagna11, K. W. 1957. Chemistry of the Rare Radioelements PoloniumActimum. Butterworths Scientific Publications, London. 177 p.

The book deals mainly with the discovery; separation, uses, solution chenistry, electrochemistry, and compounds of polonium. Actinium, astatine, francium, and ricion are also discussed.

Bagnal1, K. W. 1972. The Actinide Elements. Elsevier Publishing Company, New York.

This book gives a complete description of the discovery, occurrence and synthesis of the actinides. Separation and purification methods are given as well as the physical and chemical properties of the metals and their compounds.

For this environmental study the chapter on aqueous solution chemistry is pertinent.

Bain, G. W. 1953. Experimental Simulation of Plateau Type Uranium Deposits. RMO-44,

Experimental simulation of Colorado Plateau type $U$ deposits is divided into seven jarls. The first three summarize the essential features of geological occurrence for the ores. The last four parts outline the results of experimental investigation arranged according to each geological group of features influencing mode of occurrence. Both field distribution and laboratory approaches to the problem suggest that the origin for the $U$ and for the $V$ are disconnected problems. The plateau ores occur in or adjacent to fluviatile sediments and generally avoid flnod plain and aeolian accumulations. For this reason, a large part of the rocks of the plateau section are not potential host to economic deposits. The principal deposits occur well down towards the bottom of synclines and are there distributed frequently along a near-contour line; this ore axis may transgress several strata al though it stays usually on contour in a stratum. Of the several explanations suggested, only the one attributing the ore to slight redistribution by artesian groundwater fails to leave anomalous situations. The structural and physiographic history of the region indicates earliest age for artesian circulation as late Cretaceous and the youngest age as the Canyon Cutting cycle of the late Pliocene. The ores came into their present site during this time interval. The red jasperoid pebbles of the Shinarump conglomeratc 
carry a small amount of the primeval uranium of the Plateau deposits. The direction to the source for these pebbies was indicated by field studies. The modification of detritus during transportation was investigated experimentally to estimate how far they had come. Rate of change in size of grain and sphericity of grain was measured under controlled conditions and a source estimated to be along the westward extension of the Uncompahgre axis almost 30 miles northwest from the Dirty Devil claims on the San Rafael Swell. other source regions are believed to have supplied the primeval uranium as heavy detrital minerals and as uraninite occluded in the jasperoid pebbles. The deposition of heavy minerals in intermittent streams was investigated experimentally and the sites determined. Principal deposition occurred inchannel just below scour pools on meanders. Heavy mineral deposition occurred during flood stage and the accumulation was covered by various deposits of the ebb stage. The patterns of the deposits indicated a groundwater flow parallel to structural axes at far below the watertable level in existence when the ores were formed. A simulated aquifer showed that this happens and that the principal groundwater discharge occurs along paths parallel to structures at far below the watertable and near the structural axis of synclines. The effect of rate of recharge and plunge of the structural axis was investigated and the results are presented. Factors influencing precipitation of uranium from uranyl solutions were investigated and it was found that the principal cause for precipitation was reduction in availability of the "vehicle" anion for the uranyl cation. Uranyl sulphate was the principal solution studied. Calcite and $V_{2} \mathrm{O}_{5}$ abstracted $\mathrm{SO}_{4}$ ion and caused precipitation of uranium. Precipitation in the case of calcite was proportional to the original uranyl ion concentration and to the thickness of calcite penetrated. Vanadium was very effective in removing $\mathrm{SO}_{4}$ ion and caused precipitation of uranium up to exhaustion of the $\mathrm{V}_{2} \mathrm{O}_{5}$. Many materials, hitherto considered important precipitants, were found to have only minor influence unless accompanied by an $\mathrm{SO}_{4}$ ion "abstractor". (auth)

Bain, G. W. and H. W. Schreiber. 1954. Influences on Migration of Uranium and Radioactivity. RME-3086.

Migration of uranium and of radioactivity, which had been suggested by radiometric and chemical analyses of field samples and of mine water, was investigated in an experimental arrangement for more than 2000 hours. Feed solutions for all arrangements had a Hydrion concentration to give $\mathrm{pH} 4 \pm$ 0.2 . An acquisition test showed radioactivity removed in greater amount than uranium from a uraninite bearing sand at first contact but indicated extraction of only insignificant amounts from the deposit as a unit. This accounts for outcrops showing deficient radioactivity although samples at on ly feet in from the surface have much unsupported radioactivity; the disparity is due as much to migration of radioactivity as it is to uranium depletion. Changes within the deposit, although very complex, are very systematic and orderly. The Happy Jack Mine study is used as a field example of the laboratory leaching experiment. Uranium removed from a deposit increases in proportion to the logarithm of thickness of deposit penetrated. The logarithm of the uranium precipitation rate by calcareous 
sand is proportional to the logarithm of the depth of calcite penetrated until the uranium-calcite ratio is about 1 to $8-1 / 2$, when precipitation essentially ceases. The Hydrion concentration of the solutions decreases approximately in proportion to the logarithm of the distance of calcite penetration. (auth)

Barsukov, V. L., T. M. Sushchevskaya, and B. I. Malyshev. 1971. Composition of Solutions Responsible for the Formation of U-Mo Deposits. At. Energ. (USSR) 31:28-34. (in Russian).

The composition of hydrothermal solutions, which formed typical U-Mo ore deposits, was evaluated on the basis of gas-liquid inclusions in pitchblende and uraninite-bearing minerals. Aqueous extracts were analyzed for $\mathrm{Na}, \mathrm{K}$. $\mathrm{Ca}, \mathrm{My}, \mathrm{Cl}, \mathrm{SO}_{4}$, dild $\mathrm{HCO}_{3}$, and the therinodyramic instability constants of a number of $\mathrm{Ca}$ salts at 25 and $150{ }^{\circ} \mathrm{C}$ were calculated as the basis for further discussion of the mechanics of ore formation. (NSA)

Baturin, G. N. 1966. Uranium Content in Caspian Sea Sediments. At. Energ. 21:515-16. (in Russian)

The content of $U$ in 34 samples of Caspian Sea sediments, taken across the sea bed, varied 1.0-23 ppm. The maximum content of $U$ was found in sediments from the central part of the middle Caspian Sea syncline and the minimum in the sediments from the western shelf of the sea. The data are compared with the $U$ content in the Caspian Sea water $(6.5-10) \times 10^{-6} \mathrm{~g} . / 1$, and with $U$ content in waters and sediments from the Black Sea and the Baltic Sea. The experimental data disproved the theory that the accumulation of $U$ in sea sediments is connected with the presence of $\mathrm{H}_{2} \mathrm{~S}$, which is absent in Caspian Sea water. (CA)

Baturin, G. N. 1968. Geochemistry of Uranium in the Baltic Sea. Geokhimiya. No. 3: 377-81 (in Russian).

The content of $U$ in the surface layers of sediments of the Baltic Sea varies from 1 to $4 \times 10^{-4 \%}$ in the coastal deposits and from 5 to $20 \times$ $10^{-4 \%}$ in deep-lying clay and silt-clay sediments. The distribution of uranium in the sediments of the Baltic Sea is of the well-regulated type with distinct pelagic maximum. The concentration of uranium in the sediments and its distribution per surface was controlled by the content and distribution of the organic material. The hydrogen sulfide contamination of water near the ground, having a local and sporadic character, is not a basic factor in the concentration of uranium in sediments of this basin. One of the reasons for the low $\mathrm{U} / \mathrm{C}_{0}$ rg relation in the sediments of the Baltic Sea is the low content, in comparison with other seas, of dissolved $U$ in its waters. (auth) 
Baturin, G. N. 1971. Uranium in Solutions of Ooze Deposits in the Southeastern Atlantic. Dok1. Akad. Nauk SSSR. 198:1186-8. (in Russian).

Determinations of uranium were made in ooze solutions of deposits after separation from the core samples under pressure. A range of 1.3 to $650 \mu \mathrm{g}$ $U / 1$ was recorded for the samples under test; in the majority of cases the $U$ content was significantly greater than in the ocean waters $(3.2 \mathrm{~g} \mathrm{U} / \mathrm{l})$. A correlation between $\mathrm{pH}$ and $U$ content of samples is shown. (NSA)

Baturin, G. N. 1973. Uranium During Sedimentation in the Black and Azov Seas. Litol. Palez. Iskop. No.. 5:21-32. (in Russian).

In rivers of the Azov-Black Sea basin, $U$ migrates predominantly in a dissolved state. The sediments of the Azov Sea exhibit a uniform distribution of $U$; in the Black Sea sediments, $U$ distribution is controlled by organic matter. The U/organic $C$ ratio in sediments shows a steady increase during sedimentation. The deposition of $U$ from marine waters occurred, during a lowering of the $E_{H}$, at the interface water-sediment. (CA)

Baturin, G. N. 1973. Uranium in the Contemporaneous Sedimentary Cycle of the Sea. Geokhimya 9:1362-1372. (in Russian).

During rocks weathering and in the river run-off, uranium is divided into the dissolved and the suspended one at an average 1:1 ratio. The average uranium content in the sum of dissolved and suspended matters of river run-off corresponds to its average content in the Earth crust; that determines uranium content in sea and ocean sediments. The share of hydrogenous uranium being concentrated in sediments of sea basins and the peripheric zones of the ocean up to $(10$ to 60$) \times 10-4 \%$ plays in the total balance a secondary role. This concentration is favored by the enrichment of sediments in organic matter and phosphorus, by the heightened uranium content in waters, by the reducing conditions near the boundary of waterbottom divide, by the slackened sedimentation rate, by the renewal of the near-bottom waters. Uranium transition from the solid phase to interstitial waters, where its concentration reaches $n \times 10^{-4} \mathrm{~g} / 1$, is a precondttion of its redistribution during diagenesis. (auth)

Baturin, G. N. and A. V. Kochenov. 1973. Uranium in Interstitial Waters of Marine and Oceanic Sediments. Geokhimiya. Nö. 10:1529-36. (in Russian).

Interstitial waters were sampled from the Atlantic and Pacific Ocean and Black Sea diatomaceous and terrigenous shelf oozes, calcareous aleuropelitic continental silts, and eupelagic and miopelagic shales. Location of the sample (latitude and longitude), depth, type of sediment, moisture content, $\mathrm{pH}$, Eh, and organic $\mathrm{C}, \mathrm{CaCO}_{3}$, and amorphous $\mathrm{SiO}_{2}, \mathrm{P}$, and $\mathrm{U}$ contents are tabulated. The $U$ content in the interstitial waters has a wide variation (from $1.3 \times 10^{-6}$ to $650 \times 10^{-6} \mathrm{~g} / 1$ ) caused by the great diagenetic mobility of $U$. The $U$ content is controlled by the $\mathrm{pH}$, Eh, and the content of organic $C$. (CA) 
Baturin, G. N., A. V. Kochenov and Y. M. Senin. 1971. Uranium Concentration in Recent Oceanic Sediments of Water Uprise Zones. Geokhimiya. No. 4:456-62. (in Russian).

Uranium concentration in recent oceanic sediments in water uprise zones (i.e., of permanent ascending currents) is several times higher near the shores of continents in comparison with deep-sea oceanic sediments. Biogenic and diagentic phosphates, which are present in these sediments, accumulate up to $10-3$ to $10-2 \%$ of uranium. In both cases uranium concentration occurs by the way of extraction from sea water. Uranium precipitation in these regions is connected with the accumulation of organic matter and phosphorus in bottom sediments and with hydrogen sulfide contamination of benthonic waters. The intensive supply of organic matter and phosphorus to sediments of shelf zones is conditioned by their high biological productivity and by periodical mass starvations of the fauna. (auth)

Be11, J. T., C. F. Coleman, D. A. Costanio arid R. E. B1ggers. 1973. Plutonium Polymerization-III The Nitrate Precipitation of Pu (IV) Polymer. Journ. Inorg. \& Nuclear Chem. 35:629-632.

The precipitation of aged $\mathrm{Pu}$ (IV) polymer by $\mathrm{HNO}_{3}, \mathrm{LiNO}_{3}, \mathrm{Al}\left(\mathrm{NO}_{3}\right)_{3}$ and $\mathrm{NaNO}_{3}$ has been observed. With the exception of $\mathrm{LiNO}_{3}$, the precipitation of $0.00678 \mathrm{M} \mathrm{Pu}(\mathrm{IV})$ polymer was dependent of the source of $\mathrm{NO}_{3}$, and the maximum amount of precipitated polymer occured at $28 \mathrm{NO}_{3}$. Further addition of $\mathrm{NO}_{3}$ redissolved the polymer. The nitrate precipitation of $\mathrm{Pu}$ (IV) polymer has been analyzed according to the solubility product principle and has been found to closely resemble a solubility product mechanism. (auth)

Bell, J. T., D. A. Costanzo and R. E. Biggers. 1973. Plutonium Polymerization-II Kinetics of the Plutonium Polymerization. Jour. Inorg. \& Nuclear Chem. 35:623-628.

Experimental data for the distribution of $\mathrm{Pu}$ (III), $\mathrm{Pu}$ (IV), $\mathrm{Pu}(\mathrm{V}), \mathrm{Pu}(\mathrm{VI})$ and $\mathrm{Pu}(\mathrm{IV})$ polymer have been used to calculate the rates of polymerization of $\mathrm{Pu}(\mathrm{IV})$. The rate of formation of $\mathrm{Pu}$ (IV) polymer is proportional to the first power of the Pu(IV) concentration and to the inverse square of the acidity as long as the solution contains a detectable amount of Pu(IV). When the concentration of Pu(IV) is not detectable, the rate of polymerization is proportional to the product of the square ronts of the $\mathrm{Pu}(\mathrm{V})$ and (III) concentrations. When the concentrations of both the Pu(IV) and (III) are nut detectable, the rate of polymerization is proportional to the product of the squares of the $\mathrm{Pu}(\mathrm{V})$ and the acid concentrations and to the inverse first power of the Pu(VI) concentration. (auth) 
Be11, K. G. 1960. Deposition of Uranium in Salt-Pan Basins. U.S.G.S. Professional Paper No. 364-G:161-9.

Drainage waters carry minute quantities of uranium into oceans, inland seas, and lakes, and when bodies of water evaporate completely in desiccating salt-pan basins, the uranium must be deposited together with all other dissolved materials. The ratio of uranium to total evaporite sediments is approximately $1: 2 \times 10^{7}$. The distribution of uranium in salt-pan basin sediments is not completely known. Some organic-rich muds, and phosphatic sediments deposited in desiccating basins may contain uranium in amounts as large as $0.0 x$ percent. Uranium may be adsorbed on clays that are deposited with some evaporite sediments. These muds, phosphatic sediments, and clays may remove nearly all of the dissolved uranium from the water of some basins. Anhydrite, gypsum, halite, and potassiumbearing evaporite minerals probably are the lease uraniferous of all rocks in the earth's crust; their uranium contents generally are less than 0.00001 percent. Within salt-pan basins where oxidizing conditions tend to prevail, and no significant amounts of organic-rich muds, clays, and phosphatic sediments are deposited, highly soluble uranium salts remain in solution and are deposited only as the basin finally is completely desiccated. These final highly soluble evaporite sediments are not likely to be preserved because they are subject to removal by wind erosion and leaching. (auth)

Blaine, D. E., R. A. Schwind, H. W. Kirby and E. L. Murphy. 1974. NewProcess for Removing Plutonium from Waste Water-A Progress Report. Proceedings of the Second AEC Environmental Protection Conference, Albuquerque, New Mexico. Apri1 16-19, 1974. WASH-1332-74-V-1: 321-338.

A process is under development at Mound Laboratory to remove ${ }^{238} \mathrm{Pu}$ from process water prior to discharge. The contaminated water normally is in the $\mathrm{pH}$ range of 6-8. Under these conditions, plutonium in all of its oxidation states is hydrolysed and exists mostly in a colloidal or polymeric state. Pilot plant tests show that a continuous fixed bed phosphate treatment of unprocessed influent waste water is feasible. However, treatment. with ferric hydroxide and polyelectrolytes is necessary to remove colloidal or polymeric plutonium before contact with calcium-hydroxyapatite. The apatite removed essentially all of the ionic plutonium but permitted the colloidal or polymeric species to pass through. Centrifugation or ultracentrifugation after processing removed $70-85 \%$ of the $\mathrm{Pu}$ in effluent solution which leads to the conclusion that colloids and polymers are not adsorbed. 
Boberg, W. W. and D. D. Runnel1s. 1971. Reconnaissance Study of Uranium in the South Platte River, Colorado. Econ. Geol. 66:435-50.

The South Platte River in Colorado drains areas of crystalline and sedimentary rocks. The water is a sodium-calcium-sulfate-chloride type throughout its length of flow in Colorado. The concentration of uranium in the water of the South Platte during the winter of 1969 to 1970 ranged from $5 \mathrm{ppb}$ to $67 \mathrm{ppb}$, making it anomalously. rich in uranium in comparison with most other rivers of the world. The concentration of uranium increases downstream, in contrast to the decrease in uranium concentration observed in other rivers that drain areas with known deposits of uranium. The South Platte contains a higher concentration of uranium than either the Colorado or North Platte rivers, despite the fact that the latter two rivers drain ore-producing areas of the United States. It is likely that most of the uranium in the South Platte is contributed by uraniferous coal seams in the Cretaceous Laramie Formation and by uranium-rich black shales in the Cretaceous Pierre Formation. The possibility that undiscovered deposits of uranium ore are present in the drainage basin of the South Platte cannot be excluded, but no major deposits are known. Use of the parameter "incremental areal uranium-1oad" permits certain portions of the drainage basin to be recognized as contributors of anomalously large amounts of uranium to the river. In the headwaters of the South Platte the incremental areal uraniumload is a low $0.00018 \mathrm{~kg} \mathrm{U} / \mathrm{day} / \mathrm{km}^{2}$, whereas for the increment of drainage between Weldona and Balzac, Colorado, the incremental areal uranium-load is $0.016 \mathrm{~kg} \mathrm{U} /$ day $/ \mathrm{km}^{2}$. This parameter may be useful for hydrogeochemcal prospecting for uranium ore in other areas. The concentration of uranium in the interstitial water of the alluvium in cutoff meanders varies seasonally, but there is no clear-cut evidence for precipitation of uranium minerals. Measurements of $\mathrm{Eh}, \mathrm{pH}$, and total vanadium in interstitial waters indicate that neither uraninite, coffinite, nor carnotite is stable. (auth)

Bonatti, E., D. E. Fisher, 0. Joensuu, and H. S. Ryde11. 1971. Postdepositional Mobility of Some Transition Elements, Phosphorus, Uranium, and Thorium in Deep Sea Sediments. Geochim et Cosmochim. Acta. 35:189-201.

Deep sea hemipelagic sediments from the east Pacific show an oxidized upper zone of variable thickness and a reduced zone below. The geochemistry of a core from this region was studied in detail. The Eh of the upper zone is close to $+100 \mathrm{mV}$, while in the lower zone it reaches about $-400 \mathrm{mV}$. Reducing conditions in the lower section of the core are related to the oxidation of organic matter in the sediment, as indicated by the gradual decrease with depth of the concentration of nitrogen in the upper part of the core. Various elements, such as $\mathrm{Mn}, \mathrm{Ni}, \mathrm{Co}, \mathrm{P}$ and $\mathrm{La}$, are enriched in the upper oxidized zone, while $\mathrm{Cr}, \mathrm{V}, \mathrm{U}$ and $\mathrm{S}$ are enriched in the lower reduced zone. Postdepositional mobility of the elements in question, mainly by diffusion in the interstitial solutions, can cxplain thcir distribution in the core. Redox reactions can account directly for the mobilization of $\mathrm{Mn}, \mathrm{Ni}, \mathrm{Co}, \mathrm{Cr}, \mathrm{V}$ and $\mathrm{U}$, indirectly for that of $\mathrm{P}$ and $\mathrm{La}$. $\mathrm{Fe}$ and $\mathrm{Cu}$ do not migrate significantly, since they are immobilized as 
sulfides in the reduced zone. Th appears not to be affected by diagenetical mobility. Some of the consequences of the postdepositional mobility of elements in deep sea sediments are: (1) The average elemental content of deep sea sediment, generally estimated from measurements of samples from the upper part of the sediment column, may be affected by errors; namely, an overestimation in the case of $\mathrm{Mn}, \mathrm{Ni}, \mathrm{Co}, \mathrm{P}$ and $\mathrm{La}$; an underestimation in the case of $\mathrm{V}, \mathrm{Cr}$ and $\mathrm{U}$. (2) Postdepositional redistribution of $\mathrm{U}$ may introduce errors in age determinations of sediments by the $230 \mathrm{Th} / 232 \mathrm{Th}$ and $230 \mathrm{Th} / 23 \mathrm{~T}_{\mathrm{Pa}}$ methods. (3) Some geographical variations in the composition of $\mathrm{Fe}-\mathrm{Mn}$ nodules can be explained by postdepositional mobility of $\mathrm{Mn}, \mathrm{Ni}$ and Co. (auth)

Bondietti, E. A. 1974. Adsorption of Pu(IV) and Th(IV) by Soil Colloids. Agronomy Abstracts.

The tetravalent actinides, $\mathrm{Pu}$ and Th, are extensively hydrolyzed in aqueous solutions above $\mathrm{pH} 2$ in the absence of complexing agents. Adsorption consequently involves interactions of hydrolytic species. Calciumsaturated, reference clays (montmorillonite and kaolinite) removed similar amounts (about 95\%) of the $\mathrm{Pu}$ and Th from the aqueous phase in batch equilibration studies at $\mathrm{pH}$ 6.5. Calcium humate removed $99.9+\%$. Desorption by Ca-citrate was extensive from the clays $(10-30 \%)$, while from humic acid less than 1\% was removed. Stronger complexers (DTPA and EDTA) were required for appreciable removal (20-30\%) of $\mathrm{Pu}$ or Th from humic acid. Soil fulvic acid also effects desorption. Adsorption-desorption studies of a soil clay (Miami silt loam) showed that removal of organic matter (0.M.) by $\mathrm{NaOCl}$ oxidation reduces the adsorption of $\mathrm{Pu}$, and $\mathrm{Fe}+0 . \mathrm{M}$. removal is not appreciably different from $0 . M$. removal alone. In all cases, however, greater than $95 \%$ of the $\mathrm{Pu}$ was adsorbed. A mixed organichydroxy complex is proposed for the reaction of Th(IV) and Pu(IV) with humic substances. The possible role of organic matter in environmental $\mathrm{Pu}$ chemistry will be discussed. (auth)

Bondietti, E. A., S. A. Reynolds, and M. H. Shanks. 1975. Interaction of Plutonium with Complexing Substances in Soils and Natural Waters. IAEASM-199/51.

The reactions of $\mathrm{Pu}$ with selected organic substances found in the environment have been studied to evaluate the valence and metal-complex behavior of $\mathrm{Pu}$. Hexavalent $\mathrm{Pu}$ (and by inference pentavalent $\mathrm{Pu}$ ) was unstable in the presence of fulvic acid, polygalacturonic acid, and alginic acid. Citrate-Pu(VI) complexes, however, were relatively more stable. Plutonium (IV) was the most stablc valence upon interaction with these organics. Further reduction of $\mathrm{Pu}$ (IV) to $\mathrm{Pu}$ (III) occurred by fulvic and humic acids. The reduction, under aerobic conditions, does not appear to occur above $\mathrm{pH}$ 3.1. The reduction mechanism is probably similar to the Fe(III) reduction previously documented for phenolic humic substances. 
Data are presented that demonstrate that $\mathrm{Pu}$ is at least partially associated with humic materials in ORNL soil contaminated 30 years ago with trace levels of $\mathrm{Pu}$. Desorption studies using solid exchange resins also showed that, while a cation exchange resin did not desorb Pu from soil after 14 weeks equilibration, chelating resin effected $\mathrm{Pu}$ desorption. The desorption rate was not constant, suggesting differential $\mathrm{Pu}$ forms. While the resin-extractable $\mathrm{Pu}$ was believed to originate from solid-phase organic complexes, over $80 \%$ of the $\mathrm{Pu}$ in this soil was not readily resin-desorbable. This indicates that more inert soil-Pu reaction products effectively immobilize soil Pu. Some of these associations also appear to be organic. (auth)

Borkov, F. P., N. E. Egorov, and E. V. Zaitsev. 1971. Peculiarities of Formation of an Increased Uranium Concentration in Oxidizing Conditions. Izv. Vyssh. Ucheb. Zaved., Geol. Razved. 14:51-7:(in Russian).

The peculiarities of the formation of an enhanced $U$ concentration under oxidizing conditions were examined. Similar concentrations are generally adapted to an oxidation zone of $U$ deposits and are scarcely ever encountered in rocks with a Clark content of uranium. The $U$ concentrations in oxidation zones of rocks with normal or somewhat increased Clark radioactive elements are usually adapted to regions of arid climate, and their formation is considered to be a result of an evaporative concentration of elements in ground waters (insolation). The $U$ concentrations in the ore phenomena under consideration did not agree with these notions, but instead are examples of favorable geological conditions and geochemical circumstances. An epigenetic accumulation of $U$ might occur under conditions of an oxidizing medium through its fixation in the hexavalent state. (auth)

Breger, I. A. 1974. The Role of Organic Matter in the Accullulation of Uranium. The Organic Geochemistry of the Coal-Uranium Association. IAEASM-183/29. IN:Formation of Uranium Ore Deposits pp. 99-124.

Geochemical studies have been carried out on 64 specimens of coalified logs from Triassic and Jurassic uranium-bearing sediments of the Colorado Plateau and from Paleocene and Eocene sediments of Wyoming. These logs contain from 0.0005 to $16.5 \%$ uranium. Autoradiographic studies and observations of relative reflectivities of uraniferous and non-uraniferous specimens demonstrate that uranium was introduced into the coal epigenetically in solution along micro-faults and/or shrinkage cracks. Following its introduction, probably as a complex alkali uranyl carbonate, the uranium was reduced by the coal to form uraninite or coffinite.

Data indicate that radiation from the uranium and its equilibrium daughter products causes radiochemical dehydrogenation and demethanation of the coal. This transformation results in significantly higher reflectivity and hardness related to cross-linking that produces diamond-like clusters of 
carbon atoms. Irradiation of the coal does not cause its rank to rise to that of anthracite.

Organic sulphur contents up to $13.1 \%$ have been noted for coalified logs of Triassic age from the San Rafael Swell area. Such unusual values have been attributed to the interaction between the coal and hydrogen sulphide from underlying sediments at temperatures of 110 to $120{ }^{\circ} \mathrm{C}$ corresponding to burial under about $3000 \mathrm{in}$. of overburden. If uranium was introduced into the sediments following the interaction between the coal and the hydrogen sulphide, this mineralization could not have occurred before Late Cretaceous time.

This work, in context with previous studies, has led to a generalization of principles underlying the association of uranium with coal. (auth)

Breger, I. A., M. Deul, and R. Meyrowitz. 1955. Geochemistry and Mineralogy of a Urainferous Subbituminous Coal. Econ. Geol. 50:610-24.

A sample of subbituminous uraniferous coal from the Red Desert, Sweetwater County, Wyoming, has been studied mineralogically. The coal contains gypsum $(6 \%)$ kaolinite $(1 \%)$, quartz $(0.3 \%)$, calcite (trace), and limonite (trace). This suite of minerals and the absence of pyrite show that the coal has been subjected to weathering and oxidation. No uranium minerals have been found; mechanical fractionation has indicated that the uranium is associated with the organic constituents of the coal. The minerals that have been isolated contain $0.0006 \%$ uranium, a content that is to be expected for nonuraniferous sedimentary rocks. The organic components of the coal contain approximately $0.002 \%$ uranium. On the basis of materialbalance calculations, the organic components carry $98 \%$ of the uranium in the coal. Batch extraction of the Wyoming coal with $6 \mathrm{~N}$ hydrochloric acid leads to the solution of almost $90 \%$ of its uranium. Recovery of uranium is independent of the particle size of the coal between -4 and -20 mesh, and is accompanied by the solution of approximately $70 \%$ of the inorganic constituents (ash) of the coal. The extract contains, together with uranium, a concentration of several element.s such as manganese, cerium, and vanadium that are present in the coal. Fischer assays of this weathered coal from the Red Desert indicate a yield of 16.7 gallons of tar per ton. Yields of both tar and char are about 15\% lower if the coal is first treated with $6 \mathrm{~N}$ hycrochloric acid to extract the uranium. It is suggested that uranium was introduced into the coal by means of ground water carrying soluble alkaline or alkaline earth uranyl carbonate complexes. The mineral schroeckingeritc-a similar complex-is found near this subbituminous coal in the Red Desert of Wyoming. These complexes, which are unstable in acid medium, release the uranyl ion $\left(\mathrm{UO}_{2}{ }^{++}\right)$, which may then react with organic constituents of the coal to form ionic uranyl-organic compounds that are insoluble above a pH of about 2.2. Preliminary data indicate that the uranium is associated with various humic components of the coal. The distribution of uranium among the components of the subbituminous coal from Wyoming is similar to the distribution in a lignite from South Dakota. There is no indication that uranium was intrijduced into 
or retained by the two coals by appreciably different geochemical processes. (auth)

Browne11, L. E., G. R. Chiaaramonte, and R. E. Issacson. 1970. A Stopper for Radioactive Wastes. ARH-1658.

The recommendations of the National Academy of Sciences National Research Council Committee on Geologic Aspects of Radioactive Waste Disposal have been reviewed noting that "the concept the Committee favors above all others (is) a procedure of disposal involving concentration of radioactive solutions, their conversion to almost insoluble solids, and subsequent burial far below freshwater aquifers in a Tmost impermeabTe rock....". This objective may be fulfilled by conversion of radioactive wastes to insoluble silicates similar to basalt and stable in basalt-water systems. A very dense basalt with almost zero transmissibility at a depth between 3,000 and 3,200 feet below surface at Hanford, Washington should prove ideal for such isolation. Cesium would be trapped as pollucite--a cesium aluminum silicate clathrate, strontium as strontium anorthite and plutonium as plutonium silicate an anlog of zircon. Pollucite, anorthite and zircon are stable. mineral rocks. (auth)

Bukhsh, M. N., J. Flegenheimer, F. M. Hall, A. G. Maddock, and C. F. de Miranda. 1966. The Chemistry of Protactinium. The Fluoro-Complexes IN: Physico-Chimie Du Protactinium. No. 154. Colloques International Du Centre National De La Recherche. Scientifique. pp. 181-188.

Ion-exchange and conductimetric titration experiments suggest the existence of the $\mathrm{PaF}_{8}{ }^{3-}$ anion. Pure samples of $\mathrm{K}_{2} \mathrm{PaF} 7$ and $\mathrm{Na}_{3} \mathrm{PaF}_{8}$ have been prepared and analyzed. The salt $\mathrm{KPaF}_{6}$ has been made, but a completely pure product could not be obtained from solution. Some observations have been made on the I.R. and n.m.r. spectra of the three complexes. Using an electrochemical method a preliminary set of values for the successive complexing constants $k_{1-8}$ for the protactinium fluoro-complexes has been obtained.

Burney, G. A. and R. M. Harbour. 1974. Radiochemistry of Neptunium. NAS-NS-3060. Tech. Info. Center, or. uf Info. Serv. USAEC.

The book deals with general properties and solid and solution phase chemistry of neptunium. The methods of analysis and procedures for separating neptunium from various materials are also discussed.

Calvo, M. M. 1974. The Role of Humic Natural Organic Matter in Uranium Concentration. IAFA-SM-183/33. IN: Formation of Uranlum Ure Deposits.

The paper reports a short experiment on the metallogenetic aspect of the uranium-organic matter association in nature. The author carried out several experiments on uranium fixation by organic matter with different 
degrees of maturity. Although further studies are considered necessary, the results already obtained lead to the following conclusions: When uraniferous solutions come into contact with humic organic matter, the efficiency and nature of the uranium-organic matter association thus established depends on the degree of carbonization attained by the humic material. At the beginning of the development process, the organic matter has high chemical activity and the uranium tends to occur in stable organic phases. As the process continues, a stage is reached from which uranium tends to form its own minerals independently of organic matter. From the coalification stage onwards the tendency towards uranium-organic matter association becomes increasingly less in any form. Petrographically the humic constituents to which uranium is closely and positively related beiong to the huminite maceral group. Lastly, it is considered that when the organic matter is present as an accessory constituent in other sedimentary rocks and with quite low maturity indices, there is greater favourability for the formation of uranium deposits. (auth)

Campbe11, D. 0. 1966. Studies of the Behavior of Protactinium in Sulfuric Acid. IN: Physico-Chimie Du Protactinium. No. 154. Colloque-Internationaux Du Centre National De La Recherche Scientifique. pp. 209-224.

Our studies of the chemistry of protactinium in sulfuric acid solutions have continued, utilizing primarily the solvent extraction method. Emphasis has been placed on the behavior at relatively high protactinium concentrations, up to several $\mathrm{mg} / \mathrm{ml}$. Data is reported for extractions into $0.03 \mathrm{M}$ trilaurylamine from $2.5,3.2$, and $4.17 \mathrm{M}$ sulfuric acid. In all cases a reasonably constant extraction coefficient is observed if the protactinium concentration in the aqueous phase is below about $0.004 \mathrm{mg} / \mathrm{ml}$, but at higher. concentrations extraction increases sharply. Above $0.01 \mathrm{mg} / \mathrm{ml}$ consistent extraction coefficients are observed for the higher acid concentrations, but for $2.5 \mathrm{M}$ acid results are not reproductible. Rates of extraction are very slow for the higher protactinium concentrations. The change in extraction behavior with protactinium concentration is interpreted in terms of the existence of several species which are probably polymeric in protactinium. At least two of these are extractable, but the species formed at higher protactinium concentrations are inextractable although they reach quilibrium with the extractable species very slowly.

Preliminary results are presented for measurements of the ultraviolet absorption spectra. Three different spectra have been observed for protactinium in concentrated sulfuric acid,depending on the source of protactinium. This indlcales lhat the spectra may yicld some evidence about species in these solutions. 
Casso1, A., L. Magon, R. Portanova, and E. Tondel10. 1972. Hydrolys is of Plutonium (VI): Acidity Measurements in Perchlorate Solutions. Radiochimica Acta 17:28-32.

The hydrolysis equilibria of the plutonyl (VI) ion have been studied at $25{ }^{\circ} \mathrm{C}$ in solutions with $1 \mathrm{M}(\mathrm{Na}) \mathrm{ClO}_{4}$ by e.m.f. measurements of $\left[\mathrm{H}^{+}\right]$. The experimental data obtained at various PuVI concentrations in the range $0.1-$ $30 \mathrm{mM}$ indicate that the main hydroxo complexes are polynuclear. Several combinations of hydrolysis products were tried in order to get the best fit with the data, using graphical procedures and a least squares program. It is concluded that, in the range of $\bar{n}$ values from 0 to 1 , the species produced in important amounts and their equilibrium constants are: $\left[\mathrm{PuO}_{2}\right.$ $\left.\left.(\mathrm{OH})]^{+}, \log { }^{*} \mathrm{~B}\right] 1=-5.97 \pm 0.05 ;\left[\mathrm{PuO}_{2}\right)_{2}(\mathrm{OH})_{2}\right]^{2+}, \log { }^{*} \mathrm{~B}_{22}=-8.51 \pm 0.05$; $\left[\left(\mathrm{PuO}_{2}\right)_{3}(\mathrm{OH})_{5}\right]+, \log \star_{B_{53}}=-22.16 \pm 0.03$.

Christenson, C. W., M. G. Ettinger, G. G. Robeck, E. R. Hermann, K. C. Kohr, and J. F. Nowe11. 1951. Removal of Plutonium from Laboratory Wastes. Ind. \& Eng. Chem., 43: 1509-1515.

Methods investigated for Pu removal included adsorption on Kaolin, pumice, tuff, Celite and activated carbon, alum and iron flocs pH adjusted with $\mathrm{Ca}(\mathrm{OH})_{2}$, lime and phosphate flocs. Polyphosphates and citric acid interfered with Pu removal and formation of good flocs.

Adsorption methods resulted in larger sludge volumes-recirculation of sludges reduced sludge volume.

Cleveland, J. M. 1967. Compounds of Plutonium. IN: Wick, 0. J. (ed.). Plutonium Handbook, A Guide to the Technology. Chapter 12, 1:335-401.

Plutonium forms compounds with all of the nonmetallic elements except the noble gases and astatine, and in addition forms many complex compounds containing more than one other element. A number of these compounds have been studied extensively and are now quite well known; other compounds, while known to exist, have received only a minimum of attention. Plutonium (III) and (IV) form a number of stable compounds; fewer compounds of Pu (V) and $\mathrm{Pu}$ (VI) are known, and they are less stable than the corresponding uranium compounds. Plutonium compounds tend to vary slightly in stoichiometry and hydration depending on the method of preparation; careful control of conditions is required, therefore, to prepare componinds with reproducible. compositions. (auth)

Cleveland, J. M. 1967. Solution Chemistry of Plutonium. IN: Wick, 0. J. (ed.), Plutonium Handbook, a Guide to the Technology. Chapter 13, 1:403= 520.

The chemistry of plutonium in aqueous solutions is, in every sense of the word, complex. The multiplicity of oxidation states in solution and the 
involved equilibrium and kinetic relationships between them, combined with the strong complexing tendencies of Pu(IV) ions, result in a very

complicated system with countless opportunities for fundamental research. The process applications of these chemical properties are widespread. There has been considerable interest in the molten-salt chemistry of plutonium, and this field promises to become increasingly important. The status of research in these systems is reviewed at the end of this chapter. (auth)

Cleveland, J. M. 1970. The Chemistry of Plutonium. Gordon and Breach Science Publishers, New York.

The book gives a detailed account of general principles, solution chemistry, solid compounds, and chemical processing of plutonium.

Cohen, P. 1961. An Evaluation of Uranium as a Tool for Studying the Hydrogeochemistry of the Truckee Meadows Area, Nevada. J. Geophys. Res. $66: 4199-4206$.

Forty-seven water samples collected in the Truckee Meadows, an alluviated intermontane basin in western Nevada, were analyzed for uranium and for the principal dissolved constitutents. Some of the relationships between uranium and other chemical constituents described by other writers are verified in the study of the hydrogeochemistry of the Truckee Meadows area; others are not. The following relationships between uranium and bicarbonateplus-carbonate content, uranium and chloride content, and uranium and sulfate content were observed in the waters of the Truckee Meadows area: uranium content tends to increase as the bicarbonate-plus-carbonate content increases; thermal, chloride-rich waters of the Steamboat Springs area are relatively deficient in uranium; and some waters high in sulfate content are relatively rich in uranium; others are not. Because of the variability in concentration and the complex interrelationships between the bicarbonate, carbonate, sulfate, and chloride anions, and because uranium content appears to be dependent upon these variables, uranium has little value as a tool for studying the hydrogeochemistry of the area. (auth)

Cordfunke, E. H. P. 1969. The Chemistry of Uranium-Including Its Applications in Nuclear Technology. Elsevier Publishing Company. Amsterdam. $250 \mathrm{p}$.

The buok deals with the extrictive metallurgy, properties of the met.al, interaction with other metals, solid compounds, solution species and their reactions, applications in nuclear technology, and analytical chemistry of uranium. 
Costanzo, D. A., R. E. Biggers and J. T. Bell: 1973. Plutonium Polymerization - I. A Spectrophotmetric Study of the Polymerization of Plutonium (IV). Jour. Inorg. and Nuclear Chem. 35:609-622.

Standard spectra of the Pu species have been observed and then used in the calculations of the distribution of Pu(III), (IV), (V), (VI), and polymeric $\mathrm{Pu}(\mathrm{IV})$ in solutions containing $\sim 0.009 \mathrm{M}$ metal $\mathrm{Pu}$ at initial acidities of $0-1,0-075,0-06$ and $0-04 \mathrm{M} \mathrm{HNO}_{3}$, and at $25{ }^{\circ} \mathrm{C}$ and $75{ }^{\circ} \mathrm{C}$. The distributions of the $\mathrm{Pu}$ species are given for the four acidities at $25{ }^{\circ} \mathrm{C}$, and the distributions are given for the initial acidity of $0-075 \mathrm{M} \mathrm{HNO}_{3}$ at $25{ }^{\circ} \mathrm{C}, 50{ }^{\circ} \mathrm{C}$ and $75{ }^{\circ} \mathrm{C}$.

In these studies the polymer is not formed when the initial acidity is $0-1 \mathrm{M}$ and the temperature is $25^{\circ} \mathrm{C}$, but the degree of polymerization continuously increases at the lower aciditics and is almost quantitalive when the inftial acidity is 0-04 M. The effect of an increasing temperature is to increase the rate of polymerization at the expense of the ionic. Pll species. The amount of polymer formed at $75{ }^{\circ} \mathrm{C}$ is $儿 3-5$ times as great as the amount at $25^{\circ} \mathrm{C}$ when the initial acidity is 0-075 M. (auth)

Cuddihy, R. G., R. 0. McClellan, L. D. Chapman, J. R. Wayland and V. L. Dugan. 1975. Simulation Modeling of Environmental Transport and Health Consequences of Radioactive Effluents from Nuclear Power Systems, IAEA-SM-199/107.

Developing programs for widespread production of electrical power from nuclear reactor systems require detailed analyses of anticipated radioactivity releases, environmental contamination and potential impact upon human health. This report describes a simulation model of the environment, including man, developed to study evaluations of risks associated with radioactive releasefrom nuclear fuel cycle facilities. Ihe model provides predictions of the. tilile-relaled development of potential health effects in human populations and facilitates the determination of the sensitivity of resulting risk estimates to the many rate constants, physical variables and siting assumptions incorporated into the mode1. Initial modeling efforts have been directed toward releases of transuranic elements from the Liquid Metal Fast Breeder Reactor fuel cycle including $238 \mathrm{Pu}, 239 \mathrm{Pu}, 240 \mathrm{Pm}, 241 \mathrm{Am}, 242 \mathrm{Cm}$ and $244 \mathrm{~cm}$. Output from the model includes estimates of tumer and genetic defect incidences related to projected growth of nuclear reactor programs through future generations. This information and the sensitivity analyses are directed toward determining the more important model pathways to man dild 1 dentlfying areas of the analysis where fundamental information is lacking. (auth) 
Dall'aglio, M., R. Grayham, and E. Locardi. 1974. Geochemical Factors Controlling the Formation of the Secondary Minerals of Uranium. IAEA-SM183/21. IN: Formation of Uranium Ore Deposits. pp. 33-48.

The formation of secondary uranium minerals directly from natural waters is examined in this paper. There is evidence of some geochemical processes which are capable of creating conditions favourable for the precipitation of secondary minerals, even when there are no primary uranium (IV) occurrences.

Direct experience indicates that at least two hydrogeochemical processes are responsible for the precipitation of secondary uranium minerals; namely (1) the leaching of crystalline rocks, even with a normal content, under particular erosion and weathering conditions in the wet temperate climatic zone. This process occurs, for instance, on the Sila Plateau in the Calatria region (Italy) where actunite is still precipitating; and (2) evaporitic processes of inland waters under arid climatic conditions, an example of which is furnished by carnotite deposits in the calcrete area of Western Australia.

In the paper the results obtained in the course of hydrogeochemical studies carried out in the Sila Plateau and in Western Australia are presented. The secondary mineral precipitation as a step towards the forming of uranium ore bodies in a multistage minerogenetic process is discussed. (auth)

Danchev, V. J., A. M. Kornilov, M. V. Neimyshev, V. V. 01 'Kha, B. K. Proshlyakov, N. P. Strelyanov, and M. P. Sytnikov. 1959. Uranium Mineralization in Carbonate Sedimentary Rocks. Geol. Rudn. Mestorozhdenii. No. 6: 26-38.

Data indicate that the formation of $U$ deposits in carbonate rocks was strongly affected by the country rocks. The $U$ in increased amounts accumulated together with organic matter in carbonate muds and oozes during the deposition of sediments in the sea bottom, as suggested by maps of ore thicknesses (isopachs). During diagenesis, simultaneously with the transformation of carbonate muds, the transition of $U$ compounds into stable mineral associations took place together with the redislribulioin of ore material (formation of conretions, replacement of faunal remnants, etc.). At a later stage the U-bearing carbonate rocks were subjected to further transformation, strongly dependent on the degree of fracturing of the ore body. Small veinlets are characteristic for this stage. The presence of liquid petroleum, usually in domes of anticlines, is a characteristic feature of $U$ carbonate deposits. The correlation of the petroleum and $U$ indicates that the ore bodies were formed before the oil migrated into them. The oil accumulation in no way affected the distribution of ore minerals, and very often the sections most impregnated by oil are practically barren, but the presence of oil (reducing environment) sharply decreases the epigenetic migration of $U$. (CA) 
Dementer, V. S. and N. G. Syromyatnikov. 1965. On the Occurrence Form of Thorium Isotopes in Ground Waters. Geokhimiya. No. 2:211-18. (in Russian).

Concentrations and occurrence forms of the thorium isotopes, ${ }^{234} \mathrm{Th},{ }^{228} \mathrm{Th}$, $230 \mathrm{Th}$, and $232 \mathrm{Th}$ were studied in some types of ground waters of Kazakhstan. The highest thorium concentrations were noted in waters containing a large amount of suspended and colloidal particles and with a high content of organic matters. With the aid of centrifugation and dialys is methods the distribution of thorium isotopes between the particles was established and found to differ by the degree of dispersion, from ionic to coarsely suspended. Differences in the behavior of isotopes with different half lives were noted and found to be apparently connected with different conditions of accumulation in natural waters. With the aid of the ion exchange method a chiefly anionic character of sorption was established. It is suggested that the transportation of thorium isotopes into ground waters is realized bulh lif a colloidal suspension form and as anionic complexes, probably with organic acids of soils. (auth)

Dorta, C. C. and E. Rona. 1971. Geochemistry of Uranium in the Cariaco Trench. Bul1. Mar. Sci. 21:754-65.

Four core samples taken during a cruise (P6603) of the R V Pillsbury from the Cariaco Trench off the coast of Venezuela, were analyzed for major, minor, and trace elements. Special attention was given to $\mathrm{Th}, \mathrm{Pr}$, and $U$. A high concentration of $U(30 \mathrm{ppm})$ was associated with the organic reducing sediment; with a 5-fold decrease in $U$ in the oxidized clay layer. This change was dated to the last glariation. No change in Th and $\mathrm{Pr}$ concentratiuil wds noted. (CA)

Duursma, E. K. 1972. Geochemical Aspects and Applications of Radionuclides in the Sea. Oceanogr. Mar. Biol. Ann. Rev. 10:137-223.

This review is intended to update the geochemical part of the earlier review by Machline and Templeton (1964), published in this same annual review series. It covers the geochemical aspects of both artificial and natural radionuclides in the sea, and attention is paid to the use of radionuclides as tracers for sediment and water transport studies. The biological aspects of radionuclides in the marine environment will be reviewed in a separate article. The majority of the literature reviewed is that published since 1963 with some mention of relevant papers published earlier but not included in the review of Mauchline and Templeton (1964). (auth)

Duursma, E. K., and P. Parsi. 1974. Distribution Coefficients of Plutonium Between Sediment and Seawater. IN: Activities of the International Laboratory of Marine Radioactivity. IAEA-163:94-96.

The authors using a ${ }^{237} \mathrm{Pu}$ as a tracer, conducted a series of experiments to determine the distribution coefficient of plutonium on to sediments under 
oxic and anoxic conditions. The plutonium was added in three different valence states; III, IV, and VI. All three valence states showed Kd values in order of $10^{4}$ for both anoxic and oxic conditions. The authors speculate that $\mathrm{Pu}$ (IV) enters adsorption phenomenon, while $\mathrm{Pu}$ (III) and $\mathrm{Pu}$ (IV) may be precipitating in addition to active reactions.

Edgington, D. N., J. J. Alberts, M. A. Wahlgren, J. 0. Kartitunen and C. A. Reeve. 1975. Plutonium and Americium in Lake Michigan Sediments. IAEASM- 199/47.

The vertical distributions of $239,240 \mathrm{Pu},{ }^{238} \mathrm{Pu}$, and ${ }^{137} \mathrm{Cs}$ have been measured in sediment cores taken from Lake Michigan. Sections from a limited number of cores have been analyzed for $241_{\mathrm{Am}}$. In addition, grab samples from ten locations in the southern basin of the lake have been analyzed for phase distribution of $239,240 \mathrm{pu}$ using a sequential extraction technique.

The results indicate that the ${ }^{239,240} \mathrm{Pu},{ }^{238} \mathrm{Pu}$, and ${ }^{137} \mathrm{Cs}$ from weapons testing, and the $241 \mathrm{Am}$ formed in situ are concentrated in the sediments. A comparison of the total deposition of $239,240 \mathrm{Pu}$ deposition in the sediments. Values of the $238 \mathrm{pu} / 239,240 \mathrm{pu}$ ratio are in agreement with values reported in Lake Ontario sediments (and Lake Michigan plankton) and show little variation with depth. 241 Am data support the concept of in situ production with little preferential mobility after formation.

Studies of sedimentary phase distributions show that $239,240 \mathrm{Pu}$ is associated with hydrous oxide phases which are chemically stable under the prevailing conditions in the lake sediments. Since Lake Michigan sediments remain aerobic, relatively little $239,240 \mathrm{Pu}$ is available for chemical mobilization from the hydrous oxide or organic phases present in the sediments. (auth)

Ekstrom, A. and A. B. McLaren. 1971. The Kinetics and Mechanism of the Oxidation of Pu(IV) by Ce(IV) in Sulfate and Nitrate Media. Journ. Inorg. \& Nuclear Chem. 33:3511-3520.

The oxidation of $\mathrm{Pu}$ (IV) by $\mathrm{Ce}$ (IV) was studied in the presence of sulphate and nitrate ions. The rate of reaction is strongly inhibited by sulphate ion, being inversely proportional to between the square and cube of the $\mathrm{HSO}_{4}^{-}$concentration at a given acid concentration. In the range 10-3 $10-1 \mathrm{M}$ nitrate, the reaction rate is independent of nitrate concentration, but is inversely proportional to the square of the hydrogen ion concentration. Possible reaction mechanisms consistent with the observed data are discussed. (auth) 
Erametsa, 0., K. J. Lounamaa, and M. Haukka. 1969. Vertical Distribution of Uranium in Finnish Peat Bogs. Suom. Kemistilehti B. 42:363-70.

$U$ has a rather high tendency to escape from the 7 ithosphere into the hydrosphere. It is transported mainly in the form of the highly stable uranyl dicarbonate and tricarbonate complexes. Humic acids also form stable complexes with $U$. The capture and the distribution of $U$ from ground waters by solid humic acids was studied in 14 arbitrarily chosen peat bogs scattered in different parts of Finland. The uranium concentration generally peaks to a very sharp maximum at a level beginning $1 / 4$ from the bottom of the bog. In every other bog, at the depth mentioned, the $U$ content exceeded the detection limit of $30 \mathrm{mg} / \mathrm{kq}$ in ash. The method of analysis was by $X$-ray fluorescence, as developed, to detect small amounts of substance. The maximum conçentration was $1450 \mathrm{mg} \mathrm{V} / \mathrm{kg}$ in agh. The amount uf $U$ was evenly distributed over the total bog area. In 1 bog the distribution of $\mathrm{Pb}$ and $\mathrm{Ni}$ was compared with the distribution of $\mathrm{U}$. (CA)

Ermolaev, N. P., A. P. Zhidikora, and V. A. Zarinski. 1965. On the Silicate Form of Uranium Transport in Aqueous Solutions. Geokhimiya No. 7 : 813-26. (in Russian).

One of the transportation forms of uranium under certain natural conditions in the silicate aqueous solutions appears to be a hydroxyuransilicate compound with the approximate formula $\left(\mathrm{UO}_{2} \mathrm{OH}\right)\left(\mathrm{HSiO}_{3}\right)$. The hydrosilicate complex ion is considered as a group that is stabilizing hydroxyuran in a solution or the former as the addendum of a weak complex. The size of these particles (in solution) is between that of colloid and ionic particles. The established form of uranium migration in solution exists in the nearneutral and weak basir. range of $\mathrm{pH}$ and temperatures til1 $200{ }^{\circ} \mathrm{C}$, the concentrations of strong electrolytes in a solution being relatively low (i.e., not higher than the equilibrium concentration with uranyl or silicate.) The silicate form of uranium transport in carbonate aqueous solutions is destroyed and uranium forms a complex with carbonate. (auth)

Evseeva, L. S. and N. P. Fomina. 1963. Study of Oxidation-Reduction Properties of Sedimentary Uraniferous Rocks. Geokhimiya. No. 11:1050-4 (in Russian).

Oxidation-reduction properties of uraniferous sandstones and rocks of coaly-carbonaccous composition were studied. The relative oxidationreduction capacity of rocks is established by the mentioned potential being the value of the decrease of the solution-oxidant potential interactions with the rock sample. It is shown that an epigenetic enrichment of sedimentary rocks in uranium, the degree of their uranium content, is directly proportional to the value of the mentfoned potential of the rocks. (NSA) 
Fardy, J. J. and J. M. Pearson. 1974. An Ion Exchange Study of the Sulfate Complexes of Plutonium(IV). Journ. Inorg. \& Nuclear Chem. $36: 671-677$.

The sulphato-complexes of plutonium(IV) were studied at $25{ }^{\circ} \mathrm{C}$ in 1 and $2 \mathrm{M}$ perchloric acid media using the jon-exchange method of Fronaeus. Beta liquid scintillation counting of the $241 \mathrm{pu}$ normally present in plutonium samples was used to measure the distribution of plutonium between resin and solution to avoid interference from the alpha-active $24 T_{\mathrm{Am}}$. Valence instability caused problems until solutions were stabilized by the addition of ni,trite ion. Only two complexes, PuSOz- and $\mathrm{Pu}\left(\mathrm{SO}_{4}\right)_{2}$, were formed in the range of ligand concentration investigated, $5.0 \times 10-3$ to $0.2 \mathrm{M} \mathrm{HSO}_{4}{ }^{-}$The stability constants for the complex equilibria

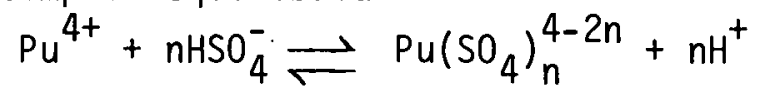

in an ${ }_{\star}$ acid perchlorate medium of ionic strength $I=2$, are $\beta_{7}^{\star}=556 \pm 16$ and $\beta_{2}^{\star}=(27.2 \pm 0.8) \times 10^{3}$. Stability constants of the sulphatocomplexes of the tetravalent actinides are tabulated and compared. The stability sequence $\mathrm{Th}^{4+}<\mathrm{U}^{4+}>\mathrm{Np}^{4+}<\mathrm{Pu}^{4+}$ generally follows the simple electrostatic model, with the reversal of the $\mathrm{Np}^{4+}$ being attributed to changes in the shape and size of the hydration shell. (auth)

Fischer, R. P. and J. H. Stewart. 1961. Copper, Vanadium, and Uranium Deposits in Sandstone - Their Distribution and Geochemical Cycles. Econ. Geo1. 56:509-20.

Deposits of copper, vanadium, and uranium in nonmarine sandstones are numerous and widespread. Copper deposits, with or without uranium, are mainly resident in first-generation arkosic sandstones derived from granitic rock terrains; deposits rich in vanadium, with or without much uranium, are dominantly in second-generation sandstones derived from sedimentary rocks; and the uranium deposits with little or no vanadium or copper are in either first-or second-generation sandstones, many of which are associated with beds containing volcanic debris. All three metals are dispersed in igneous rocks but not in close association. Copper and uranium enter the hydrothermal environment, but the record of vanadium in hydrothermal solutions and veins is scant. Some of the uranium and most of the copper minerals in igneous rocks and veins oxidize readily and the metals go into surface- and ground-water solutions, but the vanadium in igneous rocks is not so easily mobilized-under normal geologic conditions, conceivably it may require diagenetic reactions and a second period of weathering to solubilize much vanadium. All three metals precipitate from solutions in the presence of a reducing agent, such as carbonaceous material or associated sulfide ions, either in sediments as they accumulate or in existing rocks. These geochemical habits permit the concept that igneous rock terrains and hence might accumulate in first-generation sediments, whereas vanadium would be commonly available only after a second period of weathering. Perhaps the oxidation or devitrification of volcanic debris may contribute uranium to ground waters as does the weathering of igneous rocks. (auth) 
Frondel, C. The Mineralogy of Thorium. U.S.G.S. Professional Paper 300, 567-79.

A review with 40 references of the mineralogy and geochemistry of Th, and a comparison with those of $\mathrm{U}, \mathrm{Ce}$, and $\mathrm{Zr}-\mathrm{Hf}$. Tables 1 ist minerals of these elements and their components. (CA)

Fukai, R. and C. N. Murray. 1974. Adsorption and Desorption of Plutonium and Americium in Freshwater - Sediment and Seawater - Sediment Systems. IN: Activities of the International Laboratory of Marine Radioactivity. IAEA163:96-103.

The particulate and soluble fractions of added ${ }^{237} \mathrm{Pu}$ (III, IV, VI) and ${ }^{241} \mathrm{Am}$ (III) to filtered sea and river waters at various $\mathrm{pH}$ values, and adsorption and desorption of $\mathrm{Pu}$ (III and IV) and Am (III) by sediments and sewage effluents were studied.

The particulate formation is shown to be dependent upon the nature of solution and the $\mathrm{pH}$. The particulate fractions of all species increased with the increase in $\mathrm{pH}$. For river water at $\mathrm{pH} \mathrm{4}$, some 25, 20, and 30 percent of the added $237 \mathrm{Pu}$ were associated with particulate $(>0.45 \mu)$ for the III, IV, and $V$ valence states, respectively. However, there does not seem to be any particulate formation for river water at $\mathrm{pH}$ values <4.5. The percentage of particulate formation was $>60$ at $\mathrm{pH} 8$ for all species, except $\mathrm{Pu}(\mathrm{VI})$.

More than 80 percent of the plutonium was adsorbed by sediment suspensions when added as Pu(III) in $\mathrm{pH}$ range 3 to 11 and $\mathrm{Pu}$ (IV) at phin8. Adsorption of $\mathrm{Am}$ (III) was highly $\mathrm{pH}$ dependent. There was hardly any adsorption of $\mathrm{Am}$ (III) below pH 6.5 and more than 80 percent at pH 8 . The desnrption of $\mathrm{Pu}$ (III and IV) was less than 10 percent in 3-10 $\mathrm{pH}$ range, while the desorption of Am(III) showed pH dependence. The addition of sewage effluent to sediment suspensions increased the adsorption of Pu(III) by about 10 percent at $\mathrm{pH} 8.1$.

Garrels; R. M. 1955. Some Thermodynamic Relationc Amnng the Uranium Oxides and Their Relation to the Oxidation States of the Uranium Ores of the Colorado Plateaus. Am. Mineralogist 40: 1004-1021.

Fields of stability of uranium(VI) and uranium(IV) hydroxides and oxides in water solution at $25^{\circ} \mathrm{C}$ and one at atmosphere pressure have been calcu. lated as functions of Eh and $\mathrm{pH}$. Equilibrium values of the activity of $\mathrm{UU}_{2++i}+\mathrm{on}$ and of $\mathrm{U}++$ ion also have been calculated and are shown as contours on the stability fields. Thermodynamic relations among the uranium(VI) hydroxides and hydrated oxides indicate that the free energy differences among the various species are small. The data are interpreted to mean that a variety of such uranium(VI) compounds may form and even coexist. Similar studies of the uranium(IV) hydroxide indicate that it is unstable relative to the oxide and may well be expected to change to the 
oxide at a finite rate. Uranium(V) compounds probably have a transitory existence because of the instability of the $\mathrm{UO}_{2}^{7}$ ion; uranium(III) oxides and hydroxides would not be expected to occur naturally because the uranium(III) ion would decompose water. A comparison of the behavior of the vanadium(III) and (IV) hydroxides with uranium(IV) oxide and uranium(VI) hydroxides indicates that vanadium(III) hydroxide should oxidize to the vanadium(IV) hydroxide at a lower potential than that required for the change from uranium(IV) to uranium(VI). A rather highly speculative diagram showing probable fields of stability of many of the major minerals of the Colorado Plateaus is presented, and the suggestion is made that a consistent picture results if it is assumed that the ores, as viewed today, represent the superimposition of a weathering environment on a mineral assemblage that was formed in a primary reducing environment. It is emphasized that such an interpretation is consistent but not necessarily unique. (auth)

Garrels, R. M. and E. S. Larsen. 1959. Geochemistry and Mineralogy of the Colorado Plateau, Uranium Ores. U.S.G.S. Professional Paper No. 320.

The studies reported are aimed at testing the oxidation concept of $U$ ores, developing a knowledge of the stability relations of $V$ and $U$ minerals under varying conditions of $\mathrm{pH}$ and oxidation-reduction potentials, and defining the nature and equilibrium conditions of the primary (low-valent) ores. The first five parts present topical data of general application to the Colorado Plateau; parts 6 through 15 cover the results of theoretical, experimental, or empirical studies relating to the chemical and physical nature of ores and their oxidation; in parts 16 through 19 are described the geological relationships between oxidized and unoxidized ore in several ore deposits on the Plateau; part 20 concerns the broad geochemical relationships of $V$ and $U$ throughout the world. The final part summarizes conclusions and particularly emphasizes the salient problems requiring further study. (NSA)

Gel'man, A. D., A. I. Moskvin, L. M. Zaitsev, and M. P. Mefod'eva. 1962. Complex Compounds of Transuranium Elements. Trans. from Russian by C. N. Turton and T. A. Turton. Consultants Bureau. New York, 195 p.

This book contains the following chapters: complex formation by neptunium in aqueous solutions, complex formation by plutonium in aqueous solutions, synthesis and properties of some complex compounds of tri-, tetra-, and hexavalent plutonium, complex formation by transplutonium elements in solution, and application of complex compounds in the isolation and separation of transuranium elements. 
Grainger, L. 1958. Uranium \& Thorium. George Newnes Ltd. London. 204 p.

Various chapters of the book deal with uranium and thorium- from mineral to metal, chemistry of and properties, health hazards, and the use of uranium and thorium as nuclear fuels.

Grindler, J. E. 1962. The Radiochemistry of Uranium. NAS-NS-3050. 350 p.

Various chapters of the publication deal with general review of chemistry, isotopes, features (such as solution chemistry, separation of uranium, determination procedures, and dissolution) of uranium chemistry that are of chief interest to radiochemists, and collection of detailed procedures for uranium analysis.

Habashi, F. 1962. Correlation Between the Uranium Content of Marine Phosphates and Other Rock Constituents. Econ. Geo1. 57:1081-4.

Sulfate and uranium appear to be genetically related in phosphorites. From the analysis of seven samples of sedimentary phosphates of different origin, it was found that the uranium content increases with decreasing sulfate content. This is attributed to the formation of sulfate complexes of uranium during sedimentation processes. The increase of uranium content with increasing $\mathrm{P}_{2} \mathrm{O}_{5}$ content previously reported in the 1 iterature was verified. A sample of magmatic phosphate was found not to behave in a manner similar to the sedimentary phosphate. (auth)

Haglund, D. S., G. M. Friedman, and D. S. Miller. 1969. The Effect of Freshwater on the Redistribution of Uranium in Carbonate Sediments. $\mathrm{J}$. Sediment. Petrol. 39:1283-1296.

The uranium concentration of two independent carbonate sediment sample suites was studied to establish the effect of fresh water alteration on the redistribution of uranium. Recent carbonate sands and their ancient analogs were studied in Bermuda and along the east coast of the Mediterranean Sea in Israel. The results of the uranium analyses are compared to established indicators of fresh water alteration in carbonate sediments. Interpretation of the data from both areas yields the same conclusions. As the metastable minerals aragonite and $\mathrm{Mg}$-calcite are removed by fresh water from the sediment system and the sample type changes from unconsolidated carbonate sand to consolidated limestone there is a concomitant decrease in uranium content. The uranium and calcite concentrations show an inverse relation and indicate that the product of fresh water alteration, calcite, accepts less uranium than the original aragonite. The relationship between uranium and the stable carbon and oxygen isotopes for the Bermuda suite is inconclusive, whereas the same plots for the Israeli Coast suite show a direct relationship between decreasing uranium content and increasingly negative 
delta values. The relations between uranium and established indicators of fresh water alteration provide converging lines of evidence indicating that fresh water dissolution and replacement of marine carbonates cause a reduction, up to 50 percent over the Pleistocene samples, in total sample uranium content. (auth)

Higgins, G. H. 1960. The Radiochemistry of the Transuranium Elements. NAS-NS-3031. 35p.

The chemistry of transuranium elements and especially those features that are of interest to radiochemists are discussed.

Holland, H. D. and J. L. Kulp. 1954. The Mechanism of Removal of Thorium and Radium from the Oceans. Geochim. et. Cosmochim. Acta 5:214-24.

The adsorption and base exchange of Th and $\mathrm{Ra}$ on deep-sea red clay, globigerina ooze, and green clay were investigated by use of 228Th and $224 \mathrm{Ra}$ as tracers. At equilibrium the fraction of radioactivity remaining in the sea-water solution is independent of the total quantity of tracer added. Extrapolation of the data to actual concentrations of $\mathrm{Th}$ and $\mathrm{Ra}$ in sea water indicates that the concentrations of these elements in sediments is comparable to that of these expts. It is concluded that base exchange is the method by which Th and Ra are taken up by the sediments. (CA)

Horvath, E. 1965. The Laboratory Investigation of Some Factors Influencing the Aqueous Dissolution of the Uranium Contents of Rocks. Part I. At . Kozlemen. 7:85-93 (in Hungarian).

Investigations were made of how the change in the grain size of a certain rock and in the time of contact between rock and water influences the quantity of dissolved uranium. The experiments were made by percolating through andesitic granitic rocks distilled water or water containing $2 \mathrm{~g} / 1$ iter $\mathrm{NaHCO}_{3}$. On the basis of the results of the experiments it was found that the influence of grain size (i.e., the surface of sulution) of the examined rocks upon the dissolved uranium quantity is much less than expected. In the case of experiments made under identical circumstances the increase of the surface of solution with two orders of magnitude led only to a triple or fourfold rise in the concentration of the dissolved uranium. In connection with the time function of the solution it was found that the dissolving concentration which considerably increased in the beginning with the increase of the time of contact, after a certain period of time (in the case of our experyments 150-240 minutes, depending on the rock examined) does not change any more with the increase of time. (auth)

Hyde, E. L. 1960. The Radiochemistry of Thorium. NAS-NS-3004.

This book reviews the soluble and insoluble salts; complexes of thorium and radiochemical illelliods of determination of thorium. 
Imahashi, M. 1970. Uranium and Thorium in Hydrothermally Altered Rocks Under Acid Conditions. As exemplified by Silicified Rocks from Tateyama Jigokudani, Toyama. Nippon Kagaku Zasshi. 91:668-0. (In Japanese).

Uranium and thorium content in hydrothermally-altered rocks from the Tateyama Jigokudani hot spring area, Toyama, were determined in order to study the mobilities of these elements under acid conditions. The leachabilities of these elements were calculated on the basis of content. It was found that silica is not leachable during the alterations. The calculations demonstrated that 60 percent of the thorium as well as 50 percent of the uranium could be removed from original rocks. The mobilities of these elements under acid conditions are greater than those during weathering processes under neutral conditions. (auth)

Ivanov, I. V. and 0. V. Kolpakov. 1965. Geochemistry of Soils and Overburdens Over the Korobovsk Deposit. Tr. Volgog ad. Nauch.-Issled. Inst. Neft. Gaz. Prull. Nu. 8:274-28 (in Kussian).

The complex radiogeochemical survevs (auto-borne $\gamma$-survey alona 7 profiles, $\beta$-survey, and rock and soif analyses) were made in 1962 in the territory of the Korobovsk deposit. The chemical characteristics of soils (absence of sulfates, small chloride content, and $\mathrm{Mg}$ chloride composition over deposit) were ascertained, together with the decrease of $\mathrm{pH}(6.2)$ in soils over a petroleum deposit in comparison with the soils ( $\mathrm{pH} 6.9$ ) outside of the deposits and an incrase in the $\mathrm{pH}$ with increased depths. The geochemistry of radioactive elements was studied. The content of $\mathrm{Ra}$ in soils somewhat increased from clays to sands but it did not decrease over the petroleum deposits. This was attributed to a weak inigration capacity of $\mathrm{Ra}$. The largest amount of $U$ in rocks over deposits was detected in loams. The clay soils, where the sorption compensated for deficiency in U-containing mirlerals, the content of $U$ was only somewhat higher than in sands. The content of $U$ was not the same in various soils because of nigher (than for the $\mathrm{Ra}$ ) coefficient of aqueous migration of $U$. The effect of petroleum deposits was observed in argillaceous soils which contained mobile forms of $U$. The amount of $U$ in clay soils over $0 i 1$ deposits decreased by 22 percent in comparison with its content in the soils situated in areas containing no oil deposits. This is attributed to the migration of $U$ from petroliferous areas. It is suggested to investigate the following factors during study of the effects of deposit on behavior of radioactive elements: (1) the actual geochemical environment, (2) the degree of annmaly of the areas in comparison with the normal background determined by a topographic-genchemical method, (3) the anomaly in the section, and (4) migration capacity of elements and effect on it of the mineral composition of soils and rocks. (CA).

Jayaram, K.M. V., K.K. Dwivedy, M.C. Bhurat, and S.G. Kulshiestha. 1974. A study of the Influence of Microflora on the Genesis of Uranium Occurrences at Udaisager, Udaipur District, Rajasthan. IAEA-SM-183/31. IN: Formation of Uranium Ore Deposits. pp. 89-98. 
An area of $6 \mathrm{~km}^{2}$ in the vicinity of Udaisager shaft was investigated to study the role of sulphur and iron-oxidizing bacteria in the mobilization of uranium in the carbonaceous phyllites and its redeposition in breccias and the fault gouge.

The Aravalli metasediments consisting of conglomerates, phyllities, impure limestones, carbonaceous phyllites and femageous-breccia are intruded by granites and gneisses. The general strike is: $N 20^{\circ}-30^{\circ} \mathrm{W}-\mathrm{S} 20^{\circ}-30^{\circ} \mathrm{E}$ with an easterly dip of $60-85^{\circ}$.

Uranium mineralization is confined to a fault gouge in a $6 \times 200 \mathrm{~m}$ zone, at a depth of 25-45 $\mathrm{m}$ from the surface. The ore contains stringers of uraninite associated with uranyl minerals and some iron and copper sulphides. In analyses of 0.7 percent $\mathrm{FeO}, 2.31$ percent $\mathrm{Fe}_{2} \mathrm{O}_{3}, 6.3$ percent $\mathrm{C}, 2.97$ percent $\mathrm{SO}_{4}{ }^{-2}, 0.85$ percent moisture and 0.03-0.06 percent $\mathrm{U}_{3} \mathrm{O}_{8}$ and has a bacterial population of $2.3 \times 106 / \mathrm{g}$ of dry solids. It has a pH of 2.2 to 4.5 and a redox potential of -360 to $-480 \mathrm{mV}$. The ore samples show disequilibrium in favour of uranium.

Samples of the ore analysing 0.03 percent and 0.06 percent $\mathrm{U}_{3} \mathrm{O}_{8}$ yielded a leachability of 43.3 percent and 67.8 percent respectively at 60 percent P.D. (solids) in 6-h leaching time, using water alone.

The carbonaceous phyllites in the immediate vicinity analyse 3.04 percent $\mathrm{FeO}, 2.96$ percent $\mathrm{Fe}_{2} \mathrm{O}_{3}, 11.2$ percent $\mathrm{C}$. 0.11 percent $\mathrm{SO}_{4}{ }^{-2} 0.15$ percent moisture and 0.0005 to 0.0027 percent $\mathrm{U}_{3} \mathrm{O}_{8}$ with a $\mathrm{pH}$ of $7.0-8.5$ and $\mathrm{a}$ redox potential of -200 to $-280 \mathrm{mV}$.

The occurrence of significantly higher radon values in the vicinity of the shaft $\left(35.5 \mathrm{pCi} / \mathrm{cm}^{3}\right)$, the shallow nature of the deposit, absence of any major channel for waterborne transportation as indicated by resistivity surveys, the presence of elemental sulphur, soluble sulphates and microflora in the ore samples and the high leachability of uranium in water alone show that uranium is mobilized from the carbonaceous phyllites and redeposited in the fault gouge. Auth.

Kapkov, Y. N. 1969. Geochemistry of Uranium in Channel Sediments of the Stream Network in a Mountaneous Taiga Ared. Zap Leningrad Gorn. Inst. 56: 73-80. (in Russian).

A study of the dispersion processes of uranium in granitoid development showed that the basic mass of transportable material occurs in the form of thin suspensions, true and colloidal solutions, and represents a significant fraction in rock-forming minerals, perhaps as much as 75 to 98 percent. Uranium is extracted by natural waters relatively easily. It does not play an important role in accessory minerals in the total balance of river-bed deposition. The mobility and the sorption property of uranium in organic material depend on the reaction medium, which in the mountainous Siberian 
forest region, leads to leaching of the uranium from the upper strata. All this causes a high geochemical background of uranium and the formation of "concentration" flows, and difficulties in separating out the "ore" flows. (auth)

Karkhanavala, M. D. 1958. On Radioactive Uraniferous Iron Oxides. Geochim. et. Cosmochin, Acta 15:229-36.

A study has been made of uranium bearing iron oxides from the shear-zone of Bihar, with particular reference to the nature of the association of uranium with magnetite and hematite. In veins where none or very little hematitization has taken place, the primary magnetite and uraninite coexist. Where hematitization has taken place the uranium is very intimately associated with the hematite, probably as a very limited solid solution. A sample of hematite containing uranium equivalent of 0.15 percent $\mathrm{U}_{3} \mathrm{O}_{8}$ was found to be metamict, the reconstitution of which was established by $x$ ray and differential thermal analysis methods. It is believed that a primary oxidizing solution containing uranyl ions caused the oxidation of the ferrous hydrosol to magnetite and the simultaneous precipitation of uraninite. A later stage oxidizing solution or normal agents of weathering converted the magnetite to hematite and the uraninite to probably $\mathrm{U}_{3} \mathrm{O}_{8}$ or $\mathrm{UO}_{3}$, a small amount of which was then somehow taken up in the hematite lattice, and the rest being converted to secondary uranium minerals, the presence of which is known. (auth)

Katz, J.J. and E. Rabinowitch. 1951. The Chemistry of Uranium. Part I. The Element, Its Binary and Related Compounds. National Nuclear Energy Series, Div. VIII, Vol. 5, N.Y. McGraw-Hill Book Company, Inc.

A comprehensive detailed summary of the "dry chemistry" of $U$ is presented. The occurrence of $U$ in nature, its extraction from ores, and the physical and chemical properties of the metal are treated thoroughly. Binary compounds of $\mathrm{U}$ with $\mathrm{H}, \mathrm{O}, \mathrm{N}$, and the halogens, among others, receive extensive discussion, including methods of preparation and physical properties such as crystal structure, thermochemistry, and volatility. This volume is to be followed by a companion book dealing with the properties of ionic $U$ in aqueous solution. (NSA)

Katz, J. J. and G. T. Seaborg. 1957. The Chemistry of the Actinide Elements. John W1ley \& Sons, Inc., New York. $508 \mathrm{p}$.

Details regarding the nature, occurrence, preparation, isolation, determination, chemical properties, and compounds of $\mathrm{Ac}, \mathrm{Th}, \mathrm{Pa}, \mathrm{M}, \mathrm{Np}$, $\mathrm{Pu}, \mathrm{Am}$, and $\mathrm{Cu}$ are given. Bk, $\mathrm{Cf}, \mathrm{Es}, \mathrm{Fr}$, Md, and No are discussed briefly. 
Keller, C. 1971. The Chemistry of the Transuranium Elements. Kernchemie in Einzeldarsteilungen, Volume 3. Verlagchemie GmbH. Weinheim/Bergstr., Germany.

This is a comprehensive book on the chemistry of actinides ( $T h, \mathrm{~Pa}, \mathrm{U}$, $\mathrm{Np}, \mathrm{Pu}, \mathrm{Am}, \mathrm{Cm}, \mathrm{Bk}, \mathrm{Cf}, \mathrm{Es}, \mathrm{Md}, \mathrm{No}, \mathrm{Lr}$ ) and is divided into two parts. The first part deals with transuranium elements, as a whole, discussing their preparation, use and properties. The second part deals with the individual transuranium elements, emphasizing the properties and characteristics of each element.

Khalturin, G. V. and Y. P. Sevast'ganova. 1972. Standard Plutonium Nitrate and Citrate Solutions for Biological Experiments. AEC-tr-7457, pp. 303-8.

A technique is recommended for preparation of standard nitrate solutions of polymeric $\mathrm{Pu}(+4)$ with a $\mathrm{pH}$ of $1.0-2.0$ and $\mathrm{Pu}(+5)$ and for preparation of standard nitrate solutions of $\mathrm{Pu}(+6)$. It was shown that $\mathrm{Pu}(+6)$ is stable for 3 months in solutions containing 2-12 $\mathrm{m} / 1$ iter nitric acid. $\mathrm{Pu}$ $(+6)$ is unstable in solutions with a pH of 2.0. A method has been proposed for preparation of standard citrate solutions of polymeric $\mathrm{Pu}(+4), \mathrm{Pu}$ $(+4)(\mathrm{sic})$, and $\mathrm{Pu}(+6)$. It was shown at $\mathrm{Pu}(+5)$ is very unstable in citrate medium. (Auth)

Kimura, Y., H. Morishuma, T. Koga, H. Kawai and Y. Honda. 1968. Studies on the Behavior and Distribution of Radioactive Substances in Coastal and Estuarine Waters. Kinki Daigaku Genshiryaku Kenkyusho Nonpo. 7:21-31 (in Japanese).

Low-level liquid radioactive wastes are continuously disposed of from fuel processing plants or radicisotope laboratories into coastal waters. For an estimation of the influence of these disposals on our environment, the variation of concentration of thorium and rare earth elements contained in coastal and estuarine waters was investigated with the tidal change. It was observed that the concentration of thorium and rare earth elements in coastal water varied widely with the tidal change. This seems to be not only due to simple dilution by the water mass but also to the various physicochemical conditions such as salinity, $\mathrm{pH}$ or water, wind, and tidal motion. Since thorium and rare earth elements are apt to be colloidal or particulate in seawater, this character is greatly different from the case of soluble elements. (auth)

Kochenov, A.V. and G.N. Baturin. 1967. Distribution in Aral Sea Sediments. Oceanology (USSR). 7:484-7.

Sediment samples were taken by bottom grab in the period August-0ctober 1965. Uranium was determined chemically by the pearl-luminescent method. Great similarity was revealed on comparison of the areal distribution of uranium in the Aral Sea and a bottom sediment chart. The main types of sediment differ cledrly in terms of their $U$ content. The least $U(0.0001$ to 0.0002 percent) was noted in the sand and silty ooze of the coastal zone; $U$ content increased in the calcareous and argillacrous sediments of the central areas 
of the basin to 0.001 percent. Similar high contents were noted in the argillaceous sediments of the northern bays and the semi-isolated bays of the eastern shore. At the junction between fresh river water and salt seawater, $U$ content was as low as throughout the coastal zone of sandy and silty oozes, between 0.0001 and 0.0005 percent. There is a distinct correlation between uranium content in Aral Sea sediments and organic matter. It appears that as much $U$ is annually supplied to the bottom sediments as is brought in by the rivers, i.e., part of the $U$ enters the basin in solution and passes into the sediment, as a result of which the latter is enriched to several times the level of the suspended matter of the river. This explains the increased abundance ratio of uranium in the sediments of the central areas of the Aral Sea. The distribution of $U$ in the water over the area of the sea is uneven and to some extent related to general salinity; $U$ content around the river mouths where the freshening effect of the rivers is felt is $(3$ to 3.5$) \times 10^{-5} \mathrm{~g} / 1 \mathrm{iter}$, whereas in the central areas of the sea it increases to (5 to 6$) \times 10-5 \mathrm{~g} / 1 \mathrm{iter}$. The relatively low extraction of $U$ into the sediment from Aral water is apparently to be explained by its high carbonate content and oxygen saturation, and by the low content of the organic component in the sediment. (NSA)

Koczy, F. F. 1949. Thorium in Sea Water and Marine Sediments. Geol. Foren. i Stockholm Forh. $71: 238-42$.

Experiments are described which show the precipitation of thorium in sea water. The adsorption of isotopes of radium and thorium on red clay, powdered maganous dioxide, and a powdered manganese nodule was determined. Radium adsorbed on all three powders, which is not the case with thorium. The thorium content of a few samples of marine sediments has been measured. They contain about $1 \times 10^{-7} \mathrm{~g} \mathrm{Th} / \mathrm{g}$. One manganese nodule investigated was found to hold as much as $1.3 \times 10^{-6} \mathrm{~g} \mathrm{Th} / \mathrm{g}$. The geochemistry of thorium and uranium in sea water is briefly discussed. An attempt is made to estimate the thorium content of sea water with the aid of the ratio Io: Th in the sedjments. The thorium content of sea water is calculated to be 1 to $10 \times 10^{-9} \mathrm{~g} \mathrm{Th} / 1$. (NSA)

Koczy, F. F., E. Tomic, and F. Hecht. 1957. Geochemistry of Uranium in the Baltic Sea Basin. Geochim. et Cosmochim. Acta 11:86-102. (in German)

In order to study the geochemistry of $U$ on typical shelf zones, samples of river water and sea water, as well as samples of sediment from the Baltic Sea region, have been examined. The Baltic Sea region was chosen for the investigation since its hydrography is well known, water transport to and from it can be estimated to a high degree of accuracy, and the region can be well sampled. The $U$ content of river water originating in regions of igneous rocks is low, averaging $0.5 \times 10^{-6} \mathrm{~g} \mathrm{U} / 1$. The $U$ content of rivers from sedimentary rock regions seems higher by a factor of two or more, the maximum value found being $12.8 \times 10^{-6} \mathrm{~g} \mathrm{U} / 1$. It may be concluded that the 
$U$ is more easily leached out from sedimentary regions. While the southern and eastern rivers supplying water to the Baltic Sea have not been investigated, it can be assumed that their $U$ content is high, especially since the sea area surrounding the mouths of these rivers exhibit high $U$ values. The $\mathrm{Ra}$ content of river water is not in equilibrium with the $U$, amounting to only 10 percent of the latter. It is thus concluded that $U$ is more soluble than $\mathrm{Ra}$. The $U$ content of water from the Baltic Sea is also variable ranging from 0.77 to $5.9 \times 10^{-6} \mathrm{~g} \mathrm{U} / 1$. High salinity inflowing water shows $1.8 \times 10^{-6} \mathrm{~g} \mathrm{U} / 1$, while that of outflowing water is less, averaging $0.9 \times$ $10^{-6} \mathrm{~g} \mathrm{U} / 1$. Except for the southeastern regions and deep water areas, a marked correlation of salinity and $U$ content exists. An increase of deep water $U$ content correlates with a surface water increase. Surface water increases can be explained by the high $U$ content of inflowing river waters; high deep water values are correlated with an 0 deficiency. Here it may be assumed that the $U$ (VI) is reduced to $U$ (IV) forming insoluble complex compounds with organic material. This settles slowly to the bottom, and explains the rather high $U$ content of the sediment (values range between 3.2 and $10.3 \times 10^{-6} \mathrm{~g} \mathrm{U} / \mathrm{g}$; the normal content in clays is about $2 \times 10^{-6} \mathrm{~g}$ $U / g)$. By an intense study of the distribution of $U$ in sediments, completed by age determination by aid of Cl4, it may be possible to follow the changes in the past of the state of ventilation of the deep basins of the Baltic Sea. The attempt to work out a $U$ balance sheet for Baltic Sea $U$ demonstrates precipitation about equals that which is brought in by rivers. Influx totals 1100 to 1400 metric tons per year, efflux 700 to 1000 , leaving about 100 to 700 tons of precipitated material. The investigation carried out shows that a considerable quantity of $U$ is precipitated on the Baltic Sea shelf. It appears to be caused by biological activity in the sea which in turn causes an 0 deficiency. The process is slow. Rivers with a high $U$ content can raise the $U$ content of the sea water if they empty under conditions wherein the above factors are not fulfilled. On the other hand, in estuaries and bays into which $U$ bearing rivers do not flow, $U$ can be precipitated from sea water by a high biological activity, which is connected with 0 deficiency. When the minerogenous sedimentation is at the same time very small, the $U$ content of the sediment is enriched, amounting to $200 \times 10^{-6} \mathrm{~g} \mathrm{U} / \mathrm{g}$ and more. (auth)

Koliadin, L. B., D. S. Nikolaev, S. M. Grashchenko, Y. V. Kuznetzov, and K. F. Lazarev. 1960. States of Uranium Detected in Black Sea Waters. Doklady Akad. Nauk SSSR. 132:915-17 (in Russian).

A carbonate complex of hexavalent uranium was found in a Black Sea layer between 0 to $2000 \mathrm{~m}$. The data indicate the physico-chemical impossibility of uranium precipitation by reduction to the tetravalent state in the Black Sea hydrogen sulfide zone. (NSA)

Kolodny, Y. 1969. Studies in Geochemistry of Uranium and Phosphorites University of California. Thesis 
This dissertation is composed of three almost independent parts; the abstracts are therefore separate. Three experimental studies were performed to determine: the uranium isotopes in sea floor phosphorites; the uranium in a anoxic fjord; and the carbon and oxygen isotopes in apatite $\mathrm{CO}_{2}$. Analyses using $\alpha$-spectroscopy techniques of uranium concentration and $234 U / 238 U$ activity ratios were performed on 40 samples of marine phosphorites, almost all of them dredged from the sea floor. In each sample, the concentration and isotopic composition of total uranium and U(IV) were analyzed. Uranium concentrations in the analyzed nodules vary between 6 and $524 \mathrm{ppm}$, tetravalent uranium constituting 38-84 percent of the total. Whereas the mean activity ratio for total uranium is 0.97 , the ratio in the U(IV) uranium is 0.71 and the calculated activity ratio for U(VI) uranium is 1.57. This indicates that: all the analyzed nodules are old (probably older than $8 \times 10^{5}$ years), and are at the present being eroded rather than deposited and the difference in isotopic ratios between the two oxidation states of uranium generally confirms previously proposed mechanisms of uranium isotope fractionation. Differential nxidation of $234 \mathrm{~J}$ is largely responsible for the measured $234 \mathrm{U} / 238 \mathrm{U}$ disequilibrium ratios. A model for evolution of uranium isotope activity ratios in different oxidation states is presented. A fairly simple chemical fractionation technique was tested for separation of authigenic uranium from its detrital counterpart. $234 \mathrm{U} / 238 \mathrm{U}$ activity ratios can serve as an excellent indicator for testing the efficiency of such a technique. Uranium is effectively removed from sea water into anoxic sediments. This process is extremely fast compared to the rate of removal into deep sea sediments. Authigenic uranium is most strongly correlated with organic carbon content of the sediments, probably because of the formation of organo-uranyl complexes. Analysis of interstitial waters can serve as an indicator for the chemical state of uranium in the solid phases. About half of the uranium in sediment from the center of Saanich Inlet is strongly bound (as a chemical complex) to organic matter. The other half is about evenly divided between detrital minerals duthigenic tetravalent uranium, and uranium adsorbed on organic matter. Analysis of stable carbon and oxygen isotopes has been applied to a solution of a mineralogical problem: elucidation of the relation of the carbonate ion to the apatite structure. Calcite was separated from co-existing apatite in pelletal phosphorites, phosphatized limestones and synthetically prepared apatites by dissolving calcite in triammonium citrate. Both ralcite and apatite $\mathrm{CO}_{2}$ were then analyzed for carbon and oxygen isotopes. Carbon and oxygen in the $\mathrm{CO}_{2}$ associated with apatite are enriched in their light isotopes as compared to the coesisting calcites. This indicates that carbonate ion is a structural part of apatite, a conclusion which is in accord with other mineralogical studies (NSA)

Kolodny, Y. and I. R. Kaplan, 1970. Deposition of Uranium in the Sediment and Interstital Water of an Anoxic Fjord. Conf. $=700965-1$. 
The distribution of uranium in the sediments of Saanich Inlet was determined using chemical fractionation methods to separate authigenic uranium from detrital uranium. $234 \mathrm{U} / 238 \mathrm{U}$ activity ratios were found to be good indicators for determing the efficiency of the separation. Uranium concentration in the sediment shows a significant enrichment relative to deep sea sediment. Authigenic uranium correlates most strongly with the organic carbon content of the sediment, and is probably bound as organo-uranyl complexes. Approximately half the uranium in the sediment of the central fjord is organically complexed and the remainder is distributed among detrital minerals, authigenic tetravalent uranium and uranium adsorbed on organic matter. Uranium is highly enriched in interstitial water (both oxidizing and reducing waters with an Eh range of $+380 \mathrm{mV}$ to $-140 \mathrm{mV}$ ) relative to its concentration in normal seawater. Its concentration appears to depend on the oxidation state and the organic content of the sediment. Concentration of uranium by the sediments was found to be very efficient in this environment. The residence time of uranium in the water column was found to be 3 or 4 orders of magnitude less than estimated for the open ocean. (auth)

Kovalev, A.A. 1962. Uraniferous 0ccurrences Through Evaporation in Arid Regions. CEA-tr-R-1707. (in French).

In arid regions, in zones of eruptive and sedimento-metamorphic rocks, there is a high $U$ occurrence. The great majority of these occurrences, constituted by schrockingerite and uranophane and some secondary $U$ minerals, has a superficial character. Because of the coincidence with zones of fracture and hydrothermal alteration of the encasing rocks, the secondary accumulation can be considered as oxide outcrops of hydrothermal deposits of $U$. The essential geological peculiarities of the secondary $U$ accumulations near the surface allow a differentiation of the oxide outcrops. The essential processes of formation of the secondary accumulations of $U$ is the evaporation of uraniferous waters. The source of $U$ in the beds formed by evaporation is essentially from rocks possessing a high $U$ concentration. (NSA)

Kovalev, V. A. 1965. Geochemical Aspects of the Th/U Ratio Investigation in Rocks Geokh1mya. No. 9: 1171-3 (in Russian).

The Th/U ratio can be used to estimate the intensity of weathering processes. $U$ is more mobile than Th. Black schists and phosphorites show a low Th/U ratio (less than two). Littoral sands and alluvial deposites show a high Th/U ratio (greater than 7 ). Most clay deposits. show an intermediate Th/U ratio of 2 to 7 . Leaching experiments with 3 percent $\mathrm{HCl}$ on a $0.01 \mathrm{~mm}$ fraction of mineral showed that only 40 percent of the Th could be leached out, while 70 percent of the $U$ was removed from the mineral. The Th accumulated in the heavler, accessury minerals, and was not leached out readily.

Kraus, K. A., and F. Nelson. 1950. Hydrolytic behavior of metal ions. I. The acid constants of Uranium (IV) and Plutonium (IV). Journal Amer. Cheill. Soc. 72: 3901-3906 
1. Through $\mathrm{pH}$ measurements of $\mathrm{UCl}_{4}$ solutions, $\mathrm{U}^{+4}$ was established to be the species of uranium (IV) in acidic solutions.

2. The acid constant of $\mathrm{U}^{+4}$ was determined as a function of ionic strength for chloride and perchlorate solutions through a spectrophotometric method. The molarity constants could be fitted approximately to a Debye-Huckel limiting law and the activity constant $K_{a}=0.21=0.02$ was estimated for the equilibrium $\mathrm{U}+4+2 \mathrm{H}_{2} \mathrm{O} \rightleftarrows \mathrm{UOH}+3+\mathrm{H}_{3} \mathrm{O}+$.

3. The stability constant for the reaction $\mathrm{U}^{+4}+\mathrm{Cl}^{-} \rightleftarrows U \mathrm{UCl}+3$ was estimated to be $K_{c}=c a$. $0.63(\mu=0.5)$ and $K_{c}{ }^{O}=7.0(\mu=0)$.

4. The acid constant of $\mathrm{Pu}^{+4}\left(K_{\mathrm{m}}=0.025, \mu=0.5\right)$ was found to be almost identical with though slightly smaller than that of $U^{+4}\left(K_{m}=0.032, \mu=0.5\right)$.

5. The spectral data, the quantitative hydrolytic data and the ohservation that the chloride complexes of uranium (IV) and plutonium (IV) are weak, are confirmatory evidence of the hypothesis that these elements are members of a "rare-earth-like" series. (auth)

Krendelev, F. P. and V. A. Bobrov. 1970. Clarke Contents of Uranium, Thorium, and Potassium in Weathering Profiles Developed on Acidic Igneous and Metamorphic Rocks of the Enisei Ridge. Geokhim. Mineral. Radioaktiv. Elem. Sib. pp. 105-155 (in Russian).

The radioactive elements enter into minerals with different degrees of stability and, therefore, the values of $T h / U, T h / K$, and $U / K$ ratio depend strongly on the conditions of bedrock disintegration and sediment formation. This result is evident from recent sediments where the values of $T h / U$ and $\mathrm{Rh} / \mathrm{K}$ ratios vary sharply. An especially strong increase of the Th/U ratio is observed in redeposited products of weathering profiles, e.g., oligomictic sandstones and gravelstones. The $U$ and $K$ are removed with the same intensity and redeposited together. A certain accumulation of $U$ was observed only in the soils. The total radioactivity of weathering profile products correlates with the $\mathrm{Fe}_{2} \mathrm{O}_{3} / \mathrm{FeO}$ ratio. (CA)

Krylov, A. Y. and M. M. Shats. 1958. Some Regularities of Uranium Migration in Waters of Northwestern Districts of USSR. AEC-tr-4474:319-32.

Data on the uranium contents of some water bodies in northwestern USSR are presented. The factors influencing uranium transfer into and precipitation from water are discussed at length and applied to a few examples. Precipitation of uranium is shown to occur mostly through the action of iron hydroxide and humic compounds. (NSA)

Kubose, D.A., M. G. Lai, H. A. Goya, and H.I. Cordova, 1968. Radioactivity Release from Radionuclide Power Sources. VIIa. Dissolution Studies of Plutonium Dioxide in the 0cean, 5 months' Exposure. USNRDL-TR-68-74.

Post-ocean-exposure examinations have been made on plutonium dioxide microspheres recovered after a 5-month exposure on the bottom at a depth of 50 feet off San Clemente Island. These examinations established that 
approximately 70 percent of the microspheres became encrusted with marine growth. Determination of the distribution of the microspheres and adsorbed activity in the ocean-bottom material was made in addition to post exposure laboratory dissolution measurements, microscopic examination and $X$-ray diffraction measurements. (auth)

Kuznetsov, Y. V., V. K. Legin, A. P. Lisitsyn and Z. N. Simonyak. 1967. Radioactivity of Oceanic Suspensions. II. Uranium in Oceanic Suspensions. Radiokhimiya. 9:489-97 (in Russian).

Data are given on the concentration of uranium in oceanic suspensions. The fraction of $U$ in the ocean water, coordinated with the suspensions, was evaluated. The relation between uranium concentration in suspensions and concentration of basic components of the granulometric and chemical states of the suspension was investigated. The direct correlation dependence between $\mathrm{CaCO}_{3}$ concentration and uranium in the suspension was established. (auth)

Kuznetsov, Y. V., Z. N. Simonyak, A. P. Lisitsyn and M. S. Frenlikh. 1968. Thorium I sotopes $(230 \mathrm{Th}, 232 \mathrm{Th})$ in the Surface Layer of the Indian Ocean Sediments. Geochem. Inst. 5:169-77.

It has been demonstrated that the content of ionium (230Th) in the surface layer of oceanic sediments depends on the depth of water, effective surface area of the sedimentary particles, and on the rate of sedimentation. $230 \mathrm{Th}$ is co-precipitated with the hydroxides and phosphates of $\mathrm{Fe}$ and $\mathrm{Mn}$, while $232 \mathrm{Th}$ is contained in the sedimentary detrital particles. (auth)

Kuznetsov, Y. V., Z. N. Simonyak, A. P. Lisitsyn and M. S. Frenlikh. 1968. Uranium and Radium in the Surface Layer of Oceanic Sediments. Geokhimiya. No. 3:323-33 (in Russian):

Data on uranium and thorium concentration in the surface layer of the Indian Ocean bottom sediments are given. Peculiarities of uranium and radium distribution over the ocean floor were investigated. Paragenetic associations of uranium and thorium with components of the chemical and granulometric composition of bottom sediments were studied. Bonds between uranium and organic carbon and phosphorus were established which provides evidence in favor of the existence of a certain mechanism of uranium withdrawal from ocean water. The presence of radium directly precipitated from oceanic water was proved. (auth)

Labeyrie, L. D., H. D. Livingston and V. T. Bowen. 1975. Comparison of the Distributions in Marine Sediments of the Fallout Derived Nuclides $55 \mathrm{Fe}$ and 239,240Pu: A New Approach to the Chemistry of Environmental Radionuclides. IAEA-SM-199/115. 
We present data showing the distribution of $55 \mathrm{Fe}$ radioactivity in marine sediment cores taken from a large range of water depth; these data are compared with the 239,240 pu analyses of the same or similar cores. The report is preliminary in that only a small part of the world ocean has yet been studied.

Evaluation of the results available suggests:

First, that in a good deal of their marine geochemistry, iron and plutonium move separately.

Second, that in the open Atlantic Ocean, ${ }^{55} \mathrm{Fe}$ has sedimented in association with a mixed population of particles, exhibiting a mean sinking of about $350 \mathrm{~m}$ per year.

Third, part of the iron in coastal sediments is redissulved, probably by reduction associated will decaylng organic matter; this process affects a higher proportion of the $55 \mathrm{Fe}$ than of the total iron. The solubilized iron should reprecipitate, after return to the overlying water and oxidation, as microparticulates. These very fine particles, dispersed by currents, may translocate ${ }^{55} \mathrm{Fe}$ toward the open sea, only slowly becoming associated with larger, faster-sinking mineral particles. It is suggested that this process may be important in the translocation of other insoluble trace elements, and even of part of the 239,240pu. (auth)

Lahr, V. H., and W. Knoch. 1970. Bestimmung von Stabilitatskonstanten einiger. Alatinidenkomplexe. II. Nitrat-Und Chloridkomplexe von Uran, Neptunium, Plutonium and Americium. Radiochimica Acta 13:1-5.

Stability constants of the nitrato complexes of several actinides have been determined under identical experimental conditions: U-IV, U-VI, Np-IV, Np-V, Np-VI, Pu-III, Pu-IV. Pu-VI, Am-III. The ionic strength was held constant $(\mu=8)$ by addition of $\mathrm{HClO}_{4}$. A collection of known constants is givein for comparison. A systematic relation between cationic radius, ionic charge and complex strength within a series of actinides of equal valency or different oxidation states of one element could not be established. (auth)

Lambet, M. S. and D. S. Nikolaev. 1962. The Mode of Uranium Occurrence in the Waters of the Azov Sea and in a number of estuaries and rivers of the Azov-Black Sea Basin. Doklady Akad. Nauk SSSR. 142:681-2 (in Russian).

It had been shown previously that uranium exists in nonn water as a slable carbullate complex. However, there are no data on the state of uranium in river water. Hence, samples of river water were filtered at a pressure of 10 to $12 \mathrm{~atm}$ through a cellophane membrane having a pore size of about $1 \mathrm{~m} \mu$. The uranium content was determined by a luminescence method, and the $\mathrm{pH}$ was taken potentiometrically. All measurements were taken immediately after sampling. The results show that uranium passed through the filter and exists in ionic form in the water as a carbonate complex. The possibility of the existence of a uranium organic complex with humic acid in a number of the samples is not excluded. The uranium content of the water increases with an increase in the sait content of the water. (NSA) 
Lauderdale, R. A. 1951. Treatment of Radioactive Water by Phosphate Precipitation. Industrial and Engineering Chemistry 43:1538-1540.

The work was done to check the effectiveness of a calcium phosphate floc in removing radioisotopes from large quantities of water.

In almost every case the phosphate was found to be more efficient that either alum or ferric hydroxide. Maximum removals were obtained under conditions of high $\mathrm{pH}$ and in the presence of an excess of phosphate. In general, good removals were obtained for those isotopes which would be precipitated under the same conditions if they were present in macro quantities.

While the data must be considered preliminary in nature, they indicate that coagulation and filtration techniques, if performed under the proper conditions, can be applied to treat liquid wastes containing low levels of radioactivity. The total reduction obtained in the activity of the waste will be dependent on the radioisotopes present. (auth)

Legin, V. K., Y. V. Kuznetsov and K. F. Lazarev. 1966. Uranium Occurrence in Marine Sediments. Geokhimiya No. 5:606-8 (in Russian).

The total $U$ and mobile $U$ contents were determined in samples taken from the $\mathrm{H}_{2} \mathrm{~S}$-contaminated zone of the Black Sea, from the coastal zone of the Black Sea not contaminated with $\mathrm{H}_{2} \mathrm{~S}$, and from the central part of the Azov Sea. The mobility of $U$ was determined by leaching the samples with $0.7 \mathrm{~N} \mathrm{NaHCO}_{3}$ and $3 \mathrm{~N} \mathrm{HCl}+3 \mathrm{~N} \mathrm{H}_{2} \mathrm{SO}_{4}$. The mobility of $\mathrm{U}$ in contemporary sediments from the Black Sea zone contaminated with $\mathrm{H}_{2} \mathrm{~S}$ was much higher than in the sediments of the Azov Sea. Only 4-6 percent of the $U$ was extended from the Azov Sea sediments after 2-fold leaching with $\mathrm{NaHCO}_{3}$ whereas, under the same conditions, practically all of the $U$ was extended. from the sediments of the Black Sea. This marked difference in the mobility of $U$ suggested different forms of occurrence for the $U$ in these sediments. It also suggested the portion of $U$ from the Black Sea water and the terrigenous form of $U$ occurrence in the sediments of the Azov Sea. (CA)

Lisitzin, A. K. 1962. On the Forms of Uranium Occurrence in Underground Waters and the Conditions of its Deposition in the Form of $\mathrm{UO}_{2}$, Geokhimiya, No. 9:763-9 (in Russian).

For estimating the forms of uranium in underground waters, physicochemical constants of its equilibrium in aqueous solutions were used. It is shown that in weak acid, neutral, and alkalescent underground waters of different mineralization anionic forms of uranium prevail in the form of di- and tricarbonateuranyl. The values Eh of the equilibrium in solution with $\mathrm{U}_{2 \mathrm{sol}}$ are in accordance with the results of detailed hydrogeochemical observations and analyses. The value Eh of the beginning of precipitation of the tetravalent uranium oxide from underground waters ranges approximately 
from 0 to -0.2 volt depending on the uranium concentration in solution, the magnitude and character of the total mineralization of water, the $\mathrm{pH}$, and the concentration of $\mathrm{HCO}_{3}$ ion. (auth)

Lisitsin, A. K. 1969. Deposition Conditions of Molybdenum and Selemum in Exogenitic Epigenetic Uranium Deposits. Litol Polez. Iskop. No. 5: 27-35 (in Russian).

$U$ contents of ground waters are discussed in terms of $E_{H^{-}}-\mathrm{pH}$ diagrams. Mo migrates under exogenic conditions as $\mathrm{MoO}_{4} 2$ - ions. Deposition as $\mathrm{MoS}_{2}$ is conditioned by reducing environment and by $\mathrm{H}_{2} \mathrm{~S}$ produced by sulfatereducing bacteria. $\left[\mathrm{SeO}_{4}\right]^{2-},\left[\mathrm{SeO}_{3}\right]^{2-}$, and $\left[\mathrm{HSeO}_{3}\right]-$ are the possible forms of Se transport. By lowering $E_{H}$ of the ground waters, $S_{\theta}$ is deposited first, mafnly in environmentes of increased acidily. The deposition of $U$ and Mo is within the fields of FeO stability. $\mathrm{MoS}_{2}$ is deposited under lower $E_{H}$ than $U$ oxides. The lack of $\mathrm{Se}$ in the reducing geochemical barriers is explatned by low Sc in the enclosiliy rucks and ground waters, the lack of Mo by specific conditions required for $\mathrm{MoS}_{2}$ deposition. (NSA)

Lisitsin, A. K., I. A. Kondrat'eva and G. V. Komarova. 1969. Genetic Interpretation of Epigenetic Alterations in Sedimentary Rocks. Litol. Polez. Iskop. No. 3:5-19 (in Russian).

The correlation between compositions of surface waters and authigenous minerals of the last stage of epigenetic alteration was observed in rocks of waterbearing horizons in some ore deposits. A comparison of mincralogical-geuchemical zoning of rocks with hydrogeochemical zoning of waters was used to restore conditions of epigenetic mineralization of several $U$ deposits in the USSR. The conditions of epigenetic mineralization can be determined directly on complete agreement of epigenetic and hydrogeochemical zoning. A partial agreement of these zonings, observed during study of $U$ deposits, was interpreted by comparison of ore-controlling epigenetic zoning with hydrogeochemical zoning in petroleum-bearing carbonate rocks of the area. It suggested that epigenetic mineral association was formed by intrusion of infiltration waters into petroleum-water horizon. Complete disagreement of recent hydrogeochemical environment with paleohydrogeological conditions of ore formations was observed in the U-Se deposit in continental varicolored stratum. The correlation of hydrogeological and geochemical conditions of deposit formation was then made. from lithologic facies and mineralogical geochemical studies. Formation of $U$ and Se concentrations was attributed to groundwaters leaching proluvial formations rich in fragments of acidic effusive rocks. Precipitation of $U$ and Se occurred in the zone of reducing geochemical barrier confined to the boundary of proluvium with river bed deposits rich in plant remnants. The climate during ore deposition was semiarid according to the paleogeographical study, which promoted increase in $U$ and Se concentrations in groundwaters by water evaporation. (NSA) 
Lopatkina,.A. P. 1967. Conditions of Uranium Accumulation by Peats. Geokhimiya. No. 6:708-19 (in Russian).

A substantial part of uranium in waters of humid regions is present in an unstable state and may be precipitated by peats. The peat composition, the uranium content in waters, and the general mineralization of the waters influence the uranium concentration in peat. No more than $20 \times 10^{-4}$ percent of uranium accumulates in peats at the expense of average contents in rocks amounting to 1 to $3 \times 10^{4}$ percent. (auth)

McKelvey, V. E., D. L. Everhart and R. M. Garrels. 1955. Origin of Uranium Deposits. Econ. Geol. 50:464-533.

Uranium is concentrated in certain silicic and silica-alkalic igneous rocks, pegmatites, veins, lenticular sandstones and conglomerates, low-ranking high-ash coals, asphaltic materials, marine black shales, and phosphorites. Its distribution in igneous rocks, pegmatites, and veins shows its tendency to concentrate in late stage differentiates. In the granitic rocks, uranium occurs mainly as a minor constituent of accessory minerals that have cations (such as rare earths, thorium, and calcium) for which uranium can substitute isomorphously, but it also occurs as an acid-soluble interstitial constituent. In pegmatites, uranium occurs both in uraninite and in other uranium minerals in combination with niobium, thorium, and rare earths. Uranium is found in both high-temperature veins, where it is mainly in the titanium minerals davidite and brannerite, and low-temperature veins, where it is mainly in pitchblende, the botryoidal variety or uraninite, and coffinite. The lowtemperature veins are of several over-lapping types, but all are characterized by sulfides and many contain disseminated iron oxide. Whereas thorium is associated with uranium in igneous rocks and pegmatites, it is rare in the vein deposits of uranium. This separation may be accomplished by oxidation of $\mathrm{U}^{+4}$ at a late magmatic stage to $\left(\mathrm{UO}_{2}\right)^{+2}$ in which form it is carried away from the unoxidizable $\mathrm{Th}^{+4}$. Subsequently $\left(\mathrm{UO}_{2}\right)^{+2}$ is reduced and deposited as pitchblende along with sulfides and other low-valent minerals in veins. The sandstone uranium deposits resemble the pitchblende veins in their mineralogic assemblage except that many of the sandstone deposits disu contain vanadium, a metal nnt abundant in veins. Isotopic studies indicate that the Colorado Plateau deposits are epigenetic and suggest that the uranium was derived from a deep-seated source. The uranium in coal and associated carbonaceous shale beds occurs in the form of metalloorganic compounds but secondary uranium minerals like meta-autunite are found in coals that contain more than 0.1 percent uranium. The uranium in marine black shales and phosphorites was derived from seawater. The precipitation of uranium in the shales probably is brought about by chemical adsorption by living or dead plankton, but reduction evidently plays an inportant role in its precipitation and stabilization in the shale. Uranium in the phosphorites substitutes for calcium in the apatite structure. Its absorption by apatite is hindered by abundance of calcium ions, with which it competes for positions in the structure, and by carbonate and hydroxyl ions, which complete with phosphate groups for structure positions and form less stable compounds with uranium. (auth) 
Magon, L., A. Bismondo, G. Tomat and A. Cassol. 1972. Interaction of Neptunium (V) with Dicarboxylate Ligands. Radiochimica Acta 17:164-167.

Equilibria involved in the interaction of neptunyl ( $V$ ) ion and oxalic, malonic, succinic, phthalic and maleic acids in aqueous solutions have been investigated by means of potentiometric measurements of hydrogen ion concentration at $20^{\circ} \mathrm{C}$ and in an ionic medium $1 \mathrm{M} \mathrm{NaClO} 4$.

In the $\mathrm{pH}$ range examined, the formation of chelate complexes with one and two ligands for the neptunyl (V)-oxalate system and with one ligand only for the other systems has been ascertained. The formation constants have been determined. The stability of the complexes is briefly discusses in correlation with the different basicity and structure of the ligands. (auth)

Manheim, F. 1961. Geochemical Profile in the Baltic Sea. Geochim. et Cosmochim. Acta 25:52-70.

The rclationship belween depositional environment and element distribution in central Baltic sediments was investigated by means of chemical composition, $\mathrm{pH}$, Eh, chlorinity, and temperature determinations. Central Baltic sediments show an unusually short, basinward transition from coarse oxygenated sediment to find stagnant sediment. This is because of the salinity stratification of the Baltic Sea and the permanent 0 deficit found in deeper layers. Sapropelic sediments with $\mathrm{H}_{2} \mathrm{~S}$ and high organic contents occur in the deeps, where overlying $\mathrm{H}_{2} \mathrm{~S}$-bearing water is stagnant and lacks 0 . Gyttjas (graygreen organic mucks) with or without $\mathrm{H}_{2} \mathrm{~S}$ form in quiet areas, where some 0 renewal takes place in the water. $A \mathrm{pH}$ of 7 or less, and lower $\mathrm{pH}$ in the sediment than in the overlying water are characteristic of low-carbonate ( $<0.1$ percent $\mathrm{CO}_{2}$ ) sediments, while higher $\mathrm{pH}$ values are found in sediments of higher carbonate contents. Heavy trace metals, such as $\mathrm{Cu}, \mathrm{Ag}, \mathrm{U}$, and Mo dre concentrated in the sapropels. Maximum enrichment, Mo possibly excepled, occurs at the peripheries (transition zones) of the stagnaril basins. Owiny to cooprecipitation, Mo follows Fe sulfides. Maximum $U$ content found in the Baltic is $130 \mathrm{~g} /$ ton which is not consistent with the hypothesis of Koezy, et al., (CA 51,7979f). Direct precipitation, or adsorption from water is indicated, not organic complexing. Mn-Fe nodules occur in a peripheral region of aerated bottom water under moderately reducing sediment conditions. The sediment is apparently the source of the Mn and Fe, which are solution in the interstitial, but not in the uverlying waters. The concretions differ from deep-sea nodules in their lower trace-element contents. Unusual, Mn-enriched (up to 5.2 percent $\mathrm{MnO}$ ), sapropelic sediments were found in two Baltic deposits $\mathrm{A}$ mixed $\mathrm{Mn}-\mathrm{CaCO}_{3}$ mineral, approximately ( $\mathrm{Mn}_{72} \mathrm{Ca} 76 \mathrm{Mg}_{12}$ ) carbonate, and structurally suggestive of rhodochrosite, is apparentiy the carrier. (CA)

Martin, W. E., S. G. Bloom and R. J. Yorde, Jr. 1974. NAEG Plutonfum Study Modeling Program: Plutonium Transport and Dose Estimation Model. IN: Dunaway, P. B. and M. G. White (eds.). The Dynamics of Plutonium in Desert Environments. NVO-142 (NVO-AEIC-74-1 or UC-2):331-360. 
A computer program based on a matrix exponential method was used to solve a system of ordinary differential equations which simulate the behavior of $\mathrm{Pu} 239$ in desert ecosystems such as those found at and near the Nevada Test Site. The model was used to estimate the rates of Pu 239 transport, via several environmental pathways, to Standard Man, who was assumed to live in a contaminated area. These estimates were then used to calculate radiation doses and dose commitments, as a function of time, to different organs.

The model provides a method for evaluating the potential radiological hazard to man due to the presence of $\mathrm{Pu} 239$ in a given area. However, the studies designed to implement the model, by providing accurate estimates of critical parameters, are still in progress. Therefore, the results to data are incomplete and inconclusive.

On the basis of present assumptions and parameter values, the model indicates a 70-year dose commitment to the pulmonary lymph nodes of 13.6 rem per $\mathrm{pCi}$ (Pu 239)/g (soil). Comparable values for other organs are: bone, 0.14 rem; lung, 0.10 rem; kidney, 0.015 rem; liver, 0.014 rem; G. I. tract, $0.007 \mathrm{rem}$; and total body, 0.003 rem. Inhalation accounts for 100 percent of the dose to the lungs and pulmonary lymph nodes, a neglibible fraction of the dose to the G.I. tract, and about 56 percent of the dose to bone, kidney, liver, and total body. This means that all but a negligible fraction of the dose to the G.I. tract and 44 percent of the $\mathrm{Pu} 239$ entering the bloodstream is due to ingestion of soil, vegetation, milk, beef, and beef liver. It is quite possible that the relative importance of inhalation has been overestimated, while the relative importance of ingestion has been underestimated. (auth)

Masuda, K. and T. Yamameto. 1971. Studies on Environmental Contamination by Uranium. II. Adsorption of Uranium on Soil and Its Desorption. $J$. Radiation Res. 12:94-9.

Experimental studies on the behavior of uranium on soils were carried out using three kinds of soil; volcanic ash, alluvial, and sandy soils. The results showed that uranium dissolved in water ( 1 to $100 \mu$ as $U / \mathrm{ml}$ ) was almost completely adsorbed on every soil examined. The desorption of uranium from soil with salt solutions was extremely difficult especially from volcanic ash soil. (auth).

Mazor, E. 1963. Notes concerning the Geochemistry of Phosphorus, Fluorine, Uranium, and Radium in some Marine Rucks in Israel. Israel J. Earth-Ssi. $12: 41-52$.

Phosphorus, F, U, Ra, Th, and $K$ were analyzed in 38 samples of marine sediments ranging in age from Santonian to Eocene and including phosphorite, diagenetically changed phosphoritic rocks, limestone, chalk, and marl. The abundances of the first four mentioned elements were found to be in constant ratios, although the $\mathrm{P}_{2} \mathrm{O}_{5}$ content varied from less than 1 up to 33 percent. There seellis to be essentially one kind of phosphate mineral in all the 
samples, its $F$ to $P$ ratio being that of a carbonate-fluorapatite. The radioactive equilibrium of the $U$ and $R a$ indicates that the apatite has not be been disturbed by weathering processes for at least the last 10,000 years. All the above geochemical relation agree well with data published on phosphorites in other parts of the world. The carbonate-fluorapatite in the samples of the Senonian Mottled zone formation and in the ferruginous phosphorites, accompanying the Companian-Eocene unconformity in the Ramon area, was not affected by diagenetic processes. (auth)

Milyukova, M. S., N. I. Gusev, I. G. Sentyurin and I. S. Sklyarenko. 1967. Analytical Chemistry of Plutonium translated by J. Schmorak. Israel Program for Scientific Translations. Weiner Bindery Ltd. Jerusalem.

This book covers the general chemistry of $\mathrm{Pu}$ as perceived by Russian workers. Pertinent chapters for this environemtnal study include those of the behavior of plutonium in aqueous solutions and portions of chapter of separation of $\mathrm{Pu}$ which pertain to cation and anion exchange properties of Pu solutions.

Miner, F. J. and H. W. Miller. 1972. Plutonium Bchavior in the sull/Water Environment. IN: M. A. Thompson (ed.) Research and Ecology, Semi-Annual Progress Report Jan-June 1972. Chemistry Research and Devclopment RFP-1921-A:1-3.

Attempts to identify the sorption differences between "soluble" forms of plutonium $\mathrm{Pu}(\mathrm{OH})_{n}{ }^{4-n}$ and of insoluble forms of plutonium $\mathrm{P}_{n} \mathrm{O}_{2}$ have been futile.

Distribution coefficients for plutonium on $2 \mathrm{~g}$ of soil from $10 \mathrm{ml}$ of solutions will be determined by centrifugation.

Miner, F. 1., P.A. Glover, and W.L. Polzer. 1974. Plutonium Behavior in the Soil/Water Environment I. Sorption of Plutonium by Soils. Agronomy Abstracts, p. 35, 1974.

As part of a larger program to study the behavior of plutonium in the environment, the movement of plutonium in soil/water systems is being investigated. Sorption and elution characteristics are heing used to measure this moveinienl. The equilibrium sorption of plutonium has been determined for 13 soils. The soils were initially characterized shemically and physically (mechanicdily). Three plutonium concentrations, 10-8, 10-7, and 10-6 moles/liter, were used rur the sorption measurements. The plutonium sorption was rapid and quite high: 59 percent of the time the equilibrium sorption was greater than 99 percent $\left(K_{d}(m)>430\right)$ and only 5 percent of the time was it below 90 percent sorption $\left(K_{d}(m)<39\right)$. Using principal component analysis, a statistically significant relationship was found between the sorption of plutonium and groups of chemical and physical characteristics of the soils that are associated either with the ion exchange capabilities of the soils or their acidities. Plutonium column elution behavior has been investigated for three soils. There is some plutonium in the eluate (less than 2 percent of the amount of plutonium placed in the soil column) but the amount varies with the soil. (auth) 
Mizuno, A., S. Sekine, J. Nakazawa, A. Takaku, K. Onodera, and M. Ono. 1969. Uranium Concentration in the Bottoms of the Lakes Shinji-Ko and Naka-umi: With Special Reference to Its Genetic Relation with the Sedimentary Environment. Chishitsu Chosasho Hokoku. No. 232:317-52 (in Japanese).

The bottom areas of the lakes Shinji-ko and Naka-umi, along the San'in coast of Japan Sea (mainly oligohaline and polyhaline brackish lakes, respectively are divided into 3 sections with respect to the $U$ content. The Ist contains the lower content of $U$ (1-3 ppm.), represented by coastal sandy bottoms of both the lakes and the channels, and of the Ohashi-gawa and Sakai-Suido rivers. The 2nd contains an intermediate content (4-5 ppm.U), which is widely developed in the muddy bottoms of both lakes. The last contains the higher content (6-11 ppm. U), only occurring in the muddy part of the Yonago Bay of Naka-umi. The tentative conclusions as to $U$ distribution in the bottoms of the lakes are as follows: In the sections of lower and intermediate $U$ content, $U$ probably exists in fine-grained minerals such as zircon, derived from granitic rocks. On the other hand, a portion (1-6 $\mathrm{ppm})$ of the $U$ contained in the section of higher $U$ content was probably derived from the lake water containing $2.8 \mathrm{\gamma} \mathrm{U} / \mathrm{l}$ (maximum) by direct precipitation (or) coprecipitation with organic and inorganic colloids, controlled mainly by $\mathrm{pH}$ and Eh conditons. (CA)

Nascimben, P. 1970. Distribution of Uranium in Some Itálian Deposits of Lignite. Ind. Mineraria 21:1-27 (i.n Italian)

A survey was conducted on some Italian lignite deposites in order to determine the uranium content and distribution. To this purpose, geological and radiometric field surveys were supplemented by 548 laboratory analyses for $\mathrm{U}_{3} \mathrm{O}_{8}$ in lignite ashes. By means of these analyses, the content of $\mathrm{U}_{3} \mathrm{O}_{8}$ dealing with lignite samples was determined. It was found that about 12,000 tons of $\mathrm{U}_{3} \mathrm{O}_{8}$ are contained in the lignites of some important deposits. About 90 percent of this potential is located in the Sulcis area (Sardinia), where the $\mathrm{U}_{3} \mathrm{O}_{8}$ content (in lignites and in ashes) is substantially higher than that found in the other major lignite deposits. Because of the low $\mathrm{II}_{3} \mathrm{O}_{8}$ content found in the examined samples, none of the Italian lignite deposits can be regarded as uranium-bearing formations. Furthermore, at the present state of technological progress, uranium extraction from the ashes, as by-product of lignite burning, is not feasible, because of the high cost of chemical processing and the limited quantities of ashes available for treatment. By means of statistical analyses of the analytical data and geological surveys of the deposits it was possible, moreover, to determine which type of lignite is the most favorable for uranium as well as to advance hypotheses on source and accumlation to explain the occurrence for uranium in Italian lignite deposits. (NSA)

Naumnov, G. B. 1961. Some Physics - Chemical Peculiarities of Uranium Behavior in Hydrothermal Solutions. Geokminiya. No. 2:115-32 (in Russian). 
The most typical components of uranium-containing hydrotherms are carbon dioxide, silcic acid, fluorine, and sulphur; the most typical cations are alkaline metals. A study of uranium behavior showed transport in the form of complicated complex ions, among which the carbonate and the fluoride ions are the most probable. The processes of complex formation provide a reliable transport of hexavalent uranium under conditions where $\mathrm{UO}^{+}{ }^{+}$is reduced to $\mathrm{UO}_{2}$. On the basis of an analysis of the behavior of complex uranium ions; the principle causes of nasturan deposition were traced. (auth)

Newton, T. W. and F. B. Baker. 1967. Aqueous 0xidation-Reduction Reactions of Uranium, Neptanium, Plutonium, and Americanum in Advances. IN: Chemistry Series. 71:268-295.

The experimental observations on the actinide uxidation-reduction reactions are described, and the empirical results are tabulated. The rate laws have been interpreted in terms of net activation processes, and these have bcen! tabulatcd togethei willh the associated activallun parameters -- $\Delta F^{\star}$, $\Delta H^{\star}$, and $\Delta S^{\star}$. An electrical analog is described which has been useful in interpreting complicated rate laws. Empirical correlations have been found between the formal entropies nf the activatcd complexes and their charges, and for sets of similar reactions, between the hydrogen ion dependence and $\Delta F^{0}$, between $\Delta F^{*}$ and $\Delta F^{0}$, and betwecn $\Delta H^{*}$ and $\Delta H^{0}$. The kinetic and physical evidence for binuclear species is discussed. (auth)

Nikolaevskii, V. B., V. P. Shilov and N. N. Krot. 1974. Estimation of Oxidation Potential of Americium (VI) in an Alkaline Medium. Radioklinilliya.

Am (VI) is a strong oxidant and is reduced by water to form Am (V). The half-reduction period of Am (VI) in $1 M \mathrm{NaOH}$ was $1 \mathrm{hr}$. Np (VII) is much more stable than Am (VI) changing very litlle in many days in $1 \mathrm{M} \mathrm{NaOH.} \mathrm{No} \mathrm{was}$ present as $\mathrm{NnnG}^{3-}$. Am probably jiresent as $\mathrm{AmU}_{4}{ }^{-2}$ or $\mathrm{AmO}_{2}(\mathrm{OH})_{4}^{-}\left(\mathrm{H}_{2} \mathrm{O}\right)_{2}^{-}$?. In $1 \mathrm{M} \mathrm{NaOH}$, the potential value of the Am (VI) to Am (V) couple is $\sim 0.65 \mathrm{~V}$.

Pak, A. I. 1974. Epigenetic Zoning and Genesis of Uranium Deposits in Weathering Crust.s of Sand-Clay Formatiuns. Metallog. Geokhim. UZb. p. 48-53 (in Russian).

The weathering crusts formed in the littoral marine and continental sedimentary rocks have 3 zones: (a) a surface oxidation zone, (b) a stratal oxidation zone, and (c) a cementation (reduction) zone. Lone (a) has an upper gypsiferous subzone with gypsum $\leq 80$ percent. Mn oxides, and carbonates and silicates of $U$; a middle subzone of fractured rocks with goethite, hydrogoethite, gypsum, $\mathrm{Mn}$ oxides, and $\mathrm{CaCO}_{3}$; and a lower mottled oxidation subzone with goethite. The rocks in zone a were altered by atmospheric agents and ground waters with positive Eli ( $<250 \mathrm{miv})$, presence of 0 , and content of $U\left(X \times 10^{6}\right)$ $\left(x \times 10^{3}\right) \mathrm{g} / 1$. Zone (b) had 3 subzones: (1) complete oxidation (of organic matter), with hydrogoethite, hemati.te, and various supergene minerals including kaolinite, sepiolite, halloysite, and jarosite; (2) reddish brown rock characterized by hydrohematite, goethite hydrogoethite, and high 
radioactivity; and (3) mottled oxidation, with $\mathrm{Fe}$ hydroxides, native $\mathrm{S}$, uranophane, etc. Rocks of zone (b) were altered by 0 containing $(0.2 \mathrm{mg} / 1)$ formation waters containing $U\left(X \times 10^{5}\right)$, Mo $\left(X \times 10^{5}\right)$, and $\operatorname{Se}\left(X \times 10^{4}\right)$ $\mathrm{g} / 1$. Zone (c) has epigene minerals of $U$ oxides; sulfides and carbonates of $\mathrm{Fe}$, Mo, and Se; quartz calcite, dolomite, etc. and has subzones, from top to bottom, of Se, $U$, and Mo mineralization. The subzone of $U$ mineralization has pitchblende and sooty uranite associated with Fe disulfides (pyrite, Marcacite, and melnikovite). (CA)

Palei, P. N. (comp). 1962. Analytical Chemistry of Uranium. Translated by $\mathbb{N}$. Kaner. 1963. Israel Program for Scientific Translations Ltd. $421 \mathrm{p}$.

Various chapters of this book of uranium deal with general information, chemico-physical properties and compounds, detection, determination (methods of analysis), methods of separation from accompanying elements, determination in natural materials and industrial products, and determination of impurities in pure uranium preparations.

Pal'shin, E. S., B. F. Myasoedov and A. V. Davydov. 1970. Analytical Chemistry of Protactinium. Translated by J. Schmorak. 1970. Israel Program for Scientific Translations Ltd. 233p

Various chapters of this book on protactinium deal with general properties, analytical chemistry of the element and its compounds, detection, quantitative determination, and separation from accompanying elements.

Pluman, I. I. 1971. Uranium Content in Black Argillites of the Volga Stage of the West Siberian Platform as Criterion of Geochemical Conditions of Sedimentation. Geokhimiya. No. 9:1138-43 (in Russian).

A similarity of geochemical peculiarities and in particular of uranium content has been established between recent deposits of seas with hydrosulfuric contamination (Black Sea, and others) and bituminiferous black argillites of the Upper Jurassic Volga stage of the West-Siberian platform. On this basis it was concluded that the geochemical sedimentation medium is identical with that of the Black Sea, i.e., it is hydrosulfuric in the above-bottom part of the sedimentation basin. (auth)

Polzer, W. L. 1971. Solubility of Plutonium in Soil/Water Environments. IN: Proceedings of Rocky Flats Symposium on Safety in Plutonium. CONF-710401, p. $411-430$.

Thermodynamic data was used to construct Eh-pH diagrams for plutonium oxides, plutonium hydroxides, and some solution species of plutonium. These diagrams show that at equilibrium $\mathrm{P}_{\mathrm{u}} \mathrm{O}_{2}$ would control the solution levels of plutonium. 
Polzer, W. L. and F. J. Miner. 1974. Plutonium Behavior in the Soil/Water Environment II. Mechanisms of Plutonium Sorption by Soils. Agronomy Abstracts, p. 37.

Sorption of plutonium by 13 soils, as measured by distribution coefficients, was observed in most cases to be dependent on the initial concentration of plutonium which ranges from $10^{-8}$ to $10^{-6}$ moles/liter. This dependency is attributed to several factors: the presence of monomeric or low molecular weight polymeric plutonium species (as indicated by solubility calculations), complexes of plutonium carbonate ions, and in a few cases, the possible existence of non-equilibrium sorption conditions. A lower sorption of plutonium was observed in the presence of low molecular weight polymers in solution, apparently due to a lower charqe density nf the polymers. A decrease in sorption was also observed at the initial plutonium concentration of 10-8 moles/liter and is attributed in some cases to possible nonequilibrium conditions as indicated by changes in sorption when recarbonate ions may react with plutonium to form quantities sufficient to influence the sorption of plutonium by soils, irrespective of the initial plutonium concentration. (auth)

Price, S. M. and L. L. Ames. 1975. Characterization of Actinide-Bearing Sediments Underlying Liquid Waste Disposal Facilities at Hanford. IAEASM-199/87.

Past liquid waste disposal practices at the U. S. Energy Research and Development Administration's Hanford Reservation have included the discharges of solutions containing trace quantities of actinides directly into the ground via structures collectively termed "trenches". Characterization of samples from two or these trenches, the 216-Z-9 and the 216-Z-1A(a), has been initiated to determine the present form and migration potential of plutonium stored in sediments which received high salt, acidic waste liquids.

Analysis of samples acquired by drilling has revealed that the greatest measured concentration of $\mathrm{Pu}, \sim 10^{6} \mu \mathrm{Ci} 239 \mathrm{Pu} / 1$ iter of sediment, occurs in both facilities just below the points of release of the waste liquids. This concentration decreases to $\sim 10^{3} \mu \mathrm{Ci} 239 \mathrm{Pu} / 1$ iter of sediment within the first 2 meters of the underlying sediment columns and to $\sim 10 \mu \mathrm{Ci}$ $239 \mathrm{Pu} / 1$ iter of sediment at the maximum depth sampled ( 9 meters). Examination of relatively undisturbed sediment cores illustrated two types of $\mathrm{Pu}$ occurrence responsible for this distribution. One of these types if composed of Pu particles ( $\$ 70$ wt\% $\mathrm{PuO}_{2}$ ) added to the disposal site in the same form. This "particulate" type was "filtered out" within the upper 1 meter of the sediment column, accounting for the high concentration of Pu/liter of sediment in this region. The second type of $\mathrm{Pu}\left(<0.5 \mathrm{wt} \% \mathrm{PuO}_{2}\right)$ was originally disposed of as soluble Pu(IV). This "nonparticulate" type penetrated deeper within the sediment profile and was deposited in association with silicate hydrolys is of the sediment fragments. (auth) 
Prout, W. E. 1959. Adsorption of Fission Products by Savannah River Plant Soil. DP-394.

Data are presented for the equilibrium distribution of cesium, strontium, plutonium, ruthenium, and zirconium-niobium between soil of the Savannah River plant and various aqueous solutions. Low cation concentration and a pH range of 7 to 9 were most favorable for absorption of these elements on the soil. (auth)

Pyalling, A. 0. 1970. Effect of Physiochemical Conditions of the Medium on the Leaching of Uranium from Natural Dahllite. Probl. Regional

Geol. Petrogr. Sibiri Metedy Geokhim. Geofiz. Issled. No. 2:88-91 (in Russian).

The $U$ from natural dahllite was leached in various media under normal conditions ( $1 \mathrm{~atm}, 19-200)$. The $\mathrm{pH}$ and $\mathrm{E}_{\mathrm{H}}$ of solns. were measured. The $U$ was determined by the Tuminescence-bead and phosphor-hydroquinone methods. The leaching of $U$ from phosphates in a carbonate medium $\left(4.2 \times 10^{-4}\right.$ and $\left.9.43 \times 10^{-2} \mathrm{M} \mathrm{Na}{ }_{2} \mathrm{CO}_{3}\right)$ did not depend on the $\mathrm{E}_{\mathrm{H}}$ of the system within the range from +0.74 to $-0.27 \mathrm{~V}$. A small amount of $U$ was transferred into solution during a change of $\mathrm{Na}_{2} \mathrm{CO}_{3}$ concentration from $4.2 \times 10^{-4}$ to $9.43 \times 10^{-2} \mathrm{M}$. A decrease of $\mathrm{pH}$ to 4.5 resulted in decomposition of the dahllite lattice and in an increase in the $U$ content to $120 \mathrm{ppm}$.

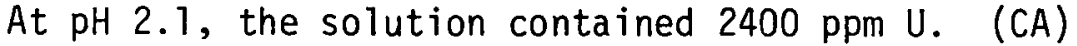

Rackley, R. I. 1971. Environment of Wyoming Tertiary Uranium Deposits. American Ass. Petroleum Geologists Bul1. 56:755-74.

Four major uranium districts in Tertiary rocks of central Wyoming are in fluvial sandstones derived from the granitic rock of the ancestral Sweetwater arch and deposited in adjacent intermontane basins. Sediment transported southward into the Great Divide basin was deposited on an apron of alluvial fans. Sedimentation in the Gas Hills area of the Wind River basin was on an alluvial fan in which ridges of older rock disrupted the normal development of the fan. Sediment in west Shirley basin was deposited on an alluvial fan, but in east Shirley basin and in the Powder River basin sedimentation was channel and flood-basin deposits of a meandering stream. The sandstones are subarkosic to arkosic, medium grained to conglomeratic, angular and poorly sorted. Sandstones intertongue with green or carbonaceous shales. Sedimentation was in a warm, humid climate with abundant vegetation. Decay of the organic material created reducing conditions in the sediment which caused partial carbonization of some of the plant debris, formation of pyrite, and precipitation of uranium minerals. Following burial, uplift-induced changes in the hydrodynamic system caused an invasion of the reduced sediment by oxygenated water far below the static water table. This caused destruction of carbonaceous material, oxidation of pyrite, and accumulation of uranium and other susceptible metals in a wave or front. just ahead of the invading oxidizing environmment. The invading oxidation was a dynamic, expanding process which moved through the permeable zones of the fluvial sequence until its dimensions measured miles in areal extent and hundreds of feet in thickness. This geochemical cell had a 
sharply defined boundary produced by biochemically controlled changes in physical and chemical conditions. Oxygenated waters, aided by Thiobacillus ferrooxidans, oxidized pyrite to produce sulfuric acid and ferric sulfate, a strong oxidizer, which leached uranium and other susceptible elements. In the reducing part of the cell, anaerobic bacteria, including the sulfate reducer Desulfovibrio, consumed the organic material in the sediments and the sulfates from the oxidizing area, to produce hydrogen, hydrogen sulfide, and a mildly alkaline, strongly reducing environment which precipitated pyrite, uranium, and other metals on the front. Migration of the cell was controlled by the permeability of the sandstone and by availability of carbon and pyrite. The cell advanced faster in the more permeable zones and was retarded in zones of reduced permeability and areas of greater pyrite and carbon content. The position of the mineral front was a function of the initial sedimentary pattern. Sedimentation, alteration, and mineralization in the Gas Hills and Shirley basin districts illustrate these conditions and processes. (auth)

Rafal'skii, R. P. 1963. Physico-Chemical Investigation of Conditions Conducive to Formation of Uranium Ores. Gosatomizdat (in Russian).

Physicochemical studies were made of the primary mineralization of uraniumbearing deposits. The crystalization of amorphous silica and the mechanism of hydrothermal transformation of silica glass to quartz under isothermal conditions are analyzed. The solubility of U(IV) and U(VI) compounds in aqueous solutions and the reduction of U(IV) and U(VI) by divalent iron, sulfur, sulfur compounds, and other reducing agents are discussed as well as the reduction and precipitation of uranium hy minerals. The hydro= thermal lransport and deposition of uranium are discussed. 152 references. (NSA)

Rafalskii, R.P. and K.F. Kudinova. 1959. Cundttions for the Reduction and Precipitation of Uranium by Minerals. Atomnaya Energ. 7:333-7 (in Russian).

It is postulated that primary uranium minerals were precipitated by iron, sulfur, and arsenic reduction of U(VI) present in hydrothermal solutions. Experiments produced crystalline pitchblende, collomorphic uranium powder, and sooty uranium black formed by reduction of U(VI) to $U$ (IV) by acid solutions at 100 to $135^{\circ} \mathrm{C}$. The character of the formation depends upon the precipitator mineral, interaction temperature, and in some cases on the concentration of uranium in solution. (NSA)

Rancon, D. 1973. The Behavior in Underground Environments of Uranium and Thorium Discharged by the Nuclear Industry. IN: Environmental Behavior of Radionuclides Released in the Nuclear Industry. IAEA-SM-172/55:333346 (in French). 
Following various studies on the radioactive contamination of soil by fission products from a variety of effluents, it has been found necessary also to establish in what way long-lived heavy radionuclides could be diffused in underground environments. A proposal is made for the study of the behaviour in the soil of uranium and thorium originating from outside as compared with the uranium and thorium existing as natural constituents of the soil. Use was made of various types of soil (acid and alkaline) and or various minerals (argillaceous minerals, calcite and quartz). Uranium in solution, or uranyl ion to be more precise, has a certain degree of mobility in soils. The coefficient for the distribution of uranyl ion between the solution and the mineral was measured at various concentrations. The influence of the $\mathrm{pH}$ of the soil-water solution is very considerable; the retention of uranium by the soil shows a marked increase within certain narrow pH ranges. Thorium is subject to high retention by argillaceous and calcareous soils, some of the latter strongly fixing the whole amount. The influence of various parameters ( $\mathrm{pH}$, concentration, soil composition) is also substantial, as retention can be very much reduced under certain extreme conditions. The risk of the spread of thorium in dilute solution over long distances is negligible in most soils. On the other hand, a certain degree of uranium diffusion under the influence of ground-water movements is to be anticipated; diffusion evaluations are presented. (auth)

Rao, V. K., C. J. Shahani, and C. L. Rao. 1970. Studies on the Phosphate Complexes of Actinium and Lanthanum. Radiochimica Acta 14:-31-34.

The stability constants for the formation of $\mathrm{AC}_{-} \mathrm{H}_{2} \mathrm{PO}_{4}{ }^{2+}$ and $\mathrm{La}-\mathrm{H}_{2} \mathrm{PO}_{4} 2+$ have been determined at ionic strength $0.5 \mathrm{M}$ using the 1 iquid cation exchanger, dinonyl naphthalene sulphonic acid $\left(\mathrm{NH}_{4}+\right.$ form). It has been found that in acid phosphate solutions (at $\mathrm{pH} 2.0$ and 3.0), complexation occurs mainly with $\mathrm{H}_{2} \mathrm{PO}_{4}$ - ion while complex formation due to $\mathrm{HPO}_{4}{ }^{2-}$ and $\mathrm{PO}_{4}$ 3- ions is negligible. (auth)

Rekharskaya, V. M. 1971. Uranium Distribution in Clay Minerals in an 0xidation 7nne. At Energ. USSR 31:61-3 (in Russian).

Argillaceous minerals with an increased $U$ content in the zone of oxidation were examined chemically and physically. The data show that kaolinite and similar minerals collect $U$ in the oxidation zone, and in such zones the most favored areas are those in which iron sulfide has been retained. (NSA)

Rosholt, J. N., E. L. Garner and W. R. Shields. 1964. Fractionation of Uranium Isotopes and Daughter Products in Weathered Granite and UraniumBearing Sandstone, Wind River Basin Region, Wyoming. U.S.G.S. Professional Papers No. 501, B84-7. 
Isotopic ratios of ${ }^{235} \mathrm{U} /{ }^{234} \mathrm{U}$ for three samples representing different stages of weathering of granite show 7 to 23 percent deficient $234 \mathrm{U}$. The slightly weathered rock is most deficient, suggesting major $234 \mathrm{U}$ leaching at an early stage in the decomposition. Isotopic ratios in samples from a uranium deposit in sandstone showed slight excess $234 \mathrm{U}$ in unoxidized sandstone and up to 72 percent excess $234 \mathrm{U}$ in parts of the adjoining oxjdized sandstone characterized by relatively high uranium content. $230 \mathrm{Th} / 234 \mathrm{U}$ ratios indicate relatively recent deposition of redistributed uranium in parts of the oxidized sandstone where the $234 \mathrm{U} / 235 \mathrm{U}$ ratio is high. The low $234 \mathrm{U} / 235 \mathrm{U}$ ratios prevailing in uranium-poor parts of the oxidized sandstone are believed to have resulted from preferential leaching of $234 \mathrm{U}$ in these places and over a considerable time. (auth)

Rosholt, J. N., W. R. Shields, and E. L. Garner. 1963. Isotopic Fractionation of Uranium in Sandstone. Science. 139:224-6.

Relatively unoxidized black uranium ores from sandstone deposits in the western United States show deviations in the uranium-235 to uraniuili-234 ratio throughout a range from $40 \%$ excess uranium-234 to $40 \%$ deficient uranium-234 with respect to a reference uranium-235 to uranium-234 ratio. The deficient uranium-234 is leached preferentially to uranium-238 and the excess uranium-234 is believed to result from deposition of uranium-234 enriched in solutions from leached deposits. (auth)

Rozze11, T. C., and J. B. Andelamn. 1971. Plutonium in the Water Environment. II. Sorption of Aquenus Plutonium on Silica Surfaces. Advances in Chemistry Series 106: 280-298.

ihe sorption and desorption of aqueous plutonium in the range of $10^{-7}$ to $10^{-8} \mathrm{M}$ was studied on quartz and other silica surfaces. Sorption continued typically for 12 to 15 days before apparent equilibrium was reached, and the distribution of plutonium particle sizes sorbed on the silica was different from that in solution. At $\mathrm{pH} 7$, sorption increased with increasing ionic strength, but decreascd when bicarbullate was added. The amount of sorption varied at $\mathrm{pH} 5$ and 7 , but differently at high and low ionic strengtlis, as well as with the age of the solution. Plutonium desorption indicated that there were two basically different surbed species, and the rate and quantity of desorbed material increased at $\mathrm{pH} 5$ compared with 7 and 9 . (auth)

Ryabchikov, D. I. and E. K. Gol'braikh. 1960. Analytical Chemistry of Thorium. Trans. by A. Aladjem. 1963. Israel Program for Scientific Translations Ltd. 289 p.

This book gives detalls of thorium occurrence in nature and its properties, chemical and physicochemical methods for determination, methods for separation from accompanying elements, determination in natural materials and in industrial products, and determination of impurities in metallic thorium. 
Sackett, W. M., W. S. Broecker, and D. L. Thurber. 1965. The Geochemistry of Protactinium - 231 and the Dating of Pelagic Sediments. Annual Report. TID-21522.

Papers are included on sediment deposition rate determination by the protactinium method and on measured rates of marine sediment deposition and implications for accumulation rates of extraterrestrial dust. Separate abstracts were prepared for these papers. (NSA)

Sackett, W. M. and G. B. Cook. 1969. Uranium Geochemistry of the Gulf of Mexico. Translation, Gulf Coast Ass. Geol. Sco. 19:233-8.

$U$ concentrations $(10-6 \mathrm{~g} / 1)$ and the ratio $234 \mathrm{U} / 238 \mathrm{U}$ were determined: Gulf of Mexico, 3.4-3.6, 1.14-1.18; estuaries and bays along the Gulf, 2.1$17.3,1.12-1.54$; four rivers in Texas and 0klahoma, 0.6-3.0, 1.01-1.44. The high $U$ concentrations in $U$. S. rivers are considered to be due to the dissolution of $U$ from phosphate fertilizers. Determinations of $U$, Th, and the ratio ${ }^{234} \mathrm{U} / 238 \mathrm{U}$ are given for sediments of the Gulf and of Rivers.

Sackett, W. M., T. Mo, R. F. Spaling and M. E. Exner. 1973. A Revaluation of the Marine Geochemistry of Uranium. IN: Radioactive Contamination of the Marine Environment. IAEA-SM-158/51:757-769. .

Approximately $10^{15} \mu \mathrm{g} / \mathrm{yr}$ of dissolved uranium are being removed from the ocean by each of the generally accepted significant sinks for uraniumcarbonate deposits and deep anoxic basin sediments. However, these sinks account for only 10 percent of the estimated present-day input of uranium. Possible explanations for this discrepancy are: 1) contemporary input values are too high owing to a significant contribution from man's effects, such as uranium input via phosphate fertilizers or world-wide cultivation leading to premature leaching of uranium from soils, or 2) there are other important uranium sinks such as the abundant siliceous oozes or continental shelf anoxic sediments. (auth)

Sakanoue, M. 1960. Geochemical Studies on the Radiactive Sediments. II. Uranium Content of Natural Waters from the Ningyo-Pass Mining Area. Nippon Kagakii Zasshi 81: 896-8.

In order to find the amounts of $U$ leached from the U-bearing sedimentary bed by the action of natural waters, $U$ was determined paper chromatographically in water samples collected inside the drift of thc NingyoPass mine and from the rivulets and streams near the mine. Waters that have passed through the unoxidized zone tend to contain higher concentrations of $U(80$ and $250 \mathrm{r} / 1$.$) than that passed through the oxidized zone (21-33$ $\gamma 1)$. This tendency was confirmed by a model experiment; 2 ore samplesned obtained from the two zones were treated with water of different $\mathrm{pH}$ values, and the supernatant liquids were analyzed for $U$.

(CA) 
Sakanoue, M. 1960. Geochemical Studies on the Radioactive Sediments. III. Uranium, Phosphorus, and Arsenic in the Sedimentary Bed at Ningyo Pass. Nippon Kagaku Zasshi 81:898-902.

$U, P$, and As were determined in core samples taken from the unoxidized zone where ningyoite occurred, oxidized zone where autunite occurred, mixed zone, and shale beds containing fairly large amounts of $U$. Arsenic was determined by a modified Gutzeit method, and $P$ by the molybdenum blue method after evolution of arsine. In the unoxidized zone correlation is highly positive between $U$ and $P$, suggesting that the $U$ in these sediments was deposited mainly as a compound whose composition corresponds to that of ningyoite, a $\mathrm{Ca}^{++} \mathrm{U}^{4+}$ phosphate mineral. In the unoxidized zone $\mathrm{U}$ also shows a positive correlation with As, and the presence of As-bearing pyrte (as high as 0.76 percent As) was confirmed. It is pointed out that pyrite is related to the deposition of $U$. (CA)

Schel1, W. R. and R. L. Walters. 1974. Plutonium in Aqueous Systems. RLO-2225-T18-11. 26 p.

A review was made of the available information concerning Pu in the dyuattc environment. The levels are low and the data on the environmental concentrations in lake and marine environment.s are very limitcd. Of parlicular relevance to biological accumulation processes is the physicalchemical state of Pu. Limited information is available in natural environmental waters. Indications are that the plankton has the highest concentration factors and that the concentration factors decrease with increasing complexity of the organisms. Results of recent studies of $239 \mathrm{Pu}, 240 \mathrm{pu}$, and $241 \mathrm{Am}$ concentrations in water, sediment, and biota at Bikini and Eniwetok Atolls are given. The water samples measured indicate that $\mathrm{Pu}$ exists in the particulate, soluble and colloidal physical-chemical states. The plutonium is being injected into the water column from the sediments and has not been removed from the biogeochemical cycle after 16 years. Concentrations of $\mathrm{Pu}$ in vertebrates and invertebrates measured at Eniwetok were low and ranged from .001 to $.2 \mathrm{pCi} / \mathrm{g}$ wet in fish muscle. Additional data are required to better evaluate the potential hazards to man of $\mathrm{Pu}$ in the aquatic environment. A computer program was developed to estimate the final forms of soluble $P u$ in natural waters under cerlain conditions of acidjty, oxidation potential, and complexing factors. (CH)

Schmidt-Collerus, J. J. 1969. Research in Uranium Geochemistry. Investigation of the Relationship Between Organic Matter and Uranium Deposits. Part II. Experimental Investigations. Final Report. GJ0-933-2.

The feasibility of the micropyrolysis-gas chromatography-mass spectrometry (MPGM) method for the characterization of the organic matter associated with uranium in fluviatile ure deposits was investigated. The role of biogenically generated hydrogen sulfide in the reduction and precipitation 
of uranium in particular in the roll-type deposits was also investigated. It was found that the MPGM method, applied successfully to the characterization ("fingerprinting") of various intractable natural bioliths, can equally well be applied to the characterization of the organic matter in uranium ore deposits and to the study of the nature of this association. The enrichment of uranium in the roll-type deposits appears to be associated principally with the organic matter present and caused by specific ligating moieties in it, the role of hydrogen sulfide is probably of a secondary nature. Nonetheless, if hydrogen sulfide was synergistically involved in the reduction and precipitation of uranium together with the organic matter it is more likely that its origin was mainly biogenic in nature because of the facile availability of organic matter as energy source for the $\mathrm{H}_{2} \mathrm{~S}$ producing microorganisms. This mechanism for the $\mathrm{H}_{2} \mathrm{~S}$ production appears also the less complicated one than that assumed for the inorganic mechanisms, involving oxidation of sulfides to sulfites and disproportionation of the latter to form $\mathrm{H}_{2} \mathrm{~S}$ and sulfates -- although the possible simultaneous partial formation by the latter reaction mechanism can not be excluded. (NSA)

Schulz, R. K. 1965. Soil Chemistry of Radionuclides. Health Physics. $11: 1317-24$.

The naturally occurring radionuclides found in the soil in significant amounts include ${ }^{14} \mathrm{C}, 40 \mathrm{~K},{ }^{87} \mathrm{Rb}$, and members of the $U, A c$, and $T h$ series. More than 300 radioisotopes will be undetectable, because of their short half-lives. $\mathrm{Y}, \mathrm{Pr}, \mathrm{Pm}$, Th, $\mathrm{Pa}, \mathrm{Zr}$, and $\mathrm{Nb}$ occur in soils, but are either very strongly adsorbed by the clay particles or are present as insoluble oxides or hydroxides. In either of these states, these elements will be immobile in the soil and largely unavailable to plants. The elements which have a greater degree of mobility include $\mathrm{Sr}, \mathrm{Ba}, \mathrm{U}, \mathrm{Ra}, \mathrm{Pb}, \mathrm{Mn}, \mathrm{Co}, \mathrm{Zn}, \mathrm{Fe}, \mathrm{Ru}, \mathrm{Cr}, \mathrm{K}, \mathrm{Rb}$, $\mathrm{Ca}$, and $\mathrm{C}$. In considering the mobility of any ion, all others have to be taken into account. The amount and species of the complementary ions will have a strong influence on the redistribution of these isotopes in the soil profile and will affect plant uptake. (CA)

Seaborg, G. T. and J. J. Katz. (ed.). 1954. The Actinide Elements. Mc-Graw Hill Book Company, Inc. New York. 879p

This book is a compilation of chapters written by various authorities on actinide chemistry. In order to indicate the contents of this book, the chapters are listed below: Introduction; the chemistry of actinium; nuclear properties of uranium; protactinium, and thorium isotopes;

the chemistry of thorium; the chemistry of protactinium; the chemistry of uranium; nuclear properties of the plutonium isotopes; oxidation states, potentials, equilibria, and oxidation-reduction reactions of plutonium; ionic and molecular species of plutonium in solution; preparation and properties of the neptunium isotopes; the chemistry of neptunium; nuclear properties of transplutonium nuclides $(\mathrm{Am}, \mathrm{Cm}, \mathrm{Bk}, \mathrm{Cf})$; the chemistry of 
transplutonium elements ( $\mathrm{Am}, \mathrm{Cm}, \mathrm{Bk}, \mathrm{Cf}$ ); radiochemical separations of the actinide elements; radiochemical assay by alpha and fission measurements; correlation of properties as actinide transition series; crystal chemistry of the $5 \mathrm{f}$ elements; optical properties of some compounds of uranium, plutonium, and related elements; and slow-neutron and spontaneous-fission properties of heavy nuclei.

Shcherbina, V. V. 1962. Methods of Elucidating the Transportation Form of Chemical Elements in Geochemical Processes. Geokhimiya. No. 11:945-52 (in Russian).

The paragenetic interrelations of minerals were investigated as criteria fur the elucidation of possible transportation forms of chemical elements in geochemical processes. The compounds must possess such physicochemical properties which make their transportation possible in a real geochemical environment (composition of the medium, alkalinity or acidity, oxidation -reduction level, temperature, and pressure). All natural reactions tend to proceed by the most simple way. The transformation forms of chemical elements define their ability for migration, the types of chemical reaction and the environmental conditions of mineral formation. (auth)

Shcherbina, V. V. Geochemistry of Uranium in Oxidation Zone of Ore Deposits According to Experimental Data. A/CONF 15/P2066 (in Russian).

Investigations of geochemical processes in the oxidation zone of ore deposits and reproduction of these processes by experiment made it possible to reveal the nature of chemical reactions which account for the formation of uranium minerals in the oxidation zone of ore deposits. Superposition of later geochemical processes on the products of earlier processes, their stage of development, and the resulting mineralogical zonality are ubserved. The reactions proceeding in the oxidation zone of uranium ore deposils are as follows: hydrolysis; ionic exchange resulting in hardly soluble compounds; oxidation-reduction reactions; formation and destruction of complex compounds; and sorption processes. The nature of these reactions depends on humid or arid types of weathering. Examples of reactions that account for paragenesis of exogenous uranium minerals and their connection with endogenous mineralization are given. (auth)

Sillen, L. G. and A. E. Martell. 1964. Stability Constants of Metal Ion Complexes. 2nd ed, Spec. Puh. No. 17. The Chemical Socity, Londur.

This book gives equilibrium constants for various reactions of some of the actinide lons and compounds ( $\mathrm{Th}, \mathrm{Pa}, \mathrm{U}, \mathrm{Np}, \mathrm{Pu}, \mathrm{Am}, \mathrm{Cm}, \mathrm{Bk}$ ) with organic and inorganic ligands. This is a comprehensive source for metal-ion complexes of organic and inorganic iigands. 
Silver, G.. L. 1970. Disproportionation of Tetravalent and Pentavalent Plutonium Ions in the Presence of Hexavalent Plutonium. MLM-1744. $47 \mathrm{p}$.

The concept that the disproportionation reactions of tetravalent and pentavalent plutonium ions are special cases of the general plutonium equilibrium problem is illustrated with the estimation of the distribution of plutonium valence states when tetravalent and pentavalent plutonium ions are allowed to disproportionate in the presence of excess hexavalent plutonium. Sources of errors in disproportionation stoichiometry coefficients are described, and a table of relative errors is presented. A computer program suitable for estimating plutonium valence state distributions for any initial plutonium oxidation number is included. Application of the program to the study of the autoreduction of solutions of hexavalent $238 \mathrm{Pu}$ and $239 \mathrm{Pu}$ is suggested. (auth)

Silver, G. L. 1971. Potential-pH Diagram for Plutonium. Radiochem. Radioanal. Letters. $7: 1: 1-5$.

A method for solving the general plutonium equilibrium problem is presented, and a potential-pH diagram for plutonium is constructed with the aid of this method. Four conditions of acidity and oxidation number calculated to result in equal concentrations of three plutonium species are suggested, and the locus of each "triple point" is indicated in the potential-pH diagram. (auth)

Silver, G. L. 1971. Disproportionation Coefficients of Plutonium. Journ. - Inorganic and Nuclear Chem. 33:577-583.

The usual disproportionation for $\mathrm{Pu}$ (IV) is written $3 \mathrm{Pu}(\mathrm{IV})+2 \mathrm{H}_{2} \mathrm{O}=$ $2 \mathrm{Pu}(\mathrm{III})+\mathrm{Pu}(\mathrm{VI}) \mathrm{O}_{2}{ }^{2+}+4 \mathrm{H}^{+}$, with no Pu(V). Pu(V) has been shown to result from $\mathrm{Pu}(\mathrm{IV})$ disproportionation. Silver proposes equations based on electron balances that include pentavalent plutonium fractional distributions of Pu species are presented for a range of $H \underline{M}$ of perchloric acid neglerting hydrolysis.

Silver, G. L. 1971. Plutonium in Natural Waters. MLM-1870. $15 \mathrm{p}$.

A method for estimating the concentrations of soluble Pu(III, Pu(IV), and $\mathrm{Pu}(\mathrm{V})$ and $\mathrm{Pu}(\mathrm{VI})$ is given by means of a small computer program. Pu polymer Presoluble ratio also can be determined. The water potential and $\mathrm{pH}$ are required as input.

Silver, G. L. 1972. Aqueous Plutonium Chemistry: Some Minor Problems. MLM-1871. p. 1-68. 
A method is presented for estimating the distribution of plutonium valence states in dilute aqueous acids which do not contain sequestersing agents. The effects of plutonium disproportionation reactions upon the acidity of plutonium solutions is discussed and a method for estimating such effects is illustrated with a computer program by Steven Tomes. Effects of uncertainties in the solubility product of tetravalent plutonium hydroxide on the $\mathrm{pH}$ region calculated to yield a maximum equilibrium concentration of pentapositive plutonium are described, and an analogy between aqueous tetravalent plutonium and a weak acid is suggested. The free energy of formation of tetravalent plutonium polymer is estimated as about $-340 \mathrm{kcal} / \mathrm{mole} \mathrm{Pu}$, and this estimate is used to define the region of acidity and plutonium concentration which is conductive to the formation of plutonium polymer. Also mentioned is the reaction of plutonfum with hydrogen peroxide, the temperature stability of pentapositive plutonium, and the study of plutonium in natural waters. (auth)

Silver, G. L. 1972. Instability of Heptavalent Plutonium in Water Solutions. (p. 7-10); Determination of Plutonium in Soil. (p. 18-20). MLM-1829. Mound Laboratory Chemistry and Physics Progress Report: April-June 1971

Instability of Heptavalent Plutonium in Water Solutions

One of the interesting discoveries in recent times is the heptavalent state of plutonium. If this newly discovered oxidation state can be stabilized in water solutions, many new procedures for processing plutonium and making plutonium compounds may become available. Present prospects for easy stabilization of heptavalent plutonium are not sanguine, however.

Determination of Plutonium in Soil

A complete procedure was established for the determination of plutonium in soil by a fusion technique, and results were rcported previuusly for blank determinations and soil samples.

Silver, G. L. 1972. Plutonium in Natural Waters. Haman, et al., 1972. Determination of Plutonium in Soi1. MLM-1888. Mound Lab Chem and Physics Progress Report: Oct-Dec. 1971. p. 13-14,15.

First article by Silver gives some computations for Pu(IV) - Pu(V) distributions in soluble species Polymer of Pu(IV) may not form in seawater due to low Pu concentrations.

Second article describes continuing work on determination of $\mathrm{Pu}$ by a fusion process.

Silver, G. L. 1972. Suggestion for the Study of Plutonium in Environmental Waters. MLM-1903. Mound Lab. Chem. \& Physics Progress Report. Jan-March, 1972. pp. 20-21. 
Some thoughts by Silver on ascertaining the form and valence state of $\mathrm{Pu}$ in environmental waters including approximation of alpha coefficients for $\mathrm{Pu}^{2+}, \mathrm{Pu}^{4+}, \mathrm{PuO}_{2}{ }^{+}$and $\mathrm{PuO}_{2}{ }^{2+}$.

Silver, G. L. 1972. Suggestion for the Determination of Plutonium Valencies in Aqueous Solutions. Radiochem. and Radioanalytical Letters. 9:315-320. $315-320$.

An equation is derived which may be useful in the determination of plutonium oxidation state concentrations in aqueous solutions. (auth)

Silver, G. L. 1972. Valence State Distributions of Uranium, Neptunium, and Plutonium in Acid Solutions. MLM-1933. 58 p.

Mathematical approaches developed for the study of plutonium disproportionation reactions appear to be adaptable to the study of the distribution of the valencies of uranium and neptunium in aqueous solutions. Valence state distributions of uranium and neptunium for various conditions of solution acidity and oxidation-reduction potential are presented in tabular form. A small computer program for the estimation of valence state distributions is presented, and a "solubility product" of tetravalent plutonium polymer is suggested. The Nernst Equation. is used to suggest a maximum in the concentration of soluble pentavalent plutonium when the hydrous oxides of tetravalent and hexavalent plutonium are in equilibrium. (auth)

Silver, G. L. 1973. Ambiguous Variable Combinations in Plutonium Chemistry. Radiochem. Radional. Letters. 13:2:101-108.

Forbidden, tolerable and ambiguous combinations of plutonium oxidation number with given fractions of hexavalent plutonium are graphically presented. A graph of ambiguous combinations of trivalent and hexavalent plutonium is also given, and the suggestion is made that there are some combinations of fractions of two valence states (e.g., hexavalent and tetravalent plutonium) which characterize plutonium soluliurs uniquely. (auth)

Silver, G. L. 1973. Stability of Pentavalent Plutonium. Journ. Inorg. and Nuclear Chemistry. 35:1369-72.

A method is suggested for maximizing $\mathrm{Pu}(V)$ concentration in solutions not containing hydrous plutonium oxides. An example is given of a solution containing $H=0.3$. $M$ then $=19.11$ when $M$ is the ratio of ionic hexavalent $\mathrm{Pu}$ to ionic pentevalent $\mathrm{Pu}$.

A method also is given for maximizing the concentration of $P u(V)$ in solutions containing hydrous plutonium oxides. 
Silver, G. L. 1973. Minor Problems in Aqueous Plutonium Chemistry. MLM2075. p. 55.

A method of ascertaining the acidity of the maximum concentration of trivalent and hexavalent plutonium as a function of plutonium oxidation number, and a method of estimating changes in solution acidity caused by disproportionation reactions may find application in the study of plutonium alpha coefficients. A method of ascertaining the temperature response of mixtures of plutonium ions indicates a decreased extent of disproportionation of pentavalent plutonium with increasing temperature over a narrow temperature range. The concept of representing chemical elements by polynomial equations is applied to chlorine and the reaction of plutonium with hydrogen peroxide. (auth)

Silver, G. L. 1973. Plutonium Triple Points in Nitrate Solutions (p. 4043); Effects of Ionic Strength on Plutonium Reactions (p. 44-46); Program fur the Rapid Computation of Tables ur Valence State Uistributions of Uranium, Neptunium and Plutonium ( $p$. 46-48); Valence State Distributions of Americium in Aqueous Solutions ( $p$. 46-51); Approximations in the Calculation of Disproportionation Stoichiometries of Pentavalent Plutonium at Different Temperatures ( $p$. 49-55). MLM-2080. Mound Lab. Isotopic Power Fuels Programs: April-June 1973.

A recent contention that a plutonium triple point should have been observed near $\mathrm{pH} 1$ in nitrate solutions is disputed. Other considerations affecting plutonium equilibria in dilute nitric acid solutions are also mentioned.

The effects of ionic strength upon plutonium reaction is discussed, and a comparison of theoretical predictions and experimental results is mentioned.

A program is preserited for the rapid generation of valence state distributions for uranium, neptunium, and plutonium as a function of solution acidity, actinide average oxidation number, and sequestering ability of the solution.

Approximate valence state distributions of americium as a function ur average oxidation number are presented for one molar and tenth molar perchloric acid.

Some approximations used in the calculation of disproportionation stroichiometries of pentavalent plutonium at different temperatures are discussed. While approximations used in these calculations will affect the absnlute values of stoichiometry coefficients significantly, the effect of some approximations upon the calculated disproportionation free energy change per mole of pentavalent plutonium may not be large.

Silver, G. L. 1973. The Three Actinides Equilibrium Problem. MLM-2007. p. 35 . 
Much of the aqueous chemistry of uranium, neptunium, and plutonium can be represented by the solution of a single cubic equation. This equation may take the form of a statement of charge conservation for these elements in which the unknown variable is the ratio of hexavalent to pentavalent actinide. By assigning the relative proportion of pentavalent actinide the value of unity, the fraction of each of the other three valence states may be calculated. Tables of valence state distributions of uranium, neptunium, and plutonium as a function of average oxidation number and equilibrium acidity are presented, and two numerical methods for solving the cubic equation are illustrated with computer programs. Forbidden combinations of solution acidity and fraction of pentavalent plutonium are suggested, and a method of finding these forbidden combinations is proposed. (auth)

Silver, G. L. 1974. The Representation of Chemical Elements and Chemical Reactions by Polynomial Expressions. Journ. Inorg. and Nuclear Chem., 36: 939-941.

Silver presents a method for the description of plutonium in solution by means of a single programmed equation: $\mathrm{K}_{3} \mathrm{~K}_{4}{ }^{2}[\mathrm{H}+]^{4}(3-\mathrm{N})+\mathrm{K}_{4}[\mathrm{H}+]^{4} \mathrm{M}(4-\mathrm{N})+$ $(5-N) M^{2}+(6-N) M^{3}=0 \cdot N=$ average oxidation number, $K_{3}$ and $K_{4}$ are equilibrium constants and $M=\frac{P u(V I)}{P u(V)}$. The above equation also can be used to prepare a $\mathrm{OH}$-potential $\mathrm{Pu}(\mathrm{V})$ diagram. The same method is further developed to describe a chemical reaction $\left(\mathrm{Fe}^{+2}+\mathrm{Ce}^{+4}=\mathrm{Fe}^{+3}+\mathrm{Ce}^{+3}\right)$ with polynomial expressions.

Silver, G. L. 1974. Plutonium Valence State Distributions. Journ. of Radioanal. Chem. 23:195-197.

A method for ascertaining equilibrium valence state of plutonium in acid solutions as a function of the plutonium oxidation number and the solution acidity is illustrated with an example. The method may be more practical for manual use than methods based upon polynomial equations. (auth)

Silver, G. L. 1974. Potential-pH Diagrams and Plutonium. MLM-2176. p. 23.

The concept of the greatest lower bound may be combined with conditions for the predominance of valence states to prepare potential-pH and other types of predominance region diagrams. The technique is illustrated for the case of plutonium together with the discussion of the representation of chemical elements and reactions by polynomial equations. (auth)

Silver, G. L. 1974. Topics in Aqueous Plutonium Chemistry. MLM-2108. p. 43.

The general plutonium equilibrium problem is solved with logarithms and a logarithmic form of the plutonium characteristic equation is suggested. 
Other topics include numerical methods for estimating the equilibrium acidity in plutonium solutions, a characteristic equation for the ironplutonium reaction, a method for finding some forbidden combinations of solution variables, and properties of plutonium-238 radiation concentration cells. (auth)

Spalding, Roy F. and $\%$. M. Sackett. 1972. Uranium in Runoff From the Gulf of Mexico Distributive Province: Anomalous Concentrations. Science 175: 629-31.

Uranium concentrations in North American rivers are higher than those reported 20 years ago. The increase is attributed to applications to agricultural land of larger amounts of phosphate fertilizer containing appreciable concentrations of uranium. Experiments showing a constant phosphorous - uranium ratio for various types of fertilizers and for the easily solubilized fraction of 0-46-0 fertilizers support this view. (auth)

Spitsyn, V. I. (ed). 1961. Investigations in the Field of Uranium Chemistry. ANL-Trans-33.

This is a compilation of papers on various aspects of uranium chemistry.

Stakebake, J. L. and L. M. Steward. 1973. Water Vapor Adsorption on Plutonium Dioxide. Jour. Colloid and Interface Sci. 42:328-333.

Adsorption isotherms of water vapor on plutonium dioxide were measured gravimetrically at 30,50 , and $85^{\circ} \mathrm{C}$. The data show water to be irreversibly chemisorbed until the oxide is saturated. Any subsequent adsorption is physical and completely reversible. The chemisorbed limit varied from 1 monolayer at $85^{\circ} \mathrm{C}$ to 3 monolayers at $30^{\circ} \mathrm{C}$. Gravimetric desorption showed water to be chemisorbed as two different species. A three-step model for the total adsorption process is proposed consisting of: surface hydroxylation (chemisorption); hydrogen bonding of water molecules to surface hydroxyls (quasi-chemisorption); and physisorption of water molecules. (auth)

Starik, I. E., Y. V. Kuzret.sov, F. P. Petryaev and V. K. Legin. 1983. Geochemistry Radioactive Elements. Khim. Zemnoi Kory, Akad. Nauk. SSSR Tr. Geokhim. Konf. 1:374-89.

A sludy of the geochemistry of radioactive elements in ocean water and sediments revealed several facts which cannot be explained only by the leaching of radioactive elements from minerals. This difference is most distinctly observed in a comparison of the $R a: U$ ratio, obtained during experiments in mineral leaching, with data on the $U$ and Ra contents in natural waters (formation waters of oil deposits and mineral springs) and with their contents in ocean water. The leaching of $\mathrm{Ra}$ and $\mathrm{U}$ from minerals suggests that the content of Ra in ocean water should be higher than that of $U$. Experimental data show 
the opposite. However, when the form of occurrence of these isotopes is considered, this disagreement disappears. In fact, more Ra than $U$ is delivered into water during rock leaching. But $U$ forms in seawater stable, easily soluble, complexes which migrate in aquatic medium. The Ra under conditions of natural waters ( $\mathrm{pH}>6$ ) was sorbed by suspended and colloidal particles and, together with them, precipitated into sediments. This results in relative enrichment (in comparison with $\mathrm{Ra}$ ) of ocean waters with $U$.

Starik, I. E., D. S. Nikolaev, S. M. Grashchenko, Y. V. Kuznetsov, K. F. Lazarev and V. R. Legin. Natural Radioactivity of the Waters and Sediments in the Black Sea and the Sea of Azov. AEC-tr-6641. pp. 10-13.

Radioactivity was measured in water and bottom sediments from the Black Sea and the Sea of Azov during 1958 and 1959. Uranium concentrations varied from 1.5 to $2.8 \times 10^{-6} \mathrm{~g} / 1$ with no apparent regularity of variation in either horizontal or vertical traverses. The constancy of the $U$ concentration in both seas was shown to be related to the presence of the carbonate complex of uranium. Although the uranium contents in the waters of both seas were similar, the concentrations in the upper portion of the bottom sediments were different, a difference explained by variation of hydrochemical conditions. Thorium-232, 226 Th, and Ra were also determined. (NSA)

Stevenson, P. C. and W. E. Nervik. 1961. The Radiochemistry of the Rare Earths, Scandium, Yttrium, and Actinium. NSA-NS-3020. $282 \mathrm{p}$.

This book gives a general review of chemistry of scandium, yttrium, and actinium. Details of chemistry (metals, amalgams, and various oxidation states; soluble salts; insoluble salts; sepectrometry, titration, and colorimetry; complex ions and chelate compounds; extraction; ion exchange; electric and magnetic field separations), dissolution and exchange, counting techniques, and radiochemical procedures for scandium, yttrium, and actinium are given.

Stuber, C. E. 1975. Transplutonium Elements -- A Bibliography.. TID-331756. ERDA.

This bibliography, prepared especially for distribution at the IAEA/ERDA International Sumposium on the Transuranium Nuclides in the Environment, San Francisco, November 17-21, 1975, comprises 589 references on the transplutonium elements compiled through the period January 1 to October 15, 1975. The references were retrieved from the Nuclear Science Abstracts (NSA) data base using a computerized information retrieval system and were formatted for publication with indexes by computer. In each group, references are arranged in order by the original NSA abstract number, which places them in approximate chronological order. Sequence numbers appear beside each reference, and the indexes refer to these sequence numbers.

Part I includes 565 references dealing with the production and chemical, nuclear, physical, and biological properties and health, safety, and environmental aspects of elements with $Z \geq 95$. References treating more than one element are grouped 
with the element having the lowest atomic number; therefore, the subject index must be consulted for a complete set of references on an element. The Actinides group includes references dealing with the actinide elements in general or treating the actinides collectively. References dealing with $z \geq 104$ elements are included in the Transactinide group.

Part II includes 24 references dealing with the natural occurrence of the transplutonium elements. This collection of references is concerned with attempts to locate or prove the existence of the transplutonium elements in nature.

Part III, a feature added to enhance the usefulness of this bibliography to the participants at this symposium, contains 772 references on the environmental aspects of neptunium and plutonium retrieved from NSA through the period June 1, 1973 through October 15, 1975. (auth)

Sutton, J. 1949. The Hydrolys is of the Uranyl Ion. Part I. Journ. of the Chemical Society. Part V:275-86.

Cryoscopic measurements prove conclusively that the hydrolysis of uranyl salts leads to the formation of the ions $\mathrm{U}_{2} \mathrm{O}_{5}^{++}$and $\mathrm{U}_{3} \mathrm{O}_{8}{ }^{++}$, and not $\mathrm{UO}_{2}(\mathrm{OH})^{+}$ and $\mathrm{UO}_{2}(\mathrm{OH})_{2}$.

Measurements of $\mathrm{pH}$ of solution of $\mathrm{UO}_{3}$ in solutions of uranyl salts, $\mathrm{pH}$ titrations of uranyl perchlorate with sodium hydroxide, and the conductivity and absorption spectra of these solutions, point to the formation of further ions $\mathrm{U}_{3} \mathrm{O}_{8}(\mathrm{OH})^{+}, \mathrm{U}_{3} \mathrm{O}_{8}(\mathrm{OH})_{2}$, and $\mathrm{U}_{3} \mathrm{O}_{8}(\mathrm{OH})_{3}^{-}$. More highly charged anions may be formed but the evidence is still inconclusive. The equilibrium constants for the formation of some of these ions have been determined. (auth)

Swanson, 1. 1. 1973. Nature of Actinide Species Retained by Sediments at Hanford: Interim Progress Report. BNWL-B-296.

A program to develop leach procedures appropriate to characterizing the behavior of different actinide species retained by soils is in progress. Characterization of the Pu species present in samples taken from the 216-Z-8 trench has been made difficult by the presence in these samples of materials which form only sparingly soluble Pu compounds. Because of the presence of these materials, in some cases the leaching of the $\mathrm{Pu}$ is more a function of the solubility of $\mathrm{Pu}$ in the leach solution than it is a function of the $\mathrm{Pu}$ species present in the soil. Prelrealments of the soil samples wilh alcohol, with hydroxide solutions, and with TBP solutions have been found to give at least partial removal of these $\mathrm{Pu}$ solubility-limiting materials.

The percentage of the $\mathrm{Pu}$ that dissolved readily in $5 \mathrm{M} \mathrm{HNO} 3$ at room temperature (using repeated solution changes to minimize the effect of the Pu solubilitylimiting materials) was found to range from 3 to 90 percent depending on sample location and depth. The higher removal percentages were achieved with the deeper portions of the samples. 
Data on the amounts of actinides, water, and organophosphates present in the 216-2-9 trench samples used in this work are included in the Appendix. The $\mathrm{Pu}$ content was found to range from $0.06 \mathrm{mg} \mathrm{Pu} / \mathrm{g}$ soil near the 24-inch level to $10 \mathrm{mg} \mathrm{Pu} / \mathrm{g}$ soil in the surface portion of one of the samples; the water content was found to range from 4 to 33 percent and the organophosphate content ranged up to 1.4 percent. (auth)

Szalay, A. 1954. The Enrichment of Uranium in Some Brown Coals in Hungary. Acta. Geol. Acad. Sci. Hung. 2:299-311.

- Geochemical enrichment of uranium is ascertained in some brown coal strata in Hungary. These strata are situated near to the detritus zone of the two existing granitic mountains of Hungary. The uranium content of these coal strata is about the same (about 0.01 percent) as the $U$ content of bioliths (oil shales, carbonate rocks, etc.) used to be. It seems highly probable that the same unknown general geochemical law is responsible for all such enrichments in bioliths. The granitic rocks are the primary sources of uranium, the $U$ migrated into the sea or moor water during the age of chemical decomposition of the rocks. Uranium became adsorbed by the decomposing organic substance of the sediments. Laboratory experiments revealed that decomposing plant debris, peat, lignite, and brown coal have a very high adsorption power and capacity for uranium, which is in fact sufficiently high to explain geochemical enrichment. Subsequent experiments revealed and control experiments verified that the humic acid colloid particles are responsible for the adsorption, which is a cation exchange process. The adsorption equilibrium constant of humic acid substance is much higher for uranium than for cations of lower valence and lower atomic weight. It seems that the hitherto unknown law of geochemical enrichment of uranium in bioliths is herewith explained. This law may be formulated in the following manner: the geochemical enrichment of uranium in carbonate rocks (bioliths) is caused by the adsorption of dissolved uranium by the humic acid content of the sediments . The adsorption is a cation exchange process. (auth)

Szalay, A. 1957. The Role of Humus in the Geochemical Enrichment of $U$ in Coal and Other Bioliths. Acta. Phys. Acad. Sci. Hung. 8:25-35.

Investigations established that the enrichment of $U$ in peats, coals, and other bioliths is caused by adsorption on the humic acid. Adsorption isotherms have been measured and numerically evaluated. The adsorption itself is actually a cation exchange process. The enrichment factor of $1: 10,000$ agrees well with the quotient of the concentration of $U$ in bioliths and natural waters. (auth)

Tamura, T. 1974. Distribution and Characterization of Plutonium in Soils from Nevada Test Site. IN: Dunaway, P. B. and M. G. White (eds.). The Dynamics of Pluconium in Desert Environments. NVO-142. (NVO-AEIC-74-1 or $U C-2): 29-42$. 
This study was undertaken to determine the distribution and characterization of plutonium in soil fractions of the Nevada Applied Ecology Group (NAEG) intensive site study area samples. This report discusses analytical results obtained on three selected surface soil samples from two areas at Nevada Test Site.

Analytical methods are described for determination of total plutonium content, plutonium distribution in different particle size fractions, and shorttime digestion leachability by $\mathrm{HNO}_{3}$ revealed that 65 to 91 percent of the plutonium could be leached. The leaching results suggest the possibility of using the acid extraction as a means of predicting the "availability" of plutonium in soils. Preliminary data suggest that plutonium in the coarser size fractions is $\mathrm{PuO}_{2}$, whereas plutonium associated with the finer size. particles possibly is a hydrous $\mathrm{PuO}_{2}$. (auth)

Tamura, T. 1.975. Physical and Chemical Characteristics of Plutonium in Existing Contaminated Soils and Sediments. IAEA-SM-199/52.

Plutonium from three sites has been studied to provide information necessary in understanding its behavior and fate under prevailing conditions. Plutonium in soils from the Nevada Test Site (NTS) was predominantly associated (5075 percent) with the coarse silt $(53-20 \mathrm{\mu m})$ fraction. The coarse silt fraction was further segregated by density gradient zonal centrifugation; the plutonium in the sample from a bare soil ranged from 60-85 percent in the "heavy" mineral plutonium in a sandy mound taken beneath shrubbery occurred predominantly (80-95 percent) in a lighter fraction $\left(2.5-2.7 \mathrm{~g} / \mathrm{cm}^{3}\right.$ ) associated with feldspar. Soil extraction of NTS plutonium with $0.1 \mathrm{M}$ citric acid solution showed very low solubility ( $\sim 1$ percent).

The plutonium in samples from Oak Ridge National Laboratory (ORNL) and Mound Laboratory (ML) was predominantly in the clay size $(<2 \mu \mathrm{m})$. The solubility in citric acid was about 20-25 percent in the ORNL sample and 40-50 percent in the ML sample. Density gradient segregation of the clay size fraction of the ML sample showed the activity distribution to be directly related to the weight of the recovered fraction with enhanced contribution by the very light organic fraction. Approximately 71 percent was found in the $2.3-2.4 \mathrm{~g} / \mathrm{cm}^{3}$ fraction which controlled 65 percent wieght percent of the clay and 16 percent in the $<1.8 \mathrm{~g} / \mathrm{cm}^{3}$ fraction (organic fraction) which contained 6 percent of the weight fraction. (auth)

Titaeva, N. A. 1967, On the Character of Radium and Uraniulir Buund in Peat. Geokhimiya. 12:1493-99.

In little-mineralized hydrocarbonate-calcic surface waters uranium is considerably more mobile than radium. Radium is well sorbed not only by clay sediments but also by peat. In peat uranium is bound to the fraction uf humic acids and fluvoacids being soluble in alkalis, and radium to the insoluble residue. The bond of elements under oxidizing conditions has an exchange 
character. In the presence of great calcium amounts in water the radium bond in peat and in the insoluble residue becomes poorly exchangeable. In basic acid the exchange character of the radium bond is preserved. (auth)

Tugarinov, A. I. and I. B. D'yachkova. 1967. Some Common Geochemical Characteristics of Selenium and Uranium. Vop. Prikl. Radiogeol. No. 2:380-6 (in Russian).

The Se geochemistry in earth crust is controlled above all by analogy of its properties with those of $\mathrm{S}$. The highest $\mathrm{Se} / \mathrm{S}$ ratio, typical of sedimentary rocks in which the Se is present mostly in the form of native Se of selenides is accompanied, as a rule, by $U$ mineralization. The mobility of Se and $U$ under oxidizing conditions and their almost complete inert behavior in reducing medium are the main geochemical properties controlling Se and $U$ in exogenic processes. Extraction of Se and $U$ from rocks is possible by solutions, having sufficientily high En, through oxidation. The alkaline medium is the most favorable for simultaneous transfer of Se and $U$ into the mobile state. The Se and $U$, migrating in surface waters, are concentrated in rocks having high reducing capacity. If, under favorable conditions (short distance from the denudation area, oxidation character of the solution, etc.) the Se reaches the sea, then, similarly to $U$, it is precipitated immediately, and is accumulated in the continental shelf region. Absorption phenomena promote the separation of $S e$ and $S$ in addition to oxidation-reduction factors. Organic substances played a large part in the concentration of Se and $U$. Under hypogene conditions, the oxidation-reduction factor controlled to a large degree the formation of sediments of elements having changing valency in a definite sequence. (CA)

Turekian, K. K., J. P. Riley and G. Skirrow, (eds.). 1964. Geochemisty of Marine Sediments. TID-21074.

A discussion of the major features of deep-sea sediment geochemistry is presented. The information is presented in sections on components of deep-sea sediments, radioactive dating and rates of accumulation, trace-element geochemlstry in lie oceans, and geographical variations. (N.SA)

Vinogradov, A. P. 1959. The Geochemistry of Rare and Dispersed Chemical Elements in Soils. Second Edition. New York, Consultants, Bureau, Inc.

This volume consists of nineteen chapters which cover the following subjects: methods of decerminlny rare dind dispersed clements in soils; somp general geochemical regularities in the distribution of rare elements; soil-forming rocks and suils of the eastern European plain; boron in snils, fluorine, bromine, and iodine in soils; arsenic and selenium (tellurium) in soils; lithium, rubidium, and cesium in soils; strontium and barium in soils; rare earth metals and yttrium, titanium and zirconium (hafnium) in soils; vanadium, chromium, manganese, cobalt, and nickel in soils; copper, zinc and cadmium in soils; lead and tin in soils, molybdenum and tungsten, radioactive elements in soils; other dispersed element.s in soils; and geochemical regularities in the distribution of rare elements in soils. (NSA) 
Vinogradov, A. P. (ed.). 1963. Principal Characteristics of Uranium Geochemistry. Publishing House of the Academy of Sciences.

The geochemical properties of uranium are discussed. Topics include the crystal chemistry of uranium minerals; the geochemistry of uranium in magmatic, pegmatic, and metasomatic processes; the behavior of uranium in processes of deposit formation; uranium in sedimentary rocks; and uranium in natural waters. (NSA)

Vdovenko, V. M. 1960. Chemistry of Uranium and Transuranium Elements. AEC$\operatorname{tr}-6421$.

The buuk deals with solid and solution phase chemistry of uranium, neptunium, plutonium, americium, cesium, and transcurium elements. The scientific principles of the chemistry of fuel processing are also discussed.

Weeks, A. D. Mineralogy and Oxidation of the Colorado Plateau Uranium Ores. U.S.G.S. Professional Paper 300, 187-93.

The $V$-rich ores contain mainly rescocnte and montroseite. Primary ores with $V / U 15: 1$ to $1: 1$ contain the $U$ as uraninite and coffinite, the $V$ as montroseite. Ores lacking $V$ contain chiefly uraninite with pyrite, Cu sulfides, and galena. On oxidation; trivalent $V$ yields quadrivalent and quinquevalent $V$ minerals such as rauvite, melanovanadite, and corvusite. Further oxidation yields minerals containing $U(V I)$ and $V(V)$, such as carnotite, tyuyamunite, hewettite, pascoite, and others. Oxidation on nonvanadiferous $U$ ores yields a wide variety of U(VI) uxides, carbonates, sulfates, phosphates, arsenates, and. silicates. Oxidation of the ores is much slower in ore below the water table. (CA)

Yabuki, H. and M. Shima. 1973. Uranium and Other Heavy Elements in DeepSea Sediments Coexisting with Manganese Nodules. Sci. Pap. Inst. Phys. Chem. Ris. (in Japanese).

$\mathrm{Mn}, \mathrm{Fe}, \mathrm{Cu}, \mathrm{Ni}$, and $\mathrm{Co}$ were analyzed by atomic absorption spectrometry and $\mathrm{U}$ was determined by the induced fission-track method by applying internal std. addition. The saluples were deep-sea sediments, a kind of foraminiferous ooze which consists mainly of $\mathrm{CaCO}_{3}$ found in the area with the Mn nodules. The analyses were compared with similar data obtained previously for the Mn nodules. The nodules were richer by a factor of $G$ for $U$ and by a factor of $>100$ for the other elements. This tendency of $U$ is also seen in the relation between seawater and nodules or sediments. This may mean that. $0^{2+}$ ion in seawater rarely coprecipitates with Mn or Fe by scavenging effect, but forms complex ions with carbonate and is adsorbed on the surface of sediments or nodules. Data suggest that $\mathrm{Mn}, \mathrm{Ni}$, and $\mathrm{Co}$ are accumulated in both nodules and sediments at about the same rate. Results imply that Cu coprecipitates with $\mathrm{Fe}$, rather than $\mathrm{Mn}$. (CA) 
Yakobenchuk, V. F. 1968. Radioactivity and Chemical Properties of SodPodzolic Soils in the Ukrainian Western Polesie. Visn. Sil's' Kogospod. Nauki. 11:45-50. (in Ukranian).

The level of $\alpha$-radioactivity of sod-podzolic soils of the area is dependent on the content of $\mathrm{Al}$ sesquioxide $\mathrm{Al}_{2} \mathrm{O}_{3}$. The level of $\beta$-radioactivity is correlated with the amount of sandy and muddy particles of mechanical composition of the soil, and with the amount of $K, U$, and sesquioxides of $A 1$ and Fe. The concentration of $U$ is correlated with the amounts of oxides of $\mathrm{Si}, \mathrm{Fe}, \mathrm{Al}$, Th, and $\mathrm{Ra}$. The amount of Th is dependent on the reaction of soil solution and on the amount of $\mathrm{CaO}$. The amount of Ra is correlated with the amount of organic substances in the soil. Chemical analyses are tabulated. $(C A)$

Yamamoto, T., E. Yunoki, M. Yamakawa and M. Shimizu. 1973. Environmental Contamination by Uranium. III. Effects of Carbonate Ion on Uranium Adsorption to and Desorption from Soil. Journal Radiat. Res. 14:219-224.

Adsorption of uranium on soils and its desorption from uranium-adsorbed soils in the presence of carbonate ion were examined by using three kinds of soils: alluvial soil, sandy soil and volcanic ash soil. The absorption ratio of uranium for each soil was approximately 100 percent for the mixtures of uranyl ( 1 to $50 \mu \mathrm{gU} / \mathrm{ml}$ ) and carbonate solutions $\left(4.3\right.$ to $109 \mu \mathrm{gCO}_{3}{ }^{2-} / \mathrm{ml}$ ). In the uranium adsorbed soil ( 7.1 to $500 \mu \mathrm{gU} / \mathrm{g}$ air-dried soil) with carbonate ion $(4.3,43.4 \mathrm{\mu g} / \mathrm{ml})$, the desorption ratio of uranium for each soil was low ( 0.09 to 1.2 percent). The adsorped soils with stream water were probabiy similar to those with carbonate solution. (auth)

Yastrebov, M. T. 1971. Natural Radioactivity of Some Black-Earths in the European Areas of the USSR. Biol: Pochvoved. 26:93-97 (in Russian).

The radionuclides $238 \mathrm{U}, 226 \mathrm{Ra}, 232 \mathrm{Th}$, and $40_{\mathrm{K}}$ in black-earth were determined by gamma spectrometry, with a maximum error of 11 percent. The orderi $\mathrm{f}$.
absorption of these heavy nuclides by plant roots is $226 \mathrm{Ra}>238 \mathrm{U}>232 \mathrm{Th}$. In the southern chernozems the $238 \mathrm{U}$ content in the humus-accumulating layers was a factor of 1.3 to 1.8 lower than in rock beçause 8 f the loss of this isotope by being taken up in plant roots. The ${ }^{226} \mathrm{Ra}, 232 \mathrm{Th}$, and $40 \mathrm{~K}$ contents of the southern chernozem layer is 1.3 to 1.5 times that in rock, apparentiy because of less intense removal by plants. In distinction from the leached soils, the $238 \mathrm{U}$ accumulation in carbonate illuvial layers of the southern chernozems is small. Analytical data are tabulated. (NSA) 


\section{THIS PAGE}

\section{WAS INTENTIONALLY \\ LEFT BLANK}


MIGRATION AND ACCUMULATION OF

ACTINIDES IN SEDIMENTS

REVIEW OF MIGRATION AND ACCUMULATION

OF INDIVIDUAL ACTINIDES

The migration and accumulation of individual actinides in sediments is reviewed below.

Actinium

No articles on the migration and accumulation of actinium were found in the li terature.

\section{Thorium}

The association of thorium with other constituents in soils and sediments has been studied by numerous scientists. Two Soviet articles by Yakobenchuck (1968) and Pokidin, et al., (1972), found thorium to be associated with the calcium carbonate content of a podzolic soil and Caspian Sea sediment, respectively.

Menzel (1968) and Kuznetsov, et al., (1964), found thorium concentrations to correlate with phosphate content in rocks and marine suspended particulates, respectively.

Pashneva, et al., (1965), found the thorium content in Tomsk region Russian soils to increase with increasing humus content. Hansen and Huntington (1969) found a similar correlation with organic matter in Sierra Mountain soils. In contrast, Tyuruykanova and Kalugina (1971) found low thorium in peats and forest podzol soils compared to alluvial soils.

Adams, et al., (1959), suggest that thorium is concentrated by clay minerals. Schulz (1965) found the thorium in soils which he studied to be strongly adsorbed by clay particles or present as insoluble oxides and hydroxides. Rubtsov (1966, 1972) found thorium to associate with the fine grained particles during soil weathering. Ritchie, et al., (1972), found the thorium content of sediments in a freshwater environment to increase with decreasing particle size distribution.

Thorium incorporation into sediments by precipitation mechanisms is documented. Koczy (1949) performed experiments in which thorium directly precipitated in seawater. Pettersson (1949) also hypothesized thorium precipitation to the sea bottom to explain the distribution of thorium and radium.

Kuznetsov and co-workers (1964, 1966, 1969) reported studies in which the distribution of the two thorium isotopes, $230 \mathrm{Th}$ and $232 \mathrm{Th}$, are quite different in the marine environment. In suspended particulates and bed sediments $230 \mathrm{Th}$ associated with phosphates, hydroxide precipitates, organics and calcium carbunates. 232 Th was associated in sedimentary detrital particles. 
In the natural environment, thorium migration differs from uranium in that it moves primarily in colloidal form. [Baranov, et al., (1962)] [Lazarev, et al., (1961)] [Kimura, et al., (1968)]. Bernat and Goldberg (1969), Titaeva (1969) and Baturin, et al., (1971) reported in natural weathering cycles, both freshwater and marine, that thorium is least likely to migrate of the elements $\mathrm{Ra}, \mathrm{U}$, Th. But Somayajula and Church (1973) did find thorium (230Th and $232 \mathrm{Th}$ ) concentrations in interstitial waters of a Pacific 0cean sediment to be higher by a factor of $10-1000$ over their concentrations in seawater.

Natural weathering and laboratory leaching studies have been described by several investigators. Pliler and Adams (1962) found only 25 percent of the thorium in Boulder, Colorado, grandiorites were removed during the first stages of weathering. A laboratory leaching of fresh grandiorite by an acidic solution demonstrated 90 percent thorium removal. Kolalev (1965) leached the $0.01 \mathrm{~mm}$ fraction of a schist with 3 percent $\mathrm{HCl}$ and removed only 40 percent of the thorium compared to 70 percent of the uranium. Sugimura (1964) leached ocean sediments with cold $\mathrm{HCl}$ and found 60-70 percent of the thorium was extracted. Imahashi (1970) observed hydrothermal weathering of rocks in a Japanese hot spring area. Sixty percent of the thorium and 50 percent of the uranium was weathered from the rock. Dementev and Syromyatrukov (1965) concluded that thorium migration in groundwaters occurred in both colloidal suspension and anionic complexes probably with organic acids.

Iskra, et al., (1969) studied an interior-drained freshwater basin and determined the main sinks for thorium were the plant detritus and soils.

Thorium adsorption studies were performed by several investigators. Holland and Kulp (1954) found red clay, globigerina ooze and green clay readily adsorbed thorium. They concluded that ion exchange was the adsorption mechanism.

Katsurayama (1968) determined the distribution coefficient of thorium (KdTh) but data are not presented in the available abstract. Desai and Ganguly (1970) showed humic acids from a coastal marine sediment solubilized 100 percent of the thorium added to an ammonia solution $(2.5 \mathrm{~N})$. Thorium in this solution without humic acid was observed to predominantly precipitate (95 percent). The humic acid-thorium complex was non-cationic. In an identical experiment, fulvic acid extract was shown to solubilize 59 percent of thorium added to an ammonia solution. Again, the solubilized organicthorium fraction was non-cationic.

Nishiwaki, et a1., (1972) spiked seawater and seawater-distilled water mixtures with $\mathrm{Th}^{+4}$ and measured the sorption on a medium sand, very fine sand and silt-clay. Twenty grams of soil were contacted with four liters of spiked water and mixed until equilibrium was reached. KdTh increased as the particle size distribution of the soil decreased. Chlorosity of the water did not appear to consistently affect the KdTh for the find sand or silt-clay. The KdTh for the medium sand increased as the 
chlorosity of the water decreased. The chlorosity effect was confounded by a variable $\mathrm{pH}$ of the various salt solutions, so that the exact cause of the trend is not determinable. KdTh for the medium sand, very fine sand and silt-clay ranged $40-130,310-470$ and $2700-10,000 \mathrm{ml} / \mathrm{g}$, respectively.

Rancon (1973) measured KdTh for a clay soil and pure illite at $0.1 \mathrm{~g} / \mathrm{l}$ Th in natural groundwater vs $\mathrm{pH}$. Above $\mathrm{pH} 6$, sorption was complete $K d \mathrm{dh}>10^{5}$ while below $\mathrm{pH} 2 \mathrm{Kd}$ Th was low $<2 \mathrm{ml} / \mathrm{g}$. For an organic rich soil the $\mathrm{Kd}$ Th acted in an opposite fashion above $\mathrm{pH} 7.6$. Dissolution of humic acids which complex thorium and thus diminish sorption was hypothesized. Calcareous soils were observed to neutralize even concentrated Th wastes ( $\mathrm{pH} 2.6,10$ $\mathrm{g} / 1 \mathrm{Th})$ to a $\mathrm{pH} 6$ and precipitate $\mathrm{Th}(\mathrm{OH})_{4}$. For soils devoid of calcium carbonate and organic material, the $\mathrm{Kd} T \mathrm{~T}$ decreased as the initial thorium concentration increased. For example, the $\mathrm{Kd} T h$ for an altered schist soil and pure illite clay at pH 3.2 are shown in Table 4.

TABLE 4

$\mathrm{Kd} T \mathrm{Th} / \mathrm{l}$

\begin{tabular}{|c|c|}
\hline $\begin{array}{l}\text { Th Initial } \\
1 \mathrm{~g} / 1\end{array}$ & $\begin{array}{c}\text { Th Initial } \\
0.1 \mathrm{~g} / \mathrm{T}\end{array}$ \\
\hline $\begin{array}{l}\text { Schist } \\
\text { I11ite } 120\end{array}$ & $\begin{array}{r}60 \\
1000\end{array}$ \\
\hline
\end{tabular}

The drop in $\mathrm{Kd}_{\mathrm{Th}}$ was caused by saturation of available sorption sites. Rancon also presented data showing the KdTh to be concentration dependent at least to concentrations as $10 \mathrm{w}$ as $1 \mathrm{mg} \mathrm{Th} / 1$. In general, Rancon found three types of soil-thorium adsorption reactions, a) $\mathrm{Th}(\mathrm{OH})_{4}$ precipitation caused by calcareous soil buffering; b) for clay soils and dilute thorium solutions $(<1 \mathrm{~g} / 1 \mathrm{Th}$ and $\mathrm{pH}>2$ ) strong adsorption; and $\mathrm{c}$ ) for organic soils at neutral and acidic solution conditions strong adsorption but reduced adsorption in basic solutions caused by humic acid dissolution.

Bondietti (1974) studied the adsorption of thorium from waters at pH 6.5 by calcium saturated reference clays (montmorillionite and kaolinite) and calcium humate and found 95 percent and $99.9+$ percent sorption, respectively. Desorption studies utilizing calcium citrate removed 10-30 percent of the thorium from the clays but only one percent from the humate. Stronger complexers (DTPA and EDTA) removed (20-30 percent) of the thorium from the humate.

\section{Protactinium}

Only two articles were found which contain data on protactinium association with sediment properties, migration and adsorption properties.

Bernat and Goldberg (1969) found $231 \mathrm{~Pa}$ to appear to be preferentially accumulated by phillipsite (an authigenic zeolite) in a marine sediment core. 
Davydov, et a1., (1966) studied the adsorption of protactinium by silica gel from acid solutions. From 1-10 $\mathrm{M} \mathrm{HNO}_{3}$ and from 1-6 $\mathrm{M} \mathrm{HClO}_{4}$ solutions, 90 percent protactinium adsorption took place, independent of the acid concentration. Adsorption followed a Freundlich isotherm. Desorption was achieved with organic complexants (oxalic, citric, tartaric acids) and the inorganics $\left(\mathrm{H}_{3} \mathrm{PO}_{4}\right.$ and $\left.\mathrm{H}_{2} \mathrm{O}_{2}\right)$.

\section{Uranium}

There is a large amount of literature on the geochemistry of uranium because of its great value as a fuel for nuclear reactors. The uranium chemistry in the natural environment has been well studied with the practical objective to better predict the occurrence of ores.

Fischer and Stewart (1961) found uranium widespread in non-marine sandstones and igneous rocks. The uranium in the igneous rocks oxidized readily and caused uranium resolubilization into surface and groundwater solutions. The uranium would reprecipitate in the presence of a reducing agent such as sulfide ions or carbonaceous material.

Gabelman (1971) found uranium to remain stable in reducing environments typical of carbonaceous shales. He hypothesized adsorption on organic matter as the stabilizing force. In marine environments ionic substitution in phosphate rich sediments stabilizes uranium.

Kashirtseva (1969) believed bacterial formation of sulfide caused uranium to precipitate in pyritic rock material. Thismechanism is consistent with the findings of others who observed uranium to be stable in reducing environments.

Kolodny $(1969,1970)$ showed that uranium is very rapidly removed from seawater by anoxic sediments and the removal showed correlations with the sediment organic curtent. About 50 percent of the uranium in anoxic Saanich Inlet. was stronlyly bound chenically to organics. The rest was evenly divided between detrital minerals, authigenic tetravalent uranium and uranium adsorbed on organic matter. Dorta and Rona (1971) found high concentrations of uranium in organic reducing sediments in the Cariaco Trench off of Venezuela and a five fold decrease in uranium in oxidized clay layers of the same cores.

Koliadin (1960) and co-workers found a soluble hexavalent uranium carbonate complex in the upper $2000 \mathrm{~m}$ of the Black Sea often in the presence of hydrogen sulfide. They thus hypothesized that reduction to tetravalent uranium and precipitation was not the mechanism of uranium incorporation into the sediment. Agamirov (1963) hypothesized just such a reduction by hydrogen sulfide and precipitation reaction as the sedimentation mechanism occuring in the Black Sea.

Baturin (1971) and Baturin and Kochenov (1973) measured the properties of marine interstitial waters and found the concentration of uranium to be controlled by the $\mathrm{pH}$, Eh and organic carbon content of the water. 
Kolodny and Kaplan (1970) measured the uranium concentration in the interstitial waters of Saanich Inlet (an anoxic fjord). The uranium was highly enriched in both oxidizing (+280 mv) and reduced (-140 mv) interstitial waters relative to seawater concentrations. The uranium content appeared to depend on its oxidation state and the organic content present in the sediment.

Bell (1960), after finding high uranium contents in rock; asphalt and other bitumens concluded that the dissolved organics and hydrogen sulfide might provide the reducing environment necessary to precipitate uranium from groundwater.

Koide and Goldberg (1965) explained the disequilibrium between U-238 and its daughter U-234 in groundwaters as follows. U-238 is bound to crustal rocks in the +4 state, as it decays to U-234 electrons are lost from the nucleus to form uranium 6 . This latter form is preferentially leached by waters and mobilizes as a carbonate complex.

The mobility of actinides is addressed by Adams, Osmand and Rogers (1959). Processes in which the minerals holding the uranium are put into true solution increase uranium mobility. These usually occur under oxidizing conditions, conversely reducing conditions, often caused by organic matter decay precipitate uranium. The direct complexation by the organic matter is also a possible immobilization mechanism. Baturin $(1966,1973)$ and co-workers observed such precipitation in the Azov and Black Seas at the sediment-water interface where the Eh drops rapidly. Similar Eh controlled mobilization or precipitation phenomena are described by Koczy, et. al., (1957) Rafalskii and Kudinova (1959), Lisitzin (1962) in which the precipitation was also a function of $\mathrm{pH}$ and bicarbonate concentration, Veeh (1962), Tugarinov and D'yachkova (1967), Bonatti, et. al., (1971) and Sakanoue (1960).

Haji-vassiliou (1969) studied the association of uranium with natural occuring organic materials in the Colorado Plateau and concluded that uranium found in petroleum bearing rock is actually associated with the mineral content whereas coal-like bearing rocks show the uranium associated with the organic material.

Breger, Deul and Meyrowitz (1955) studied uranium rich coal and found 98 percent of the uranium to be associated with organic coal. They suggest that the uranium was introduced by alkaline groundwater carrying soluble uranyl carbonate complexes which break down in the acidic coal media to form $\mathrm{UO}_{2}{ }^{++}$ ions. These uranyl ions react with the organic matter and precipitate at $\mathrm{pH}$ 's above 2.2.

Baturin (1969). studied Indian Ocean sediments and found high uranium in high organic carbon and phosphorus sediments. Uranium was inversely proportional to the sediment calcium carbonate content. These facts again support uranium immobilization by organic and phosphate rich sediments.

Baturin (1967, 1971, 1973, 73) and Baturim and co-workers (1966, 1967, 1969 , 1971) measured the uranium concentrations in Black Sea, Mediterranean Sea, Aral Sea, Baltic Sea, and Pacific Ocean and found positive correlation 
with organic matter content. For the nearshore ocean sediments in upwelling regions the uranium precipitation correlated with phosphorus content also. Clay sediments in the Aral Sea also contained relatively high uranium concentrations.

Mo, Suttle, and Asckett (1973) studied the uranium concentrations in various sediments and found direct proportionality between organic carbon and uranium contents.

Erametsa, Lounamaa and Haukka (1969) found the humic acids present in peat bogs capable of sorbing carbonate complexed uranium from natural groundwaters.

Krylov and Shats (1958) studied the uranium contents in northwestern Russian water bodies and concluded that uranium precipitation was controlled by iron hydroxide and humic compounds.

Menzel (1968) has found phosphate rock samples in the United States to be relalively high in uranium content.

Bell (1960) studied the fate of uranium in desiccating salt-pan basins. When oxidizing conditions prevailed and no significant amounts of organicrich muds, clays, or phosphates were present, uranium salts remained in solution. When organic-rich muds, clays and phosphates were present, nearly a 11 of the uranium was removed from solution. Possible mechanisms include adsorption by organic material, adsorption on clays and precipitation as phosphates.

Uranium geochemistry in marine sediments has been studied by numerous scientists. Kolodny $(1969,1970)$ studied marine phosphorites dredged from the sea floor. The concentration of total uranium and $U(I V)$ were determined. Tetravalent uranium consisted of 38-84 percent of the total uranium found in the phosphorites.

Habashi (1962) found the uranium content to increase with increasing $\mathrm{P}_{2} \mathrm{O}_{5}$ content of marine sediments again verifying the uranium-phosphate association.

The correlation of uranium and phosphorus in sediments points to the uranium phosphate insolubility as another immobilization process. Sakanoue (1960), Mihauk (1968) and Kuznetsov, et al:, (1968) present corraboralive ddta showing phosphate precipitation sharply curtailing uranium movement.

Haglund (1968, 1969) studied the diagensis of uranium in rerent carbonate sediments. Core samples of marine carbonate sediments showed a constant uranium content with depth. The uranium content in similar sediments in contact with freshwater showed uranium concentrations to decrease with depth. The decrease was hypothesized to represent an increasing crystallinity of calcite grains. As aragnnite is altered to calcite and consolidated to limestone in the freshwater environment, Hagland calculates a 50 percent loss in uranium content from marine carbonates laid down during the Pleistocene period. The uranium is probably removed as soluble carbonate complexes. 
Yabuki and Shima (1973) measured the metal concentrations of carboneous ooze and nearby manganese modules and concluded that the 20 times smaller concentration of uranium in the nodules in comparison with other metals meant that the $\mathrm{UO}_{2}{ }^{++}$ion in seawater rarely coprecipitated with manganese and iron. The uranium present in nodules probably represented surface adsorped uranyl carbonate complexes.

Naumov (1961) in a study of hydrothermal water found uranium transport was by complex ions among which carbonate and fluoride ions were the most probable.

Lambet and Nikolaev (1962) filtered river water through $1 \mathrm{m \mu}$ membrane and found an ionic carbonate complex present. The uranium content of the water increased with an increase in salt content. The existence of a humic aciduranium soluble complex in several waters was not.excluded.

Mobilization of uranium as soluble and colloidal carbonate complexes have been described by Ermolaev, Zhidikora and Zarinskii (1965) Kuznetsov and co-workers (1967) and Pyalling (1970).

Rubtsov (1972) determined the uranium content in forest podzolic mountain soils and found a relatively high level of uranium in the $>1$ micron particle size fraction of the podzolic $A_{2}$ horizon. In general for the soils studied, 58 percent of the total uranium was found in the $>1$ micron soil fractions.

Mizuno and co-workers $(1969,1970)$ studied the relationship of total uranium contents with sediment properties in Japanese brackish lakes and nearby coastal ocean sediments. Contrary to many investigators' results uranium showed no relation to carbon contents. The uranium concentrations did progressively increase as the sediment particle size distribution decreased. Weak and somewhat circumstantial evidence to a clay adsorption mechanism being important is shown in the following works, Frederickson (1948), Manheim (1961) and Kanaziewicz (1966).

Yakobenchuck (1968) correlated the total uranium content in Russian sodpodzilic soils from the Ukraine with other soil constituents. Uranium showed correlation with the oxides of silicon, iron, and aluminum suggesting co-precipitation or inclusion.

Kovalevskii (1967) found the uranium content of non-cultivated soils in western Siberia increased with the clay content of the soils. Clay soils contained at least three times as much uranium as sands.

Ritchie, Hawks, and McHenry (1972) also found the uranium content of sediments from the Little Tallahatchie River to increase with decreasing particle size.

Uranium sorption from waters by sediments with a high organic matter content was ascertained by Baranov and co-workers (1961, 1962). Da11'Aglio (1971) found organics in soils and stream sediments in the Italian Alps to precipitate uranium. 
Baturin and Kochenov (1969, 1973) calculated the amount of uranium in river runoff to be 20,000 tons of which 50 percent was truely dissolved and 50 percent was suspended particulates. The ultimate fate of the uranium was believed to be sediment enrichment in organic and phosphorus rich sediments. In non-running freshwaters, Iskra, Kulikov and Bakhurov (1969) concluded that the main reservoir of uranium is in plant biomass. Sacket, et al., (1973) concluded that the main reservoirs of uranium in the ocean are the seawater, carbonate deposits, and anoxic sediments.

Dall'Aglio and Casentini (1970) followed the behavior of uranium at a solar plant on the Italian coast. Uranium remained in solution and concentrated in the final bitterns. The uranium concentration in the precipitated gypsum and sodium chloride was quite low.

Bostroem and Fisher (1971) found high concentrations of uranium in sediments in active volcanic areas of the Indian 0cean suggesting volcanism as a likely source of uranium.

Numerous investigators have reported on the leachability of uranium from geologic material. Brown and Keller (1952) leached a uranium bearing black shale with various solvents. Hydrochloric acid, nitric acid, sulfuric acid, aqua regia and dilute sodium carbonate were effective solvents for leaching uranium. Hot water, cold water, ethyl alcohol, carbon disulfide and carbon tetrachloride did not extract measurable uranium. Attempts to exchange the uranium with competing cations indicated uranium was not readily exchangeable.

Breger, Deul and Rubinstein (1955) extracted 88.5 percent of the uranium from $l i g n i t e$ by two consecutive treatments with boiling $1 \mathbb{N}$ hydrochloric acid. Continuous extraction with hot $6 \mathrm{~N}$ hydrochloric acid removed 98.6 percent of the uranium. Only 1.2 percent of the uranium in the coal was cxchangeable with treatment using a lanthanum nitrate solution. The results showed uranium was present as an organo-uranium rompound or somplex which solubilized be Iuw pH 2.2.

Alberti, et a1., (1959) leached uranium ore deposits with water and found the precentage leached to depend on the acidity of the solution. On the average, 18 percent of the total uranium solubilized in water, while 20 percent sulfuric acid leached 60 percent of the total uranium.

Pliler and Adams (1962) leached granodiorite rocks found near Boulder, Colorado with hot $2 \mathrm{~N}$ hydrochloric acid and removed 60 percenl of the uranium.

Guldsztein and Ros (1963) leached Mediterranean Sea sediments with $2 \mathrm{~N}$ nitric acid and found 60 percent of the uranium in continental shelf sediment and 36 percent of the uranium in abyssal plain scdiments to be leachable.

Kovalev (1965) leached the $0.01 \mathrm{~mm}$ fraction of a predominantly schist and phosphorite rock material with three percent $\mathrm{HCl}$ and removed 70 percent of the uranium. 
Legin, Kuznetsov and Lazarev (1966) leached sulfide bearing sediments from the Black Sea and sediments from the Azov Sea with $0.7 \mathrm{~N}$ sodium bicarbonate. The sulfide rich Black Sea sediment's uranium quantitatively leached whereas only 4-6 percent of the uranium in the Azov Sea sediment mobilized.

Titaeva and Veksler (1969, 1969) found uranium leached from metamorphic gneiss and crystalline schists by groundwaters from the Russian permafrost area. The waters contained high organic loads, oxygen and carbon dioxide contents which from a geochemical standpoint all favor uranium mobilization. Uranium migrated fastest, radium slower and thorium slowest in the extremely cold groundwaters. Baturin, Ilyina and Popov (1971) found the same order of migration in a marine sedimentary regime.

Imahashi (1970) removed 50 percent of the uranium content of hydrothermallyaltered rocks. Leaching performed under acid weathering conditions is more rapid than weathering processes under neutral conditions.

Jayaram and co-workers (1974) leached 43.3 to 67.8 percent of the total uranium from ores containing 0.03 percent and 0.06 percent $\mathrm{U}_{3} \mathrm{O}_{8}$ in a six hour leach study using water. The uranium ore consisted of uraninite, iron and copper sulfides and organic material ( 6.3 percent carbon content).

Uranium adsorption studies have been performed by several investigators. Szalay (1954, 1957) showed that uranium adsorption by decomposing plant debris, peat, lignite and brown coal is quite high. He determined that humic substances in these materials were responsible for the adsorption which was described as an ion exchange like sorption. Adsorption isotherms for the humic acid were measured.

Horvath (1960) measured the enrichment factor for the adsorption of uranium by peat and obtained an average of 200-350. Although it is not possible to determine what methods or exactly what the enrichment factor means from the English translated abstract, it is assumed that the data represent a KdU of 200-350 by weight or volume.

Masuda and Yamamoto (1971) studied the adsorption of uranium (1-100 ppm U) dissolved in water onto volcanic ash, alluvial, and sandy soils. The uranium was almost completely adsorbed on each of the so11s. Uraniuir desorption with salt solutions was extremely difficult especially for the volcanic ash. Similar studies by Yamamoto, et al., (1973) on the three soils using uranium (1-50 ppm U) and carbonated waters (4-109 ppm $\mathrm{CO}_{3}^{-2}$ ) showed approximately 100 percent adsorption and less than 2 percent desorption.

Rancon (1973) studied the adsorption behavior of uranium added to soils to simulate nuclear energy discharges as compared to natural weathering events. Rancon chose four soils: a) a river sediment containing a mixture of clay, calcium carbonate and organic matter; b) a highly organic riverine peat; c) a clay-calcium carbonate soil; and d) a clay and pure illite, calcite and quartz. The first two soils were exposed to river water containing uranium while the latter two solutions were exposed to their respective groundwaters both at $10 \mathrm{ppm} U$. The KdU in $\mathrm{ml} / \mathrm{g}$ are shown in Table 5. 
TABLE 5

Ká Values for üranium

\begin{tabular}{lr}
\multicolumn{1}{c}{ Adsorbate } & Kdy \\
\cline { 1 - 1 } Clay-Carbonate-Organic Mix & 39 \\
Alkaline Peat & 33 \\
Clay-Carbonate & 16 \\
Clay & 270 \\
Pure Quartz & 0 \\
Pure Calcite & 7 \\
Illite & 139
\end{tabular}

An increase in initial uranium concentration above $1 \mathrm{ppm} U$ which causes a subsequent $\mathrm{pH}$ decrease in the water causes the $\mathrm{Kd}_{4}$ to drop. At 10,000 $\mathrm{ppm} \mathrm{U}(\mathrm{pH} 2.5)$ the $\mathrm{Kd}_{U}$ is $\mathrm{nil}$ for the first two soils. A saturation of the adsorbate sites is proposed as a partial cause of the drop in $\mathrm{Kd}$. Rancon also presents data on the variation of $\mathrm{Kd}_{U}$ with $\mathrm{pH}$ at $7 \mathrm{ppm} \mathrm{U}$. For the clay soil, three peaks were observed; around pH $5.5\left(\mathrm{Kd}_{U}=300\right)$, a larger peak at $\mathrm{pH} 10\left(\mathrm{Kd}_{U}=2000\right)$, and a peak at $\mathrm{pH} 12\left(\mathrm{Kd}_{U}=270\right)$. Since soils are of variable composition, Rancon concludes the peaks correspond to sorption maxima corresponding to electrokinetic potential (surface charge) maxima for certain constituents. The uranyl ion $\mathrm{UO}_{2}^{++}$ is electrostatically adsorbed at these points. Other explanations for carbonate and humic bearing soils are discussed. The KdU for the alkaline peat is very low compared to the KdU for acidic peats.

Ames (1960) studied uptake of uranium VI at pH 12 from phosphate wastes by calcite. As apatite [ $\left.\mathrm{Ca}_{3}\left(\mathrm{PO}_{4}\right)_{2}\right]$ formed by substitution of calcite, cations were removeci frorii solution. Ames presented figures depicting the removal of $U(V I)$ as a function of phosphate concentration, temperature and flow rate. At low flow rates (below $50 \mathrm{~cm} / \mathrm{hr}$ ) uranium effluent solutions contained less than one percent of the initial one $\mathrm{ppm} \mathrm{U}$.

Desai and Ganguly (1970) showed that in ammonia solutions in which humic acids are soluble, humic acids solubilize all the uranium added and that 70 percent of the solubilized uranium was non-cationic. In a similar ammonia solution without humatr., urnnium was found to precipitale (57 percenll) as insoluble uranium compounds. Conversely, at natural environmental pH's where humates are often insoluble, large adsorption of uranium might be expected in humate rich soils. This type of humic acid adsorption was studied and verified by Calvo (1974).

Al though it is beyond the scope of this bibliography to document the biological interactions of uranium in the environment, one must not disregard biological mobilization and accumulation phenomena. 
Gruzdev (1971, 1972) found radium to be accumulated by plants much more readily than uranium and thorium. Also, thorium, unlike uranium, does not accumulate in forest litter high in humus. Yastrebov (1971, 1973) studied the adsorption of heavy nuclides by plant roots from soils. The order of accumulation followed the above order, $\mathrm{na}>U>\mathrm{Th}$. lilagne and co-workers (1974) report on the solubilization and insolubilization by bacteria of uranium. Under certain conditions bacteria were observed to increase the solubilization of uranium by 2 to 97 times over mine waters low in biological growth.

\section{Neptunium}

Very little work has been performed on the accumulation and migration of neptunium in soils and sediments. Robertson (1974) determined the speciation of neptunium in the cooling water effluent from the Hanford $\mathrm{N}$ reactor.

Through the use of filter membranes and cation and anion exchange resins, the following distribution was observed: 26 percent particulate, 70 percent cationic, < 3 percent anionic and less than 1 percent non-ionic.

Routson, et a1., (1975) determined the KdNp for a Washington sand and South Carolina sandy clay as a function of calcium and sodium. Batch tests with.10g and $25 \mathrm{ml}$ of solution at $\mathrm{pH} 2.5$ to 3.1 equilibrated for 24 hours were used. Results are shown in Table 6 .

TABLE 6

KdNp AS A FUNCTION OF SOIL AND SOLUTION

\begin{tabular}{|c|c|c|c|c|}
\hline & \multicolumn{2}{|c|}{$\mathrm{Ca}$} & \multicolumn{2}{|c|}{$\mathrm{Na}$} \\
\hline & $0.002 \mathrm{M}$ & $0.2 M$ & $0.015 \mathrm{M}$ & $3.00 \mathrm{M}$ \\
\hline Burbank Sand & 2.37 & 0.36 & 3.9 & 3.2 \\
\hline SC Sandy Clay & 0.25 & 0.16 & 0.7 & 0.4 \\
\hline
\end{tabular}

Price $(1973,1973,1974)$ presented data on the effect of organic acid chelators on the plant uptake of neptunium. Contrary to other transuranics studied, organic chelators suppress the uptake of soil amended neptunium by plants.

\section{Plutonium}

Aside from a miniscule amount of plutonium formed in "natural" reactors within the earth, the occurrence of plutonium in the environment is antropogenic. The bulk of the plutonium which occurs on the earth's surface has come from atomic weapons testing, a few airplane crashes and satellite burnups, and releases from nuclear power and fuel reprocessing plants. 
Articles which describe the distribution of fallout in the terrestrial and marine environment include Noshkin (1972), Noshkin and Bowen (1973), Bowen, et al., (1971, 1975), Miyake and Sugimmura (1975) and Hardy (1974). In the marine water column these investigators find plutonium to become geochemically separated from $90 \mathrm{Sr}$ and $137 \mathrm{Cs}$ and removed more quickly, possibly because of biological processes. The depth distribution of fallout nuclides shows plutonium to migrate downward at a rate intermediate to cesium (slow) and strontium (fast). In both the marine and terrestrial environment, plutonium appears to be more mobile than laboratory predictions.

Rates of removal of plutonium from the atmosphere are addressed by Hanson (1974). Ninety five percent of the SNAP-9A satellite burnup deposited on the earth's surface within six years.

Although this review deals only with chemical and physical migration of the actinides through geological material, the transport by particulate resuspension in air and biological processes must not be overlooked in assessing the total environmental impact. A few selected articles on these subjects include: Anspaugh, et al., (1973), Au (1974), Au and Beckert (1974), Beckert and Au (1975), Bennet (1974, 1975) Bowen and Noshkin (1973), Gromov and Spitsyn (1974), Hanson (1974, 1975), Jacobson and 0verstreet (1948), Matluch (1974), Price (1973, 1974) and Wildung, et al., (1973, 1974).

Observations on the movement of plutonium in the neighborhood of nuclear and fuels reprocessing plants offer most of the data to date on transuranics in the environment.

The movement of plutonium on the Hanford Reservation has been closely monitored for over twenty years. Liquid wastes disposed to the unsaturated sandy soil in several instances included trace amounts of plutonium. Typically, plutonium has not been found to percolate through the soils to any extent. Typical data (Brown, 1967) show 99.9+ percent of 1ong-1ived radionuclides such as plutonium to be sorbed within the first ten meters of soi1. Crawley (1969) reports on plutonium penetration at two facilities. Plutonium in a sand to which slightly acidic high salt wastes were released had penetrated at least 18 feet. Plutonium in a sand to which neutralized low salt water had been released penetrated less than two feet.

Ames (1974) and Price and Ames (1975) characterized the actinide-bearing sediment underneath a liquid waste disposal facility which received high salt, acidic wastes. The distribution in core samples shows a surface soil plutonium concentration of near $0.5 \mathrm{mci} \angle 39 \mathrm{Pu} / \mathrm{g}$. This concentration decreases to about $0.0 \mathrm{\mu Ci} 239 \mathrm{Fu} / \mathrm{g}$ within the first two meter's or underlying sediment and to less than $60 \mathrm{pci} / \mathrm{g}$ at the maximum depth sampled (nine meters). Examination of the contaminated soils showed at least two types of plutonium present: 1) discrete $\mathrm{PuO}_{2}$ particles (> 70 percent weight percent) and 2) hydrolyzed plutonium ( $<0.5$ weight percent $\mathrm{PuO}_{2}$ ). The $\mathrm{PuO}_{2}$ particulate form "filtered out" within the upper one meter of sediment. The "hydrolysis" type of plutonium penetrated deeper with in the sediment and deposited in association with silicate hydrolysis products as the soils buffered the acid waste. 
Emery and co-workers (1974, 1974, 1975) have studied the ecological behavior of one Hanford liquid waste pond. Ninety-five percent of the incoming low level waste percolates through the desert sands. The sediments are the principal repository, with the top ten centimeters containing an average $390 \mathrm{pci} \mathrm{Pu} / \mathrm{g}$. The overlying water contains $0.01 \mathrm{pci} \mathrm{Pu} / 1$. Assuming that these values constitute equilibrium conditions, an estimate of the Kdpu can be made. The resultant $\mathrm{Kdpu}$ value is $3.7 \times 10^{7} \mathrm{ml} / \mathrm{g}$. Pu in the interstitial waters appeared to be mainly cationic or nonionic forms. Plutonium in the pond water appeared to be mainly fine particulates possibly signifying that the waste stream plutonium content is predominantly $\mathrm{PuO}_{2}$ particles.

Schmalz (1972) reported that plutonium wastes buried as solids at the National Reactor Testing Station (Idaho Falls) have been leached under saturated conditions and plutonium deposited in nearby pit lining soils. The study concluded that moisture movement was the principal transport factor and any action inhibiting water entry to the contaminated zone would be desirable.

Krey and Hardy (1970), the General Electric Company (1970) and Whicker, Little and Winser (1973) reported on plutonium distributions found in the soil around the Rocky Flats installation. Soils within the plant boundaries showed 66 percent of the total plutonium to be present in the upper $5 \mathrm{~cm}$ of soil; outside the plant in the direction of prevailing winds, 39-9l percent of the total plutonium was found in the upper $5 \mathrm{~cm}$. The deepest plutonium penetration was observed to be $13 \mathrm{~cm}$. From the results obtained, it was concluded that soil constitutes the principal plutonium reservoir in the terrestrial environs of Rocky Flats, and that although plutonium is detectable in all environmental samples assayed, there is, at present, no evidence of significant biological concentration mechanisms.

Articles on the distribution of plutonium at the Nevada Test Site include: Romney, Mork and Larson (1970), Wallace and Romney (1974), Fowler and Essington (1974) and Essington, et al., (1975). Periodic surveys of plutonium movement since the detonation of atomic bombs have taken place for over fifteen years. Downward migration of plutonium fallout particles has occurred in undisturbed soil profiles, and wind and water erosion have accounted for some redistribution of plutonium. Plutonium has moved down into the soil as much as $9 \mathrm{~cm}, 19$ years after the detonations. The $239 \mathrm{Pu} /$ $241 \mathrm{Am}$ ratio is not constant, which suggests different mobilities for the elements. Many soil profile samples show a decrease in the above ratio with depth indicating that americium is more mobile.

Half the profiles taken on the Nevada Test Site and Tonopah Test Range show 95 percent of the plutonium to be in the top $5 \mathrm{~cm}$. Plutonium accumulated at the top of the $B$ horizon in small quantities at most sites studled. At all sites plutonium is observed to a depth of $25 \mathrm{~cm}$ and probably would be found at greater depths. A study of one site in 1958 and 1973 suggested a small amount of plutonium was continually being removed from the surface. The data may indicate that maximum downward movement occurs shortly after deposition and only a small but continuous amount moves thereafter. 
Investigations on the movement of liquid plutonium wastes dumped in Los Alamos canyons and plutonium movement at the Trinity Test Site (our first atom bomb test) have been reported. Christenson, et a1., (1958, 1962), Purtymun (1971, 1974), Hakonson, et a1., (1973, 1973, 1975) and Richinond and Sullivan (1974) conclude that the plutonium concentration of the canyon soils receiving low level wastes has moved slowly downstream. Sorption studies on the tuff material which lies below the alluvial soils show high Pu retention. The tuff contains many cracks and fissures through which plutonium has penetrated to a depth of 28 feet in localized areas. High percentages of clays, deposited by local weathering, sorbed plutonium and result in local high alpha activity. Since 1963 nearly $2 \times 10^{5}$ liters/day of low level waste has been discharged. Comprehensive sampling of the stream bed from the outfall to a distance of 10 kilometers downstream show 35-40 percent of the calculated inventory present in the first kilometer downstream, which happens to represent lhe region containing permanent surface water. nver 50 percent of the plutonium is present in the lower portion of the canyon where the streall channel is norlially dry, indicating that considerable downstream transport had occurred. Rainstorm runoff has been shown to be the transport merhanism. During one runoff study 99 percent of the radionuclide inventory in the slurry was associated with suspended particulates. The faster stream velocities suspend more and larger particles and physically move plutonium down the canyon. To date plutonium migration down the canyon has been less than 5 kilometers and held within the Los Alamos boundaries. Plutonium concentration patterns with depth are not consistent and show considerable verticle mixing has occured.

At the Trinity Bomb Site after 27 years plutonium has penetrated $7.5 \mathrm{~cm}$ into the soil but vegetation and rodents in the area have not developed harmful hody tiurdens.

Fried, et a1., (1973, 1974, 1974) found that plutonium adsorbed to limestones, shales, and sandstones would very slowly migrate through the pores. The velocity of migration relative to the leaching water was $3 \times 10^{-5}$ for limestone and $6 \times 10^{-5}$ for basalt. If the leaching solution was saturated with $\mathrm{CO}_{2}$ an increased elution from the limestone and sandstone was observed. Studies of plutonium movement along a fissure crack in basalt shows plutonium movement in two phases: the slower moving phase absorbs similar to $\mathrm{Pu}^{+4}$, but a faster moving phase with only about $1 / 10$ the tendency to sorb was also observed. Fried, et al., hypothesized a polymeric state for this phase.

Studies of migration of plutonium from land burial sites and surface soils at Savannah River, Fenimore (1964) and McClearen (1974) show no migratinn of plutonium from solid wastes but that plant operations have increased surface soil plutonium concentrations within a two kilometer radius. Ninety percent of the soil plutonium in 30 centimeter cores was found in the top 15 centimeters.

Meyer (1975) reported on the migration of plutonium from a commercial waste burial site at Maxey Flats, Kentucky. Between 1963 and 1974, 104,000 $\mathrm{m}^{3}$ of solid and $2.25 \times 10^{6}$ liters of solidified liquid radioactive wastes were buried. In 1972, elevated levels of radioactivity were detected in 
monitoring samples. Plutonium was detected in surface soil, soil cores 90 $\mathrm{cm}$ deep, in monitoring wells, and streams which drain the site. The chemicial form, pathways, and mechanisms by which the plutonium moved out of the trenches has not been satisfactorily explained to date. A possible transport mechanism is infiltrating precipitation into the trenches coupled with organic matter decomposition product acids and chelating agents forming mobile plutonium species.

Plutonium migration in the marine environment off the English Windscale outfall is reported by Templeton and Preston (1966) and Hetherington, et al., (1975). Plutonium is removed rapidly to the sediments and 83 percent of the plutonium in nine inch deep cores is found in the upper three inches. The highest concentration of plutonium is found in fine muck close to the outfall.

Pillai and Mathew (1975) studied the migration of plutonium from a fuel reprocessing plant in the marine environment off Trombay, India. Nearly 99 percent of the plutonium in the waste was rapidly removed by sediments. Sediments near the outfall contained 10-100 times the plutonium concentration of background sediment. Plutonium levels decreased with distance from the discharge site although resuspension, tidal transport and seasonal effects complicated the distribution. Resuspension of plutonium-laden sediments in seawater did not increase the filtered water concentration, therefore, plutonium transport is mainly with silt movement.

Mango, et al., (1970), Noshkin, et al., (1971, 1975), Sche11, et al., (1974), and Nevissi, et al., (1975), described some of the plutonium migration observations made at Bikini and Enewetak Atolls in the Pacific at which nuclear weapons tests were performed. Plutonium released to the lagoon system became insoluble and rapidiy settled. Up to 90 percent of the plutonium in the lagoons is associated with particulates but heterogeneity abounds. Resuspension of fine material and wave driven water transport actively cause redistribution. Detailed studies show plutonium to exist in particulate, soluble and colloidal states in the lagoon waters. Studies of the groundwaters at several islands in Enewetak Atoll show that small quantities of plutonium radionuclides have migrated through the soil columns ( $80 \mathrm{~m}$ in one instance) and are redistributed throughout the groundwater reservoirs. Distribution of plutoritum is spatially heterogeneous and independent of processes controling the cycling of $137 \mathrm{Cs}$ and freshwater. A linear correlation was found between the average surface water concentrations and soil plutonium concentrations independent of the physical, chemical and biological characteristics of the islands. Whatever the transport mechanism, plutonium has proven to be very mobile in the water-saturated coral-soil environment.

The plutonium distribution of surface soils on Bikini Atoll followed the same pattern as fission products. Horizontal movement of plutonium due to soil erosion and transport was localized and restricted to areas without vegetation and organic detritus. Air resuspension appeared to be minor. A vertica? soil profile showed 70 percent of the plutonium retained in the 
top $5 \mathrm{~cm}, 28$ percent retained in the $5-25 \mathrm{~cm}$ layer and the remaining 2 percent as deep as $100 \mathrm{~cm}$. Of the possible transport mechanisms: solution, biological and suspension and resuspension of particles, the latter probably dominates.

The plutonium cycling and sedimentation in Lake Michigan has been the subject of numerous studies; Wahlgren and Nelson (1972, 1973, 1973, 1974) and Edgington, et al., (1975). The source of almost all of Lake Michigan's plutonium is atmospheric fallout. Plutonium impinging on the lake's surface rapidly falls to the bottom sediments with a removal half-life of about one year. Some evidence points to a biological mechanism such as incorporation in plankton followed by rapid settling of fecal pellets and dead plankton. The particle size of the plutonium reaching the water is greater than 75 percent colloidal or subcolloidal, i.e., passes through $0.45 \mu \mathrm{m} \mathrm{fil-}$ ters. In all cores studied, plutonium activity was confined to the top six centimeters and in many, to the top three centimeters which agrees with known deposition rates. Cesium and plutonium from fallout appear to be depositing with equal efficiency and mobility is reduced to only aperiodic resuspension by physical or biological means. Plutonium to americium ratios in the sediments show no elemental differences in mobility. Chemical leaching experiments to be described later show plutonium to be chemically immobile as long as oxidizing conditions are present.

In investigations at the Thule Greenland air crash site, Aarkrog (1972), two years after the incident, shows plutonium levels above background as far as $15 \mathrm{~km}$ from the point of impact. Samples of bottom sediments yield a. vertical movement of plutonium to a depth of at least $10 \mathrm{~cm}$.

Concentrations of plutonium in soils and sediments versus overlying waters usually show concentration factors of $10^{4}$ or greater as evidenced by long, et a 1., (1970), Noshkin, et al., (1975).

Bowen, Livingston and Burke (1975) described in detail the role of biological processes in the vertical migration of $\mathrm{Pu}$ and present some core data to substantiate their hypothesis. They believe biota are responsible for both the downward migration and upward migration with possible water remobilization, especially in shallow water marine environments. Buzzard Bay, Massachusetts, sediments showed no concentration of plutonium in the fine fraction of the sediments. Contradictory evidence showing plutonium concentrations in the ocean sediments to increase with decreasing particle size is presented by Fukai, et al., (1974).

Tallura (1975, 1975) evaluated the plutonium content of various size fractions of contaminated Nevada Test Site and Oak Ridge soils and Mound Lab sediments. Bacause the results are based on only a few observations, the source terms differed and the particle size fraction separations were technique dependent, the results should be considered exploratory in nature. The NTS soils showed different particle size - plutonium associations depending on location from ground zero. In general, the coarse silt $(20-53 \mu \mathrm{m})$ and medium silt $(5-20 \mu \mathrm{m})$ fractions contained about 80-85 percent of the total 
plutonium. The Oak Ridge plutonium was more evenly distributed in the silt and clay sizes, with clay slightly higher. The Mound Lab sample showed 70 percent of the plutonium in the clay fraction.

Jakubick (1975) presented a transport model which predicts the vertical migration of plutonium fallout $\left(\mathrm{PuO}_{2}\right)$ once it impinges the ground. From HASL soil profile data, Pu air data, deposition data, precipitation data and soil water velocity data, Jakubick has constructed a mathematical transport model. $\mathrm{PuO}_{2}$ removal from a $5 \mathrm{~cm}$ thick soil layer appears to obey an exponential law with a characteristic turnover time of 5.7 years. For an instaneous soil contamination under given environmental conditions $\mathrm{PuO}_{2}$ migration of $0.8 \mathrm{~cm} / \mathrm{yr}$ is calculated. Assuming a $\mathrm{KdPu}$ for $\mathrm{Pu}^{+4}$ ions of $2 \times 10^{4} \mathrm{ml} / \mathrm{g}$, the migration of fine grain $\mathrm{PuO}_{2}$ particles would be one hundred times faster than $\mathrm{Pu}^{+4}$ ions.

Several investigators have performed leaching studies on plutonium contaminated soils and sediments to investigate the potential for remobilization and migration. Tamura, et a1., (1972) and Tamura (1974, 1975, 1975) investigated the amounts of plutonium which could be extracted from various soils and sediments by numerous chemical treatments.

Preliminary tests on bentonite contaminated with soluble plutonium and fired before extraction with $8 \mathrm{M} \mathrm{HNO}_{3}$ show the percentage of $\mathrm{Pu}$ removable to depend on the temperature at which the bentonite was heated. At firing temperatures of $40^{\circ} \mathrm{C}$ or below, 100 percent of the plutonium was removed from bentonite by $8 \mathrm{M} \mathrm{HNO}_{3}$. A temperature of $950^{\circ} \mathrm{C}$ before extraction showed the bentonite to release only 12 percent of the plutonium. Tamura used $8 \mathrm{M} \mathrm{HNO}_{3}$ acid extraction to remove plutonium from Nevada Test Site surface soils prior to a total digestion in $\mathrm{HF}-\mathrm{HNO}_{3}-\mathrm{HCl}$. Soils categorized as desert pavement, blow sand and Area 13 surface soils released from 58-91 percent of the total plutonium burden upon $8 \mathrm{M} \mathrm{HNO}_{3}$ leaching. Later studies on Nevada Test Site, Oak Ridge and Mound Lab samples showed 10-15 percent, 60-75 percent, 80-85 percent, respectively, leachability with $8 \mathrm{M} \mathrm{HNO}_{3}$. Further studies utilizing $0.1 \mathrm{M}$ citric acid $(\mathrm{pH} 2.0)$ and $0.1 \mathrm{M}$ sodium citrate $(\mathrm{pH} 8.5)$ were performed. Citrate complexes plutonium, but only slowly plutonium polymer, so that this treatment provides information on whether polymer exists in the samples. Citric acid extracted about 0.4-1.5 percent, 23-24 percent, and 43-59 percent of the NTS, ORNL and ML soil plutonium. Sodium citrate extracted only 7-8 percent and 8-14 percent of the ORNL and ML soil plutonium showing citrate extraction to be rather $\mathrm{pH}$ dependent. Citrate extractable plutonium may relate to plant availability but many more data are needed to investigate this possible relation.

Sequential chemical extraction of Hanford Uranium Pond sediments with 0.1 $\mathrm{M} \mathrm{NaCl}, 0.1 \mathrm{M}$ oxalic acid - 2.M $\left(\mathrm{NH}_{4}\right)_{2} \mathrm{C}_{2} \mathrm{O}_{4}$, and $0.01 \mathrm{M}$ EDTA revealed plutonium releases of 1-3 percent, 3-5 percent, and 2-22 percent, respectively of the total plutonium. The first extractant should have removed ion exchangeable $\mathrm{Pu}$, the second amorphous hydrous oxide bound and the third complexable $\mathrm{Pu}$ (Emery, et al., 1974). 
Swanson (1973) leached high salt, acidic waste contaminated soil with various chemicals to investigate the geochemical distribution of sorbed plutonium. Carbon tetrachloride and ethyl alcohol, which should remove many organiccomplexed plutonium species, removed 0.01-3 percent and 0.1-9 percent of the total Pu, respectively. Very little plutonium was removed by dilute nitric acid but $5 \mathrm{M} \mathrm{HNO}_{3}$ removed substantial amounts of the plutonium. Successive extractions showed the $\mathrm{Pu}$ concentration in successive acid extracts, irregardless of the leach times, to reach the same concentration until well over 40 percent of the total plutonium had been leached. This suggests that plutonium was being controlled by a solubility reaction with the leach solution rather than by the rate of dissolution of the soil plutonium. Pretreatment of the soil with $\mathrm{KOH}$, ethyl alcohol or TBP before $5 \mathrm{M} \mathrm{HNO}_{3}$ leaching showed larger amounts of $\mathrm{Pu}$ to be leachable from several soil samples. This suggests that organic compounds in the soil may have been scavenging the plutonium in the leachate solutions. Other experiments reported tend to support the hypothes is that a ligand(s) which was solubilized from the soil by many chemical leachates to variable degrees was controlling the amount of plutonium removed.

Edgington, et al., (1975) treated fallout contaminated Lake Michigan sediments with various extractants to investigate plutonium speciation. A sequential treatment with $0.1 \mathrm{M} \mathrm{Mg} \mathrm{Cl} 2$, sodium dithionite - $0.3 \mathrm{M}$ sodium citrate, $0.1 \mathrm{~N} \mathrm{NaOH}$ and finally total fusion was tried. In general the results showed none or small amounts of $\mathrm{Pu}$ in the $\mathrm{Mg} \mathrm{Cl} 2, \mathrm{NaOH}$ and fusion extracts. Almost all of the plutonium was found in the citrate-dithionite extract. Changing the sequence of the chemical extractions did not significantly change the results. It was, therefore, concluded that plutonium in the sediments was present in a reductant soluble form such as hydrous oxides and not as ion exchangeable, humic bound or refractory particles.

Wilson and Cline (1966) added a small amount of $\mathrm{Pu}\left(\mathrm{NO}_{3}\right)_{4}$ solution to two soils and later extracted portions of the soil with iN ammonium acetate, . IN nitric acid, iN nitric acid and $2 \times 10^{-4} \mathrm{M}$ DTPA solutions. The percentages of the plutonium added that was leachable by the above extractants were .06 percent, . 14-.64 percent, .25-.32 percent, and 0.03 to 0.1 percent, respectively.

Hajek (1966) studied the mobility of plutonium. Contaminated soils from 216-Z-9 crib site which received high salt, acidic wastes, were packed in small columns and leached with either groundwater or $1 \mathrm{M} \mathrm{NaN03.} \mathrm{The} \mathrm{ground-}$ water effluent leached a value of 0.1 percent of the total soil plutonium burden after thirteen column volumes; further leaching removed very little. The $1 \mathrm{M} \mathrm{NaNO} 3$ solution leached 3.5 percent of the total soll pluturium after 100 column volumes and continued to leach a small portion as if a solubility mechanism was present.

Pillaj and Mathew (1975) quantitatively leached the plutonium present in Bombay sediments with $8 \mathrm{M} \mathrm{HNO}_{3}$. Hydrogen peroxide treatment at $80^{\circ} \mathrm{C}$ and pH 5.8 did not appear to release plutonium but under these conditions it 
is likely released $\mathrm{Pu}$ would precipitate or quickly resorb. Alkali treatment to extract organics removed 0.4 to 7.5 percent of the total plutonium. Contaminated sediments stirred with uncontaminated seawater for eight hours before filtration did not release any plutonium into the seawater.

Mo and Lowman (1975) placed plutonium contaminated calcareous sediment in aerated seawater and anoxic seawater and stirred the system until solution activities were at equilibrium. The resultant $\mathrm{KdPu}$ distributions were $1.64 \times 10^{4}$ and $3.85 \times 10^{5}$.

Noshkin, et al., (1975) took seven plutonium contaminated soil samples from Enewetak and equilibrated them with uncontaminated seawater. At equilibrium water filtered through $0.4 \mu \mathrm{m}$ filters and soils were analyzed for plutonium contents. The Kdpu calculated from these samples was $8 \times 10^{4} \mathrm{ml} / \mathrm{g}$. Particulates in the groundwater versus the groundwaters themselves gave an average $\mathrm{Kd}_{\mathrm{Pu}}$ equal to $2.5 \times 10^{5} \mathrm{ml} / \mathrm{g}$.

The dissolution rate of plutonium oxide particles by seawater and tapwater have been reported by Adams (1971), Kubose, et al., (1968) and Patterson, et a1., $(1974,1974)$. The dissolution rate is quite complex and dependent on such properties as $\mathrm{pH}, \mathrm{T}^{\circ}$, Eh, complexing agents, oxide surface area, and radiation field intensity. Environmental chamber work showed that rain on large chunks of $238 \mathrm{PuO}_{2}$ radioactively heated to $200^{\circ} \mathrm{C}$ led to increases in release of $\mathrm{Pu}$ of three orders of magnitude due to spallation.

Two review articles which contain discussions on adsorption reactions of plutonium and soils are available, Francis (1973) and K. Price (1971, 1973a).

One of the first investigations on plutonium was performed at Savannah River by Prout $(1958,1959)$. Plutonium adsorption by a soil (80 percent sand-20 percent clay) with the clay mineral kaolinite dominant was determined vs $\mathrm{pH}$ for distilled water traced with plutonium $\left(\sim 10^{-6 M}\right)$. The soil/solution ratio was 1:10 and the mixtures shaken for two hours before phase separation by centrifugation. Adsorption of plutonium was dependent on $\mathrm{pH}$ and the valence state of the plutonium added to solution. Adsorption was more than 90 percent complete from solutions of $\mathrm{Pu}$ (III) and $\mathrm{Pu}(\mathrm{IV})$ between $\mathrm{pH} 2.5$ and 12 and from solutions of $\mathrm{Pu}(\mathrm{VI})$ at $\mathrm{pH}$ 's greater than 6 . Flgure 15 shows Prout's results where the $\mathrm{Kdp}$ has the units $\mathrm{ml} / \mathrm{g}$. Strong sorption at mildy acidic to mildly basic pH's is probably due to a combination of cation exchange and precipitation of hydrolysis products. Decreased sorption above $\mathrm{pH} 9$ possibly represents the formation of soluble negatively charged $\mathrm{Pu}$ complexes which do not readily exchange with the soil.

Rhodes (1952, 1957, 1957) performed similar KDpu sorption determinations on a Hanford sand soil (92 percent sand) with 2 percent calcium carbonate content. Using a soil to solution ratio of $1: 20$ and neutral pH, Rhodes found rapid adsorption. Analysis vs time yielded an equation for the amount sorbed vs contact time, \%PuADS $=81+5.2 \log \mathrm{Time}(\mathrm{min})$. For example, after one minute, 20 minutes and 60 minutes, 81 percent, 88 percent, and 90 percent, respectively of the solution $\mathrm{Pu}$ concentration was adsorbed. Increases in the soil/solution ratio were also observed to increase the percent sorbed. 


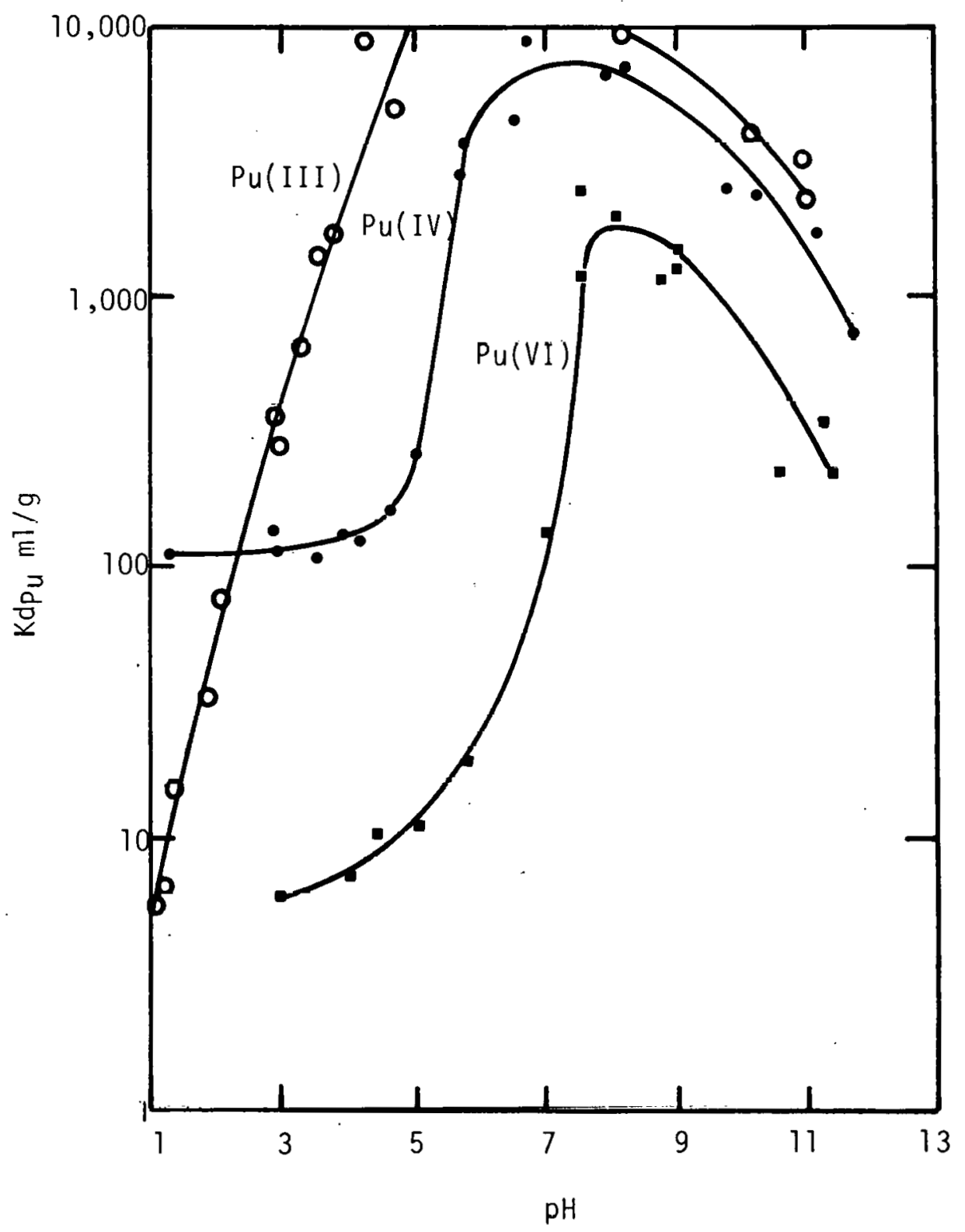

FIGURE 15. EFFECT OF PH AND PLUTONIUM OXIDATION STATE ON THE ADSORPTION OF PLUTONIUM BY SOIL (Prout, 1959) 
Rhodes also obtained sorption vs $\mathrm{pH}$ data and found rapid decreases in sorption below pH 2 but almost total sorption ( $\mathrm{Kdpu}>2000$ ) between $\mathrm{pH} \mathrm{3-8.5.}$ Decreases at $\mathrm{pH}$ 10-12 were believed to indicate changes in plutonium speciation. In other epxeriments coarse sand was observed to adsorb only 47 percent of the plutonium present compared to $97-99.8 \%$ for soils and clay minerals. Rhodes felt all these data indicated ion exchange sorption mechanisms. Yet plutonium adsorption from distilled water, a synthetic high salt waste and an actual high salt waste all showed greater than 98 percent removal. Plutonium solution loading experiments onto soil columns at various $\mathrm{pH}^{\prime} \mathrm{s}(1,4,10)$ showed good removal at the first two pH's until the high acid case had destroyed the $\mathrm{CaCO}_{3}$ buffering capacity. As the effluent $\mathrm{pH}$ dropped to $\mathrm{pH} \mathrm{1,} \mathrm{increasing} \mathrm{plutonium} \mathrm{breakthrough} \mathrm{was} \mathrm{observed.} \mathrm{-}$ Plutonium breakthrough at pH 10 was highly variable and rapid possibly caused by fine plutonium particulate dispersion or polymer formation. Plutonium sorption from distilled water, $4 \mathrm{M} \mathrm{NaNO} 3$ and $2 \mathrm{M}\left(\mathrm{NH}_{4}\right)_{2} \mathrm{HPO}_{4}$ solutions was above 96 percent but a 4M ammonium acetate solution showed only 59 percent sorption. Further studies showed increasing the acetate concentration from $0.01 \mathrm{M}$ to $8 \mathrm{M}$ dropped plutonium adsorption from 74 percent to 21 percent. Acetate solutions were also observed to have the capacity of extracting plutonium sorbed on soils. Figure 16 shows Rhodes' plutonium adsorption data from distilled water vs $\mathrm{pH}$, for comparison with Prout's data. Bensen (1960) presented data showing that oxalate salts also inhibit plutonium sorption by soluble Pu-oxalate complex formation. Bensen also re-interpreted Rhodes' data and concluded precipitation reactions not ior exchange probably control plutonium sorption on soils.

Thorburn (1950) reported a sorption experiment in which plutonium in water was percolated through a soil column. The soil was then wet sieved and the activity of each particle size fraction counted. The results are shown in Table 7 .

TABLE 7

PU ADSORPTION VS PARTICLE SIZE

$\begin{array}{cc}\text { Size }(\mathrm{mm}) & \frac{\mathrm{Pu} \mathrm{d} / \mathrm{min} / \mathrm{g}}{39.3} \\ >1.19 & -- \\ 1.19-.25 & 1,171 \\ .25-.15 & 929 \\ .15-.10 & 8,578\end{array}$

Uncentrifugible Silt and Clay 62,750 


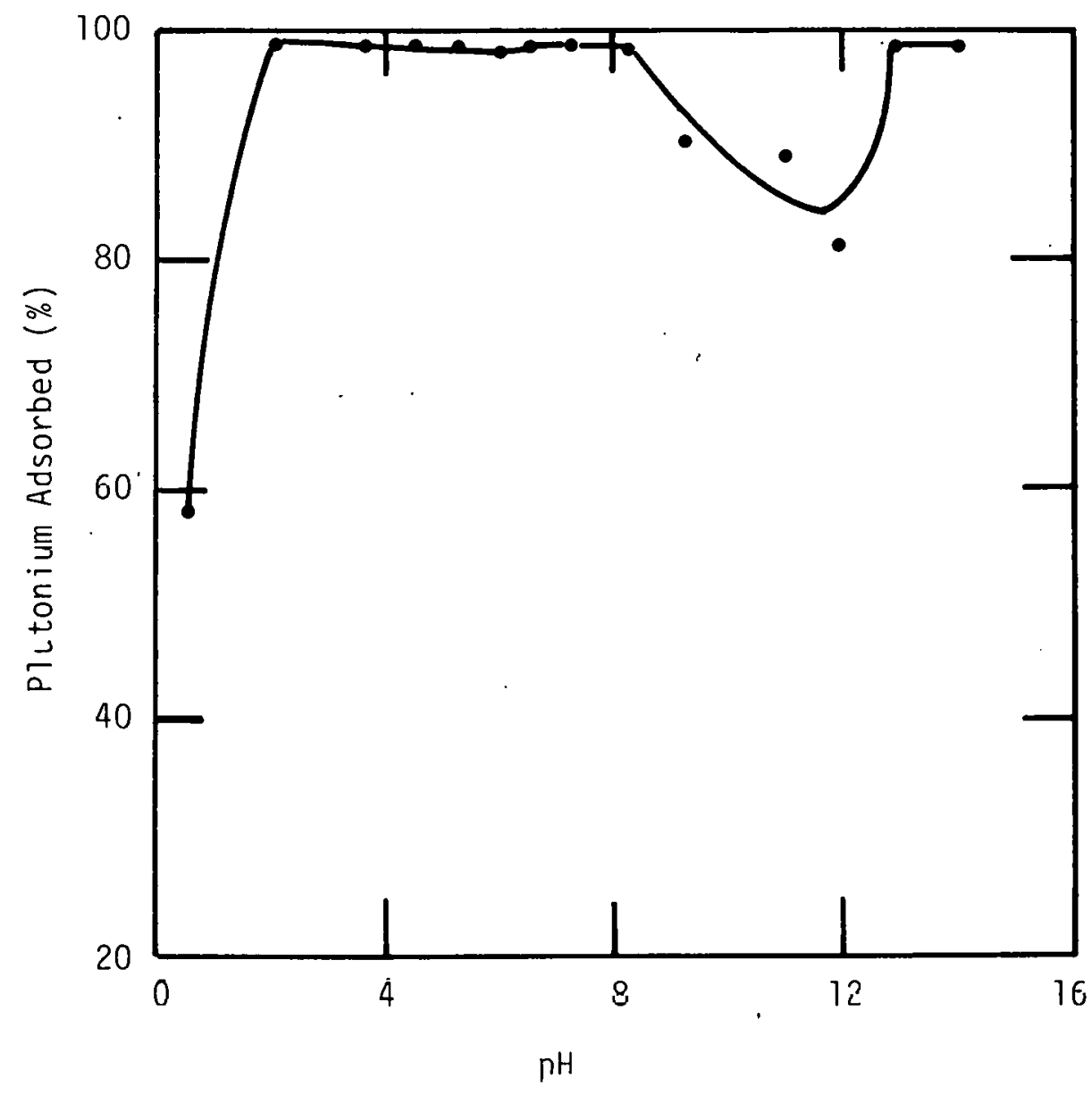

FIGURE 16. ADSORPTION OF PLUTONIUM BY SOIL AS A FUNCTION OF pH (Rhodes, 1957) 
In other sorption experiments, Thorburn placed small aliquots of actual plutonium waste on top of soil columns and eluted with distilled water or saturated magnesium-calcium carbonate. There was no significant differences in the elution curves. It is interesting to note that the elution curves had higher Pu activity in the first volume out of the column and always showed a small leakage which might signify physical transport of fines. Thorburn took the effluent from the distilled water leached column and percolated it through a second soil column at various flow rates. The data show effluents through the second column varied with flow rate. The faster the flow the more plutonium in the effluent. Filtration of the influent through a fine filter paper did not change the results. Explanations of these phenomena are obscure. Final sorption studies of plutonium in water vs $\mathrm{pH}$ by soil columns showed 87 percent adsorption at pH 3.8, 77 percent at pH 7.2 and 24 percent at pH 10. These results are similar to Rhodes!

Ames (1960) presented column sorption data on plutonium from phosphate wastes at $\mathrm{pH} 12$ by calcite. The plutonium appeared to be incorporated into lattice sites as apatite replaced calcite. Plutonium sorption as a function of phosphate concentration, temperature, flow rate and plutonium valence state are given.

Miner, et al., (1973, 1974) and Polzer and Miner (1974) describe experiments in progress to measure the adsorption of both "soluble" plutonium and particulate plutonium $\left(\mathrm{PuO}_{2}\right)$ in numerous soils at three plutonium levels $10^{-6}-10^{-8}$ $M$. The plutonium sorption is rapid and quite high: 59 percent of the time sorption is greater than 99 percent $(\mathrm{KdPu}>430)$ and only 5 percent of the time is it below 90 percent sorption ( $\left.K d p_{u}<39\right)$. Correlations were found between soil characteristics associated with soil ion exchange or acidity. The sorption is also dependent on the initial plutonium concentrations for which several possible causes are discussed.

Fried, et a1., (1974, 1974) immersed disks of 1 imestone and basalt in Pu(NO3)4 solution at $4 \times 10^{-5} \mathrm{M}$ Pu. After equilibration the activity in the solutions were re-measured. Losses in $\mathrm{Pu}$ were equated to sorption on the rocks. Basalts sorbed more plutonium than limestone on a surface area basis. The effects of salt solutions of $\mathrm{Na}^{+}, \mathrm{Ca}^{++}, \mathrm{Sr}^{++}, \mathrm{La}^{+3}$, and $\mathrm{Zr}^{+4}$ were al so studied. In all cases the salts displaced some of the plutonium from the rocks. The higher the concentration and the larger the valence charge; the easier was the displacement similar to the trends expected for ion exchange mechanisms. A leaching study showed eight column volumes of $0.5 \mathrm{M} \mathrm{HCl}$ removed 30 percent of the plutonium adsorbed on shale. Eight additional column volumes of $4 \mathrm{M} \mathrm{HC} 1$ removed an additional 20 percent.

Relyea and Brown (1975) studied the adsorption-desorption rclations of plutonium solutions added to water at. $\mathrm{pH} 2$. The ratio of plutonium adsorbed by the soil to that in the equilibrium solution was greater than 99.1. Diffusion of plutonium in four soils was found to be much slower than for exchangeable soil cations. 
VanDalen, et a1., (1975) determined the distribution coefficient, Kdpu, for several Dutch subsoils from 90 percent saturated $\mathrm{NaCl}$ solutions between $\mathrm{pH} 7-8$. Clay samples of mainly illite and kaolinite had a $\mathrm{KdPu}$ of $\sim 10^{4}$ and for a river sand a Kdpu of $200 \mathrm{ml} / \mathrm{g}$. Gypsum bearing and clay bearing sandstones were intermediate. The $\mathrm{pH}$ dependence on sorption of plutonium was minor between $\mathrm{pH} \mathrm{5-8.}$

Rozzell and Andelman (1971) studied the sorption-desorption of aqueous Pu $\left(10^{-8}\right.$ to $\left.10^{-7} \mathrm{M}\right)$ on quartz and other silica surfaces. Sorption continued typically for 12 to 15 days before apparent equilibrium was reached. At $\mathrm{pH} 7$, sorption increased with increasing ionic strength, but decreased when $\mathrm{HCO}_{3}$ was added. The amount of sorption varied at $\mathrm{pH} 5$ and 7 , but differently at high and low ionic strengths, as well as with age of the solution. Plutonium desorption indicated that there were two basically different sorbed speeies. There was a qreat net desurpliun at. $\mathrm{pH} 5 \mathrm{vs} \mathrm{nH}$ 7-9.

Many investigations have been performed on plutonium adsorption by sediments, both freshwater and marine. Schneider and Block (1968) found plutonium to sorb more than $\mathrm{I}^{-}$and $\mathrm{Sr}^{+2}$ but less than $\mathrm{Zn}^{+2}$ or $\mathrm{Cs}^{+1}$ on Rhine River sediments. Equilibrium was reached within 24 hours.

Duursma, et a1., (1971, 1973, and 1974) have determined the proclivity of plutonium to sorb in the marine environment. The adsorption of plutonium is intermediate; less than $\mathrm{Cs}, \mathrm{Rb}, \mathrm{Zn}, \mathrm{Fe}, \mathrm{Zr}-\mathrm{Nb}, \mathrm{Ru}$ and $\mathrm{Pm}$ and greater than $\mathrm{Ca}$ and $\mathrm{Sr}$. Plutonium has been observed to penetrate sediments at least to $8-14 \mathrm{~cm}$ and in the early $1970 \mathrm{~s}$, inventories in the sediment appear to show losses. Biological processes or upward migration in inter.slitial waters as a reduced species are two possible explanations although Mo and Lowman (1975) show data which find reducing conditons tend to lower $\mathrm{Pu}$ mobility. Changes in the $\mathrm{Am} / \mathrm{Pu}$ ratio from waters to sediments in the ocean led Duursma to coriclude Americium is preferentially sorbing or not being remobilized as fast as plut.nnium. In seawater $\left.\mathrm{PuO}_{2}\left(\mathrm{CO}_{3}\right)_{3}\right)^{-4}$ may predominate and cause the lower plutonium sorption. Using a $237 \mathrm{Pu}$ tracer in valence states $+3,+4$, and +6 in both oxic and anoxic seawaters at pH 7.88.0 the $\mathrm{KdPu}$ for marine sediments was found to be about $10^{4}$. Valence states and solution Eh states did not cause marked differences.

Fukai and Murray (1974) performed plutonium sorption-desnrptinn experiments for both freshwater and saline conditions. Plutonium (III) sorption experiments from river water to river sediments $(100 \mathrm{ml}$ traced solution/g sediments) were performed. The initial staqe of adsurpliun was raptd; 50 perceril withtn 10 hours. For pH's 3-11 over 90 percent of the Pu(III) was adsorbed by the river sediment. Desorption experiments were performed where in the sediments used in the adsorption experiments were suspended in seawater. Over the $\mathrm{pH}$ range 4-10 about 10 percent of the adsorbed plutonium was released without anparent pH differences. Similar adsorption-desorption experiments were performed with river sediments contacted with various dilutions of freshwater sewage effluent at $\mathrm{pH} 8.1$. The $\mathrm{Pu}$ (III) adsorption increased from 85 percent in 
river water to over 95 percent at 100 percent sewage effluent. These sediments were next contacted with seawater and desorption monitored. At equilibrium, river sediments which had not been contacted with sewage effluent released only 5 percent of its plutonium whereas sediments contacted with 5-100 percent by volume sewage effluent released 12 percent of their plutonium burden.

Bondietti $(1975,1975)$ determined the KdPu for clays separated from a soil (Miami silt loam) and montmorillionite using $5 \times 10^{-3}$ M calcium solutions at $\mathrm{pH} 6.5$ for two plutonium valence states. The results are shown in Table 8.

TABLE 8

KdPu AS FUNCTION OF VALENCE STATE

\begin{tabular}{|c|c|c|}
\hline Material & Initial Valence & $\mathrm{KdP} u$ \\
\hline $\begin{array}{l}\text { Soil Clay Fraction } \\
\text { Montmorillionite }\end{array}$ & $\begin{array}{l}\mathrm{Pu}(\text { IV }) \\
\mathrm{Pu}(\mathrm{VI}) \\
\mathrm{Pu}(\mathrm{IV}) \\
\mathrm{Pu}(\mathrm{VI})\end{array}$ & $\begin{array}{l}1.0-1.7 \times 10^{5} \\
7.5-10^{4} \\
2.1 \times 10^{4} \\
2.5 \times 10^{2}\end{array}$ \\
\hline
\end{tabular}

The high sorption of $\mathrm{Pu}(V I)$ to the soil clay, as contrasted to montmorillionite, indicated that $\mathrm{Pu}$ reduction by clay components must have occurred, yielding sorption values similar to the $\mathrm{Pu}(\mathrm{IV})$. Pu(VI) also appears to adsorb less than $\mathrm{Pu}(\mathrm{IV})$.

The role of organics in fuel reprocessing waste streams, natural waters and sediments on accumulation or migration of plutonium has been studied.

Knoll (1965, 1969) and Hajek and Knoll (1966) reported studies on high salt wastes with organic contaminants typical of fuel reprocessing. An acid (.3M) high salt ( $5.4 \mathrm{M} \mathrm{NO}_{\overline{3}}$ ) waste spiked with actual americium and plutonium wastes were percolated through soil columns. After $0.3,1.5$ to 4.0 and 20 column volumes of effluent the plutonium breakthrough was 20-30 percent, 50 percent, and 70-95 percent, respectively, for several columns. Batch sorption tests on the high salt acid wastes from storage tanks showed low sorption $\mathrm{Kdpu} 2.4$ $2.9 \mathrm{ml} / \mathrm{g}$ with resultant soil $\mathrm{pH}^{\prime} \mathrm{s}$ of $2-3$. If the waste was neutralized and the supernatant used in batch sorption tests the Kdpu increased. Addition of suspected organic contaminants to a concentration of 20 percent by volume decreased the $\mathrm{K}_{\mathrm{dP}} \mathrm{u}$ for the neutralized waste to 1:1. Water leachates of the sludge produced on neutralization contained some plutonium. Upon soil contact the $\mathrm{Kdp}$ for this leachate rose to $1540 \mathrm{ml} / \mathrm{g}$. If the high salt acid waste is neutralized in the presence of molar quantities of citric acid, no precipitation is observed. If this citrate-neutralized waste is percolated through soil columns most of the plutonium is removed. A constant low leakage percentage of plutonium was observed and may have been caused by a solubility or particle transport mechanism. In other experiments tap water 
spiked with plutonium was percolated through soil columns to allow sorption. The soil columns were then leached with various organics: TBP-CCl4, DBBP-CCl4, Fab 0 i1,. D2EHPA in hydrocarbons $\mathrm{C}_{10}-\mathrm{C}_{14}$, and hydroxyacetic acid. These organics are all commonly used in various process streams during fuel reprocessing. TBP in carbon tetrachloride after 130 column volumes had caused only five percent of the soil sorbed $\mathrm{Pu}$ to leach, DBBP removed 40 percent of the soil sorbed $\mathrm{Pu}$ in 80 column volumes, fab oil removed less than four percent in 30 column volumes, D2EHPA removed about 30 percent of the plutonium, and hydroxyacetic acid removed no less than 40 percent of the plutonium depending on the acid concentration. If the plutonium is added to the organics and then percolated through the soils, much different results were obtained; as very little soil sorption was observed.

Experiments at Savannah River (Anon. 1975) with degraded TBP-DBBP-kerosene wastes containing plutonium showed rapid migration through soils (Kdpu) (1. 0.4). If small portions of the solvent waste were placed on dry solls and then leached by groundwater very little plutonium migration was observed $(K d p u \sim 6000)$.

Desai and Ganguly (1970) determined the ability of humic and fulvic acid in ammoniacal solutions to solubilize plutonium. In this basic solution without humic or fulvic extract, only 13 percent of added plutonium remained in solution, with humic extract 54 percent of the added plutonium remained in solution and further testing showed that the soluble plutonium was noncationic. The fulvic acid extract solubilized 58 percent of the plutonium and again the complex was non-cationic.

Bondietti (1974, 1975, 1975) found purified soil humates to absorb plutonium strongly, $99.99^{+}$percent, while reference clays (montmorillionite and kaolinite) adsorbed about 98 percent and 96 percent of plutonium added to a water solution at $163 \mu \mathrm{g} \mathrm{Pu} / \mathrm{g}$ of solid. If clay materials had their organic matter and iron oxide coating removed, plutonium adsorption was 95 percent vs 99.9 percent while intact. Leaching solutions, citrate, DTPA, and fulvate removed small amounts of adsorbed plutonium as shown in Table 9.

TABLE 9

PERCENT PU REMOVED BY EXTRACTANTS

\begin{tabular}{lcccc} 
Extractant & & Humate & Mont. & Kaol. \\
\cline { 5 - 6 } 10-3M Citrate & 0.3 & 8 & 11 \\
$10^{-3 M}$ DTPA & 30 & 15 & 20 \\
$10^{-2 M}$ Fulvate & 5 & 0.9 & 3
\end{tabular}

Thus it appears that natural soil organic matter can very strongly adsorb plutonium. The ability of soil organic matter to alter the valence state of plutonium in soil water solutions was also verified. Pu(VI) and by 
inference $\mathrm{Pu}(\mathrm{V})$ were instable in the presence of fulvic acid, polygalacturonic acid and alginic acid. Positive proof of reduction to $\mathrm{Pu}(\mathrm{IV})$ was shown at environmental pH's 6.5-8. Plutonium (IV) was the most stable valence upon interaction with these organics. Further reduction of $\mathrm{Pu}($ IV) to $\mathrm{Pu}$ (III) occurred in the presence of humic or fulvic acids, but was not observed above pH 3.1 under aerobic conditions. Bondietti also demonstrated that plutonium is at least partially associated with humic materials in ORNL soil contaminated 30 years ago.

The removal of plutonium in wastes and drinking waters by precipitation and/ or sorption techniques has been studied by Lauderdale (1951), Christenson, et a1., (1951), Grebenshahikova, et a1., (1971), Blain, et a1., (1974) and Corey and Boni (1975). Calcium phosphate, alum, ferric hydroxide, and barium phosphate flocculations all are effective in removing most of the plutonium in waste streams at basic pH's. Adsorption on Kaolin, pumice, tuff, celite and activated carbon has also been used to remove plutonium. In all methods a variable percentage of plutonium remains in solution, probably as a polymeric or colloidal form. Ultracentrifugation results tend to corroborate that colloidal species are less readily adsorbed or 1 ikely to precipitate.

Americium

Americium found in the environment exists principally from plutonium-241 decay in nuclear fallout and liquid and solid wastes from fuel reprocessing plants.

The migration of americium has been studied by several investigators and often compared with the migration of plutonium. Crawley (1969) determined the movement of americium in soils contaminated with high salt, acidic wastes, and low salt, neutral wastes. In the first instance, americium percolated the full extent of the sampling (18 feet). For the latter case, americium penetration was less than two feet. In neither case was the americium migration measurably different than plutonium. Ames (1974) studied the distribution of americium and plutonium in sands in which high salt acid wastes had been dumped. In this case there appeared to be some evidence showing plutonium-americium separation with americium migrating somewhat farther.

Fowler and Essington (1974), Wallace and Romney (1974, and Essington, et a1., (1975) found a decreasing Pu/Am ratio with soil depth at the Nevada Test Site. The decreasing ratio suggests that americium migrates faster than plutonium.

Schmalz (1972) reported that both $\mathrm{Am}$ and $\mathrm{Pu}$ had been leached from solid wastes buried at the Idaho Falls Operations and deposited in nearby soils. The study concluded that. mnisture movement was the principle transport factor but did not address differences in Pu-Am transport.

Bowen and Livingston (1975) and Bowen (1975) reviewed the distribution of americium in the marine environment and suggested americium may be more mobile than-plutonium. Hetherington, et al., (1975) measured the americium and plutonium concentrations in the top two centimeters of marine sediments 
around the Windscale nuclear power facilities effluent. The Am/Pu ratio in the sediments did not vary and there was no evidence that the ratio changed with distance from the outfall. It was concluded that the behavior of americium was qualitatively similar to plutonium. One core taken to 25 centimeters also gave supporting evidence that both plutonium and americium become incorporated into the sediments and remained fixed to the same extent. Variable ratios of $\mathrm{Am} / \mathrm{Pu}$ from month to month and year to year in the outfall effluent may mask small differences in the mobility of these transuranics.

The ecological behavior of americium in a freshwater waste pond on the Hanford Reservation has been reported by Emery, et al., (1974). Results pertinent to migration of americium include the fact that 93 percent of the americium in the ecosystem is tightly bound to sediment particles and transportable only with the particles. Americium in the water column is low and associated with fine particles. Algal detritus concentrates americium to twice the value of sediments on a dry weight basis. Americium in the interstitial waters appears to be cationic in form.

Edgington, et al., (1975) concluded after studies of the concentrations of $24 \mathrm{Im}$ with depth in Lake Michigan that there was little or no preferential mobility of americium over plutonium.

A few studies pertaining to the leachability of americium from contaminated soils have been performed. Swanson (1973) found $5 \mathrm{M} \mathrm{HNO} 3$ removed substantial quantities of the total americium present in a sandy soil which had received high salt acid wastes. In most cases 90 percent americium was removed from the soil and in all cases no less than 20 percent was removed. In all cases americium leachability was greater than plutonium leachability. Pretreatment of the soil with $\mathrm{KOH}$, ethyl alcohol or TBP-NPH did not increase the leachability of americium by $5 \mathrm{M} \mathrm{HNO}_{3}$ as the pretreatment did for plutonium. The Am/Pu ratios versus soil depth did not support preferential migration of americium over plutonium.

Hajek (1966) leached contaminated Hanford soils with groundwater and iN $\mathrm{NaNO}_{3}$ solutions. Thirteen column volumes of groundwater leached 7.5 percent of the total americium present compared to only 0.1 percent of the plutonium. The first 30 columir volumes of sodium leach solution removed 33 percent of the total americium, but subsequent leaches did not contain addilional americium. The results suggest a portion (33 percent) of the soil americium was present as an exchangeable form.

The adsorption of americium by soils has been studied by several investigators. Hajek and Knoll (1966) and Knoll (1965, 1969) described several americiull adsorption experiments on Hanford-like wastes with emphasis on the effect of organics. An acidic high salt ( $\left.5.4 \mathrm{M} \mathrm{N} 0_{3}\right)$ waste spiked with organics typically found in waste streams (1ard oil, carbon tetrachloride, DBBP and TBP) which contained americium showed very rapid breakthrough when percolated through a Hanford sand. The KdAm was less than $1 \mathrm{ml} / \mathrm{g}$ at soil-solution $\mathrm{pH}^{\prime} \mathrm{s}$ as high as 3. Plutonium in these solutions had Kdpu's of $2-3 \mathrm{ml} / \mathrm{g}$. If the wastes were neutralized and the resultant supernate contacted with soils, the $\mathrm{Kd}_{A \mathrm{~m}}$ increased to $212 \mathrm{ml} / \mathrm{g}$. If this neutralized supernatant was mixed with 
20 percent by volume organics, the KdAm dropped to 41 . A water leach of the neutralized sludge mobilized some americium which, upon contact with soil, yielded a $\mathrm{Kd}_{\mathrm{Am}}$ of 500 . In all cases, the $\mathrm{KdAm}<\mathrm{KdPu}$. In other experiments Knoll loaded columns of soil with tap water spiked with americium. Various organic solutions were then percolated through the columns and the quantity of americium leached recorded. One hundred thirty column volumes of TBP (20 percent)- $\mathrm{CCl}_{4}$ (80 percent) leached 10 percent of the americium sorbed versus 5 percent of the plutonium. DBBP (30 percent)-CCl4 (70 percent) after 160 column volumes leached 15 percent of the americium and 40 percent of the plutonium. D2EHPA-TBP in normal paraffin hydrocarbons after 30 column volumes leached 80 percent of the Am and 30 percent of the Pu. Hydroxyacetic acid at $0.25 \mathrm{M}$ released 100 percent of the $\mathrm{Am}$ and 55 percent of the Pu after 10 column volumes. At a lower concentration, $0.025 \mathrm{M}$, hydroxyacetic acid removed 50 percent of the $A m$ and 40 percent of the plutonium after 70 column volumes. If the americium and plutonium are added to the organic solution and then percolated through soil columns, the Kd values listed in Table 10. are observed assuming a column bulk density of $1.5 \mathrm{~g} / \mathrm{ml}$.

TABLE 10

KdAm AND KdPu VS ORGANIC SOLUTION

\begin{tabular}{|c|c|}
\hline & $\mathrm{Kd} \mathrm{d}_{\mathrm{Am}}$ \\
\hline $\operatorname{TBP}(20 \%)-\mathrm{CC}_{4}(80 \%)$ & 1.6 \\
\hline $\operatorname{DBBP}(30 \%)-\mathrm{CC}_{4}(70 \%)$ & 0.6 \\
\hline D2EHPA-TBP in Hydrocarbons & 0 \\
\hline
\end{tabular}

Americium sorption experiments for several soils, Dutch subsoils and rocks were performed by Routson, et al., (1975), VanDalen, et al., (1975) and Fried, et al., (1974), respectively. Routson, et al., (1975) used batch sorption experiments ( $10 \mathrm{~g}$ soil to $25 \mathrm{ml}$ solution) and twenty four hour equilibrattons lo delermine KdAm for desert sand and Eastern sandy clay. The $\mathrm{KdAm}$ was determined as a function of solution calcium and sodium concentration at an initial $\mathrm{pH}$ of 2.5 to 3.1 . The $\mathrm{KdAm}$ for the sandy clay decreased as the calcium concentration increased. At $0.002 \mathrm{M} \mathrm{Ca} \mathrm{KdAm} \mathrm{was}$ $67 \mathrm{ml} / \mathrm{g}$; at .20M Ca the $\mathrm{Kd}$ Am was $1 \mathrm{ml} / \mathrm{g}$. For the Burbank sand, the $\mathrm{KdAm}$ was greater than 1200 for all concentrations of calcium. The KdAm for the sandy clay also was a function of the sodium concentration in solution; 280 at $0.015 \mathrm{M} \mathrm{Na}$ and 1.6 at 3.00M Na.

VanDalen, et al., (1975) determined the KdAm for Dutch subsoils from 90 percent saturated $\mathrm{NaCl}$ solutions at $\mathrm{pH} 7$ to 8 . Samples consisting of mainly illite and kaolinite had a KdAm of $5 \times 10^{4}$, for a river sand KdAm was 400 . Gypsum bearing and clay bearing sandstones had intermediate. $\mathrm{KdAm}$ 's. The $\mathrm{pH}$ dependence on sorption processes for americium between $\mathrm{pH}$ 5-8 was minor. 
Fried, et al., $(1974,1974)$ determined the sorption of americium onto a basait: A sorption value based on the surface area of the basalt was 1.6 times greater than the sorption of plutonium. Addition of salts to the solution lowered the adsorption of americium. $\mathrm{La}^{+3}$ and $\mathrm{Zr}^{+4}$ cations lowered the americium adsorption much more than $\mathrm{Sr}^{+2}$ and $\mathrm{Na}^{+}$.

Fukai and Murray (1974) added $A m(\bar{I} \bar{I})$ to $100 \mathrm{ml}$ of river water containing $1 \mathrm{~g}$ of river sediment and mixed for 96 hours at various $\mathrm{pH}^{\prime} \mathrm{s}$. Below pH 6.5 adsorption of americium on the sediment was low. Between $\mathrm{pH} 6.5$ and 8.5 the percentage americium adsorption increased from 20 percent to 95 percent. The contaminated sediments were next contacted with seawater and desorption measured as a function of $\mathrm{pH}$. Desorption of americium increased as the $\mathrm{pH}$ was decreased, at $\mathrm{pH} 8.5$ less than 10 percent Am was desorhed while 25 percent was desorbed at $\mathrm{pH} 5.5$.

Articles pertaining to the uptake of americium by plants, Cline (1967), Hale and Wallace (1970), Wallace (1972, 1972), Price (1973, 1973, 1974), in general find americium to be taken up to a greater extent than plutonium. Chelating agents such as DTPB and EDDHA greatly increased the uptake of americium from soil.

Fowler and Heyraud (1974) and Fukai and Murray (1974) described experiments in which americium added to seawater and freshwaters precipitates at neutral and basic pH's.

Curium

Thomas and Jacobs (1969) determined the sorption chararteristics of ${ }^{242} \mathrm{Cm}$ on several clays from distilled water and $0.1 \mathrm{M} \mathrm{NaCl}$. Sorption was not a function of exchange as more $\mathrm{Cm}$ adsorbed in the presence of $0.1 \mathrm{M} \mathrm{NaCl}$. When sorption studies were made as a function of $\mathrm{pH}$, some curium was removed from solution even without the addition of clay at $\mathrm{pH}$ values above 3 . This was due ton precipitation or to sorption on glass walls. Addition of clay caused a considerable increase in sorption possibly due to increased surface area available for deposition. Column loading studies of $242 \mathrm{Cm}$ tagged $0.1 \mathrm{M} \mathrm{NaCl}$ showed normal ion exchange chromatographis hreakthrough at $\mathrm{pH} 1$. Above $\mathrm{pH} \mathrm{I}$, the effluent deviated from normal chromatographic curves and remained constant during the entire run. The effluent/influent ratio at $\mathrm{pH} 3$ was about 0.008 , at $\mathrm{pH} 7$ the ratio was 0.028 , and at. $\mathrm{pH} 10$ the ratio was 0.150 . Although $242 \mathrm{Cm}$ precipitated from stock solution at $\mathrm{pH}$ values above 3 , the leakage of curium increased with increasing $\mathrm{pH}$. The leakage is probably caused by hydroxy and oxo-complexes forming radiocolloids. Movement of curium tirough soil is probably restricted by filtration and surface adsorption of radiocolloids rather than by ion exchange. Thomas and Jacobs (1969) and Price (1973, 1974) reported on the plant uptake behavior of curium in soils.

Berkelium, Californium, Eisteiniun, Fermium, Mendelevium, Nobelium and Lawrencium

No information was found in the literature on the accumulation or migration of these actinide elements in sediments. 
ANNOTATED BIBLIOGRAPHY

Aarkrog, A. 1972. Re-examination of Plutonium at Thule, Greenland, in 1970. EUR-4800 1\&2:1213-19.

From International symposium on radioecology applied to the protection of man and his environment; Rome, I taly (September 7, 1971):

After the accidental release of plutonium at Thule in January 1968 a radioecological study was carried out in the following summer. Increased plutonium levels appeared in samples collected as far as 15 kilometers from the point of impact. Especially bottom animals showed increased levels. To investigate the distribution as well as the migration of plutonium in the food-chains at Thule a re-examination was undertaken in August 1970. As in 1968, samples of seawater, bottom sediments, bottom animals, zooplankton, fish, seabirds, seals, seaplants, and lichen were collected. The investigation showed that although the levels in most samples had decreased since 1968 plutonium was still present in concentrations significantly above the fallout background. Samples of bottom sediments showed a vertical movement of plutonium in the sediments down to a depth at least $10 \mathrm{~cm}$. Bivalves as far as 30 kilometers from the point of impact contained plutonium from the accident. (auth)

Adams, J. A. S., J. K. Osmond and J. J. W. Rogers. 1959. The Geochemistry of Thorium and Uranium. IN: Physics and Chemistry of the Earth. 3.

L. H. Ahrens, F. Press, K. Rankama and S. K. Runcorn (eds.):298-348.

The natural distribution of uranium and thorium in the crustal rocks is reviewed along with the average abundance in each rock and sediment type. The separation of uranium and thorium during weathering processes is accomplished in three ways: 1) solution processes in which the minerals holding the thorium and uranium are put into true solution; 2) physical movement of resistates containing uranium and thorium; and 3) precipitation with clays, opal and other similar minerals.

Adams, W. H. 1971. Solubility of Plutonium-238 Labeled $\mathrm{PuO}_{2}$ in Los Alamos Tap Water. LADC- 12900.

The solubility of 238-labeled $\mathrm{PuO}_{2}$ microspheres of various sizes was studied with time. Los Alamos tap water was used for this study.

Agamirov, S. S. 1963. Precipitation of $U$ in Black Sea. leokhimiya. No. 1: 92-3 (in Russian). 
Hydrochemical tests of the northeast portion of the Black Sea Basin during July 1961 indicated $2.4 \mathrm{~g} / 1 \mathrm{U}$ in the upper $500-\mathrm{m}$ layer, $1.6 \mathrm{~g} / 1 \mathrm{U}$ between 1000 and $18000 \mathrm{~m}$, and much smaller amounts at greater depths. Further studies showed the feasibility of hexavalent uranium reduction to tetravalent by hydrogen sulfide contamination, followed by a precipitation to a depth of 1700 to $2000 \mathrm{~m}$ where the eH value is 0.10 to $0.20 \mathrm{v}$, resulting in an enrichment of Black Sea sediments. (NSA)

Alberti, G., C. Bettinali; G. Grassini and F. Silvestro. 1959. Leaching Tests of Uranium of Canale Monterano. IN: Studie Ricerche Della Divisione Geomineraria. 2:129-53.

Short descriptions of the deposit, of the various hypotheses of its origin and of the methods of sampling are given. The results of the radiometric and chemical analyses of samples collected in the various galleries are reported. The conditions of solubilization of the uranium in pure water and in acidic and alkaline solutions were studied, taking in account the concentration of the solutions, the time of leaching, the temperature, the grain size of the crushed material, the presence of oxidizing compounds and of oxygen under pressure. It was found that in the case of leaching by water only, the percentage of uranium going in solution is strictly linked to the acidity of the material. Most of the examined samples shows pHvalues between 2.4 and 3.2 , but also extreme values, such as 1.8 and 5.5 were observed. On the average, about 18 percent of the total uranium present goes in solution in pure water, while, in solutions with 20 percent sulfuric acid, maximally 60 percent of the uranium could be leached out: (auth)

Ames, L. L., Jr. 1960. Some Cation Substitutions During the Formation of Phosphorite from Calcite. Econ. Geol. 55:354-362.

The nature of cation substitution during replacement of calcite by phosphorite allows the statistical treatment of data concerning such substitution.

Log-probability plots of data yield straight lines that allow easy and accurate extrapolations. Data are presented to show the effect of phosphate ion concentration, temperature, flow rate, and $\mathrm{Na}$ concentration on the primary inclusion of the radioisotopes of $\mathrm{Pm}$ (III), $\mathrm{Sr}$ (II), U (IV), and Pu (IV). (auth)

Ames, L. L., Jr. 1974. Characterization of Actinide Bearing Soils: Top Sixty Centimeters of 216-Z-9 Enclosed Trench: USERDA Report. BNWL-1812.

The author examined the sediment-plutonium relationships in sediment core samples from the first two feet of 216-Z-9 covered trench. At least two types of plutonium occrrrences were found in.216-Z-9 sediments that received 
high salt, acid wastes from plutonium process operations. Plutonium particles identified by $X$-ray diffraction tracings as $\mathrm{PuO}_{2}$ were the most conspicuous form. The $\mathrm{PuO}_{2}$ was filtered out of the waste solution in the first few inches of the sediment column, and probably entered 216-2-9 as discrete $\mathrm{PuO}_{2}$ particles.

Anonymous. 1975. Savannah River Laboratory Quarterly Report Waste Management. April-June 1975, DPST-75-125-2.

Pu Distribution coefficients are reported from synthetic, high salt basic wastes onto Duolite ARC-359 resin, three inorganic zeolites and hydrous zirconium oxide. Kd values for Pu varied from 1 to 240 on the Duolite resin.

The leachabilities of sludge-silicate waste forms were determined (as alpha) in $\mathrm{g} / \mathrm{cm}^{2} /$ day of waste.

The migration of solvent-complexed $\mathrm{Pu}$ through dry and moist soils was determined. $\mathrm{Pu}$ in solvent $\mathrm{K}_{d}=\sim 0.4 ; \mathrm{Pu}$ in aqueous phase $\mathrm{K}_{d}=>30$.

Anspaugh, L. R., P. L. Phelps, N. C. Kennedy and H. G. Booth. 1973. WindDriven Redistribution of Surface-Deposited Radioactivity. Environmental Behavior of Radionuclides Released in the Nuclear Industry. I.A.E.A., Vienna, 1973. pp. 167-184.

The deposition of radionuclides on a terrestrial surface can result in the delivery of dose to man through external radiation exposure, food chain contamination or inhalation of suspended particles. $239 \mathrm{Pu}$ is one of the few radionuclides generally regarded as constituting an inhalation hazard through wind-driven resuspension. No adequate models of resuspension exist. Two major problem areas have been identified: the rate at which initially deposited debris weathers into a less erodible state as a function of time, and a source term factor in material removed per unit time per unit area, applicable to a source of any configuration. In experiments conducted at the US Atomic Energy Commission's Nevada. Test Site, concentrations in air of particles moving in suspension were studied over a period of six weeks following the nuclear cratering event Project Schooner and over a 10month period following accidental venting of an underground nuclear explosion. Suspended air activity was observed to decrease in time with half-times of from 35 to 80 days; this factor appears to be much more important than variations in meterological parameters over these relativley short time periods. Movement of small particles in suspension accounts for only a minor fraction of the total mass movement. As much as $50 \%$ of the initially deposited debris was moved by saltation within a 24-hour period. Such movement can result in extensive micro-inhomogeneities with accumulation of debris under bushes or other places affording shelter from erosive forces. More detailed study of the resuspension process in an aged $239 \mathrm{Pu}$ field is now in progress. Preliminary data are given on the particle size distribution of the total mass and the 239pu moving in suspension. (auth) 
Au, F. H. F. 1974. The Role of Soil Microorganisms in the Movement of Plutonium. IN: Dunaway, P. B., and M. G. White (eds). The Dynamics of Plutonium in Desert Environments. NV0-142 (NVO-AEIC-74-1 or UC-2): 135141.

Microbial studies which are completed or in progress were designed to determine the ability of microorganisms to absorb plutonium, to quantify the uptake, and to determine the microbial population of soils of the Nevada Test Site (NTS). Results of the microbial inventory of Area 13 (NTS) showed that about $2 \%$ of the Aspergillus was near the surface of the hummock and increased with distance away from the plants. Penicillium, on the other hand, showed an inverse pattern in that its relative abundance decreased away from the plants.

A method was developed for in vitrn studies in which aerial fungal spores were collected to determine soluble plutonium uptake from agar medium. The concentration of plutonium in mature spores was approximately onefourth of that in the growth medium. (auth)

Au, F. H. F. and W. F. Beckert. 1975. Influence of Selected Variables on Transport of Plutonium to Spores of Aspergillus Niger. IN: White, M. G. and P. B. Dunaway (eds.). The Radioecology of Plutonium and Other Transuranics in Desert Environments. NVO-153 (UC-2):187-196.

Studies were carried out on the influences of different chemical forms and concentrations of plutonium at two hydrogen ion concentrations of the culture medium on uptake and transport of plutonium to the spores of Aspergillus niger. Results indicated that plutonium, when added to the culture medium as dioxide microspheres, nitrate, or citrate complex, was transported to the spores, and that an almost linear relationship existed between transport and concentration. Raising the $\mathrm{pH}$ of the culture medium from 2.5 to 5.5 generally increased transport of plutonium to spores for all three chemical forms. At plutonium concentrations of $224 \mathrm{pCi} / \mathrm{g}$ in the culture media, and for both $\mathrm{pH} 2.5$ and 5.5 , transport of plutonium to spores was approximately three times as high from the nitrate or citrate form as from the dioxide microspheres. (auth)

Baranov, V. I., A. B. Ronov, and K. G. Kinashova. 1956. On Geochemistry of Dispersed Thorium and Uranium in Clays and Carbonate Rocks of Russian Platform. Geokhimiya No. 3:3-8.

In sedimentation processes $U$ migrates to a considerable extent in the form of soluble compounds, whereas Th migrates in colloidal form. Magnitude of Th: $U$ ratio is twice as large in clays as in carbonate rocks, and in the latter Th is contained in the insoluble portion. Clays of the Russian Platform contain on the average 1.$] \times 10^{-3} \%$ Th and $4.1 \times 10^{-4} \% \mathrm{U}$; cartonate rocks $2.4 \times 10^{-4} \%$ Th and $2.1 \times 10^{-4} \% \mathrm{U}$. Maximum content of $\mathrm{Th}$ is noted in rocks formed during periods of most intensive erosion of crystalline 
rocks or shell of weathering. Content of $U$ in rocks of different composition and geological age varies to a considerably lesser extent than than of Th. A certain enrichment in $U$ is observed in rocks having an increased content of organic substances. (NSA)

Baranov, V. I. and N. I. Titaeva. 1961. Uranium, Thorium, Radium, and Ionium Content in the Quartenary Deposits of the River Lena. Geokhimiya: No. 2:110-14 (in Russian).

Data are given on the content of radioactive elements in young continental sedimentary formations of Siberia. Uranium capture from aqueous environment by sediments with a high content of organic matter is ascertained. The enrichment of the sediments in uranium on the background of low thorium, radium, and ionium contents is indicative of the possibility of using the ionium method to ascertain the time of their formation. (auth)

Baturin, G. N. 1968. Geochemistry of Uranium in the Baltic Sea. Geokhimiya. No. 3:377-81 (in Russian).

The content of $U$ jn the surface layers of sediments of the Baltic Sea varies from 1 to $4 \times 10^{-4} \%$ in the coastal deposits and from 5 to $20 \times 10-4 \%$ in deeplying clay and silt-clay sediments. The distribution of uranium in the sediments of the Baltic Sea is of the well-regulated type with distinct pelagic maximum. The concentration of uranium in the sediments and its distribution per surface was controlled by the content and distribution of the organic material. The hydrogen sulfide contamination of water near the ground, having a local and sporadic character, is not a basic factor in the concentration of uranium in sediments of this basin. One of the reasons for the low $U / C_{\text {org }}$ relation in the sediments of the Baltic Sea is the low content, in comparison with other seas, of dissolved $U$ in its waters. (auth)

Baturin, G. N. 1969. Uranium in the Surface Layer of Sediments in the Northwestern Part of the Indian Ocean. Okeanologiya. 9:1031-7 (in Russian).

The average content of $U$ in sediments of the northwestern Indian Ocean is the same as that in sedimentary rocks on the continents. Higher $U$ concentrations are reported in two samples with high organic $C$ content, and in fish scales. U concentrations are not related to the quantity of pelitic fractions, but are inversely proportional to $\mathrm{CaCO}_{3}$ concentrations and are correlated with organic $C$ and $P$. Relatively high $U$ concentrations are confined to shelves and the continental slope. The concentrations are minimum in sediments of the abyssal plains. (CA) 
Baturin, G. N. 1971. Uranium in Solutions of Ooze Deposits in the Southeastern Atlantic. Dokl. Akad. Nauk. SSSR. 198:1186-8 (in Russian).

Determinations of uranium were made in ooze solutions of deposits after separation from the core samples under pressure. A range of 1.3 to 650 $\mu \mathrm{g} \mathrm{U} / 1$ was recorded. for the samples under test; in the majority of cases the $U$ content was significantly greater than in the ocean waters $(3.2 \mathrm{~g}$ $U / 1)$. A correlation between $\mathrm{pH}$ and $U$ content of samples is shown. (NSA)

Baturin, G. N. 1973. Uranium During Sedimentation in the Black and Azov Seas. Litol. Polez. Iskop. No. 5:2l-32 (in Russian).

In rivers of the Azov-Black Sea basin, $U$ migrates predominantly in a dissolved state. The sediments of the nzov Sca cxhibit a uniform distribution of $U$; in the Black Sea sediments, $U$ distribution is controlled by organic matter. The $U /$ organic $C$ ratio in sediments shows a steady increase during sedimentation. The deposition of $U$ from marine waters occurred, during a lowering of the $E_{H}$, at the interface water-sediment. (CA)

Baturin, G. N. 1973. Uranium in the Contemporaneous Sedimentary Cycle of the Sea.

During rocks weathering and in the river runoff, uranium is divided into the dissolved and the suspended one at an average 1:1 ratio. The average uranium content in the sum of dissolved and suspended matters of river runoff corresponds to its average content in the Earth crust; that determines uranium content in sea and ocean sediments. The share of hydrogenous uranium being concentrated in sediments of sea basins and the peripheric zones of the ocean up to $(10$ to 60$) \times 10^{-4} \%$ plays in the total balance a secondary role. This concentration is favored by the enrichment of sediments in organic matter and phosphorus, by the heightened uranium content in waters, by the reducing conditions near the boundary of water--bottom divide, by the slackened sedimentation rate, by the renewal of the nearbottom waters. Uranium transition from the soljd phase to interstitial waters, where its concentration reaches $n \times 10^{-4} \mathrm{~g} / 1$, is a precondition of its redistribution during diagenesis. (auth)

Baturin, G. N. and E. M. Emel'anov. 1973. Distribution of Uranium in the Sediments of the Mediterranean Sea. Okeanologiya. 13:814-20 (in Russian).

Basic types of sea bed sediments were sampled from the $0-5 \mathrm{~cm}$ horizon and analyzed by chemical. Tuminescence. The $U$ concentration was $2-50 \times 10^{-4} \%$, the mean value being $17 \times 10^{-4} \%$. The minimum $U$ concentration was found in coarse silts of the southern part of the basin and the maximum in the fine silty muds of the peripheral parts of the sea. $U$ deposits show correlation with organic $C$. (CA) 
Baturin, G. N., T. D. Ilyina, and N. I. Popov. T971. Soviet Investigations of Natural Radionuclides in Marine and Ocean Sediments. Proc. Roy. Soc. Edinburgh, Section B, 72:183-91.

Investigations of the radioactivity of marine and ocean sediments, begun in the USSR in 1944, helped to reveal the basic traits of marine geochemistry of natural radioelements. Among them $U$ is the most mobile and 232Th the most inert in the marine sedimentary cycle. Considerable work has been done in developing the absolute dating methods based on the use of Th and $U$ isotopes. It seems that the $230 \mathrm{Th}-23 \mathrm{I}_{\mathrm{Pa}}$ method is the most reliable for oceanic conditions. The determinations of the total radioactivity and the analysis of the gamma spectrum of marine sediments made in situ and in the laboratory are largely used for revealing tectonic structures as well as the facies composition and content of certain radioelements in sediments. (auth)

Baturin, G. N. and A. V. Kochenov. 1969. Migration of Uranium in Rivers and the Duration of Its Presence in Waters of the World's Oceans, Seas, and Lakes. Geokhimiya. No. 6:715-23 (in Russian).

The average uranium content in the total amount of dissolved and suspended materials of river run-of, is similar to its average content in rocks of the Earth's crust. The rivers of the Earth every year supply the World ocean with approximately 20,000 tons of dissolved uranium and with approximately as much suspended uranium at a ratio of $1: 1$. In final run-off basins the prevailing part of dissolved uranium is precipitated together with terrigenous material on shelfs and continental slopes. The time of dissolved uranium stay in waters of the basins varies from tens of years to hundreds of thousands years and depends on their depth. (auth)

Baturin, G. N. and A. V. Kochenov. 1973. Uranium in Interstitial Waters of Marine and Oceanic Sediments. Geokhimiya. No. 10:1529-36 (in Russian).

Interstitial waters were sampled from the Atlantic and Pacific Ocean and Black Sea diatomaceous and terrigenous shelf oozes, calcareous aleuropelitic continental silts, and eupelagic and miopelagic shales. Location of the sample (latitude and longitude), depth, type of sediment, moisture content, $\mathrm{pH}$, Eh, and organic $\mathrm{C}, \mathrm{CaCO}_{3}$, and amorphous $\mathrm{SiO}_{2}, \mathrm{P}$, and $\mathrm{U}$ contents are tabulated. The $U$ content in the interstitial waters has a wide variation (from $1.3 \times 10^{-6}$ to $650 \times 10^{-6} \mathrm{~g} / 1$ ) caused by the great diagenetic mobility of $U$. The $U$ content is controlled by the $\mathrm{pH}$, Eh, and the content of organic C. (CA) 
Baturin, G. N., A. V. Kochenov, and S. A. Kovaleva. 1966. Some Aspects of the Distribution of Uranium in Black Sea Waters. Dokl. Akad. Nauk SSSR. 166:698-700 (in Russian).

During the 16th voyage of the scientific-research ship "Mikhail Lomonosov" in August-September 1964, 46 samples were taken at various depths of the waters of the Black Sea at 16 different stations, including 15 samples of the bottom layer. According to the determinations, the uranium content of the Black Sea waters (except the bottom layer) ranges from $2 \cdot 10^{-6}$ to $4 \cdot 10^{-6} \mathrm{~g} / 1$, the average being $2.8 \times 10^{-6} \mathrm{~g} / 1$. The uranium content of the bottom layer is much lower, frequently dropping to $n \times 10^{-7} \mathrm{~g} / 1$. This is attributed to the removal of uranium by adsorption on the sediments. One of the major factors in the adsorption of uranium by the sediments is thought to be the presence in the latter of organic matter whose particles can occlude this metal while it is still precipitating in the mass of the water as a result of its reaction with hydorgen sulfide contaminating the water. (NSA)

Baturin, G. N., A. V. Kochenov, and Y. M. Senin. 1971. Uranium Concentration in Recent Oceanic Sediments of Water Uprise Zones. Geokhimiya. No. 4:456-62 (in Russian).

Uranium concentration in recent oceanic sediments in water uprise zones (i.e., of permanent ascending currents) is several times higher near the shores of continents in comparison with deep-sea oceanic sediments. Biogenic and diagentic phosphates, which are present in these sediments, accumulate up to $10^{-3}$ to $10^{-2}: \%$ of uranium. In both cases uranium concentration occurs by the way of extraction from sea water. Uranium precipitation in these regions is connected with the accumulation of organic. matter and phosphorus in bottom sediments and with hydrogen sulfide contamination of benthonic waters. The intensive supply of organic matter and phosphorus to sediments of shelf zones is conditioned by their high biological productivity and by periodical mass starvations of the fauna. (auth)

Baturin, G. N., A. V. Kochenov, and K. M. Shimkus. 1967. Uranium and Minor Metals in Columns of Bottom Sediments of the Black and Mediterranean Seas. Geokhimiya. No. 1:41-50 (in Russian).

The similar distribution of metals ( $U, M 0, \mathrm{Co}, \mathrm{Ni}$, and $\mathrm{V}$ ) was observed in sedimentary columns of the Black and Mediterranean Seas. The metal distribution was correlated with that of organic substances. In bottom sediment columns of the Black Sea the correlation with organic $C$ was most typical for $U$ and Mo. The correlation of rare metals and $C_{o r g}$ in the sedimentary columns was contrastingly different from the surface layer of muds. This indicated the diagenetic redistribution of rare metals in the sea sediments. The transformation of organic substances was the main factor affecting mobility of metals in the sedimentary formations. 
Beckert, W. F. and F. H. F. Au. 1975. Plutonium Uptake by a Soil Fungus and Transport to Its Spores. IAEA-SM-199/72.

Three concentrations of plutonium-238 nitrate, citrate, and dioxide were each added to separate plates of malt agar buffered to $\mathrm{pH} 2.5$ and 5.5 to determine the uptake of plutonium from these chemical forms and concentrations by a common soil fungus, Aspergillus niger. After inoculation and incubation, the aerial spores of Aspergillus niger were collected using a technique that excluded the possibility of cross-contamination of the spores by the culture media or by mycelial fragments.

Plutonium-238 was taken up from all three chemical forms and transported to the aerial spores of Aspergillus niger at each concentration and at both $\mathrm{pH}$ levels. The specific activities of the spores grown at $\mathrm{pH} 5.5$ were generally at least twice those of the spores grown at $\mathrm{pH} 2.5$. The uptake of plutonium from the dioxide form was about one-third of that from the nitrate and citrate forms at both $\mathrm{pH}$ levels. The term "transport factor" is used as a means to compare the transport of plutonium from the media to the fungal spores; the concentration-independent transport factor is defined as the specific activity of the spores divided by the specific activity of the dry culture medium. Through the transport factors were

Bell, K. G. 1960. Deposition of Uranium in Salt-Pan Basins. U.S.G.S. Professional Paper No. 354-G:161-9.

Drainage waters carry minute quantities of uranium into oceans, inland seas, and lakes, and when bodies of water evaporate completely in desiccating salt-pan basins, the uranium must be deposited together with all other dissolved materials. The ratio of uranium to total evaporite sediments is approximately 1:2 $\times 10^{7}$. The distribution of uranium in salt-pan basin sediments is not completely known. Some organic-rich muds, and phosphatic sediments deposited in desiccating basins may contain uranium in amounts as large as $0.0 \mathrm{X}$ percent. Uranium may be adsorbed on clays that are deposited with some evaporite sediments. These muds, phosphatic sediments, and slays may remove nearly all of the dissolved uranium from the water of some basins. Anhydrite, gypsum, halite, and potassium-bearlng evapurite minerals probably are the lease uraniferous of all rocks in the earth's crust; their uranium contents generally are less than 0.00001 percent. Within salt-pan basins where oxidizing conditions tend to prevail, and no significant amounts of organic-rich muds, clays, and phosphatic sediments are deposited, highly soluble uranium salts remain in solution and are deposited only as the basin finally is completely desiccated. These final highly soluble evaporite sediments are not likely to be preserved because they are subject. to removal by wind erosion and leaching. (auth)

Bell, K. G. 1960. Uranium and Other Trace Elements in Petroleums and Rock Aspha]ts. U.S.G.S. Professional Paper 356-B. 
Uranium is a minor trace-element constituent of petroleums and their natural derivatives. The quantity of uranium in crude oils produced by primary-recovery processes generally ranges from none to $5 \mathrm{ppb}$ although some crude oils may contain as much as a few tens of parts per billion. The average uranium content for all crude $0 i 1$ is estimated to be about $1 \mathrm{ppb}$, or about one-third that of the average content of sea water. Paraffin-base crude oils have the smallest uranium content, less than $1 \mathrm{ppb}$. Mixed-base and asphalt-base crude oils, in general, contain a slightly greater quantity of uranium and show a rough positive correlation between specific gravity and uranium content. There is no correlation between uranium contents of crude oils and geologic ages of reservoir rocks. Crude oils from one region are no more uraniferous than those from any other, except perhaps as a result of local predominance of heavy aromatic and asphaltic constituents. As a group, the crude oil of the

Bennet, B. G. 1974. Environmental Pathways of Transuranic Elements. WASH-1359, pp. 131-152.

A large number of laboratory and ecological studies have been performed to elucidate specific aspects of these pathways, such as resuspension of deposited activity, plant uptake, and physical and biological transfers in terrestrial and aquatic environments. In addition, the measurements of fallout $\mathrm{Pu}$, tracing the course of this material in air and diet to man, provide some of the most directly appropriate data regarding the environmental pathways. It is generally recognized that for an initially airborne release, the inhalation pathway is the dominant contributor to the bndy burden in man. The low solubility of the transuranic elements inhibits plant uptake and absorption form the gastrointestinal tract and minimizes the importance of the ingestion pathway. The physical illechantsms of transfer of activity are thereby emphasized instead of liological accumulation mechanisms. Dispersion nf airborne radioactivity is governed by the local and regional meteorology. For contamination which originates on the ground surface, such as leakages or spills, resuspension could be an important consideration. (NSA)

Bennet, B. G. 1975. Transuranic Element Pathways to Man. IAFA-SM-199/40.

Transfer to man of transuranic element contamination may occur by the inhalation or ingestion pathways. The measurements of globally dispersed fallout radioactivity have provided pertinent data on the environmental behavior of plutonium. Additional data may eventually become available for americium. From the measured and inferred concentrations of fallout plutonium, the inhalation intake has been determined and the ICRP Task Group lung model used to estimate deposition in the lung and transfer to other body organs. The cumputed body burden reached a maximum of $4 \mathrm{pC} i$ in 1964 and is currently about 2.5 pCi. A complete diet sampling has been conducted to determine ingestion intake. Plutonium concentration in food ranged from $0.01 \mathrm{pCi} / \mathrm{kg}$ is shellfish to undetected (less than 0.0003 $\mathrm{pCi} / \mathrm{kg}$ ) in milk. Annual intake in total diet is estimated to have been 
$1.6 \mathrm{pCi}$ in 1972. Low uptake by the gastrointestinal tract makes contribution to organ burdens form ingestion negligible. Long-term pathway considerations include plant uptake from the cumulative deposit in soil and resuspension. Downward movement in soil may limit the significance of these long-term pathway components. (auth)

Bensen, D. W. 1960. Review of Soil Chemistry Research at Hanford. HW67201 .

Soil adsorption of cesium, strontium, plutonium, zirconium, ruthenium and the rare earth series isotopes from water and from simulated and actual waste in the laboratory and under field conditions is discussed.

Ion exchange, precipitation and in some cases mineral replacement reactions are responsible for radionuclide uptake by soil. The completeness with which an ion is taken up by ion exchange on the soil is dependent upon the concentration of the radionuclide and upon the concentration of accompanying ions. The concentration of the radionuclide and of accompanying cation species are of minor importance in precipitation and in mineral replacement reactions.

Cesium is taken up by an ion exchange reaction. In some cases a portion of the cesium is "fixed" in the soil. Strontium is also largely taken up by ion exchange. In calcareous soil strontium can be removed from alkaline solutions by a mineral replacement reactions with calcite $\left(\mathrm{CaCO}_{3}\right)$. Above pH 2 plutonium and zirconoum are largely taken up by precipitation on the soil. The rare earth nuclides and yttrium are similarly precipitated at pH above 6. Below the $\mathrm{pH}$ necessary for complete precipitation, soil uptake of these nuclides presumably occurs by a combination of ion exchange and precipitation. The uptake of trivalent ruthenium is similar to that of the rare earths.

Soil uptake of plutonium, zirconium, rare earths and ruthenium is adversely affected by anions which form complex anionic species with the nuclides.

Strontium is usually taken up from alkaline wastes more completely than cesium. However, from an acid waste, cesium uptake is better than that of strontium. The general order of radionuclide uptake from waste is:

$$
\text { Pu }>\text { R.E. }>\text { Sr }>\text { Cs }>>R u \text {. (auth) }
$$

Bernat, M. and E. D. Goldberg. 1969. Thorium Isotopes in the Marine Environment. Earth Planet. Sci. Lett. 5:308-12.

Analyses of thorium isotopes isolated from fractions of a North Pacific Core, representing authigenic and detrital minerals, indicated that there were movements of ${ }^{228} \mathrm{Ra}$ within the sedimentary column, that the thorium comes to the deposit primarily from seawater, that there is no evidence for the migration of thorium isotopes within the sedimentary column, and 
that there is a continued growth of phillipsite at depths in the column. Finally, there appeared to be a preferential accommodation of $231 \mathrm{~Pa}$ and/or 227Ac in the phillipsite, the authigenic zeolite, relative to the detrital minerals. The high values of the $228 \mathrm{Th} / 232 \mathrm{Th}$ ratios in seawater may be influenced by the contribution of $228 \mathrm{Th}$ arising from ${ }^{228} \mathrm{Ra}$ migration through the water-sediment interface. (auth)

Blaine, D. E., R. A. Schwind, H. W. Kirby and E. L. Murphy. 1974. NewProcess for Removing Plutonium from Waste Water-A Progress Report. Proceedings of the Second AEC Environmental Protection Conference, Albuquerque, New Mexico. Apri1 16-19, 1974. WASH-1332-74-V-1: 321-338.

A process is under development at Mound Laboratory to remove ${ }^{238} \mathrm{Pu}$ from process water prior to discharge. The contaminated water normally is in the $\mathrm{pH}$ range of 6-8. Under these conditions, plutonium in all of its oxidation states is hydrolysed and exists mostly in a colloidal or polymeric state. Pilot plant tests show that a continuous fixed bed phosphate treatment of unprocessed influent waste water is feasible. However, treatment with ferric hydroxide and polyelectrolytes is necessary to remove colloidal or polymeric plutonium before contact with calcium-hydroxyapatite. The apatite removed essentially all of the ionic plutonium but permitted the colloidal or polymeric species to pass through. Centrifugation or ultracentrifugation after processing removed $70-85 \%$ of the $\mathrm{Pu}$ in effluent solution which leads to the conclusion that colloids and polymers are not adsorbed.

Bonatti, E., D. E. Fisher, 0. Joensuu, and H. S. Rydell. 1971. Postdepositional Mobility of Some Transition Elements, Phosphorus, Uranium, and Thorium in Deep Sea Sediments. Geochim. et Cosmochim. Acta. 35:189-201.

Deep sea hemipelagic sediments from the east Pacific show an oxidized upper zone of variable thickness and a reduced zone below. The geochemistry of a core from this region was studied in detail. The Eh of the upper zone is close to $+100 \mathrm{mV}$, while in the lower zone it reaches about $-400 \mathrm{mV}$. Reducing conditions in the lower section of the core are related to the oxidation of organic matter in the sediment, as indicated by the gradual decrease with depth of the concentration of nitrogen in the upper part of the core. Various elements, such as $\mathrm{Mn}, \mathrm{Ni}, \mathrm{Co}, \mathrm{P}$ and $\mathrm{La}$, are enriched in the upper oxidized zone, while $\mathrm{Cr}, \mathrm{V} . \mathrm{U}$ and $\mathrm{S}$ are enriched in the lower reduced zone. Postdepositional mobility of the elements in question, mainly by diffusion in the interstitial solutions, can explain their distribution in the core. Redox reactions can account directly for the mobilization of $\mathrm{Mn}, \mathrm{Ni}, \mathrm{Co}, \mathrm{Cr}, \mathrm{V}$ and $\mathrm{U}$, indirectly for that of $\mathrm{P}$ and $\mathrm{La}$. $\mathrm{Fe}$ and $\mathrm{Cu}$ do not migrate significantly, since they are immobilized as sulfides in the reduced zone. Th appears not to be affected by diagenetical mobility. Some of the consequences of the postdepositional mobility of elements in deep sea sediments are: (1) The average elemental content 
of deep sea sediment, generally estimated from measurements of samples from the upper part of the sediment column, may be affected by errors; namely, an overestimation in the case of $\mathrm{Mn}, \mathrm{Ni}, \mathrm{Co}, \mathrm{P}$ and La; an underestimation in the case of $\mathrm{V}, \mathrm{Cr}$ and $\mathrm{U}$. (2) Postdepositional redistribution of $U$ may introduce errors in age determinations of sediments by the 230Th/ $232 \mathrm{Th}$ and ${ }^{230} \mathrm{Th} /{ }^{23} \mathrm{~Pa}$ methods. (3) Some geographical variations in the composition of Fe-Mn nodules can be explained by postdepositional mobility of $\mathrm{Mn}, \mathrm{Ni}$ and $\mathrm{Co}$. (auth)

Bondietti, E. A. 1974. Adsorption of Pu (IV) and Th (IV) by Soil Colloids. Agronomy Abstracts.

The tetravalent actinides, $\mathrm{Pu}$ and $\mathrm{Th}$, are extensively hydrolyzed in aqueous solutions above $\mathrm{pH} 2$ in the absence of complexing agents. Adsorption consequently involves interactions of hydrolytic species. Calciumsaturated, reference clays (montmorillonite and kaolinite) removed similar amounts (about 95\%) of the $\mathrm{Pu}$ and Th from the aqueous phase in batch equilibration studies at $\mathrm{pH} 6.5$. Calcium humate removed $99.9+\%$. Desorption by Ca-citrate was extensive from the clays $(10-30 \%)$, while from humic acid less than 1\% was removed. Stronger complexers (DTPA and EDTA) were required for appreciable removal (20-30\%) of $\mathrm{Pu}$ or Th from humic acid. Soil fulvic acid also effects desorption. Adsorption-desorption studies of a soil clay (Miami silt loam) showed that removal of organic matter (0.M.) by $\mathrm{NaOCl}$ oxidation reduces the adsorption of $\mathrm{Pu}$, and $\mathrm{Fe}+\mathrm{O}$.M. removal is not appreciably different from 0. M. removal alone. In all cases, however, greater than $95 \%$ of the Pu was adsorbed. A mixed organic-hyciroxy complex is proposed for the reaction of Th (IV) and Pu (IV) with humic substances. The possible role of organic matter is environmental Pu chemistry will be discussed. (auth)

Bondietti, E. A., S. A. Reynolds, and M. H. Shanks. 1975. Interaction of Plutonium with Complexing Substances in Soils and Natural Waters. IAEASM-199/51.

The reactions of $\mathrm{Pu}$ with selected organic substances found in the environment have been studied to evaluate the valence and metal-complex behavior of Pu. Hexavalent $\mathrm{Pu}$ (and by inference pentavalent Pu) was unstable in the presence of fulvic acid, polygalacturonic acid, and alginic acid. Citrate-Pu(VI) complexes, however, were relatively more stable. Plutonium (IV) was the most stable valence upon interaction with these organics. Further reduction of $\mathrm{Pu}$ (IV) to Pu(III) occurred by fulvic and humic acids. The reduction, under aerobic conditions, does not appear to occur above $\mathrm{pH}$ 3.1. The reduction mechanism is probably similar to the Fe(III) reduction previously documented for phenolic humic substances. 
Data are presented that demonstrate that $\mathrm{Pu}$ is at least partially associated with humic materials in ORNL soil contaminated 30 years ago with trace levels of Pu. Desorption studies using solid exchange resins also showed that, while a cation exchange resin did not desorb Pu from soil after 14 weeks equilibration, chelating resin effected $\mathrm{Pu}$ desorption. The desorption rate was not constant, suggesting differential $\mathrm{Pu}$ forms. While the resin-extractable $\mathrm{Pu}$ was believed to originate from solid-phase organic complexes, over $80 \%$ of the $\mathrm{Pu}$ in this soil was not readily resin-desorbable. This indicates that more inert soil-Pu reaction products effectively immobilize soil Pu. Some of these associatioris also appear to be organic. (auth)

Bostroem, K. and D. E. Fisher. 1971. Volcanogentc Uraniull, Valladiurii, and Iron in Indian Ocean Sediments. Earth Planet. Sci. Lett. 11:95-8.

About one hundred $U, V$, and $F e$ analyses of Indian Ocean sediments indicate that enrichments of $U$ and $V$ occur in hemipelagic sediments close to the continents, probably associated with biogen constituents. The highest concentration, however, of $U, V$, and $F e$ occurs in active ridge sediments, suggesting that submarine volcanism is an important source of these elements. (auth)

Bowen, V. T. 1975. Transuranic Elements in Marine Environments. HASL-291.

Transuranic elements are present in marine environments as a result of six types of human artivity: 1) worldwide fallout; 2) close-in fallout; 3) the SNAP-9A burnup; 4) pipeline disposal of reprocessing wastes; 5) neutron capture by uranium in one-pass colling-water reactors; and 6) the B-52 crash in Thule, Greenland.

Distributions and movements of these nuclides friin these introductions are being studied partly because the transuranic elements themselves are geochemically interesting, partly because they appear to serve as tracers for specific oceanographic processes, and partly because of concern that man is faced with the problem of disposal of rapidly increasing amounts of transuranics as radioactive waste, and that we must be able, soon, to predict the fates and effects of those amounts that reach the coastal waters or the deep oceans.

Plutonium and americium are widely distributed in the oceans as a result of man's activities. But appear to be more moblle than expected, and $\mathrm{Pu}$ shows little behavior in these environments that had been predicted from laboratory studies. Although their associations with biological material seem to be most striking for rooted plants or Sargassum, it is too premature to dismiss the possihility of their being a real hazard to marine life. For all the abundantly produced transuranics (neptunium, plutonium, americium, and curium) many more data are needed. (auth) 
Bowen, V. T. and H. D. Livingston. 1975. Americium 242m in Nuclear Test Debris Nature (in press).

$242 m_{A m}$ was produced in nuclear explosions by neutron capture by 241 Am and decays to $242 \mathrm{~cm}$, according to these authors. Decay scheme $=242 \mathrm{mAm} \rightarrow$ $242 \mathrm{gAm} \rightarrow-242 \mathrm{Cm} \rightarrow-238 \mathrm{Pu} \quad 1 / 2 \mathrm{life}=122 \mathrm{yrs}, 1 / 2 \mathrm{life}=16$ hours.

$242 \mathrm{mAm}_{\mathrm{Am}}$ was suggested by the authors as a source of $\mathrm{Pu}$ more mobile than that $\mathrm{Pu}$ produced in the original event.

Bowen, V. T., H. D. Livingston and J. C. Burke. 1975. Distributions of Transuranium Nuclides in Sediment and Biota of the North Atlantic Ocean. IAEA-SM-199/96.

The effects of the interaction of marine sediments with their biotic population on the penetration, redistribution, sediment association and biotic availability of delivered transuranium nuclides are discussed as a function of both sedimentation regimes and in-fauna populations. Data on the penetration and redistribution patterns of fallout transuranium nuclides in the shallow sediments of Buzzards Bay, Massachusetts, are discussed in terms of the known parameters of sedimentation and 'in sediment' biological activity. In this (and most common) type of sedimentation regime, translocation of bioturbationally downmixed transuranium nuclides back toward (and probable loss from) the sediment surface is demonstrated. Various biological and biochemical mechanisms are advanced that may act on these nuclides within sediments. The increased availability to marine biota of sediment transuranium nuclides by these remobilization processes, is indicated by data showing accumulations of these nuclides in marine invertebrates and fish. (auth)

Bowen, V. T. and V. E. Noshkin. 1973. Plutonium Concentration Along Fresh Water Food Chains of the Great Lakes, U.S.A. General Summary of Progress, 1972-1973. COO-3568-3.

The following radiochemical data are tabulated for analyses of samples in Lake Ontario during 1972: $239 \mathrm{Pu}, 137 \mathrm{Cs}$, and $90 \mathrm{Sr}$ values in water samples: $238 \mathrm{Pu}, 239 \mathrm{Pu}, 237 \mathrm{Cs}$, and $90 \mathrm{Sr}$ values in sediment samples; and $239 \mathrm{pu}$ and $137 \mathrm{Cs}$ for values in plankton, fishes, and clams. A discussion is presented of the quality of the data. The results indicated that bottom-feeding fish such as the gizzard shad, redhorse sucker, carp, bullhead, or drum had higher $239 \mathrm{pu}$ concentrations than predators such as yellow perch or largemouth bass. The data were not consistent with a very striking food-chain magnification of plutonium in fresh-water ecosystems. It is suggested that plutonium concentrated on silt particles is remobilized by digestive processes of filter feeders or bottom feeders and that there may be rather large differences among species with regard to the efficiency of this. (NSA) 
Bowen, V. T., K. M. Wong, and V. E. Noshkin. 1971. Plutonium 239 in and over the Atlantic Ocean. Journal Marine Res. 29:1:1-10.

Plutonium 239 has been found in over-ocean aerosols in about the same ratio to Strongium 90 as that reported over land. In seawater, $\mathrm{Pu} 239, \mathrm{Sr} 90$ ratios are shown to be less than half of those in over-ocean aerosols, confirming geochemical separation of these nuclides in the ocean. It is suggested that the sedimentation of $\mathrm{Pu} 239$ may be more involved with biological processes than has been found for Ce 144 or $\mathrm{Pm} 147$. (auth)

Breger, I. A., M. Deul, and R. Meyrowitz. 1955. Geochemistry and Mineralogy of a Uranifernus Subbituminous Coal. Econ. Geol. 50:610-24.

$\Lambda$ sample of subbituminous uranifernus coal from the Red Desert, Sweetwater County, Wyoming, has been studied mineralogically. The coal contains gypsum $(6 \%)$, kaolinite $(1 \%)$, quartz $(0.3 \%)$, calcite (trace), and limonite (lrace). This suite of mincrals and the absence of pyrite show lihat the coal has been subjected to weathering and oxidation. No uranium minerals have been found; mechanical fractionation has indicated that the uranium is associated with the organic constituents of the coal. The minerals that have been isolated contain $0.0006 \%$ uranium, a content that is to be expected for nonuraniferous sedimentary rocks: The organic components of the coal contain approximately $0.002 \%$ uranium. On the bas is of materialbalance calculations, the organic components carry $98 \%$ of the uranium in the coal. Batch extraction of the Wyoming coal with $6 \mathrm{~N}$ hydrochloric acid leads to the solution of almost $90 \%$ of its uranium. Recovery of uranium is independent of the particle size of the coal between -4 and -20 mesh, and is accompanied by the solution of approximately $70 \%$ of the inorganic constituents (ash) of the coal. The extract contains, together with uranium, a concentration of several elements such as manganese, cerium, and vanadium that are present in the coal. Fischer assays of this weathered coal from the Red Desert indicate a yield of 16.7 gallons of tar per ton. Yields of both tar and char are about 15\% lower if the coal is first treated with $6 \mathrm{~N}$ hydrochloric acid to extract the uranium. It is suggested that uranium was introduced into the coal by means of ground water carrying soluble alkaline or alkaline earth uranyl carbonate complexes. The mineral schroeckingerite--a similar complex--is found near this subbituminous cual in the Red Desert of Wyoming. These complexes, which are unstable in acid medium, release the uranyl ion $\left(\mathrm{UO}_{2}++\right)$, which may then react with organic constituents of the coal to form ionic uranyl-organic compounds that are insoluble above a $\mathrm{pH}$ of about 2.2. Preliminary data indicate that the uranium is associated with various humic components of the coal. The distribution of uranium among the components of the subbituminous coal from Wyoming is similar to the distribution in a lignite from South Dakota. There is no indication that uranium was introduced into or retained by the two coals by appreciably different genchemical processes. (auth) 
Breger, I. A., M. Deul, and S. Rubinstein. 1955. Geochemistry and Mineralogy of a Uraniferous Lignite. Econ. Geol. 50:206-26.

Detailed studies have been carried out on a uraniferous lignite from the Mendenhall strip mine, Harding County, South Dakota. By means of heavyliquid separations, a mineral-free concentrate of the lignite was obtained that contained $13.8 \%$ ash and $0.31 \%$ uranium in the ash. The minerals (gypsum $69 \%$, jarosite $10 \%$, quartz $2 \%$, kaolinite and clay minerals $19 \%$, and calcite trace) contain only $7 \%$ of the uranium in the original coal, indicating an association of the uranium with the organic components of the lignite. Batch extractions show that $88.5 \%$ of the uranium can be extracted from the lignite by two consecutive treatments with boiling $1 \mathrm{~N}$ hydrochloric acid. Continuous extraction with hot $6 \mathrm{~N}$ hydrochloric acid, removes $98.6 \%$ of the uranium. Columns of coal were treated with water, in hydrochloric acid, $6 \mathrm{~N}$ hydrochloric acid, and a solution of lanthanum nitrate. The experiment with lanthanum nitrate indicated that only $1.2 \%$ of the uranium in the coal is held by ion exchange. The elutriation experiments showed that the uranium is held in the coal as an organouranium compound or complex that is soluble at a pH of less than 2.18. A geochemical mechanism by which the uranium may have been introduced into and retained by the lignite is discussed. (auth)

Brown, D. J. 1967. Migration Characteristics of Radionuclides Through Sediments Under Lying the Hanford Reservation. IN: 1AEA-SM-93/16. pp. 215-228, Disposal of Radioactive Wastes Into the Ground.

The US Atomic Energy Commission's Chemical Separation Plants at Hanford have discharged large volumes of intermediate and low-level radioactive liquid waste to the ground for more than twenty years. The information acquired by tracing the movements of radionuclides through the underlying sediments via an extensive network of monitoring wells and sophisticated monitoring equipment has increased our knowledge of the migration characteristics of radionuclides associated with these wastes.

Sediment samples obtained by core drilling a disposal facility at the time it was removed from service and again ten years later, show that over $99.9 \%$ of the long-lived radionuclides are contained within the first ten metres of the 60-metre partially saturated sediment column underlying the disposal facility. All radionuclides with half-lives of less than one year, except ruthenium-103 and strontium-89, decay to below detection limits before they reach the regional groundwater table. The relative permanency of fixation of the long-lived radionuclides is attested to by leaching studies. For caesium-137 and strontium-90, the data show that after passing 50 column volumes of groundwater through sediments, obtained from beneath an abandoned disposal site, $11 \%$ of the caesium is removed and $4 \%$ of the strontium; 500 column volumes removes an additional $4 \%$ of the caesium and $27 \%$ of the strontium. Equilibrium coefficeint and soil column tests indicate that the trace amounts of strontium-90 and caesium-137, leached from sediments underlying a disposal facility, are resorbed in the saturated 
zone below the water table. The distribution coefficients determined in these saturated sediments were approximately 300 for caesium-137 and 50 for strontium-90. Three radionculides (ruthenium-106, technetium-99 and tritium), not readily sorbed on sediments, enter the groundwater at about the same concentration as that measured in the waste stream prior to release. The movements of these nuclides are traced in the groundwater for distances up to fifteen miles by routine analysis of well water samples. At distances of only two and a half miles from the disposal sites, all radionuclides concentrations in ghe groundwater are below the established drinking water limits. (auth)

Brown, J. H. and W. D. Keller. 1952. Uranium in the Clay of a Black Radioactive Shale. Science. 116:632-3.

The results of a brief study of a black radioactive shale from St. Genevieve County, Missouri, show that the $U$ contained in it is located predominantly in a relatively fixed condition in the fine clay fraction, and not in the black organic matter. This result is at variance with recent suggestions that the $U$ in black shales is more likely attached to the organic matter. Leaching experiments were conducted to determine the ease of removal of the $\mathrm{U}, \mathrm{HCl}, \mathrm{HNO}_{3}, \mathrm{H}_{2} \mathrm{SO}_{4}$, aqua regia, and dilute $\mathrm{Na}_{2} \mathrm{CO}_{3}$ were effective solvents, but hot and cold $\mathrm{H}_{2} \mathrm{O}$, ethyl alcohol, $\mathrm{CS}_{2}$, and $\mathrm{CCl}_{4}$ did not extract enough $U$ from $2 \mathrm{~g}$ of shale to produce fluorescence. Propyl alcohol dissolved a small amount of $U$. Attempts to exchange the $U$ cationically indicated that the $U$ is held by the clay minerals in a not easile exchangeable condition. (NSA)

Calvo, M. M. 1974. The Role of Humic Natural Organic Matter in Uranium Concentration. IAEA-SM-183/33. IN: Formation of Uranium Ore Deposits.

The paper reports a short experiment on the metallogenetic aspects $0:$ the uranium-organic matter association in nature. The author carried out several experiments on uranium fixation by organic matter with different degrees of maturity. Although further studies are considered necessary, the results already obtained lead to the following conclusion: when uraniferous solutions come into contact with humic organic matter, the efficiency and nature of the uranium-organic matter association thus established depends on the degree of carbonization attained by the humic material. At the beginning of the development process, the organic matter has high chemical activity and the uranium tends to occur in stable organic phases. As the process continues, a stage is reached from which uranium tends to form its own minerals independently of organic matter. From the coalification stage onwards the tendency towards uranium-organic matter association becomes increasingly less in any forll. Petrographically, the humic constituents to which uranium is closely and positively related belong to the huminite maceral group. Lastly, it is considered that when the organic matter is present as an accessory constituent in other sedimentary rocks and with quite low maturity indices, there is greater favourability for the formation of uranium deposits. (auth) 
Christenson, C. W., M. B. Ettinger, G. G. Robuck, E. R. Hermann, K. C. Kohr, and F. F. Newe 11. 1951. Removal of Plutonium from Laboratory Wastes. Ind. at Eng. Chem. 43:7:1509-15.

Methods investigated for Pu removal included adsorption on Kaolin, pumice, tuff, Celite and activated carbon, alum and iron flocs $\mathrm{pH}$ adjusted with $\mathrm{Ca}(\mathrm{OH})_{2}$, lime and phosphate flocs. Polyphosphates and citric acid interfered with Pu removal and formation of good flocs.

Adsorption methods resulted in larger sludge volumes - reciruclation of sludges reduced sludge volume.

Christenson, C. W., E. B. Fowler, G. L. Johnson, E. H. Rex, and F. A. Virgil. 1958. Soil Adsorption of Radioactive Wastes at Los Alamos. Sewage and Industrial Waste. 30:1478-1489.

Plutonium wastes had formerly been disposed by discharge to seepage pits or canyons at the Los Alamos project. Areas receiving plutonium waste have been monitored repeatedly and no appreciable movement has been noted. Observations were made, however, that the concentration of plutonium in the soil of a canyon receiving low level wastes has moved progressively downstream. Because of this movement, which has not been extensive and is within acceptable tolerance levels, investigations were made of the movement of plutonium through local sites of the Los Alamos area under varying conditions. Strontium 90 and cesium 137 were also included in the study because of the possibility of introduction of those wastes in the future. Cores of tuff were cut from unweathered rock and solutions of the radionuclides and mixtures of the nuclides were allowed to pass through the cores. Alpha, beta, and gamma activity were measured. When activity of the effluent indicated breakthrough of the nuclide, autoradiographs were made to determine distribution of the radionuclide within the core. Tuff local to Los Alamos has shown a high capacity for retention of various nuclides. Cs 137 is apparently tightly bound to the tuff and resists leaching. $\mathrm{Pu} 239$ is also readily retained, however, it is possible that this nuclide could be released at some future time by inadvertent discharge of solutions such as versene in the same area. $\mathrm{Sr} 90$ is not retained as well and disposal of this radionuclide should be undertaken with extreme caution. (ORNL-72-21)

Christenson, C. W. and P. G. Thomas. 1962. Movement of Plutonium Through Los Alamos Tuff. TID-7628, Part of Second Ground Disposal of Radioactive Wastes Conference Atomic Energy of Canada Limited Chalk River, Canada, September 26-29, 1961. p. 248-281.

Uncontrolled and uncontained ground disposal of plutonium can be dangerous under field conditions. Plutonium species penetrate at least 28 feet in Los Alamos tuff. Moisture data, rates of flow of liquid and physical 
inspection indicated that this penetration takes place along fissures. The amount of activity sorbed at any one point in depth is dependent upon the chemical and physical nature of the substructure in that area. High percentages of clays, deposited by local weathering, will sorb plutonium species and result in a localized area of high alpha activity. As the species percolates through the soil, changes in valence state may also occur with changes in chemical environment; sorption or even solution may result. (ORNL-72-21)

Cline, J. F. 1967. Uptake of Americium 241 and Plutonium 239 by Plants. BNWL-714:8.24-8.25.

Concentrations of Am 241 were 20-30 times greater than those of Pu 239 in plant tissues grown on substances containing equal anounts of radioisotopes. Americium was more toxic than plutonium to growing roots. It was bound tightly to soil particles but showed some movement with irrigation water, especially in basic soils. (auth)

Corey, J. C. and A. L. Moni. 1975. Removal of Plutonium from Drinking Water by Community Water Treatment Facilities. IAEA-SM-199/81.

Plutonium removal factors (RF) averaged $14 \pm 10$ during a study of the effectiveness of three drinking-water treatment plants for removing plutonium from Savannah River water. Plutonium concentrations between 0.1 and $3.5 \mathrm{fCi} /]^{\star \star}$ were measured in raw and finixhed water samples. From 50 to 10,000 liter samples of water were concentrated by ion exchange techniques and processes to determine the concentrations of plutonium-239, 240 and to derive plutonium RF's. The similarity between RF's observed for both plutonium and suspended solids suggests a colloidal behavior for plutonium. Plutonium RF's may be limited by low-level buildup on the treatment facility filters and subsequent bleeding into finished water, and thus may be higher during abnormal plutonium releases to the environment. Flocculation and filtration appear to be the primary factors in the water treatment process contributing to plutonium removal. The similarity between the plutonium contents of finished water from treatment facilities upstream and downstream of the Savannah River Plant (SRP) indicates that there is no measurable dose-to-man from SRP plutonium releases in the water. The 70-year bone dose commitment to an individual for consumption for one year of 1.65 liters per day of treated Savannah River water, based on the plutonium concentrations of finished water from the three trrntment. facilities is $5 \times 10^{-5} \mathrm{mrem}$.

Crawley, D. T. 1969. Plutonium-Americium Soil Penetration at 234-5 Building Crib Sites. ARH-1278. 
Plutonium-americium carried in a slightly acid, high salt waste had penetrated to a depth of 18 feet in the Z-lA tile field, the limit of sampling. Plutonium-americium contained in neutralized low salt waste routed to the $Z-12$ crib had penetrated the soil to a minor extent, based on sampling to 16 feet. At each disposal site, some concentration of the plutoniumamericium was noted at the top layer of soil. (auth)

Dall'Aglio, M. 1971. Study of the Circulation of Uranium in the Supergene Environment in the Italian Alpine Range. Geochim. et Cosmochim. Acta. 35:47-59.

Geochemical prospecting surveys for uranium, carried out in the metamorphic basement of the Italian Alpine Range, detected marked anomalies both in alluvia and waters in the Martello Valley (Trentino Region, Northern Italy). Detailed surveys showed that no uranium occurrences or deposits outcrop in the vicinity of the geochemical anomalies. A detailed study was therefore made in order to determine the causes of these anomalies. Analysis of uranium were made on fresh water, rock, stream sediment and soil samples. The water samples were also analyzed for all the major as well as for some trace elements. Leaching tests on rock samples provided additional information with a view to understanding better the dissolution of uranium with respect to the major elements. The results of these studies emphasize some characteristics of uranium in the supergene environment. Uranium, particularly that contained as uraninite in the pegmatites, is the element which passes most readily into the natural waters, where it may reach anomalous values, even starting from rocks with a normal content. Part of the uranium dissolved in fresh waters is precipitated by the organic matter of soils and stream sediments. The percentage of the uranium precipitated is not high, but it is sufficient to raise the uranium content of the alluvia to significant anomalous values. These processes, in the particular environment of the explored region, explain the anomalous values found in waters and alluvia, starting from rocks whose uranium contents average slightly more than the clarke value (approximately $5 \mathrm{ppm}$ ). (auth)

Dall'Aglio, M. and E. Casentini. 1970. Distribution of Uranium Between Precipitates and Brines in the Solar Salt Plant of Margherita Di Savoia. Geochemical and Geological Considerations. Boll. Soc. Geol. Ital. $89: 475-84$.

The behavior of uranium during the solar salt production process was studied. The research was conducted at one of the world's largest solar salt plants-located at Margherita di Savoia, Foggia--producing 600,000 tons of sodium chloride per year. The uranium content was determined in the brines, in the gypsum, and the sodium chloride precipitates. The results obtained 
show that uranium is concentrated in the final bitterns, the contents of which exceeds 30 micrograms per liter. The contents of uranium in the gypsum and sodium chloride are very low, i.e., from 0.1 to $0.001 \mathrm{ppm}$. The acid insoluble residues of salts show a higher uranium content, that is in the order of ppm. The geochemical and geological significance of the results obtained is also discussed. (auth)

Davydov, A. V., I. N. Marov and P. N. Palei. 1966. Adsorption Du Protactinium Pentavalent Su Le Silicagol En S-lutions Acides. IN: PhysicoChemie Du Protactinium. No. 154. Collogues Internationaux DuCentre National De La Recherche. Scientifque, pp. 196-207.

The adsorption of $231 \mathrm{~Pa}$ and $233 \mathrm{~Pa}$ by silicagel from acid solutions of protactinium has been studied. From $1-10 \mathrm{M} \mathrm{HNO} 3$ and from $1-6 \mathrm{M} \mathrm{HClO} 4$ solutions, 90 percent adsorption takes place, independently of acid concentration. The distribution coefficient is 3,440. Adsorption from hydrochloric and from sulphuric acid media decreases when acidity increases. Aulsorption follows a Freundlich isotherm and the silicagel capacity in $6 \mathrm{M} \mathrm{HNO}_{3}$ is $0.11 \mathrm{milligramm-atom}$ of $\mathrm{Pa}$ per gramme of silicagel. Desorption may be achieved with solutions of complexing agents, both organic (oxalic, critic, tartaric acids) and inorganic $\left(\mathrm{H}_{3} \mathrm{PO}_{4}, \mathrm{H}_{2} \mathrm{O}_{2}\right)$.

Selective adsorption of protactinium from $6 \mathrm{M} \mathrm{HNO}_{3}$ solution has been utilized for the separation of $233 \mathrm{~Pa}$ from neutron irradiated thorium.

The formula and the formation constants of some protactinium complexes are derived from distribution data on the adsorption of $233 \mathrm{~Pa}$ by silicagel from acid solutions containing $\mathrm{HCl},\left(\mathrm{HN}_{4}\right)_{2} \mathrm{SO}_{4}, \mathrm{H}_{2} \mathrm{C}_{2} \mathrm{O}_{4}$, and $\left(\mathrm{NH}_{4}\right)_{2} \mathrm{HOP}_{4}$.

Dementev, V. S. and N. G. Syromyatnikov. 1965. On the Occurrencc Form of Thorium Isotopes in Ground Waters. Gcokhimiya. No. 2:211-18 (in Russian).

Concentrations and occurrence forms of the thorium isotopes, ${ }^{234} \mathrm{Th},{ }^{228} \mathrm{Th}$, and 232 Th were studied in some types of ground waters of Kazakhstan. The highest thorium concentrations were noted in waters containing a large amount of suspended and colloidal particles and with a high cunlenl ur organic matters. With the aid of centrifugation and dialys is methods the distribution of thorium isotopes between the particles was established and found to differ by the degree of dispersion, from ionic to coarsely suspended. Differences in the behavior of isotopes with different halflives were noted and found to be apparently cumlecled with different conditions of accumulation in natural waters. With the aid of the ion exchange metiod a chiefly anionic character of sorption was established. It is suggested that the transportation of thorium isotopes into ground waters is realized both in a colloidal suspension form and as anionic complexes, probably with organic acids of soils. (auth) 
Desai, M. V. M. and A. K. Ganguly. 1970. Interaction of Trace Elements with Organic Constituents in the Marine Environment. B.A.R.C.-488, p. 102.

Includes pertinent chapters on interaction of a marine humic acid and a fulvic acid with thorium, uranium and plutonium.

Dorta, C. C. and E. Rona. 1971. Geochemistry of Uranium in the Cariaco Trench. Bull. Mar. Sci. 21:754-65.

Four core samples taken during a cruise (P6603) of the R/V Pilisbury from the Cariaco Trench off the coast of Venezuela, were analyzed for major, minor, and trace elements. Special attention was given to $T h, \mathrm{Pr}$, and $U$. A high concentration of $U(30 \mathrm{ppm})$ was associated with the organic reducing sediment; with a 5-fold decrease in $U$ in the oxidized clay layer. This change was dated to the last glaciation. No change in Th and $\mathrm{Pr}$ concentration was noted. (CA)

Duursma, E. K. and D. Eisma. 1973. Theoretical, Experimental and Field Studies Concerning Reactions of Radioisotopes with Sediments and Suspended Particles of the Sea. Part C: Applications to Field Studies. Netherlands Journal of Sea Research. 6(3):265-324.

With the help of a number of national institutes a cooperative study was made of the radionuclide sediment behavior of 59 characteristic marine sediments. The sediment samples were obtained from the sea floor of the three oceans, the Arctic Seas, the Baltic Sea, the North Sea, the Mediterranean, the Black Sea and the Red Sea. The radionuclides studied were ${ }^{90} \mathrm{Sr}$, ${ }^{137} \mathrm{Cs}$, $65 \mathrm{Zn}, 60 \mathrm{Co}, 95 \mathrm{Zr} / \mathrm{Nb}, 54 \mathrm{Mn},{ }^{59} \mathrm{Fe}, 106 \mathrm{Ru}, 147 \mathrm{Pm}$ and $144 \mathrm{Ce}$. On $7 \mathrm{y}$ wj th Mediterranean sediment the behaviour of $240 \mathrm{Pu},{ }^{45} \mathrm{Ca},{ }^{86} \mathrm{Rb}$ and $210 \mathrm{~Pb}$ was investigated.

The sediment composition has been investigated for clay minerals in different grain-size fractions, for median grain size and sorting, for specific surface, for exchange capacity, for nrganic matter, and for the extractability of the ions $\mathrm{Na}, \mathrm{K}, \mathrm{Ca}, \mathrm{Mg}$ and $\mathrm{Fe}$ with acetic acid. $\mathrm{NH}_{4}$-acetate, $0.1 \mathrm{~N} \mathrm{HCl}$, 20 percent $\mathrm{HCl}$, and concentrated $\mathrm{HCl}$. Each of the parameters of the sediment composition has been related to the distribution coefficient of sorption which characterizes the radionuclide sediment behaviour. The best relationships were found with the base-exchange capacities and the specific surface values of the sediments.

The results of these studies may be applied to description and prediction of the behaviour of varinus radionuclides in seawater sediment systems. Using these data together with knowledge on the hydrography and sedimentology of an area, it may be possible to predict some of the consequences of future waste-disposal practices in this area. 
Duursma, E. K., and M. G. Gross. 1971. Marine Sediments and Radioactivity. IN: Radioactivity in the Marine Environment. National Academy of Sciences, Washington, D. C. :147-160.

Sediments and sedimentary particles have a substantial capacity to remove radionuclides from seawater. The particles may be deposited on the ocean bottom or picked up by filter-feeding organisms that may concentrate the radionuclides and pass them into man's food supply.

Certain radionuclides are more strongly sorbed on sediment particles than others. Mineral-related reactions, each with a degree of specificity, appear to be controlled by chemical species of the radionculides and the physico-chemical conditions of the sediments and sedimentary particles. In some laboratory experiments, the amount of radionuclides taken up by sediments and sedimentary particles depends on the history of the sedimentwater system prior to the introduction of the radionculide; this makes it difficult to predict radionuclide behavior in sediment-laden water.

Radionuclides may move through the sediment after depositon. Among the processes by whihc radionculides move are diffusion through the interstitial water, movement with the interstitial water expelled from the sediment by compaction, and groundwater discharge through the sea bottom. Where sediment accumulation is sufficiently rapid, the radioactive particles may be covered by later sedimentary deposits before these relatively slow movements can move the nuclides through the sediment-water interface. On a large part of the continental shelf and on much of the deep-ocean bottom, rates of sediment accumulation are slow enough that diffusinn processes may be duminant.

Sediment particles and their associated radionuclides may be mixed or moved by burrowing ar.tivity of benthic organisms, near-bullull currents, wave action, turbidity currents, Inngshore currents, or by ice.

Sediments or sedimentary particles can remove radionuclides from seawater and deposit them on the sea bottom. Calculations have been given to indicate the effect of such applications of sediments, and criteria have been presented to guide the selection of materials to be used in such applications. (auth)

Duursma, E. K., and P. Parsi. 1974. Distribution Coefficients of Plutonium Betwenn Sediment and Sedwaler. IN: Activities of the International Laboratory of Marine Radioactivity. IAEA-1 $\overline{63}: 94-96$.

The authors using a ${ }^{237} \mathrm{Pu}$ as a tracer, conducted a series of experiments to determine the distribution coefficient of plutonium on to sediments under oxic and anoxic conditions. The plutonium was added in three different valence states; III, IV, and VI. All three valence states showed Kd values in order of $10^{4}$ for both anoxic and oxic conditions. The authors speculate - that Pu (IV) enters adsorption phenomenon, while Pu (III) and Pu (IV) may be precipitating in addition to active reactions. 
Edgington, D. N., J. J. Alberts, M. A. Wahlgren, T. 0. Karttunen and C. A. Reeve. 1975. Plutonium and Americium in Lake Michigan Sediments. IAEASM-199./47.

The vertical distributions of $239,240 \mathrm{Pu}, 238 \mathrm{Pu}$, and ${ }^{137} \mathrm{Cs}$ have been measured in sediment cores taken from Lake Michigan. Sections from a limited number of cores have been analyzed for $241_{A m}$. In addition, grab samples from ten locations in the southern basin of the lake have been analyzed for phase distribution of $239,240 \mathrm{pu}$ using a sequential extraction technique.

The results indicate that the $239,240 \mathrm{Pu},{ }^{238} \mathrm{Pu}$, and ${ }^{137} \mathrm{Cs}$ from weapons testing, and the $24 \mathrm{~T}_{A m}$ formed in situ are concentrated in the sediments. $A$ comparison of the total deposition of $239,240 \mathrm{Pu}$ and $137 \mathrm{Cs}$ indicates that 131 Cs may be valuable as a monitor for $239,240 \mathrm{pu}$ deposition in the sediments. values of the $238 \mathrm{Pu} / 239,240 \mathrm{Pu}$ ratio are in agreement with values reported in Lake Ontario sediments (and Lake Michigan plankton) and show little variation with depth. 241 Am data support the concept of in situ production with little preferential mobility after formation.

Studies of sedimentary phase distributions show that $239,240 \mathrm{Pu}$ is associated with hydrous oxide phases which are chemically stable under the prevailing conditions in the lake sediments Since Lake Michigan sediments remain aerobic, relatively little $239,240 \mathrm{pu}$ is available for chemical mobilization from the hydrous oxide or organic phases present in the sediments.

Emery, R. M., and T. R. Garland. 1974. The Ecological Behavior of Plutonium and Americium in a Freshwater Ecosystem: Phase II. Implications of Differences in Transuranic Isotopic Ratios, BNWL-1879.

The ecological behavior of $\mathrm{Pu}$ and $\mathrm{Am}$ in a freshwater processing waste pond has been studied since July 1973 to characterize the pond's 1 imnology and define the isotopic distributions in this ecosystem (Emery, et al. 1974). Results from this study show that that the history of transuranics discharged to the pond has created a complex combination of source terms and isotopic ratios. Since these source terms and chemical forms entering Llie pond have not been clearly defined, a material balance for Pu and $\mathrm{Am}$ in this ecosystem cannot be developed. Relatively large quantities of $U 238$ have been released to the pond, and these, along with unidentified levels of Th 232 and Th 228 create a problem of interpreting the ecological behavior of $\mathrm{Pu}$ and $\mathrm{Am}$ in this ecosystem. Ratios of Pu 238 to $\mathrm{Pu} 239,240$ found in the pond are much higher than those in the processing wastewaters released to the pond. Ratios of Pu 238 to Pu 239, 240 and Am 241 to Pu 239, 240 are signifricantly higher in the pond biota than in the sediments suggesting a common source of availability to the biota. This contention is supported by the rapid establishment of these ratios in goldfish (Carassius) which were experimentally introduced into the pond. Ratios of Am 241 to $\mathrm{Pu} 238$ in the pond biota are also significantly different from those of the sediments but to a lesser degree than ratios of $\mathrm{Pu} 238$ 
to $\mathrm{Pu} 239,240$ an Am 241 to $\mathrm{Pu} 239,240$. A wide range of particle sizes of $\mathrm{Pu} 238$ and $\mathrm{Pu} 239,240$ may exist in the pond sediments. The pond sediments, however, may not be the major source of "available" Pu and Am because results of this study suggest that sediments in a trench carrying the processing wastes to the pond may be the primary source. (auth)

Emery, R. M., D. C. Klopfer, T. R. Garland, and W. C. Weimer. 1975. Ecological Behavior of Plutonium and Americium in a Freshwater Pond. BNWLSA-5346, (CONF-750503-19). 38 p.

A Pu processing waste pond on the Hanford Reservation has been studied since mid-1973 to characterize the pond's limnology and determine the ecological behavior in this ecosystem. This shallow 14-acre pond has existed and received $\mathrm{Pu}$ processing wastes for about 30 years. During this period about $8.1 \mathrm{~kg}$ of $\mathrm{Pu}$ was reported to have been discharged into waste trenches leading to the pond. This ultra-eutrophic pond has a water inflow rate of $10 \mathrm{~m} / \mathrm{min}$. of which greater than 95 percent leaves the pond by percolation. Macrophytes (mainly Potamogeton), algae (mainly Cladophora), benthic invertebrates (mainly dipterna and odonate larvae, hemipternas, amphipods, and gastropods) and goldfish are the major biotic components of the system. Sediments are the principal reposjtory of $\mathrm{Pu}$ and Am having mean concentration for 238Pu, 239,240 Pu, and $241 \mathrm{Am}$ of 169,177 , and $81 \mathrm{pCi} / \mathrm{g}$ (dry), respectively. Mean ratios of isotopes in the sedimets are 0.85 for $238 \mathrm{Pu}$ to $239,240 \mathrm{Pu}, 0.61$ for $241_{\mathrm{Am}}$ to $238 \mathrm{Pu}$, and 0.49 for $241_{\mathrm{Am}}$ to $239,240 \mathrm{PU}$. Levels of $\mathrm{Pu}$ and $\mathrm{Am}$ in the interstitial water range from 0.5 to $13 \mathrm{pCi} / \mathrm{g}$ (dry weight of sediment) and exist mainly in cationic or nonionic forms. For $238 \mathrm{pu}$ in pond water the mean concentration is $0.007 \mathrm{pCi} / 1$, for $239,240 \mathrm{pu}$ it is $0.002 \mathrm{pCi} / 1$, and for $241_{\mathrm{Am}}$ it is $1.08 \mathrm{pCi} / 1$. Algal floc (decomposing algal material) is the major concentrator of $\mathrm{Pu}$ and $\mathrm{Am}$ in the pond having mean concentrations for $238 \mathrm{Pu}$ of $986 \mathrm{pCi} / \mathrm{g}$, for $239.240 \mathrm{pu}$ of $615 \mathrm{pCi} / \mathrm{g}$, and for 241 Am of $256 \mathrm{pCi} / \mathrm{g}$. Watercress (Rorippa) had $\mathrm{Pu}$ levels about equal to those of the sediments, while dragonfly larvae (Libellula) and snails (Lymnaea) along with watercress had Am levels approximating those of the sediments. The remaining biota had $\mathrm{Pu}$ and Am levels which were generally well below those of the sediments. Although goldfish remain in the pond longer than any of the other fauna, and feed most heavily on plant, algae, and organic debris, they concentrate relatively small amounts of $\mathrm{Pu}$ and Am (about 10 to $15 \mathrm{pCi} / \mathrm{g}$ ). In situ experiments indicate that goldfish reach an equilibrium level for $\mathrm{Pu}$ of about $15 \mathrm{pCi} / \mathrm{g}$ with in a few days of exposure to the pond, after which they may remain active in the pond for many months without further accumulation. The biological availability of 238Pu appeared to be greater than that of $239,240 \mathrm{Pu}$ since most of the pond organisms sampled accumulated more $238 \mathrm{pu}$ than $239,240 \mathrm{pu}$ on an activity basis. Ratios of $238 \mathrm{Pu}$ to $239,240 \mathrm{Pu}$, and $241_{\mathrm{Am}}$ to $239,240 \mathrm{Pu}$ are significantly higher in the pond biota than in the pond sediments. These results primarily indicate that transuranics are being made available and/or utilized by pond organisms in ratios which are not reflected by pond sediment concentrations. A common source of avajlable Pu and Am for pond biota is suggested by the rapid establishment of $238 \mathrm{Pu}$ to $239,240 \mathrm{Pu}$, and $241_{\mathrm{Am}}$ to $239,240 \mathrm{Pu}$ 
ratios in imported goldfish. Within 2 weeks after these fish had been introduced into the pond they had accumulated transuranic ratios which were similar to those of all other pond biota and dissimilar to those of the pond sediment. Ratios of $241 \mathrm{Am}$ to $238 \mathrm{Pu}$ in U-Pond biota are significantly different from those of the sediments but to a lesser degree than ratios of $238 \mathrm{Pu}$ to $239,240 \mathrm{pu}$ and $241 \mathrm{Am}$ to $239,240 \mathrm{Pu}$. (auth)

Emery, R. M., D. C. Klopfer, and W. C. Weimer. 1974. Ecological Behavior of Plutonium and Americium in a Freshwater Ecosystem. Phase I. Limnological Characterization and Isotopic Distribution. BNWL-1867. 82 p.

A Pu processing waste pond on the Hanford Reservation was studied since July 1973 to characterize the pond's limnology and determined the ecological distribution of $\mathrm{Pu}$ and $\mathrm{Am}$ in this ecosystem. This shallow 14-acre pond has existed and received processing wastes for about 30 years, having a possible total $\mathrm{Pu}$ input of $8.1 \mathrm{~kg}$. Limnological studies have characterized the pond as having a simple food web existing under ultra-eutrophic conditions, with physical circulation and mixing being primarily controlled by wind and secondarily by heated water entering the pond. This pond receives about $10 \mathrm{~m}^{3}$ of water per minute, of which at least 95 percent leaves via percolation through the desert-like soil. Macrophytes (mainly Potamogeton), algae (mainly Cladophora), benthic invertebrates (mainly dipteran and odonate larvae, hemipternas, amphipods, and gastropods) and goldfish are the major biotic components of this system. Sediments are the principal repository of $\mathrm{Pu}$ and $\mathrm{Am}$, containing about $390 \mathrm{pCi}$ of

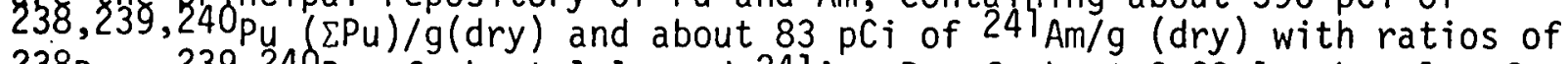
238Pu: $239,240 \mathrm{Pu}$ of about $1: 1$, and $241 \mathrm{Am}: \Sigma \mathrm{Pu}$ of about $0.23: 1$. Levels of these transuranics in the pond, water are much lower having concentrations of SP of about $0.01 \mathrm{pCi} / 1$ and $241 \mathrm{Am}$ of about $1.1 \mathrm{pCi} / 1$, with ratios of $238 \mathrm{Pu}: 239,240 \mathrm{Pu}$ of about $3.5: 1$ and $241 \mathrm{Am}: \Sigma \mathrm{Pu}$ of about 120:1. In the biota the prinicpal concentrator of $\mathrm{Pu}$ an $\mathrm{Am}$ is decomposing algal material (designated as algal floc, and rich in microorganisms) with levels of $\Sigma \mathrm{Pu}$ of abot $2 \mathrm{nCi} / \mathrm{g}$ (dry) and $24 \mathrm{I}_{\mathrm{Am}}$ of about $250 \mathrm{pCi} / \mathrm{g}$ (dry). This material serves as a major energy source for most of the pond fauna. In spite of the relatively high levels present in the sediments and major food source most of the biola have accumulated relatively lower levels of $\mathrm{Pu}$ and $\mathrm{Am}$. Qn 1 y an ephmeral growth of watercress (Rorippa) exceeds both $\Sigma \mathrm{Pu}$ and $241 \mathrm{Am}$ levels in the sediments. However watercress, dragonfly larvae (Libellula), and the snail Lymnaea had higher 241 Am concentrations than that of the sediments. Levels of these transuranics in other aquatic flora and fauna are also reported which range from 0.5 to $154 \mathrm{pCi}$ of $\Sigma \mathrm{Pu} / \mathrm{g}$ and 0.3 to $50 \mathrm{pC} i$ of $241 \mathrm{Am} / \mathrm{g}$. Ratios of $238 \mathrm{Pu}: 239,240 \mathrm{Pu}$ in biota were generally higher than that of the sediments (i.e., $>1: 1$ ), bug lower than that of pond water (i.e., <3.5:1). The same was true for ratios of $241_{\mathrm{Am}: \Sigma \mathrm{Pu}}$ in biota as most organisms had ratios exceeding $0.23: 1$ (with maximum of $2: 1$ ), but not approaching that of pond water (120:1). Also discussed are concentrations 
factors for pond biota with respect to various expressions of biological availability. Depending upon assumptions made for availability the CF values for any organism may range by many orders of magnitude. (auth)

Erametsa, 0., K. J. Lounamaa, and M. Haukka. 1969. Vertical Distribution of Uranium in Finnish Peat Bogs. Suom. Kemistilehti B. 42:363-70.

$U$ has a rather high tendency to escape from the lithosphere into the hydrosphere. It is transported mainly in the form of the highly stable uranyl dicarbonate and tricarbonate complexes. Humic acids also form stable complexes with $U$. The capture and the distribution of $U$ from ground waters by solid humic acids was studied in 14 arbitrarily chosen peat bogs scattered in different parts of Finland. The uraniuli concentration generally peaks to a very sharp maximum at a level beginning $1 / 4$ from the bottom of the bog. In every other bog, at the depth mentioned, the $U$ content exceeded the detection 1 imit of $30 \mathrm{mg} / \mathrm{kg}$ in ash. The method of analys is was by. $x$-ray fluorescence, as developed, to detect imall amounts of substance. The Illdxlinum concentration was $1450 \mathrm{mg} \mathrm{U} / \mathrm{kg}$ in ash. The amount of $U$ was evenly distributed over the total bog area. In 1 bog the distribution of $\mathrm{Pb}$ and $\mathrm{Ni}$ was compared with the distribution of $\mathrm{U}$. (CA)

Ermolaev, N. P., A. P. Zhidikora, and V. A. Zarinski. 1965. On the Silicate Form of Uranium Transport in Aqueous Solutions. Geokhimiya No. 7: 813-26. (in Russian).

One of the transportation forms of uranium under certain natural conditions in the silicate aqueous solutions appears to be a hydroxyuransilicate compound with the approximate formula $\left(\mathrm{UO}_{2} \mathrm{OH}\right)\left(\mathrm{HSiO}_{3}\right)$. The hydrosilicate complex ion is considered as a group that is stabilizing hydroxyuran in a solution or the former as the addendum of a weak complex. The size of these particles (in solution) is between that of colloid and ionic particles. The established form of uranium migration in solution exists in the nearneutral and weak basic range of $\mathrm{pH}$ and temperatures till $200^{\circ} \mathrm{C}$, the concentrations of strong electrolytes in a solution being relatively low (i.e., not higher than the equilibrium concentration wi th uranyl or silicate.) The silicate form of uranium transport in carbonate aqueous solutions is destroyed and uranium forms a complex with carbonate. (auth)

Essington, E. H., R. O. Gilbert, L. L. Eherhardt, and E. B. Fowler. 1975. Plutonium, Americium and Uranium Concentrations in Nevada Test Site Soil Profiles. IAEA-SM-199/76.

Many soil profile samples were collected by the Nevada Applied Ecology Group from five nuclear safety test sites on the Nevada lest Site and Tonopah Test Range in Nevada, U.S.A. The profile samples were analyzed for plutonium, americium, and in some cases uranium in order to estimate 
the depth of radionuclide penetration and level of contamination at specfic sampling depths after an extended period of time since deposition on the surface. Nearly 70 individual profiles were examined. About onehalf of the profiles exhibited a smooth leaching pattern with more than 95 percent of the plutonium in the top $5 \mathrm{~cm}$. Other profile patterns are discussed relative to 1) mechanical disturbance of the profile after the initial deposition, 2) accumulation of plutonium in specific zones within the soil profile, and 3) occurrence of large amounts of plutonium in the deepest parts of the soil profile. The implications of these observations are discussed with respect to redistribution of radioactivity by wind, water, and burrowing animals, ingestion by burrowing and grazing animals, uptake by vegetation, and cleanup operations. (auth)

Fenimore, J. W. 1964. Land Burial of Solid Radioactive Waste During a 10-Year Period. Health Physics 10:229-236.

Since the initial land burial of solid radioactive waste in 1953 at the Savannah River Plant, 577,000 c of fission products and induced radioactivity has been buried. Routine surveillance of thirteen test and observation wells has indicated no migration of radioactive material. Geologic and hydrologic studies, radioassays of soil samples, and measurements of groundwater velocity using tritium as a tracer, indicate little possibility of introducing this buried radioactivity into public zones. Maximum movement detected by radioassay of soil was $2 \mathrm{ft}$, with one exception. (auth)

Fischer, R. P. and J. H. Stewart. 1961. Copper, Vanadium, and Uranium Deposits in Sandstone - Their Distribution and Geochemical Cycles. Econ. Geol. 56:509-20.

Deposits of copper, vanadium, and uranium in nonmarine sandstones are numerous and widespread. Copper deposits, with or without uranium, are mainly resident in first-generation arkosic sandstones derived from granitic rock terrains; deposits rich in vanadium, with or without much uranium, are dominantly in second-generation sandstones derived from sedimentary rocks; and the uranium deposits with little or no varladiulii or - copper are in either first- or second-generation sandstones, many of which are associated with beds containing volcanic debris. All three metals are dispersed in igneous rocks but not in close association. Copper and uranium enter the hydrothermal environment, but the record of vanadium in hydrothermal solutions and veins is scant. Some of the uranium and most of the copper minerals in igneous rocks and veins oxidize readily and the metals go into surface- and ground-water solutions, but the vanadium in igneous rocks is not so easily mobilized--under normal geologic conditions, conceivably it may require diagenetic reactions and a second period of weathering to solubilize much vanadium. All three 
metals precipitate from solutions in the presence of a reducing agent, such as carbonaceous material or associated sulfide ions, either in sediments as they accumulate or in existing rocks. These geochemical habits permit the concept that copper and uranium are made available by weathering of igneous rock terrains and hence might accumulate in first-generation sediments, whereas vanadium would be commonly available only after a second period of weathering. Perhaps the oxidation or devitrification of volcanic debris may contribute uranium to ground waters as does the weathering of igneous rocks. (auth)

Fowler, E. B., and E. H. Essington. 1974. Soils Element Activities, October 1972 - September 1973. IN: Dunaway, P. B., and M. G. White (eds.). The Dynamics of Plutonium in Desert Environments. NVO-142 (NVO-AEIC-74-1 or UC-2):7-16.

This report presents a general review of the Soils Element Activities for the year October, 1972 - September, 1973. Areas declassified, areas sampled, and analytical results for plutonium 239, 240, and americium 241 are briefly discussed. Changes found in the ratio of Pu 239-240 to Am 241 , as well as the implications of the changing ratio are presented. It is suggested that the observed increasing ratio with depth of soil profile may be related to "differential solubility" of the two radionuclides, and that with passing time, Am 241 may become the radionuclide of prime concern. A modified analytical method for plutonium in soils, the LASLHASL leach method, is discussed. (auth)

Fowlcr, 5. W. and M. Heyhaud. 1974. Accumulation and Retention of ${ }^{241} \mathrm{Am}$ in Marine Plankton. IN: Activities of the International Laboratory of Marine Radioartivity. Report. IAEA-163, pp. 28-32.

$\mathrm{Am}^{+3}$ probably rapidly lost from seawater ( $\mathrm{pH} 8.3$ ), 17 percent remains at four days, 50 percent remains at one day, and 80 percent remains at two hours. Particulate 40 percent after 24 hours drops to 20 percent at four days possibly sorbed on walls. Algal cells sorp readily, brine shrimp lose accumulated very rapidly as strongly bound and surface adsorption (stayed on molted shell).

Francis, C. W. 1973. Plutonium Mobility in Soil and Uptake in Plant.s: A Review. Juurn. Environ. Quality, 2:67-70.

A survey of the published literature pertaining to the movement of plutonium in soil and uptake in plants reveals that a major portion of the investigations pertain to soils developed under arid or semiarid climates. In some instances subsoil samples were used to describe plutonium adsorption characteristics and often short-term greenhouse experiments were used to predict plant uptake. Some recent long-term greenhouse studies indicate a substantially greater plant uptake of plutonium from a higher contami- 
nated soil after 5 years of cropping as compared to the first year. It appears the most likely mode of plutonium entry into food chains leading to man would be that chelated with naturally occurring organic soil

components. Chelation mechanisms have not been established. (auth)

Frederickson, A. F. 1948. Some Mechanisms for the Fixation of Uranium in Certain Sediments. Science. 108:184-5.

A new theory for the concentration of uranium in the sedimentary crust of the earth is given. It is suggested that large $\mathrm{U}^{t^{+}}$ions are formed and that these, adsorbed between graphite layers of carbonaceous material, may form a strong structure. The uranium may be in the form of adsorbed ions and not of discrete minerals, due to base exchange on clays and other layer-lattice minerals. The conclusion is that if the source containing uranium is weathered to clays with a high base exchange capacity, these clays show a high radioactivity. Support for the theory is given by the fact that kaolinite, which has almost no base exchange capacity, has negligible radioactivity. Several samples are compared supporting the theory. (NSA)

Fried, S. M., A. M. Friedman, and L. H. Fuchs. 1973. Retention of Actinide Elements on Soils and Rock in the Natural Environment. ANL-7996. pp. 6-7.

Investigations included elution of $\mathrm{Pu}$ from crushed sedimentary rock at neutral $\mathrm{pH}$, adsorption of $\mathrm{Pu}$ by rock and effects of varying $\mathrm{pH}$ on limestone, shale and sandstone. All absorb Pu strongly with elution of about $1 / 10^{5}$ column volumes. Increased elution occurs with limestone and sandstone if influent is $\mathrm{CO}_{2}$-saturated. About 30 percent $\mathrm{Pu}$ is removed from shale by eight column volumes of $0.5 \mathrm{M} \mathrm{HCl}$ and 20 percent more with eight column volumes of $4.0 \mathrm{~m} \mathrm{HCl}$.

Fried, S. M., A. M. Friedman, and L. A. Quarterman. 1974. Annual Report on Project AN0115A, Fiscal Year 1974. ANL-8115.

Three types of measurements relating to the migration of actinide elements in the lithosphere have been performed. These were studies of surfaceabsorption coefficients, migration coefficients, and transport along the surfaces of fissures. A computer analys is of the fissure experiments indicates that all these phenomena are related and can be understood in terms of surface absorption.

In addition, it has been found that at least two migratory forms of plutonium are present. (auth) 
Fried, S., A. M. Friedman and R. Weeber. 1974. Studies of the Behavior of Plutonium and Americium in the Lithosphere. ANL-8096. pp. 10-11.

Rates of migration of radionuclides from buried wastes will be largely determined by the rate of flow of water through the burial site. The authors proposed to measure the soil and rock ion exchange characteristics from planned disposal sites. Prototype experiments used a pressure apparatus to obtain a flow of contaminated solution through a rock plug of Niagara limestone. 238pu adsorption coefficients were obtained as a function of $\mathrm{NaCl}, \mathrm{CaCl}_{2}, \mathrm{LaCl}_{3}$ and $\mathrm{ZrCl}_{4}$ molarities. (auth)

Fukai, R., and C. N. Murray. 1974. Adsorption and Desorption of Plutonium and Americium in Freshwater - Sediment. and Seawater - Sediment Systems. IN: Activities of the International Lahnratonry nf Marine Radioactivity. IAEA-i63.96-103.

The particulate and soluble fractions of added $\mathrm{Pu} 237$ (III, IV, VI) and Alll 241 (III) to filtered sea waters at various $\mathrm{pH}$ values, and adsorption and desorption of $\mathrm{Pu}$ (III and IV) and Am (III) by sediments and sewage effluents were studied.

The particulate formation is shown to be dependent upon the nature of solution and the $\mathrm{pH}$. The particulate fractions of all species increased with the increase in $\mathrm{pH}$. For river water at $\mathrm{pH} 4$, some 25,20 , and 30 percent of the added $\mathrm{Pu} 237$ were associated with particulate $(>0.45 \mu)$ for the III, IV, and $V$ valence states, respectively. However, there does not seem to be any particulate for motion for river water at $\mathrm{pH}$ values $<4.5$. The percentage of particulate formation was $>60$ at $\mathrm{pH} 8$ for all species, except $\mathrm{Pu}(V I)$.

More than 80 percent of the plutonium was adsorbed by sediment suspensions when added as $\mathrm{Pu}$ (III) in $\mathrm{pH}$ range 3 to 11 and $\mathrm{PU}$ (IV) at $\mathrm{pH} \sim 8$. Adsorm ption of Am (III) was highly pH dependent. There was hardly any adsorption of Am (III) below pH 6.5 and more than 80 percent at pH 8 . The desorption of $\mathrm{Pu}$ (III and IV) was less than 10 percent in 3-10 pH range, while the desorption of Am (III) showed $\mathrm{pH}$ dependence. The addition of sewage effluent to sediment suspensions increased the adsorption of $\mathrm{Pu}$ (III) by about 10 percent at $\mathrm{pH} 8.1$.

Fukai, R., C. N. Murray, G. Statham, and K. Asari. 1974. Radionuclide Measurements of Water. Sediment.s, and. Binta, Collected from the Ligurian Sea: Pu 239 240, Sr 90, and Co 137. IN: Activities of the International Laboratory of Marine Radioactivity. I IAEA-163:134-138.

The authors reported $\mathrm{Pu} 239,240$ values for surface water ( $5 \mathrm{~m}$ depth) of 0.5 to $2.8 \times 10^{-15} \mathrm{Ci} / \mathrm{Kg}$, which are similar to values reported for Pacific and Atlantic ocean waters The $\mathrm{Pu} 239,240$ content of the sediments ranged from 0.3 to $4.2 \times 10^{-12} \mathrm{Ci} / \mathrm{kg}$. In general, the plutonium concentration decreased with the increase in particle size. 
Gabelman, J. W. 1971. Sedimentology and Uranium Prospecting. Sediment. Geol. 6:145-86.

The world's principal economic uranium resources occur in continental sandstones or conglomerates often associated with preferred sedimentary structures. These relations have long been recognized and used empirically in exploration. Although the genesis of the uranium and the controls over its fixation are still debated, the epigenetic nature of deposits in sandstone is now generally accepted, and the argument has shifted to whether it is intrinsic or extrinsic to its present environment. In reducing oxygen-poor magmas and pegmatitic or hypothermal fluids, uranium enters into complex, refractory multiple oxides. It is more easily leached from volcanic glasses, but is not commonly available from any syngenetic source without corrosive alteration. Once liberated, uranium oxidizes readily and is mobile in the surficial environment. Reducing conditions in shallow, cool environments will stabilize uranium. It also may be stabilized in oxidized form by complexing with $P, V$, or As, or by loss of water in arid climates. Upon rock destruction, unaltered refractory minerals commonly remain intact to form placers. Liberated uranium is oxidized and dispersed in the fluid medium. It is extracted chiefly by ionic substitution or absorption in marine phosphates, and by adsorption on organic matter in carbonaceous shales. Both processes prevail everywhere during sedimentation of these uniform rocks, and uranium remains dispersed. It is rarely mobilized from these rocks because the chemical reducing environment remains so widespread. For economic deposits uranium must be concentrated from a mobilized dispersed state or introduced in concentrations. Epigenetic uranium migrates in fluid media through permeability systems that govern the quantity delivered to a precipitation site. Concentrations developed only where permeable rocks offered a precipitation mechanism. Altered rock matrices of most districts suggest that mineralizing fluids pervaded large blocks of ground, but formed deposits only in a few selected stratigraphic units under optimum combinations of permeability, host rock precipitants, and structures with interrupted permeability which allow the precipitants time to act. The most favorable structures are paleostream channels, intraformational unconformities of sandstone lenses in mudstone (or vice versa), and crossbeds. The sedimentary environment of each major productive formation in the United states is discussed, ranging from Triassic to late Tertiary. In each stratum only a small portion of the area of regionally similar sedimentational environment is mineralized. Only a few of the similar widespread sedimentary structures contain uranium, with no apparent differences between productive and barren examples. A common denominator of uranium districts within favorable host units appears to be the similarity in their tectonic position. (auth)

General Electric Company, Rucky Flats Division, Golden, C0. 1970. AEC Study Tends to Confirm Nonhazardous Plutonium Levels Near Rocky Flats. Nucleonics Week:11:1a-1b. 
Nucleonics Week reports from the contamination area near Rocky Flats: Reporting on a several-month sampling study of Colorado soil up to 40 miles east and north of the AEC Rocky Flats plutonium plant operated by Dow Chemical Co., AEC's Health and Safety Laboratory (HASL) in New York City estimates the presence of $2.6 \mathrm{Ci}$ of $\mathrm{Pu} 239$ in an irregularly shaped area totaling some 43 square miles. HASL found that the likely source of the $\mathrm{Pu} 239$ was contaminated oil that spilled from leaky barrels in storage at Rocky Flats between the mid-1960s (when the leakage was discovered) and 1968 (when something was done about it); during periods of high wind the radioactive material became airborne. HASL took soil samples as far as 40 miles north and east (prevailing wind direction) of the plant. HASL found more plutonium in the area than previous investigatorssbecause HASL went up to $20 \mathrm{~cm}$ into the soil. However, HASL found no plutonium deeper than $13 \mathrm{~cm}$. (auth)

Goldsztein, M. and J. Ros. 1963. On the Uranium Content of Sediments of the Western Basin of the Mediterranean. Bull. Inst. Oceanog. $19 \mathrm{p}$. (in French).

The $U$ content of the sediments of the Mediterranean sea was studied. Three hundred samples were analyzed from the French Continental Shelf, from the Balearic Continental Shelf, and from the Abyssal Plain. The average $U$ content is $2.3 \mathrm{ppm}$. In the sediments of the Continental Shelves, $60 \%$ of the $U$ is leachable with $2 N$ nitric acid; while this figure is $36 \%$ in the sediments of the Abyssal Plain. (auth)

Grebenslichikuvd, V. I., Y. P. Uavydov, and A. S. Pershin. 1971. The Adsorption of Plutonium (+4) on a Precipitate of Barium Sulfate. Soviet Radiochemistry. 13:457-459.

Mechanisms relating to the adsorption of plutonium (IV) on a barium sulfate precipitate at various solution pHs, electrical potential and time are evaluated. (auth)

Gromov, V. V. and V. 1. Spitsyn. 1974. Influence of Photoplankton on the Physicochemical State of $239 \mathrm{Pu}, 106 \mathrm{Ru},{ }^{99} \mathrm{TC}$ and ${ }^{60} \mathrm{Co}$ in Sea Water. Trans1. Dok1. Akad. Nauk SSSK. 215:2:451-453.

The change in the physiochemical state of $239 \mathrm{Pu}, 106 \mathrm{Ru},{ }^{99} \mathrm{Tc}$, and ${ }^{60} \mathrm{Co}$ due to their assimilation by phytoplankton was investigated. It was round thal biological assimilation by phytoplankton is decisively important in the stabilization of physicochemical forms of these radioisotopes, as a result of which the state of $\mathrm{Pu}, \mathrm{Ru}, \mathrm{Tc}$, and $\mathrm{Co}$ in the marine environment is altered, which in turn leads to variation in the entrapment of these elements by bottom sediment and, evidently, by suspended matter. (NSA) 
Gruzdev, B. I. 1971. Combined Analysis of Some Components of a Biogeocoenosis During a Study of the Migration of Radioactive Elements. Metody Radioekol. Issled. pp. 54-8 (in Russian).

Investigation of $U$ and $R a$ migration in a system plant-mineral showed that $\mathrm{Ra}$ was accumulated by all experimental plants more readily than $U$. Combined analysis of plants and their mineral substratum indicated that the bjological accumulation coefficient for uranium was $0.02-6.8$, increasing in the sequence mosses < foliaceous lichens < fruticose lichens < shrubs $<$ trees. Corresponding values for Ra were higher, the highest accumulation being found in mountain ash and Korean rhododendron. (CA)

Gruzdev, B. I. and D. M. Rubtsov. 1972. Accumulation of Thorium, Uranium and Radium by Plants and Organogeneous Horizons of Soils. IN: Radioekologichoeskie Issledovaniya v Prirodnykh Bigeotsenozakh. I. $\mathrm{N}$. Verkhovskava (ed.). Izdatelistvc Nauka, Moscow, USSR. pp. 112-123.

The accumulation and distribution of thorium, uranium, and radium in plants of the taiga zone was studied in relation to the content of radioelements in the soil. Only radium is accumulated by plants in substantial quantities, its biological accumulation coefficients as a rule exceeding 1.0. It was found that the European mountain ash (Scorbus aucuparia L.) is possessed a selective capacity of radium absorption, expressed in its high absolute content (up to $n$. 10(E-8)\%) and characterized by a significant (up to 100) accumulation coefficient. Uranium and thorium accumulation coefficients are as a rule lower than 1 , decreasing to 0.09 to 0.01 with a considerable increase of thorium in the soil. The study of the distribution of radioelements in plants showed that the greatest quantities of these elements concentrate in the older organis and tissues (bark, branches, wood) and the least in young ones (leaves, inflorescences). It is shown that radium, uranium, and thorium are elements with an acropetal distribution. The accumulation of thorium in forest litters follows the same trend as in the vegetative cover, that is no enrichment of the humus horizon with thorium is observed at a high content of this element in the soil. (auth)

Habashi, F. 1962. Correlation Between the Uranium Content of Marine Phosphates and Other Rock Constituents. Econ. Geol. 57:1081-4.

Sulfate and uranium appear to be genetically related in phosphorites. From the analysis of seven samples of sedimentary phosphates of different nrigin, it was found that the uranium content increases with decreasing sulfate content. This is attributed to the formation of sulfate complexes of uranium during sedimentation processes. The increase of uranium content with increasing $\mathrm{P}_{2} \mathrm{U}_{5}$ content previously reported in the literature was verified. A sample of magmatic phosphate was found not to behave in a manner similar to the sedimentary phosphate. (auth) 
Haglund, D. S. 1968. The Distribution of Uranium in Recent Carbonate Sediments and Skeletons of Organisms and the Effect of Diagenes is on Uranium Redistribution. Rensselaer Polytechnic Institute. Thesis.

A study of the uranium concentrations of calcium carbonate skeletons from recent molluscs, corals, algae, hydrozoans, and a barnacle and unconsolidated skeletal sands was undertaken to establish relations between environmental, mineralogical, and taxonomic control of uranium uptake. In addition, two suites of carbonate sediments each composed of recent unconsolidated marine beach sands and consolidated Pleistocene limestones were examined to establish the effect of fresh water alteration on the uranium content.

Analytical work included uranium analyses by the fission track powder method and quantitative mineralogy by $X$ pay diffration techniques. Environmental designations of the samples are made of the bas is of geomorphology.

The mean uranium content of all samples is $1.08 \mathrm{ppm}$, which is approximately half of the uranium clarke of limestones. The difference is due to the influence of low uranium molluscs and the exclusion of non-rarbonate held uranium. Tlie urantum concentration ranges of each environmental exhibit broad overlap between the environments. Gross sample uranium content is not judged to be a reliable environmental indicator. Corals contain an average uranium content of $2.96 \mathrm{ppm}$ and aragonitic marine molluscan shells contain an average of $0.15 \mathrm{ppm}$. A taxonomic effect on uranium uptake exists for the corals and the molluscs containing all or some calcite are among those molluscs with the lowest uranium content.

The uranium content of the fresh water samples shows a biomodal distribution. One mode contains pure aragonite molluscs with less lhan .02 ppm uranium, the other contains pure calcite samples with grealer than .05 ppm uranium. The Calcite samples include oncolites, algal reef sands, and inorganic precipitates. The distinction between the uranium concentration modes is related to the ability of molluscs to discriminate against uranium incorporation in their shells.

The mean uranium concentration per environment of all recent molluscs appears to be related to the salinity of the environment although broad overlap exists for all environments. The uranium concentration of samples from cores of the marine environment indicate the uranium concentration of the skeletal sands is constant while the samples are in contact with marine water. The uranium content of cure samples truil fresh water environment decreases with depth in core and is related to increasing crystallinity of the calcite grains.

Uranium concentrations of the recent and Pleistocene carbonate sediments from Bermuda and the Mediterranean Coast of Israel are compared to accepted indicators of fresh water alteration. Aragonite and uranium contents of 
the beach sands show a trend with high positive correlation, an effect of the coral content of the sands. An inverse relation exists between the uranium and $\mathrm{Mg}$-calcite content of the beach sands. As the fresh water metastable aragonite and Mg-calcite are removed from the sediment system and the sample type changes from unconsolidated beach sand to consolidated limestone there is a concomitant decrease in uranium content. The uranium and calcite concentrations show an inverse relation and indicate the product of fresh water alteration, calcite, rejects uranium. The uranium-stable carbon and oxygen isotope relations for the Bermuda suite are inconclusive, whereas the same plots for the Israeli Coast suite show a direct relation between decreasing uranium content and increasingly negative delta values. The relations of uranium and accepted fresh water alteration indicators provide converging lines of evidence indicating that fresh water dissolution and replacement of marine carbonate sediments causes a reduction, up to 50 percent over the Pleistocene period, in total sample uranium content. (auth)

Haglund, D. S., G. M. Friedman, and D. S. Miller. 1969. The Effect of Freshwater on the Redistribution of Uranium in Carbonate Sediments. J. Sediment. Petrol. 39:1283-96.

The uranium concentration of two independent carbonate sediment sample suites was studied to establish the effect of fresh water alteration on the redistribution of uranium. Recent carbonate sands and their ancient analogs were studied in Bermuda and along the east coast of the Mediterranean Sea in Israel. The results of the uranium analyses are compared to established indicators of fresh water alteration in carbonate sediments. Interpretation of the data from both areas yields the same conclusions. As the metastable minerals aragonite and $\mathrm{Mg}-\mathrm{calcite}$ are removed by fresh water from the sediment system and the sample type changes from unconsolidated carbonate sand to consolidated limestone there is a concomitant decrease in uranium content. The uranium and calcite concentrations show an inverse relation and indicate that the product of fresh water alteration, calcite, accepts less uranium than the original aragonite. The relationship between uranium and the stable carbon and oxygen isotopes for the Bermuda suite is inconclusive, whereas the same plots for the Israeli Coast suite show a direct relationship between decreasing uranium content and increasingly negative delta values: The relations between uranium and established indicators of fresh water alteration provide converging lines of evidence indicating that fresh water dissolution and replacement of marine carbonates cause a reduction, up to 50 percent over the Pleistocene samples, in total sample uranium content. (auth)

Hajek, B. F. 1966. Plutonium and Americium Mobility in Soils. BNWl-CC-925. Laboratory scale diffusion and leaching experiments show that only a small amount of plutonium from surface soil material in the $216-2-9$ crib is mobile. About 0.1 percent of the plutonium can be leached by invading groundwater; 
however, the leach rate is slow and plutonium migration, after being leached into lower soil layers, is about $10^{4}$ times less than the transporting solution velocity. Movement by diffusion will be negligible in a ten half-life period. (auth)

Hajek, B. F. and K. C. Knoll. 1966. Disposal Characteristics of Plutonium and Americium in a High Salt Acid Waste. BNWL-CC-649.

This study confirmed that adsorption of plutonium and americium on soil material from the surface to groundwater was minor from AAW waste and showed that soil neutralization of complexing agents would not satisfactorily improve adsorption. Gelling in soil pores could be induced by partial neutralization; however, permeability was lost. Precipitation by neutralization effectively scavenged both plutonium and americium in a waste containing only saturation amounts of organic and produced a supernate with improved soil adsorption characteristics. (auth)

Haji-Vassiliou, A. 1969. The Association of Uranium with Naturally Occurring Organic Materials in the Colorado Plateau and Other Areas. Thesis. Columbia Unvicraity.

Urano-organic associations may be divided into various types mainly on the basis of their geological mode of occurrence. In order to understand the nature of these associations more fully, the following problems have been considered: the origin or source of the associated organic matter; the form of occurrence of the associated uranium; and the probable mechanisms responsible for their formation. Most of the types of associations studied here represent occurrences in the Colorado Plateau area. Selected localities include the sandstone-type deposits at Temple Mountain, Utah and at Ambrosia Lake, New Mexico; the uraniferous carbonaceous shale near Gallup, New Mexico; and the urano-organic matter in sulfides and altered volcanic rocks at La Bajada, New Mexico. The non-Plateau occurrences are also included: The uraniferous lignite of South Dakota, and the thucholite of the Rand conglomerates of South Africa. The two basically different sources of organic matter in rocks and sediments are terrestrial plant derivatives (or coal) and petroleum derivatives. Geological evidence indicates that both petroleum and plant derivatives have contributed to the formation of the Temple Mountain ore. Similar evidence shows that plant derivatives constitute the most probable source for the organic fractions in the uranoorganic deposits at Ambrosia Lake and Callup, and, certainly, in the uraniferous lignitr. The mode of occurrence uf the ore at La Bajada suggests petroleum as the source. The source for the thucholite is not clearly differentiated in terms of geological evidence alone. Physical properties did not decisively relate the origin of the impregnated organic matter to either of the two basic sources, but furnished certain suggestions. These suggestions became definite indications upon consideration of refractive indices and chemical-structural data obtained mainly through organic elemental analysis, infrared spectroscopy, and vacuum differential thermal 
analysis. A final consideration of both geological and physio-chemical evidence indicates plant derivatives as a major source for the organic components in all but one of the deposits. Petroleum is indicated as the main source for the organic fractions in the La Bajada deposit, as well as a major source (along with coal) for the Temple Mountain ore. Microscopic and $X$-ray data show the presence of primary uranium minerals (uraninite or coffinite) in the urano-organic ores at Temple Mountain and Ambrosia Lake, and in the thucholite. No uranium minerals were identified in the La Bajada ore or in the uraniferous organic shale. Only secondary uranium minerals have been found in the highly uraniferous lignite. The relationship of the uranium content to the ash content of mechanically fractionated portions of representative samples from each deposit indicates that most of the uranium in the urano-organic materials from Temple Mountain, Ambrosia Lake, and La Bajada is related to the mineral content of these materials; and most of the uranium content of the lignite and carbonaceous shale is closely associated with the organic components. Several investigators have demonstrated the capacity of organic matter to adsorb or reduce large amounts of uranium from uranium-bearing solutions. In terms of the evidence obtained on the nature of the urano-organic deposits, the accumulation and deposition of most of the uranium in the lignite, the carbonaceous shale, and the ore at Ambrosia Lake and La Bajada may be attributed to such a capacity for the organic components. The major mechanism of formation of the South African Thucholite and the ore at Temple Mountain seems to be the pseudomorphic replacement of pre-existing uraninite by activated organic matter. (NSA)

Hakonson, T. E. and L. J. Johnson. 1973. Distribution of Environmental Plutonium in the Trinity Site Ecosystem After 27 Years. Proceedings of the Third International Congress of the International Radiation Protection Association, pp. 242-247.

The results are presented for a radioecological survey of the Trinity Site environs, where the world's first (July 1945) atomic bomb was detonated. The temporal behavior of the low environmental levels of the plutonium produced by this detonation are discussed. The data from this study were compared with similar data obtained in the Trinity Site environs nearly 20 years ago. The major change which was observed was an increased migration of $\mathrm{Pu}$ into the soils. Concentrations of $\mathrm{Pu}$ in vegetation and rodents were too low to make valid comparisons. (auth)

Hakonson, T. E., L. J. Johnson and W. D. Purtymun. 1973. The Distribution of Plutunium in Liquid Waste Disposal Areas at Los Alamos. IN: Proceeding of the Third International Congress of the International Radiation Protection Assucialion, September 9-14, 1973, Washington, DC, pp. 248-253, CONF-730907-P1. 
This paper describes an ecological investigation of plutonium in the Los Alamos Scientific Laboratory environs. Data are presented on the distribution of plutonium in the alluvial sediments, water, vegetation and rodents from Mortandad Canyon, an area which has been used for liquid waste disposal for 10 years.

Hakonson, T. E., J. W. Nyhan and W. D. Purtymum. 1975. Accumulation and Transport of Soil Plutonium in Liquid Waste Discharge Areas at Los Alamos. IAEA-SM-199/99.

The soils component of terrestrial ecosystems appears to be the major reservoir of plutonium originating from both weapons and industrial sources. Data presently available indicate that transport of plutonium within the soils component and from soils to biotic components can occur by physical processes with biological and chemical processes playing a largely undefined role in the redistribution of this element. Relatively high concentrations of plutonium in native vegetation and in pelt and lung samples from small ground dwelling rodents are usually attributed to resuspension processes whereby the plutonium associated with the soil is redeposited on external surfaces or is inhaled.

The purpose of this study was to investigate the accumulation and transport of plutonium in the sediments of Mortandad Canyon in Los Alamos, New Mexico. This area has received plutonium in treated liquid effluents since 1963. Data are presented on the horizontal distribution of plutonium and total inventories in stream channel sediments for two sampling periods spanning a seven monthinterval in 1972 and 1973. Data were also gathered on the importance of storm runoff in the downstream transport of plutonium contaminated sediment. (auth)

Hale, V. Q. and A. Wallace. 1970. Effect of Chelates on Uptake of Some Heavy Metal Radionuclides from Soil by Bush Beans. Soil Science 109: 262-263.

DTPA has the ability to increase uptake by plants of several metals. In the present study DTPA increased uptake from Hacienda and Yolo loam soils of $\mathrm{Pb} 210$ and Am 241. There was a decreased effect in the 2nd and 3rd harvest.s relative to the first. It had to effect on uptake of Sb 125 or $\mathrm{Hg} 203$. EDDHA increased uptake of Sb 125 from Yolo loam, and of Am 241 from both soils. The effect of EDDHA did not persist in the soil as much as did that of DTPA, DTPA increased slightly the uptake of Cs 137. (auth)

Hansen, R. 0. and G. L. Huntington. 1969. Throium Movements in Morainal Soils of the High Sierra, California. Soil Science. 108:257-65. 
Thorium distributions in a sequence of morainal soils in Bench Valley, California, were determined by gamma spectrometry of profile samples. Concentrations of thorium ranged from $10.8 \mathrm{ppm}$ in a $\mathrm{B} 2 \mathrm{~h}$ horizon, to 24.0 ppm in a $B 2 i r$ horizon. The data indicated distinct thorium accumulation in horizons immediately underlying horizons of high organic content. A2 or B2ir horizons respectively contained higher thorium concentrations when overlain by $A 1$ or B2h horizons. Soil organic matter apparently complexed with thorium as well as with iron, although the leached iron accumulated visibly in horizons of $\mathrm{pH} 5.5$ or greater, whereas thorium distributions were more diffuse and apparently less affected by change in $\mathrm{pH}$. Radium was distributed ( 0.85 to $1.91 \mathrm{picograms} / \mathrm{g})$ more irregularly than was thorium reflecting the effects of the soil chemistry of $238 \mathrm{U},{ }^{234} \mathrm{U},{ }^{230} \mathrm{Th}$, as well as $226 \mathrm{Ra}$, with the passage of time. Radium distributions are explained in terms of uranium retention by organic matter, mobilization of 230 Th by organic matter, plant absorption of radium, and time. Potassium concentrations ranged from 1.9 to 4.8 percent, being generally higher in $A 2$ horizons than in Al horizons. (NSA)

Hanson, W. C. 1974. Behavior of Plutonium in the Environment. CONF-740115. pp. 64-71.

Data available on the behavior of $\mathrm{Pu}$ in the environment are reviewed. Once into the environment $\mathrm{Pu}$ is subject to a variety of factors that modify its behavior in terms of concentration and/or discrimination within ecosystem components. The contamination of large land areas within significant quantities of $\mathrm{Pu}$ in the past has usually been by controlled releases of treated radioactive wastes, as in the canyon ecosystems at Los Alamos; nuclear weapons tests, such as the Trinity Site in central New Mexico and the Nevada Test Site; or nonnuclear detonation of nuclear weapons, such as occurred at Palomares and Thule. Most of our knowledge of characteristic $\mathrm{Pu}$ behavior in the atmosphere has come from plutonium isotopes that were injected into the stratosphere as a result of atmospheric nuclear weapons tests. Another source resulted from the reentry and burnup of the SNAP-9A power generator during April 1964. Both of these major sources have been elosely studied and results indicated that the ratio of $239 \mathrm{pu}$ to $90 \mathrm{Sr}$ produced by nuclear weapons testing in the atmosphere essentially remained constant at about 2 percent. Such estimates showed that, of the $0.4 \mathrm{MCi}$ of $\mathrm{Pu}$ produced by nuclear weapons testing through 1962, more than 98 percent had been deposited by 1965. About $0.3 \mathrm{MC}$ i had been deposited as worldwide fallout, and the remaining $0.1 \mathrm{MC} i$ was locally deposited at the test sites. Latitudinal distribution was closely correlated with rainfall belts at 40 to $60^{\circ}$ north latitude and 30 to $50^{\circ}$ south latitude and 80 percent of the total deposition occurred in the Northern Hemisphere, where most of the $\mathrm{Pu}$ had been injected into the stratosphere. Plutonium 238 from weapons tests represented about 0.024 of the total plutonium in soils collected at various worldwide locations prior to the fallout from the SNAP-9A device, compared to a ratio of about 3 percent for $238 \mathrm{pu} / 239 \mathrm{Pu}$ which is characteristic of most nuclear weapons test debris. The SNAP-9A 238Pu had 
an entirely different distribution pattern, principally because of its injection into the Southern Hemisphere. Stratospheric inventories indicated that, by mid-1970, 95 percent of this debris was deposited on the earth's surface. Over 75 percent of it was in the Southern Hemisphere, compared to only 20 percent of the total weapons $238 \mathrm{pu}$ fallout that occurred in that hemisphere. Interception of atmospheric $\mathrm{Pu}$ by vegetation is one means of biological transport that has been shown to depend on local fallout phenomena and physiognomy of the vegetation. Plutonium concentration in trees of an eastern forest was reported to be 16 to 100 percent more than that on adjacent pastureland plants. And $\mathrm{Pu}$ deposition on lichen communities of the Thule, Greenland, arca was more efficient per centimeter of precipitation than deposition on lichen communities of northern Alaska. The uptake and transport of Pu by wild animals also occurs. So il Characteristics have an impurtant influence upon Pu movement. One of the most important and most controversial aspects of $\mathrm{Pu}$ in soils is the phenomenon of resuspension, defined by Langham as the ratio of the air concentration of plutonium (in micrograms of plutonium per cubic meter) to the surface deposition (in micrograms of plutonium per square meter) below the air mass. (NSA)

Hanson. W. C. 1975. Ecological Considerations of the Behavior of Plutonium in the Environment. Health Physics 28:529-537.

Radiological considerations of plutonium released to the environment are logicilly based upon an understanding of ecosystem structure and functions. Studies of $\mathrm{Pu}$ in the atmosphere, lithosphere, terrestrial ecosystem of the biosphere, and in the hydrosphere are reviewed. to evaluate areas for consideration of environmental consequences of nuclear wastes. Soil is the major reservoir of deposited $\mathrm{Pu}$ in most terrestrial ecosystems. Resuspension of $\mathrm{Pu}$ into the air mass above contaminated soil occurs over a highly variable range of $10^{-2}$ to $10^{-11} \mathrm{~m}^{-1}$, reflecting important effects of several physical and biological variablcs. Uptake by most natural plant species is of the order of 10-4 (acceptor/prccursor). npprcciable cxternal deposition of fu upon plants through resuspension is a complicating factor in interpretation of field data. Pu concentrations in smaller terrestrial mammals also emphasize the greater importance of physical processes rather than physiological or chemical proccsses in the movement of Pu through terrestrial ecosystems. Freshwater and marine investigations indicate that $\mathrm{Pu}$ is generally concentrated over ambient levels in water but with decreases of about a factor of ten at each trophic level of a food chain. An apparent change in availability of $\mathrm{Pu} 238$ is indicated by several studies and physical pror cesses that may account for this are discussed. (auth)

Hardy E. 1974. Depth Distributions of Global Fallout ${ }^{90} \mathrm{Sr},{ }^{137} \mathrm{Cs}$, and 239-240 Pu in Sandy Loam Soi1. HASL-286:I-2 to I-10.

The first of a series of depth Profile soil samples taken at an undisturbed site on Cape Cod have been analyzed for $90 \mathrm{Sr}$, 137 Cs, and 239-240 44 Cesium 137 shows the least tendency to migrate downward followed by $239-240 \mathrm{Pu}$ 
and $90 \mathrm{Sr}$, in that order. The objective of this experiment is to measure the depth distributions of these isotopes on a bi-annual basis to estimate rate of movement. (auth)

Hetherington, J. A., D. F. Jefferies, N. J. Mitchell, R. J. Pentreath and D. S. Woodhead. 1975. Environmental and Public Health Consequences of the Controlled Disposal of Transuranic Elements to the Marine Environment.

IAEA-SM-199/11.

Experience from the controlled disposal of liquid radioactive wastes from the nuclear power programme of the United Kingdom has shown that the only releases of transuranic elements of potential environmental significance occur following fuel reprocessing. In this context attention has been directed principally to plutonium because of its long half-life and high radiotoxicity, although the next most important transuranic element, americium, has also been studied.

The paper reviews the radiological significance of these radionuclides following discharge to the marine environment, in terms of both dose to man and to environmental resources. Both plutonium and americium are found in each of the three compartments, water, seabed sediment and biota, the highest concentrations being found in sediment, particularly the fine mud found in estuaries close to the Windscale outfall. Both elements have been detected in a range of biota including seaweeds, fish and shellfish. The public health significance of those biota which represent potential human exposure pathways has been evaluated and estimates of the dose rate to critical groups from current discharges have been made. In parallel studies attention has been focussed on the exposure of fish and shellfish stocks. The dose rates have been estimated by use of environmental data on contamination levels combined with simple dosimetry models, and the results and their significance are discussed. (auth)

Holland, H. D. and J. L. Kulp. 1954. The Mechanism of Removal of Ionium and Radium From the Oceans. Geochim. et Cosmochim. Acta. 5:214-24.

The adsorption and base exchange of Th and Ra on deep-sea red clay, globjgerina ooze, and green clay were investigated by use of $T^{228}$ and $\mathrm{Ra}^{224}$ as tracers. At equilibrium the fraction of radioactivity remaining in the sea-water solution is independent of the total quantity of tracer added. Extrapolation of the data to actual concentrations of Th and $\mathrm{Ra}$ in sea water indicates that the concentrations of these elements in sediments is comparable to that of these experiments. It is concluded that base exchange is the method by which Th and Ra are taken up by the sediments. (CA) 
Horrath, $\bar{E}$. 1960. Investigations of Uranium Adsorption to Peat in Natural Waters Containing U-Traces. Magyar Tudományos Akad. Atommag Kutato Intézete, Közlemenyek 2:177-83 (in Hungarian).

Adsorption tests were made with previously standardized peat samples in well waters of the vicinity of Debrecen, Komadi, and the Taktakoz region. The investigations revealed an average value of 2 to $3,5 \times 10^{2}$ for the equilibrium constant, the so-called "enrichment factor" of uranium adsorption by peat. (auth)

Imahashi, M. 1970. Uranium and Thorium in Hydrothermally Altered Rocks Under Acid Conditions. As Exemplified by Silicified Rocks From Tateyama Jigokudani, Toyama. Nippon Kagaku Zasshi. 91:668-9 (in Japanese).

Uranium and thorium content in hydrothermally-altered rocks from the Tateyama jigokudani hot spring area, Toyama, were determined in order to study the mobility of these elements under acid conditions. The leachabilities of these elements were calculated on the bas is of content. It was found that silica is not leachable during the alterations. The calculations demonstrated that $60 \%$ of the thorium as well as $50 \%$ of the uranium could be removed from original rocks. The mobilities of these elements under acid conditions are greater than those during weathering processes under neutral conditions. (auth)

Iskra, A. A., N. V. Kulikov, and U. G. Bakhurov. 1969. Behavior of Natural Radioactive Elements in Non-Rurning Freshwater Basin. A. Energ. (U.S.S.R). 27:134-7 (in Russian).

Experimental data are given on the distribution and accumulation of ${ }^{238} U$ and ${ }^{226}{ }_{R a}$ in model systems of a non-running freshwater basin: water; groundwater; groundwater plants; water plants. It was found that uranium accumulates in the biomass of plants (elodea and water milfoil), thorium-in detritus and ground (and sand), while radium is evenly distributed in the components of the water basin. Accumulation coefficients are given for the major components, which according to their accumulative ability form the following series: detritus > plants > ground. The coefficients reach their highest values (hundreds of thousands and several millions) in detritus. The intensity of accumulation of the elements by plants, detritus and ground may be represented by the series: thorium > radium > uranium. (auth)

Jacobson, L. and R. Overstreet. 1948. The Uptake by Plants of Plutonium and Some Products of Nuclear Fission Adsorbed on Soil Colloids. Soil Science. Soil Science. 65:129-34. 
Barley and pea plants have been found to take up the fission elements $Y$, $\mathrm{Ce}, \mathrm{Zr}+\mathrm{Cb}, \mathrm{Te}, \mathrm{Sr}$, and the three valence states of $\mathrm{Pu}$, even when these elements are present in trace amounts on the surfaces of clay or soil particles. For all the elements tested, the greatest fixation is in or on the roots. With the exception of Sr, translocation occurs only to a limited extent. The translocation of $\mathrm{Sr}$ is relatively large. Activity levels of 0.1 microcurie per gram soil are sufficient to cause very pronounced injury over a 3-month period. (auth)

Jakubick, A. T. 1975. Migration of Plutonium in Natural Soil. IAEA-DM199/3.

The present work deals with the deposition and migration of fallout plutonium which is considered here as analogous to $\mathrm{PuO}_{2}$ contamination of soil. By correlating the few Pu239,240 measurements available in Germany with the fallout data coming from Ispra the probable history of $\mathrm{Pu}$ concentration in the air is reconstructed for SW Germany. From these data, the Pu input function in the vicinity of Heidelberg is derived. The calculated cumulative deposition seems to agree well with the existing measurements of the total amount of $\mathrm{Pu}^{239,240}$ in the soil. For to find out the transport mechanism of $\mathrm{Pu}$ in soil, the estimations of Pu distribution in soil provided by HASL are interpreted. The removal of $\mathrm{PuO}_{2}$ particles from a given layer seems to obey an exponential law with a characteristic turnover time of 5-6 years in a $5 \mathrm{~cm}$ thick partially saturated soil layer.

Using the previously derived input function and the estimated turnover time, the probable Pu-concentration in the top soil in Germany was computed. Furthermore, the case of an instantaneous soil contamination is considered. It is shown that a model using a sequence of boxes leads to a Poison-type equation which predicts for $\mathrm{PuO}_{2}$ a migration velocity of $0.8 \mathrm{~cm}$ per year. Finally the relative migration velocities of $\mathrm{PuO}_{2}$ an $\mathrm{Pu}\left(\mathrm{NO}_{3}\right)_{4}$ are compared. The comparison indicates that the migration of $\mathrm{PuO}_{2}$ is about 100 times faster than that of plutonium when applied to soil in $\mathrm{Pu}\left(\mathrm{NO}_{3}\right)_{4}$ form. (auth)

Jayaram, K. M. V., K. K. Dwivedy, M. C. Bhurat, and S. G. Kulshrestha. 1974. A Study of the Influence of Microflora on the Genesis of Uranium Occurrences at Udaisagar, Udaipur District, Rajasthan. IAEA-SM-183/31. IN: Formation of Uranium Ore Deposits, pp. 89-98.

An area nf $6 \mathrm{~km}^{2}$ in the vicinity of Udaisagar shaft was investigated to study the role of sulphur and iron-oxidizing bacteria in the mobllizaliun of uranium in the carbonaceous phyllites and $i$ ts redeposition in breccias and the fault gouge. The Aravalli metasediments consisting of conglomerates, phyllites, impure limestones, carbonaceous phyllites and ferruginousbreccia are intruded by granites and gneisses. The general strike is: $\mathrm{N} 20^{\circ}-30^{\circ} \mathrm{W}-\mathrm{S} 20^{\circ}-30^{\circ} \mathrm{E}$ with an easterly dip of $60-85^{\circ}$. Uranium mineralization is confined to a fault gouge in a $6 \times 200 \mathrm{~m}$ zone, at a depth of $25-45 \mathrm{~m}$ 
from the surface. The ore contains stringers of uraninite associated with uranyl minerals and some iron and copper sulphides. It analyzes $0.7 \%$ $\mathrm{Fe} 0,2.31 \% \mathrm{Fe}_{2} \mathrm{O}_{3}, 6.3 \% \mathrm{C}, 2.97 \% \mathrm{So}_{4}^{-}, 0.85 \%$ moisture and $0.03-0.06 \% \mathrm{U}_{3} \mathrm{O}_{8}$ and has a bacterial population of $2.3 \times 10 \% \mathrm{~g}$ of dry solids. It has a pH of 2.2 to 4.5 and a redox potential of -360 to $-480 \mathrm{mV}$. The ore samples show disequilibrium in favor of uranium. Samples of the ore analyzing $0.03 \%$ and $0.06 \% \mathrm{U}_{3} \mathrm{O}_{8}$ yielded a leachability of $43.3 \%$ and $67.8 \%$ respectively at $60 \%$ P.D. (solids) in 6-h leaching time, using water alone. The carbonaceous phyllites in the immediate vicinity analyze $3.04 \% \mathrm{Fe} 0,2.96 \% \mathrm{Fe}_{2} \mathrm{O}_{3}, 11.2 \% \mathrm{C}$, $0.11 \% \mathrm{SO}_{4}^{2-}, 0.15 \%$ moisture and 0.0005 to $0.0027 \% \mathrm{U}_{3} \mathrm{O}_{8}$ with a $\mathrm{pH}$ of $7.0-8.5$ and a redox potential of -200 to $-280 \mathrm{mV}$. The occurrence of significantly higher radon values in the vicinity of the shaft $\left(35.5 \mathrm{pCi} / \mathrm{cm}^{3}\right)$, the shallow nature of the deposit, absence of any major channel for waterborne transportation as indicated by resistivity surveys, the presence of elemental sulpliur. soluhle sulphates and microflora in the ore samples and lhe high leachability of uranium in water alone show that uranium is mobilized from the carbonaceous phyllites and redeposited in the fault gouge. (auth)

Kanasiewicz, J. 1966. Geochemical nistribution of Unanium, Sclenium, and Khenium in the Zechstein Layer of Leszczyn Deposits. Kwart. Geo1. 10:13 (in Polish).

The highest concentrations of $U$, Se, and Re occur in the layers of low Zechstein, the average content of $U$ being 11.3, of Se 1.31, and Re $1.06 \mathrm{ppm}$. The sorption properties of silt favor retention in deposits all of the ele $=$. ments present in sea water, as testified by a.higher $U$ content in marls, $\sim 12.1 \mathrm{ppm}$ as compared to 1 imestone, $\sim 9.4 \mathrm{ppm}$. The layers of new red sandstone and medium and upper 7erhstein are markcdly lower in the cunlenll of these elements. (CA)

Kashirtseva, M. F. 1969. Effect of Material Composition of Rocks on Formation of Epigenetic Uranium Concentrations. Int. Geol. Rev. 11:530-8.

Analysis of the different forms of physical composition nf rocks of different $U$ content showed that accumulations of $U$ are confined to rocks of the pyritic geochemical type. The confinement of epigenetic pyrite and of accumulations of $U$ to the pyritic type of rocks is evidence that the oxidation processes and production of hydrogen sulfide by bacteria are conducive to precipitation of $U$, as they are responsible for the steep Eh threshold at the contact between oxidized and unoxidized rocks. In prospecting for $U$ or deposits of the infiltrational type, the physical composition of the host rocks should be considered, together with other indications, inasmuch as the rocks may be favorable or adverse to the formation of economic ores, by virtue of their inherent geochemical characteristics. Accumulations of various elements, particularly $U$, are favored by the presence of substantial quantities of easily oxidized minerals in the rock, particularly in rocks of the pyritic type in which 
the sulfide forms of iron should at least be about $0.3 \%$. The chloritesideritic type, in which these forms do not exceed $0.1 \%$ of the rock, by weight, and the iron minerals are not easily oxidizable, as a whole, is not as favorable for the accumulations. Rocks in which the iron is mainly clastic and the sulfides are negligible $(0.2$ to $0.3 \%)$ are unfavorable for accumulations of such elements as $\mathrm{U}$, Se, Mo, Pb, Fe, and others. Ore deposits of the type described are rare in nature because only in rare circumstances are all the factors essential for their development simultaneously operative. Among these factors, the physically favorable composition of the host rocks is the indispensable prerequisite. (auth)

Katsurayama, K. 1968. Accumulation of Radioactivity in Rice Fields. Annu. Rep. Res. Reactor Inst., Kyoto University. 1:293-97.

The adsorption capacity of the following radioactive isotopes in the soil is discussed: Li, $\mathrm{Na}, \mathrm{K}, \mathrm{Rb}, \mathrm{Mg}, \mathrm{Cs}, \mathrm{Ca}, \mathrm{Co}, \mathrm{Ba}, \mathrm{Sr}, \mathrm{H}, \mathrm{La}$, and Th. Equations are given for coefficients of distribution and exchange. Ion exchange capacity of the soil is discussed. Estimation of radioactive concentration in the root zone of rice fields is based on the following phenomena: introduction of water into the rice field; percolation in the superficial soil of the rice field; disintegration of radioactive elements; and accumulation of radioactivity in cultivable soil. A method for estimating the quantity of radioactivity carried by irrigation water into the rice field in the course of a year is described. (NSA)

Kimura, Y., H. Morishuma, T. Koga; H. Kawai and Y. Honda. 1968. Studies on the Behavior and Distribution of Radioactive Substances in Coastal and Estuarine Waters. Kinki Daigaku Genshiryaku Kenkyusho Nonpo. 7:21-31 (in Japanese).

Low-level liquid radioactive wastes are continuously disposed of from fuel processing plants or radioisotope laboratories into coastal waters. For an estimation of the influence of these disposals on our environment, the variation of concentration of thorium and rare earth elements contained in coastal and estuarine waters was investigated with the tidal change. It was observed that the concentration of thorium and rare earth elements in coastal water varied widely with the tidal change. This seems to be not only due to simple dilution by the water mass but also to the various physicochemical conditions such as salinity, pH or water, wind, and tidal motion. Since thorium and rare earth elements are apt to be colloidal or particulate in seawater, this character is greatly different from the case of soluble elements. (auth)

Knoll, K. C. 1965. Reaction of High Salt Aqueous Plus Organic Waste With Soi1. BNWL-CC-313. 
Soil has considerable capacity for this high salt, acidic waste containing organic compounds and can imbibe it almost as readily as water. These data, obtained from column measurements in the laboratory, would be less favorable than those obtained in the field as the moisture cannot spread horizontally in a column. Uptake of plutonium by the soil was very minor and of amercium negligible.

Knol1, K. C. 1969. Reactions of Organic Wastes in Soils. BNWL-860.

The passage of certain organic wastes from a radionuclide separations plants has little effect on the permeability of the soil for later passage of a high salt aqueous waste, or on the ion exchange properties of the suil. Soil removed $\mathrm{Pu} 23 \dot{9}$ and Am 241 slowly from some of the organics and not at all from others. Radionuclides were leached from soils most noticeably by two of the wastes. One was a mixture of $0.4 \mathrm{M}$ bis (2-ethylhexyl) ester of phosphoric acid and $0.2 M$ tributyl phosphate in paraffin hydrocarbons (C10 to $\mathrm{Cl1}$ ); the other was hydroxyacetic acid. Both of these removed Sr 85 and Am 241 and to a lesser extent Pu 239. (auth)

Kochenov, A. V. and G. N. Baturin. 1967. The Distribution of Uranium in the Bottom Sediments of the Aral Sea. Okeanologiya. 7:623-7 (in Russian).

Chemical determination of $U$ in 178 sediment cores was made to determine its distribution over the bottom of the Aral Sea. The $U$ content is distinctly controlled by lithologic facial types and the organic matter content of the sediments. The $U$ maximum is found in the contral zones of the bays and lagoons rich in organic matter, reaching aboye $10^{-3} \%$ in some regions; most of the lake has a concentration between $10^{-4}$ and $5 \times 10^{-4} \%$. 0 ther higher deposits include argillaceous silts of the central lake and black argillaceous silt of western coastal indentations; only in the central lake docs the $\mathrm{C}_{\text {org }}$ fail to reach 3.1 to $3.5 \%$ as in the rest; there it is only $0.7 \%$. The balance of the sea was studied. The two rivers flowing into the lake, the Amu-Dar'ya and the Syr-Dar'ya, carry 387 tons/yr of U;

Kochenov, A. V. and G. N. Baturin. 1967. Uranium Distribution in Aral Sea Sediments. Oceanolọgy (U.S.S.R.). 7:481-7.

Sediment samples were taken by bott.nm grab in the pcriod August-0cluber 1965. Uranium was determined chemically by the pearl=luminescont method. Greal simflarlty was revealed on comparison of the areal distribution of uranium in the Aral Sea and a bottom sediment chart. The main types of sediment differ clearly in terms of their $U$ content. The least $U(0.0001$ to $0.0002 \%$ ) was noted in the sand and silty ooze of the coastal zone; $U$ content increased in the calcareous and argillaceous sediments of the central areas of the basin to $0.001 \%$. Similar high contents were noted in the argillaceous sediments of the northern bays and the semi-isolated 
bays of the eastern shore. At the junction between fresh river water and salt seawater, $U$ content was as low as throughout the coastal zone of sandy and silty 00zes, between 0.0001 and $0.0005 \%$. There is a distinct correlation between uranium content in Aral Sea sediments and organic matter. It appears that as much $U$ is annually supplied to the bottom sediments as is brought in by the rivers, i.e., part of the $U$ enters the basin in solution and passes into the sediment, as a result of which the latter is enriched to several times the level of the suspended matter of the river. This explains the increased abundance ratio of uranium in the sediments of the central areas of the Aral Sea. The distribution of $U$ in the water over the area of the sea is uneven and to some extent related to general salinity; $U$ content around the river mouths where the freshening effect of the rivers is felt is $(3$ to 3.5$) \times 10^{-5} \mathrm{~g} / 1 \mathrm{iter}$, whereas in the central areas of the sea it increases to $(5$ to 6$) \times 10^{-5} \mathrm{~g} / 1 \mathrm{iter}$. The relatively low extraction of $U$ into the sediment from Aral water is apparently to be explained by its high carbonate content and oxygen saturation, and by the low content of the organic component in the sediment. (NSA)

Koczy, F. F. 1949. Thorium in Sea Water and Marine Sediments. Geol. Foren. i Stockholm Forh. $71: 238-42$.

Experiments are described which show the precipitation of thorium in sea water. The adsorption of isotopes of radium and thorium on red clay, powdered maganous dioxide, and a powdered manganese nodule was determined. Radium adsorbed on all three powders, which is not the case with thorium. The thorium content of a few samples of marine sediments has been measured. They contain about $1 \times 10^{-7} \mathrm{~g} \mathrm{Th} / \mathrm{g}$. One manganese nodule investigated was found to hold as much as $1.3 \times 10^{-6} \mathrm{~g} \mathrm{Th} / \mathrm{g}$. The geochemistry of thorium and uranium in sea water is briefly discussed. An attempt is made to estimate the thorium content of sea water with the aid of the ratio Io: Th in the sedjments. The thorium content of sea water is calculated to be 1 to $10 \times 10^{-9} \mathrm{~g} \mathrm{Th} / 1$. (NSA)

Koczy, F. F., E. Tomic, and F. Hecht. 19b/. Geochemistry of Uranium in the Baltic Sea Basin. Geochim. et Cosmochim. Acta 11:86-102. (in German)

In order to study the geochemistry of $U$ on typical shelf zones, samples of river water and sea water, as well as samples of sediment from the Baltic Sea region, have been examined. The Baltic Sea region was chosen for the investigation since its hydrography is well? known, water transport to and from it can be estimated to a high degree of accuracy, and the regton can be well sampled. The $U$ content of river water originating in regions of igneous rocks is low, averaging $0.5 \times 10^{-6} \mathrm{~g} U / 1$. The $U$ content of rivers from sedimentary rock regions seems higher by a factor of two or more, the maximum value found being $12.8 \times 10^{-6} \mathrm{~g} \mathrm{U} / \mathrm{l}$. It may be concluded that the 
$U$ is more easily leached out from sedimentary regions. While the southern and eastern rivers supplying water to the Baltic Sea have not been investigated, it can be assumed that their $U$ content is high, especially since the sea area surrounding the mouths of these rivers exhibit high $U$ values. The $\mathrm{Ra}$ content of river water is not in equilibrium with the $U$, amounting to only 10 percent of the latter. It is thus concluded that $U$ is more soluble than $\mathrm{Ra}$. The $U$ content of water from the Baltic Sea is also variable ranging from 0.77 to $5.9 \times 10^{-6} \mathrm{~g} \mathrm{U} / 1$. High salinity inflowing water shows $1.8 \times 10^{-6} \mathrm{~g} \mathrm{U} / 1$, while that of outflowing water is less, averaging $0.9 \mathrm{x}$ $10^{-6} \mathrm{~g} \mathrm{U} / 1$. Except for the southeastern regions and deep water areas, a marked correlation of salinity and $U$ content exists. An increase of deep water $U$ content correlates with a surface water increase. Surface water increases can be explained by the high U content of inflowing river waters; high deep water values are correlated with an 0 deficiency. Here it may be assumed that the $U$ (VI) is reduced to $U$ (IV) forming insoluble complex compounds with organic material. This settles slowly to the bottom, and explains the rather high $U$ content of the sediment (values range between 3.2 and $10.3 \times 10^{-6} \mathrm{~g} \mathrm{U} / \mathrm{g}$; the normal content in clays is about $2 \times 10^{-6} \mathrm{~g}$ $\mathrm{U} / \mathrm{g})$. By an intense study of the distribution of $U$ in sediments, completed by age determination by aid of $\mathrm{Cl4}^{74}$, it may be possible to follow the changes in the past of the state of ventilation of the deep basins of the Baltic Sea. The attempt to work out a $U$ balance sheet for Baltic Sea $U$ demonstrates precipitation about equals that which is brought in by rivers. Influx totals 1100 to 1400 metric tons per year, efflux 700 to 1000 , leaving about 100 to 700 tons of precipitated material. The investigation carried out shows that a considerable quantity of $U$ is precipitated on the Baltic Sea shelf. It appears to be caused by biological activity in the sea which in turn causes an 0 deficiency. The process is slow. Rivers with a high $U$ content can raise the $U$ content of the sea water if they empty under conditions wherein the above factors are not fulfilled. On the other laand, in estuaries and bays into which $U$ bearing rivers do not flow, $U$ can be precipitated from sea water by a high brological activity, which is connected with 0 deficiency. Whan the minerogenous sedimentation is at the same time very small, the $U$ content of the sediment is enriched, amounting to $200 \times 10^{-6} \mathrm{~g} \mathrm{U} / \mathrm{g}$ and more. (auth)

Koide, M. and E. D. Goldberg. 1965. Uranium-234/Uranium-238 Ratios in Sea Water. Progr. Oceanogr. 3:173-7.

The importance of radioactive disequilibrium within the lid tural uranium238 series in various natural systems has steadily gained imporlance especially in geuchronological and geochemical studies. Russian workers have shown that the parent member, U-238, and the daughter, U-234, in groundwaters do not exist in radioactive equilibrium concentrations. It has been postulated that while $U-238$ exists in crustal rocks primarily 
in the +4 state, as a result of the radioactive decays producing the daughter U-234, electrons are lost from the nucleus such that a part of the U-234 ends up in the +6 state. The latter form is preferentially brought into solution by weathering waters due to the formation of the strong complexes formed between uranyl and carbonate ions. Thus, the activity ratio $A(U-234) / A(U-238)$ often exceeds one in surface waters. Experimentally determined values of the activity ratio in surface and deep sea waters from the Atlantic and Pacific Oceans and the Mediterranean Sea are uniform with a value of $1.14 \pm 0.014$. The error arises from the counting statistics in the radioactive assay of the alpha particles emitted by these two isotopes of uranium. This constancy in the ratio is consistent with the long residence time of uranium and relative lack of reactivity in sea waters. (auth)

Koliadin, L. B., D. S. Nikolaev, S. M. Grashchenko, Y. V. Kuznetzov, and K. F. Lazarev. 1960. States of Uranium Detected in Black Sea Waters. Doklady Akad. Nauk S.S.S.R. 132:915-17 (in Russian)

A carbonate complex of hexavalent uranium was found in a Black Sea layer between 0 to $2000 \mathrm{~m}$. The data indicate the physico-chemical impossibility of uranium precipitation by reduction to the tetravalent state in the Black Sea hydrogen sulfide zone. (NSA)

Kolodny, Y. 1969. Studies in Geochemistry of Uranium and Phosphorites. University of California. Thesis.

This dissertation is composed of three almost independent parts; the abstracts are therefore separate. Three experimental studies were performed to determine: the uranium isotopes in sea floor phosphorites; the uranium in an anoxic fjord; and the carbon and oxygen isotopes in apatite $\mathrm{CO}_{2}$. Analysess using $\alpha$-spectroscopy techniques of uranium concentration and $234 \mathrm{U} / 238 \mathrm{U}$ activity ratios were performed on 40 samples of marine phosphorites, almost all of them dredged from the sea floor. In each sample, the concentration and isotopic composition of total uranium and U(IV) were analyzed. Uranium concentrations in the analyzed nodules vary between 6 and 524 ppm, tetravalent uranium constituting $38-84 \%$ of the total. Whereas the mean activity ratio for total uranium is 0.97 , the ratio in the U(IV) uranium is 0.71 and the calculated activity ratio for U(VI) uranium is 1.57. This indicates that: all the analyzed nodules are old (probably older than $8 \times 10^{5}$ years), and are at the present being eroded rather than deposited and the difference in isotopic ratios between the two oxidation states of uranium generally cunfirms previously proposed mechanisms of uranium isotope fractionation. Differential oxidation of ${ }^{234} \mathrm{U}$ is largely responsible for the measured $234 \mathrm{U} / 238 \mathrm{U}$ disequilibrium ratios. A model for evolution of uranium isotope activity ratios in different oxidation states is presented. A fairly simple chemical fractionation technique was tested for separation of authigenic uranium from its detrital counterpart. $234 \mathrm{U} / 238 \mathrm{U}$ activity 
ratios can serve as an excellent indicator for testing the efficiency of such a technique. Uranium is effectively removed from sea water into anoxic sediments. This process is extremely fast compared to the rate of removal into deep sea sediments. Authigenic uranium is most.strongly correlated with organic carbon content of the sediments, probably because of the formation of organo-uranyl complexes. Analysis of interstitial waters can serve as an indicator for the chemical state of uranium in the solid phases. About half of the uranium in sediment from the center of Saanich Inlet is strongly bound (as a chemical complex) to organic matter. The other half is about evenly divided between detrital minerals, authigenic tetravalent uranium, and uranium adsorbed on organic matter. Analysis of stable carbon and oxygen isotopes has been applied to a solution of a mineralogical problem: elucidation of the relation of the carbonate ion to the apatite structure. Calcite was separated from coexisting apatite in pelletal phosphorites, phosphatized limestones and synthetically prepared apatites by dissolving calcite in triammonium citrate. Both calcite and apatite $\mathrm{CO}_{2}$ were then analyzed for carbon and oxygen isotopes. Carbon and oxygen in the $\mathrm{CO}_{2}$ assoclated with apatite are enriched in their light isotopes as compared to the coexisting calcites. This indicates that carbonate ion is a structural part of apatite, a conclusion which is in accord with other mineralogical studies. (NSA)

Kolodny, Y. and I. R. Kaplan. 1970. Deposition of Uranium in the Sediment and Interstitial Water of an Anoxic Fjord. CONF-700965-1.

The distribution of uranium in the sediments of Saanich Inlet was determined using chemical fractjonation methods to separate authigenic uranium from detrital uranium. $234 \mathrm{U} / 238 \mathrm{U}$ activity ratios were found to be good indicators for determining the efficiency of the separation. Uranium concentration in the sediment shnws a significant cnrichment relalive to deep sea sediment. Authigenic uranium correlates most strongly wilh the organic carbon content of the sediment, and is probably bound is urgano-urdany complexes. Approximately half the uranium in the sediment of the central fjord is organically complexed and the remainder is distributed among detrital minerals, authigenic tetravalent uranium and uranium adsorbed on organic matter. Uranium is highly enriched in interstitial water (both oxidizing and reducing waters with an Eh range of $+380 \mathrm{mV}$ to $-140 \mathrm{mV}$ ) relative to its concentration in normal seawater. Its concentration appears to depend on the oxidation state and the organic content of the sediment. Concentration of uranium by the sediments was found to be very efficient in this environmilul. The residence time of uranium in the water column was found to bo 3 or 4 orders of illagnitude less lhan estimated for the open ocean. (auth) 
Kovalev, V. A. 1965. Geochemical Aspects of the Th/U Ratio Investigation in Rocks Geokhimya. No. 9: 1171-3 (in Russian).

The Th/ $U$ ratio can be used to estimate the intensity of weathering processes. $U$ is more mobile than Th. Black schists and phosphorites show a low Th/U ratio (less than two). Littoral sands and alluvial deposits show a high $T h / U$ ratio (greater than 7 ). Most clay deposits show an intermediate $T h / U$ ratio of 2 to 7 . Leaching experiments with $3 \% \mathrm{HCl}$ on a $0.01 \mathrm{~mm}$ fraction of mineral showed that only $40 \%$ of the Th could be leached out while $70 \%$ of the $U$ was removed from the mineral. The Th accumulated in the heavier, accessory minerals, and was not leached out readily. (NSA)

Kovalevskii, A. L. 1967. Dependence of the Content of Some Trace Elements on the Clayiness of Soils. Mikroelem. Biosfere Ikh Primen. Sel. Khoz. Med. Sib. Dal'nego Vostoka, Dok1. Sib. Knof., 2nd. 1964. 0. V. Makew. Buryat. Khizhn. Izd.: Ulan-Ude, USSR.

The effect is studied of the clayiness of sod-meadowy noncultivated soils in the west Siberian lowlands (northern and central part) on the amount of total and available trace elements. Samples were taken from a depth of $0.3-3.0 \mathrm{~m}$. The results show for most of the elements an increase in clayey (fraction $<0.01 \mathrm{~mm}$ ) soil as compared with sandy soils, the ratio being 3.0-6.2 ( $\mathrm{B}, \mathrm{Ni}, \mathrm{Co}, U)$. The greatest difference was noted in the content of $\mathrm{Pm} \mathrm{Co}$, and org. C. Analysis of various fractions according to size showed that the clayey part (0.001-0.01 mm) contains $\mathrm{Li}, \mathrm{Zn}$, and $\mathrm{Ni}$ 25-50 times, $\mathrm{Mn}$ and $\mathrm{Co} 13-25, \mathrm{Sr}, \mathrm{Mg}, \mathrm{Fe}$ and $\mathrm{Ti} 7-13$, and $\mathrm{Ba}, \mathrm{Sn}, \mathrm{Al}$ and Cr 3-7 times as much as the sandy fraction $(0.05-0.25 \mathrm{~mm})$. Correlation between $\alpha$-activity and $\mathrm{Co}_{0}$ and $\mathrm{Ni}$ is demonstrated. Correlation between radioactivity and trace elements for the mapping of the concentration by aerogram and auto $\gamma$-photos is regarded as promising. (CA)

Krey, P. W. and E. P. Hardy, Jr. 1970. Plutonium in Soil Around the Rocky Flats Plant. Health and Safety Laboratory, USAEC. HASL-235, p. 44.

Soil samples were collected to a depth of $20 \mathrm{~cm}$ at 33 sites extending as far as 40 miles from the Dow Chemical Co.'s Rocky Flats plant in Colorado. Deposition concentrations of Pu-239 as high as $2000 \mathrm{mCi} / \mathrm{km}^{2}$ were found off the plant site but these high concentrations decreased rapidly with distance. The contamination pattern extends eastward from the plant in the direction of the resultant wind vector and has virtually no westward component. The pattern is incompatible with the wind direction on the day of the May 11, 1969 fire. Leaking barrels of plutonium laden cutting oil stored in the southeast corner of the plant are considered the likely source of the contaminant. 
Three $\mathrm{mCi} / \mathrm{km}^{2}$ of $\mathrm{Pu}-239$ is the lowest contour readily discernible in the contamination pattern and extends about $8 \mathrm{miles}$ east and southeast of the plant. The inventory of Rocky Flats Pu-239 within the $3 \mathrm{mCi} / \mathrm{km}^{2}$ contour but excluding AEC controlled land is $2.6 \mathrm{Ci}$. The extent of the Rocky Flats $\mathrm{Pu}-239$ beyond this contour is difficult to determine because the deposition of $\mathrm{Pu}-239$ from nuclear weapon tests fallout is not precisely known in the Denver area. Our best estimate of the cumulative fallout Pu-239 is 1.5 $\mathrm{mCi} / \mathrm{km}^{2}$ based upon a 1965 soil sample from nearby Derby, Colorado. The most distant sites at 40 miles to the east and north of the plant show a slightly higher value of $2.0 \mathrm{mCi} / \mathrm{km}^{2}$. The intervening sites average 2.4 $\mathrm{mCi} / \mathrm{km}^{2}$. If the extreme and unlikely assumption is made that the entire area lying 40 miles to the east and north of the plant is contaminated

Krylov, A. Y. and M. M. Shats. 1950, Some Regularities of Uranium Migration in Waters of Northwestern Districts of USSR. AEC-tr-4474:319-32.

Data on the uranium contents of some water bodies in northwestern USSR are presented. The factors influencing uranium transfer into and precipitation from water are discussed at length and applied to a few examples. Precipitation of uranium is shown tn ns.rur mostly through the action ot iron hydroxide and humic compounds. (NSA)

Kubose, D.A., M. G. Lai, H. A. Goya, and H.I. Cordova, 1968. Radioactivity Release from Radionuclide Power Sources. VIIa. Dissolution Studies of, Plutonium Dioxide in the Ocean, 5 months' Exposure. USNRDL-TR-68-74.

Post-oceàn-exposure examinations have been made on plutonium dioxide microspheres recovered after a 5-month exposure on the bottom at a depth of 50 feet off San Clemente Island. These examinations established that approximately 70 percent of the microspheres became encrusted with marine growth. Determination of the distribution of the microspheres and adsorbed activity in the ocean-bottom material was made in addition to post exposure laboratory dissolution measurements, microscopic examination and $x$-ray diffraction measurements. (auth)

Kuznetsov, Y. V. 1969. On Occurrenre Fnrms of Ionium ( ${ }^{230}$ Th) and Thorium (232Th) in the Ocean. Geokhimiya. No. 2:177-84 (in Russian).

Collected data indicate that ${ }^{230} \mathrm{Th}$ and $232 \mathrm{Th}$ are present in different forms not only in oceanic waler's but also in other components of the oceanic system, in oceanic sediments and suspensions. It is assumed that most of the ionium in the ocean exists in hydrolytic forms which are sorbed on suspesion particles while thorium is carried into oceans from continents in the composition of residual minerals. Significance of this conclusion x. in relation to the geochronology of oceanic sediments and the geochemistry of thorium in the ocean is considered. (auth) 
Kuznetsov, Y. V., V. K. Legin, A. P. Lisitsyn, and Z. H. Simonyak. 1964. Radioactive Ocean Suspensions. I. Isotopes of Thorium in Ocean Suspensions. Radiokhimiya. 6:242-54 (in Russian).

Samples of ocean suspensions were taken at numerous places in the Indian ocean. The concentrations of ionium and thorium in the various types of suspensions were determined. The relationships between these elements and the principal other components as well as the granulometric size of the suspension particles were determined. Since the relationships of the two elements were found to be very different, it was concluded that ionium and thorium are in very different forms in the suspensions. A close relationship was established between the ionium content in the suspension and the total phosphorus, iron, organic, and calcium carbonate contents. No relationship was detectable between ionium and amorphous silicon or magnesium carbonate or between thorium and iron, organic, calcium carbonate, or amorphous silicon. The data obtained indicated the possibility of determining the rate of sedimentation from the Io/Th ratio. The ionium and thorium contents in the water of the Caspian and Baltic seas and in muds of the Indian Ocean are shown for comparison. (NSA)

Kuznetsov, Y. V., V. K. Legin, A. P. Lisitsyn, and Z. N. Simonyak. 1967. Radioactivity of Oceanic Suspensions. II. Uranium in Oceanic Suspensions. Radiokhimiya. 9:489-97 (in Russian).

Data are given on the concentration of uranium in oceanic suspensions. The fraction of $U$ in the ocean water, coordinated with the suspensions, was evaluated. The relation between uranium concentration in suspensions and concentration of basic components of the granulometric and chemical states of the suspension was investigated. The direct correlation dependence between $\mathrm{CaCO}_{3}$ concentration and uranium in the suspension was established. (auth)

Kuznetsov, Y. V., Z, N. Simonyak, A. P. Lisitsyn, and M. S. Frenklikh. 1968. Thorium Isotopes $(230 \mathrm{Th}, 232 \mathrm{Th})$ in the Surface Layer of the Indian Occan Sediments. Geochem. Int. 5:169-77.

It has been demonstrated that the content of ionium $\left({ }^{230} \mathrm{Th}\right)$ in the surface layer of oceanic sediments depends on the depth of water, effective surface area of the sedimentary particles, and on the rate of sedimentation. ${ }^{230}$ Th is co-precipitated with the hydroxides and phosphates of $\mathrm{Fe}$ and $\mathrm{Mn}$, while $232 \mathrm{Th}$ is contained in the sedimentary detrital particles. (auth)

Kuznetsov, Y. V., Z. N. Simonyak, A. P. Lisitsyn, and M. S. Frenklikh. 1968. Uranium and Radium in the Surface Layer of Oceanic Sediments. Geokhimiya. No. 3:323-33 (in Russian). 
Data on uranium and thorium concentration in the surface layer of the Indian 0cean bottom sediments are given. Peculiarities of uranium and radium distribution over the ocean floor were investigated. Paragenetic associations of uranium and thorium with components of the chemical and granulometric composition of bottom sediments were studied. Bonds between uranium and organic carbon and phosphorus were established which provides evidence in favor of the existence of a certain mechanism of uranium withdrawal from ocean water. The presence of radium directly precipitated from oceanic water was proved. (auth)

Lambet, M. S. and D. S. Nikolaev. 1962. The Mode of Uranium Occurrence in the Waters of the Azov Sea and in a number of estuaries and rivers of the Azov-Black Sea Basin. Doklady Akad. Nauk SSSR. 142:681-2 (in Russian).

It had been shown previously that uranium exists in ocean water as a stable carbonate complex. However, there are no data on the state of uranium in river water. Hence, samples of river water were filtered at a pressure of 10 to $12 \mathrm{~atm}$ through a cellophane membrane having a pore size of about $1 \mathrm{m \mu}$. The uranium content was determined by a luminescence method, and the $\mathrm{pH}$ was taken potentiometrically. All measurements were taken immediately after sampling. The results show that uranium passed through the filter and exists in ionic form in the water as a carbonate complex. The possibility of the existence of a uranium organic complex with humic acid in a number of the samples is not excluded. The uranium content of the water increases with an increase in the salt content of the water. (NSA)

Lauderdale, R. A. 1951. Treatment of Radioactive Water by Phosphate Precipitation. Industrial and Engineering Chemistry 43:15.38-1540.

The work was done to check the effectiveness of a ralsium phosphate floc in removing radiuisotopes from large quantities of water.

In almost every case the phosphate was found to be more efficient than either alum or ferric hydroxide. Maximum removals were obtained under conditions of high $\mathrm{pH}$ and in the presence of an excess of phosphate. In general, good removals were obtained for those isotopes which would be precipitated under the same conditions if they were present in macro quantities.

While the data must be considered preliminary in nature, they indicate that coagulation and filtration techniques, if performed under the proper conditions, can be applied to treat liquid wastes containing low levels of radioactivity. The total reduction obtained in the activity of the waste will be dependent on the radioisotopes present.

Lazarev, K. F., D. S. Nikolaev, and S. M. Grashchenko. 1961. Concentration of Thorium Isotopes in Sea Water. Radiokhimiya. 3:623-35 (in Russian) 
A method was developed for concentrating thorium in large volumes of natural water (200 to 5001 1) using iron hydroxide precipitation at low temperature. The contents of thorium and ionium in the Black Sea are $(2.2 \pm 0.2) x$ $19^{-9}$ and $(2.5 \pm 1.0) \times 10^{-13} \mathrm{~g} / 1$, respectively. The content of thorium decreases from the coastal area to the open sea. Moreover, the thorium content decreases much faster than the ionium because larger quantities of $\mathrm{Th}^{232}$ are found in coarse terrigeneous suspension, while ionium occurs in fine colloidal suspensions that do not settle as easily to the bottom and are carried farther into the open basin. (NSA)

Legin, V. K., Y. V. Kuznetsov and K. F. Lazarev. 1966. Uranium Occurrence in Marine Sediments. Geokhimiya No. 5:606-8 (in Russian).

The total $U$ and mobile $U$ contents were determined in samples taken from the $\mathrm{H}_{2} \mathrm{~S}$-contaminated zone of the Black Sea, from the coastal zone of the Black Sea not contaminated with $\mathrm{H}_{2} \mathrm{~S}$, and from the central part of the Azov Sea. The mobility of $U$ was determined by leaching the samples with $0.7 \mathrm{NaHCO}_{3}$ and $3 \mathrm{~N} \mathrm{HCl}+3 \mathrm{~N} \mathrm{H}_{2} \mathrm{SO}_{4}$. The mobility of $\mathrm{U}$ in contemporary sediments from the Black Sea zone contaminated with $\mathrm{H}_{2} \mathrm{~S}$ was much higher than in the sediments of the Azov Sea. Only 4-6 percent of the $U$ was extended from the Azov Sea sediments after 2-fold leaching with $\mathrm{NaHCO}_{3}$ whereas, under the same conditions, practically all of the $U$ was extended. from the sediments of the Black Sea. This marked difference in the mobility of $U$ suggested different forms of occurrence for the $U$ in these sediments. It also suggested the portion of $U$ from the Black Sea water and the terrigenous form of $U$ occurrence in the sediments of the Azov Sea. (CA)

Lisitzin, A. K. 1962. On the Forms of Uranium Occurrence in Underground Waters and the Conditions of its Deposition in the Form of $\mathrm{UO}_{2}$, Geokhimiya, No. 9:763-9 (in Russian).

For estimating the forms of uranium in underground waters, physicochemical constants of its equilibrium in aqueous solutions were used. It is shown that in weak acid, neutral, and alkalescent underground waters of different mineralization anionic forms of uranium prevail in the form of di- and tricarbonateuranyl. The values Eh of the equilibrium in solution with $\mathrm{UO}_{2 \mathrm{sol}}$ are in accordance with the results of detailed hydrogeochemical observations and analyses. The value Eh of the beginning of precipitation of the tetravalent uranium oxide from underground waters ranges approximately from 0 to $=0.2$ volt depending on the uranium concentration in solution, the magnitude and character of the total mineralization of water, the $\mathrm{pH}$, and the concentration of $\mathrm{HCO}_{3}$ ion. (auth) 
McClearen, H. A. (1974). Plutonium in Soil at the Savannah River Plant in Proceedings of the Second AEC Environmental Protection Conference, Albuquerque, NM, Apri1 16-19, 1974. WASH-1332-74. 1:495-510.

Savannah River Plant (SRP) perimeter and off-site soil samples show a background deposition level of approximately $2 \mathrm{mCi} / \mathrm{Km}^{2}$. This is well within the range of deposition noted in Southeastern United States and indicates that off-site deposits due to SRP operations are small compared to background. Samples taken within a $2 \mathrm{~km}$ radius of each of the two chemical separations areas show higher levels $51 \mathrm{mCi} / \mathrm{Km}^{2}$, indicating some plant contribution. Perimeter and off-site soil samples show $90 \%$ of plutonium in a $30 \mathrm{~cm}$ core to occur in the top $15 \mathrm{~cm}$.

Magne, R., J. R. Berthelin, and Y. Dommergues. 1974. Solubilization and Insolubilization of Uranium From Granites by Heterotrophic Bacteria. IAEA-SM-183/18. IN: Formation of Uranium Ore Deposits.

Batch cultures and semi-continuous flow perfusions are used as experimental devices to study microbial solubilization and insolubilization of uranium from granites by heterotrophic bacteria. The nutrient media are synthetic (with dextrose or amino acids) or natural (with mine water containing organic compounds). Microbial artivity increases 2 to 97 times the solubilization of uranium. The processes are biosyntheses of complexing or chelating compounds. The micro-organisms involved are soil microflora and bacteria of mine water and granites. Some species are identified. Microbial insolubilizations of uranium are described in batch cultures. These processes involve biodegradation of uranium binding organo-compounds. These biodegradations occur after long periods of incubation and promote some neoformations of uranium deposits. Black and yellow deposits are observed and described. These experimental results suqqest the miodel described in lhe paper. This model seems to apply easily to superfirial pricesses of solubilization and concentration of uranium and in reworking deposits. However, in the case of primary intragranitic uranium deposits it is only an hypothesis correlated by the existence of favorable environmental conditions for bacterial growth and by some geological observations mentioned in the paper. (auth)

Mango, P., T. Rearey, and J. Apedianaskis. 1970. IN: Proceedings 5th Annual Health Physics Society. Midyear Topical Symposium. pp. 208-220. 1970.

The authors reported that the plutonium released to the fresh water became insoluble and settled rapidly in the lagoon system. Ninety-two percent of the plutonium released by the lagoon to the surrounding streams was associated with suspended material. 
Manheim, F. 1961. Geochemical Profile in the Baltic Sea. Geochim. et Cosmochim. Acta. 25:52-70.

The relationship between depositional environment and element distribution in central Baltic sediments was investigated by means of chemical computation, $\mathrm{pH}, \mathrm{E}_{\mathrm{H}}$, chlorinity, and temperature determinations. Central Baltic sediments show an unusually short, basinward transition from coarse oxygenated sediment to fine stagnant sediment. This is because of the salinity stratification of the Baltic Sea and the permanent 0 deficit found in deeper layers. Sapropelic sediments with $\mathrm{H}_{2} \mathrm{~S}$ and high organic contents occur in the deeps, where overlying $\mathrm{H}_{2} \mathrm{~S}$-bearing water is stagnant and lacks 0 . Gyttjas (gray-green organic mucks) with or without $\mathrm{H}_{2} \mathrm{~S}$ form in quiet areas, where some 0 renewal takes place in the water. A pH of 7 or less, and lower $\mathrm{pH}$ in the sediment than in the overlying water are characteristic of low-carbonate $\left(<0.1 \% \mathrm{CO}_{2}\right)$ sediments, while higher $\mathrm{pH}$ values are found in sediments of higher carbonate contents. Heavy trace metals, such as $\mathrm{Cu}, \mathrm{Ag}, \mathrm{U}$, and Mo are concentrated in the sapropels. Maximum enrichment, Mo possibly excepted, occurs at the peripheries (transition zones) of the stagnant basins. Owing to coprecipitation, Mo follows $\mathrm{Fe}$ sulfides. Maximum U content found in the Baltic is $130 \mathrm{~g} / \mathrm{ton}$, which is not consistent with the hypothesis of Koczy, et al. (CA57, 7979f). Direct precipitation, coprecipitation, or adsorption from water is indicated, not organic complexing. Mn-Fe nodules occur in a peripheral region of aerated bottom water under moderately reducing sediment conditions. The sediment is apparently the source of the $\mathrm{Mn}$ and $\mathrm{Fe}$, which are soluble in the interstitial, but not in the overlying waters. The concretions differ from deep-sea nodules in their lower trace-element contents. Unusual, Mnenriched (up to $5.2 \% \mathrm{MnO}$ ), sapropelic sediments were found in two Baltic deeps. A mixed $\mathrm{Mn}_{-} \mathrm{CaCO}_{3}$ mineral, approximately $\left(\mathrm{Mn}_{72} \mathrm{Ca}{ }_{16} \mathrm{Mg}{ }_{12}\right)$ carbonate, and structurally suggestive of rhodochrosite, is apparently the carrier. (CA)

Masuda, K. and T. Yamamoto. 1971. Studies on Environmental Contamination by Uranium. II. Adsorption of Uranium on Soil and Its Desorption. J. Radiat. Res. 12:94-9.

Experimental studies on the behavior of uranium on soils were carried out using three kinds of soil; volcanic ash, alluvial, and sandy soils. The results showed that uranium dissolved in water ( 1 to $100 \mu \mathrm{g}$ as $\mathrm{U} / \mathrm{ml}$ ) was almost completely adsorbed on every soil examined. The desorption of uranium from soil with salt solutions was extremely difficult especially from volcanic ash soil. (auth)

Matlack, G. M. 1974. The Chemistry of Plutonium in Relation to Its Behavior in Biological and Environmental Systems. pp. 2-7. IN: Plutonium Information Meeting, Los Alamos, New Mexico. CONF-740115:2-7. 
This article is a cram course in plutonium chemistry ranging from a discussion of metallic plutonium through hydrolysis and disproportionation. Inorganic and organic plutonium complexes and ion exchange reactions also listed and discussed.

Menzel, R. G. 1968. Uranium, Radium, and Thorium Content in Phosphate Rocks and Their Possible Radiation Hazard. J. Agr. Food Chem. 16:231-34.

A survey of phosphate rock samples from all major phosphate producing areas of the world showed that phosphate rocks from Florida, the main source of fertilizer phosphates in the United States, ranked relatively high in content of uranium, radium, and thorium. In areas where crops are fertilized with high rates of phosphate from Florida, the addition of uranium and radium may equal the amounts occurring naturally in the plow layer of soils, but the addition of thorium would be less than the amount occurring naturally. The radiation hazard, which might result from uptake of radium into food plants, appears to be negligible. (auth)

Meyer, G. L. 1975. Preliminary Data on the Occurrence of Transuranium Nuclides in the Environment at the Radioactive Waste Burial Site. Maxey Flats, Kentucky. IAEA-SM-199/105.

Between 1963 and 1974, approximately 104,000 $\mathrm{m}^{3}$ of solid "low-level" radioactive waste were buried at the Maxey Flats, Kentucky, site. These wastes contained approximately $80 \mathrm{~kg}$ of plutonium-239 and a large undetermined quantity of other plutonium isotopes. In 1972, elevated levels of radioactivity were detected in monitoring samples collected near the burial facility by the Kentucky Department for Human Resources (KDHR).

Subsequently, the KDHR conducted a special radiological study of the burial site and its environs. Based on the concentration of plutonium present or the ratio of plutonium-238 to $-239,49$ of 50 samples collected on or near the burial site were contaminated with plutonium from a source other than atmospheric fallout. Plutonium was deterted in surface soil, in soil cores $90 \mathrm{~cm}$ deep, in monitoring wells, and in streams which drain the site.

During the past 13 years, infiltrating precipitation collected in the burial trenches, forming a mobile plutonium-contaminated leachate. The chemical form, pathways, and mechanisms by which the plutonium moved out of the trenches have not been explained satisfactorily. Extensive studies of the burtal stte are in progress.

The primary conclusion drawn from the hydrogeology of the site and the plutonium data is that plutonium has moved from the facility; possibly via several pathways including surface water runoff, atmospheric fallout from an evaporator, lateral migration through the soil, and migration through jointed subsurface geologic formations. 
Mihalik, P. 1968. Uranium Compounds in the Dominion Reefs, and Their Association With Phosphorus Compounds. NIM-415.

Nine samples of uranium ore from the Bramley Shaft of the Dominion Reefs Mine were investigated mineralogically and with the electron microprobe to find the cause of the poor leaching characteristics of a fraction of the uranium minerals. The investigation, which is at present still in its preliminary stage, has shown that, in samples that exhibit good leaching characteristics, uranium is generally not intimately associated with phosphorus compounds, whereas the converse is generally true of samples having poor leaching characteristics. The existence of a number of hitherto unknown uranium minerals is also indicated, and it is suggested that they may contribute to the refractory nature of some of these uranium ores. (auth)

Miner, F. J., P. A. Glover and H. W. Miller. 1973. Plutonium Behavior in the Soil/Water Environment. RFP-2004-A, pp. 1-3.

A standard solution of less than 10 micrometer Pu02 particles suspended in water, along with a nitric acid solution as a source of "soluble" plutonium, was used in distribution studies of plutonium between characterized soils and the above solutions. The division between soluble and insoluble plutonium was chosen as 0.02 micrometers in diameter, on the basis of plutonium work reported in the literature. This was later modified to $0.1 \mu \mathrm{m}$. Equilibrium between $\mathrm{Pu}$ in $\mathrm{HNO}_{3}$ and a Rocky Flats soil was reached in about three hours but a South Carolina soil did not attain equilibrium after 24 hours of contact time.

Miner, F. J., P.A. Glover, and W.L. Polzer. 1974. Plutonium Behavior in the Soil/Water Environment I. Sorption of Plutonium by Soils. Agronomy Abstracts, p. 35, 1974.

As part of a larger program to study the behavior of plutonium in the environment, the movement of plutonium in soil/water systems is being investigated. Sorption and elution characteristics are being used to measure this movement. The equilibrium sorption of plutonium has been determined for 13 soils. The soils were initially characterized chemically and physically (mechanically). Three plutonium concentrations, 10-8, 10-7, and $10^{-6}$ moles/liter, were used for the sorption measurements. The plutonium sorption was rapid and quite high: 59 percent of the time the equilibrium sorption was greater than 99 percent $\left(K_{d}(m)>430\right)$ and only 5 percent of the time was it below 90 percent surption $\left(K_{d}(m)<39\right)$. Using principal component analysis, a statistically significant relationship was found between the sorption of plutonium and groups of chemical and physical characteristics of the soils that are associated either with the ion exchange capabilities of the soils or their acidities. Plutonium column elution behavior has been investigated for three soils. There is some plutonium in the eluate (less than 2 percent of the amount. of plutonium placed in the soil column) but the amount varies with the soil. (auth) 
Miyake, $Y$. and $Y$. Sugimura. 1975. The Plutonium Content in the Pacific Ocean Waters. IAEA-SM-199/22.

The content of plutonium in sea water collected during the cruises of 1968 to 1973 in the entire Pacific Ocean mainly along the line of $170^{\circ} \mathrm{W}$ and $146^{\circ} \mathrm{W}$ longitude extending from $50^{\circ} \mathrm{N}$ to $68^{\circ} \mathrm{S}$, not only in the surface layer but also in the deep layer down to $3,000 \mathrm{~m}$ depth was determined. Results obtained in the eastern South Pacific and some of the western North Pacific were also reported. The plutonium content in the North Pacific surface water ranged from 2.2 to $9.4 \times 10^{-4} \mathrm{pCi} / 1$ while it is lower in the South Pacific ranging from 1.3 to $3.4 \times 10^{-4} \mathrm{pCi} / 1$. Intimate correlation was observed between the plutonium content in surface water and ${ }^{90} \mathrm{Sr}$ fall rate. The ratio of $238 \mathrm{Pu}_{\mathrm{u}} / 239,240 \mathrm{Pu}$ in surfacc water ranged from 10 to $81 \%$ in the North Pacific and 35 to $240 \%$ in the South Pacific. Thesc values are in the same grder of magnitude as scen in the land fallout during the same period. $239,240 \mathrm{Pu} /{ }^{3} 3 \mathrm{Cs}$ in surface water ranged from 0.09 to $0.28 \%$ and it is lower than the average ratio of $0.6 \%$ in fallout in Tokyo. In the intermediate or deep layer relatively higher ratio was observed as compared with those in surface water. This suggests that a faster downward transport of plutonium in marine environment than strontium or cesium. (auth)

Mizuno, A. and T. Mochizuki. 1970. Distribution of Uranium in the Sediments From San' in Off-Shore, Southwestern Japan. Chishitsu Chosasho Geppo. 21:287-92 (in Japanese).

The distribution of $U$ in the sediments and $i$ ts relation to the mud, clay, and $C$ contents were studied. The very fine-grained or muddy sands in the Miho Bay contain on the average $1.8 \mathrm{ppm} U$. An off-shore progressive increase of $U$ contents is observed; in the sand of the shelf area $(0.98$ ppm U), the clayey silt of outer. shelf and upper slnpe (2.2), and the silty clay of slope (3.1). The abundance of $U$ in the sediments agrees with the general tendency in sea area. U contents are in direct proportion to mud or clay contents, but no regular relation is found between $U$ and $C$ contents. $U>5 \mathrm{ppm}$ (maximum $8 \mathrm{ppm}$ ) is found in the horizon $>30$ $\mathrm{cm}$ from the top of core, in which the relation between $U$ and $C$ contents is quite different from that of surface sediments. (CA)

Mizuno, A., S. Sekine, J. Nakazawa, A. Takaku, K. Onodera, and M. Ono. 1969. Uranium Concentration in the Bot.toms of the Lakes Shinji-ko and Naka-umi, With Special Reference to Its Genetic Relation With the Sedimentary Environment. Chishitsu Chosasho Hokoku. No. 232:317-52 (in Japanese).

The bottom areas of the lakes Shinji-ko and Naka-uml, along the San'in coast of Japan Sea (mainly oligohaline and polyhaline brackish lakes, respectively), are divided into three sections with respect to the $U$ content. The first contains the lower content of $U(1-3 \mathrm{ppm})$, represented 
by coastal sandy bottoms of both the lakes and the channels, and of the Ohashi-gawa and Sakai-Suido rivers. The second contains an intermediate content (4-5 ppm U), which is widely developed in the muddy bottoms of both lakes. The last contains the higher content (6-11 ppm U), only occurring in the muddy part of the Yonago Bay of Naka-umi. The tentative conclusions as to $U$ distribution in the bottoms of the lakes are as follows: In the sections of lower and intermediate $U$ content, $U$ probably exists in fine-grained minerals such as zircon, derived from granitic rocks. On the other hand, a portion (1-6 ppm) of the $U$ contained in the section of higher $U$ content was probably derived from the lake water containing 2.8 Y $\mathrm{U} / \mathrm{I}$ (maximum) by direct precipitation and (or) coprecipitation with organic and inorganic colloids, controlled mainly by $\mathrm{pH}$ and $\mathrm{E}_{\mathrm{H}}$ conditions. (CA)

Mo, T and F. G. Lowman. 1975. Laboratory Experiments on the Transfer Dynamics of Plutonium from Marine Sediments to Seawater and to Marine Organisms. CONF-750503-5, $35 \mathrm{p}$.

The leachability of $239,240 \mathrm{Pu}$ from a fine contaminated calcareous sediment to aerated open seawater and to anoxic seawater was measured. The distribution coefficient for $239,240 \mathrm{pu}$ from sediment to seawater was $6.1 \times 10^{-5}$ for aerated water and $2.6 \times 10^{-6}$ for anoxic water. Experiments on the uptake of $239,240 \mathrm{pu}$ by the clams Donax denticulatus, and Lucina pectinata, were done in aquaria containing kilogram quantities of sediment from the Bravo Crater at Bikini Atoll. The concentration factor for $239,240 \mathrm{Pu}$ by the soft parts of these clams was about 200 . All the plutonium taken up in the soft parts was associated with the gill, mantle and siphon. No plutonium was detected in the adductor muscles of hepatopancreas. The smooth surfaces of the shells of the Donax did not show any detectable plutonium, but the rough shell surfaces of the Lucina concentrated plutonium by a factor of $1.10 \times 10^{4}$ over that in the seawater. Marineperiphyton cultured on glass plates in an aquarium concentrated $239,240 \mathrm{Pu}$ by a factor of about $7 \times 10^{3}$ over that in the seawater. (auth)

Mo, T., A. D. Suttle, and W. M. Sackett. 1973. Uranium Concentrations in Marine Sediments. Geochim. et Cosmochim. Acta. 37:35-51.

A direct proportionality was observed between the percentage of organic $C$ and $U$ in sediments deposited in an anoxic environment in the Pettaquamscutt River in Rhode Island with concentrations of organic C 7-14\% and U 7-30 ppm. A similar relation was found in cores of sediments deposited on the Sigsbee Knolls in the Gulf of Mexico. For Mn nodules a direct relation was found between $\mathrm{U}$ and $\mathrm{Ca}$ concentrations, and both decrease with increasing depth of deposition. For nodules from $4500 \mathrm{~m}$ in the Pacific, concentrations are $3 \mathrm{ppm} U$ and $0.3 \% \mathrm{Ca}$ compared with $14 \mathrm{ppm} U$ and $1.5 \% \mathrm{C}$ at $1000 \mathrm{~m}$. Relatively high $U$ concentrations were observed in carbonates deposited in the deepest parts of the Gulf of Mexico, with the $>88 \mu$ carbonate fraction in Sigsbee Knoll cores having $\leqq 1.20 \mathrm{ppm}$. (CA) 
Naumov, G. B. 1961. Some Physico-Chemical Peculiarities of Uranium Behavior in Hydrothermal Solutions. Geokhimiya. No. 2:115-32 (in Russian).

The most typical components of uranium-containing hydrotherms are carbon dioxide, silicic acid, fluorine, and sulphur; the most typical cations are alkaline metals. A study of uranium behavior showed transport in the form of complicated complex ions, among which the carbonate and the fluoride ions are the most probable. The processes of complex formation provide a reliable transport of hexavalent uranium under conditions where $\mathrm{UO}^{+}$is reduced to $\mathrm{UO}_{2}$. On the basis of an analysis of the behavior of complex uranium ions; the principle causes of nasturan deposition were traced. (auth)

Nevissl, A., W. R. Schell, and V. A. Nelson. 1975. Plutonium and Americium in Soils of Bikini Atoll. IAEA-SM-199/63.

A sludy has been made to determine the concentrations of plutonium and americium in surface soils and in soil profiles on Bikini Atoll. The soils consist of calcareous materials and a thin layer of organic matter which has produced a shallow organic rich horizon suitable for certain plant growth. During the testing period from 1946 through 1958, Bikini Atoll was the site of 23 nuclear detonations which contaminated the islands of the atoll with radioactive fallout including the transuranium elements. Plutonium and americium measurements of surface soj samples collected on 6 of the 26 islands of the atoll show that $239,240 \mathrm{Pu}$ values vary from

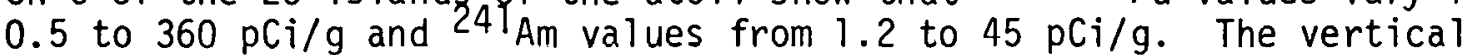
distribution of plutonium in soil varies from area to area. Although about $98 \%$ of the plutonium is retained in the top $25 \mathrm{~cm}$ in one core profile, the remaining $2 \%$ is detectable as deep as $100 \mathrm{~cm}$. The suspension and resuspension of plutonium and plutonium bearing particles by rainfall (150-175 cin/yr) seems to be the principal mode of plutonium transport in the soil. A greater retention of plutonium is found associated with the algal crust of the atoll soils. The present levels of $239,240 \mathrm{Pu}$ and its distribution at Bikini are not ijkely to change significantly whereas $24 l_{\text {Am }}$ levels will increase by $241 \mathrm{Pu}$ decay and will attain maximum radioactivity in about 50 years. (auth)

Nishiwaki, Y., Y. Honda, Y. Kimura, H. Morishima, T. Koga, Y. Miyaguchi, and H. Kawai. 1972. Behavior and Mistribution of Radioactivc Substances in Coastal and Estuarine Waters. IN: IAEA-SM-158/11. Radioactive Contamination of the Marine Environment. pp. 177-193.

To understand the problems of environmental radioactive contamination due to continuous discharge of low-level liquid radioactive waste into the seawater, a study must be made of the behavior and distribution of various nuclides which may occur in both ionic and colloidal or particulate state in the coastal and estuarine waters. However, the behavior and distribution of the various radionuclides in the estuarine water are much more complicated 
than those in the open sea, because of the complex topographical and marine meteorological variations and the changes in salinities and $\mathrm{pH}$ of the water. Since thorium and rare-earth elements had been continuously discharged through a small river into the estuarine water at Osaka Bay, a study was made of the variation of concentration of these elements under various natural conditions. Experimental studies on adsorption of these elements on some bottom sediments were also carried out in the water with different salinities and $\mathrm{pH}$. One important factor influencing the concentration of the elements in the water is tidal oscillation. The gross beta activities in water at the same location in the estuary widely varied at each time of sampling. The average values from April to December in 1966 were $9.5 \pm 4.9$ $\mathrm{pCi} / 1$ at higher tidal level, $84 \pm 68 \mathrm{pCi} / 1$ at middle tidal level and $157 \pm$ $106 \mathrm{pCi} / 1$ at lower tidal level, respectively. However, the concentrations of thorium and total rare-earth elements in the water were not observed to change regularly with the tidal change. The dispersion of the elements in the estuarine water were not interpreted by simple dilution and diffusion of the element in water mass. The presence of the mud flats, as well as the marine meteorological conditions, seem to affect markedly the distribution of the element in the estuarine water. The adsorption of the element on the bottom sediment was influenced not only by the coarseness of the sediment but also by the salinjty and $\mathrm{pH}$ of the water. The highest distribution coefficients of $9 T_{Y}$ and ${ }^{44} \mathrm{Ce}$ in the clay sediment were obtained at the chlorosity of $14 \mathrm{~g} / 7$ and $\mathrm{pH} 7.3$ of the water. (auth)

Noshkin, V. E. 1972. Ecological Aspects of Plutonium Dissemination in Aquatic Environments. Health Physics 22:537-549.

The available data concerning the dissemination of plutonium and other transuranics in the aquatic environment are drawn together for appraisal. The most studied isotope has been $\mathrm{Pu} 235$ derived from worldwide fallout. Essentially all the published work has been concerned with levels in the marine environment where plutonium is found widespread among planktonic, pelagic and benthic organisms. The concentrations are higher in organisms feeding on sediment or on surfaces than in those drawing largely on the water itself. Among the species where data are available are a variety of convenient "indicator organisms" for plutonium. There is some evidence that plutonium concentrations are increased in organisms of higher trophic levels. Bone and liver are major repositories for plutonium in marine vertebrates while muscle tissue of both marine vertebrates and invertebrates contain relatively lower concentrations. Plutonium is geochemically separated from both $\mathrm{Sr} 90$ and Cs 137 in the water column and the sedimentation of $\mathrm{Pu} 239$ may be more involved with biological processes than has been found for fallout rare earth isotopes. In marine sediments, as in soils, plutonium is more mobile than was originally expected. What little is known of the behavior of plutonium in the marine environment should be used conservatively to assess the behavior and distribution of new plutonium additions derived from sources other than fallout, and even more conservatively in predicting the impact of other transuranics 
in the aquatic environment. Considerably more understanding of the aquatic radioecology of several of the elements is a major priority especially since it now appears that when the relative biological effectiveness of alpha versus gamma or beta radiations is considered, fallout $\mathrm{Pu} 239$ contributes more than fallout Sr 90 or Cs 135 to the artificial radiation exposure of many marine species. (auth)

Noshkin, V. E. and V. T. Bowen. 1973. Concentrations and Distributions of Long-Lived Fallout Radionuclides in Open Ocean Sediments. IN: Radioactive Contamination of the Marine Environment. IAEA, Vienna. IAEA-SM158/45:671-686.

Analysis of deep open-ocean sediment cores from the north and south Atlantic. and the Mediterranean Sea show the presence of $\mathrm{Sr} 90, \mathrm{Cs} 137$, and Pu 239, 240 in measurable amounts distributed to depth within the sediment columns. Comparison of the quantities of these radionuclides accumulated in the sediments with either estimated integrated deliveries to the sea surface or the measured inventories in the overlying water masses has been used to estimate the residence times of the radionuclides in the water column. For Sr 90 and Cs 137 these computed residence times are orders of magnitude shorter than those estimated for the stable elements. Plutonium, we find, is being removed from the water column significantly more rapidly than either Sr 90 or CS 137. The ratio of Cs 137 to Sr 90 in the sediments is higher than that found in precipitation, suggesting that a larger fraction of ocean water Cs 137 is associated with sedimenting particles than has been previously assumed. A simple model assuming plutonium to associate with a mixed population of particles, sinking at rates of 392 to $70 \mathrm{~m} / \mathrm{yr}$, predicts very well both the relation of sediment inventory of plutonium to depth of sediment, and the plutonium distribution vertically in the water column. (auth)

Noshkin, V. E., K. M. Wong, R. J. Eagle, and C. Gatrousis. 1971. Transuranics at Pacific Atolls. I. Concentrations in the Waters at Enewetak and Bikini. UCRL-51612 (TID-4500, UC-48).

This report presents the available results on the concentrations and distributions of $\mathrm{Pu} 239,240$ and other transuranic radionuclides in the lagoon waters of Enewetak and Bikini Atolls. The data are derived from a series of samples collected during the period 0ctober-December 1972. The samples are being radinchemically processed and analyzed for spcrific radionuclides; the available results for $\mathrm{Sr} 90, \mathrm{Cs} 137, \mathrm{~Np} 237, \mathrm{Pu} 238$, $\mathrm{Pu} 239,240, \mathrm{Pu} 241$, and Am 241 in specific water samples are presented and discussed. The two Pacific atolls, sites of nuclear testing series in the 1940s and 1950s, act as sources of radionuclides, contributing quantities greatly exceeding the fallout deposition to the lagoon marine environments. The distributions of plutonium in the two lagoons are very heterogeneous; strong concentration gradients are evident in both lagoons, and the horizontal stratifications define areas of water renewal. The concentrations are affected by wave-driven water transported across the 
reefs and by flow through the main channels. Three to $90 \%$ of the $\mathrm{Pu} 239$, 240 in Bikini lagoon is associated with a particulate phase. Pu 239,240 concentrations associated with bottom particulates generaliy exceed the surface levels, suggesting that resuspension of fine material is an active mechanism for redistributing some plutonium throughout the lagoon. In the soluble phase, however, surface plutonium concentrations generally exceed bottom concentrations, indicating slow vertical mixing in the water column, and suggesting (1) that plutonium is derived from several sources, and (2) that surface and bottom currents independently redistribute different forms of the radionuclide to different areas of the lagoon. The $\mathrm{Pu} 239$, $240 /$ Cs 137 ratios in the surface waters are not constant, indicating that different sources or mechanisms govern the redistribution of specific radionuclides in the water column of the lagoon. (auth)

Nosinkin, V. E., K. M. Wong, K. Marsh, R. Eagle, G. Holladay, and R. W. Buddemeier. 1975. Plutonium Radionuclides in the Ground Waters at Enewetak Atol1. IAEA-SM-199/33.

In 1974 a groundwater program was initiated at Enewetak Atoll to study systematically the hydrology and the ground water geochemistry on selected islands of the Atoll. The program provides chemical and radiochemical data for assessment of water quality on those islands designated for rehabilitation. These and other data are used to interpret the mechanisms by which radionuclides are cycled in the soil-groundwater system. Because of the international concern over the long-term buildup, availability, and transport of plutonium in the environment, this program emphasizes analysis of the element. The results of the study show that on all islands sampled, small quantities of plutonium radionuclides have migrated through the soil columns and are redistributed throughout the groundwater reservoirs. The observed maximum surface concentrations are less than $0.02 \%$ of the maximal recommended concentration for drinking water. Concentrations of $137 \mathrm{Cs}$ are found to correlate with water freshness, but those of 239,240pu show no such relationship. The mechanisms moving $239,240 \mathrm{Pu}$ through the ground water reservoirs are independent of the processes controlling the cycling of $137 \mathrm{Cs}$ and fresh water. A reasonable linear correlation is found between mean surface-water concentrations and soil burdens. This indicates that the quantities of $239,240 \mathrm{pu}$ migrating to the groundwater surface layers are, to a first approximation, independent of the physical, chemical or biological characteristics of the islands. (auth)

Pashneva, G. E., T. P. Slavnina, and V. V. Serebrennikov. 1965. Rare Earth and Thorium Content in Soils of Tomsk Region. Izv. Sibirsk. Otd. Akad. Nauk SSSR, No. 4 Ser. Biol.-Med. Nauk. No. 1:48-52 (in Russian).

The concentration of rare earth elements, $Y$, and Th in leached black earth podzolic, turf podzolic, light gray wood, dark gray wood, meta, and river alluvial soils of the tomsk region was determined. The concentration of Th and rare earth elements in the soils depend on the quantity of humus 
and increases with the increase of the concentration of humus in the soil. The distribution of Th in these soils depends on the development of turf and podzolic processes. The concentration of Th increases in the upper humus-accumulation horizon because of biogenesis and in the alluvial horizon because of the erosion of its eluvial horizon where the concentration of $T h$ is lower than in the $A_{1}, B_{1}$, and $B_{2}$ horizons. The percent relation of rare earth elements shows that in the soils studied the rare earth elements of a cerium group predominate, with the exception of turf podzolic and light ray wood soil which have a comparatively high concentration of Er. (auth)

Patterson, J. H., G. M. Matlack and G. B. Nelson. 1974. The Inter-. action of $238 \mathrm{PuO}_{2}$ Heat Sources with Simulated Terrestrial Environments. Am. Nuclear Society Transactions. 19:33-34.

Environmental chamber work showed that rain on larqe chumks of ${ }^{238} \mathrm{PuO}_{2}$ at $200^{\circ} \mathrm{C}$ led to an increase of release rate of $0.04 \mu \mathrm{Ci} /$ month to $4.0 \mu \mathrm{Ci} /$ month due to spallation. Fines were at ambient temperature and actually decreased in release rate from $0.8 \mu \mathrm{Ci} /$ month to $0.4 \mu \mathrm{Ci} /$ month.

Patterson, J. H., G. B. Nelson and G. M. Matlack. 1974. The Dissolution of $238 \mathrm{Pu}$ in Environmental and Biological Systems. LA-5624.

Results from our experiments on dissolution rates of $238 \mathrm{PuO}_{2}$ and $239 \mathrm{PuO}_{2}$ in distilled water and normal saline solution were compared with rates calculated from data in the literature on various $\mathrm{PuO}_{2}$ dissolution experiments. The initial comparatively rapid dissolution rates were found to vary widely, even between experiments performed ostensibly under the same conditions. In contrast, the lower rate of dissolution, which began a few hours after contact of the oxide with the aqueous medium, was found to be constant and fell within a range of 1 to $6 \mathrm{ng} / \mathrm{m}^{2} \mathrm{~s}$ under wirizly varying conditions. (auth)

Pettersson, H. 1949. Exploring the Bed of the Ocean. Nature. 164:468-70.

A preliminary report is given of the extensive results obtained during a 15-month Swedish deep-sea expedition. The data taken include a continuous record of the bottom profile along a nautical course of 20,000 nautical miles and 200 long cores taken from depths belweell 2,000 and more than 4,000 fathoms. In addition there were obtained more than 400 oscillograms from explosions in depths between 300 and 3,500 fathoms and their echoes (taken with a special ultrasonic echograph), and approximately 4,000 samples of sea water from varying depths, some of them large volume, for uranium and radium analyses. Ten thousand temperature records by reversing thermometers or, in the surface layers, by bathythermographs, are included in the oceanographical data, which were mainly concentrated along cross sections 
through the equatorial current system. Observations were also made on submarine daylight, in different spectral regions, including the ultra-violet, and on the occurrence of light-scattering particles suspended in the deeper water layers. Special attention was given to the very lowest water layers down to about two fathoms from the bottom. Confirming the results previously obtained from more limited samples, it was found that the uranium content of large-volume samples of sea-water from various localities and depths is fairly constant, varying between limits of 1.0 and $1.6 \mu \mathrm{g} / 1$. The radium content is always considerably less than the theoretical value in radioactive equilibrium with the uranium. The radium content also is found to increase with increasing depth. This deficiency in radium supports the hypothesis of a precipitation of the intervening element, ionium, $\left(\mathrm{Th}^{230}\right)$, to the sea bottom; this would also explain the generally high content of radium in the red clay and in radiolarian ooze. (NSA)

Pillai, K. C. and E. Mathew. 1975. Plutonium in Aquatic Environment -Its Behavior, Distribution and Significance. IAEA-SM-199/27.

Plutonium as a contaminant appeared in the human environment as a result of nuclear weapon testing. In view of the accelerated growth of nuclear power reactors and subsequent establishment of many irradiated fuel reprocessing facilities and increasing use of plutonium, the possibility of more plutonium entering the environment has increased.

Plutonium being long-lived and being one of the most toxic radionuclides, its environmental behavior answers significance.

The inventory of fall out plutonium in the environment is discussed. The fall out levels of plutonium in sea woods, rain water, soils and aquatic surface sediments from Bombay Region were measured by radiochemical separation using $236 \mathrm{Pu}$ as an internal tracer and alpha spectrometry.

The behavior of trace amounts of plutonium discharged from fuel reprocessing operations into the aquatic environment of Bombay Harbour Bay is investigated in detail and the distribution of this radionuclide in different matrices of the marine environment -- seawater, silt sediments, organism and solar salt -- were studied. The suspended silt and bottom sediments of coastal waters have been found to have high capacity for removal of plutonium from seawater. Kd factors of about $10^{5}$ were obtained in silt. Build-up of plutonium with time in sediments of the aquatic environment has been studied. Nearly 99 percent of the plutonium gets removed by sediments from silt laden coastal water. The preferntial uptake of plutonium by benthic organisms were observed.

The interaction of plutonium solutions and also trace plutonium present in the: fuel reprocessing effluents with seawater were studied and the formation of ionic as well as non-ionic species of plutonium were investigated. Organic matter added to seawater was found to inhibit hydrolysis 
and precipitation of added $\mathrm{Pu}$ and the anionic apecies formed increased with time. Further investigations are made on the interaction of plutonium directly iwth organic matter extracted from sediments and the ionic nature of the complexes formed. The extraction of organic matter from coastal sediments contaminated with plutonium showed the presence of the element in the purified organic fraction.

To average concentration of $\mathrm{Pu}$ in benthic organisms from discharge locale is only 0.01 percent of the limiting values. Biological uptake and transport of $\mathrm{Pu}$ might be insignificant in coastal areas. Sediments being the major depository of all released $\mathrm{Pu}$, needs further study to understand its biological and geochemical significance.

Pliler, R. and J. A. S. Adams. 1962. The Distribution of Thorium and Uranium in a Pennsylvanian Weathering Profile. Geochim. et Cosmochim. Acta. $26: 1137-46$.

Eleven samples representing a pre-Pennsylvanian weathering profile on the Boulder Creek granodiorite near Boulder, Colorado, were analyzed for thorium and uranium by $\gamma$-ray spectrometric and chemical methods. In an effort to determine the possible sites of thorium and uranium in the samples, a study of their leachability in hot $2 \mathrm{~N}$ hydrochloric acid was undertaken. Fresh granodiorite was found to contain $9.3 \mathrm{ppm}$ thorium and $2.5 \mathrm{ppm}$ uranium. The first stages of weathering resulted in an apparent removal of $25 \%$ of the thorium and $60 \%$ of the uranium present in the original granodiorite. The leaching study of the fresh granidiorite demonstrated. that as much as $90 \%$ of the thorium and $60 \%$ of the uranium could be removed by an acid leach solution. This seems to indicate that most of the thorium and uranium in the fresh rock is situated in acid soluble minerals or in interstitial materials. After the initial drop of the concentration in the lowest part of the weathered mantle, the total uranium and thorium content of the weathered rock increased by a factor of at least 4 in the uppermost, most-weathered rock material. Leaching studies of the weathered rock indicated that uranium is present largely in the primary resistates, such as zircon, xenotime, and apatite, and thorium occurs mainly in or on clays or in the secondary resistates--minerals formed during weathering. (auth)

Pokidin, V. K., Y. V. Kuznetov, E. A Prozorovich, and F. A. Asadullaeva. 1972. Radioactivity and Rate of Sediment Formation in the Caspian Sea. Geokhtimiya. No. 7:834-43 (in Russian).

On the basis of data on the vertical distribution of ${ }^{226} \mathrm{Ra},{ }^{230} \mathrm{Th},{ }^{232} \mathrm{Th}$, and $238 \mathrm{U}$ in sediments of the Caspian Sea and with the aid of the radiumionic method the formation rates of deep-sea and shallow water sediments have been determined, which equal respectively: 6.0 to 26.0 and $100 \mathrm{~cm}$ for 1000 years. The difference of vertical sections of ${ }^{230} \mathrm{Th}$ and ${ }^{232} \mathrm{Th}$ distribution in deep-sea sediments of the Caspian Sea is shown, which con- 
firms the hypothesis about different forms of supply to these isotopes to the sea bottom. A close direct connection between the distribution of ${ }^{230}$ Th and calcium carbonate in deep-sea sediments was established, which bears witness of the sorption character of the ${ }^{230}$ Th withdrawal from water by chemogenic calcite. (auth)

Polzer, W. L. and J. F. Miner. 1974. Plutonium Behavior in the Soil/Water Environment. II. Mechanisms of Plutonium Sorption by Soils. Agronomy Abstracts, p. 37.

Sorption of plutonium by 13 soils, as measured by distribution coefficients, was observed in most cases to be dependent on the initial concentration of plutonium which ranges from $10^{-8}$ to $10^{-6}$ moles/liter. This dependency is attributed to several factors: the presence of monomeric or low molecular weight polymeric plutonium species (as indicated by solubulity calculations), complexes of plutonium carbonate ions, and in a few cases, the possible existence of nonequilibrium sorption conditions. A lower sorption of plutonium was observed in the presence of low molecular weight polymers in solution, apparently due to a lower charge density of the polymers. A decrease in sorption was also observed at the initial plutonium concentration of $10^{-8}$ moles/liter and is attributed in some cases to possible nonequilibrium conditions as indicated by changes in sorption when recarbonate ions may react with plutonium to form quantities sufficient to influence the sorption of plutonium by soils, irrespective of the initial plutonium concentration: (auth)

Price, K. R. 1971. A Critical Review of Biological Accumulation, Discrimination and Uptake of Radionuclides Important to Waste Management Practices. BNWL-B-148.

The objective of this survey is to screen the world literature for data on biological uptake and accumulation or the discrimination against uptake of certain radionuclides associated with nuclear waste management. Historical aspects based on the publication sequence of biological research are briefly considered, and relevant research findings are discussed under several categories. One category is devoted to transuranic elements and is accompanied by a special bibliography. The application of research findings to the Hanford situation is discussed and projects for future study are recommended. An annotated list of 119 references is presented. (auth)

Price, K. R. 1973. A Review of Transuranic Elements in Soils, Plants, and Animals. Jour. Environ. Quality. 2:1:62-66.

Published information concerning the distribution and fate of neptunium, plutonium, americium, and curium in terrestrial ecosystems is reviewed and areas needing further study are identified. In the final analysis of 
environmental quality, radionuclides with very long half lives will become increasingly important to man as they continually constitute a greater proportion of environmental radioactivity. The transuranic elements have been identified as the most hazardous radionuclide by-products of nuclear reactor operations. The relatively few studies conducted indicate that transuranic elements do not remain in solution in soils, plants, or animals but organic complexes and chelation greatly enhance mobility. The elucidation of natural organic complexes and chelating agents has not been attempted. Oxidation state also influences mobility, but possible biological mechanisms permitting exodation or reduction remain uninvestigated. Ingestion is the most important transfer mechanism in ecosystems, but assimilation of transuranics from natural food sources is mostly unknown. Evidence in the literature suggests three possible mechanisms leading to the observed increase in plant uptake with time: the formation of organic complexes or chelates, a buildup of radionuclide concentration at root surface, or the slow but continual uptake by perennial plants. Each of these mechanisms deserves further study. (auth)

Price, K. R. 1973. Tumbleweed and Cheatgrass Uptake of Transuranium Elements Applied to Soil as Organic Acid Complexes. BNWL-1775.

Plant uptake of radioactive waste materials is a biological interaction important to the environmental management of waste storage sites. This study on the uptake of $24 \uparrow_{\mathrm{Am}}, 244 \mathrm{Cm}, 237 \mathrm{~Np}$, and $239 \mathrm{Pu}$ from soil by plants demonstrates that shoot uptake is clearly influenced by the chemical form of the transuranic. It is unclear at this time whether soil or plant mechanisms, or both, are responsible. Future studies are planned to investigate these aspects. The observation that some organic acids suppress plant uptake of americium and curium will be investigated further to evaluate the use of soil additives to suppress plant uptake of transuranics. Test results indicate that nrganic acid complexes of plutonium such as oxalate or citrate can increase plant uptake when added to soil as compared to uptake from dilute nitric acid solutions. (auth)

Price, K. R. 1974. The Behavior of Waste Radionuclides in Soil-Plant Systems. IN: Pacific Northwest Laboratory Annual Report for 1973 to the USAEC Division of Biomedical and Environmental Research, Part 2, Ecological Sciences. BNWL-1850 Pt. 2 (US-48, Biology and Medicine): $38-40$.

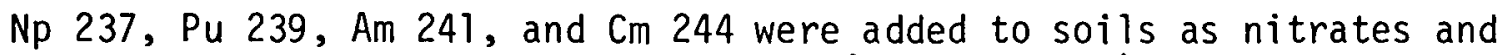
chelates of EDTA and DTPA. Tumbleweed (Salsola Kali) and cheatgrass (Bromus tectorum) were grown in soils for two months and the shoot uptake of radionuclides from chelates was compared with uptake from nitrate solutions. EDTA increased the uplake of $\mathrm{Pu}$ (about 10 fold) and of $\mathrm{Am}$ and $\mathrm{Cm}$ only slightly, whereas, reduced the uptake of $\mathrm{Np}$. DTPA increased the uptake of $\mathrm{Pu}$ (more than 800 fold) and of $\mathrm{Am}$ and $\mathrm{Cm}$ (about 100 fold), whereas, reduced the uptake of $\mathrm{Np}$. (auth) 
Price, S. M. and L. L. Ames. 1975. Characterization of Actinide-Bearing Sediments Underlying Liquid Waste Disposal Facilities at Hanford. IAEASM-199/87.

Past liquid waste disposal practices at the U. S. Energy Research and Development Administration's Hanford Reservation have included the discharges of solutions containing trace quantities of actinides directly into the ground via structures collectively termed "trenches". Characterization of samples from two or these trenches, the 216-Z-9 and the 216-Z-1A(a), has been initiated to determine the present form and migration potential of plutonium stored in sediments which received high salt, acidic waste liquids.

Analysis of samples acquired by drilling has revealed that the greatest measured concentration of $\mathrm{Pu}, \sim 10^{6} \mu \mathrm{Ci} 239 \mathrm{Pu} / 1$ iter of sediment, occurs in both facilities just below the points of release of the waste liquids. This concentration decreases to $\sim 10^{3} \mu \mathrm{Ci} 239 \mathrm{Pu} / 1 \mathrm{iter}$ of sediment within the first 2 meters of the underlying sediment columns and to $\sim 10 \mu \mathrm{Ci}$ $239 \mathrm{pu} / 1$ iter of sediment at the maximum depth sampled ( 9 meters). Examination of relatively undisturbed sediment cores illustrated two types of $\mathrm{Pu}$ occurrence responsible for this distribution. One of these types if composed of $\mathrm{Pu}$ particles ( $\$ 70 \mathrm{wt} \% \mathrm{PuO}_{2}$ ) added to the disposal site in the same form. This "particulate" type was "filtered out" within the upper 1 meter of the sediment column, accounting for the high concentration of Pu/liter of sediment in this region. The second type of $\mathrm{Pu}\left(<0.5 \mathrm{wt} \% \mathrm{PuO} \mathrm{O}_{2}\right)$ was originally disposed of as soluble Pu(IV). This "nonparticulate" type penetrated deeper within the sediment profile and was deposited in association with silicate hydrolysis of the sediment fragments. (auth)

Prout, W. E. 1958. Adsorption of Radioactive Wastes by Savannah River Plant Soil. Soil Sci. 86:13-17.

The adsorption of radioisotopes on soil was investigated in the laboratory to determine the behavior of low-level radioactive waste solutions discharged to the ground. Strontium, cesium, and plutonium distributions between soil and waste solutions were studied. The effects of cation concentration and acidity were determined. The results of the distribution experiments, and material balance considerations, permit prediction of the behavior of activity in beds of soil. Laboratory tests with beds of soil gave results that agreed with these predictions. These results can be applied to the disposal of radioactive solutions to the ground. A typical application is discussed. (auth)

Prout, W. E. 1959. Adsorption of Fission Products by Savannah River Plant Soi1. DP-394. 
Data are presented for the equilibrium distribution of cesium, strontium, plutonium, ruthenium, and zirconium-niobium between soil of the Savannah River plant and various aqueous solutions. Low cation concentration and a $\mathrm{pH}$ range of 7 to 9 were most favorable for absorption of these elements on the soil. (auth)

Purtymun, W. D. 1971. Plutonium in Stream Channel Alluvium in the Los Alamos Area, New Mexico. LA-4561.

A survey of plutonium isotopes plutonium 238 and plutonium 239 in the alluvium of major canyons in the Los Alamos Area was made to determine concentrations and movement of soil-bound plutonium. Trace concentrations of plutonium were found in alluvium in those canyons which have received or are receiving treated effluents from operations of the Laboratory. The concentrations of plutonium in the alluvium of the remainder of the canyons were no greater than those concentrations attributed to worldwide fallout from atmospheric tests. (auth)

Purtymun, W. D. 1974. Storm Runoff and Transport of Radionuclides in DP Canyon, Los Alamos County, New Mexico. LA-5744, pp. 1-7.

Study determined runoff volume, suspended sediment load and amount of radioactivity carried out of DP Canyon by storm runoff. During summer of 1967,23 runoff events carried $\sim 88,000 \mathrm{~kg}$ of suspended sediments in $\sim 36,800 \mathrm{~m}^{3}$ of water. Sediments carried out $\sim 70 \mu \mathrm{Ci}$ of gross alpha, $211,300 \mu \mathrm{Ci}$ gross beta. About $3,000 \mu \mathrm{Ci} 90 \mathrm{Sr}$ left canyon in solution as did traces of $238 \mathrm{Pu}, 239 \mathrm{Pu}, 24 i_{\mathrm{Am}}$. (auth)

Pyalling, A. 0. 1970. Effect of Physiochemical Conditiurs of the Medium on the Leaching of Uranium from Natural Dahllite. Probl. Regional

Geol. Petrogr. Sibiri Metedy Geokhim. Geofiz. Issled. No. 2:88-91 (in Russian).

The $U$ from natural dahllite was leached in various media under normal conditions ( $1 \mathrm{~atm}, 19-200)$. The $\mathrm{pH}$ and $E_{H}$ of solns. were measured. The $U$ was determined by the luminescence-bead and phosphor-hydroquinone methods. The leaching of $U$ from phosphates in a carbonate medium $\left(4.2 \times 10^{-4}\right.$ and $\left.9.43 \times 10^{-2} \mathrm{M} \mathrm{Na}_{2} \mathrm{CO}_{3}\right)$ did not depend on the $\mathrm{E}_{\mathrm{H}}$ of the system within the range from +0.74 to $-0.27 \mathrm{~V}$. A small amount of $U$ was transferred into solution during a change of $\mathrm{Na}_{2} \mathrm{CO}_{3}$ concentration from $4.2 \times 10^{-4}$ to $9.43 \times 10^{-2} \mathrm{M}$. A decrease of $\mathrm{pH}$ to 4.5 resulted in decomposition of the dahllite lattice and in an increase in the $U$ content to $120 \mathrm{ppm}$. At $\mathrm{pH} 2.1$, the solution contained $2400 \mathrm{ppm} \mathrm{U.} \mathrm{(CA)}$

Rafalskii, R.P. and K.F. Kudinova. 1959. Conditions for the Reduction and Precipitation of Uranium by Minerals. Atomnaya Energ. 7:333-7 (in Russian). 
It is postulated that primary uranium minerals were precipitated by iron, sulfur, and arsenic reduction of U(VI) present in hydrothermal solutions. Experiments produced crystalline pitchblende, collomorphic uranium powder, and sooty uranium black formed by reduction of $U(V I)$ to $U(I V)$ by acid solutions at 100 to $135^{\circ} \mathrm{C}$. The character of the formation depends upon the precipitator mineral, interaction temperature, and in some cases on the concentration of uranium in solution. (NSA)

Rancon, D. 1973. The Behavior in Underground Environments of Uranium and Thorium Discharged by the Nuclear Industry. IN: Environmental Behavior of Radionuclides Released in the Nuclear Industry. IAEA-SM-172/55:333346 (in French).

Following various studies on the radioactive contamination of soil by fission products from a variety of effluents, it has been found necessary also to establish in what way long-lived heavy radionuclides could be diffused in underground environments. A proposal is made for the study of the behaviour in the soil of uranium and thorium originating from outside as compared with the uranium and thorium existing as natural constituents of the soil. Use was made of various types of soil (acid and alkaline) and or various minerals (argillaceous minerals, calcite and quartz). Uranium in solution, or uranyl ion to be more precise, has a certain degree of mobility in soils. The coefficient for the distribution of uranyl ion between the solution and the mineral was measured at various concentrations. The influence of the $\mathrm{pH}$ of the soil-water solution is very considerable; the retention of uranium by the soil shows a marked increase within certain narrow pH ranges. Thorium is subject to high retention by argillaceous and calcareous soils, some of the latter strongly fixing the whole amount. The influence of various parameters ( $\mathrm{pH}$, concentration, soil composition) is also substantial, as retention can be very much reduced under certain extreme conditions. The risk of the spread of thorium in dilute solution over long distances is negligible in most soils. On the other hand, a certain degree of uranium diffusion under the influence of ground-water movements is to be anticipated; diffusion evaluations are presented. (auth)

Relyea, J.F. and D. A. Brown. 1975. The Diffusion of Pu 238 in Aqueous and Soil Systems. Agronomy Abstracts, p. 124.

Movement of $\mathrm{Pu} 238$ in aqueous salt solutions and soil systems was studied by measuring the diffusion coefficients in both phases and the absorptiondesorption relationship between the phases. Aqueous diffusion coefficients were measured using the capillary tube technique. The diffusion coefficicnt in soils was determined by the quick-freeze method. Adsorptiondesorption relations were studied by adding $\mathrm{Pu} 238$ as the nitrate of $5 \mathrm{mi}$ of $\mathrm{H}_{2} \mathrm{O}$ at a pH of 2.0 and allowing it to equilibrate with one gram of soil. The effectiveness of $\mathrm{Ca}$ and $\mathrm{Ce}$ in replacing $\mathrm{Pu} 238$ from the soil were subsequently studied. Aqueous diffusion coefficients of Pu 238 were 
several times lower than the values found for exchangeable soil cations (order of $5 \times 10^{-6} \mathrm{~cm}^{2} / \mathrm{sec}$ ). The ratio of $\mathrm{Pu} 238$ adsorbed by the soil to that in the equilibrium solution was greater than 99.1. Diffusion of $\mathrm{Pu} 238$ in four different soils was also found to be much slower than for exchangeable soil cations as would be predicted from aqueous diffusion and adsorption data. (auth)

Rhodes, D. W. 1952. Preliminary Studies of Plutonium Adsorption in Hanford Soil. HW-24548.

Some preliminary studies of the adsorption of plutonium by soil indicate that at concentrations $<100,000 \cdot \mathrm{d} / \mathrm{m} / \mathrm{ml}$ and a neutral or slightly acid $\mathrm{pH}$, plutonium is adsorbed very effectively (>99\%) from an aqueous solution. The greater portion of the plutonium is adsorbed almost instaneously and seems to be adsorbed just as effectively from a solution containing as much as $82 \mathrm{mg} / 1$ of salts as from distilled water. Plutonium is adsorbed must effectively by the soil constituents having a high specific surface and a high cation exchange capacity. The results in general indicate that an exchange reaction is probably the predominate mechanism involved in the removal of plutonium from solution by soil. (auth)

Rhodes, D. W. 1957. The Adsorption of Plutonium by Soil. Soil Science. $84: 465-471$.

The experimental data suggest the definite existence of a polymer or radiocolloid for tracer concentrations of plutonium in sollution at $\mathrm{pH}>2$ with the possible exception of the $\mathrm{pH}$ range 9 to 12. Apparently the polymer formed carries a positive charge that enables it to be taken up rapidly by the soil. The rather complex chemistry of plutonium suggests that the polymer probahly has a composition approximately liat of a plutonium hydroxide al though the exact composition of the polymer undoubledly changes as the conditions of the solution are changed. The desorption of plutonium from soil is difficult to accomplish with aqueous solutions of inorganic salts, but may be accomplished readily by solutions containing orgaric anions which complex the plutonium. (auth)

Rhode3, D. H. 1957. The Effect of $\mathrm{pH}$ on the Uptake of Radioactive Isotopes From Solution by a Soil. Soil Science Soc. of Am. Proc. 21:389-392.

The reactions with natural earth illaturials of fission products and plutonium are of current interest in the field of atomic energy waste disposal and soil chemistry. Solutions containing less than $1 \times 10^{-9}$ miles per liter of selected radioisotopes were equilibrated with samples of a calcareous subsoil. The uptake of these radioactive isotopes by the soil was measured 
as a function of $\mathrm{pH}$. The uptake of $\mathrm{Cs}^{137}$ was not affected appreciably by varying the $\mathrm{pH}$ between 4 and 10 . The maximum uptake of $\mathrm{Sr} 90$ occurred at about $\mathrm{pH}$ ]0 and decreased rapjdly as the $\mathrm{pH}$ was lowered. The radioisotopes $\mathrm{Pu}^{239}, \mathrm{Ce} 44, \mathrm{Zr}^{95},-\mathrm{Nb}^{95}, \mathrm{Y}^{91}$ and $\mathrm{Ru}$ T06 exhibited a maximum uptake between approximately $\mathrm{pH} 4$ and $\mathrm{pH} 8$. Above $\mathrm{pH} 8$ a region of reduced uptake occurred and persisted up to at least $\mathrm{pH} 11$ for most of the polyvalent radioisotopes. The addition of high concentrations of sodium salts to the solution inhibited the uptake of both $\mathrm{Cs}_{5} 137$ and $\mathrm{Sr}^{90}$ by soil. A relatively small concentration of phosphate $(0.01 \mathrm{M})$ added to the system was found, in effect, to nullify the interference of sodium ion with the uptake of $\$ r^{90}$, but the phosphate ions had no apparent influence on the uptake of $\mathrm{Cs}_{S} 937$.' (auth)

Richmond, C. R. and E. M. Sullivan. 1974. Annual Report of Biomedical and Environmental Research Program of the LASL Health Division, JanuaryDecember 1973. LA-5633-PR.

Characterization of Los Alamos canyon soils - Eroded soils contained 1-2\% silt and clay in top $2.5 \mathrm{~cm}, 3-4 \%$ silt and clay in remainder of profile with CEC 2-10 meq/100 g. Noneroded soils contained up to $54 \%$ silt and clay with CEC 11-21 meq/100 g. Honey bees can be used as $3 \mathrm{H}$ contamination indicators. Radiation Ecology Studies of Liquid Waste Disposal Sites $137 \mathrm{Cs}, 238,239 \mathrm{Pu}-\mathrm{Cs}^{137}$ in soils of discharge area-depth sampling-log normal distribution. Radiation Ecology Studies at Trinity Site - 260 $\mathrm{PCi} / \mathrm{g} 239 \mathrm{Pu}$ at $\mathrm{Gr}$. Zero. Pu has penetrated $7.5 \mathrm{~cm}$ into soil in 20 years. Hydrological Characterization of Soils at the Trinity Site.

Ritchie, J. C., P. H. Hawks and J. R. McHenry. 1972. Thorium, Uranium, and Potassium in Upper Cretaceous, Pateocene, and Eocene Sediments of the Little Tallahatchie River Watershed in Northern Mississippi. Southeast. Geol. $14: 221-31$.

Size analyses and $\gamma$-ray spectrometric analyses were made of 129 outcrop samples that contained: Th $0.9-29.9$, average $8.4 \mathrm{ppm} ; U$ 0.3-10.9 average

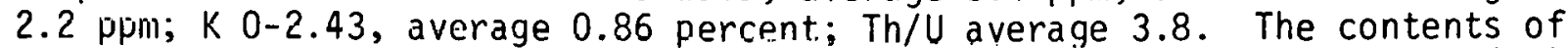
$U$, Th, and $K$ in the sediments increase with decreasing particle size. (CA)

Robertson, D. E. 1974. Physiochemical Characterization of N-Reactor Effluent Radionuclides in Soil and Water Systems. BNWL-1950, Pt. 2, pp. 82-85.

The study of the fate of introduced chemical and particulate matter in freshwater ecosystems is fundamental to our understanding of the structure and function of these water bodies. These inputs can be in a variety of forms and need not be solely related to the movement of radioactive materials despite the inherent emphasis in our programs on these isotopes. Intrinsic to investigations of this nature is understanding not only where and in what quantities these materials appear in various ecosystem components, but 
also knowing what chemical, physical, and biological processes mediate their movement. Our studies in this field have emphasized the Columbia River and its associated ecosystems for several years, and work on the chemical characterization of reactor effluents before and after their passage through the soil before reaching the Columbia is continuing. Emphas is in this program, however, has shifted to more detailed studies of lentic habitats receiving low-level radioactive effluents. Our goal is to provide basic data on the cycling of radionuclides within these ponds which will be useful to both ecologists and waste management personnel. (auth)

Romney, E. M., H. M. Mork and K. H. Larson. 1970. Persistence of Plutonium in Soil, Plants and Small Mammals. Health Physics. 19:487491.

Periodic surveys during a 10 year period were made of the persistence of residual $239 \mathrm{Pu}$ in soil, plants and small mammals indigenous to fallout areas contaminated with $239 \mathrm{Pu}$ dispersed by high explosive detonations. Downward migration of fallout particles occurred in undisturbed soil profiles, and wind and water erosion accounted for some redistribution of the initial $239 \mathrm{Pu}$ contamination $1 \mathrm{nng}$-torm cropping experillents shuwed a relatively low degree of $239 \mathrm{pu}$ transfer from soil to plants, but there was a consistent increase in its accumulation in plant tissue during a five year cropping sequence. Plant uptake of $239 \mathrm{pu}$ from soil was enhanced by DTPA chelating agent. Qualitative trends from these surveys indicate that the accumulation of residual $239 \mathrm{Pu}$ in kangaroo rats and jackrabbits was highest in bone tissue; considerable amounts also were found in lung tissue. Inhalation is known to be the major pathway for plutonium deposition in lung and bone, but the high levels found in the gastrointestinal tracts indicate that ingestion is also an important route through which these small mammals maintained contact with the residual $239 \mathrm{Pu}$ contamination in the environment.

Reytson, 'R. C., G. Jansen and A. V. Robinson. 1975. Sorption of ${ }^{99} \mathrm{TC}$, $23 \%_{\mathrm{Np}}$ and $24 \hat{T}_{\mathrm{Am}}$ on Two Subsoils From Differing Weathering Intensity Areas. BNWL-1889. 15 p.

Distribution coefficients (Kd values) were determined on subsoils from Washingtül and South Carolina for ${ }^{24} \mathrm{Am},{ }^{23} \mathrm{~Np}$, and ${ }^{99} \mathrm{Tc}$ as a function of equilibrium solution concentration of calsium $\left(\mathrm{Ca}^{+2}\right)$ and of sudium $\left(\mathrm{Na}^{+}\right)$. $\mathrm{Kd}$ values decredsed in all cases with increasing solution concentraliuns of $\mathrm{Ca}^{+2}$ and $\mathrm{Ni}+$ For lhe south Carolina subsoil Kd values ranged from 1.0 to 67 for ${ }^{241} \mathrm{Am}$ as a function $0 \mathrm{f}_{\mathrm{Ca}}+2,1.6$ to 280 for $24 \mathrm{Am}_{\mathrm{Am}} \mathrm{a}$ function of $\mathrm{Na}^{+}, 0.43$ to 0.66 for $237 \mathrm{~Np}$ as a function of $\mathrm{Ca}^{+2}$, and 0.16 to 0.25 for $237 \mathrm{~Np}$ as a function of $\mathrm{Na}^{+}$. For the Washington soil Kd values were greater than 1200 for $24 l_{A m}$ and ranged from 0.36 to 2.37 as a function of $\mathrm{Ca}^{* 2}$ and rrom 3.19 to 3.90 for $237 \mathrm{~Np}$ as a function of $\mathrm{Na}^{+}$. Kd values for ${ }^{99} \mathrm{Tc}$ were essentially $\mathrm{O}$ at all $\mathrm{NaHCO}_{3}$ concentrations on the South Carolina subsoil. (auth) 
Rozzell, T. C., and J. B. Andelamn. 1971. Plutonium in the water Environment. II. Sorption of Aqueous Plutonium on Silica Surfaces. Advances in Chemistry Series 106: 280-298.

The sorption and desorption of aqueous plutonium in the range of 10-7 to $10^{-8} \mathrm{M}$ was studied on quartz and other silica surfaces. Sorption continued typically for 12 to 15 days before apparent equilibrium was reached, and the distribution of plutonium particle sizes sorbed on the silica was different from that in solution. At pH 7, sorption increased with increasing ionic strength, but decreased when bicarbonate was added. The amount of sorption varied at pH 5 and 7 , but differently at high and low ionic strengths, as well as with the age of the solution. Plutonium desorption indicated that there were two basically different sorbed species, and the rate and quantity of desorbed material increased at $\mathrm{pH} 5$ compared with 7 and 9 . (auth)

Rubtsov, D. M. 1966. Distribution of Thorium in Various Soils. Pochvovedenie. No. 3:55-67 (in Russian).

Different concentrations of thorium and its decay products in soils cause different levels of $\gamma$ radiation output above the surface of the soil mantle. The concentration of thorium in fine grain soil, that is, products of weathering and soil formation, is higher than in basement rock-schists with layers of quartzite. Increased concentration of thorium in the fine gra in soil is related to processes of weathering and soil formation. The fluctuating concentration of thorium in the soil determines basically the concentration. of thorium in the air near the ground. The presence of thorium in vegetable objects indicates that it is in the biological cycle in nature. The uptake of thorium in vegetative objects is determined not only by the concentration of thorium in the fine grained soil but is also regulated by the species of vegetative association and by the trend in the soil-making process. The processes of soil formation, characteristic of a bioclimatic zone, appear as the basic source of the transdistribution ut thorium in the soil profile. (auth)

Rubtsov, D. M. 1972. Thorium and Uranium Content in the Clay Fraction of Podzolic Mountain Soils of Thin Forests. Radioekol. Issled. Prir. Biogeotsenozakh, D. . 53-65 (in Russian).

Th and $U$ were quantities determined in clay fractions of individual genetic horizons of thin forest pudzolid mountain soils from localities with significantly different levels of $\gamma$-radiation above the soil surface. Th in the $<0.001 \mathrm{~mm}$ fraction appears to be the primary sourse of Th accumulation in soil. This fraction can be involved in the soil-plant biological cycle and it is capable of forming organo-mineral complexes. The maximum content of Th was in the $A_{2}$ and $B C$ horizons. The soil fractions $>0.001 \mathrm{~mm}$ contained 57-96 percent of total $U$ in the soil; this is explained by the high miner- 
izing capacity of $U$ compounds. A relatively high level of $U$ was found in the $>0.001 \mathrm{~mm}$ fractions of the podzolic $A_{2}$ horizon. Th was found in some organic matter fractions. Forest litter contained more $U$ than Th. (CA)

Sackett, W. M., T. Mo, R. F. Spaling and M. E. Exner. 1973. A Revaluation of the Marine Geochemistry of Uranium. IN: Radioactive Contamination of the Marine Environment. IAEA-SM-158/51:757-769.

Approximately $10^{15} \mathrm{\mu g} / \mathrm{yr}$ of dissolved uranium are being removed from the ocean by each of the generally accepted significant sinks for uraniumcarbonate deposits and deep anoxic basin sediments. However, these sinks account for only 10 percent of the estimated present-day input of uranium. Possible explanations for this discrepancy are: 1) contemporary input values are too high owing to a significant conlribution from man's effects, such as uranium input via phosphate fertilizers or world-wide cultivation leading to premature leaching of uranium from soils, or 2) there are other important uranium sinks such as the abundant siliceous oozes or continental shelf anoxic sediments. (auth)

Sakanoue, M. 1960. Geochemical Studies on the Radiactive Sediments. II. Uranium Content of Natural Waters from the Ningyo-Pass Mining Area. Nippon Kagakii Zasshi 81: 896-8.

In order to find the amounts of $U$ leached from the U-bearing sedimentary bed by the action of natural waters, $U$ was determined paper chromatographically in water samples collected inside the drift of the NingyoPass mine and from the rivulets and streams near the mine. Waters that have passed through the unoxidized zone tend to contain higher concentrations of $U(80$ and $250 \mathrm{\gamma} / \mathrm{l}$.$) than that passed through the oxidized zone (27-33$ $\gamma 1)$. This tendency was confirmed by a model experiment; 2 ore samplesned obtained frum the two zones were treated with water of different pH values, and the supernatant liquids were analyzed for $U$. (CA)

Sakanoue, M. 1960. Geochemical Studies on the Radioactive Sediments. III. Uranium, Phosphorus, and Arsenic in the Sedimentary Bed at Ningyo Pass, fippon Kagaku Zasshi $81: 898-902$.

$U, P$, and As were determined in core samples taken from the unoxidized zone where ningyoite occurred, oxidized zone where outunite occurred, mixed zone, and shale beds containing fairly large amounts of U. Arsenic was determined by a modified Gutzeit method, and $P$ by the molybdenum blue method after evolution of arsine. In the unoxidized zone correlation is highly positive between $U$ and $P$, suggesting that the $U$ in these sediments was deposited mainly as a compound whose composition corresponds to that of ningyoite, a $\mathrm{Ca}^{++} U^{4+}$ phosphate mineral. In the unoxidized zone $U$ also shows a positive correlation with As, and the presence of As-bearing pyrite (as high as 0.76 percent As) was confirmed. It is pointed out that pyrite is related to the deposition of $U$. (CA) 
Schel1, W. R. and R. L. Walters. 1974. Plutonium in Aqueous Systems. RLO-2225-T18-11. $26 \mathrm{p}$.

A review was made of the available information concerning $\mathrm{Pu}$ in the aquatic environment. The levels are low and the data on the environmental concentrations in lake and marine environments are very limited. of particular relevance to biological accumulation processes is the physicalchemical state of Pu. Limited information is available in natural environmental waters. Indications are that the plankton has the highest concentration factors and that the concentration factors decrease with increasing complexity of the organisms. Results of recent studies of $239 \mathrm{Pu}, 240 \mathrm{Pu}$, and 241 Am concentrations in water, sediment, and biota at Bikini and Eniwetok Atolls are given. The water samples measured indicate that $\mathrm{Pu}$ exists in the particulate, soluble and colloidal physical-chemical states. The plutonium is being injected into the water column from the sediments and has not been removed from the biogeochemical cycle after 16 years. Concentrations of $\mathrm{Pu}$ in vertebrates and invertebrates measured at Eniwetok were low and ranged from .001 to $.2 \mathrm{pCj} / \mathrm{g}$ wet in fish muscle. Additional data are required to better evaluate the potential hazards to man of $\mathrm{Pu}$ in the aquatic environment. A computer program was developed to estimate the final forms of soluble $\mathrm{Pu}$ in natural waters under certain conditions of acidity, oxidation potential, and complexing factors. (CH)

Schmalz, B. L. 1972. Radionuclide Distribution in Soil Mantle of the Lithosphere as a Consequence of Waste Disposal at the National Reactor Testing Station. ID0-10049, pp. 27-55.

The movement of Pu wastes from Rocky Flats, buried as solids, was monitored via bore holes in the burial grounds. From lab tests, the diffusion coefficient of plutonium was estimated as $4.8 \times 10^{-12} \mathrm{~cm}^{2} / \mathrm{sec}$, resulting in movement of $8.5 \mathrm{~cm}$ in $2.4 \times 10^{5}$ years. However, $\mathrm{Pu}$ and $\mathrm{Am}$ have been leached from the wastes under saturated conditions and deposited in pit soil lining. The study concluded that moisture movement was the principle transport factor and any action inhibiting water entry to the contaminated zone would be desirable. (auth)

Schneider, H. and W. Block. 1968. On the Question of the Capacity of the Rhine for Radioactive Nuclides. Sorption of Radionuclides by Sediments of the Rhine. Gas Wasserfach. 109:1410-15. (in German).

For estimation of the action of decontaminating sediments and suspended material in rivers charged with radionuclides, the sorbability of depusits of the Rhine for several nuclides was determined; the sorbability increases in the following order: $I^{-}, \operatorname{Sr}($ II) $, P u(I V), \operatorname{In}(I I), C S(I)$. Saluration was reached by sediments after 24 hours at the latest for all nuclides. The sediment samples were taken from Oehningen (Upper Rhine), Koblenz (Middle Rhine), and Wesel (Lower Rhine). Data were compared with the organic content ior each sample. The sorption of $337 \mathrm{Cs}$ is dependent on grain size but not on orqanic material. A sudden release by living or 
dead organic material of radionuclides is not possible, though desorption from mineral suspended material is more rapid, often occurring within a few hours. Less than 1\% of transported nuclides in the Rhine under any conceivable conditions would be bound to suspended material or sediments. (NSA)

Schuiz, R. K. 1965. Soil Chemistry of Radionuclides. Health Physics. $11: 1317-24$.

The naturally occurring radionuclides found in the soil in significant amounts include $14 \mathrm{C}, 40 \mathrm{~K}, 87 \mathrm{Rb}$, and members of the $U$, Ac, and Th series. More than 300 radioisotopes will be undetectable, because of their short half-1ives. $\mathrm{Y}, \mathrm{Pr}, \mathrm{Pm}, \mathrm{Th}, \mathrm{Pa}, \mathrm{Zr}$, and $\mathrm{Nb}$ occur in soils, but are either very strongly adsorbed by the clay particies or are present as insoluble oxides or hydroxides. In either of these states, these elements will be immobile in the soil and largely unavailable to plants. The elements which have a greater degree of mobility include $\mathrm{Sr}$, Ba, U, Ra, Pb, Mn, Co, Zn, Fe, Ru, Cr, K, Rb, $\mathrm{Ca}$, and $\mathrm{C}$. In considering the mobility of any ion, all others have to be taken into account. The amount and species of the complementary ions will have a strong influence on the redistribution of thesc isotopes in life soil profile and will affect plant uptake. (CA)

Somayajulu, B. L. K. and T. M. Church. 1973. Radium, Thorium, and Uranium Isotopes in the Interstitial Water from the Pacific Ocean Sediment. $\mathrm{J}$. Geophy. Res. 78:4529-31.

The $\mathrm{Ra}$, Th, and $U$ isotopic concentrations were determined in the interstitial water expressed from a deep sea core of the eastern equatorial Pacific. The isotopes $226 \mathrm{Ra}, 228 \mathrm{Ra}, 230 \mathrm{Th}$, and $228 \mathrm{Th}$ are higher by 1 to 3 orders of magnitude than their concentrations in seawater. Ra release from sedimentary phascs with migralion into the water column is indicated. The results are also compatible with the excess $228 \mathrm{Th}$ (relative to $232 \mathrm{Th}$ ) found in authigenic deep sea minerals. (CA)

Sugimura, Y. 1964. Natural Radioactive Elements in the Ocean. Kagaku No Ryoiki. 18:89-101 (in Japanese).

A review is given of the distribution of natural radioactive elements and isotopes in seawaters and sediments. The $U$ contents in seawatrors are tabulated; Lhe average is $3.3 \times 10^{-6} \mathrm{~g} \mathrm{U} / 1$. The $234 \mathrm{U} / 238 \mathrm{U}$ ratio is discussed. The $U$ contents in sea sediments are from 0.1 to 80 ppm. Attempts were made to determine $231 \mathrm{~Pa}$ in seawaters and sediments. Seawaters contain $2 \times 10^{-9}$ $1 \times 10^{-7} \mathrm{~g} \mathrm{Th} / 1$ and $\mathrm{n} \times 10^{-11} \mathrm{n} \times 10^{-14} \mathrm{~g} 230 \mathrm{Th} / 1$. Sea sediments contain 6-13 ppm Th; 60-70 percent. of the Th is lcached with cold $\mathrm{HCl}$. Studies were made to defermine the sedimentation rate of sediment from the contents of $232 \mathrm{Th}$ and $230 \mathrm{Th}$ (Io). Many data are available on the $226 \mathrm{Ra}$ contents in 
seawaters, and the table is given. These contents are less than those in equilibrium with $U$. Pelagic sediments contain an average of $10 \times 10^{-12} \mathrm{~g}$ $226 \mathrm{Ra} / \mathrm{g}$. Distributions of $210 \mathrm{~Pb}, 210 \mathrm{Po}, 227 \mathrm{Ac}$, etc., are discussed. The surface seawaters off Cal ifornia contain $0.2 \times 10^{-6} \mathrm{~Pb} / 1$. The sea sediments contain an average of $30 \mathrm{ppm} \mathrm{Pb}$. (NSA)

Swanson, J. L. 1973. Nature of Actinide Species Retained by Sediments at Hanford: Interim Progress Report. BNWL-B-296.

A program to develop leach procedures appropriate to characterizing the behavior of different actinide species retained by soils is in progress. Characterization of the $\mathrm{Pu}$ species present in samples taken from the 216-Z-8 trench has been made difficult by the presence in these samples of materials which form only sparingly soluble $P u$ compounds. Because of the presence of these materials, in some cases the leaching of the $\mathrm{Pu}$ is more a function of the solubility of $\mathrm{Pu}$ in the leach solution than it is a function of the $\mathrm{Pu}$ species present in the soil. Pretreatments of the soil samples with alcohol, with hydroxide solutions, and with TBP solutions have been found to give at least partial removal of these $\mathrm{Pu}$ solubility-limiting materials.

The percentage of the $\mathrm{Pu}$ that dissolved readily in $5 \mathrm{M} \mathrm{HNO} 3$ at room temperature (using repeated solution changes to minimize the effect of the Pu solubilitylimiting materials) was found to range from 3 to 90 percent depending on sample location and depth. The higher removal percentages were achieved with the deeper portions of the samples.

Data on the amounts of actinides, water, and organophosphates present in the 216-Z-9 trench samples used in this work are included in the Appendix. The $\mathrm{Pu}$ content was found to range from $0.06 \mathrm{mg} \mathrm{Pu} / \mathrm{g}$ soil near the 24 -inch level to $10 \mathrm{mg} \mathrm{Pu} / \mathrm{g}$ soil in the surface portion of one of the samples; the water content was found to range from 4 to 33 percent and the organophosphate content ranged up to 1.4 percent. (auth)

Szalay, A. 1954. The [nrichment of Uranium in Some Brown Coals in Hungary. Acta. Geol. Acad. Sci. Hung. 2:299-311.

Geochemical enrichment of uranium is ascertained in some brown coal strata in Hungary. These strata are situated near to the detritus zone of the two existing granitic mountains of Hungary. The uranium content of these coal strata is about the same (about 0.01 percent) as the $U$ content of bioliths (oil shales, carbonate rocks, etc.) uscd to be. It seems highly probable that the same unknown general geochemical law is responsible for all such enrichments in biollths. The granitic rocks are the primary sources of uranium, the $U$ migrated into the sea or moor water during the age of chemical decomposition of the rocks. Uranium became adsorbed by the decomposing organic substance of the sediments. Laboratory experiments revealed that decomposing plant debris, peat, lignite, and brown coal have a very high adsorption power and capacity for uranium, which is in fact sufficiently high 
to explain geochemical enrichment. Subsequent experiments revealed and control experiments verified that the humic acid colloid particles are responsible for the adsorption, which is a cation exchange process. The adsorption equilibrium constant of humic acid substance is much higher for uranium than for cations of lower valence and lower atomic weight. It seems that the hitherto unknown law of geochemical enrichment of uranium in bioliths is herewith explained. This law may be formulated in the following manner: the geochemical enrichment of uranium in carbonate rocks (bioliths) is caused by the adsorption of dissolved uranium by the humic acid content of the sediments. The adsorption is a cation exchange process. (auth)

Szalay, A. 1957. The Role of Humus in the Geochemical Enrichment of $U$ in Coal and 0ther Bioliths. Acta. Phys. Acad. Sci. Hung. 8:25-35.

Investigations established that the enrichment of $U$ in peats, coals, and other bioliths is caused by adsorption on the humic acid. Adsorption isotherms have been measured and numerically evaluated. The adsorption itself is actually a cation exchange process. The enrichment factor of $1: 10,000$ agrees well with the quotient of the concentration of $U$ in bioliths and natural waters. (auth)

Tamura, T. 1974. Distribution and Characterization of Plutonium in Soils from Nevada Test Site. IN: Dunaway, P. B. and M. G. White (eds.). The Dynamics of Plutonium in Desert Environments. NV0-142 (NVO-AEIC-74-1 or $U C-2): 29-42$.

This study was undertaken to determine the distribution and characterization of plutonium in soil fractions of the Nevada Applied Ecology Group (NAEG) intensive site study area samples. This report discusses analytical results obtained on three selected surface soil samples from two areas at Nevada Test Site.

Analytical methods are described for determination of total plutonium content, plutonium distrihution in different particle size fractions, and shorttime digestion leachability by $\mathrm{HNO}_{3}$ revealed that 65 to 91 percent of the plutonium could be leached. The leaching results suggest the possibility of using the acid extraction as a means of predicting the "availability" of plutonium in soils. Preliminary data suggest that plutonium in the coarser size fractions is $\mathrm{PuO}_{2}$, whereas plutonium associated with the finer size particles possibly is a hydrous $\mathrm{PuO}_{2}$. (auth)

Tamura, T. 1975. Characterization of Plutonium in Surface Soils From Area 13 of the Nevada Test Site. IN: White, M. G. and P. B. Dunaway (eds.). The Radioecology of Plutonium and Other Transuranics in Desert Environments. NV0-153 (UC-2):27-41. 
Total plutonium was determined in nine surface soil samples $(0-5 \mathrm{~cm})$ from Area 13 in the Nevada Test Site (NTS). Particle size segregation was performed, and each particle size fraction of seven samples was analyzed for plutonium. The coarse silt fraction [53-20 micrometers $(\mu \mathrm{m})$ ] contained the highest percentage of plutonium in the soil (about $65 \%)$. Evidence of erosional translocation of plutonium was observed in one sample and corroborative evidence was noted in describing the soil type. Tests with 8 molar (M) nitric acid showed that about $13 \%$ of the plutonium was leached from the NTS sample, about $70 \%$ from sediments at Oak Ridge, and about $83 \%$ from sediments at Mound Laboratory. In $0.1 \mathrm{M}$ citric acid, about $1 \%$ of the plutonium was extracted from an NTS sample, $25 \%$ from Oak Ridge samples, and $44 \%$ from Mound. Implications of these results on transport of plutonium within the NTS are discussed. (auth)

Tamura, T. 1975. Physical and Chemical Characteristics of Plutonium in Existing Contaminated Soils and Sediments. IAEA-SM-199/52.

Plutonium from three sites has been studied to provide information necessary in understanding its behavior and fate under prevailing conditions. Plutonium in soils from the Nevada Test Site (NTS) was predominantly associated (5075 percent) with the coarse silt $(53-20 \mu \mathrm{m})$ fraction. The coarse silt fraction was further segregated by density gradient zonal centrifugation; the plutonium in the sample from a bare soil ranged from 60-85 percent in the "heavy" mineral plutonium in a sandy mound taken beneath shrubbery occurred predominantly (80-95 percent) in a lighter fraction $\left(2.5-2.7 \mathrm{~g} / \mathrm{cm}^{3}\right)$ associated with feldspar. Soil extraction of NTS plutonium with $0.1 \mathrm{M}$ citric acid solution showed very low solubility ( $\sim 1$ percent).

The plutonium in samples from Oak Ridge National Laboratory (ORNL) and Mound Laboratory (ML) was predominantly in the clay size $(<2 \mu \mathrm{m})$. The solubility in citric acid was about 20-25 percent in the ORNL sample and 40-50 percent in the ML sample. Density gradient segregation of the clay size fraction of the ML sample showed the activity distribution to be directly related to the weight of the recovered fraction with enhanced contribution by the very light organic fraction. Approximately 71 percent was found in the $2.3-2.4 \mathrm{~g} / \mathrm{cm}^{3}$ fraction which contr 1] led 65 percent wieght percent of the clay and 16 percent in the $<1.8 \mathrm{~g} / \mathrm{cm}^{3}$ fraction (organic fraction) which contained 6 percent of the weight fraction. (auth)

Tamura, T., E. R. Eastwood and 0. M. Sealand. 1972. Applied Soils and Waste Management Studies. IN: Environmental Sciences Division Annual Progress Report Ending September 30, 1972, ORNL-4848. pp. 49-51. 
A recovery technique for $\mathrm{Pu}$ is outlined. Total extraction was accomplished from $\mathrm{Pu}$ contaminated soil by use of $\mathrm{HNO}_{3}-\mathrm{HF}-\mathrm{HCl}$, ferric hydroxide and anion exchange purification and electrodeposition. Only about $12 \%$ of the $\mathrm{Pu}$ was extracted by a 2-hour digestion with $8 \mathrm{MHNO}_{3}$.. Eventual goal is to characterize the Pu-soil relationship and migration. (auth)

Taylor, C. I. (ed.). 1975. Environmental Sciences Division, Annual Progress Report for Period Ending September 30, 1974. ORNL-5016 (UC-48 Biology and Medicine): 1-8.

Initial adsorption measured after three weeks of addition of $163 \mu \mathrm{g} \mathrm{Pu} / 1$ solid, showed that Ca-saturated humic acid was a very effcctive surber and did not release $P u$ readlly upon equilibration with citrate. Camontmorillonite and Ca-kaolinite did not sorb $2-3 \%$ of the $163 \mu \mathrm{g} / \mathrm{g} P u$ added. When $P u$ was added at the rate of $0.6 \mu \mathrm{g} / \mathrm{g}$ solid, the removal of natural organic matter and/or iron oxide coatings from clay reduced the efficiency of Pu sorption by clay by only 1-5\%. The higher Pu solubility of soils in which Pu was associated with clay fraction compared to soils in which $\mathrm{Pu}$ was mainly associated with coarser silt sand fractions indicate that the solubility differences may be due to particle size of plutonium particles. (auth)

Templeton, W. L. and A. Preston. 1966. Disposal of Radioactive Waters into Seas, Oceans and Surface Waters. IN: IAEA Publication. pp. 267-289.

Authors reported that various radioactive materials penetrate or redistrihute with depth in seabed materials in different propgrtions 106 The penetration was in the following order: $239 \mathrm{Pu}{ }^{37} \mathrm{Cs}{ }^{9} 0_{\mathrm{Sr}}{ }^{106} \mathrm{Ru}$. The penetration ratio (amount in 15-23 cm depth divided by amount in $0-5 \mathrm{~cm}$ depth) for plutonium and cesium were 0.17 and 0.08 , respectively. (auth)

Thomas, W. A. and D. G. Jacobs. 1969. Curium Behavior in Plants and Soil. Soil Science. 108:305-307.

$\mathrm{Cm}^{242}$ was used to measure curium sorption by several clays in equilibrium experiments and in loading and leakaqe of hydrobiotite coluuris. Results indirated that above d $\mathrm{pH}$ of about 3, an increasing amount of radiocolloid existed as the $\mathrm{pH}$ was increased. Plants grown on a curium-contaminated soil relocaled very little of the curium to foliage. (auth)

Thorburn, R. C. 1950. Absorption on Hanford Soil and Related Soil Properties. $\mathrm{NW}-15655$.

The effects of a solution of $\mathrm{MgCO}_{3}$ and $\mathrm{CaCO}_{3}$ on the retention of $\mathrm{Pu}$ by Hanford soil columns was ascertained. There was no effect on measured effluents as compared to noncarbonate-containing influents. From 55 to 
$94 \%$ of the water eluted $\mathrm{Pu}$ was resorbed by another soil column. Only $24 \%$ of the Pu was retained on a soil at pH 10 compared to $77 \%$ to $87 \%$ at pH 3.8 to 7.2 . (auth)

Titaeva, N. A. 1969. Behavior of Natural Radioactive Elements During Mechanical and Chemical Transportation Under Yakutia Conditions. Vestn. Mosk. Urui., Geol. 24:88-91 (in Russian).

Modes of chemical and mechanical migration of radioactive elements under the extremely cold continental climate of Uakutia are studied. Average concentration (c) and standard deviation (e) of $U$ and $T h$ in the alluvial transported sands of Aldan-Timptonsk and Lena are $1.3(U, C)$ and 1.7 (Th, $\mathrm{C}$ ), respectively. The $T h / U$ ratio ranges $4.1-11.7$. Chemical migration of radioactive elements is more prominent in slightly mineralized $\left(\mathrm{Na}-\mathrm{HCO}_{3}\right)$ waters of Yakutia. The coefficient of migration of $234 \mathrm{U}>238 \mathrm{U}>226 \mathrm{Ra}>230 \mathrm{Th}>232 \mathrm{Th}$.

Titaeva, N. A. and T. I. Veksler. 1969. Uranium and Thorium During Weathering of Yakutia Rocks. Geokhimiya. No. 6:740-4. (in Russian).

The behavior of $U$ and Th was studied during weathering of bedrock under specific conditions of the sharply continental climate of Yakutia and widely distributed permafrost, i.e., under conditions inducive to intense physical weathering. Cold waters over the permafrost layer are rich in organic substances and have elevated $\mathrm{O}_{2}$ and $\mathrm{CO}_{2}$ concentrations favorable for chemical weathering of upper thawing layers of rocks. The study was made in two areas in the upper reaches of the Vilyui River and in the Aldan-Timpton interfluve. The first region was within the large differentiated trap intrusion and the second consisted of an Archean metamorphic gneiss and crystalline schist complex. Noticeably high removal of Th, accumulating in alluvium, was observed in both areas. The $U$ was also removed from all rocks. The removal of $U$ somewhat lagged behind that of other metal components in rocks which were relatively easily chemical weathered (carbonate rocks, tuffs, and dolerites), the $U$ concentration increasing somewhat in the eluvium from these rocks. This was not observed in crystalline metamorphosed and aridic igneous rocks where the eluvium had a somewhat low concentration of $U$. The mobile $U$ was removed first. The Th/U ratio increased in the weathering products of all rocks. The Th/U ratio can be used as an indicator of chemical weathering of rocks. (CA)

Tugarinov, A. I. and I. B. D'yachkova. 1967. Some Common Geochemical Characteristics of Selenium and Uranium. Vop. Prikl. Radiogeol. No. 2:380-6 (in Russian).

The Se geochemistry in earth crust is controlled above all by analogy of its properties with those of $\mathrm{S}$. The highest $\mathrm{Se} / \mathrm{S}$ ratio, typical of sedimentary rocks in which the Se is present mostly in the form of native Se of selenides 
is accompanied, as a rule, by $U$ mineralization. The mobility of Se and $U$ under oxidizing conditions and their almost complete inert behavior in reducing medium are the main geochemical properties controlling Se and $U$ in exogenic processes. Extraction of $S e$ and $U$ from rocks is possible by solutions, having sufficiently high En, through oxidation. The alkaline medium is the most favorable for simultaneous transfer of Se and $U$ into the mobile state. The Se and $U$, migrating in surface waters, are concentrated in rocks having high reducing capacity. If, under favorable conditions (short distance from the denudation area, oxidation character of the solution, etc.) the Se reaches the sea, then, similarly to $U$, it is precipitated immediately, and is accumulated in the continental shelf region. Absorption phenomena promote the separation of $S e$ and $S$ in addition to oxidation-reduction factors. Organic substances played a large part in the concentration of Se and $U$. Under hypogene conditions, the oxidation-reduction factor controlled to a large degree the furmation of sediments of elements having changing valency in a definite sequence. (CA)

Tyuryukanova, E. B. and V. A. Kalugina. 1971. The Behavior of Thorium in Soils. Soviet Journal of Ecology. 2:467-469.

An Investigation of thorium distribution in soil profiles showed that it accumulated in the ferruginous humus horizon or in the humus hurizon of meadow soils. The latter accumulation may be indicative of biological cycling. Thorium contents were lowest in peaty horizons indicating limited uptake of thorium by bog plants.

Van Dalen, A., F. de Witte and J. Wiskstra. 1975. Distribution Coefficients for Some Radionuclides Between Saline Water and Clays, Sandstones and Other Samples From the Dutch Subsoil. Reactor Centrum Nederland, 75-109.

Distribution coefficients for $\mathrm{Pu}$ and Am were determined on Dutch subsoils of marine origin from $90 \% \mathrm{NaCl}$ saturated solutions at $\mathrm{pH} 7$ to 8 . For samples composed of mainly illite and kaolinite $\mathrm{Kd} \mathrm{Pu}$ is $\sim 10^{4}$ and $\mathrm{Kd} \mathrm{Am}$ is $25 \times 10^{4}$. The $\mathrm{Kd} \mathrm{Pu}$ and $\mathrm{Kd} \Lambda \mathrm{m}$ for river sand are respectively 200 and 400. Gypsum-bearing and clay-bearing sandstones were intermediate. The $\mathrm{pH}$ dependence on sorption processes for the elements $\mathrm{Pu}$ and $\mathrm{Am}$ between pH 5-8 was minor. (auth)

Veeh, H. H. 1967. Deposition of Uranium from the Ocean. Earth Planet. Sci. Lett. 3:145-50.

Anaerobic sediments from the upper continental slope in the eastern Pacific, the Gulf of California, and a Norwegian Fjord have been analyzed for their total uranium content and $234 \mathrm{U} / 238 \mathrm{~J}$ ratios by alpha-spectrometry. The uranium concentrations range from 4.8 to $39 \mathrm{ppm}$ and are thus significantly higher than the average uranium content of three ppm in deep sea clays, stream sediments and soils. The $234 \mathrm{U} / 238 \mathrm{U}$ ratios approach the seawater 
value of 1.15 in samples with high uranium content. These results indicate that uranium is being removed from seawater in near shore areas under certain conditions. If such conditions prevail in only 0.4 percent of the total area covered by the ocean, an amount of uranium equal to that supplied by streams (assuming $0.04 \mu \mathrm{g} / 1$ ) can be removed from the ocean, on the basis of measured accumulation rates in the Gulf of California, off southern California, and in other areas. The effect of Pleistocene sea level fluctuations as a controlling factor in determining the concentration of uranium in seawater is diminished by the occurrence of extensive areas of uranium deposition below $200 \mathrm{~m}$ and by the very long residence time of uranium in the ocean. (auth)

Wahlgren, M. A. and D. M. Nelson. 1972. Plutonium in Lake Michigan Water. IN: Radiological and Environmental Research Division Annual Report. Ecology, Jan.-Dec. 1972. ANL-7960, Part III, pp. 7-14.

$239 \mathrm{Pu}$ fallout is rapidly sedimented in Lake Michigan with half 1 ife of removal $1.0 \pm .3$ years. There is no vertical or horizontal plutonium gradients in early June in Lake Michigan waters.

Three percent of the plutonium fallout deposition is in water column at any given time.

Wahlgren, M. A. and D. M. Nelson. 1973. Evidence of an Annual Plutonium Cycle in the Near-Surface Waters of Lake Michigan. ANL-8060 (Pt. 3), pp. 90-92.

The rapid depletion of ${ }^{239} \mathrm{pu}$ from the surface waters of Lake Michigan during July and August, the concurrent changes in the season, and the demonstrated preferential sorption of fallout ${ }^{239} \mathrm{Pu}$ over ${ }^{137} \mathrm{Cs}$ by net plankton all suggest that a biological mechanism is the major removal step in a cycling process involving $\mathrm{Pu}$ and may contribute to the eventual removal of this element to the sediments. (NSA)

Wahigren, M. A. and D. W. Nelson. 1973. Plutonium in the Five Great Lakes: Comparison of Surface Waters. ANL-8060 (Pt. 3), pp. 93-98.

Studies of the fallout radionucludes ${ }^{239} \mathrm{Pu}, 137 \mathrm{Cs}$, and ${ }^{90} \mathrm{Sr}$ in Lake Michigan demonstrated that a homogeneous distribution can be found throughout the water solumn following the winter mixing period, provided that the input of new fallout radioactivity is low as was the case ill 1972 and 1973. Assuming that generally similar mixing behavior prevails in all the Great Lakes, surface water and plankton samples were ub tained during May and June, 1973, and analyzed for $239 \mathrm{Pu}, 137 \mathrm{Cs},{ }^{90} \mathrm{Sr}$ and ${ }^{125} \mathrm{Sb}$ as an indicator of recent fallout. The results of the interlake comparison stydy are consistent with the results of more detailed studies on $239 \mathrm{Pu}$ and 13. Cs in Lake Michigan, indicating that the major fraction of both of 
these fallout isotopes has been removed relatively rapidly to the sediment, and suggesting that the average cumulative deposition rate in sediments will approximate that on land for all five Great Lakes. (NSA)

Wahlgren, M. A. and D. M. Nelson. 1974. Studies of Plutonium Cycling and Sedimentation in Lake Michigan. Proc. 17th Conf. Great Lakes Res. $1974: 212-218$.

Estimates of cumulative deposition, together with the results of extensive lakewide sampling in 1972, yielded estimates of mean halftimes for removal from the water column of Lake Michigan of $1.0 \pm 0.3$ years for Pu 239,240 and $1.4 \pm 0.3$ years for C.S 137. However, data frum 1971, 19\%, and 1973 water samples indicate that the recent halftime is much greater than the 1963-1972 average, presently being on the order of 3 to 4 years for both $\mathrm{Pu} 239$ and Cs 137. The longer turnover time is consistent with the Cs 137 turnover time in the water column deduced from analysis of preserved Lake Michigan alewives. Water filtration experiments have demonstrated that $>75 \%$ of the plutonium is nonfilterable and is present as colloid or subcolloidal sized fractions. At an offshore station near Grand Haven, Michigan, the concentration of Cs 137 in the epilimnion underwent a slight but significant decline from June to November, whereas Pu 239 was reduced to a small fraction of its spring value. In net plankton samples dominated by phytoplankton as much lower mean Cs 137: Pu 239 ratio is observed than in water samples, indicating a preferential sorption of Pu 239 over Cs 137 by phytoplankton. The results of these experiments suggest that sorption by phytoplankton (and the subsequent rapid settling from the epilimnion of phytodetritus and/or zouplankton fecal pellets) is responsible for the rapid removal of Pu 239 from the epilimnion. (auth)

Wallace, A. 1972. Effect of Soil pH and Chelating Agent (DTPA) on Uplake by and Dis Lribution of Americium 241 in P.lant Parts of Bush Beans. Radiation Botany. 12:433- 5 .

Bush Bean (Phaseolus vulgaris L. var. Improved Tendergreen) plants were grown with and without chelating agent diethylenetriaminepentaacetate (DTPA) in Yolo loam soil, which was amended to give a range of soil pH values, A level of 1.68 uCi Am 241 was urilformly mixed with each $500 \mathrm{~g}$ quantity of soil. Highest amounts of Am 241 were found in plant parts at soil $\mathrm{pH}$ around 7.7 with the DTPA. The results are interpreted as chelated Am 241 not only being available to the plants especially at $\mathrm{pH}$ 7.7 but also the Am 241 being transported through the plants as the metal chelate. (auth)

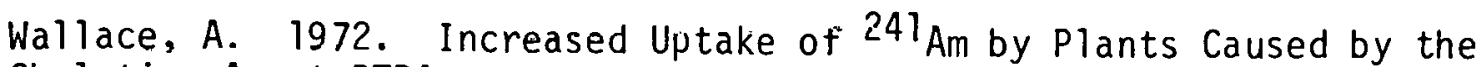
Chelating. Agent DTPA. Health Physics. 22:559-562. 
The chelating agent diethylenetriaminepentaacetic acid (DTPA) which has the ability to increase uptake by plants of several metals and is widely used as a practical means of correcting iron deficiency in plants has been shown to greatly increase the uptake from soils of 241 Am by plants. Application of high levels of zinc or manganese salts decreased $241_{\text {Am content of plants }}$ 201y slightly, indicating little, if any, competing effect. Most accumulated 241 Am was transported to leaves of all species studied. The ability of plants to accumulate 241 Am was not related to root temperature. During a subseguent growth period after applications of $241_{A m}$ to bush beans, some of the 241 Am was transported from the old leaves to the new leaves and also to new roots. The chelating agent DTPA had no effect on the retranslocation, however. Extraction studies with soil indicated that DTPA, but not EDDHA, could quantitatively extract ${ }^{24}$ Am from soil. (auth)

Wallace, A. and E. M. Romney. 1974. Feasibility and Alternate Procedures for Decontamination and Post Treatment Management of Pu-Contaminated Areas in Nevada. UCLA-12-973, 90 p.

This report was prepared in response to needs for determining the feasibility and environmental impact of cleaning up Pu-contaminated areas in Nevada. Instead of considering all aspects of radioactive decontamination; it deals primarily with findings from pertinent land area decontamination and post-management experiences that can be applied to solving $\mathrm{Pu}$ problems at the Nevada Test Site and the Tonopah Test Range. Previous experiences from accidental and planned releases of $\mathrm{Pu}$ in the environment are discussed along with those gained from nuclear fallout decontamination studies. Considerable attention is given to problems concerning revegetation of arid lands. The fragile nature of the desert is such that any drastic alteration will result in a seriously damaged ecosystem. Revegetation by natural means is difficult, if not impossible, from a practical point of view. Posttreatment management of disturbed areas is almost always necessary to insure recovery. Correction of the damage may require greater efforts than the decontamination, and may have more far-reaching consequences than those concerned with the present status of the land. Alternate procedures are discussed which may be useful in Nevada, providing the neccssary experimental work is done to test the validity of the assumptions made. Many answers to pertinent questions can be obtained from investigations conducted outside of the Pu areas. Recommendations are made for experimental work that should be done to determine the best course of action before cleanup begins. (auth)

Whicker, F. W., C. A. Little and T. F. Winsor. 1973. Plutonium Behavior in the Terrestrial Environs. IN: Environmental Surveillance Around Nuclear Installations. Warsaw Symposium, IAEA, November 5-9, 1973.

Soil represents the principal storage area for $\mathrm{Pu}$ in the Rocky Flats environs. Pu concentration in the soils and related vegetation and mammals is given, and surveillance for Pu around Rocky Flats is described. (auth) 
Wildung, R. E. and T. R. Garland. 1974. Relative Solubility of Inorganic and Complexed Forms of Pu 238 and Pu 239 in Soil. BNWL-1950, Pt. 2. pp. 23-25.

Pu was added to the soil as nitrate and DTPA complexes amended with starch, nitrogen and water. Pu nitrates were only 0.05 to $5 \%$ soluble. Pu DTA complexes were $100 \%$ water soluble for the first 40 days. The 238 Pu DTA complex became somewhat less soluble after 40 days. (auth)

Wildung, R. E., T. R. Garland and H. Drucker. 1973. Potential Role of the Soil Microbiota in the Solubilization of Plutonium in Soil. BNWL1850, Pt. 2. pp. 21-22.

Sterile and nonsterile soils werc inoculated will $10 \mu$ fl/g Pu(IV) nitrate and incubated for 30 days. A liter of water was used to leach a gram of soil for four hours with filtration through $5,0.5$ and $0.0 / \mu \mathrm{m} \mathrm{millipore}$ filters. The 0.01 and $0.5 \mu \mathrm{m}$ material were considered to be solubilized. Results suggested that the solubility of $\mathrm{Pu}$ in soil is influenced by soil microflora. (auth)

Wilson, D. 0. and J. F. Cline. 1966. Removal of Plutonium 239, Tungsten185 and Lead-210 From Soils. Nature. 209-5026:941-942.

The authors confirmed that only small amounts of ${ }^{239} \mathrm{Pu}$ were translocated from the sediments to plant leaves during plant growth. Leaf to soil ratios of $239 \mathrm{Pu}$ were about 0.001 on the average for barley grown on Milville silt loam, Cinebar silt loam and Ephrata fine sandy loam. (auth)

Wong, K. M., V. E. Noshkin, L. Surprenant and V. T. Bowen. 1970. Plutonium 239 in Some Marine Orgarrisms and Sediments. HASL-227, pp. I-25-I-33.

Sediments may show concentration factors over contacting seawater for $\mathrm{Pu}$ of $10^{4}$ or greater. Fish mussels and clams collected from various parts of the world's oceans showed lesser Pu concentration factors with bottom feeders among the higher values. (auth)

Yabuki, H. and M. Shima. 1973. Uranium and Other Heavy Elements in DeepSea Sediments Coexisting with Manganese Nodules. Sci. Pap. Inst. Phys. Chem. Ris. (in Japanese). 67:155-6.

$\mathrm{Mn}, \mathrm{Fe}, \mathrm{Cu}, \mathrm{Ni}$, and $\mathrm{Co}$ were analyzed by atomic absorption spectrometry and $U$ was determined by the induced fission-track method by applying internal standard addition. The samples were deep-sea sediments, a kind of furaminiferous ooze which consists mainly of $\mathrm{CaCO}_{3}$ found in the area with the $\mathrm{Mn}$ nodules. The analyses were compared with similar data obtained previously for the Mn nodules. The nodules were richer by a factor of $\sim 5$ for $U$ and by a factor of $>100$ for the other elements. This tendency of $U$ is also seen 
in the relation between seawater and nodules or sediments. This may mean that $\mathrm{UO}^{2+}$ ion in seawater rarely coprecipitates with $\mathrm{Mn}$ or Fe by scavenging effect, but forms complex ions with carbonate and is adsorbed on the surface of sediments or nodules. Data suggest that $\mathrm{Mn}, \mathrm{Ni}$, and $\mathrm{Co}$ are accumulated in both nodules and sediments at about the same rate. Results imply that Cu coprecipitates with Fe, rather than $\mathrm{Mn}$. (CA)

Yakobenchuk, V. F. 1968. Radioactivity and Chemical Properties of Sod-Podzolic Soils in the Ukrainian Western Polesie. Visn. Sil's' Kogosped. Nauki. $11: 45-50$ (in Ukranian).

The level of $\alpha$-radioactivity of sod-podzolic soils of the area is dependent on the content of $\mathrm{Al}$ sesquioxide $\mathrm{Al}_{2} \mathrm{O}_{3}$. The level of $B$-radioactivity is correlated with the amount of sandy and muddy particles of mechanical composition of the soil, and with the amount of $K, U$, and sesquioxides of $A 1$ and $\mathrm{Fe}$. The concentration of $U$ is correlated with the amounts of oxides of $\mathrm{Si}, \mathrm{Fe}, \mathrm{Al}$, Th, and $\mathrm{Ra}$. The amount of $\mathrm{Th}$ is dependent on the reaction of soil solution and on the amount of $\mathrm{CaO}$. The amount of $\mathrm{Ra}$ is correlated with the amount of organic substances in the soil. Chemical analyses are tabulated. (CA)

Yamamoto, T., E. Yunoki, M. Yamakawa and M. Shimizu. 1973. Environmental Contamination by Uranium. III. Effects of Carbonate Ion on Uranium Adsorption to and Desorption from Soil. Journal of Radiat. Res. 14: 219-224.

Adsorption of uranium on soils and its desorption from uranium-adsorbed soils in the presence of carbonate ion were examined by using three kinds of soils: alluvial soil, sandy soil and volcanic ash soil. The absorption ratio of uranium for each soil was approximately 100 percent for the mixtures of uranyl ( 1 to $50 \mu \mathrm{gU} / \mathrm{ml}$ ) and carbonate solutions $\left(4.3\right.$ to $109 \mu \mathrm{gCO}{ }_{3}^{2-} / \mathrm{ml}$ ). In the uranium adsorbed soil ( 7.1 to $500 \mu \mathrm{gU} / \mathrm{g}$ air-dried soil) with carbonate ion $(4.3,43.4 \mu \mathrm{g} / \mathrm{ml})$, the desorption ratio of uranium for each soil was low (0.09 to 1.2 percent). The adsorption of uranium on soils and the desorption from uranium adsorbed soils with stream water were probably similar to those with carbonate solution. (auth)

Yastrebov, M. T. 1971. Natural Rarioactivity of Some Black-Earths in the European Âreas of the USSR. Biol. Pochvoved. 26:93-97 (in Russian).

The radionuclides $238 \mathrm{U}, 226 \mathrm{Ra}, 242 \mathrm{Th}$, and $40 \mathrm{~K}$ in black earth were determined by gamma spectrometry, with a maximum error of 11 percent. The order ${ }^{\prime} f$ In the southern chernozems the $238 \mathrm{U}$ content in the humus-accumulating layers was a factor of 1.3 to 1.8 lower than in rock because of the loss of this isotope by being taken up in plant roots. The $226 \mathrm{Ra}, 232 \mathrm{Th}$, and $40 \mathrm{~K}$ contents of the southern chernozem layer is 1.3 to 1.5 times that in rock, 
apparently because of less intense removal by plants. In distinction from the leached soils, the $238 \mathrm{U}$ accumulation in carbonate illuvial layers of the southern chernozems is small. Analytical data are tabulated. (NSA)

Yastrebov, M. T., 1973. Natural Radioactivity of Some Soils in Landscapes of the Tamov Forest Steppe. Vestn. Mosk. Univ., Biol., Pochuved. 28:91-6 (in Russian).

Behavior of $238 \mathrm{U}, 226 \mathrm{Ra}, 232 \mathrm{Th}$ and $40 \mathrm{~K}$ in meadow soils in well watered $\mathrm{Ca}-\mathrm{Na}$ forest-meadow landscape and in typical paleohydromorphic chernozems was described. Data on ion mobilities of these isotopes were tabulated and the level of natural isotopes determined at various depths. The contents of the four isotopes in such soils was determined mainly by their content in the horizons and mineral structures, by land profiles, by the action of surface and soil watcrs, and by bjuacculluldulon. In $A$ i horizons of the chernozems and meadow soils the $226 \mathrm{Ra}$ predominated over $238 \mathrm{U}$ owing to greater bioaccumylation of the former. In chernozem-meadow and chernozemoid bottom soils; $238 \mathrm{U}$ predominated over $226 \mathrm{Ra}$ owing to greater inflow in the water supplies. (CA) 


\section{CULTURAL ACTINIDE DISTRIBUTIONS IN SEDIMENTS}

Cultural actinide distributions are those distributions resulting from mans' activity. Cultural activities leading to cultural actinide distributions would include such actions as weapons testing, mining and milling of uranium ores and radioactive waste disposal. Such actions result in unusual distributions of actinide elements in sediments, or the presence of transuranium elements not normally encountered in sediments.

A general criticism of the field cultural actinide distribution work to date is that the results are preponderantly from the mass balance approach. Relatively little work has been done on the delineation of specific sediment-actinide reaction mechanisms. Even in the case of transuranic particle fallout studies, additional work could be justified on the relationship between radioactive particles and sediments, and on characterization of the particles.

Laboratory studies are beginning to move toward a more thorough characterization of actinide solutions and sediments before their use in experimental work. This is necessary before even empirical results, such as equilibrium distribution coefficients, can be compared between laboratories or between sediments, with a degree of certitude. However, the laboratory use of nearneutral, dilute actinide solutions is often accompanied with many difficulties, especially in the case of plutonium, even though these solutions may more closely represent the groundwater solution in contact with sediments than a more easily-characterized, higher plutonium, acid soluition. 


\section{THIS PAGE}

WAS INTENTIONALLY

LEFT BLANK 
Aarkrog, A. 1971. Radioecological Investigations of Plutonium in an Arctic Marine Environment. Health Physics 20:31-47.

Samples of the human food chain at Thule, Greenland, were collected during the summer of 1968, after the nuclear weapon incident in January. As was to be expected from the increased plutonium levels in bottom sediments, the highest animal levels were found in bivalves, crustacea, polychaeta, and echinodermata. The levels in these bottom animals were on the average two orders of magnitude as high as the fallout background, in a few cases four magnitude. Fish from the bottom water also showed an increased plutonium content, whereas seaweed, plankton, sea birds, seals, and walruses did not differ significantly from the fallout background. The plutonium concentration in sea water was twice the fallout background. No samples displayed plutonium levels that were considered hazardous to man or higher animals in the Thule district or in any other part of Greenland. (auth)

Aarkrog, A. 1972. Re-examination of Plutonium at Thule, Greenland, in 1970. EUR-4800 182:1213-19.

From International symposium on radioecology applied to the protection of man and his environment; Rome, Italy (September 7, 1971).

After the accidental release of plutonium at Thule in January 1968 a radioecological study was carried out in the following summer. Increased plutonium levels appeared in samples collected as far as 15 kilometers from the point of impact. Especially bottom animals showed increased levels. To investigate the distribution as well as the migration of plutonium in the food-chains at Thule a re-examination was undertaken in August 1970. As in 1968, samples of seawater, bottom sediments, bottom animals, zooplankton, fish, seabirds, seals, seaplants, and lichen were collected. The investigation showed that although the levels in most samples had decreased since 1968 plutonium was still present in concentrations significantly above the fallout background. Samples of bottom sediments showed a vertical movement of plutonium in the sediments down to a depth at least $10 \mathrm{~cm}$. Bivalves as far as $30 \mathrm{kilometers}$ from the point of impact contained plutonium from the accident. (auth)

Aleksakhin, R. M. 1963. Radloactive Contamination of Soil and Plants. AEC-tr-6631; TT66-51002; USSR Academy of Sciences Publishing House. p. 108

Fallout contamination of soil and plants is discussed. The laws governing the fallout of radioactive substances after nuclear tests, as well as the forms and composition of these substances are examined in order to estimate their availability for uptake and retention by plants. The significance 
of $\mathrm{Pu} 239$ in soils is described and attention is given to the migration of $\mathrm{Sr} 90$ and $\mathrm{Cs}$ 137. The scientific research on reducing the uptake and retention in plants of radioactive fission products and soil decontamination are also discussed. A very extensive bibliography (23 pages) is included. (ORNL-EIS-73-21 (supp I. 1.)).

Alvarez-Ramis, C. and A. G. delos Santos. 1974. Contamination of Terrestrial Gasteropoda in a Biotope with Low Levei a Contamination Due to Plutonium and Uranium. LA-tr-74-11, (CONF-690918-5), $20 \mathrm{p}$.

A study was made of the degree of $\alpha$ contamination of the terrestrial gasteropoda (Leucocroa Candidissima, Helix punctata, and Hel ix pisana) caused by the rupture of a thermonuclear bomb at Palomares (Almeria, Spain). Data are included on the a radioactivity of the plants on which they live, whether cultivated plants (corn, broad beans, tomatoes, cabbages, etc.), or wild plants typical of the subtropical climate of this zone (Lygeum spartum, Asparagus horidus, Passerina hirsuta, etc.). The degree of a radioactivity of the different soil types was also studied. Radioactivity was measured in the first five centimeters depth of the first layer where the fixed radioactivity acts most easily and directly on the gasteropoda. The relationships existing between soil, plant, and gasteropoda flesh and shell contamination was studied. (auth)

Ames, L. L., Jr. 1960. Some Cation Substitutions During the Formation of Phosphorite from Calcite. Econ. Geol. 55:354-362.

The nature of cation substitution during replacement of calcite by phosphorite allows the statistical treatment of data concerning such substitution.

Log-probability plots of data yield straight lines that allow easy and accurate extrapolations. Data are presented to show the effect of phosphate ion concentration, temperature, flow rate, and $\mathrm{Na}$ concentration on the primary inclusion of the radioisotopes of $\mathrm{Pm}$ (III), Sr (II), U (IV), and Pu (IV). (auth)

Ames, L. L., Jr. 1974. Characterization of Actinide Bearing Soils: Top Sixty Centimeters of 216-Z-9 Enclosed Trench. USERDA Report. BNWL-1812.

The author examined lhe sediment-plulunfum relationships in sediment core samples from the first two feet of 216-z-9 covered trench. At least two types of plutonium occrrrences were found in 216-Z-9 sediments that received high salt, acid wastes from plutonium process operations. Plutonium particles identified by $X$-ray diffraction tracings as $\mathrm{Pu}_{2} \mathrm{O}_{2}$ were the most conspicuous forlll. The $\mathrm{PuO}_{2}$ was filtered out of the waste solution in the first few inches of the sediment column, and probably entered 216-Z-9 as discrete $\mathrm{PuO}_{2}$ particles. 
The second type of plutonium occurrence is associated with rock fragment silicate hydrolysis caused by the highly acidic nature of the waste solutions. The second type of plutonium was originally in solution in the acid waste. The localized pH rise that occurred during the hydrolysis reaction may have caused the precipitation of the accompanying plutonium. Hydrolys is reactions were more intense at high surface area lenses of fine-grained silts in the sediment column. As a result, higher plutonium concentrations associated with the silt lenses occur at random in the thirty feet of sediments investigated. It was not clear how well-fixed the two types of plutonium occurrences might be. (auth)

Andelman, J. B., and T. C. Rozze11. 1970. Plutonium in the Water Environment, ACS Advances in Cehmistry No. 93 (Washington: American Chemical Society).

In the pH range of natural waters colloidal plutonium (IV) hydroxide forms from polymeric hydrolysis products and ages slowly. At least over a period of several days an increase in particle sizes is observed. At pH 7 such solutions aged for a few months showed a significant increase in size of the colloidal plutonium as the ionic strength increased from 0.002 to 0.1 . The centrifugability of the colloid, aged for three and seven days at $\mathrm{pH} 7$, decreased for plutonium concentrations less than 10-7 $\mathrm{M}$. The addition of macroscopic grains of crystalline silica affected the colloidal plutonium size distribution as did the variation in $\mathrm{pH}$ over the range of 5 to 8 . The addition of $10^{-2} \mathrm{M}$ bicarbonate ions at $\mathrm{pH} 7$ also influenced the distribution but less systematically. (auth)

Anonymous. 1972. Determination of Plutonium in Soil. MLM-1829, Mound Lab Chemical and Physics Progress Report: April-June 1971, pp. 18-20.

Procedure for determination of plutonium in soil by a fusion technique reported previously in MLM-1792 and MLM-1815. Precision of technique established by spiking two standard soil samples with $238 \mathrm{Pu}$ - average standard deviation was $\pm 5.50 \%$. An actual soil sample yielded $37.5 \%$ standard deviation suggesting nonuniform plutonium distribution.

Anonymous. 1974. Analysis of Natural Systems. BNWL-1950, Pt. 2. pp. 1-19.

The usefulness of kinetic models for monitoring changes in aquatic pollution is discolssed. The use of computer calculations to predict the uptake and retention of DDT and $65 \mathrm{Zn}$ in fish is cited as an example. A slraliried random sampling program (FIDLER) was used to estimate the geographical distribution of activities from 239pu and $210 \mathrm{Pu}$ in surface soil and vegetation at the Nevada Test Site. Models and procedures used for studies of fallout $137 \mathrm{Cs}$ transport through the forage-cattle-milk food chain and lichen-caribou-Eskimo food chain in Alaska are described. The statistical and mathematical aspects of sampling programs for ecological 
studies and data acquisition and analysis systems are discussed, with emphasis on methods for the evaluation of the impact of nuclear power plants on the environment and the radiation dose to human populations. (NSA)

Anonymous. 1974. Environmental Studies. LA-5883-PR. pp. 46-62.

The research activities of the Environmental Studies Group include: environmental resources inventory; radiation ecology studies; Alaskan arctic ecosystem studies; and atmospheric transport studies. The environmental resources inventory includes: understory vegetation analysis; species diversity and composition of small mammal communities; radiotelemetry st.udy of mammalian predators; soils of the LASL; and a National Evnironmental Research Park proposal. The radiation ecology studies include: honeybees as biological indicators of radfonuclide contamination; radiation ecology studies of canyon liquid waste disposal areas; small mammal studies in Los Alamos liquid waste disposal areas; small mammal population densities and composition at Trinity site; distribution of $\mathrm{Pu}$ in Trinity soils; waste disposal canyon intensive site studies; and Rio Grand River studies. The Alaskan arctic ecosystem studies include: ecological investigation of Alaskan North Slope oil field development; and radiation ecology studies of northern Alaska. Terrain influence on low-level meteorological transport is the only atmospheric transport study discussed. (NSA)

Anonymous. 1974. Freshwater Sciences. BNWL-1950, Pt. 2. pp. 67-106.

Results are reported from studies on the effects of thermal effluents on the incidence of diseases, behavior and sensory physiology of fish in the columbia kiver, the combined effects of chemical pollution and temperature on the incidence of diseases in fish, and the effects of tritium irradiation during embryogenes is of immune reactions in trout. The physicochemical characteristics of radionuclides in Hanford $\mathrm{N}$-reactor effluent water discharged to a seepage trench were studied as they percolated through soil and emerged in seepage springs along the bank of the Columbia River, with emphasjs on the hiolggical availability and geuchemical reactivity of ${ }^{0}{ }_{\mathrm{Co}},{ }^{10} 3_{\mathrm{Ru}}, 106_{\mathrm{Ru}},{ }^{2} 2{ }_{\mathrm{Sb}},{ }^{12} 4_{\mathrm{Sb}}$, and $125 \mathrm{Sb}$ present in reactor effluent water partitioned among particulate, cationic, anionic, and nonionic species. Results of an aerial survey of salmon spawning in the Hanford reach of the Columbia River during 1974 are compared with surveys made in previous years. Results are reported from a study of the combined effects of water temperature and $\gamma$ radiation on the survival of rainbow trout. The uptake and retention of $137 \mathrm{Cs}$ and $65 \mathrm{Zn}$ by periphyton in the Columbia River and the ratios of $238 \mathrm{pu}$ to $239 \mathrm{Pu}$, $240 \mathrm{Pu}$, and $241_{\mathrm{Am}}$ in biota and sediments in a Hanford waste pond were determined. (NSA) 
Anonymous. 1974. Marine Sciences. BNWL-1950, Part 2. pp. 107-152.

The HAPO Marine Research Laboratory, Sequim, Washington, is described and preliminary results are reported from a study of the physical, chemical, and biological characteristics of Sequim Bay. Results are reported from studies on: the effects of petroleum and petroleum products in effluents released to coastal waters on the ecology of animals and plants of intertidal communities; the uptake and retention of hydrocarbons by plankton; the effects of thermal effluents discharged from nuclear power plants to coastal waters on the number and occurrence of annelids, anthropods, and molluscs in marine communities; the effects of temperature changes on the growth and survival of shrimp (Pendelus danae); a literature survey on the distribution and effects of Cu on marine ecosystems; and the rates and mechanisms of air-seawater exchange and mixing of cosmogenic $7 \mathrm{Be}$, fission products, and Pu isotopes in fallout in North Pacific surface waters. A program, GEOSECS, was developed to characterize the biogeochemical and physicodynamic processes occurring in the oceans on the basis of chemical and radionuclide constituents. The distribution of $\mathrm{Hg}, \mathrm{Ag}$, and $\mathrm{Co}$ in the Atlantic and Pacific Oceans at various geographical and vertical levels was estimated using the GEOSECS sampling program and neutron activation techniques. A method was developed for the measurement of Sc in seawater samples. Methods for measuring trace element and radionuclide pollution in marine sediments are discussed, with emphasis on $55 \mathrm{Fe}$ in marine organisms. Data are jncluded from studies on the concentration and distribution of $239 \mathrm{Pu}$ and $241_{\mathrm{Am}}$ in seawater, sediments, and marine organisms collected at Thule, Greenland and Eniwetok Atoil.

Anonymous. 1974. Potential for Plutonium Complexation in Soil and Uptake by Plants. BNWL-1850, Part 2. pp. 19-24.

Previous studies have indicated that plutonium is largely insoluble in soil over the short-term and is not accumulated by plants. However, it is possible that naturally occurring ligands in soil arising from organic matter decomposition processes may form complexes with plutonium increasing plutonium solubility in soil and uptake by plants. Furthermore, the possibility exists that the chemical form of plutonium may be directly altered by the soil microflora as has been demonstrated for other metals. The present studies were undertaken to determine (1) the effects of plutonium on the soil microbial population and on soil microbial processes, (2) the potential for formation of plutonium complexes in soil and the role of the soil microflora in this process, (3) the extent of plant uptake and translocation of plutonium or its complexes, and (4) the bond types and chemical forms of plutonium or its metabolites in microbial and plant tissues and soils. The progress of these investigations is summarized below. (auth)

Anonymous. 1974. Terrestrial Ecology. BNWL-1950, Part 2. pp. 157-207.

Dita are summarized on the ecology of wild animals and plants of the Hanford Reservation, with emphasis on populations of mule deer and birds. Data are included on the content of $95 \mathrm{Zr}$, ${ }^{106 \mathrm{Ru}},{ }^{137} \mathrm{Cs}$, and ${ }^{144} \mathrm{Ce}$ in the 
eggs of Canada geese nesting in the area; ${ }^{238} \mathrm{Pu}$ content in soils, forage, and field crops; the content of ${ }^{29}$ I in jitter and soil from grass and forest communities; the relationship of 129 I to stable 127 I in aquatic organism and sediments; the content of $127 \mathrm{I}$ and $129 \mathrm{I}$ in the diet and tissues of swine in the area; and the content of $137 \mathrm{Cs}$ in native residents of Anaktuvuk Pass, Alaska during 1969 to 1975. (NSA)

Anonymous. 1975. Appendix II. 1-H-Laboratory Investigation of Plutonium Movement in Hanford Soils. Environmental Statement Waste Management Operations Hanford Reservation, Richland, Washington. WASH-1538.

From $\mathrm{pH} 1.0$ to 4.0 , Pu removal mechanism changes from ion exchange to precipitation and subsequent filtration.

At pH 9-12, polymer neutral-1ike and colloidal and passes thru sediment.

Organic compounds can retard soil's removal of $\mathrm{Pu}$.

Z-9 crib (a) $\mathrm{PuO}_{2}$ particles filtered near soil surface (b)pH rise at surface of particle causes Pu precipitation.

Solubility of Pu in soil influenced by soil microflora.

Anonymous. 1975. Savannah River Laboratory Quarterly Report. Waste Management, Apri1-June 1975. DPST-75-125-2.

Pu distribution coefficients are reported from synthetic, high salt basic wastes onto Duolite ARC-359 resin, three inorganic zeolites and hydrous zirconium oxide. $K_{d}$ values for Pu varied from 1 to 240 on the Duolite resin.

The leachabilities of sludge-silicate waste forms were determined (as alpha) in $\mathrm{g} / \mathrm{cm}^{2} /$ day of waste.

The migration of solvent-complexed $\mathrm{Pu}$ through dry and moist soils was determined. $\mathrm{Pu}$ in solvent $\mathrm{K}_{d}=00.4 ; \mathrm{Pu}$ in aqueous phase $\mathrm{K}_{d}=>30$.

Anspaugh, L. R., P. L. Phelps, N. C. Kennedy and H. G. Booth. 1973. WindDriven Redistribution of Surface-Deposited Radioactivity, Environmental Behavior of Radionuclides Released in the Nuclear Industry. I.A.E.A., Vienna, 1973. pp. 167-184.

The deposition of radionuclides on a terrestrial surface can result in the delivery of dose to man through external radiation exposure; food chain contamination or inhalation of suspended particles. $239 \mathrm{Pu}$ is one of the few radionuclides generally regarded as constituting an inhalation hazard through wind-driven resuspension. No adequate models of resuspension exist. 
Two major problem areas have been identified: the rate at which initially deposited debris weathers into a less erodible state as a function of time, and a source term factor in material removed per unit time per unit area, applicable to a source of any configuration. In experiments conductcd at the US Atomic Energy Commission's Nevada Test Site, concentrations in air of particles moving in suspension were studied over a period of six weeks following the nuclear cratering event Project Schooner and over a 10month period following accidental venting of an underground nuclear explosion. Suspended air activity was observed to decrease in time with half-times of from 35 to 80 days; this factor appears to be much more important than variations in meterological parameters over these relativley short time periods. Movement of small particles in suspension accounts for only a minor fraction of the total mass movement. As much as $50 \%$ of the initially deposited debris was moved by saltation within a 24-hour period. Such movement can result in extensive micro-inhomogeneities with accumulation of debris under bushes or other places affording shelter from erosive forces. More detailed study of the resuspension process in an aged ${ }^{239} \mathrm{Pu}$ field is now in progress. Preliminary data are given on the particle size distribution of the total mass and the 239pu moving in suspension. (auth)

Anspaugh. L. R., P. L. Phelps, N. C. Kennedy, H. G. Booth, R. W. Goluba, J. R. Reichman and J. S. Koval. 1974. Resuspension of Plutonium: A Progress Report. UCRL-75484. $62 \mathrm{p}$.

Progress is reported for a research program on the resuspension in the atmosphere of plutonium fallout deposited on the earth surface. The long-range goal of the resuspension studies is to produce a set of equations which can be used to predict the time-dependent average concentration of resuspended material downwind from a source of any geometrical configuration and soil surface characteristics. The experiments are conducted at the Nevada Test Site where plutonium-high explosive tests were performed during the period from 1954 to early 1956. The investigations have included: monitoring of soil samples for Pu; development of ultra-high volume air samplers, in-situ particle spectrometers, particle counters, and a micrometeorology field laboratory; determination of $\mathrm{Pu}$ redistribution due to the rolling of soil particles pushed by winds (creep), the bouncing of wind-pushed particles (saltation), and transport by dust devils; and measurements of meteorological parameters. Results from these experiments will be used to establish a data bank on radioisotope distribution and meteorological conditions at NTS and to provide information of the relation between the source and the dose to man from existing radioactivity. (NSA)

Anspaugh. L. R., J. H. Shinn and P. L. Phelps. 1975. Resuspension and Redistribution of Plutonium in Soils. UCRL-76419. p. 37.

Formulas were derived which parameterize dust and plutonium fluxes in terms of micrometeorological and soil erodibility parameters. Interim, simple models utilizing the time-dependent resuspension factor and massloading approaches are derived which may be used to predict the average 
concentration of resuspended plutonium. Intensive measurements of the resuspension of plutonium at the USAEC's Nevada Test Site are summarized in terms of a resuspension rate through the use of Healy's model of transport and diffusion. Values of the resuspension rate varied from $2.7 \times 10^{-12}$ to $4.8 \times 10^{-10} \mathrm{sec}^{-1}$. The relationship between the resuspension rate and the historical resuspension factor is developed. The various models and formulations used are shown to be internally consistent for this experimental site. (auth).

Au, F. H. F. 1974. The Role of Soil Microorganisms in the Movement of Plutonium. IN: Dunaway, P. B., and M. G. White (eds). The Dynamics of Plutonium in Desert Environments. NVO-142 (NVO-AEIC-74-1 or UC-2): 135141.

Microbial studies which are completed or in progress were designed to determine the ability of microorganisms to absorb plutonium, to quantify the uptake, and to determine the microbial population of soils of the Nevada Test Site (NTS). Results of the microbial inventory of Area 13 (NTS) showed that about $2 \%$ of the Aspergillus was near the surface of the hummock and increased with distance away from the plants. Penicillium, on the other hand, showed an inverse pattern in that its relative abundance decreased away from the plants.

A method was developed for in vitro studies in which aerial fungal spores were collected to determine soluble plutonium uptake from agar medium. The concentration of plutonium in mature spores was approximately onefourth of that in the growth medium. (auth)

Audidiere, P., F. Balard, J, Dupouy and F. Van Kote. Distribution of Radioactivity in Lava from the Cavity of a Nuclear Explosion. UCRLTrans. 105714.

A series of experiments aimed at defining the methods of incorporation of active materials into the substrate at the site of a nuclear explosion is reported. From the properties discovered during the studies, it may be inferred that during cavity formation the behavior of the o-emitting elements is different from those emitting $\beta-\gamma$ radiation. The $\alpha$-emitters distributed evenly in the molten rock must be incorporated into it relatively easily and simply diffuse into the liquefied lava. They were not present in the white crystalline fragments. The $\beta-\gamma$ emitters whose characteristic distribution was strongly heterogeneous preferentially accompanied the dark constituents of the minerals (micas). It is believed that they condense at a later period than the heavy elements. They were not found in the crystalline inclusions. (NSA) 
Auerbach, S. I. 1958. The Soil Ecosystem and Radioactive Waste Disposal to the Ground. Ecology. 39:522-9.

A review of the knowledge of the soil ecosystem is presented including some aspects of current research pertaining to soil disposal of fission products. Some of the results of research started at ORNL on 1 imited aspects of the problem are included. (NSA)

Ayres, J. A. 1951. Treatment of Radioactive Waste by Ion Exchange. Industrial and Engineering Chemistry 43:1526-1531.

With the installation of new laboratories for radiochemical research in populated areas, the treatment of the wastes presents a problem. It is desirable to reduce the activity of these wastes to a safe level before discharging them into the ground or sewage systems.

This paper describes a preliminary study of the application of ion exchange processes to problems of radioactive waste disposal. The general behavior of the common radioactive isotopes and the effect of impurities which might be expected to be present in general laboratory wastes are discussed. Two general plans for ion exchange treatment of laboratory wastes are presented. One plan utilizes cation exchange to remove the bulk of the radioactivity and give an effluent free from the ions which usually adsorb or precipitate in neutral or basic solutions. The other plan utilizes two columns or a mixed bed to provide complete demineralization and give an effluent having an activity level below the detectable limit.

This preliminary study points out the advantages and limitations of ion exchange procedures for treatment of laboratory wastes and makes it possible to evaluate such procedures or suggest further research along these lines.

Baestle, L. H. and J. Souffriau. 1967. Installation of Chemical Barriers in Aquifers and their Significance in Accidental Contamination. IN: IAEA-SM-93/21. pp. 301-315. Disposal of Radioactive Wastes Into the Ground.

After the principles of chemical barrier formation are reviewed, the principal results of laboratory research on the system 'Silica-HFAntimonic acid' are discussed in some detail. Field experiments have del ineated the zone created by injecting reagents traced with ${ }^{82} \mathrm{Br}$ into an aquifer. The economics of experimental procedure for the injection of the reagents $\mathrm{HF}$ and $\mathrm{K}_{2} \mathrm{H}_{2} \mathrm{Sb}_{2} \mathrm{O}_{1}$ into the aquifer. The retention capacity of the installed barrier for $\mathrm{S} r$ is also discussed in relation to its significance for environmental safety al reprocessing plants. (auth)

Barbier, G. and G. Muchion. 1954. Disposal of Low-Activity Waste and Accumulation in Cultivated Soils. IN: Disposal of Radioactive Wastes. Conference Procedure. 2:401-6. IA $\overline{E A}$, Vienna. 
A method is described for accumulating long-lived radioisotopes in soils and calculating the maximum contamination they would cause in vegetables grown on these soils. A way is suggested for expressing this contamination and a formula is given by which the maximum contamination of $1 \mathrm{~kg}$ of the harvested produce in relation to the tolerated contamination per liter of irrigation water could be calculated. (auth)

Barr, N. F. 1975. The Radiological Significance of Transuranium Radioisotopes Released to the Environment During Operation of the LMFBR Fuel Cycle. IAEA-SM-199/102.

Estimates based on current knowledge and conservative assumptions indicate that release of transuranium elements form the Liquid Metal Fast Breeder Reactor (LMFBR) fuel cycle are likely to produce population dose commitments small compared to those produced by naturally occurring alpha emitters and globally dispersed transuranium radioisotopes from tests of nuclear weapons in the atmosphere. Potential health consequences of these relaeases to current and future generations are estimated to be very small compared to risks associated with the production of energy by fossil fuels. The estimates are subject to a number of uncertainties imposed by lack of knowledge. Some of the uncertainties are not likely to be greatly reduced until LMFBR facilities are designed and operated. OLhers may be significantly reduced prior to facility design and operation. The paper discusses the sensitivity of the estimates to uncertainties and approaches to reducing those uncertainties which strongly influence the estimates. (auth)

Beckert, W. F. and F. H. F. Au. 1975. Plutonium Uptake by a Soil Furgus and Transport to Its Spores. IAEA-SM-199/72.

Three concentrations of plutonium-238 nitrate, citrate, and dioxide were each added to separate plates of malt agar buffered to $\mathrm{pH} 2.5$ and 5.5 to determine the uptake of plutonium from these chemical forms and concentrations by a common soil fungus, Aspergillus niger. After inoculation and incubation, the aerial spores of Aspergillus niger were collected using a technique that excluded the possibility of cross-contamination of the spores by the culture media or by mycelial fragments.

Plutonium-238 was taken up from all three chemical forms and transported to the aerial spores of Aspergillus niger at each concentration and at both $\mathrm{pH}$ levels. The specific activilies of the spores grown at $\mathrm{pH} 5.5$ were generally at least twice those of the spores grown at $\mathrm{pH} 2.5$. The uptake of plutonium from the dioxide form was about one-third of that from the nitrate and citrate forms at both $\mathrm{pH}$ levels. The term "transport factor" is used as a means to compare the transport of plutonium from the media to the fungal spores; the concentration-independent transport factor is defined as the specific activity of the spores divided by the specific activity of the dry culture medium. Through the transport factors were 
less than 1, which indicates discrimination against the transport of plutonium238 from the culture media to the spores, these findings suggest that this common soil fungus may be solubilizing soil-deposited plutonium and rendering it more biologically available for higher plants and animals. (auth)

Bennet, B. G. 1974. Environmental Pathways of Transuranic Elements. WASH-1359, pp. 131-152.

A large number of laboratory and ecological studies have been performed to elucidate specific aspects of these pathways, such as resuspension of deposited activity, plant uptake, and physical and biological transfers in terrestrial and aquatic environments. In addition, the measurements of fallout Pu, tracing the course of this material in air and diet to man, provide some of the most directly appropriate data regarding the environmental pathways. It is generally recognized that for an initially airborne release, the inhalation pathway is the dominant contributor to the body burden in man. The low solubility of the transuranic elements inhibits plant uptake and absorption form the gastrointestinal tract and minimizes the importance of the ingestion pathway. The physical mechanisms of transfer of activity are thereby emphasized instead of biological accumulation mechanisms. Dispersion of airborne radioactivity is governed by the local and regional meteorology. For contamination which originates on the ground surface, such as leakages or spills, resuspension could be an important consideration. (NSA)

Bennet, B. G. 1975. Transuranic Element Pathways to Man. IAEA-SM-199/40.

Transfer to man of transuranic element contamination may occur by the inhalation or ingestion pathways. The measurements of globally dispersed fallout radioactivity have provided pertinent data on the environmental behavior of plutonium. Additional data may eventually become available for americium. From the measured and inferred concentrations of fallout plutonium, the inhalation intake has been determined and the ICRP Task Group lung model used to estimate deposition in the lung and transfer to other body organs. The computed body burden reached a Illa imuin of $4 \mathrm{pCi}$ in 1964 and is currently about $2.5 \mathrm{pCi}$. A complete diet sampling has been conducted to determine ingestion intake. - Plutonium concentration in food ranged from $0.01 \mathrm{pCi} / \mathrm{kg}$ is shellfish to undetected (less than 0.0003 $\mathrm{pCi} / \mathrm{kg}$ ) in milk. Annual intake in total diet is estimated to have been 1.6 $\mathrm{pC} i$ in 1972. Low uptake by the gastrointestinal tract makes contribution to organ burdens form ingestion negligible. Long-term pathway considerations include plant uptake from the cumulative deposit in soil and resuspension. Downward movement in soil may limit the significance of these long-term pathway components. (auth)

Bensen, D. W. 1960. Review of Soil Chemistry Research at Hanford. HW67201 . 
Soil adsorption of cesium, strontium, plutonium, zirconium, ruthenium and the rare earth series isotopes from water and from simulated and actual waste in the laboratory and under field conditions is discussed.

Ion exchange, precipitation and in some cases mineral replacement reactions are responsible for radionuclide uptake by soil. The completeness with which an ion is taken up by ion exchange on the soil is dependent upon the concentration of the radionuclide and upon the concentration of accompanying ions. The concentration of the radionuclide and of accompanying cation species are of minor importance in precipitation and in mineral replacement reactions.

Cesium is taken up by an ion exchange reaction. In some cases a portion of the cesium is "fixed" in the soil. Strontium is also largely taken up by ion exchange. In calcareous soil strontium can be removed from alkaline solutions by a mineral replacement reactions with calcite $\left(\mathrm{CaCO}_{3}\right)$. Above $\mathrm{pH} 2$ plutonium and zirconoum are largely taken up by precipitation on the soil. The rare earth nuclides and yttrium are similarly precipitated at $\mathrm{pH}$ above 6. Below the $\mathrm{pH}$ necessary for complete precipitation, soil uptake of these nuclides presumably occurs by a combination of ion exchange and precipitation. The uptake of trivalent ruthenium is similar to that nf the rarc carths.

Soil uptake of plutonium, zirconium, rare earths and ruthenium is adversely affected by anions which form complex anionic species with the nuclides.

Strontium is usually taken up from alkaline wastes more completely than cesium. However, from an acid waste, cesium uptake is better than that of strontium. The general order of radionuclide uptake from waste is:

$$
\text { Pu }>\text { R.E. }>\text { S } r>\text { r.s }>>R u . \quad \text { (auth) }
$$

Bilss, W., and L. Dunn. 1971. Measurement of Plutonium in Soil Around the Nevada Test Site. IN: Fowler, E. B., R. W. Henderson, and M. F. Milligan (co-chairmen). Proceedings of Environmental Plutonium Symposium held at LASL, August 4-5. LA-4756 (UC-41):89-92.

Experiments conducted at the Atomic Energy Commission's Nevada Test Site between 1951 and 1963, using plutonium in both critical and subcritical configurations, have resulted in distribution of plutonium beyond the boundaries of the. Test Site. The Southwestern Radiological Health Laboratory of the Envirnmmental Portection Agency is conducting a survey to assess the distribution and concentration of plutonium in the off-site environment.

Special sampling methods were devised since desert soil is too coarse and dry for sugar and cookie cutter sampling techniques. Soll sample analyses are performed by a dissolution, ion exchange, and electrode-position procedure followed by alph spectroscopy. Plutonium has been detected in four locations 
around the Nevada Test Site. These locations correspond to fallout areas previously identified for the various test series. Plutonium concentrations in the top $3 \mathrm{~cm}$ of soil were 10 to 100 times greater than the concentration in soils from areas not subject to contamination by these series.

Bliss, W. A., and F. M. Jakubowski. 1975. Plutonium Distribution in the Environments of the Nevada Test Site - Status Report. IN: White, M. G., and P. B. Dunaway (eds). The Radioecology of Plutonium and other Transuranics in Desert Environments. NV0-153(UC-2):237-250.

In September, 1970, the National Environmental Research Center-Las Vegas began a study to define the distribution of plutonium in the environment surrounding the Nevada Test Site (NTS). As a part of this study, off-NTS air and soil are being investigated for plutonium content.

Air sample analyses have been limited to filters collected at selected Air Surveillance Network Stations over a period from 1966 to 1973.

Soil samples have been collected in close proximity to the NTS. Extensive soil sampling has been conducted downwind from the NTS in accordance with old atmosphereic fallout patterns. Since the plutorium-in-soil study began, several special related projects have been started.

A basin study is under way to determine the movement of plutonium with surface water drainage. A fruit and vegetable study has just been completed. The study was designed to determine the uptake of radionuclides in locally grown and consumed crops. Another special related project has been designed to define the transport of radionuclides off the NTS via Fortymile Canyon. A resuspension study is being designed to measure the ambient levels of plutonium northeast of the NTS.

The collection and analysis of both air and soil samples should remain the same as in the past. Whenever special related projects such as those noted above are designed, appropriate plutonium studies should be included. (auth)

Bondietti, E. A. 1974. Adsorption of Pu (IV) and Th (IV) by Soil Colloids. Agronomy Abstracts.

The tetravalent actinides, $\mathrm{Pu}$ and $\mathrm{Th}$, are extensively hydrolyzed in aqueous solutions above $\mathrm{pH} 2$ in the absence of complexing agents. Adsorption consequently involves interactions of hydrolytic species. Calciumsaturated, reference clays (montmorillonite and kaolinite) removed similar amounts (about 95\%) of the Pu and Th from the aqueous phase in batch equilibration studies at $\mathrm{pH} 6.5$. Calcium humate removed $99.9+\%$. Desorption by Ca-citrate was extensive from the clays (10-30\%), while from humic acid less than $1 \%$ was removed. Stronger complexers (DTPA and EDTA) were required for appreciable removal (20-30\%) of Pu or Th from humic acid. 
Soil fulvic acid also effects desorption. Adsorption-desorption studies of a soil clay (Miami silt loam) showed that removal of organic matter (O.M.) by $\mathrm{NaOCl}$ oxidation reduces the adsorption of $\mathrm{Pu}$, and $\mathrm{Fe}+0 . \mathrm{M}$. removal is not appreciably different from $0 . M$. removal alone. In a 11 cases, however, greater than $95 \%$ of the Pu was adsorbed. A mixed organic-hydiroxy complex is proposed for the reaction of Th (IV) and $\mathrm{Pu}$ (IV) with humic substances. The possible role of organic matter is environmental Pu chemistry will be discussed. (auth)

Bortoli, M. de, and P. Gaglione. 1968. Environmental Radioactivity. EUR408.

In this report are hriefly described the measurcmonts of environmental radioactivity performed during 1967 by the site survey group of the Protection Service. Data are given on the concentrations of $5 \mathrm{r} 90, \mathrm{Cs} 137$, $\mathrm{Pu} 239$, Pu 238, and other radionuclides in fallout, air, soil, waters, herbage, animal bones, and foods. (auth)

Bortoli, M. C. de, and P. Gaglione. 1969. Natural and Fallout Radioactivity in the Soil. Heaith Physics 17:701-710.

The long-1ived radionuclides (Sr 90, Cs 137, and $\mathrm{Pu} 239$ ) from weapon fallout were measured in soil samples collected in the surroundings of the Euratom Ispra Establishment (northern Italy). The vertical profile of the contamination and the distribution of $C_{S} 137$ in soil particles of different size were studied. In addition, also the concentration of natural radionuclides was determined and the caluclated air dose rate was comparcd with ionization chamber. (auth)

Bourrier, J., P. Bovard, and A. Grauby. 1960. Practical Measurement of the Ability of Solls to Retain Radioelements. Compt. rend. acad. agr. France. 46:349-52 (in French).

A method for studying the hehaviour of radioelements in soils subjected to radioactive submersion of rain is presented. This method is based on two operations: evaluation, by counting, of the residual radioactivity of the eluates; localization by autoradiography of the radioactivity in the mass. Results, obtained on soils in position which have retained their main. parameters, allow a rapid deduction of path of the inns and the chances of contamination of the sub-soil or the water table. (auth)

Bowen, V. T. 1971. General Summary of Progress, 1970-1971. NY0-2174129.

The 1970 research activities of the Woods Hole Oceanographic Institute which were related to determining fallout distribution in oceans are described. These activities include: the analyses of reagent blanks for $137 \mathrm{Cs}$ and 
$90 \mathrm{Sr}$; interlaboratory comparisons of results from reference sample analyses; measurement of ${ }^{90} \mathrm{Sr}$ content in Atlantic 0cean surface waters; and measurement of the vertical penetration of fallout in both seawater columns and ocean sediment columns. Data are presented on the $137 \mathrm{Cs}$ and $90 \mathrm{Sr}$ arialysis of seawater samples, ${ }^{90} \mathrm{Sr}$ content of Atlantic 0cean waters; $137 \mathrm{Cs}$ and $90 \mathrm{Sr}$ vertical penetration in waters of Atlantic Ocean and Sargasso Sea; and $137 \mathrm{Cs}, 239 \mathrm{Pu}$, and $90 \mathrm{Sr}$ vertical profiles in both water columns and sediment cores from the North Atlantic and the western Mediterranean. (NSA)

Bowen, V. T. 1974. Plutonium and Americium Concentration along Freshwater Food Chains of the Great Lakes, U.S.A. C00-3568-4, 47 p.

Samples of water, sediments, and biological materials were collected and analyzed for radioisotopes. Tables are presented to show results of radiochemical analysjs of water for $137 \mathrm{Cs}, 239 \mathrm{Pu}$, and $90 \mathrm{sr}$; of sediments for $137 \mathrm{Cs}, 239 \mathrm{Pu}$, $240 \mathrm{Pu}$, and $90 \mathrm{Sr}$; of fish and plankton for $137 \mathrm{Cs}, 239 \mathrm{Pu}$, and $240 \mathrm{Pu}$; and of shoreline plants for $241_{\mathrm{Am}},{ }^{127} \mathrm{Cs}$, and $239 \mathrm{Pu}$. (NSA)

Bowen, V. T. 1974. Radioelement Studies in the Oceans. Progress Report, C00-3563-28, $23 \mathrm{p}$.

Results are reported from studies on the distribution of fallout ${ }^{137} \mathrm{Cs}$, $90 \mathrm{Sr}, 239 \mathrm{Pu}$, and $240 \mathrm{pu}$ in Atlantic 0cean waters sampled at various locations. These radionuclides were also used as tracers for studies of upwelling in Gulf Stream rings. Samples of plankton, algae, fishes, marine invertebrates, and birds were analyzed for $239 \mathrm{Pu}$ and $240 \mathrm{pu}$ content, and sediment cores from various locations were analyzed for $137 \mathrm{Cs}, 239 \mathrm{Pu}$, $240 \mathrm{Pu}$, and $241 \mathrm{Am}$. (NSA)

Bowen, V. T. 1974. Transuranic Elements and Nuclear Wastes. Oceanus, $18: 1: 43-54$.

The author suggests that larger and longer-term studies are needed on the mechanisms of actinide movements and distributions at disposal sites.

Bowen, V. T. 1975. Transuranic Elements in Marine Environments. HASL-291.

Transuranic elements are present in marine environments as a result of six types of human activity: 1) worldwide fallout; 2) close-in fallout; 3) the SNAP-9A burnup; 4) pipeline disposal of reprocessing wastes; 5) neutron capture by uranium in one-pass colling-water reactors; and 6) the B-52 crash in Thule, Greenland.

Distributions and movements of these nuclides from these introductions are being studied partly because the transuranic elements themselves are geochemically interesting, partly because they appear to serve as tracers. 
for specific oceanographic processes, and partly because of concern that man is faced with the problem of disposal of rapidly increasing amounts of transuranics as radioactive waste, and that we must be able, soon, to predict the fates and effects of those amounts that reach the coastal waters or the deep oceans.

Plutonium and americium are widely distributed in the oceans as a result of man's activities. But appear to be more mobile than expected, and $\mathrm{Pu}$ shows little behavior in these environments that had been predicted from laboratory studies. Although their associations with biological material seem to be most striking for rooted plants or Sargassum, it is too premature to dismiss the possibility of their being a real hazard to marine life. For all the abundantly produced transuranics (neptunium, plutonium, americium, and curium) many more data are needed. (auth)

Bowen, V. T. and H. D. Livingston. 1975. Americium 242m in Nuclear Test Debris. Nature (in press).

$242 m_{A m}$ was produced in nuclear explosions by neutron capture by 241 Am and decays to $242 \mathrm{Cm}$, according to these authors. Decay scheme $=242 \mathrm{mAm} \rightarrow$ $242 \mathrm{gAm} \rightarrow 242 \mathrm{Cm} \rightarrow 238 \mathrm{Pu} \quad 1 / 2$ life $=122 \mathrm{yrs}, 1 / 2 \mathrm{life}=16$ hours

$242 \mathrm{~m} A m$ was suggested by the authors as a source of $\mathrm{Pu}$ more mobile than that $\mathrm{Pu}$ produced in the original event.

Bowen, V. T., H. D. Livingston and J. C. Burke. 1975. Distributions of Transuranium Nuclides in Sediment and Biota of the North Atlantic Ocean. 1AEA-SM-199/96.

The effects of the interaction of marine sediments with their biotic population on the penetration, redistribution, sediment association and biotic availability of delivered transuranium nuclides are discussed as a function of both sedimentation regimes and in-fauna populations. Data on the penetration and redistribution patterns of fallout transuranium nuclides in the shallow sediments of Buzzards Bay, Massachusetts, are discussed in terms of the known parameters of sedimentation and 'in sediment.' hiological activity. In this (and most common) type of sedimentation regime, translocation of bioturbationally downmixed transuranium nuclides back toward (and probable loss from) the sediment surface is demonstrated. Various biological and biochemical mechanisms are advanced that may act on these nuclides within sediments. The increased availability to marine biota of sediment transuranium nuclides by these remobilization processes, is indicated by data showing accumulations of these nuclides in marine invertebrates and fish. (auth)

Bowen, V. T. and V. E. Noshkin. 1973. Plutonium Concentration Along Fresh Water Food Chains of the Great Lakes, U.S.A. General Summary of Progress, 1972-1973. CO0-3568-3. 
The following radiochemical data are tabulated for analyses of samples in Lake Ontario during 1972: $239 \mathrm{Pu}, 137 \mathrm{Cs}$, and $90 \mathrm{Sr}$ values in water samples; $238 \mathrm{Pu}, 239 \mathrm{Pu}, 237 \mathrm{Cs}$, and $90 \mathrm{Sr}$ values in sediment samples; and $239 \mathrm{Pu}$ and $137 \mathrm{Cs}$ for values in plankton, fishes, and clams. A discussion is presented of the quality of the data. The results indicated that bottom-feeding fish such as the gizzard shad, redhorse sucker, carp, bullhead, or drum had higher $239 \mathrm{Pu}$ concentrations than predators such as yellow perch or largemouth bass. The data were not consistent with a very striking food-chain magnification of plutonium in fresh-water ecosystems. It is suggested that plutonium concentrated on silt particles is remobilized by digestive processes of filter feeders or bottom feeders and that there may be rather large differences among species with regard to the efficiency of this. (NSA)

Bowen, V. T., K. M. Wong, and V. E. Noshkin. 1971. Plutonium 239 in and over the Atiantic Ocean. Journal Marine Res., 29:1:1-10.

Plutonium 239 has been found in over-ocean aerosols in about the same ratio

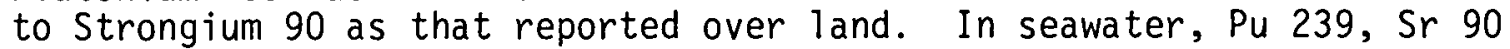
ratios are shown to be less than half of those in over-ocean aerosols, confirming geochemical separation of these nuclides in the ocean. It is suggested that the sedimentation of Pu 239 may be more involved with biological processes than has been found for Ce 144 or Pm 147 . (auth)

Brady, D. N. and B. W. Church. 1975. Discussion of NAEG Distribution and Inventory Program Sampling Data in Preparation for Initiation of Phase III. IN: White, M. G., and P. B. Dunaway (eds.). The Radioecology of Plutonium and other Transuranics in Desert Environments. NV0-153(UC-2): 217-230.

The Nevada Applied Ecology Group (NAEG) Distribution and Inventory Program's soil sampling effort during 1974 was significantly upgraded by implementation of improved sampling techniques. Initiation of Phase III sampling, based upon results of the overview phase, was achiexed. Preliminary data analysis aided in designing a program to infer 239-240 pu result.s by $\mathrm{Ge}(\mathrm{Li})$ scanning techniques. (auth)

Brown, D. A. 1974. Adsorption and Diffusion of Pu in Soils. OR0-4700-1. $3 \mathrm{p}$.

Progrcss is reported on the following projects: development of spccial equipment for safe handling of $\mathrm{Pu}$ in adsorption and diffusion experiments; development of a manually operated cryostatic microtome for partitioning soil cores and of a large glove box for containing diffusion and radioassay instruments; completion of a temperature controlled plutonium laboratory including the necessary air sampling and alpha radiation monitoring systems; preparation of mineral samples of kaolinite, illite, and montmorillonite for adsorption and diffusion experiments; chemical characterization 
of soils and clays; and experiments on diffusion of ${ }^{237} \mathrm{Pu}$ and ${ }^{238} \mathrm{Pu}$ in salt solutions and in standard clay minerals. (NSA)

Brown, D. J. 1967. Migration Characteristics of Radionuclides Through Sediments Under Lying the Hanford Reservation. IN: IAEA-SM-93/16. pp. 215-228, Disposal of Radioactive Wastes Into the Ground.

The US Atomic Energy Commission's Chemical Separation Plants at Hanford have discharged large volumes of intermediate and low-level radioactive liquid waste to the ground for more than twenty years. The information acquired by tracing the movements of radionuclides through the underlying sediments via an extensive network of monitoring wells and sophisticated monitoring equipment has increased our knowledge of the migration characteristics of radionuclides associated with these wastes.

Sediment samples obtained by core drilling a disposal facility at the time it was removed from service and again ten years later, show that over $99.9 \%$ of the long-lived radionuclides are contained within the first ten metres of the 60-metre partially saturated sediment column underlying the disposal facility. All radionuclides with half-lives of less than one year, except ruthenium-IUS and strontium-89, decay to below detection limits before they reach the regional groundwater table. The relative permanency of fixation of the long-lived radionuclides is attested to by leaching studies. For caesium-137 and strontium-90, the data show that after passing 50 column volumes of groundwater through sediments, obtained from beneath an abandoned disposal site, $11 \%$ of the caesium is removed and $4 \%$ of the strontium; 500 column volumes removes an additional $4 \%$ of the caesium and $27 \%$ of the strontium. Equilibrium coefficeint and soil column tests indicate that the trace amounts of strontium-90 and caesium-137, leached from sediments underlying a disposal facility, are resorbed in the saturated zone below the water table. The distribution coefficients determined in these saturated sediments were approximately 300 for caesium-137 and 50 for strontium-90. Three radionculides (ruthenium-106, technetium-99 and tritium), not readily sorbed on sediments, enter the groundwater at about the same concentration as that measured in the waste stream prior to release. The movements of these nuclides are traced in the groundwater for distances up to fifteen miles by routine analysis of well water samples. At distances of only two and a half miles from the disposal sites, all radionuclides concentrations in ghe groundwater are below the established drinking water limits. (auth)

Brown, R. E. and H. G. Rupert. 1950. The Underground Disposal of Liquid Wastes at the Hanford Works. HW-17088.

Field occurrences of $\mathrm{Pu}$ were noted as a result of waste disposal operations. The bulk of the plutonium in waste solutions at near-neutral pH was removed by the sediments relatively close to the disposal point. 
Brownel1, L. E., G. R. Chiaaramonte, and R. E. Issacson. 1970. A Stopper for Radioactive Wastes. ARH-1658.

The recommendations of the National Academy of Sciences National Research Council Committee on Geologic Aspects of Radioactive Waste Disposal have been reviewed noting that "the concept the Committee favors above all others (is) a procedure of disposal involving concentration of radioactive solutions, their conversion to almost insoluble solids, and subsequent burial for below freshwater aquifers in almost impermeable rock. " This objective may be fulfilled by conversion of radioactive wastes to insoluble silicates similar to basalt and stable in basalt-water systems. A very dense basalt with almost zero transmissibility at a depth between 3,000 and 3,200 feet below surface at Hanford, Washington should prove ideal for such isolation. Cesium would be trapped as pollucite - a cesium aluminum silicate clathrate, strontium as strontium anorthite and plutonium as plutonium silicate an analog of zircon. Pollucite, anorthite and zircon are stable mineral rocks. (auth)

Brownel1, L. E., C. H. Kindle, T. L. Theis. 1973. Review of Literature Pertinent to the Aqueous Conversion of Radionuclides to Insoluble Silicates with Selected References and Bibliography: Atlantic Richfield Hanford Company (ARH-2731).

The type of aluminosilicate produced depends upon the composition of the liquid waste and the reactants used. Wastes with large amounts of $\mathrm{NaOH}$ and $\mathrm{NaNO}_{3}$ give a salt filled cancrinite. Relatively pure radioactive cesium salts convert to mineral pollucite by clay reaction process (reacting Bentonite, Pyrophyllite, or Kaolinite + silica gel with alkaline solutions of cesium salts) reaction occurs by distillation of minerals to form amorphous material and at temperatures $80-100^{\circ} \mathrm{C}$ produces spherical cyrstallites of pollucite as a product. The presence of $\mathrm{NO}_{3}$ in solution causes the formation of cancinite; whereas halites, phosphates, perchlorate and other anions cause sodalite to form. The anions, in some cases, are considered to behave as structural templates in zeolites crystallizations, causing specific aluminosilicates to form.

Clays react with alkaline wastes at relatively low temperature $\left(70-100^{\circ} \mathrm{C}\right)$ at $100^{\circ} \mathrm{C}$ reaction is fast, reaching completion less than one day. All cations in groups II through VIII from insoluble silicates or aluminosilicates.

Bruns, L. E. 1974. Trip Report Nevada Applied Ecology Groups Meeting, October 9-10, 1974. Las Vegas, Nevada. ARH-LD-106.

The meeting was attended by approximately 150 people and consisted of three parts. The first day, October 9, 1974, consisted of presentations by members of the Nevada Applied Ecology Group (NAEG). The second day was divided into two parts; one, presentations on transuranic studies by organizations other than NAEG and secondly, presentations by five representatives of the Atomic Energy Commission - Headquarters (AEC-HQ) groups concerning what they 
considered to be appropriate future research work. This report is divided into four parts: (a) summary of the meeting, (b) NAEG research highlights, (c) other research highlights, and (d) recommendations for Atlantic Richfield Hanford Company derived from the meeting.

Buchholz, J. R., W. H. Adams, C. W. Christenson, and E. B. Fowler. 1971. More on the Plutonium Particle Size Problem. LADC-12898.

Soil analyses are directly effected by the particle size of plutonium. Larger plutonium particles tend to cause problems with analytical reproduceability.

Butler, F. E., R. lieherman, A. B. Strong, and U. R. Moss. 1971. Sampling and Analysis of suils for Plutonlum. IN: Fowler, E. B., R. W. Henderson, and M. F. Milligan (co-chairmen). Proceedings of Environmental Plutonium Symposium, held at LASL, August 4-5. LA-4756 (UC-41):47-50.

This paper describes the progress in analysis of soils artificially spiked with plutonium, soils, containing particulate plutonium deposited from a processing plant, and soils containing fallout plutonium. The emphasis is on distribution of the actinide determined after both fusion and acid leaching techniques.

The residue from multiple evaporations of soil with hydrofluoric acid is fused with potassium fluoride and potassium pyrosulfate, dissolved in dilute sulfuric acid, and the solution evaporated to remove fluorides. Plutonium is then extracted with a hydrochloric acid solution with triisootylamine (TIOA) and stripped from TIOA with dilute acid. Plutonium is coprecipitated with $\mathrm{LaF}_{3}$, the precipitate filtered onto a $0.2 \mu$ polycarbonate filter membrane, and the plutonium counted in an alpha spectrometer.

Recovery, indicated by Pu 239 tracer added to each sample, is $75 \pm 6 \%$ for $5 \mathrm{~g}$ soils. Recovery is higher for smaller samples. Assays of five interlaboratory cross-check soils in the range 0.5 to $16.0 \mathrm{pCi} / \mathrm{g}$ yielded an average error of only $3.6 \%$ by this method. (auth)

Carfagno, D. G., And W. H. Westendorf. 1972. Environmental Monitoring Report: July-December 1971 and 1971 Summary. MLM-1922.

The environment surroundings Mound Laboratory was monitored and repurled on for the second half of 1971 and for the entire year. Samples analyzed and reported on include air, water, foodstuffs, soil, and silt. For radioactive species the average concentrations of polonium 210, plutonium 238 and tritium detected were well within the stringent standards adopted by the Atomic Energy Commission and the Fnvironmental Protection Agency. Data concerning llumradioactive species in air and water are presented for the first time. Data for these indicate the Mound Laboratory operations have negligible effect on the environment. (auth) 
Champlin, J. B. F. 1969. Transport of Radioisotopes by Fine Particulate Matter in Aquifers. PB-232179, $200 \mathrm{p}$.

Information on the long-term movement of radioactive fission products and other pollutants from waste pits, fallout, and underground nuclear explosions is persued through theoretical and experimental investigations of the various phenomena that pertain to ion transport or retention by soils. The theoretical section explores the interactions between solids in water that result from thermal forces, electrostatic charges, and Van der Waals forces. The particle range considered is that of the large colloid to the finest silt. Special attention is given to sources of energy sufficient to cause breakage of adsorption bonds, additive bonding, and the relationship between suspended particles and the granules making up the aquifer. The experimental section explores factors which influence either retention of radioactivity by the sand bed or transport of the activity through such a bed by micro-particles. (NSA)

Cherdyntsev, V. V. I. V. Kazachevskii, L. D. Sulerzhitskii, and E. A. Kuz'mina. 1965. 239 Pu in Nature. Geochemical International. 2:918-20.

The occurrence of $\mathrm{Pu}$ in some natural minerals was studied. Plutonium was separated from the other elements in ion-exchange columns and precipitated electrolytically on $\mathrm{Ni}$-plated tablets used for activity measurements by an ionization a spectrometer. The yield of $239 \mathrm{Pu}$ was controlled by adding the carrier $238 \mathrm{Pu}$; it amounted to 5 to $20 \%$. The association of this $\alpha$ radiation source, with an energy of $5.15 \mathrm{MeV}$, with the $\mathrm{Pu}$ isotopes was confirmed by reprecipitation of some samples: this radiation source always followed by the 238pu. A typical a spectrogram is illustrated. A considerable number of mineral samples (over 300) from natural sources did not contain measurable amounts of $239 \mathrm{pu}$. The content of $239 \mathrm{pu}$ in natural waters was as high as $n \times 10^{-13} \mathrm{~g} / 1$, with $\alpha=n \times 10^{-7}$, which is many times higher than for $U$ minerals; as such, it indicates a different source of $\mathrm{Pu}$ enrichment. This isotope was identified in deep carbonate waters, as well as in some fresh waters, namely in waters of ore vein areas. Among the Pu-bearing minerals of ore vejns were sphene, molybdenite, magnetite, and particularly apatite $\left(3.6 \times 10^{-12} \mathrm{~g} / \mathrm{g}\right)$ and zircon $\left(2.9 \times 10^{-12} \mathrm{~g} / \mathrm{g}\right)$. Among the Quaternary deposits, P.u was observed in ferruginous carbonates and exhalation products of submarine volcanism. The low Th/U ratio in these products suggests that the ore substance was not likely enriched by radioelements from the ocean waters, nor was there any likelihood of an industrial origin for ${ }^{239} \mathrm{Pu}$. Furthermore, Pu was qualitatively identified in middle Pleistocene soils (Siberia), calcareous tuffs, and some formation waters. (NSA)

Cherdyntsev, V. V. and V. F. Mikhailov. 1963. The Primordial Transuranium Isotope in Nature. Geokhimiya. Number 1:3-14 (in Russian).

In some young natural samples a primodial radioactive $\alpha$-emitter is obtained. The $\alpha$-spectrum main line extends from 4.2 to $4.6 \mathrm{Mev}$ and the gamma rays 
have the energy in the region: 90 to $250 \mathrm{kev}$. This isotope apparently, is $\mathrm{Cm}^{247}$. Decay products of $\mathrm{Am}^{243}$ and $\mathrm{Pu}^{239}$ accompany it. The $\mathrm{Cm} 247$ content in natural minerals is about $n \times 10-8 \%$ and $\mathrm{Cm}^{247} / \mathrm{U}^{238}=\mathrm{n} \times 10^{-2}$ (activity units). The decay period of the isotope is estimated as $2.5 \times 10^{8}$ years. (auth)

Cherdyntsev, V. V., V. L. Zverev, V. M. Kuptsov, and G. I. Kislitsina. 1968. 239 Pu In Nature. Geokhimiya. Number 4:395-401. (in Russian).

The content of ${ }^{239} \mathrm{Pu}$, the product of decay of the transuranium isotope (porbably $247 \mathrm{Cm}$ ) with 4.4 to $4.6 \mathrm{MeV}$ energy, was investigated in various natural formations. In a number of cases preparations of the transuranium isotope were investigated. The best resulls were obtained by sublimation from nitrate solutions. By its chemical properties the isotope most closely approaches osmium. In ferruginous - manganese deposits of recent volcanism the content of plutonium reaches $7.4 \times 10-10 \%$, and in meteorites $3.5 \times$ $10^{-12 \%}$ when the Pu/U ratios are $1.7 \times 10^{-5}, 1.8 \times 10^{-6}$, respectively. The geochemical features of plutonium behavior are considered. (auth)

Cherdyntsev, V. V., V. L. Zverer, V. M. Kuptsov, and G. I. Kislitsina. 239Pu in Nature. Geochem. Int. 5:355-61.

The content of $239 \mathrm{Pu}$, the $\alpha$-decay (4.4 to $4.6 \mathrm{MeV}$ ) product of an unknown transuranium isotope, was determined in various natural materials. The geochemical features of Pu and the chemical behavior of the unknown isotope are discussed. (auth)

Christenson, C. W., M. B. Ettinger, G. G. Robuck, E. R, Hermann, K. C. Kohr, and F. F. Newe 11. 1951. Removal of Plutonium Prum Laboratory Wastes. Ind. at Eng. Chem. 43:7:1509-15.

Methods investigated for Pu removal included adsorption on Kaolin, pumice, tuff, Celite and activated carbon, alum and iron flocs $\mathrm{pH}$ adjusted with $\mathrm{Ca}(\mathrm{OH})_{2}$, lime and phosphate flocs. Polyphosphates and citric acid interfered with $\mathrm{Pu}$ removal and formation of good flocs.

Adsorption methods resulted in larger sludge volumes - reciruclation of sludges reduced siudge volume.

Christenson, C. W., E. B. Fowler, G. L. Johnson, E. H. Rex, and F. A. Virgi1. 1958. Soil Adsorption of Radioactive Wastes at Los Alamos. Sewage and Industrial Waste. 30:1478-1489.

Plutonium wastes had formerly been disposed by discharge to seepage pits or canyons at the Los Alamos project. Areas receiving plutonium waste have been monitored repeatedly and no appreciable movement has been noted. 
Observations were made, however, that the concentration of plutonium in the soil of a canyon receiving low level wastes has moved progressively downstream. Because of this movement, which has not been extensive and is. within acceptable tolerance levels, investigations were made of the movement of plutonium through local sites of the Los Alamos area under varying conditions. Strontium 90 and cesium 137 were also included in the study because of the possibility of introduction of those wastes in the future. Cores of tuff were cut from unweathered rock and solutions of the radionuclides and mixtures of the nuclides were allowed to pass through the cores. Alpha, beta, and gamma activity were measured. When activity of the effluent indicated breakthrough of the nuclide, autoradiographs were made to determine distribution of the radionuclide within the core. Tuff local to Los Alamos has shown a high capacity for retention of various nuclides. Cs 137 is apparently tightly bound to the tuff and resists leaching. $\mathrm{Pu} 239$ is also readily retained, however, it is possible that this nuclide could be released at some future time by inadvertent discharge of solutions such as versene in the same area. Sr 90 is not retained as well and disposal of this radionuclide should be undertaken with extreme caution. (ORNL-72-21)

Christenson, C. W. and P. G. Thomas. 1962. Movement of Plutonium Through Los Alamos Tuff. TID-7628, Part of Second Ground Disposal of Radioactive Wastes Conference Atomic Energy of Canada Limited Chalk River, Canada, September 26-29, 1961. p. 248-281.

Uncontrolled and uncontained ground disposal of plutonium can be dangerous under field conditions. Plutonium species penetrate at least 28 feet in Los Alamos tuff. Moisture data, rates of flow of liquid and physical inspection indicated that this penetration takes place along fissures. The amount of activity sorbed at any one point in depth is dependent upon the chemical and physical nature of the substructure in that area. High percentages of clays, deposited by local weathering, will sorb plutonium species and result in a localized area of high alpha activity. As the species percolates through the soil, changes in valence state may also occur with changes in chemical environment; sorption or even solution may result. (ORNII-77-21)

Christ1, R. J. 1964. Storage of Radioactive Wastes in Basement Rock Beneath the Savannah River Plant. DP-844(TID-4500, 28th Edition):C14C17.

The effect of simulated waste solutions (1-4 M NaOH and $3 \mathrm{M} \mathrm{HNO}_{3}$ ) on the dissolution of individual minerals revealed that the minerals react with these solutions t.n produce soluble silica gel, $x \mathrm{SiO}_{2} \cdot \mathrm{xH}_{2} \mathrm{O}$, or sodium orthosilicate $\left(\mathrm{Na}_{4} \mathrm{SiO}_{4}\right)$. The neutralization equivatents (grams dissolved per mole of $\mathrm{HNO}_{3}$ or $\mathrm{NaOH}$ ) of rock tested with $1 \mathrm{M} \mathrm{NaOH}$ or $1 \mathrm{M} \mathrm{HNO}_{3}$ was between 35 and 55 , which is in agreement with the calculated values (23-58) based on petrographic analyses and the individual mineral reactions. 
Chruch, B. W., D. N. Brady, I. Aoik, and W. A. Bliss. 1974. Distribution and Inventory, Element Activities on-NTS and off-NTS. IN: Dunaway, P. B., and M. G. White (eds.). The Dynamics of Plutonium in Desert Environments. NV0-142 (NOV-AEIC-74-1 or UC-2):311-319.

The Nevada Applied Ecology Group Distribution and Inventory Element has expanded its activities this past year to include investigation of all plutonium-contaminated areas on and near the NTS. This progress summary report describes the element activities underway, but does not include compiled data. A separate comprehensive element progress report is in preparation, which will include details of the Distribution and Inventory Element activities to date. (auth)

Church, B. W., E. S. Medling, and D. N. Brady, 1975. A Different look at Aréa 13, FIDLER Survey Date. IN: White, M. G., and P. B. Dunaway (eds.). The Radioecology of Plutonium and other Transuranics in Desert Environments. NVO-153(UC-2):231-236.

FIDLER (Field Instrument for Detection of Low-Energy Radiation) data corresponding to soil samples analyzed for $239 \mathrm{pu}$ is evaluated for all isopleths of Area 13 of Nevada Test Site. It was found that when considering data for the total area, a function can be derived predicting surface $239 \mathrm{pu}$ concentrations approximately within a factor of 2 . (auth)

Cline, J. F. 1967. Uptake of Americium 241 and Plutonium 239 by Plants. BNWL-714:8.24-8.25.

Concentrations of Am 241 were 20-30 times greater than those of $\mathrm{Pu} 239$ in plant tissues grown on substances containing equal amounts of radioisotopes. Americium was more toxir. than plutonium to growing roots. It was bound tightly to soil particles but showed some movement with irrigation water, especially in basic soils. (auth)

Corley, J. P., D. M. Rubertson, änd F. H. Brauer. 1971. Plutonium in Surface Soil in the Hanford Plants Environments. IN: Fowler, E. B., R. W. Henderson, and M. F. Milligan (co-chairmen). Proceedings of Environmental Plutonium Symposium, held at LASL, August 4-5. LA-4756 (UC-41): 85-88.

Surface soil sampling from February, 1970 through Apri1, 1971 on and around the Atomic Energy Commission's Hanford Reservation is described. The sample sites selected were from less than 1 mile to as far as 30 miles from major plutonium-handling facilities, including sites around the perimeter of the AEC controlled land.

The top one-half inch of soil was sampled. Vegetative litter and rootmat were avoided as much as possible. Portions of the mixed soil samples were 
dried and analyzed for plutonium content, using acid leaching, solvent extraction, and alpha counting. Several locations were sampled in replicate. Certain samples were analyzed in duplicate. The plutonium results (all as dpm plutonium per $g$ of dry soil) grouped by general location were: within restricted areas, from 0.05 to 1.4 ; outside restricted areas but within the reservation boundaries, <0.01 to 0.28 ; and outside the plant boundary, from $<0.01$ to 0.13 . (auth)

Costanzo, D. A., R. E. Biggers, and J. T. Bel1. 1973. Plutonium Polymerization - I A Spectrophotometric Study of the Polymerization of Plutonium (IV). Jour. Inorg. and Nuclear Chem. 35:609-622.

Standard spectra of the Pu species have been observed and then used in the calculations of the distribution of $\mathrm{Pu}$ (III), (IV), (V), (VI), and polymeric $\mathrm{Pu}$ (IV) in solutions containing $\sim 0.009 \mathrm{M}$ metal $\mathrm{Pu}$ at initial acidities of $0-1,0-075,0-06$, and $0-04 \mathrm{M} \mathrm{HNO}_{3}$, and at $25^{\circ}$ and $75^{\circ} \mathrm{C}$. The distributions of the $\mathrm{Pu}$ species are given for the four acidities at $25^{\circ} \mathrm{C}$, and the distributions are given for the initial acidity of $0-075$ $\mathrm{M} \mathrm{HNO} 3$ at $25^{\circ}, 50^{\circ}$, and $75^{\circ} \mathrm{C}$.

In these studies the polymer is not formed when the initial acidity is $0-1 \mathrm{M}$ and the temperature is $25^{\circ} \mathrm{C}$, but the degree of polymerization continuously increases at the lower acidities and is almost quantitative when the initial acidity is 0-04 M. The effect of an increasing temperature is to increase the rate of polymerization at the expense of the ionic $\mathrm{Pu}$ species. The amount of polymer formed at $75^{\circ} \mathrm{C}$ is $\sim 3-5$ times as great as the amount at $25^{\circ} \mathrm{C}$ when the initial acidity is 0-075 $\mathrm{M}$. (auth)

Crawley, D. T. 1969. Plutonium-Americium Soil Penetration at 234-5 Building Crib Sites. ARH-1278.

Plutonium-americium carried in a slightly acid, high salt waste had penetrated to a depth of 18 feet in the Z-lA tile field, the limit of sampling. Plutonium-americium contained in neutralized low salt waste routed to the Z-12 crib had penetrated the soil to a minor extent, based on sampling to 16 feet. At each disposal site, some concentration of the plutoniumamericium was noted at the top layer of soil. (auth)

Cummings, S. L., and L. Bankert. 1971. The Uptake of Cerium-144, Promethium-147, and Plutonium-238 by Oat Plants from Soils. Radiological Health Data and Reports 2:83-85.

The uptakes of cerium-144, promethium-147, and plutonium-238 by nat plants were determined for nine soils, and promethium-147 and plutonium-238 uptakes were compared with cerium-144 uptake. The percentage uptake values for all three radionuclides were very low, ranging from $10^{-5}$ to $10^{-3}$ percent. Nitrogen and potassium fertilizers increased the uptake of promethium-147 
by oat plants from an Amite soil. Because the amount of cerium-144, promethium-147, and plutonium-238 taken up by plants from soils is very smal1, the health hazards to man by the soil-plant-man pathway from these radionculides will probably be negligible at the levels used in this study. (auth)

Davy, D. R., M. S. Giles, and N. Conway. 1973. Pre-0perational Assessment of the Discharge Limits and Relative Importance of Radioactive and other Wastes from Uranium Production. In Australia's Northern Territory. IAEASM-172/6. Environmental Behavior of Radionuclides Released in the Nuclear Industry, pp. 37-54.

The paper examines the sources and nature of the wastes likely to arise from the uranium extractive industry now being developed in the Northern Territory of Australia. The area in question is tropical and has a season of monsoonal rain with heavy run-off, which alternates with a long dry season. In the dry season river flow is minimal and parts of the river systems become isolated and subject to heavy loss from evaporation. In consequence, the environmental problems associated with the uranium mines and mills are unusual. Ecological mapping to define senisitive habitats and toxicity studies undertaken on sensitive species indicate that the levels that can be allowed for heavy metals will dictate criteria fur lreatment and containment of wastes from extraction plants. On the other hand, radiological considerations will govern disposal of pit water and runoff from storage and overburden dumps.

The naturally occurring level's and transfer mechanisms have been examined for uranium, radfum and lead. These characteristics can be used to assess the environments of particular mines. For each of four probable mine locations four possible exposure routes for $226 \mathrm{Ra}$ and $210 \mathrm{ph}$ ran be identifcd and have beell evaluated separately. Although their local environments are very similar, the critiral exposurc routes differ for at least three of the possible mine sites. This is because transfer and dispersion mechanisms, and land use, differ between the sites. (auth)

Desai, M. V. M. and A. K. Canguly. 1970. Interaction of Trace Elements with Organic Constituents in the Marine Environment. B.A.R.C. $-488, \Gamma .102$.

Includes pertinent chapters on interaction of a marine humic acid and a fulvic acid with thorium, uranium and plutonium.

Duursma, E. K., and M. G. Gross. 1971. Marine Sediments and Radioactivity. IN: Radioactivity in the Marine Environment. National Academy of Sciences, Washington, D. C. :147-160.

Sediments and sedimentary particles have a substantial capacity to remove radionuclides from seawater. The particles may be deposited on the ocean 
bottom or picked up by filter-feeding organisms that may concentrate the radionuclides and pass them into man's food supply.

Certain radionuclides are more strongly sorbed on sediment particles than others. Mineral-related reactions, each with a degree of specificity, appear to be controlled by chemical species of the radionculides and the physico-chemical conditions of the sediments and sedimentary particles. In some laboratory experiments, the amount of radionuclides taken up by sediments and sedimentary particles depends on the history of the sedimentwater system prior to the introduction of the radionculide; this makes it difficult to predict radionuclide behavior in sediment-laden water.

Radionuclides may move through the sediment after depositon. Among the processes by whihc radionculides move are diffusion through the interstitial water, movement. with the interstitial water expelled from the sediment by compaction, and groundwater discharge through the sea bottom. Where sediment accumulation is sufficiently rapid, the radioactive particles may be covered by later sedimentary deposits before these relatively slow movements can move the nuclides through the sediment-water interface. On a large part of the continental shelf and on much of the deep-ocean bottom, rates of sediment accumulation are slow enough that diffusion processes may be dominant.

Sediment particles and their associated radionuclides may be mixed or moved by burrowing activity of benthic organisms, near-bottom currents, wave action, turbidity currents, longshore currents, or by ice.

Sediments or sedimentary particles can remove radionuclides from seawater and deposit them on the sea bottom. Calculations have been given to indicate the effect of such applications of sediments, and criteria have been presented to guide the selection of materials to be used in such applications. (auth)

Duursma, E. K. 1972. Geochemical Aspects and Applications of Radionuclides in the Sea. Oceanogr. Mar. Biol. Ann. Rev. 10:137-223.

This review is intended to update the geochemical part of the earlier review by Mauchline and Templeton (1964), published in this same annual review series. It covers the geochemical aspects of both artificial and natural radionuclides in the sea, and attention is paid to the use of radionuclides as tracers for sediment and water transport studies. The biological aspects of radionuclides in the marine environment will be reviewed in a separate article. The majority of the literature revlewed is tiat published sincc 1963 with some mention of relevant papers published earlier but not included in the review of Mauchline dild Templeton (1964). (auth)

Duursilla, E. K., and P. Parsi. 1974. Distribution Coefficients of Plutonium Between Sediment and Seawater. IN: Activities of the International Laboratory of Marine Radioactivity. IAEA-163:94-96. 
The authors using a $\mathrm{Pu} 237$ as a tracer, conducted a series of experiments to determine the distribution coefficient of plutonium onto sediments under oxic and anoxic conditions. The plutonium was added in three different valence states; III, IV, and VI. All three valence states showed $\mathrm{Kd}$ values in order of $10^{4}$ for both anoxic and oxic conditions. The authors speculate that $\mathrm{Pu}$ (IV) enters adsorption phenomenon, while $\mathrm{Pu}$ (III) and $\mathrm{Pu}$ (VI) may be precipitating in addition to active reactions. (DR)

Eberhardt, L. L., and R. D. Gilbert. 1974. General Statistical Considerations in Environmental Plutonium Studies. IN: Dunaway, P. B., and M. G. White (eds.). The Dynamics of Plutonium in Desert Environments. NV0-142 (NVO-AEIC-74-1 or UC-2):43-49.

The high sampling variability encountered in environmental plutonium studies, along with high analytical costs, makes it very important that efficient sampling plans be used. However, efficient sampling depends on explicit and simple statements of the objectives of the slurly. When there are multiple ubjectives, as in the Nevada Applied Ecology Group (NAEG) study, it may be difficult to devise a wholly suitable sampling scheme. Sampling for long-term changes in plutonium concentration may also be complex and expensive. Further attention to problems associated with compositing samples is recommended, as is the consistent use of random sampling as a basic technique. (auth)

Edgington, D. N., J. J. Alberts, M. A. Wahlgren, T. 0. Karttunen and C. A. Reeve. 1975. Plutonium and Americium in Lake Michigan Sediments. TAEASM-199/47.

The vertical distributions of $239,240 \mathrm{Pu}, 238 \mathrm{Pu}$, and ${ }^{137} \mathrm{Cs}$ have bcen measured ill sediment cores taken from Lake Michigan. Sections from a limited number. uf cores have been analyzed for 241 Am. In andition, grab samples früu len lucaliuns in the southern basin of the lake have been analyzed for phase distribution of $239,240 \mathrm{Pu}$ using a sequential extraction technique.

The results indicate that the $239,240 \mathrm{Pu},{ }^{238} \mathrm{Pu}$, and ${ }^{137} \mathrm{Cs}$ from weapons testing, and the $24 \mathrm{~T}_{A m}$ formed in situ are concentrated in the sediments. A comparison of the total deposition of $239,240 \mathrm{Pu}$ and $137 \mathrm{Cs}$ indicates that 137 Cs may be valjuahleas 29 monitor for $239,240 \mathrm{pu}$ depusition in the sediments. Values of the $238 \mathrm{Pu} / 239,240 \mathrm{Pu}$ ratio are in agreement with values reported in Lake Ontario sediments (and Lake Michigan plankton) and show little variation with depth. ${ }^{241}$ Am data support the concept of in situ production with litlle preferential mobility after formation.

Studies of sedimentary phase distributions show that $239,240 \mathrm{Pu}$ is associated with hydrous oxide phases which are chemically stable under the prevailing conditions in the lake sediments since Lake Michigan sediments remain aerobic, relatively little $239,240 \mathrm{pu}$ is available for chemical mobilization from the hydrous oxide or organic phases present in the sediments. 
Emery, R. M., and T. R. Garland. 1974. The Ecological Behavior of Plutonium and Americium in a Freshwater Ecosystem: Phase II. Implications of Differences in Transuranic Isotopic Ratios, BNWL-1879.

The ecological behavior of $\mathrm{Pu}$ and Am in a freshwater processing waste pond has been studied since July 1973 to characterize the pond's limnology and define the isotopic distributions in this ecosystem (Emery, et a1. 1974). Results from this study show that that the history of transuranics discharged to the pond has created a complex combination of source terms and isotopic ratios. Since these source terms and chemical forms entering the pond have not been clearly defined, a material balance for $\mathrm{Pu}$ and $\mathrm{Am}$ in this ecosystem cannot be developed. Relatively large quantities of $\mathrm{U} 238$ have been released to the pond, and these, along with unidentified levels of Th 232 and Th 228 create a problem of interpreting the ecological behavior of. $\mathrm{Pu}$ and $\mathrm{Am}$ in this ecosystem. Ratios of $\mathrm{Pu} 238$ to $\mathrm{Pu} 239,240$ found in the pond are much higher than those in the processing wastewaters released to the pond. Ratios of $\mathrm{Pu} 238$ to $\mathrm{Pu} 239,240$ and $\mathrm{Am} 241$ to $\mathrm{Pu}$ 239, 240 are significantly higher in the pond biota than in the sediments suggesting a common source of availability to the biota. This contention is supported by the rapid establishment of these ratios in goldfish (Carassius) which were experimentally introduced into the pond. Ratios of Am 241 to $\mathrm{Pu} 238$ in the pond biota are also significantly different from those of the sediments but to a lesser degree than ratios of $\mathrm{Pu} 238$ to $\mathrm{Pu} 239,240$ an $\mathrm{Am} 241$ to $\mathrm{Pu} 239,240$. A wide range of particle sizes of $\mathrm{Pu} 238$ and $\mathrm{Pu} 239,240$ may exist in the pond sediments. The pond sediments, however, may not be the major source of "available" Pu and Am because results of this study suggest that sediments in a trench carrying the processing wastes to the pond may be the primary source. (auth)

Emery, R. M., D. C. Klopfer, T. R. Garland, and W. C. Weimer. 1975. Ecological Behavior of Plutonium and Americium in a Freshwater Pond. BNWLSA-5346, (CONF-750503-19). $38 \mathrm{p}$.

A Pu processing waste pond on the Hanford Reservation has been studied since mid-1973 to characterize the pond's limnology and determine the ecological behavior in this ecnsystem. This shallow 14-acre pond has existed and received $\mathrm{Pu}$ processing wastes for about 30 years. During this period about $8.1 \mathrm{~kg}$ of $\mathrm{Pu}$ was reported to have been discharged into waste trenches leading to the pond. This ultra-eutrophic pond has a water inflow rate of $10 \mathrm{~m}^{3} / \mathrm{min}$. of which greater than 95 percent leaves the pond by percolation. Macrophytes (mainly Potamogeton), algae (mainly Cladophora), benthic invertebrates (mainly dipterna and odonate larvae, hemipternas, amphipods, and gastropods) and goldfish are the major biotic components of the system. Sediments are the principal repository of $\mathrm{Pu}$ and Am having mean concentration for $238 \mathrm{Pu}, 239,240 \mathrm{Pu}$, and $241 \mathrm{Am}$ of 169,177 , and $81 \mathrm{pCi} / \mathrm{g}(\mathrm{dry})$, respectively. Mean ratios of isotopes in the sedimets are 0.85 for $238 \mathrm{Pu}$ to $239,240 \mathrm{Pu}, 0.61$ for $241_{\mathrm{Am}}$ to $238 \mathrm{Pu}$, and 0.49 for $241_{\mathrm{Am}}$ to $239,240 \mathrm{PU}$. Levels of $\mathrm{Pu}$ and $\mathrm{Am}$ in the interstitial water range from 0.5 to $13 \mathrm{pCi} / \mathrm{g}$ (dry weight of sediment) and exist mainly in cationic or nonionic forms. 
For 238pu in pond water the mean concentration is $0.007 \mathrm{pCi} / 1$, for $239,240 \mathrm{pu}$ it is $0.002 \mathrm{pCi} / 1$, and for $24 \mathrm{l}_{\mathrm{Am}}$ it is $1.08 \mathrm{pCi} / 1$. Algal floc (decomposing algal material) is the major concentrator of $\mathrm{Pu}$ and Am in the pond having mean concentrations for 238pu of $986 \mathrm{pCi} / \mathrm{g}$, for $239,240 \mathrm{pu}$ of $615 \mathrm{pCi} / \mathrm{g}$, and for $241_{\mathrm{Am}}$ of $256 \mathrm{pCi} / \mathrm{g}$. Watercress (Rorippa) had Pu levels about equal to those of the sediments, while dragonfly larvae (Libellula) and snails (Lymnaea) along with watercress had Am levels approximating those of the sediments. The remaining biota had $\mathrm{Pu}$ and Am levels which were generally well below those of the sediments. Although goldfish remain in the pond longer than any of the other fauna, and feed most heavily on plant, algae, and organic debris, they concentrate relatively small amounts of Pu and Am (about 10 to $15 \mathrm{pCi} / \mathrm{g}$ ). In situ experiments indicate that goldfish reach an equilibrium level for $\mathrm{Pu}$ of about $15 \mathrm{pCi} / \mathrm{g}$ within a few days of exposure to the pond, after which they may remain active in the pond for many months without further accumulation. The biological availability of $238 \mathrm{Pu}$ appeared to be greater than that of $239,240 \mathrm{Pu}$ since most of the pond organisms sampled accumulated more $238 \mathrm{pu}$ than $239,240 \mathrm{pu}$ on an activity basis. Ratios of $238 \mathrm{Pu}$ to $239,240 \mathrm{Pu}$, and $24 \mathrm{I}_{\mathrm{Am}}$ to $239,240 \mathrm{Pu}$ are significantly higher in the pond biota than in the pond sediments. These results primarily indicate that transuranics are being made available and/or utilized by pond organisms in ratios which are not reflected by pond sediment concentrations. A common source of avajlahble Pu and Am for pond biota is suggested by the rapid establishment of $238 \mathrm{Pu}$ to $239,240 \mathrm{Pu}$, and $241_{\mathrm{Am}}$ to $239,240 \mathrm{Pu}$ ratios in imported goldfish. Within 2 weeks after these fish had been introduced into the pond they had accumulated transuranic ratios which were similar to those of all other pond biota and dissimilar to those of the pond sediment. Ratios of $241 \mathrm{Am}$ to $238 \mathrm{Pu}$ in U-Pond biota are significantiy different from those of the sediments but to a lesser degree than ratios of $238 \mathrm{Pu}$ to $239,240 \mathrm{pu}$ and $241 \mathrm{Am}$ to $239,240 \mathrm{Pu}$. (auth)

Eberhardt. L. L., and R. 0. Gilbert. 1972. Statistical Analys is of Soil Plutonium Studies, Nevada Test Site. BNWL-B-217.

This report has been written to summarize the results of our efforts to date in the plutonium environmental studies program of the Nevada Applied Ecology group. Many of the field studies are currontly not completed, but it seems desirable to produce a summary analysis of the statistical asperts at this time. We believe the report will be useful in planning further studies at the Test Site. It should also serve as a basis for discussion of the kinds of data needed for statistical appraisals of particular problems.

Much of our effurt thus far has been directed towards the problems of estimating the inventory of plutonium in soil. The only extensive set of data available to us thus far is from the GMX area. That data suggests that is is quite feasible to proceed with an inventory for GMX with the tools at hand. The other kinds of objectives (described under SAMPLING TECHNIQUES) require more data and various decisions as to what is wanted from the studies. 
The report provides some preliminary results on the use of the FIDLER instrument in Area 13, but we believe it is not profitable to try to do too much interpretation of such comparisons without more crosschecking FIDLER counts against "wet" chemistry or similar analyses. Another section of the report provides a basis for decisions on the number of replicates for interlaboratory comparisons. It should be noted that this section serves for planning purposes - once the study is completed, the results should be analyzed by other procedures (most likely an analysis of variance). (auth)

Emery, R. M., D. C. Klopfer, and W. C. Weimer. 1974. Ecological Behavior of Plutonium and Americium in a Freshwater Ecosystem. Phase I. Limnological Characterization and Isotopic Distribution. BNWL-1867. $82 \mathrm{p}$.

A Pu processing. waste pond on the Hanford Reservation was studied since July 1973 to characterize the pond's limnology and determined the ecological distribution of $\mathrm{Pu}$ and. Am in this ecosystem. This shallow 14-acre pond has existed and received processing wastes for about 30 years, having a possible total $\mathrm{Pu}$ input of $8.1 \mathrm{~kg}$. Limnological studies have characterized the pond as having a simple food web existing under ultra-eutrophic conditions, with physical circulation and mixing being primarily controlled by wind and secondarily by heated water entering the pond. This pond receives about $10 \mathrm{~m}^{3}$ of water per minute, of which at least 95 percent leaves via percolation through the desert-like soil. Macrophytes (mainly Potamogeton), algae (mainly Cladophora), benthic invertebrates (mainly dipteran and odonate larvae, hemipternas, amphipods, and gastropods) and goldfish are the major biotic components of this system. Sediments are the principal repository of $\mathrm{Pu}$ and $\mathrm{Am}$, containing about $390 \mathrm{pC} i$ of

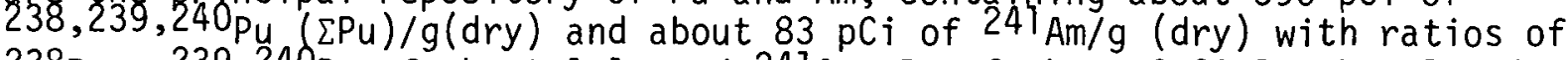
238Pu: $239,240 \mathrm{Pu}$ of about $1: 1$, and $241 \mathrm{Am}: \Sigma \mathrm{Pu}$ of about $0.23: 1$. Levels of these transuranics in the pond, water are much lower having concentrations of spy of about $0.01 \mathrm{pCi} / 1$ and $241 \mathrm{Am}$ of about $1.1 \mathrm{pCi} / 1$, with ratios of $238 \mathrm{Pu}: 239,240 \mathrm{Pu}$ of about $3.5: 1$ and $241 \mathrm{Am}: \Sigma \mathrm{Pu}$ of about 120:1. In the biota the prinicpal concentrator of $\mathrm{Pu}$ an $\mathrm{Am}$ is decomposing algal material (designated as algal floc, and rich in microorganisms) with levels of $\Sigma \mathrm{Pu}$ of abot $2 \mathrm{nCi} / \mathrm{g}$ (dry) and $241 \mathrm{Am}$ of about $250 \mathrm{pCi} / \mathrm{g}$ (dry). This material serves as a major energy source for most of the pond fauna. In spite of the relatively high levels present in the sediments and major food source most of the biota have accumulated relatively lower levels of $\mathrm{Pu}$ and Am. Only an ephmeral growth of watercress (Rorippa) exceeds both $\Sigma \mathrm{Pu}$ and $24 \mathrm{Am}$ levels in the sediments. However watercress, dragonfly larvae (Libellula), and the snail Lymnaea had higher 241 Am concentrations than that of the sediments. Levels of these transuranics in other aquatic flora and fauna are also reporled which rarlye from 0.5 to $154 \mathrm{pCi}$ of $\Sigma \Gamma \mathrm{F} / \mathrm{g}$ and 0.3 to $50 \mathrm{pCi}$ of $241 \mathrm{Am} / \mathrm{g}$. Ratios of $238 \mathrm{Pu}: 239,240 \mathrm{Pu}$ in biota were generally higher than that of the sediments (i.e., >1:1), bug lower than that of pond water (i.e., <3.5:1). The same was true for ratios of $241_{\mathrm{Am}}: \Sigma \mathrm{Pu}$ in biota as most organisms had ratios exceeding $0.23: 1$ (with maximum of 2:1), but not approaching that of pond water (120:1). Also discussed are concentrations 
factors for pond biota with respect to various expressions of biological availability. Depending upon assumptions made for availability the CF values for any organism may range by many orders of magnitude. (auth)

Emery, R. M., D. C. Klopfer, T. R. Garland, and W. C. Weimer. 1974. Ecological Distribution and Fate of Plutonium and Americium in a Processing Waste Pond on the Hanford Reservation. BNWL-1950. Part 2. pp. 96-100.

A study concerned with the ecological behavior of $\mathrm{Pu}$ and $\mathrm{Am}$ is being carried out in a shallow waste pond (14 acres) which has existed and received $\mathrm{Pu}$ processing wastes for about 30 years. The system is ultra-eutrophic and the major organisms are macrophytes (mainly Potamogeton), algae (mainly Cladophora), benthic invertebrates (mainly dipteran and odonate larvae. heiiniplerials, umphipods, ariul ydslropods) and goldtish. Sediments are the principal repository of $\mathrm{Pu}$ and Am containing about $390 \mathrm{pCI}$ of $238,239,240 \mathrm{Pu}$ $(\Sigma \mathrm{Pu}) / \mathrm{g}$ (dry) and about $83 \mathrm{pCi}$ of $241 \mathrm{Am} / \mathrm{g}$. Pond water had much lower concentrations of $\sum \mathrm{Pu}(0.01 \mathrm{pCi} / 1)$ and $241_{\mathrm{Am}}(1.1 \mathrm{pCi} / 1)$. In the biota the principal concentrator of $\mathrm{Pu}$ and $\mathrm{Am}$ is decomposing algal material, the major feeding substrate for the system, containing about $2 \mathrm{pCi}$ of $\Sigma \mathrm{Pu} / \mathrm{g}$ and 250 $\mathrm{pC} i$ of $241 \mathrm{Am} / \mathrm{g}$. In spite of these levels, the remaining biota have relatively lower soncentrations, ranging from 8.5 to $154 \mathrm{pCi}$ of $\Sigma \mathrm{Pu} / \mathrm{g}$ and 0.3 to $50 \mathrm{pC} i$ of $241 \mathrm{Am} / \mathrm{g}$. Ratios of $238 \mathrm{Pu}$ to $239,240 \mathrm{Pu}$ in the biota are generally higher than that of the sediments (0.9), but lower than that of pond water (3.5). The same was true for ratios of $241_{A m: \Sigma P u}$ in biota; most organisms had ratios exceeding those for sediments, but considerably less than those for water. (auth)

Essington, E. H., R. 0. Gilbert, L. L. Eberhardt, and E. R. Fowler. 1975. Plutonium, Americium and Uranium Concentrations in Nevada Test Site Soil Protiles. IAEA-SM-199/76.

Many soil profile samples were collected by the Nevada Applied Ecology Group from five nuclear safety test sites on the Nevada Test Site and Tonopah Test Range in Nevada, U.S.A. The profile samples were analyzed for plutonium, americium, and in some cases uranium in order to estimate the depth of radionuclide penetration and level of contamination at specfic sampling depths after an extended period of time since deposition on the surface. Nearly 70 individual profiles were examined. About onehalf of the profiles exhibited a smooth leaching pattern with more than 95 percent of the plutonium in the top $5 \mathrm{~cm}$. Other profile patterns are discussed relative to 1) mechanical disturbance of the profile after the initial deposition, 2) accumulation of plutonium in specific zones within the soil profile, and 3) occurrence of large amounts of plutonium in the deepest parts of the soil profile. The implications of these observations are discussed with respect to redistribution of radioactivity by wind, water, and burrowing animals, ingestion by burrowing and grazing animals, uptake by vegetation, and cleanup operations. (auth) 
Fedorov, E. A. and G. N. Romanov. 1970. Quantitative Characteristics of the Relation Between the Environmental Contamination Levels and Radioisotope Concentrations in Selected Types of Farm Produce. A-AC-82/G/2-1286:AEC-tr7128:112-126.

Studies on the effects of the environment on radioisotopes and the effects of global fallout on contamination levels of farm produce led to the determination of proportionality factors for certain farm products. Establishment of these quantities made it possible to estimate the contamination of farm products for known levels of radioactive fallout and a known content of radioisotopes in the soil. Tables are presented to show soil proportionality factors for Cs $137, \mathrm{Ce} 144, \mathrm{Bu}$ 106 , Sr 89, and Sr 90 in hay, wheat, leafy vegetables, potatoes, and root vegetables. Data on uranium concentrations in farm crops show that there is a close relationship to the content of the available form of the uranium in the soil. A formula is presented for determining the air proportionality factor for I 131. Ratios between levels of Sr 90 and Cs 137 contents of milk and fallout levels were studied. (NSA)

Fenimore, J. W. 1964. Land Burial of Solid Radioactive Waste During a 10-Year Period. Health Physics 10:229-236.

Since the initial land burial of solid radioactive waste in 1953 at the Savannah River Plant, 577,000 c of fission products and induced radioactivity has been buried. Routine surveillance of thirteen test and observation wells has indicated no migration of radioactive material. Geologic and hydrologic studies, radioassays of soil samples, and measurements of groundwater velocity using tritium as a tracer, indicate little possibility of introducing this buried radioactivity into public zones. Maximum movement detected by radioassay of soil was $2 \mathrm{ft}$, with one exception. (auth)

Folsom, T. R. and V. F. Hodge. 1973. Plutonium Fuel Problem as it is Being Approached at Scripps Institution. CONF-730596-1, $18 \mathrm{p}$.

Some of the problems involved in anticipating what will be the fate of plutonium in the marine environment are considered. Problems from background variability, behavior of fallout plutonium in the marine biosphere, chemical properties of plutonium, and monitoring of large-scale oceanic trends of plutonium are discussed. (NSA)

Foster, R. F. 1961. Environmental Behavior of Chromium and Neptunium. Proceedings of the First National Symposium on Radioecology held at Colorado State University, September 10-15. V. S. Schultz and A. W. Klemet, Jr. (eds.). pp. 569-576.

The most abundant source of chromium is chromite ore with the largest known domestic reserves situated in Montana. Chromium has been detected in living 
organisms in only trace quantities and seemingly plays no essential role in the physiology of plants or animals. The principal means through which chromium enters the biosphere is the liquid and gaseous effluents of industrial plants which use this element.

Chromium is a toxic material and if present in high concentration can damage plants, animals, and humans. Aquatic organisms appear to be especially vulnerable. The hexavalent state is more readily assmilated than the trivalent state and is generally considered to be at least a hundred times more toxic than the trivalent state. The red blood cells have a strong affinity for hexavalent chromium which has led to the popular use of radiochromium (chromium-51) in clinical studies of hematologic disorders. Ultimately, chromium is concentrated in the reticuloendothelial system, and in humans it is eliminated principally in the urine.

Chromium-51 is the only radioisotope which has environmental importance at the present time, and this isotope is present in the effluent from the Hanford reactors which enters the Columbia River. Retention by Columbia River solids is measureable but not of great significance. Chromium51 accumulates in algae of the river, but its concentration diminishes rapidly in higher trophic levels.

The exposed parts of crops which have been in direct contact with irrigation water which contains chromium-51 may have detectable quantities of this isotope, but root crops and fruits contain insignificant amounts. It has not been found in milk or other products of animals grazed on irrigated pasture. Chromium-51 has little radiological significance since its decay to stable vanadium releases very little ionizing radiation.

The artificial element neptunium has two radioisotopes of some interest to ecologists. Neptunium-239 is created by the capture of a slow neutron by uranium-238 and decays with a half-life of 2.3 days to become fissionable plutonium-239. Substantial quantities of neptunium 239 are created in p]utonium-producing reactors and in conventional atomic bombs, and thus it has been measured in the environment. The alpha-emitting isotope, neptunium-237, has not entered the biosphere in appreciable quantity. It has a very long half-life $\left(2.2 \times 10^{6}\right.$ years $)$ and thus a very low specific activity. The element, which resembles the rare earths in several aspects, is not easily incorporated into ecosystems, and it has not been reported in terrestrial biota or beyond the second trophic level in aquatic forms.

The radiological importance of neptunium has primarily been associated with the presence of neptunium-239 in drinking water and the potential dose imparted to the gastrointestinal tract. (auth)

Fowler, E. B., J. R. Bucholz, C. W. Christenson, W. H. Adams, and E. R. Rodriguez. 1971. Soils and Plants as Inidcaturs of the Effectiveness of a Gross Decontamination Procedure. LA-DC-9544. CONF-680501. Proceedings of a Conference on Radiological Protection of the Public in Nuclear Mass Disasters held in Interlaken Switzerland, May 27 - June 1, 1968. pp. 456459. 
The results of an investigation on the soil-plant relationship which was initiated to obtain data relative to plutonium concentrations in the soil and possible resulting concentrations of plutonium in plants grown on those soils are presented. (NSA)

Fowler, E. B., and E. H. Essington. 1974. Soils Element Activities, October 1972 - September 1973. IN: Dunaway, P. B., and M. G. White (eds.). The Dynamics of Plutonium in Desert Environments. NV0-142 (NVO-AEIC-74-1 or UC-2):7-16.

This report presents a general review of the Soils Element Activities for the year October, 1972 - September, 1973. Areas declassified, areas sampled, and analytical results for plutonium 239, 240, and americium 241 are briefly discussed. Changes found in the ratio of Pu 239-240 to Am 241 , as well as the implications of the changing ratio are presented. It is suggested that the observed increasing ratio with depth of soil profile may be related to "differential solubility" of the two radionuclides, and that with passing time, Am 241 may become the radionuclide of prime concern. A modified analytical method for plutonium in soils, the LASLHASL leach method, is discussed. (auth)

Fowler, E. B., and E. H. Essington. 1975. Nevada Applied Ecology Group, Soils Element Activities, for the Period October 1973, through 1974. IN: White, M. G. and P. B. Dunaway (eds). The Radioecology of Plutonium and Other Transuranics in Desert Environments. NV0-153 (UC-2):1-26.

Soils Element activities were conducted on behalf of the U. S. Atomic Energy Commission's Nevada Applied Ecology Group (NAEG) program to provide source term information for the other program elements and maintain continuous cognizance of program requirements for sampling, sample preparation, and analysis.

Activities included presentation of papers; participation in workshops; analysis of soil, yegetation, and animal tissue samples for $238 \mathrm{Pu}$, $239-240 \mathrm{Pu}, 241_{\mathrm{Am}}, 13 \mathrm{Cs}, 60 \mathrm{Co}$, and gamma scan for routine and laboratory quality control purposes; preparation and analys is of animal tissue samples for NAEG laboratory certification; studies on a number of analytical, sample preparation, and sample collection procedures; and contributions to the evaluation of procedures for calculation of specialized counting statistics. (auth)

Fowler, E. B., R. 0. Gilvert and E. H. Essington. 1974. Sampling of Soils for Radioactivity: Philusophy, [xperience and Results. I.A-UR-74-1339. $13 \mathrm{p}$.

Factors to be considered by the Nevada Applied Ecology Group are choice of analytical method, choice of sampling method, and choice of sample preparation method. The interaction of all persons concerned is emphasized. 
The two major sources of radioactive material in the environment are worldwide fallout and release from accidents. Special problems such as decontamination of equipment and proper labeling are pointed out. Controllable variables include cross-contamination, sample activity levels, and sampling stratification. Determination of areal levels and vertical distribution of radioactivity at the Nevada Test Site are discussed. Information obtained on 1800 soil samples serves as a basis for other divisions of the NAEG such as Resuspension, Field Ecology, Biological Studies, and Modeling as these relate to transfer of plutonium to man. (NSA)

Fowler, E. B., R. W. Henderson, and M. F. Milligan (cochairmen). 1971. Proceedings of Environmental Plutonium Symposium, Held at LASL, August 4-5. LA-4756 (UC-41).

The purpose of this symposium was to discuss the distribution and measurement of plutonium in the environment. To this end, the subject matter has been divided into three broad categories, the first dealing with distribution or how plutonium has entered the environment, the second dealing with methodology or the means by which one obtains environmental samples and analyzes them, and the third with the results obtained from such measurements and the interpretation which can he inferred from them.

Fried, S. M., A. M. Friedman, and L. A. Quarterman. 1974. Annual Report on Project AN0115A, Fiscal Year 1974. ANL-8115.

Three types of measurements relating to the migration of actinide elements in the lithosphere have been performed. These were studies of surfaceabsorption coefficients, migration coefficients, and transport along the surfaces of fissures. A computer analysis of the fissure experiments indicates that a 11 these phenomena are related and can be understood in terms of surface absorption.

In addition, it has been found that at least two migratory forms of plutonium are present. (auth)

Francis, C. W., T. Cox, R. C. Dahlman, and L. N. Peters. 1971. Soil-Plant Relations. ORNL-4759. Ecological Sciences Division Annual Progress Report for Period Ending September 30, 1971, pp. 9-15.

Ultrazonal Centrifugational techniques were used to evaluate adsorption of PVP (polyvinylpyrrolidons) on various clays theluding illite, bentonite, and Kaolinite. PVP could be described from Kealinite and illite by water washes or ethanol. Double layer adsorption on sodium-saturated bentonite was indicated. Isosteric heat of adsorption was determined from equilibrium values at two different temperatures. 
Fried, S. M., A. M. Friedman, and L. H. Fuchs. 1973. Retention of Actinide Elements on Soils and Rock in the Natural Environment. ANL-7996. pp. 6-7.

Investigations included elution of $\mathrm{Pu}$ from crushed sedimentary rock at neutral $\mathrm{pH}$, adsorption of $\mathrm{Pu}$ by rock and effects of varying $\mathrm{pH}$ on limestone, shale and sandstone. All absorb Pu strongly with elution of about $1 / 10^{5}$ column volumes. Increased elution occurs with limestone and sandstone if influent is $\mathrm{CO}_{2}$-saturated. About 30 percent $\mathrm{Pu}$ is removed from shale by eight column volumes of $0.5 \mathrm{M} \mathrm{HCl}$ and 20 percent more with eight column volumes of $4.0 \mathrm{~m} \mathrm{HCl}$.

Fukai, R., and C. N. Murray. 1974. Adsorption and Desorption of Plutonium and Americium in Freshwater - Sediment and Seawater - Sediment Systems.

IN: Activities of the International Laboratory of Marine Radioactivity. IAEA-163:96-103.

The particulate and soluble fractions of added Pu 237 (III, IV, VI) and Am 241 (III) to filtered sea waters at various $\mathrm{pH}$ values, and adsorption and desorption of Pu (III and IV) and Am (III) by sediments and sewage effluents were studied.

The particulate formation is shown to be dependent upon the nature of solution and the $\mathrm{pH}$. The particulate fractions of all species increased with the increase in $\mathrm{pH}$. For river water at $\mathrm{pH} \mathrm{4}$, some 25, 20, and $30 \mathrm{per}-$ cent of the added $\mathrm{Pu} 237$ were associated with particulate $(>0.45 \mu)$ for the III, IV, and $V$ valence states, respectively. However, there does not seem to be any particulate for motion for river water at $\mathrm{pH}$ values <4.5. The percentage of particulate formation was $>60$ at $\mathrm{pH} 8$ for all species, except Pu (VI).

More than 80 percent of the plutonium was adsorbed by sediment suspensions when added as $\mathrm{Pu}$ (III) in $\mathrm{pH}$ range 3 to 11 and $\mathrm{Pu}$ (IV). at $\mathrm{pH} \sim 8$. Adsorption of $\mathrm{Am}$ (III) was highly $\mathrm{pH}$ dependent. There was hardly any adsorption of Am (III) below pH 6.5 and more than 80 percent at $\mathrm{pH} 8$. The desorption of $\mathrm{PU}$ ( $\mathrm{IIT}$ and IV) was less than 10 percent in 3-10 pH range, while the desorption of $A m$ (III) showed pH dependence. The addition of sewage effluent to sediment suspensions increased the adsorption of $\mathrm{Pu}$ (III) by about 10 percent at $\mathrm{pH} 8.1$.

Fukai, R., C. N. Murray, G. Statham, and K: Asari. 1974. Radionuclide Measurements of Water, Sediments, and. Biota, Collected from the Ligurian Sea: $\mathrm{Pu} 239$ 240, Sr 90, and Co 137. IN: Activities of the International Laboratory of Marine Radioactivity. I IAEA-163:134-138.

The authors reported $\mathrm{Pu} 239,240$ values for surface water ( $5 \mathrm{~m}$ depth) of 0.5 to $2.8 \times 10^{-15} \mathrm{Ci} / \mathrm{Kg}$, which are similar to values reported for Pacific and Atlantic ocean waters ${ }_{i}$ The $\mathrm{Pu} 239,240$ content of the sediments ranged from 0.3 to $4.2 \times 10^{-12} \mathrm{Ci} / \mathrm{kg}$. In general, the plutonium concentration decreased with the increase in particle size. 
Garland, T. R., R. E. Wildung, J. W. Neel, and D. A. Cataldo. 1974. Factors Affecting Uptake and Distribution of $\mathrm{Pu}$ in Barley and Soybean Plants. BNWL-1950, Part 2, pp. 30-36.

Barley and soybeans autoradiographed after growth in soil amended with $\mathrm{Pu}$ $\left(\mathrm{NO}_{3}\right)_{4}$. Split root growth technique used. Uptake from Ritzville (non calcareous, $\mathrm{pH}=6.8$ ) increased greatly with microbe nutrient supplement. Not true for Cinnebar and Forest soil which were stored since 1968. Microbes may be dead in Cinnebar and Forest soils.

Soil $\mathrm{Pu}$ levels were from $10 \mu \mathrm{Ci} / \mathrm{g}-100 \mu \mathrm{Ci} / \mathrm{g}$ and $145 \mu \mathrm{Ci} / \mathrm{g}-1450 \mu$ $\mathrm{Ci} / \mathrm{g}$.

Geiger, E. L. 1959. Radioassay of Uranium and Plutonium in Vegetation, Soil and Water. Health Physies 1:405=408.

A method is discussed for the separation of uranium and plutonium from vegetation, soil and water. The method is based on the extraction of uranium and plutonium from 4 to $6 \mathrm{~N}$ nitric acid into 50 percent tri-n-buty 1 phosphate in n-tetradecane diluent. Uranium and plutonium are recovered together with sufficient reduction in total solids to allow $\alpha$-counting and pulse height analysis. Data from several hundred "spiked" samples to which uranium and plutonium were added indicate a nearly equal recovery of uranium and plutonium. Average recoveries are $76 \pm 14$ percent for vegetation, $76 \pm 16$ percent for soil, and $82 \pm 15$ percent for water. The procedure is designed for samples that may be collected and analyzed for radioactivity as a part of a health physics regional monitoring program. (auth)

General Electric Company, Rocky Flats Division, Golden, Co. 1970. AEC Study Tends to Confirm Nonhazardous Plutonium Levels Near Rocky Flats. Nucleonics Week:11:1a-1b.

Nucleonics Week reports from the contamination area near Rocky Flats: Reporting on a several-month sampling study of Colorado soil up to 40 miles east and north of the AEC Rocky Flats plutonium plant operated by Dow Chemical Co., AEC's Health and Safety Laboratory (HASL) in New York City estimates the presence of $2.6 \mathrm{Ci}$ of $\mathrm{Pu} 239$ in an irregularly shaped area totaling some 43 square miles. HASL found that the likely source of the $\mathrm{Pu} 239$ was contaminated oil that spilled from leaky barrels in storage at Rocky Flats between the mid-1960s (when the leakage was discovered) and 1968 (when something was done about $i t$ ); during periods of high wind the radiuactive material became airborne. HASL took soil samples as far as 40 miles north and east (prevailing wind direction) of the plant. HASL found more plutonium in the area than previous investigators because HASL went up to $20 \mathrm{~cm}$ into the soil. However, HASL found no plutonium deeper than $13 \mathrm{~cm}$. (auth) 
Gera, F. 1975. Geochemical Behavior of Long-Lived Radioactive Wastes. ORNL-TM-4481. $99 \mathrm{p}$.

The hazard potential associated with the heavy elements present in high-level radioactive waste decreases greatly in the first few tens of thousands of years of decay; however, further reduction in the hazard potential becomes extremely slow after about 100,000 years. In the time period between 100,000 and 5 million years the hazard potential of high-level waste is reduced by a factor of between 10 and 20 . Current evidence seems to indicate that if radioactive waste containment were to fail after a period of 100,000 years or more, some environmental contamination would result; however, the contamination levels would be low. The radiological risk would not be significantly different from that now existing in various localities as a result of the accumulation of natural radioactive elements. With the partial exception of radium, which is concentrated in the fruit of specific perennial plants, the long-lived alpha-emitters are characterized by very low biologic availability in terrestrial ecosystems. The biologic availability may be somewhat higher in aquatic ecosystems due to the significant reconcentration factors in particular organisms. Data concerning the levels of activity in foods grown on radioactive soils seem to confirm the low biologic availability of the natural radioactive elements. Surveys of uranium mill tailings indicate little dispersal of the radioactive elements into the environment; even though untreated tailings piles would appear to be particularly vulnerable to resuspension of dust particles by wind. (NSA)

Gilbert, R. 0. and L. L. Eberhardt. 1974. Statistical Analysis of Pu in Soil at the Nevada Test Site -- Some Results. IN: Dunaway, P. B. and M. G. White (eds). The Dynamics of Plutonium in Desert Environments. NV0142 (NVO-AEIC-74-1 or UC-2):51-89.

The statistical field sampling design being used to estimate surface soil inventory in Areas 13 and 5 of the Nevada Test Site (NTS) is Pu 239, 240 in the upper $5 \mathrm{~cm}$ of soil inside the outer fence region of Area 13 is 39 curies with a standard error of 5 curies. This estimate is obtained from soil samples collected al randomly chosen locations according to a stratified random sampling plan. Correlation and regression analyses are computed, which indicates that 1 ab gamma scans on soil samples for Am 241 can, in general, predict quite well the concentrations of $\mathrm{Pu} 239,240$ present in the soil in Area 13. This suggests the determination of Pu 239, 240 may not be required on all soil samples in this area. This also appears to be the case for Area 5, although the lab analyses are incomplete. Average $\mathrm{Pu} / \mathrm{Am}$ ratios are obtalned for Areds 13,5 and the Tonopah Test Range (TTR). The average ratio for TTR appears to be considerably greater than those for Area 13 or 5 . There is also some evidence to suggest that the Pu/Am ratio may not be constant over all levels of Am 241 for the lower count per minute (cpm) regions of Areas 13 and 5. 
Correlation analyses indicate the FIDLER field instrument as used in the current sampling program (cpm readings taken $1 \mathrm{ft}$ off the ground over the soil sampling location) is not accurate in predicting $\mathrm{Pu} 239,240$ concentrations in surface soils. However, three-dimensional maps of FIDLER readings taken at grid points in Area 13 and $\mathrm{Pu} 239,240$ determinations of $\mathrm{Pu} 239,240$. Data are presented which suggest the Pu/Am ratio may decrease with depth of profile. Also, the availabie data are examined to estimate the within-lab variability on replicate samples (expressed as the coefficient of variation $c=s / x)$. The estimates of $c$ range up to 0.93 , which indicate four or five replicates may be necessary to detect even rather large differences between the three participating labs. There are no apparent consistent differences between the three participating laboratories in reporting $\mathrm{Pu} 239,240$ determinations for aliquots from the same soil samples from Area 13,5, and TTR sent to each $7 a b$. Finally, the data and analyses presented here are subject to change due to refinements in the data and statistical analyses. (auth)

Gilbert, R. 0. and L. L. Eberhardt. 1974. Plutonium Studies on the Nevada Test Site. BNWL-1950, Part 2. pp. 6-7.

Soil counting by $G a(L i)$ satisfactory a wet chemical separation is not needed. Shows readings 0.5 to $17 \mathrm{~m} \mathrm{ci/g} \mathrm{Pu} \mathrm{239,} 240$.

Gilbert, R. 0. and L. L. Eberhardt. 1974. Some Quantitative Aspects of Environmental Plutonium Studies. BNWL-1950, Part 2. pp. 5-6.

Problems caused by extreme variability encountered in Pu content. Special precautions to avoid insufficient or unrepresentative sampling are required.

Large soil particles tend to be under-represented and since larger particles tend to have lower Pu concentration than fines results biased on the high side.

Particulate nature causes very large differences between aliquots.

Gilbert, R. 0., L. L. Eberhardt, E. B. Fowler and E. H. Essington. 1974. Statistical Design Aspects of Sampling Soil for Plutonium. BNWL-SA-5144 (CONF-740921-5). 29 p.

Some of the statistical aspert.s of the design uf efflclent suil sampling programs for e:stimating the inventory (total amount) and geographical distribution of 239-240 Pu in surface soil are discussed. On-going experience with using stratified random sampling for estimating plutonium inventory in soils on "safety shot" sites on the Nevada Test Site (NTS) and the Tonopah Test Range (TTR) under the auspices of the Nevada Applies Ecology Group (NAEG) is emphasized. The NAEG is conducting plutonium environmental studies on these sites where past experiments involving plutonium devices 
and high explosives have resulted in plutonium contaminated soil. The information gained on the amounts and distribution of plutonium in soil will support the resuspension experiments currently underway at these sites. (auth)

Gilbert, R. C., L. L. Eberhardt, E. B. Fowler, E. M. Romney and E. H. Essington. 1975. Statistical Analysis and Design of Environmental Studies for Plutonium and other Transuranics at NAEG "Safety Shot". Sites. IAEA-SM-199/67

(BNWL-SA-5505).

This paper discusses the use of stratified random sampling for estimating the total amount (inventory) of $239-240 \mathrm{Pu}$ and uranium in surface soil at ten "safety-shot" sites on the Nevada Test Site (NTS) and the Tonopah Test Range (TTR) currently being studied by the Nevada Applied Ecology Group (NAEG). This sampling design has resulted in estimates of soil inventory that have smaller standard errors than would be expected if simple random sample (no stratification) had been used.

Estimates of inventory are given for 235U, 238U, and 239-240Pu at "A Site" of Area 11 on NTS. Other results presented include (i) average concentrations of one or more of these isotopes for soil and/or vegetation and in soil profile samples at depth to $25 \mathrm{~cm}$, ( $i i)$ average $234 \mathrm{U}$ and $236 \mathrm{U}$ concentrations in vegetation, and (iii) estimates of the regression relationship between uranium concentrations in adjacent soil and vegetation samples.

The applicability of using data collected via stratified random sampling for estimating plutonium concentration contours in surface soil is also investigated. Estimates of such contours are obtained using several different computer algorithms on untransformed and log-transformed data. The need for efficient field sampling designs to minimize costs is emphasized and some suggestions are offered for meeting this need. (auth)

Gillette, R. K., M. L. Curtis, E. B. Nunn, J. 0. Frye, and C. T. Bishop. 1972. Investigation into the Determination of Plutonium in Soil by a Fusion Procedure. MLM-1901.

A method for the determination of plutonium in soil is discussed. The method involves complete dissolution of the soil by a fusion technique followed by chemical separation of the plutonium, electrodeposition, and alpha pulse height analysis. Results are given for analyses of a spiked soil sample and four soil samples previously analyzed by a procedure in which the plutonium is acid-leached from the soil. The analysis of the spiked soil indicated good accuracy and precision of the fusion method. The results of the analyses of the four soil samples indicated agreement with the leaching results, but indicated that the plutonium was probably not uniformly distributed in the soil. (auth) 
Godse, V. B., A. L. Mohan, M. Singh, R. V. Amalraj and K. T. Thomas. 1967. Characterization of Trombay Soils for Disposal of Radioactive Wastes. IN: IAEA-SM-93/17, pp. 229-240. Disposal of Radioactive Wastes into the Ground.

The Bhabha Atomic Research Centre is situated on an island about $5 \mathrm{~km}$ east of Bombay Island, from which it is separated by the Bombay harbour bay. The area consists of typical horizontal basaltic flows covered by 1 to $2 \mathrm{~m}$ of loose soil followed by weathered rock to a depth of $9-10 \mathrm{~m}$. The radioactive waste disposal/storage area is located at the foot of Trombay hill between the contours of $25 \mathrm{ft}$ and $90 \mathrm{ft}$ and covers an area of $50,000 \mathrm{~m}^{2}$.

Laboratory and field studies were carried out to characterize the Trombay soils and groundwater and to examine the criteria for the safe disposal of radioactive wastes. The physical and chemical properties of the soils were determined to evaluate their retention and leaching propertiçs for radionuclides of interest.

The soil covering consists of silty clay to a clayey type of soil with ${ }^{\prime}$ base exchange capacity of 34 to $76 \mathrm{meq} / 700 \mathrm{~g}$. The relative velocity factors for the radionuclides of interest have been evaluated in the laboratory with respect to the groundwater velocity in the area.

Field studies were conducted by establishing a series of bore-holes in a grid pattern, and field permeability was studied to determine the groundwater velocity in the area. Tracer experiments were also conducted for the rate and direction of groundwater movement. As experimental study of direct discharge of solid waste from a chemical plant to the soil environment indicated that there was slight leaching of activity immediately after the monsoon. In view of the prevailing geological, hydrological and climatic conditions at Trombay area, the general policy adopted for ground disposal is to contain the radioactive wastes in solid form with adequate monitoring and environmental surveillance. (auth)

Goldberg, E. D. 1975. Marine Geochemistry Research. Progress Report. UCSD-34P84X9. $6 \mathrm{p}$.

The $239-240 \mathrm{Pu}$ and $210 \mathrm{~Pb}$ content of the coastal deposits off southern California and Baja California was measured. A continuing increase of the $239+240 \mathrm{Pu}$ concentration was detected. The primary source of these isotopes was identified as crustal rock debris mobilized by winds to the marine environment. $238 \mathrm{Pu}$ from the burned up SNAP device was detected in the Santa Barbara Basin. A substantial fraction of the $\mathrm{Pb}$ and $\mathrm{Pu}$ is istopes in atmospheric dusts is water soluble. The significance of these in the explanation of ${ }^{90} \mathrm{Sr}$ fallout is discussed. Preliminary results on $226 \mathrm{Ra}$ geochronology in the San Clemente Basin are reported. (NSA)

Gromov, V. V. and V. I. Spitsyn. 1974. Influence of Photoplankton on the Physicochemical State of $239 \mathrm{Pu}, 106 \mathrm{Ru},{ }^{99} \mathrm{Tc}$ and ${ }^{60} \mathrm{Co}$ in Sea Water, Transl. Dok1. Akad. Nauk SSSR. 215:2:451-453. 
The change in the physiochemical state of ${ }^{239} \mathrm{Pu},{ }^{106} \mathrm{Ru},{ }^{99} \mathrm{Tc}$, and ${ }^{60} \mathrm{Co}$ due to their assimilation by phytoplankton was investigated. It was found that biological assimilation by phytoplankton is decisively important in the stabilization of physicochemical forms of these radioisotopes, as a result of which the state of $\mathrm{Pu}, \mathrm{Ru}, \mathrm{Tc}$, and $\mathrm{C}_{0}$ in the marine environment is altered, which in turn leads to variation in the entrapment of these elements by bottom sediment and,evidently, by suspended matter. (NSA)

Hajek, B. F. 1966. Plutonium and Americium Mobility in Soils. BNWL-CC-925.

Laboratory scale diffusion and leaching experiments show that only a small amount of plutonium from surface soil material in the 216-2-9 crib is mobile. About 0.1 percent of the plutonium can be leached by invading groundwater; however, the leach rate is slow and plutonium migration, after being leached into lower soil layers, is about $10^{4}$ times less than the transporting solution velocity. Movement by diffusion will be negligible in a ten half-life period. (auth)

Hajek, B. F. and K. C. Knoll. 1966. Disposal Characteristics of Plutonium and Americium in a High Salt Acid Waste. BNWL-CC-649.

This study confirmed that adsorption of plutonium and americium on soil material from the surface to groundwater was minor from AAW waste and showed that soil neutralization of complexing agents would not satisfactorily improve adsorption. Gelling in soil pores could be induced by partial neutralization; however, permeability was lost. Precipitation by neutralization effectively scavenged both plutonium and americium in a waste containing only saturation amounts of organic and produced a supernate with improved soil adsorption characteristics. (auth)

Hakonson, T. E. 1975. Environmental Pathways of Plutonium into Terrestrial Plants and Animals. Health Physics. 29:583-588.

Attempts to assess the relative hazards (or lack of hazards) associated with plutonium dissemination to the environment emphasize the need for quantitative data to resolve the many unanswered questions regarding environmental plutonium behavior. This review summarizes most of the available data on plutonium in natuve terrestrial plants and animals and discusses some of the known and speculative mechanisms by which plutonium moves into biota. Factors which require consideration in preparing environmental plutonium safety evaluattons are discussed. (auth)

Hakonson, T. E. and L. J. Johnson. 1973. Distribution of Environmental Plutonium in the Trinity Site Ecosystem After 27 Years. Proceedings of the Third International Congress of the International Radiation Protection Association, pp. 242-247. 
The results are presented for a radioecological survey of the Trinity Site environs, where the world's first (July 1945) atomic bomb was detonated. The temporal behavior of the low environmental levels of the plutonium produced by this detonation are discussed. The data from this study were compared with similar data obtained in the Trinity Site environs nearly 20 years ago. The major change which was observed was an increased migration of $\mathrm{Pu}$ into the soils. Concentrations of $\mathrm{Pu}$ in vegetation and rodents were too low to make valid comparisons. (auth)

Hakonson, T. E., L. J. Johnson and W. D. Purtymun. 1973. The Distribution of Plutonium in Liquid Waste Disposal Areas at LoS Alamos. IN: Proceeding of the Third International Congress of the International Radiation Protection Association, September 9-14, 1973, Washington, DC, pp. 248-253, CONF-730907-P1.

This paper describes an ecological investigation of plutonium in the Los Alamos Scientific Laboratory environs. Data are presented on the distribution of plutonium in the alluvial sediments, water, vegetation and rodents from Mortandad Canyon, an area which has been used for liquid waste disposal for 10 years.

Hakonson, T. E., J. W. Nyhan, L. J. Johnson and K. V. Bostick. 1973. Ecological Investigation of Radioactive Materials in Waste Discharge Areas at Los Alamos for the Period July 1, 1972 - March 31, 1973. LA-5282-MS.

The ecological research program at the Los Alamos Scientific Laboratory is described and, in addition, the progress made on current project activities between JuTy $1,19 / 2$, and March 31,1973 is summarized. Information is presented on: an environmental inventory of the Los Alamos area; a radionuclide inventory in three liquid waste disposal areas; studies to determine the applicability of the honebee as an indicator of environmental radiocontamination; and a 27-year post-shot resurvey of the Trinity area to determine the bioavailability of the plutonium from the world's first nuclear detonation. Samples of soil, vegetation, rodents turtles, insects, rabbits and snakes were analyzed for $137 \mathrm{Cs}, 60 \mathrm{Co}, 90 \mathrm{Sr}, 90 \mathrm{y}, 133 \mathrm{Ba}, 152 \mathrm{Eu}$, $155 \mathrm{Eu}, 241_{\mathrm{Am}}, 238 \mathrm{Pu}$ and $239 \mathrm{Pu}$. (NSA)

Hakonson, T. E., J. W. Nyhan and W. D. Purtymum. 1975. Accumulation and Transport of Soil Plutonium in Liquid Waste Discharge Areas at Los Alamos. IAEA-SM-199/99.

The soils component of terrestrial ecosystems appears to be the major reservoir of plutonium originating from both weapons and industrial sources. Data presently available indicate that transport of plutonium within the soils component and from soils to biotic components can occur by physical processes with biological and chemical processes playing a largely undefined role in the redistribution of this element. Relatively high concentrations of plutonium in native vegetation and in pelt and 1 ung 
samples from small ground dwelling rodents are usually attributed to resuspension processes. whereby the plutonium associated with the soil is redeposited on external surfaces or is inhaled.

The purpose of this study was to investigate the accumulation and transport of plutonium in the sediments of Mortandad Canyon in Los Alamos, New Mexico. This area has received plutonium in treated liquid effluents since 1963. Data are presented on the horizontal distribution of plutonium and total inventories in stream channel sediments for two sampling periods spanning a seven monthinterval in 1972 and 1973. Data were also gathered on the importance of storm runoff in the downstream transport of plutonium contaminated sediment. (auth)

Hale, V. Q. and A. Wallace. 1970. Effect of Chelates on Uptake of Some Heavy Metal Radionuclides from Soil by Bush Beans. Soil Science 109: 262-263.

DTPA has the ability to increase uptake by plants of several metals. In the present study DTPA increased uptake from Hacienda and Yolo loam soils of $\mathrm{Pb} 210$ and $\mathrm{Am}$ 241. There was a decreased effect in the 2nd and 3rd harvests relative to the first. It had to effect on uptake of Sb 125 or $\mathrm{Hg} 203$. EDDHA increased uptake of Sb 125 from Yolo loam, and of Am 241 from both soils. The effect of EDDHA did not persist in the soil as much as did that of DTPA. DTPA increased slightly the uptake of Cs 137 . (auth)

Hanstra, J. 1975. Radiotoxic Hazard Measure for Buried Solid Radioactive Waste. Nuclear Safety. 16:5:180-189.

This article reviews the radiotoxic hazards resulting from the disposal of high-level reprocessing wastes into a deep geological formation. The term radiotoxic hazard measure (RHM), used to measure the hazard from buried radioactive wastes, is based on the maximum radionuclde concentration permissible in water.

Calculations arc made of the RHM levels for the high-level reprocessing wastes of both light-water-reactor and fast breeder reactor fuels. In comparing these RHM levels with that for the natural activity of an equivalent amount of uranium ore and its mill tailings, it is concluded that an actual additional radiotoxic hazard for buried high-level reprocessing waste only exists for the first 300 to 500 years after burial.

Hannah, S. A. and A. C. Printz, Jr. 1961. An Evaluation of the Effectiveness of Polyelectrolyte Coagulant Aids for the Removal of Radioactive Isotopes by Water Treatment Processes. Final Report. NP-11105.

Eleven polyelectrolyte coagulant aids were studied in conjunction with conventional and modified water treatment processes for removal of Cs 137 , $\mathrm{Sr}^{89}, \mathrm{Pm} 147, \mathrm{I}^{137}$, and $\mathrm{U}^{238}$. In general, the polyelectrolytes were quite 
effective in reducing turbidity and its associated activity, resulting from 1 ime soda softening or added clay, but improvements in overall removal of soluble activity were unpredictable and not sufficient to warrant the use of polyelectrolytes for this purpose alone. It is expected that greater benefits would be derived from the coagulant aids in the removal of fallout products where much of the activity is in an insoluble form. Illite and fullers earth were shown to be good adsorbents for $\mathrm{Cs}^{\uparrow 37}$, while Volclay was effective for removal of $\mathrm{Sr}^{89}$. Small dosages of chlorine were found to increase the adsorption of $I^{131}$ by activated carbon. Recommended procedures are given for removal. of individual isotopes and of fallout products. The coagulant aids are rated according to their relative efficiencies in removal of turbidity and activity. (auth)

Hanson, W. C. 1974. Behavior of Plutonium in the Environment. CONF-740115. pp. 64-71.

Data available on the behavior of $\mathrm{Pu}$ in the environment are reviewed. Once into the environment $\mathrm{Pu}$ is subject to a variety of factors that modify its behavior in terms of concentration and/or discrimination within ecosystem components. The contamination of large land areas within significant quantities of $\mathrm{Pu}$ in the past has usually been by controlled releases of treated radioactive wastes, as in the canyon ecosystems at Los Alamos; nuclear weapons tests, such as the Trinity Site in central New Mexico and the Nevada Test Site; or nonnuclear detonation of nuclear weapons, such as occurred at Palomares and Thule. Most of our knowledge of characteristic $\mathrm{Pu}$ behavior in the atmosphere has come from plutonium isotopes that were injected into the stratosphere as a result of atmospheric nuclear weapons tests. Another source resulted from the reentry and burnup of the SNAP-9A power generator during Apri1 1964. Both of these major sources have been closely studied and results indicated that the ratio of $239 \mathrm{Pu}$ to $90 \mathrm{Sr}$ produced by nuclear weapons testing in the atmosphere essentially remained constant at about 2 percent. Such estimates showed that, of the $0.4 \mathrm{MC} i$ of $\mathrm{Pu}$ produced by nuclear weapons testing through 1962, more than 98 percent had been deposited by 1965. About $0.3 \mathrm{MC} i$ had been deposited as worldwide fallout, and the remaining $0.1 \mathrm{MC} i$ was locally deposited at the test sites. Latitudinal distribution was closely correlated with rainfall belts at 40 to $60^{\circ}$ north latitude and 30 to $50^{\circ}$ south latitude and 80 percent of the total deposition occurred in the Northern Hemisphere, where most of the $\mathrm{Pu}$ had been injected into the stratosphere. Plutonium 238 from weapons tests represented about 0.024 of the total plutonium in soils collected at various worldwide locations prior to the fallout from the SNAP-9A device, compared to a ratio of about 3 percent for $238 \mathrm{pu} / 239 \mathrm{Pu}$ which is characteristic of most nuclear weapons test debris. The SNAP-9A 238Pu had an entirely different distribution pattern, principally because of its injection into the Southern Hemisphere. Stratospheric inventories indicated that, by mid-1970, 95 percent of this debris was deposited on the earth's surface. Over 75 percent of it was in the Southern Hemisphere, compared to only 20 percent of the total weapons $238 \mathrm{Pu}$ fallout that occurred in that hemisphere. Interception of atmospheric Pu by vegetation is one means of 
biological transport that has been shown to depend on local fallout phenomena and physiognomy of the vegetation. Plutonium concentration in trees of an eastern forest was reported to be 16 to 100 percent more than that on adjacent pastureland plants. And Pu deposition on lichen communities of the Thule, Greenland, area was more efficient per centimeter of precipitation than deposition on lichen communities of northern Alaska. The uptake and transport of $\mathrm{Pu}$ by wild animals also occurs. Soil Characteristics have an important influence upon $\mathrm{Pu}$ movement. One of the most important and most controversial aspects of $\mathrm{Pu}$ in soils is the phenomenon of resuspension, defined by Langham as the ratio of the air concentration of plutonium (in micrograms of plutonium per cubic meter) to the surface deposition (in micrograms of plutonium per square meter) below the air mass. (NSA)

Hanson. W. C. 1975: Ecological Considerations of the Behavior of Plutonium in the Environment. Health Physics 28:529-537.

Radiological considerations of plutonium released to the environment are logically based upon an understanding of ecosystem structure and functions. Studies of $\mathrm{Pu}$ in the atmosphere, lithosphere, terrestrial ecosystem of the biosphere, and in the hydrosphere are reviewed to evaluate areas for consideration of environmental consequences of nuclear wastes. Soil is the major reservoir of deposited $\mathrm{Pu}$ in most terrestrial ecosystems. Resuspension of $\mathrm{Pu}$ into the air mass above contaminated soil occurs over a highly variable range of $10^{-2}$ to $10^{-11} \mathrm{~m}^{-1}$, reflecting important effects of several physical and biological variables. Uptake by most natural plant species is of the order of 10-4 (acceptor/precursor). Appreciable external deposition of $\mathrm{Pu}$ upon plants through resuspension is a complicating factor in interpretation of field data. Pu concentrations in smaller terrestrial mammals also emphasize the greater importance of physical processes rather than physiological or chemical processes in the movement of $\mathrm{Pu}$ through terrestrial ecosystems. Freshwater and marine investigations indicate that $\mathrm{Pu}$ is generally concentrated over ambient levels in water but with decreases of about a factor of ten at each trophic level of a food chain. An apparent change in availability of $\mathrm{Pu} 238$ is indicated by several studies and physical processes that may account for this are discussed. (auth)

Hanson, G. L., J. D. Anderson, G. R. Kiel, B. J. McMurray and N. P. Nisick. 1973. Input and Decayed Values of Radioactive Liquid Wastes Discharged to the Ground in the 200 Areas Through 1971. ARH-2761. 62 p.

Low- and intermediate-level liquid wastes from the reprocessing of spent fuel elements have been discharged to the ground at the Hanford disposal sites since 1944. The input valves and radioactivity discharged at each site have heen reported hut no corrections for radioactive decay were made. In order to provide the decayed inventory of radioactivity discharged to each liquid waste disposal site the annual inputs of liquid volume is 1 iters, grams of plutonium or $233 \mathrm{U}$, kilograms of uranium, curies of total beta radioactivity, and curies of specific fission produces ${ }^{90} \mathrm{Cs},{ }^{90} \mathrm{Sr}$, $106 \mathrm{Ru}$, 
137 Cs, to each site, were tabulated and submitted for computerized radioactive decay using computer code DCAY1. Decay calculations were made only on the total beta activity and on the specific fission products. The annual inputs, total inputs and decayed inventory through December 31, 1971 for 200 East Area liquid waste disposal sites and for 200 West Area liquid waste disposal sites are tabulated. (NSA)

Hardy E. 1974. Depth Distributions of Global Fallout $90 \mathrm{Sr},{ }^{137} \mathrm{Cs}$, and 239-240 Pu in Sandy Loam Soi1. HASL-286:I-2 to I-10.

The first of a series of depth Profile soil samples taken at an undisturbed site on Cape Cod have been analyzed for $90 \mathrm{Sr}, 137 \mathrm{Cs}$, and $239-240 \mathrm{Pu}$ Cesium 137 shows the least tendency to migrate downward followed by $239-240 \mathrm{Pu}$ and $90 \mathrm{sr}$, in that order. The objective of this experiment is to measure the depth distributions of these isotopes on a bi-annual basis to estimate rate of movement. (auth)

Hardy, E. P. 1974. Worldwide Distribution of Plutonium. IN: Plutonium and other Transuranium Elements: Sources, Environmental Distribution and Biomedical Effects. WASH-1359:115-128.

Nuclear tests conducted in the atmosphere are the major sources of plutonium contamination on a worldwide basis. About 320 kilocuries of $\mathrm{Pu}^{239}$ have deposited about 4 kilocuries remaining in the stratosphere will reach the earth's surface. Measurements are being made of air concentrations at ground level and the deposition rate. Inhalation is the major route of human exposure and later testimony will be presented to show the resulting body burden. Contamination levels in foods have also been measured and the comparatively smaller body burden from ingestion will also be discussed. (auth)

Hardy, E. P., P. W. Krey and H. L. Volchok. 1972. Global Inventory and Distribution of $238 \mathrm{Pu}$ from SNAP-9A. HASL-250.

Following the burn-up of a SNAP generator containing 238pu in the upper a tmosphere of the Southern Hemisphere in April 1964, balloon and aircraft sampling successfully documented the atmospheric transport and inventory of the debris from this unexpected release. Attempts to measure the fallout rate on a continuous basis at sites in both the Northern and Southern Hemispheres were not successful. By the end of 1970, results of the stratospheric measurements indicated that 95 percent of the SNAP plutonium had deposited over the earth's surface. Integrated fallout in the form of soil samples collected at over 60 sites throughout the world provided the data required to assess the distribution pattern and inventory of the deposited SNAP debris. Of the $17 \mathrm{kilocuries}$ of $238 \mathrm{Pu}$ Originally in the generator, $13.4 \pm 2.2$ kilocuries are globally deposited with $3.1 \pm 0.8$ kilocuries in the Northern Hemisphere and $10.3 \pm 2.1$ 
kilocuries in the Southern Hemisphere. This accounts for essentially all of the $238 \mathrm{Pu}$ inadvertently released as a result of the satellite abort. (auth)

Hardy, E. P. and P. W. Krey. 1971. Determining the Accumulated Deposit of Radionuclides by Soil Sampling and Analysis. IN: Fowler, E. B., R. W. Henderson, M. F. Milligan (co-chairmen). Proceedings of Environmental Plutonium Symposium, held at LASL, August 4-5. LA-4756 (UC-41):37-42.

Soil sampling and analysis is a feasible way to determine the accumulated amount of long-lived radionuclides that have deposited on the ground. The Health and Safety Laboratory has measured $90 \mathrm{Sr}$ and plutonium isotopes in soil samples to determine global and regional deposition patterns and inventories. Site selection and representivity, sampling, and analytical precision and accuracy are discussed in the paper. It is shown that the precision of replicate aliquoting and analysis is the determining factor in the overall error associated with soil sampling.

Hardy, E. P., P. W. Krey and H. L. Volchok. 1972. Plutonium Fallout in Utah. HASL-257:195-I118.

Accumulated plutonium fallout in the north central and south-eastern sections of Utah was measured in soil samples collected in June 1971. The maximum values in Utah of the deposition ( $\mathrm{mCi} \mathrm{Pu} \mathrm{239,240} \mathrm{per} \mathrm{km}^{2}$ ) and deposition concentration ( $\mathrm{mCi}$ per $\mathrm{km}^{2}$ per $\mathrm{cm}$ of precipitation) were 2.2 and 3.8 times the maximum values found anywhere else in the United States. By comparing the $\mathrm{Pu} 239,240$ to $\mathrm{Sr} 90$ activity ratios of the Utah soils with the average activity ratio of 32 Northern Hemisphere soils collected in 1970-1971, we estimate that up to 60 percent of the total Pu 239, 240 activity deposited at some Utah sites was from a source other than the stratospheric reservoir. Soil samples taken at a site near the University of Utah from 1959 through 1971 revealed that the excess plutonium was delivered prior to 1959 . Nevada Test Site is the probable second source and that about $3.5 \mathrm{mC}$ i Pu. 239, 240 per $\mathrm{km}^{2}$ or twice the level expected from global fallout, deposited in the Salt Lake City areas from NTS. Excess plutonium was not evident at sites north of Salt Lake City and due east in the valley regions beyond the Wasatch range. (auth)

Hardy, E. P., P. W. Krey and H. L. Volchok. 1973. Global Inventory and Distribution of Fallout Plutonium Nature. 241:444-445.

It is stated that an accidental stratospheric injection of $238 \mathrm{Pu}$ in 1964 resulted in almost a three-fold increase in global fallout of this nuclide. The accumulated fallout and its geographical distribution from this release, as well as from weapons testing, are here reported. The accidental release occurred from a $238 \mathrm{Pu}$ power generator carried on a navigational satellite, launched from California, whose rocket failed. Stratospheric checks indicated 
that by mid-1970 95 percent of the 238pu had been deposited on the Earth's surface, and it was important to determine how this was distributed and to record the deposit. Soil analysis was used for the determination. From October 1970 until January 1971 sixty-five sites around the world were sampled. Determinations of $238 \mathrm{pu}$ and $240 \mathrm{Pu}$, assumed to be entirely derived from weapons testing, were also made. Data are shown tabulated. The weapons 238pu contribution was obtained by multiplying the 238,240 pu values by 0.024 . The distribution pattern for weapons Pu showed heaviest deposition in the Northern Hemisphere temperate latitudes and a minimum in the equatorial region. The satellite $238 \mathrm{pu}$ deposit was $326 \pm 36 \mathrm{kCj}$, and the weapons $238 \mathrm{Pu} 7.7 \pm 0.9 \mathrm{kCi}$. The estimate of the satellite $238 \mathrm{Pu}$ deposit was $13.9 \pm 2.2 \mathrm{kCi}$. (NSA)

Hamman, R. D., E. B. Nunn, M. L. Curtis and J. 0. Frye. 1972. Determination of Plutonium in Soil. MLM-1888.

The residues from leached soil samples were analyzed by the fusion procedure to determine what percentage of plutonium had been leached out of the sample. Since previous work indicated that plutonium is concentrated in a few small particles such that even multiple riffling of a large sample would not produce smaller samples of the same plutonium composition, the sample size was increased from $10 \mathrm{~g}$ to $50 \mathrm{~g}$. Two new electrolysis cells were constructed for the electroplating step to replace the existing one. (ORNL-EIS73-21 (Supp. 1)).

Harley, J. H. 1974. Transuranium Elements on Land. IN: Proceedings of the American Nuclear Society, 1y/4 Winter Meeting, Uctober $27-31$, Washington, D. C., pp. 75-76.

It is possible that with the increased development of light-water and breeder reastonrs we will he entering into a plut.nnium er.nnnmy. Plut.nnium and it.s related transuranium elements are all extremely toxic and it is necessary to improve our understanding of their behavior in the environment. Most of the experimental work on plutonium has been directed toward the study of its toxicity following injection or inhalation. This only answers the final step in the overall evaluation of hazard and it is necessary to know more about the behavior and transport of the transuranium elements in the environment under natural conditions.

We presently have plutonium deposited on the earth's surface as a result of nuclear weapons tests, as a result of failurc of a SNAP power source, and as a result of releases from nuclear processing facilities. There has been a concerted effort to use this deposited material to determine the transfer of plutonium through the environment and to estimate its uptake by man. This has required the development of sensitive analytical methods and very sophisticated counting equipment, since measurements for scientific purposes must be considerabiy more accurate than those merely designed to fulfill monitoring needs. 
The three sources can be looked at separately, since the SNAP device was 238 $\mathrm{Pu}$ and the weapons debris and production material differ in isotopic composition. Mixtures are difficult to resolve to better than about \pm 25 percent, but some useful data are availabe. For example, it has been possible to estimate the contributions of production material and fallout to various sites surrounding the Rocky Flats Plant in Colorado.

Particulates of $238 \mathrm{pu}$ show increased solubility over comparable $238 \mathrm{pu}$, probably due to radiation damage. This means that separate behavior studies are required for the two isotopes. The plutonium economy will also produce significant quantities of americium and curium isotopes which tend to have a greater biological availability than plutonium. Information on these elements is relatively scarce, but is expected to multiply in the next few years.

The greatest hazard from insoluble plutonium is through inhalation, so the present evaluation of plutonium in soil is directed toward measuring air concentrations and the particle size, which controls the lung deposition. With sufficient data, it may be possible to make rough predictions of the air concentrations from soil measurements. For the more soluble material, including americium and cesium, uptake from soil into diet components may be a long-term contributor, but is is unlikely this will be a controlling factor in hazard evaluation.

This paper will review the available data as of the time of presentation and indicate how we have improved our knowledge of the environmental behavior of the transuranium elements. (auth)

Harpaz, Y. 1959. Medium and Low Level Waste Disposal on Alluvial and Recent Deposits. VI Rassegna Internazionale Elettronica e Nucleare. Vol. I, pp. 27-32.

Earth materials underlying a plant site, their geology, texture, and groundwater hydrology have an influence on the complex evaluations called for in locating nuclear plants. Recent deposits and alluvial soils are scattered in abundance over many areas of land. Their granular constituents (gravels, sands) are a good hydraulic medium which can be treated mathematically. The silt and clay particles in such soils have the highest absorption and exchange capacity. Thus, alluvial soils may provide the plant planner with an effective and practical collector for low and medium radioactive waste solutions. The rate of disposal and the degree of permissible radioactivity will depend also on other hydrological factors, as well as on the type of installation employed. (auth)

Hawkins, R. H. 1962. Improved Burial of Solid Radioactive Wastes. TID-7628. Ground Disposal of Radioactive Wastes. pp. 462-468. 
Solid wastes have been buried for eight years at Savannah River with no detectable leakage. Bentonite has proven an effective barrier to the downward flow of groundwater.

Hayes, D. W., J. H. LeRoy and F. A. Cross. 1975. Plutonium in Atlantic Coastal Estuaries in the Southeastern United States. IAEA-SM-199/84.

A survey was made to begin to provide baseline information on the plutonium distribution of representative estuarine and coastal areas of the southeastern United States. Sediments and marsh grass (Spartina) were collected and analyzed from three locations within a tidal marsh. In three estuaries (Savannah, Neuse, and Newport), the suspended particulate matter ( 1 um and greater) was filtered from waters with different salinities, and the plutonium content of the particulates determined. The Savannah River estuary, in addition to fallout plutonium, has received up to $0.3 \mathrm{Ci}$ of plutonium from the Savannah River Plant (SRP) of the U. S. Energy Research and Development Administration. The SRP plutonium has a variable isotopic composition that can intluence plutonium isotopic ratios in the estuarine system. The other estuaries do not have nuclear installations upstream. (auth)

Healy, J. W. 1946. Absorption and Retention of Plutonium by 200 Area Topsoil. HW-74776.

Plutonium, at a $\mathrm{pH}$ above two, tended to be removed in a narrow band on the soil even in the presence of considerable salt concentrations.

Healy, J. W. 1972. Problems of Plutonium Measurement in the Environment. IEEE Transactions on Nuclear Science. Vol. NS-18, No. 1. pp. 219-223.

The author reviews the difficulties involved in getting all of the sample into soluble form, especially when the particulates of $\mathrm{PuO}_{2}$ are large and scattered.

Healy, J. W. 1974. A Proposed Interim Standard for Plutonium in Soils. L $\Lambda$-5483-MS.

Current standards for controlling health effects from plutonium in the body are discussed. Available information on possible sources of exposure of people living in an area where the soils are contaminated with plutonium is analyzed to arrive at estimates of intake. From these estimates, a recommended interim standard for the upper limit of concentration of plutonium in the soils in inhabited areas is derived. The recommendation is based upon conservative assumptions where information is lacking and further studies should result in revision. The subjects of resuspension, deposition velocity of particles and effectiveness of radioactive particulates in producing lung cancer are discussed in appendices. (auth) 
Healy, J. W. and W. J. Smith. 1974. Contamination Limits for Real and Personal Property. LA-5726-PR.

A summary is given of the work performed during this period. Studies included continuation of work on contamination transfer and the FIDLER response and a review of a petition on plutonium limits by the Natural Resources Defence Council. In addition, a summary of comments on the proposed soil standard for plutonium is included. (autr)

Hetherington, J. A., D. F. Jefferies, N. J. Mitchel1, R. J. Pentreath and D. S. Woodhead. 1975. Environmental and Public Health Consequences of the Controlled Disposal of Transuranic Elements to the Marine Environment. IAEA-SM-199/11.

Experience from the controlled disposal of liquid radioactive wastes from the nuclear power programme of the United Kingdom has shown that the only releases of transuranic elements of potential environmental significance occur following fuel reprocessing. In this context attention has been directed principaliy to plutonium because of $i$ ts long half-life and high radiotoxicity, although the next most important transuranic element, americium, has also been studied.

The paper reviews the radiological significance of these radionuclides following discharge to the marine environment, in terms of both dose to man and to environmental resources. Both plutonium and americium are found in each of the three compartments, water, seabed sediment and biota, the highest concentrations being found in sediment, particularly the fine mud found in estuaries close to the Windscale outfall. Both elements have been detected in a range of biota including seaweeds, fish and shellfish. The public health significance of those biota which represent potential human exposure pathways has been evaluated and estimates of the dose rate to critical groups from current discharges have been made. In parallel studies attention has been focussed on the exposure of fish and shellfish stocks. The dose rates have been estimated by use of environmental data on contamination levels combined with simple dosimetry models, and the results and their significance are discussed. (auth)

Hoffman, D. C F. 0. Lawrence, J. L. Mewherter and F. M. Rourke. 1971. Detection of 244 Pu in Nature. Nature 234:132-4.

Mass spectrometric measurements of plutonium isolated from Precambiran hastnaesite confirmed the presence of $244 \mathrm{pu}$ in naturc. Although the existence of $244 \mathrm{Pu}$ as an extinct radioactivity has been postulated to explain the xenon isotope ratios observed in meteorites, this is the first indication of its present existence in nature. (auth)

Horton, J. H. 1961. Disposal Practices and Experience at Savannah River Plant, IN: TID-7621, Ground Disposal of Radioactive Wastes, pp. 34-36. 
Savannah River Plant geology is heterogeneous but is generally sands or sandy clays with a low cation exchange capacity. The groundwater is generally 20 to 60 feet below the ground surface, but never lower than 100 feet. Rainfall is about 45 inches/year. To date, $3.6 \mathrm{Ci}$ of alpha emitters and $3200 \mathrm{Ci}$ of nonvolatile beta emitters have been disposed to seepage basins. Sr isotopes are poorly retained. However, tritium was the only radioisotope detected in the groundwater.

Inoue, Y. and M. Sakanoue. 1970. The Determination of Plutonium in Soil Samp 1es. 11:98-106.

The contents of plutonium 239 in soil were determined by using $\mathrm{Pu} 238$ as yield tracer. The samples were decomposed by nitric acid treatment under ultrasonic vibration and the separation of plutonium from other elements was carried out by using anion exchange resin. The surface soils showed the plutonium content of about 1 to approximately $4 \mathrm{mCi} / \mathrm{km}^{2}$ and their Plutonium 239/Strontium 90 activity ratios were 2 to approximately 5 percent. From these results, it was concluded that $\mathrm{Pu} 239$ in soil at present was brought mainly by the fallout due to the nuclear bomb test explosion. (auth)

Isaacson, R. E. and L. E. Browne11. 1972. Ultimate Storage of Radioactive Wastes in Terrestrial Environments. Atlantic Richfield Hanford Company. ARH-SA-126.

New avenues are open for the ultimate storage of radioactive wastes via the "STOPPER" and "Thermalt" processes. STOPPER is the Stone Process for Permanent Encapsulation of Radionuclides, a hydrothermal process. Thermalt is a pyrochemical process for fixing radionuclides in a basalt-like product. The products contain analogs of silicate and aluminosilicate minerals such as pollucite, strontium feldspar and "plutonite" -- a structural analog of zircon. Uitimate storage will have been effected if these product forms are secured in geochemically compatible media where the authigenic precipitation of cation aluminosilicates will provide additional protection from transport by groundwater movements. (auth)

Iyengar, M. A. R. and P. M. Markose. 1971. An Investigation into the Distribution of Uranium and Daughters in the Environment of an Uranium Ore Processing Facility. CONF-701227. IN: Proceedings of a Symposium on Radioation and Radioisotopes in Soil Studies and Plant Nutrition held in Banqalore, India, Uecember 21, 1970. Department of Atomic Energy, Bombay, India. p. 143-153.

Tabulated data are presented from the monitoring of radioactivity in soil, water, air, foodstuffs, and vegetation near the uranium mining and processing facility at Jaduquda, Bihar (India). The concentration of activity in soil patches adjacent to the river banks on the mill and mine premises was evident from the study. Air activity due to radon was found to be 
significantly higher than in Trombay and Alwaye, the two other centers handling considerable quantities of uranium-bearing cres. Water activity was found to vary widely depending on its radionuclide content. The wide range of concentration in foodstuffs is perhaps due to the varying radioisotope concentrations in different media. The hazards of utilizing the mine stream for domestic cultivation of vegetables and fishing were demonstrated. Algae is a good indicator organism in water pollution. The foodstuffs survey has not led to any selective indicator to aid in the radiological monitoring program. (auth)

Jacobs, D. G. 1974. Impacts in Groundwater of Effluents Arising in the Nuclear Industry. NP-20456, pp. vp., Paper 16.

The following topics are discussed: modes of entry of radioactive wastes into groundwater; movement of radjonuclides in the ground; degradation processes; behavior of tritium, ${ }^{90} \mathrm{Sr}$, $137 \mathrm{Cs}, 106 \mathrm{Ru}$ and transuranic elements; potential pathways to man; and impact of releases of radioactive materials to the ground compared to radiation protection standards. (NSA)

Jacobson, L. and R. Overstreet. 1948. The Uptake by Plants of Plutonium and Some Products of Nuclear Fission Adsorbed on Soil Colloids. Soil Science. Soil Science. 65:129-34.

Barley and pea plants have been found to take up the fission elements $Y$, $\mathrm{Ce}, \mathrm{Zr}+\mathrm{Cb}, \mathrm{Te}, \mathrm{Sr}$, and the three valence states of $\mathrm{Pu}$, even when these elements are present in trace amounts on the surfaces of clay or soil particles. For all the elements tested, the greatest fixation is in or on the roots. With the exception of Sr, translocation occurs only to a limited extent. The translocation of $\mathrm{Sr}$ is relatively large. Activity levels of 0.1 microcurie per gram soil are sufficient to cause very pronounced injury over a 3-month period. (auth)

Jakubick, A. T. 1975. Migration of Plutonium in Natural Soil. IAEA-SiM199/3.

The present work deals with the deposition and migration of fallout plutonium which is considered here as analogous to $\mathrm{PuO}_{2}$ contamination of soil. By correlating the few $\mathrm{Pu}^{239,240}$ measurements available in Germany with the fallout data coming from Ispra the probable history of $\mathrm{Pu}$ concentration in the air is reconstructed for SW Germany. From these data, the Pu input function in the vicinity of lleidelberg is derived. The calculated cumulative deposition seems to agree well with the existing measurements of the total amount of Pu239,240 in the soil. For to find out the transport mechanism of $\mathrm{Pu}$ in soil, the estimations of $\mathrm{Pu}$ distribution in soil provided by HASL are interpreted. The removal of $\mathrm{PuO}_{2}$ particles from a given layer seems to obey an exponential law with a characteristic turnover time of 5-6 years in a $5 \mathrm{~cm}$ thick partially saturated soil layer. 
Using the previously derived input function and the estimated turnover time, the probable Pu-concentration in the top soil in Germany was computed. Furthermore, the case of an instantaneous soil contamination is considered. It is shown that a model using a sequence of boxes leads to a Poison-type equation which predicts for $\mathrm{PuO}_{2}$ a migration velocity of $0.8 \mathrm{~cm}$ per year. Finally the relative migration velocities of $\mathrm{PuO}_{2}$ an $\mathrm{Pu}\left(\mathrm{NO}_{3}\right)_{4}$ are compared. The comparison indicates that the migration of $\mathrm{PuO}_{2}$ is about 100 times faster than that of plutonium when applied to soil in $\mathrm{Pu}\left(\mathrm{NO}_{3}\right)_{4}$ form. (auth)

Jordan, H. S. 1971. Distribution of Plutonium from Accidents and Field Experiments, pp. 2]-24. IN: Proceedings of Environmental Plutonium Symposium, Los Alamos Scientific Laboratory (LA-4756).

Outlines of accidents at

1. Thule, Greenland (B-52 bomber crash, 1968)

2. Palomares, Spain (Mid air explosion during refueling operation between B-52 bomber and $\mathrm{Kc}-135$ tanker).

Joshi, L. U. and A. K. Ganguly. 1973. Anomalous Th 228/Th 232 and Th 230/ Th 232 Activity Ratios in Backwater Sediments Along the West Coast of India, IN: Radioactive Contamination of the Marine Environment. IAEA-SM-158/50: 747-755.

Recently, remarkable disequilibrium between Th 228 and Th 232 activities has been observed in the top layer sediments of the backwaters along the Indian coast. The Th 228/Th 232 activity ratios in Bombay harbour region $\left(19^{\circ} \mathrm{N}, 73^{\circ} \mathrm{E}\right)$ and Kerala belt $\left(8^{\circ}-10 \mathrm{~N}, 76^{\circ}-77^{\circ} \mathrm{E}\right)$ have been found to be in the range of 0.55 to 0.67 , while this ratio is in the range of 2.00 to 2.19 along the rest of the West Coast of India between Bombay and Kerala region $\left(19^{\circ}-15^{\circ} \mathrm{E}, 76^{\circ}-77^{\circ} \mathrm{E}\right)$. The Th 230 and Th 232 act $1 v 1$ ties also show drlumaluus behavior in these regions. The Th $230 / \mathrm{Th} 232$ activity ratio in the Bumbay region is about 0.133 , while the ratio lies between 0.23 to 0.25 in Kerala belt. The coastal region between Bombay and Kerala, the ratio lies in the range of 0.95 to 1.07 . The variation of the Th 228/Th 232 activity ratio is governed by the Th 230 activity in waters adjacent to the sediments. In the dynamic processes in marine environment, the sediment and the water interface are the most important and equilibria are expected to be established only amongst the chemical species occurring at the surface of the sediment and the ambient medium. A geochemical study of these sediments is being carried out by leaching the samples with 5\% EDTA at pH 3.00 in order to investigate the processes occurring on the surface and the distribution of natural thorium isotopes in backwater sediments. (auth) 
Kay, W. L. (1946). Se-Pc \#91 Retention Characteristics of 200 Area Soil for Product. AEC Document No. 3-3427.

Some of the earliest laboratury work with soils and $\mathrm{Pu}$ is given. The conclusion was that $\mathrm{Pu}$ would be retained near its point of release.

Kayuha, H. J., I. Aoki and D. L. Wireman. 1974. REECo Field Activities and Sample Logistics in Support of the Nevada Applied Ecology Group. IN: Dunaway, P. B. and M. G. White (eds). The Dynamics of Plutonium in Desert Environments. NVO-142 (NVO-AEIC-74-1 or UC-2): 17-19.

The field activities and sample logistics of Reynolds Electrical and Engineering Co., Inc. (REECo), in support of the Nevada Applied Ecology Group (NAEG) plutonium studies in the Test Range complex, are discussed in this summary report. Field instrument measurements, determination of sampling sites, and procedures used in preparation of samples are included. (auth)

Kennedy, W. R. and W. D. Purtymun. 1970. Plutonium and Strontium in Soil in the Los Alamos, Espanola, and Santa Fe, New Mexico, Areas. LA-4562.

Analysis for plutonium isotopes plutonium 238 and plutonium 239 and strontium isotope strontium 90 were made of soil samples collected from the Los Alamos, Espanola, and Santa Fe areas to determine concentration levels considered as originating from world-wide fallout from atmospheric tests. On the basis of the limited number of samples, it was concluded that the concentrations in soils from the area of study were similar to but no greater than those reported by others for soil samples from Colorado, Ohio, and New York. (auth)

Keppel, H. 1969. Morphological, Physiological and Environmental Conditions Affecting the Accumulation of Long-Lived Radionuclides from Fission Products by Plants. Proceedings of a Seminar on Agricultural and Public Health Aspects of Environmental Contamination by Radioactive Materials held in Vienna, Austria, March, CONF-690317; SM-117/31. p. 99-112.

In the food chain from the seed, through food-processing factories or fodder for animals to human food the growing stage is the most liable to contamination by airborne radionuclides. This contamination of the growing plant is the main source of incorporation of radioactive materials by animals and humans. The danger of total or external contamination of plants is enhanced, in contrast to that of animals or men, on the one hand by deposition in a fixed place and on the other by the non-specific uptake of mineral nutrients. The difference in the habits of plants species, in the physiological states and in the encironmental conditions in which they grow, affect the extent of the contamination. Among the factors which influence the accumulation of radionuclides by plants is the morphological constitution of the leaves and the structure of the roots. These factors are not only capable of 
reinforcing each other but also of acting to some extent in opposite directions. Extended foliage is not always accompanied by a high rate of uptake. On the other hand, a small but finely divided root system lying immediately under the surface may lead to higher contamination than a strong and deep reaching one. The rate of the uptake proper is a function of the physiological state of the plant, and here one must differentiate between the processes of diffusion and active transport. The growth of the plant regulates the requirement of minerals, and the incorporation therefore changes within the vegetation period. Finally, the site in which the plant grows affects the accumulation of the radionuclides. This factor includes not only the climatic conditions but also the nature of the soil. Pain causes a leaching of the mineral substances which adhere to the surface of the leaves and originate in fallout or in secretion of the transpiration flow. In a soil rich in clay minerals and secretion of the transpiration capacity the elements are more fixed than in a sandy soil. Moreover, some clay minerals are able to include atoms irreversibly in their lattices. External radiation which results from the deposition of the radioactive material on the soil surface results in prevention of germination or sprouting, in a change of the morphological structure or in a decrease in the yield. The chemical and physical natures of the radionuclide must also be taken into consideration. (auth)

Knol1, K. C. 1965. Reaction of High-Salt Aqueous Plus Organic Waste with Soi1. BNWL-CC-313.

Soil has considerable capacity for this high salt, acidic waste containing organic compounds and can imbibe it almost as readily as water. These data, obtained from column measurements in the laboratory, would be less favorable than those obtained in the field as the moisture cannot spread horizontally in a column. Uptake of plutonium by the soil was very minor and of amercium negligible.

Knol1, K. C. 1969. Reactions of Organic Wastes in Soils. BNWL-860.

The passage of certain organic wastes from a radionuclide separations plants has little effect on the permeability of the soil for later passage of a high salt aqueous waste, or on the ion exchange properties of the soil. Soil removed $\mathrm{Pu} 239$ and $\mathrm{Am} 241$ slowly from some of the organics and not at al1 from others. Radionuclides were leached from soils most noticeably by two of the wastes. One was a mixture of $0.4 \mathrm{M}$ bis (2-ethylhexyl) ester of phosphoric acid and $0.2 M$ tributyl phosphate in paraffin hydrocarbons (C10 to C 14); the other was hydroxyacetic acid. Both of these removed $\mathrm{Sr} 85$ and $\mathrm{Am} 241$ and to a lesser extent Pu 239. (auth) 
Krey, P. W. 1974. ${ }^{239} \mathrm{Pu}$ Contamination in the Denver Area. Health Physics. $26: 1: 117-120$.

It is stated that there are "ommissions, errors, and misconceptions" contained in the report of Poet and Martell (Health Physics; 23: 537(1972)) which indicated plutonium contamination in the environment around the Dow Chemical Company's Rocky Flats plants near Denver, Colorado. One serious omission is the lack of a thorough evaluation of the soil sampling and analysis procedures used and another the faulty discussion of the $239 \mathrm{Pu}$ distribution with depth. Results by other workers are quoted which it is claimed were omitted by Poet and Martell and which tend to refute their conclusion on the extent of the ${ }^{239} \mathrm{Pu}$ spatial contamination. (NSA)

Krey, P. W., D. Bogen, and E. French. 1962. Plutonium in Man and His Environment. Nature. 195:262-265.

The analytical data, particularly those given for human tissue analyses, showed that inhalation was the main mode of entry into man. The authors suggested that the pulmonary lymph nodes should be considered in the assignment cf the critical organ so far as plutonium inhalation is concerned, and that the metabolism and translocation of $\mathrm{Pu}$ from fallout be further studied.

Krey, P. W. and E. P. Hardy, Jr. 1970. Plutonium in Soil Around the Rocky Flats Plant. Health and Safety Laboratory, USAEC. HASL-235, p. 44.

Soil samples were collected to a depth of $20 \mathrm{~cm}$ at 33 sites extending as far as 40 miles from the Dow Chemical Co.'s Rocky Flats plant in Colorado. Deposition concentrations of $\mathrm{Pu}-239$ as high as $2000 \mathrm{mCi} / \mathrm{km}^{2}$ were found off the plant site but these high concentrations decreased rapidly with distance. The contamination pattern extends eastward from the plant in the direction of the resultant wind vector and has virtually no westward component. The pattern is incompatible with the wind direction on the day of the May 11 , 1969 fire. Leaking barrels of plutonium laden cutting oil stored in the southeast corner of the plant are considered the likely source of the contaminant.

Three $\mathrm{mCi} / \mathrm{km}^{2}$ of $\mathrm{Pu}-239$ is the lowest contour readily discernible in the contamination pattern and extends about 8 miles east and southeast of the plant. The inventory of Rocky Flats Pu-239 within the $3 \mathrm{mCi} / \mathrm{km}^{2}$ contour but excluding AEC controlled land is $2.6 \mathrm{Ci}$. The extent of the Rocky Flats $\mathrm{Pu}-239$ beyond this contour is difficult to determine because the deposition of Pu-232 from nuelear weapon lesls ralluut is not precisely known in the Denver area. Our best estimate of the cumulative fallout Pu-239 is 1.5 $\mathrm{mCi} / \mathrm{km}^{2}$ based upon a 1965 soil sample from nearby Derby, Culurddu. The most distant sites at 40 miles to the east and north of the plant show a slightly higher value of $2.0 \mathrm{mCi} / \mathrm{km}^{2}$. The intervening sites average 2.4 $\mathrm{mCi} / \mathrm{km}^{2}$. If the extreme and unlikely assumption is made that the entire area lying 40 miles to the east and north of the plant is contaminated 
with $1 \mathrm{mCi} / \mathrm{km}^{2}$, an additional $3.2 \mathrm{Ci}$ of Rocky Flats plutonium could have been released to these remote areas. Sr-90 analyses of the Rocky Flats soils and other studies are in process which might resolve this uncertainty in the remote areas, but additional sampling may be required to thoroughly solve the problem.

The plutonium has been shown to move down into the soil as far as $13 \mathrm{~cm}$, although the distribution shows wide variability apparently depending upon soil chemistry. In several cases there is as much as $60 \%$ of the total plutonium below $5 \mathrm{~cm}$. The analytical precision of aliquoting the sample and analysis was shown to be $+20 \%$. Analyses of duplicate samples taken from the same location showed similar precision indicating that the soil sampling was representative of the area studies. (auth)

Krey, P. W., E. P. Hardy, C. Pachuck, F. Rourke, J. Coluzza and W. K. Benson. 1975. Mass Isotopic Composition of Global Fallout Plutonium in Soil. IAEA-SM-199/39.

The mass isotopic content of fallout plutonium in soil samples collected from around the world in 1970 and 1971 showed some variability which correlated with the location of nuclear weapons test sites. Omitting local effects, the global mean ratios of $\mathrm{Pu}-240 / \mathrm{Pu}-239, \mathrm{Pu}-241 / \mathrm{Pu}-239$ and $\mathrm{Pu}-242 / \mathrm{Pu}-239$ are $0.176 \pm .014,0.0086 \pm .0017$ and $0.0044 \pm .0011$, respectively corrected to January 1971. Such isotopic data provide the most sensitive technique to resolve mixtures of fallout plutonium with plutonium from a second source. From these data, the Am-241/Pu-239-240 activity ratio of integrated fallout on the earth's surface can be estimated and will peak at 0.42 in the year 2037. (auth)

Kubose, D. A., M. G. Lai, H. A. Goya and H. I. Cordova. 1968. Radioactivfty Release from Radionuclide Power Sources XIIa. Dissolution Studies of Plutonium Dioxide in the Ocean, 5 Months' Exposure. USNRDL-TR-68-74.

Post-ocean-exposure examinations have been made on plutonium dioxide microspheres recovered after a 5-month exposure on the bottom at a depth of 50 feet off San Clemente Island. These examinations established that approximately 70 percent of the microspheres became encrusted with marine growth. Determination of the distribution of the microspheres and adsorbed activity in the ocean-bottom material was made in addition to post-exposure laboratory dissolution measurements, microscopic examination and $X$-ray diffraction measurements. (auth) 
Labeyrie, L. D., H. D. Livingston and V. T. Bowen. 1975. Composition of the Distribytigns in Marine Sediments of the Fallout Derived Nuclides ${ }^{55} \mathrm{Fe}$ and $239,240 \mathrm{Pu}: \mathrm{A}$ New Approach to the Chemistry of Environmental Radionuclides. IAEA-SM-199/115.

We present data showing the distribution of ${ }^{55} \mathrm{Fe}$ radioactivity in marine sediment cores taken from a large range of water depths; these data are compared with the $239,240 \mathrm{Pu}$ analyses of the same or similar cores. The report is preliminary in that only a small part of the world ocean has yet been studied.

Evaluation of the results available suggest:

First, that in a good deal of their marine geochemistry, iron and plutonium move separately.

Second, that in the open Atlantic Ocean, ${ }^{55} \mathrm{Fe}$ has sedimented in association with a mixed population of particles, exhibiting a mean sinking of about $350 \mathrm{~m}$ per year.

Third, part of the iron in coastal sediments is redissolved, probably by reduction associated with decaying organic matter; this process affects a higher proportion of the ${ }^{55} \mathrm{Fe}$ than of the total iron. The solubilized iron should reprecipitate, after return to the overlying water and oxidation, as microparticulates. These very fine particles, dispersed by currents, may translocate ${ }^{55} \mathrm{Fe}$ toward the open sea, only slowly becoming associated with larger, faster-sinking mineral particles. It is suggested that this process may be important in the translocation of other insoluble trace elements, and even of part of the $239,240 \mathrm{Pu}$. (auth)

Langham, W. H. 1968. The Problem of Large-Area Plutonium Contamination. NP-18205. Seminar Paper No. 002. Part of Selected Papers from the Bureau of Radiological Health Seminar Program.

Large area Pu contamination is described in three examples. Risk evaluation procedures are not now very meaningful. However, it is suggested that trying to relate exposures to NRCP recommendations is the only present al ternative.

Langham, W. H. 1971. Plutonium Distribution as a Problem in Environmental Sciences. IN: Fowler, E. B., R. W. Henderson, and M. F. Milligan (cochairmen). Proceedings of Environmental Plutonium Symposium, held at LASL, August 4-5, LA-4756 (UC-41):3-11.

The potential uses of plutonium in future peace-time technology are numernus and if realized will result in a production ratc of thousands of $\mathrm{kg}$ per year by the end of the centruy. By the year 2000 it is predicted that plutonium may be producing 50\% of the country's total energy needs, 3 times the amount of electrical energy now produced from coal, gas, $0 i 1$, hydro, and nuclear energy altogether. Power sources for mechanical hearts and heart pacers alone will require large quantities of $\mathrm{Pu} 238$, as will 
thermoelectric generators for deep-space missions, space platforms, and communications satellites. The technology of plutonium production and processing is already established. Whether plutonium attains its predicted role in the future power economy may depend entirely on whether economically competitive methods of preventing its distribution in the environment can be attained. Repetition of the mercury situation cannot be tolerated although, in some ways, plutonium (by its chemical nature) is not as devious as mercury as a potential general environment contaminant. Because of its solubility and other characteristics, it is not readily taken into the ecological chain. No natural bacterial or other environmental entity has been observed that converts plutonium to a solubilized form readily enters the ecological cycle; however, this possibility is worthy of further investigation. Control of plutonium as an environmental contaminant involves control of distribution from production reactors, processing plants, storage sites, and inadvertant releases during transportation and use. An all important factor in the alleviation of plutonium distribution as a problem in environmental science is continuous surveillance with sensitive and standardized methods of monitoring not only operational discharges but environmental distribution as well, which is the theme of this conference. (auth)

Lauderdale, R. A. 1951. Treatment of Radioactive Water by Phosphate Precipitation. Industrial and Engineering Chemistry 43:1538-1540.

The work was done to check the effectiveness of a calcium phosphate floc in removing radioisotopes from large quantities of water.

In almost every case the phosphate was found to be more efficient than either alum or ferric hydroxide. Maximum removals were obtained under conditions of high $\mathrm{pH}$ and in the presence of an excess of phosphate. In general, good removals were obtained for those isotopes which would be precipitated under the same conditions if they were present in macro quantities.

While the data must be considered preliminary in nature, they indicate that coagulation and filtration techniques, if performed under the proper conditions, can be applied to treat liquid wastes containing low levels of radioactivity. The total reduction obtained in the activity of the waste will be dependent on the radioisotopes present.

Livingston, H. D., D. R. Mann and V. T. Bowen. 1974. Analytical Procedures for Transuranic Elements in Seawater and Marine Sediments. Presented at ACS annual meeting, September 1974, at Symposium on Analytical Methods in Oceanography.

Transuranic elements are extracted from seawater by coprecipitation with either ferric hydroxide or calcium/strontium oxalate, or are leached from sediments with $8 \mathrm{M}$ nitric acid. Radiochemical separations are described for the analyses of Pu 238, Pu 239, 240, Pu 241, Am 241, Cm 244, and Cm 242. 
The electroplated radionuclides are measured by alpha spectrometry using surface barrier detectors. Spectrometric interferences, especially those arising from natural series radionuclides, are discussed. Data quality is discussed in terms both of 'blank' analyses and of analyses of seawater, containing transuranics, used in interlaboratory analytical comparisons. Some marine transuranic data are included which support our belief that transuranics sink quite rapidly in the oceans--in contrast with 'soluble' fallout radionuclides. (auth)

Livingston, H. D., D. L. Schneider and V. T. Bowen. 1975. Pu 241 in the Marine Environment by a Radiochemical Procedure. Earth and Planetary Science. Letters. 25:261-267.

A purely radiochemical method is described for analysis of Pu 241 in environmental samples. Data are given showing that fallout-contaminated marine samples, of several kinds and provenances, exhibit $\mathrm{Pu} 241 / \mathrm{Pu} 239$, 240 ratios slightly higher than, but not certainly distinguishable from, those reported for fallout-contaminated soils. Such ratios, however, in samples from several planned or accidental Pu releases, are clearly different, suggesting $\mathrm{Pu} 241$ will be a useful tracer in following the spread of released Pu. The data have also clear implications for the source, and growth, of environmental Am 241. (auth)

Lomenick, T. F. and K. E. Cowser. 1962. Land Burial of Solid Waste at Oak Ridge National Laboratory. TID-7628:437-59.

The geological and hydrological conditions that exist at Burial Ground 4, now abandoned, are described, and findings with respect to surface- and ground-water contamination at the site are reported. The site was opened in February 1951 and closed to routine burial operations in July 1959. The average rate of burial during this period was about 2.5 acres per year. Approximately $50 \%$ of the buried waste at the site originated at 0ak Ridge National Laboratory, while the remainder was contributed by more than 50 off-site agencies. The burial ground is underlain by the Conasauga shale of Cambrian age. At the site the formation consists mostly of maroon and gray shales interbedded with a few thin limestone lenses. Water-level measurements indicate that the buried waste is in contact with ground water during most periods of the year. Activity was detected in water samples from a number of wells located in areas of low topography where groundwater contact with the waste is greatest. Radionuclides were also found in seeps and streams within the area. Identifiable contaminants include Ru-106, $\mathrm{Co}-60, \mathrm{Cs}-137, \mathrm{Sr}-90, \mathrm{Zr}-\mathrm{Nb}-95, \mathrm{Po}-210, \mathrm{Pu}-239-240$, and the trivalent rare earths. The contribution of activity from the burial ground to nearby White Oak Creek has been insignificant. The criteria employed in selecting Burial Ground 5, the methods used in evaluating the site and a preliminary analysis of a new burial trench design are discussed. Forty-five auger wells were drilled to determine the character of the residual cover, the depth of the water table, and the chemical and radionuclide composition of 
the ground water. Five deep wells were drilled to define the occurrence and circulation of ground water at greater depth. Pressure tests of the deep wells showed that the most permeable zones or fractures occur within the first $100 \mathrm{ft}$ of depth below ground surface. The new burial trench, including a gravel underdrain, collecting sump, observation we11, and asphalt cap, was designed to improve monitoring and restrict ground-water and surface-water contact of the waste. (auth)

Lowman, F. G. 1959. Marine Biological Investigations at the Eniwetok Test Site. IN: Disposal of Radioactive Wastes. Conference Proceedings, 2:105-38.

The results of marine biological investigations conducted at the Eniwetok Test Site since 1952 are summarized, Radioisotopes introduced into the sea from the tests at xarious times since then include fission products and other radioisotopes $\left(237_{\mathrm{U}}, 239_{\mathrm{Np}}, 54 \mathrm{Mn}, 55,59_{\mathrm{Fe}}, 57,58,60 \mathrm{Co}, 65 \mathrm{Zn}\right.$, and $\left.85 \mathrm{~W}\right)$. The levels of radioisotopes in plankton samples lakell 4 days lo 6 weeks after contamination are reported and the distribution of the radioactivity petween plankton and water is given. Grazing fishes contaiped ${ }^{65} \mathrm{Zn}, 55 \mathrm{Fe}$, $57,58,60^{\circ} \mathrm{Co}$, and ${ }^{54} \mathrm{Mn}$. Carnivorous fishes contained mostl.y ${ }^{55} \mathrm{Fe}$ and ${ }^{65} \mathrm{Zn}$. (auth)

McClearen, H. A. (1974). Plutonium in Soil at the Savannah River Plant in Proceedings of the Second AEC Environmental Protection Conference, Albuquerque, NM, April 16-19, 1974. WASH-1332-74. 1:495-510.

Savannah River Plant (SRP) perimeter and off-site soil samples show a background deposition level of approximately $2 \mathrm{mCi} / \mathrm{Km}^{2}$. This is well within the range of deposition noted in Southeastern United States and indicates that off-site deposits due to SRP operations are small compared to background. Samples taken within a $2 \mathrm{~km}$ radius of each of the two chemical separations areas show higher levels $51 \mathrm{mCi} / \mathrm{Km}^{2}$, indicating some plant contribution. Perimeter and off-site soil samples show $90 \%$ of plutonium in a $30 \mathrm{~cm}$ core to occur in the top $15 \mathrm{~cm}$.

McKay, H. A. C. 1961. Alpha Emitters in Reactor Wastes. IN: Atomic tnergy Waste, Its Nature, Use, and Disposal. pp. 99-108. E. Glueckauf, editor.

Thie four $\alpha$-emitters to be considered in waste disposal arc ${ }^{237} \mathrm{~Np},{ }^{238} \mathrm{Pu}$, $24 \mathrm{Am}_{\mathrm{m}}$, and ${ }^{242} \mathrm{Cm}$. The formation of these isotopes, hazards due to fission products in waste solutions, hazards arising from the recycling of $235 \mathrm{U}$ fuel, hazards arising from $\mathrm{Pu}$ fuel, and hazards arising from a natural $U$ fuel are discussed. It is pointed out that, with one minor exception, no $\alpha$ emitter is ever likely to be a greater hazard than ${ }^{90} \mathrm{Sr}$ in unseparated fission product wastes. In $90 \mathrm{Sr}$-denuded wastes, $\alpha$ emitters become important especially as regards airborne contamination. Data are tabulated on the most hazardous $\alpha$-emitting nuclides under various conditions. (NSA) 
McLendon, H. R. 1975. Soil Monitoring for Plutonium at the Savannah River Plant. Health Physics 28:347-354.

Since the amount of plutonium in undisturbed soils reflects the cumulative deposition from all sources, both onplant and offplant soils have been collected and analyzed for $\mathrm{Pu} 238$ and $\mathrm{Pu} 239$. Results show a background deposition level of approximately $2.0 \mathrm{mCi} / \mathrm{km}^{2}$ offsite and over most of the plant. This level is well within the range of deposition noted in the southeastern United States and indicates that offsite deposits due to SRP operations are small compared to background. Only samples taken within a $2-\mathrm{km}$ radius of each of the two chemical separations areas show higher levels of plutonium. This elevation indicates some plant contribution.

To obtain the obove information, new techniques in sample collection and preparation were developed which were comparable with other laboratories in the country. An analytical procedure, involving an anion exchange resin column, was also developed to determine the two plutonium isotopes of interest and to insure increased sensitivity when working with the low-level environmental samples. (auth)

McLendon, H. R., 0. M. Stewart, A. L. Bond, J. C. Corey, K. W. McLead, and J. E. Pinder. 1975. Relationships Among Plutonium Contents of Soil, Vegetation, and Animals Collected in and Adjacent to an Integrated Nuclear Complex in the Humid Southeastern United States. IAEA-SM-199/85.

Twenty-three representative sampling locations on and adjacent to the Savannah River Plant (SRP) site were selected to obtain information on plutonium movement in the food chain under southeastern $U$. S. environmental conditions. Soil, a resuspendible fraction of the soil, honeysuckle (Lonicera japonica), and camphor weed (Heterotheca subaxillaris) were collected at each location. Grasshoppers and cotton rats (Sigmodon hispidus) were collected at some locations. The plutonium concentrations in soil at the selected locations ranged from $1.5 \mathrm{fCi} / \mathrm{g}$ to $171 \mathrm{fCi} / \mathrm{g}$, and alpha percentages of $238 \mathrm{Pu}$ ranged from 2 to 66 . The concentration of plutonium in the vegetation and on the leaves ranged from 0.17 to $76.1 \mathrm{fCi} / \mathrm{g}$, and the alpha percentages of $238 \mathrm{Pu}$, from 3 to 61 . The concentration of plutonium in cotton rats arid yrasshoppers ranged from 0.07 to $3.58 \mathrm{fCi} / \mathrm{g}$, and the alpha percentages of $238 \mathrm{pu}$ ranged from 22 to 80 .

The average ratio of plutonium concentration of vegetation to that of the surrounding soil was $10^{-1}$; the corresponding ratio for cotton rats and soil was $10^{-2}$. These ratios appear to be independent of the plutonium concentration in the soil. Deposition on the surfaces of leaves and stems was the principal miechanism of plutonium contamination of vegetation. Comparisons among the plutonium values of the vegetation, soil, and resuspendible fraction sugges $t$ the use of a proposed resuspendible measurement technique as a monitoring method to indicate subtle changes in the plutonium concentration of the soil surface that are not detectable by routine soil sampling. Although the $238 \mathrm{pu}$ data in the various ecosystem components were not conclusive, they do support evidence presented in other studies that there is 
an apparent increase in the biological availability of ${ }^{238} \mathrm{Pu}$ relative to that of $239,240 \mathrm{Pu}$ in the environment. The plutonium concentrations of all ecosystem components decreased as the distance form the reprocessing plants increased. (auth)

Mango, P., T. Rearey, and J. Apedianaskis. 1970. IN: Proceedings 5th Annual Health Physics Society. Midyear Topical Symposium. pp. 208-220. 1970.

The authors reported that the plutonium released to the fresh water became insoluble and settled rapidly in the lagoon system. Ninety-two percent of the plutonium released by the lagoon to the surrounding streams was associated with suspended material.

Marsha11, J. S., D. N. Edgington and M. A. Wahlgren. 1973. Great Lakes Radioecology Program: Introduction. ANL-8060. Part 3, pp. 1-5.

The Great Lakes Radioecology Program has the ultimate goal of understanding and predicting the biogeochemical behavior and pathways to man of radionuclides and toxic trace elements in Lake Michigan. During 1973 the objective was to measure and assess the distribution of selected natural and long-lived artifical fallout radionuclides in water, sediments, and biota with important roles in their ecosystem cycling and food chains leading to man. As of June 1973, there were seven US nuclear power reactors in operation in the Great Lakes Basin. Because of projected increasing use of $\mathrm{Pu}$ in present-day reactors, future breeder reactors, and other applications, studies initiated in 1972 on the behavior of fallout $\mathrm{Pu}$ in Lake Michigan were intensified during 1973 and expanded to obtain comparative data on the other Great Lakes. Sampling programs included the collection of water, plankton, and sediment samples at various depths. Approximately 11 samples of Cladophora were collected for an assessment of its potential value as a biological monitor for radionucilides in the Great Lakes. Plutonium measurements to date indicate that the very small fraction of fal1out $\mathrm{Pu}$ remaining in Lake Michigan water exhibits surprisingly conservative properties, although a pronounced annual depletion and return is observed in the surface waters, and the concentration of $\mathrm{Pu}$ in Lake Michigan phytoplankton is several thousand times higher than that in the water, but it decreases by approximately an order of magnitude with each successive link in the food chains leading to man. Measurements of the vertical profiles of fallout $210 \mathrm{~Pb}$ and $33{ }_{\mathrm{Cs}}$ in sediment cores were used to determine recent sedimentation rates in Lake Michigan. These rates, which are the same as the average over the last 1,000 yedrs, are being used to interpret the distribution of possible pollutants in sediment cores in relation to physiocochemical processes and atmospheric and stream inputs. (NSA) 
Martin, W. E. and S. G. Bloom. 1975. Plutonium Transport and Dose Estimation Model. IAEA-SM-199/78.

A Standard Man is assumed to live in and obtain most of his food from a Pu-contaminated area at NTS. A Pu-transport model, based on the results of other studies at NTS, provides a basis for estimating rates of $239 \mathrm{Pu}$ inhalation and ingestion as functions of the average concentration of $239 \mathrm{pu}$ $\left(C_{s}=p C i / g\right)$ in the surface soil of the reference area. Assuming the transport system to be in equilibrium, the estimated inhalation and ingestion rates ( $\mathrm{pCi} /$ day) are $0.002 \mathrm{C}_{\mathrm{S}}$ and $0.269 \mathrm{C}_{\mathrm{S}}$, respectively.

A dose estimation model, based on parameters recommended in ICRP publications, is used to estimate organ burdens, accumulated doses, and dose commitments as functions of exposure time. Estimated doses (rems) due to inhalation and ingestion of $239 \mathrm{Pu}$ for 50 years at the rates indicated above are: thoracic lymph nodes, $0.6 \mathrm{C}_{S}$; lung, $0.025 \mathrm{C}_{\mathrm{S}}$; bone, $0.015 \mathrm{C}_{\mathrm{S}}$; liver, $0.01 \mathrm{C}_{S}$; kidneys, $0.003 \mathrm{C}_{S}$; total body, $0.0007 \mathrm{C}_{S}$; and gastrointestinal tract (LLI), $0.0003 \mathrm{C}_{\mathrm{S}}$. Inhalation accounts for $100 \%$ of the predicted dose to thoracic lymph nodes and lungs and for about $94 \%$ of the predicted dose to bone, liver, kidneys, and total body.

According to ICRP recommendations for individual members of the public, the dose rate to the lungs should not exceed $1.5 \mathrm{rems} / \mathrm{yr}$. According to the proposed model, the average concentration of $239 \mathrm{pu}$ in the soils of contaminated areas at NTS which would result in a predicted dose rate of 1.5 rems/yr to the lung is approximately $3 \mathrm{nCi} / \mathrm{g}$ or $270 \mathrm{pCi} / \mathrm{m}^{2}$. (auth)

Martin, W. E., S. G. Bloom, and R. J. Yorde, Jr. 1974. NAEG Plutonium Study Modeling Program: Plutonium Transport and Dose Estimation Model. IN: Dunaway, P. B., and M. G. White (editors). The Dynamics of Plutonium in Desert Environments. NVO-142 (NVO-AEIC-74-1 or UC-2):331-360.

A computer program based on a matrix exponential method was used to solve a system of ordinary differential equations which simulate the behavior of $\mathrm{Pu} 239$ in desert ecosystems such as those found at and near the Nevada Test Site. The model was used to estimate the rates of Pu 239 transport, via several environmental pathways, to Standard Man, who was assumed to live in a contaminated area. These estimates were then used to calculate radiation doses and dose commitments, as a function of time, to different organs.

The model provides a method for evaluating the potential radiological hazard to man due to the presence of $\mathrm{Pu} 239$ iri a given arca. However, the studies designed to implement the model, by providing accurate estimates of critical parameters, are st1ll til prugress. Thcrcfore, the resılt.s to date are incomplete and inconclusive. 
On the basis of present assumptions and parameter values, the model indicates a 70-year dose commitment to the pulmonary lymph nodes of 13.6 rem per $\mathrm{pCi}(\mathrm{Pu} 239) / \mathrm{g}$ (soil). Comparable values for other organs are: bone, 0.14 rem; lung, 0.10 rem; kidney, 0.015 rem; liver, 0.014 rem; G. I. tract, $0.007 \mathrm{rem}$; and total body, $0.003 \mathrm{rem}$. Inhalation accounts for $100 \%$ of the dose to the lungs and pulmonary lymph nodes, a negligible fraction of the dose to the G.I. tract, and about $56 \%$ of the dose to bone, kidney, liver, and total body. This means that all but a negligible fraction of the dose to the G.I. tract and $44 \%$ of the Pu 239 entering the bloodstream is due to ingestion of soil, vegetation, milk, beef, and beef liver. It is quite possible that the relative importance of inhalation has been overestimated, while the relative importance of ingestion has been underestimated. (auth)

Menzel, R. G. 1965. Soii-Plant Relationships of Radioactive Elements. Health Physics. 11:1325-13,32.

The plant concentration of various radioactive elements, after they have been added to soils in water-soluble forms, may be several orders of magnitude higher or lower than the concentration in the soil. Those that are most readily absorbed are soluble in the soil or are isotopic with elements that have metabolic functions in the plant. Those that are least absorbed are quite insoluble in the soil. The gamma radiation doses to plants would come predominantly from the soil, as would the beta radiation doses except for the beta radiation from those few elements which may be highly concentrated in certain plant tissues. The role of plants in movement of radionuclides in soil is minor except over very long periods of time. (auth)

Meyer, G. L. 1975. Preliminary Data on the 0ccurrence of Transuranium Nuclides in the Environment at the Radioactive Waste Burial Site. Maxey Flats, Kentucky. IAEA-SM-199/105.

Between 1963 and 1974, approximately 104,000 $\mathrm{m}^{3}$ of solid "low-level" radioactive waste were buried at the Maxey Flats, Kentucky, site. These wastes contained approximately $80 \mathrm{~kg}$ of plutonium-239 and a large undetermined quantity of other plutonium isotopes. In 1972, elevated levels of radioactivity were detected in monitoring samples collected near the burial facility by the Kentucky Department for Human Resources (KDHR).

Subsequently, the KDHR conducted a special radiological study of the burial site and its envirnns. Based on the concentraliun of plutonium present or the ratio of plutonium- 238 to $-239,49$ of 50 samples collected on or near the burial site were contaminated with plutonium from a source other than atmospheric fallout. Plutonium was detected in surface soil, in soil cores $90 \mathrm{~cm}$ deep, in monitoring wells, and in streams which drain the site.

During the past 13 years, infiltrating precipitation collected in the burial trenches, forming a mobile plutonium-contaminated leachate. The chemical form, pathways, and mechanisms by which the plutonium moved out of the trenches have not been explained satisfactorily. Extensive studies of the burial site are in progress. 
The primary conclusion drawn from the hydrogeology of the site and the plutonium data is that plutonium has moved from the facility; possibly via several pathways including surface water runoff, atmospheric fallout from an evaporator, lateral migration through the soil, and migration through jointed subsurface geologic formations.

This paper presents the plutonium data with commentary on its occurrence and possible significance from a hydrogeological and environmental perspective. (auth)

Miche1s, D. E. 1971. Log-Normal Analysis of Data for Plutonium in the Outdoors. IN: Fowler, E. B., R. W. Henderson, and M. F. Milligan. Proceedings of Environmental Plutonium Symposium. LA-4756 (UC-41): 105-111.

Detected amounts of plutonium are distilled log-normally for most groups of samples. When data are plotted on probability paper, sharp distinctions may sometimes be made between the background distribution and increments from a local source.

Because the detected amounts of plutonium are not distributed normally, arithmetical averaging of detected amounts is not valid. Similarly, composited samples from large areas yield analyzed values which cannot be interpreted. Additionally, the proper standard deviation for background samples refers to a ratio of concentrations rather than to an increment as is commonly reported. (auth)

Miner, F. J., P. A. Glover, and W. L. Polzer. 1974. Plutonium Behavior in the Soil/Water Environment I. Sorption of Plutonium by Soils. Agronomy Abstracts. p. 35.

As part of a larger program to study the behavior of plutonium in the environment, the movement of plutonium in soil/water systems is being investigated. Sorption and elution characteristics are being used to measure this movement. The equilibrium sorption of plutonium has been determined for 13 soils. The soils were initially characterized chemically and physically (mechanically). Three plutonium concentrations, $10^{-8}, 10^{-7}$, and $10^{-6}$ moles/ liter, were used for the sorption measurements. The plutonium sorption was rapid and quite high: $59 \%$ of the time the equilibrium sorption was greater than $99 \%\left(K_{d}(m)>430\right)$ and only $5 \%$ of the time was it below $90 \%$ sorption $\left(K_{d}(m)<39\right)$. Using principal component analysis, a statistically significant relationship was found between the sorption of plutonium and groups of chemical and physical characteristics of the soils that are associated either with the ion exchange capabilities of the soils or their acidities. Plutonium column elution behavior has been investigated for three soils. There is some plutonium in the eluate (less than $2 \%$ of the amount of plutonium placed in the soil column) but the amount varies with the soil. (auth) 
Miner, F. J. and H. W. Miller. 1972. Plutonium Behavior in the Soil/Water Environment in M. A. Thompson (editor) Research and Ecology Semi-Annual Progress Report January - June 1972. Chemistry Research and Development. RFP-1921-A:1-3.

Attempts to identify the sorption differences between "soluble" forms of plutonium $\left[\mathrm{Pu}(\mathrm{OH})_{\mathrm{m}}{ }^{-\mathrm{m}}\right]$ and of insoluble forms of plutonium [Pu02] have been futile.

Distribution coefficients for plutonium on $2 \mathrm{~g}$ of soil from $10 \mathrm{ml}$ of solutions will be determined by centrifugation.

Miner, F. J., P. A. Glover and H.W. Miller. 1973. Plutonium Behavior in the Soil/Water Environment. RFP-2004.A. PP. 1-3.

A standard solution of less than 10 micrometer $\mathrm{PuO}_{2}$ particles suspended in water, along with a nitric acid solution as a source of "soluble" plutonium, was used in distribution studies of plutonium between characterized soils and the above solutions. The division between soluble and insoluble plutonium was chosen as 0.02 micrometers in diameter on the basis of plutonium work reported in the literature. This was later modified to $0.1 \mu \mathrm{m}$. Equilibrium between $\mathrm{Pu}$ in $\mathrm{HNO}_{3}$ and a Rocky Flats soil was reached in about 3 hours but a South Carolina soil did not attain equilibrium after 24 hours of contact time.

Miyake, Y., Y. Katsuragi, and Y. Sugimura. 1970. A Study on Plutonium Fallout. Journal of Geophysical Research. 75:2329-2330.

Total depositions of $239,240 \mathrm{Pu}$ and $239 \mathrm{Pu}$ from 1958 to April 1969are, respectively, $0.97 \mathrm{mc} / \mathrm{km}^{2}$ and $42 \mathrm{11} / \mathrm{km}^{2}$ in Tokyo. The ratio of $233 \mathrm{pu}$ to 239,240pu increased in fallout remarkably since 1967. Thi's tncrease is considered to be due to Z38Pu scattered from SNAP-9A generator in 1964 . Surface values of plutonium isotopess of the Japan Sea ranged from 3.0 to $20.4 \times 10^{-15} \mathrm{~g} / 1\left(0.2\right.$ to $\left.1.2 \times 10^{-3} \mathrm{pc} / 1\right)$ with the ratio of $238 \mathrm{Pu}$ to $239,240 \mathrm{Pu}$ ranging from 13.2 to $37.7 \%$. We observed the deep penetration of these isotopes in the sea. (CA)

Miyake, Y. and Y. Sugimura. 1975. The Plutonium Content in the Pacific Ocean Waters. IAEA-SM-199/22.

The conlent of plutonium in sea water collected during the cruises of 1968 to 1973 in the entire Pacific Ocean mainly along the line of $170^{\circ} \mathrm{W}$ and $746^{\circ} \mathrm{W}$ longitude extending from $50^{\circ} \mathrm{N}$ to $68^{\circ} \mathrm{S}$, not only in the surface layer but also in the deep layer down to 3,000 $\mathrm{m}$ depth was determined. Results obtained in the eastern South Pacific and some of the western North Pacific were also reported. The plutonium content in the North Pacific surface water ranged from 2.2 to $9.4 \times 10^{-4} \mathrm{pCi} / 1$ while it is lower in the South Pacific ranging from 1.3 to $3.4 \times 10^{-4} \mathrm{pCi} / 1$. Intimate correlation was 
observed between the plutonium content in surface water and ${ }^{90} \mathrm{Sr}$ fall rate. The ratio of $238 \mathrm{Pu} / 239,240 \mathrm{Pu}$ in surface water ranged from 10 to $81 \%$ in the North Pacific and 35 to $240 \%$ in the South Pacific. These values are in the same order of magnitude as seen in the land fallout during the same period. $239,240 \mathrm{Pu} /{ }^{13} \mathrm{Cs}$ in surface water ranged from 0.09 to $0.28 \%$ and it is lower than the average ratio of $0.6 \%$ in fallout in Tokyo. In the intermediate or deep layer relatively higher ratio was observed as compared with those in surface water. This suggests that a faster downward transport of plutonium in marine environment than strontium or cesium. (auth)

Monsanto Mound Laboratory. 1972. Environmental Monitoring Report: January-June 1971. MLM-1880 (TID-4500 or UC-41).

The average concentrations of polonium 210, plutonium 238 and tritium detected in the environment surrounding Mound Laboratory, Miamisburg, Ohio, are presented for the first half of 1971. The average concentrations of these radioisotopes at the water sampling locations and the air sampling stations were well within the stringent standards adopted by the Atomic Energy Commission. The highest average concentrations of polonium, plutonium, and tritium detected in the air sampling areas during the first half of 1971 were 39,48 , and $60 \%$ lower, respectively, than those measured during 1970. The highest average concentrations of polonium, plutonium, and tritium measured at any of the water sampling locations during the first half of 1971 were 92, 75, and 89\% lower, respectively, than those measured during 1970. The highest scrapings were approximately $2 \%$ of the most restrictive levels suggested by Kathren for urban areas. Soil core samples taken during the same period were considerably lower than those reported by Krey and Hardy in an independent Health and Safety Laboratory (HASL) study. (auth)

Morgan, J. M., Jr. 1959. A Stream Survey in the Uranium Mining and Milling Area of the Colorado Plateau. Colorado and Gunnison Rivers. NYO-7831.

During June to August 1958, a stream survey was made of the ColoradoGunnison River System in Colorado during a period of infrequent rainfall and rear-minimum runoff. Approximately one hundred and seventy miles of the Colorado River and one hundred and thirty miles of the Gunnison River were investigated. Water samples were analyzed chemically, physically, and radiologically; aquatic organisms were identified and bacteriological samples taken. River bottom silt and mud samples as well as irrigation area soil samples were investigated radiologically. Three uranium ore reduction mills employing the solvent extraction process were located in the survey area. (auth)

Morisawa, S. and Y. Ionoue. 1974. On the Selection of a Ground Disposal Site for Radioactive Wastes by Means of a Computer. Health Physics 27: 447-457.

The feasibility of disposing of radioactive wastes in the ground, the optimal conditions for the site, and the evaluation of safety factors have been 
reported in previous papers. This paper discusses processes of selecting optimum locations for the disposal of radioactive wastes by means of a computer. A program for site selection is based on some reasonable assumptions and includes the data required to estimate the dose of radioactivity in the human body due to the disposed wastes of a nuclear facility along a coast. The calculations were made for a model nuclear facility that was chosen to show the general method of selecting a ground disposal site.

An optimum location for a ground disposal site is defined as a location with minimum internal dose caused by the disposed wastes. Four locations were selected using a computer, each location having a minimum internal dose based on the assumption of $0.1 \mathrm{Ci} / \mathrm{yr}$ leachate of $\mathrm{Sr} 90$. The minimum internal dose for the four locations was estimated to be lower than $10^{-80}$ $\mathrm{mrem} / \mathrm{yr}$. The method of selecting optimum locations is reasonably promising for solving current. problems of site selection fur disposal.

A chart to compare the safety of sites by evaluating each with reference to eighteen environmental factors is included.

Mork, H. M. 1970. Redistribution of Plutonium in the Environs of the Nevada Test Site. USAEC Document. UCLA 12-590.

Data are presented on redistribution of plutonium as indicated by changes in the concentrations of gummed papers, air filters, soil and animal samples collected in 1956 and 1958. The airborne concentrations were significantly higher in one area than they were two years previous..

The plutonium content of the soil ranged from less than one microgram to 2000 micrograms per square meter in the two areas studied. Some redistribution was occuring.

Plutonium was associated with the liver, the lungs, and the bune of animils in the study areas. The maximum values observed in 1958 were 0.16 and 57.5 disintegrations per minute per animal for the liver and the lungs, respectively, and 2.62 disintegrations per minute per gram of bone ash. (auth)

Murray, C, N. and H. Kaursky. 1975. Plulunlum and Americium Values in the North Sea and German Coastal Regions. IAEA-SM-199/26.

The North Sea is probably a unique sea rogion in that lic distribution of ar.lificlal radionuclides is influenced by the discharge of activity from three nuclear fuel reprocessing plants, those situated at La Hague in Northern France, Windscale in the north west of England and Dounraey in Northern Scotland, as well as from fallout from nuclear weapon testing. 
Data is presented on the distribution of ${ }^{239+240} \mathrm{Pu},{ }^{238} \mathrm{Pu}$, and ${ }^{241} \mathrm{Am}$ in seawater samples taken from the German Bight and German Baltic coastlines as well as from other parts of the North Sea up to latitude $60^{\circ} \mathrm{N}$.

Results from the Pentland Firth in the north of Pentland and the English Channel show 239+240 Pu activities in seawater between 5-15 times higher than North Atlantic fallout levels. The ratio $238 \mathrm{pu} / 239+240 \mathrm{pu}$ is significantly higher in the Pentland Firth area $(0.21 \pm 0.01)$ than in the Channel $(0.15 \pm 0.02$ and this difference may well be a reflection of different input sources of Plutonium in these water. German coastal seawater and sediment Plutonium activities appear to be due only to fallout, the isotope ratio being about $0.06 \pm 0.02$, a value in good agreement with accepted North Atlantic values. (auth)

Myers, D. S., W..J. Silver, D. G. Coles, K. C. Lamson, D. R. Mc Intyre and B. Mendoza. 1975. Evaluation of the Use of Sludge Containing Plutonium as a Soil Conditioner for Food Crops. IAEA-SM-199/42.

During the three-week period from 25 May to 16 June 1967, approximately $32 \mathrm{mC} i$ of $239 \mathrm{Pu}$ was inadvertently released from Lawrence Livermore Laboratory into the sanitary sewer system. It was concluded at the time from an investigation conducted by LLL in cooperation with ERDA-SAN and the California Department of Public Health that the release did not present a hazard to treatment plant personnel or the community.

The quantity of ${ }^{239} \mathrm{pu}$ released was determined from the analysis of the samples collected by the Laboratory's sewage sampling system. This system collects a sample which is proportional in volume to the rate of flow in the sewer.

Analysis of the liquid collected by the Laboratory's sewage sampling system indicated that the maximum daily average concentration of the release did not exceed $2.1 \times 10^{-6} \mu \mathrm{Ci} / \mathrm{mi}$. It is not known whether the chemjcal form of the ${ }^{239} \mathrm{Pu}$ was soluble or insoluble. The MPC for soluble $239 \mathrm{Pu}$, which is more restrictive than for insoluble ${ }^{239} \mathrm{Pu}$, is $1 \times 10^{-4} \mu \mathrm{Ci} / \mathrm{ml}$.

Immediately following the release, a detailed sampling program was begun at the Livermore sewage treatment plant. The results of this sampling program confirmed that approximately $30 \mathrm{mCi}$ of $239 \mathrm{Pu}$ had been released and that the $239 \mathrm{Pu}$ was essentially all contained in the digested sludge at the sewage treatment plant. This digested sludge is accumulated in holding lagoons and transferred to drying beds each year during the summer. Sludge taken from the drying beds in recent years has a ${ }^{239} \mathrm{Pu}$ contamination level of about $2.3 \times 10^{-6} \mu \mathrm{Ci} / \mathrm{g}$ (dry weight).

Large quantities of the digested sludge from the Livermore sewage treatment plant are used by municipal agencies as a soil conditioner in parks and in landscaping around public buildings. The dried digested sludge is also available without cost to the general public, and is commonly used as a soil conditioner for home lawns and gardens. 
In view of this widespread use of the sludge as a soil conditioner, a more recent evaluation was made to confirm the original assessment of the possible adverse health implications associated with the use of the sludge. Two potentially significant uptake pathways were studied: (1) the resuspension and inhalation of the ${ }^{239} \mathrm{Pu}$ when the sludge is being used as a soil conditioner, and (2) uptake of the $239 \mathrm{Pu}$ by plants grown in the sludge and its subsequent ingestion by people eating the crops. This paper presents the results of these two investigations. (auth)

National Academy of Science. 1975. Assessing Potential Ocean Pollutants. National Research Council. 3:27-63.

On balance, our findings indicate an insufficiency of information regarding the chemical and biolngical behavior of the transurantcs in the marine environment. Without such information meaningful quantitative assessment of either current or future impacts is not possible. We cannot dismiss the possibility that marine concentrations of one or more transuranics may approach levels of concern through naturally-acting mechanisms which we do not understand. Present evidence indicates that transuranic elements introduced to marine waters are rapidly transferred to the sediments. If this holds true, then any input from waste treatment or reprocessing will mainly affect the coastal zone near the point of introduction. These sources would, then, not be expected to contribute significantly to open ocean pollution which would be largely due to fallout from atmospheric releases. Predictions of the effect of transuranic elements on the marine environment cannot be formulated until more extensive knowledge of their modes of transport and their biogeochemical and radiobiological behavior is available. On this basis, we recommend conservative approaches to any releases or transuranic elements to the "environment. This applies to planning against accidental releases as well as to any planned releases. Both should be kept to an absolute minimum. Recommendations are detailed in Chapter 1. (auth)

Nyhan, J. W. and F. R. Miera, Jr. 1975. The Distribution of Plutonium in Trinity Site Soils After. 28 Years. Agronomy Abstracts. p. 124.

The soils of four intensive study sites located along the fallout pathway of Trinity, the first nuclear detonation, were sampled to determine plutonium distributional relationships and correlations with soil physicalchemical properties. Concentrations of $\mathrm{Pu} 238$ and $\mathrm{Pu} 239,240$ were determined for whole soil samples and for soil particlus with diameter ranges of <53 $\mu \mathrm{m}, 53-105 \mu \mathrm{m}, 105-500 \mu \mathrm{m}, 0.5-1.0 \mathrm{~mm}, 1-2 \mathrm{~mm}$, and 2-23 $\mathrm{mm}$ as a function of soil depth and distance from ground zero. The horizontal and vertical natural variation of plutonium in these soils was determined by replicated sampling of soils from nine depths (to a maximum of $47 \mathrm{~cm}$ ) and from nine locations within each hectare-sized study area. Soil physical, chemical and morphologic properties were compared with the distribution of plutonium in these soils. The radionuclide data from this study were compared with similar data obtained at the Trinity site nearly 20 years ago. (auth) 
Nevissi, A. and W. R. Shel1. 1975. Distribution of Plutonium and Americium in Bikini Atoll Lagoon. Health Physics 28:539-547.

Important factors that govern the redistribution and transport of radionuclides in Bikini Atoll Lagoon are particulate size and physical-chemical state. In water samples from Bikini the particulate fraction was collected on $0.3 \mathrm{um}$ millipore filters and the soluble fraction sorbed onto aluminum oxide beds. Sediments were collected by grab sampling or by coring. The

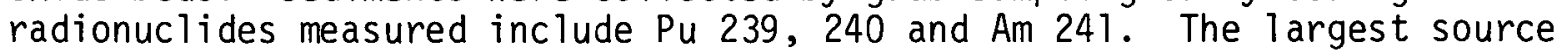
of radionuclides available for transport as indicated by $\mathrm{Am} 241$ and $\mathrm{Pu} 239$, 240 in sediments and water samples reside in the deep water in the northwestern quadrant of the lagoon within approximately $6 \mathrm{~km}$ south of the second thermonuclear detonation--Shot Bravo. Small particles and/or ions of radionuclides are released at the sediment-water interface and are transported by the currents. These particles and ions agglomerate during transport away from the sediment surface. Coagulation with detritus and incorporation with plankton would cause the effective particulate size to increase. After about 16 years, since the last nuclear test on the Atoll, the radionuclides are neither buried totally in the lagoon sediments nor have they been discharged completely to the ocean. There is a constant circulation and redistribution of the materials in the lagoon enforced by prevailing lagoon currents. The flux of americium and plutonium away from Bikini Atoll and into the North Equatorial Current are calculated to be about

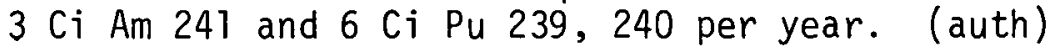

Nevissi, A., W. R. Schell, and V. A. Nelson. 1975. Plutonium and Americium in Soils of Bikini Atoll. IAEA-SM-199/63.

A study has been made to determine the concentrations of plutonium and americium in surface soils and in soil profiles on Bikini Atoll. The soils consist of calcareous materials and a thin layer of organic matter which has produced a shallow organic rich horizon suitable for certain plant growth. During the testing period from 1946 through 1958, Bikini Atoll was the site of 23 nuclear detonations which contaminated the islands of the atoll with radioactive fallout including the transuranium elements. Plutonium and americium measurements nf surface soil samples collected on 6 of the 26 islands of the atoll show that $239,240 \mathrm{Pu}$ values vary from

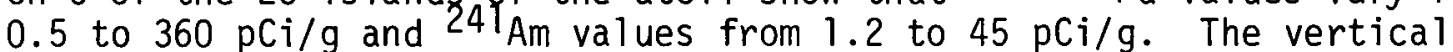
distribution of plutonium in soil varies from area to area. Although about $98 \%$ of the plutonium is retained in the top $25 \mathrm{~cm}$ in one core profile, the remaining $2 \%$ is detectable as deep as $100 \mathrm{~cm}$. The suspension and resuspension of plutonium and plutonium bearing particles by rainfall (150-175 CnI/Yr') seenls to be the principal mode of plutonium transport in the soil. A greater retention of plutonium is found associated with the algal crust of the atoll soils. The present levels of $239,240 \mathrm{Pu}$ and its distribution at Bikini are not likely to change significantly whereas $24{ }_{\text {Am }}$ levels will increase by $241 \mathrm{Pu}$ decay and will attain maximum radioactivity in about 50 years. (auth) 
Newe11, J. F., C. W. Christenson, E. R. Mathews, C. C. Ruchhoft, H. L. Kreiger, and D. W. Moeller. 1951. Laboratory Studies on Removal of Plutonium From Laundry Wastes. Industrial and Engineering Chemistry. 43:1516-1519.

Comparative studies of the chemical precipitation process and of the trickling filter process for removing plutonium from laundry wastes show the following: (1) Either process will effectively remove plutonium from the wastes. (2) The volume of sludge produced by the chemical process will be in the order of 25 to 30 times the volume produced by the trickling filter process. This factor is extremely important since the sludge is hazardous and complicated. On this basis the trickling filter process appears the more attractive. (3) A trickling filter plant design should provide the following features: (a) a holding tank to allow continuous application of the laundry waste to the filter system at a constant rate; (b) a twostage trickling filter system with provisions for varied recirculation ratios. Present data indicate that series operation with a recirculation of 6 to 1 or more over each filter will effect the desired plutonium removal. However, it may be necessary to recirculate at a rate as high as 15 to 1 while placing the filter system into operation. (c) extremely low rates of application of the raw laundry waste with respect to volume and BOD. The data show that desiren plutonium removal may be effected at an application rate of 0.3 million gallons per acre per day with a BOD loading of about 150 pounds per acre-foot per day, based upon the primary filter. (d) facilities for adding supplemental nitrogen and phosphorus to the laundry waste before it is applied to the primary filter. The nitrogen may be added in solution as ammonium sulfate and the phosphorus may be added in solution as trisodium phosphate. The amount of nitrogen in the waste should be sufficient and the mode of operation such as lo ensure that the final effluent will contain a relatively high concentration of nitrates. (e) the secondary effluent should be filtered to ensure removal of any suspended matter carried over. Exploratory studies indicate that an ordinary rapid sand filter will be effective. The filter backwash should be returned to the laundry waste holding tank. (auth)

Newton, T. D. 1959. On the Dispersion of Fission Products by Ground Water. CRT-866.

On the assumptions that the motion of ions in ground water through soils may be described by reversible processes of exchange and that active ions are present in the ground water only in trace quantities, the distribution of activity through the soil of a uniform disposal area is calculated by a slatistical method. The mean delay time in a uniform column is determined by the equilibrium distribution ratio, $D$, and the shape of the front of activity is fixed by $D$ and a parameter $N$ which represents the average number of transfers from the liquid to the solid state. An appendix shows the relation between the statistical methods used here and the exchange rate equation. (auth) 
Nishita, H., E. M. Romney, and K. H. Larson. 1965. Uptake of Radioactive Fission Products by Plants. IN: Fowler, E. G. (ed.). Radioactive Fallout, Soils, Plants, Foods, Man, Chapter 4, p. 55-81.

Root uptake largely depends upon the solubility of fallout debris, the chemical reactions of individual radionuclides in soils, and the absorptive power of radionuclides by plants. The relative order of magnitude of plant uptake of fission products and plutonium appeared to be $\mathrm{Sr} 89, \mathrm{Sr} \mathrm{90 \gg >}$ I $131>\mathrm{Ba} 140>\mathrm{Cs} 137, \mathrm{Ru} 106>\mathrm{Ce} 144, \mathrm{Y} 91, \mathrm{Pm} 147, \mathrm{Zr}-\mathrm{Nb} 95>\mathrm{Pu} 239$. Although the relative order of magnitude varied little, the absolute magnitude of uptake may be varied by certain soil management practices such as cultivation, fertilization and organic matter application. Aside from differential uptake, there was differential distribution of absorbed radionuclides among different plant parts. The soil-plant step greatly reduces the amount of radionuclides transferred along the food chain to man. (auth)

Nishiwaki, Y., Y. Honda, Y. Kimura, H. Morishima, T. Koga, Y. Miyaguchi, and H. Kawai. 1972. Behavior and Distribution of Radioactive Substances in Coastal and Estuarine Waters. IN: IAEA-SM-158/11. Radioactive Contamination of the Marine Environment. pp. 177-193.

To understand the problems of environmental radioactive contamination due to continuous discharge of low-level liquid radioactive waste into the seawater, a study must be made of the behavior and distribution of various nuclides which may occur in both ionic and colloidal or particulate state in the coastal and estuarine waters. However, the behavior and distribution of the various radionuclides in the estuarine water are much more complicated than those in the open sea, because of the complex topographical and marine meteorological variations and the changes in salinities and $\mathrm{pH}$ of the water. Since thorium and rare-earth elements had been continuously discharged through a small river into the estuarine water at Osaka Bay, a study was made of the variation of concentration of these elements under various natural conditions. Experimental studies on adsorption of these elements on some bottom sediments were also carried out in the water with different salinities and $\mathrm{pH}$. One important factor influencing the concentration of the elements in the water is tidal uscillation. The gross bcta activities in water at the same location: in the estuary widely varied at each time of sampling. The average values from April to December in 1966 were $9.5 \pm 4.9$ $\mathrm{pCi} / 1$ at higher tidal level, $84 \pm 68 \mathrm{pCi} / 1$ at middle tidal level and $157 \pm$ $106 \mathrm{pCi} / 1$ at lower tidal level, respectively. However, the concentrations of thorium and total rare-earth elements in the water were not observed to change regularly with the tidal change. The dispersion of the elements in the estuarine water were not interpreted by simple dilution and dirfusion of the element in water mass. The presence of the mud flats, as well as the marine meteorological conditions, seem to affect markedly the distribution of the element in the estuarine water. The adsorption of the element on the bottom sediment was influenced not only by the coarseness of the sediment but also by the salinjty and $\mathrm{pH}$ of the water. The highest distribution coefficients of $9 \mathrm{~T}_{Y}$ and ${ }^{144} \mathrm{Ce}$ in the clay sediment were obtained at the chlorosity of $14 \mathrm{~g} / 1$ and $\mathrm{pH} 7.3$ of the water. (auth) 
Noshkin, V. E. 1972. Ecological Aspects of Plutonium Dissemination in Aquatic Environments. Health Physics 22:537-549.

The available data concerning the dissemination of plutonium and other transuranics in the aquatic environment are drawn together for appraisal. The most studied isotope has been $\mathrm{Pu} 235$ derived from worldwide fallout. Essentially all the published work has been concerned with levels in the marine environment where plutonium is found widespread among planktonic, pelagic and benthic organisms. The concentrations are higher in organisms feeding on sediment or on surfaces than in those drawing largely on the water itself. Among the species where data are available are a variety of convenient "indicator organisms" for plutonium. There is some evidence that plutonium concentrations are increased in organisms of higher trophic levels. Bone and liver are major rcpositories for plutoniuni in marine vertebrates while muscle tissue of both marine vertebrates and invertebrates contain relatively lower concentrations. Plutoniuin is yeuchemically separated from both Sr 90 and Cs 137 in the water column and the sedimentation of $\mathrm{Pu} 239$ may be more involved with biological processes than has been found for fallout rare earth isotopes. In marine sediments, as in soils, plutonium is more mobile than was originally expected. What little is known of the behavior of plutonium in the marine environment should be used conservatively to assess the behavior and distribution of new plutonium additions derived from sources other than fallout, and even more conservatively in predicting the impact of other transuranics in the aquatic environment. Considerably more understanding of the aquatic radioecology of several of the elements is a major priority especially since it now appears that when the relative biological effectiveness of alpha versus gamma or beta radiations is considered, fallout $\mathrm{Pu} 239$ contributes more than fallout Sr 90 or C.S 135 to the artificial radiation exposure of many marine species. (auth)

Noshkin, V. E. and V. T. Bowen. 1973. Concentrations and Distributions of Long-Lived Fallout Radionuclides in Open Ocean Sediments. IN: Radioactive Contamination of the Marine Environment. IAEA, Vienna. IAEA-SM158/45:671-686.

Analys is of deep open-ocean sediment cores from the north and south Atlantic and the Mediterranean Sea show the presence of $\mathrm{Sr} 90, \mathrm{Cs} 137$, and Pu 239, 240 in measurable amounts distributed to depth within the eediment column3. Comparison of the quantities of these radionuclides accumulated in the sediments with either estimated integrated deliveries to the sea surface or the measured inventories in the overlying water masses has heen used to estimate the residence times of the radionuclides in the water column. For $\mathrm{Sr} 90$ and Cs 137 these computed residence times are orders of magnitude shorter than those estimated for the stable elements. Plutonium, we find, is being removed from the water column significantly more rapidly than either Sr 90 or CS 137. The ratio of Cs 137 to Sr 90 in the sediments is higher than that found in precipitation, suggesting that a larger fraction of ocean water Cs 137 is associated with sedimenting particles than 
has been previously assumed. A simple model assuming plutonium to associate with a mixed population of particles, sinking at rates of 392 to $70 \mathrm{~m} / \mathrm{yr}$, predicts very well both the relation of sediment inventory of plutonium to depth of sediment, and the plutonium distribution vertically in the water column. (auth)

Noshkin, V. E., V. T. Bowen, K. M. Wong, and J. C. Burke. 1971. Plutonium in North Atlantic Ocean Organisms; Ecological Relationships. IN: Nelson, D. J. (ed.). Radionuclides in Ecosystems Proc. Third Nat. Symp. Radioecology 2:681-688.

A considerable series of North Atlantic 0cean have been analyzed, by radiochemistry and alpha spectrometry, for fallout plutonium 239, 240, and 238. Organisms from the near-shore environment have been selected to show the effects, on plutonium uptake, of variations in feeding habits, association with sediment or with absorptive surfaces, and of trophic level. In general, plutonium concentrations are higher in organisms feeding on sediment or on surfaces than in those drawing largely on the water itself. There is some evidence that plutonium concentrations are higher in organisms of higher trophic levels. (auth)

Noshkin, V. E., Jr., and C. Gatrousis. 1974. Fallout Pu 240 and Pu 239 in Atlantic Marine Samples. Earth Planet. Sci. Lett. 22:11-117.

Mass spectrometric analyses of low levels of global fallout plutonium separated from Atlantic marine samples have differentiated fallout $\mathrm{Pu} 239$ and $\mathrm{Pu} 240$ in aquatic samples for the first time. The results show no single characteristic $\mathrm{Pu} 240 / \mathrm{Pu} 239$ ratio in marine samples; the observed range is from 0.11 to 0.24 on an atomic basis. There are indications that differences exist in the chemical or physical form of plutonium from atmospheric fallout in Atlantic surface water and that selective concentration in surface organisms is occurring. No single Pu 240/Pu 239 value is found in pelagic sediments collected from different depths and locations. Discounting sources other than fallout, our results show that the plutonium deposited at any given time since atmospheric testing began may have carried a unique $\mathrm{Pu} 240 / \mathrm{Pu} 230 \mathrm{tag}$. This 1 abel may be extremely useful to trace fallout plutonium through biogeochemical cycles. (auth)

Noshkin, V. E., K. M. Wong, K. Marsh, R. Eagle, G. Holladay, and R. W. Buddemeier. 1975. Plutonium Radionuclides in the Ground Waters at Enewetak Atol1. IAEA-SM-199/33.

In 1974 a groundwater program was initiated at Enewetak Atoll to study systematically the hydrology and the ground water geochemistry on selected islands of the Atoll. The program provides chemical and radiochemical data for assessment of water quality on those islands designated for rehabilitation. These and other data are used to interpret the mechanisms by which radionuclides are cycled in the soil-groundwater system. Because 
of the international concern over the long-term buildup, availability, and transport of plutonium in the environment, this program emphasizes analysis of the element. The results of the study show that on all islands sampled, small quantities of plutonium radionuclides have migrated through the soil columns and are redistributed throughout the groundwater reservoirs. The observed maximum surface concentrations are less than $0.02 \%$ of the maximal recommended concentration for drinking water. Concentrations of $137 \mathrm{Cs}$ are found to correlate with water freshness, but those of $239,240 \mathrm{pu}$ show no such relationship. The mechanisms moving $239,240 \mathrm{pu}$ through the ground water reservoirs are independent of the processes controlling the cycling of $137 \mathrm{Cs}$ and fresh water. A reasonable linear correlation is found between mean surface-water concentrations and soil burdens. This indicates that the quantities of $239,240 \mathrm{pu}$ migrating to the groundwater surface layers are, to a first approximation, independent of the physical, chemical or biological characteristics of the islands. (auth)

Noshkin, V. E., K. M. Wong, R. J. Eagle, and C. Gatrousis. 1971. Transuranics at Pacific Atolls. I. Concentrations in the Waters at Enewetak and Bikini. UCRL-51612 (TID-4500, UC-48).

This report presents the available results on the concentrations and distributions of $\mathrm{Pu} 239,240$ and other transuranic radionuclides in the lagoon waters of Enewetak and Bikini Atolls. The data are derived from a series of samples collected during the period October-December 1972. The samples are being radiochemically processed and analyzed for specific radionuclides; the available results for $\mathrm{Sr} 90, \mathrm{Cs} 137, \mathrm{~Np} \mathrm{237,} \mathrm{Pu} \mathrm{238,}$ $\mathrm{Pu} 239,240, \mathrm{Pu} 241$, and Am 241 in specific water samples are presented and discussed. The two Pacific atolls, sites of nuclear testing series in the 1940s and 1950s, act as sources of radionuclides, contributing quantities greatly exceeding the fallout deposition to the lagoon marine environments. The distributions of plutonium in the two lagoons are very heterogeneous; strong concentration gradients are evident in both lagoons, and the horizontal stratifications define areas of water renewal. The concentrations are affected by wave-driven water transported across the reefs and by flow through the main channels. Three to $90 \%$ of the $\mathrm{Pu} 239$, 240 in Bikini lagoon is associated with a particulate phase. Pu 239,240 concentrations associated with bottom particulates gerierally exceed the surface levels, suggesting that resuspension of fine material is an active mechanism for redistributing some plutonium throughout the lagoon. In the soluble phase, however, surface plutonium concentrations generaliy exceed bottom concentrations, indicating slow vertical mixing in the water column, and suggesting (1) that plutonium is derived from several sources, and (2) that surface and bottom currents independently redistribute different forms of the radionuclide to different areas of the lagoon. The Pu 239, $240 /$ Cs 137 ratios in the surface waters are not constant, indicating that different sources or mechanisms govern the redistribution of specific radionuclides in the water column of the lagoon. (auth) 
0lafson, J. H. and K. H. Larsen. 1961. Plutonium, Its Biology and Environmental Persistence. Proceedings of the First National Symposium on Radioecology held at Colorado State University September 10-15. V. S. Schultz and A. W. Klemet, Jr. (eds.). pp. 633-63.9.

Evan a cursory review of the literature pertaining to plutonium and the manifold manifestations of its toxicity leaves little doubt that it is an extremely hazardous material. Every effort should be made to minimize the extent to which man is exposed to it. Plutonium as an environmental contaminant would not, on the basis of the evidence presently available, appear to be a serious problem. Since it decays by emission of alpha particles, it presents no hazard in terms of external whole-body radiation. It is absorbed by plants growing on contaminated soil to an infinitesimal degree, although it may be found as an external contaminant on vegetation. Ingested plutonium is absorbed and retained in animal tissues to a very small degree. Therefore, relatively high levels in dietary constituents can be tolerated without producing a ponderable tissue burden. Extremely high levels of plutonium-239 are required to produce even superficial tissue damage in the digestive tract. Inhalation of airborne particulates remains as the most effective means of entry into higher animals, including man. But for this mechanism to produce a tissue burden, there must be significant airborne concentrations. The available information indicates that, even in localized regions having very high levels of deposited plutonium-239, the levels in air are, except for occasional periods, low in comparison to what is considered as tolerable concentrations for occupational exposure. Animal tissue assays have verified that very little plutonium gains entry into mammalian systems from the contaminated environment. While no one should be alarmed about concentrations of plutonium-239 in the environment of man, or more specifically in human beings themselves, we would urge caution in drawing conclusions regarding ecological implications. Are the present concentrations only the beginning of a continuously rising trend? This is a possibility because of extremely show turnover rate and long halflife. Will the apparent tendency for plutonium concentrations in reproductive tissue to increase in time following acute exposure continue an a chronic basis? If so, will such tissues in time have concentrations of genetic significance? These are only a few of the obvious questions to which ariswers are needed before a final verdict is reached. While the prognosis is encouraging, based on our present knowledge, a much treater understanding of the whole complex of environmental reactions is needed. (auth)

0lafson, J. H., H. Nishita, and K. H. Larson. 1945. The Distribution of Plutonium in the Solis of Central and Northeastern New Mexico as a Result of the Atomic Bomb Test of July 16, 1945. UCLA-406.

Soils and plants from the area of central and northeastern New Mexico, which was contaminated by fallout from the atomic bomb detonation of July 16, 1945, were analyzed for plutonium. Plutonium was found in 
amounts up to 0.07 micrograms per square foot of soil, one-half inch deep, at a distance of 88 miles northeast of the site of detonation. A maximum of 1.47 micrograms per square foot, one-half inch deep, was found on the Chupadera Mesa at a distance of 28 miles northeast of the detonation site. No plutonium was found in samples collected 3 miles south of the site. In assaying for plutonium, the method of Eisenacher was adapted to soil and plant samples. An estimated precision of $15 \%$ was obtained when the method was applied to field samples. A recovery of $98.0<3.0 \%$ was obtained when the method was applied to a "standard" soi1. Uranim and thorium do not interfere in this method even when they are present in quantities much greater than the maximum amounts normally found in soils. (auth)

Oucht, Shunichi, I. Oyawd, S. Masuda and M. Kurabayashi. 1970. Uranium Contamination of the Shinkawa Ri.ver. (CONF-700227-3) PNC-N-831-70-2: 91-8.

Low-level uranium liquid waste, about $1 \times 10^{-7} \sim 2 \times 10^{-7} \mu \mathrm{Ci} / \mathrm{cm}^{3}$ in gross beta activity, was discharged from Tokai Works to the Shinkawa River downstream for about 10 years. The total amount of uranium released is estimated to be about $64 \mathrm{mCi}$. Weight of this value calculated from chemical analys is is about $6 \times 10^{2} \mathrm{~kg}$. According to results of routine monitoring, no appreciable increase of uranium contamination of the river water and mud was observed. Environmental surveys of the Shinkawa River were carried out, placing emphasis on the river mud. It was found that the uranium liquid waste was diluted several times in volume in the Junichogawa, and 50 to 100 times between the junction and mouth of the Shinkawa, progressively. The radioactivity level of the Junichogawa was about 100 times as high as that of background. For biota samples, crawfishes (Cambaroides Clarkii) from benthos, cracians (Carassius Auratus) from nekton, and reed from plant, the uranium content was determined by fluorometric analysis. No appreciable contamination was found in the animal samples, while the uranium content in some plant samples was a little higher than that of other natural sampies. (NSA)

Pillai, K. C., R. C. Smith and T. R. Folsom. 1964. Plutonium in the Marine Enviroment. Nature. No. 4945:568-71.

Plutonium-239 and 240 were separated from seawater by radjochemical techniques and measured with an alpha spectrometer. $239,240 \mathrm{Pu}$ were found to be highly concentrated in marine organisms including phytoplankton; dinoflagellates, green algae, palm kelp, mussels and fish. (auth)

Pinder, J. E., M. H. Smith, H. R. McLendon, A. L. Boni, J. H. Horton, and J. C. Corey. 1975. Field Study to Obtain Plutonium Contents of 01d Field Vegetation and Soil Under Humid Climatic Conditions. DP-MS-74-65 (CONF750503-23). 
Soil and vegetation at the Savannah River Plant were analysed for plutonium. The data indicate that vacuumed samples have the greatest concentration of plutonium, that resuspension and fallout of plutonium is a principal contributor to the plutonium concentration of vegetation because the $238 \mathrm{Pu}$ concentrations are more closely aligned to source term values than soil values under field conditions, and that laboratory uptake studies may underestimate the plutonium content of vegetation growing under field conditions adjacent to a fuel reprocessing facility. (NSA)

Poet, S. E. and E. A. Marte11. 1972. Plutonium 239 and Americium 241 Contamination in the Denver Area. Health Physics. 23:537-548.

Procedures and results of an experimental investigation of $\mathrm{Pu} 239$ and Am 241 contamination in the environs of the Rocky Flats plutonium plant and elsewhere in the greater Denver area are presented and discussed. Measurements of $\mathrm{Pu} 239$ and $\mathrm{Sr} 90$ in the top $1 \mathrm{~cm}$ surface layer of soils show that in this layer the $\mathrm{Pu} 239$ contamination in offsite areas just east of the Rocky Flats plant ranges up to hundreds of times that from nuclear tests. In the more densely populated areas of Denver, the $\mathrm{Pu}$ contamination level in surface soils is several times fallout. The depth distribution of $\mathrm{Pu} 239$ in undisturbed soils in the more heavily contaminated areas show that the contaminant is concentrated largely in a thin surface layer. Results for soils of known last date of disturbance make it evident that most of the offsite $\mathrm{Pu}$ accumulated between 1966 and 1969. This corresponds to the period in which Pu in an oil spill area on the plant site was exposed and subjected to wind reentrainment.

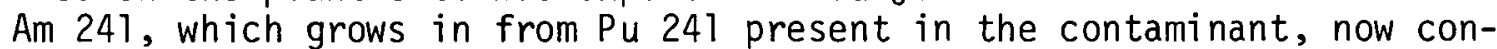
tributes between 3 and $15 \%$ as much alpha activity as Pu 239 and ulimately will approach comparable levels. The important unknowns and uncertainties involved in the estimation of inhalation exposures and the carcinogenic risks from the $\mathrm{Pu} 239$ contamination in the environs of Rocky Flats are briefly reviewed. (auth)

Poet, S. E. and E. A. Martel1. 1974. Reply to Plutonium-239 Contamination in the Denver Area by P. W. Krey. Health Physics. 20:120.22.

Reference is made to the letter of Krey (Health Phys. 26:117 (1974)) in which he spoke of "omissions, errors, and misconceptions" in the present author's previous paper (Health Phys. 23:537 (1972)). Such allegations of this author's work covering the spatial distribution of $239 \mathrm{Pu}$ contamination, the sampling and analysis techniques used, and the $239 \mathrm{pu}$ distribution with depth, are argued. (NSA)

Polzer, W. L. 1971. Solubility of Plutonium in Soil/Water Environments. CONF-710401, Proceedings of Rocky Flats Symposium on Safety in Plutonium Handling Facilities. p. 411-430. 
Phase relations of plutonium species, both solid and aqueous, are evaluated as functions of $\mathrm{pH}$ and oxidation-reduction potential (Eh) for conditions found in soil/water environments. These are based on thermodynamic calculations, using laboratory data from the literature. The significance of plutonium complexes, especially plutonium carbonate, is discussed. Plutonium dioxide, under equilibrium conditions, will control the concentration of dissolved plutonium; under nonequilibrium conditions either plutonium sesquioxide or plutonium hydroxide, depending on the Eh, will control. The dissolved plutonium species is dependent on specific environmental conditions. If the dissolved plutonium is limited by $\mathrm{PuO}_{2}$, the concentrations are lower than Radiation Concentration Guide values ( $1 \times 10 \mathrm{~F}-4$ $\mathrm{uCi} / \mathrm{ml}$, controlled areas; $2 \times 10 \mathrm{E}-6 \mathrm{uCi} / \mathrm{ml}$, uncontrolled areas) for conditions normally found in the environment. If it is limited by $\mathrm{PuO}_{2} \mathrm{O}_{3}$ of $\mathrm{Pu}(\mathrm{OH})_{4}$, the values are lower for some conditions and higher for others. Calculations of the solubility of complexes, especially $\mathrm{CO}_{2}$, yield values several orders of magnitude greater than any found in actual environmental samples. Possible reasons for this discrepancy are discussed. Parameters which should be examined in assessing environmental samples are demonstrated. (auth)

Polzer, W. L. and J. F. Miner. 1974. Plutonium Behavior in the Soil/Water Environment. II. Mechanisms of Plutonium Sorption by Soils. Agronomy Abstracts, p. 37.

Sorption of plutonium by 13 soils, as measured by distribution coefficients, was observed in most cases to be dependent on the initial concentration of plutonium which ranges from $10^{-8}$ to $10^{-6}$ moles/liter. This dependency is attributed to several factors: the presence of monomeric or low molecular weight polymeric plutonium species (as indicated by solubulity calculations), complexes of plutonium carbonate ions, and in a few cases, the possible existence of nonequilibrium sorption conditions. A lower surption of plutonium was observed in the presence of low molecular weight polymers in solution, apparently due to a lower charge density of the polymers. A decrease in sorption was also observed at the initial plutonium concentration of $10^{-8}$ moles/liter and is attributed in some cases to possible nonequilibrium conditions as indicated by changes in sorption when recarbonate ions may react with plutonium to form quantities sufficient to influence the sorption of plutonium by soils, irrespective of the initial plutonium concentration: (auth)

Price, K. R. 1971. A Critical Review of Biological Accumulation, Discrimination and Uptake of Radionuclides Important to Waste Management Practices. BNWL-B-148.

The objective of this survey is to screen the world literature for data on biological uptake and accumulation or the discrimination against uptake of certain radionuclides associated with nuclear waste management. Historical aspects based on the publication sequence of biological research are briefly 
considered, and relevant research findings are discussed under several categories. One category is devoted to transuranic elements and is accompanied by a special bibliography. The application of research findings to the Hanford situation is discussed and projects for future study are recommended. An annotated list of 119 references is presented. (auth)

Price, K. R. 1972. Uptake of Neptunium 237, Plutonium 239, Americium 241, and Curium 244 From Soil by Tumbleweed and Cheatgrass. BNWL-1688.

Tumbleweed (Salsola Kali) and cheatgrass (Bromus Tectorum) were grown under controlled conditions in pots containing surface soil common to radioactive waste disposal sites at Hanford. The soil was spiked with $\mathrm{Np} 237 \mathrm{~Np}\left(\mathrm{NO}_{3}\right)_{5}$, $\mathrm{Pu} 239 \mathrm{Pu}\left(\mathrm{NO}_{3}\right)_{4}, \mathrm{Am} 241 \mathrm{Am}\left(\mathrm{NO}_{3}\right)_{3}$, or $\mathrm{Cm} 244 \mathrm{Cm}\left(\mathrm{NO}_{3}\right)_{3}$ solutions, and $\mathrm{all}$ radionuclides were absorbed by the test plants. Large amounts of neptunium were taken up ( $>2 \%$ dose), with smaller amounts of americium and curium. Plutonium uptake was only slight: Critical levels of detection ( $L$ sub $C$ ) are calculated, and the term Minimum Soil Detection Level ( $L$ sub MSD) is introduced. The application of results to waste management is discussed. (auth)

Price, K. R. 1973. A Review of Transuranic Elements in Soils, Plants, and Animals. Jour. Environ. Quality. 2:1:62-66.

Published information concerning the distribution and fate of neptunium, plutonium, americium, and curium in terrestrial ecosystems is reviewed and areas needing further study are identified. In the final analysis of environmental quality, radionuclides with very long half lives will become increasingly important to man as they continually constitute a greater proportion of environmental radioactivity. The transuranic elements have been identified as the most hazardous radionuclide by-products of nuclear reactor operations. The relatively few studies conducted indicate that transuranic elements do not remain in solution in soils, plants, or animals hut nrganic complexes and chelation greatly enhance mobility. The elucidation of natural organic complexes and chelating agents has not been attempted. oxidation state also influences mobility, but possible biological mechanisms permitting exodation or reduction remain uninvestigated. Ingestion is the most important transfer mechanism in ecosystems, but assimilation of transuranics from natural food sources is mostly unknown. Evidence in the literature suggests three possible mechanisms leading to the observed increase in plant uptake with time: the formation of organic complexes or chelates, a buildup of radionuclide concentration at root surface, or the slow but continual uptake by perennial plants. Each of these mechanisms deserves further study. (auth) 
Price, K. R. 1973. Tumbleweed and Cheatgrass Uptake of Transuranium Elements Applied to Soil as Organic Acid Complexes. BNWL-1775.

Plant uptake of radioactive waste materials is a biological interaction important to the environmental management of waste storage sites. This study on the uptake of $241_{\mathrm{Am}},{ }^{244} \mathrm{Cm}, 237 \mathrm{~Np}$, and $239 \mathrm{Pu}$ from soil by plants demonstrates that shoot uptake is clearly influenced by the chemical form of the transuranic. It is unclear at this time whether soil or plant mechanisms, or both, are responsible. Future studies are planned to investigate these aspects. The observation that some organic acids suppress plant uptake of americium and curium will be investigated further to evaluate the use of soil additives to suppress plant uptake of transuranics. Test results indicate that organic acid complexes of plutonium such as oxalate or citrate can increase plant uptake when added to soil as comparcd to uptakc from dilute nitric acid sulutions. (aiith)

Price, K. R. 1974. The Behavior of Waste Radionuclides in Soil-Plant Systems. IN: Pacific Northwest Laboratory Annual Report for 1973 to the USAEC Division of Biomedical and Environmental Research, Part 2, Ecological Sciences. BNWL-1850 Pt. 2 (US-48, Biology and Medicine): $38-40$.

$\mathrm{Np}$ 237, Pu 239, Am 241, and Cm 244 were added to soils as nitrates and chelates of EDTA and DTPA. Tumbleweed (Salsola Kali) and cheatgrass (Bromus tectorum) were grown in soils for two months and the shoot uptake of radionuclides from chelates was compared with uptake from nitrate solutions. EDTA increased the uptake of Pu (about 10 fold) and of $\mathrm{Am}$ and $\mathrm{Cm}$ only slightly, whereas, reduced the uptake of Np. DTPA increased the uptake of $\mathrm{Pu}$ (more than 800 fold) and of $\mathrm{Am}$ and $\mathrm{Cm}$ (about 100 fold), whereas, reduced the uptake of Np. (auth)

Price, S. M. and L. L. Ames. 1975. Characterization of Actinide-Bearing Sediments Underlying Liquid Waste Disposal Facilities at Hanford. IAEASM-199/87.

Past liquid waste disposal practices at the U.S. Energy Research and Development Administration's Hanford Reservation have included the discharges of solutions containing trace quantities of actinides directly into the ground via structures collectively termed "trenches." Characterization of samples from two of these trenches, the 216-Z-9 and the 216-Z-1A(a), has been initiated to determine the present form and migration potential of plutonium stored in sediments which received high salt, acidic waste liquids. Analysis of samples acquired by drilling has revealed that the greatest measured concentration of $\mathrm{Pu}, \sim 10^{6} \mu \mathrm{Ci}$ $239 \mathrm{Pu} / 1$ iter of sediment, occurs in both facilities just below the points of release of the waste liquids. This concentration decreases to $210^{3}$ $\mu \mathrm{Ci} 239 \mathrm{Pu} / 1$ iter of sediment within the first 2 meters of the underlying sediment columns and to $\sim 10 \mu \mathrm{Ci} 239 \mathrm{Pu} / 1 \mathrm{iter}$ of sediment at the maximum 
depth samples (9 meters). Examination of relatively undisturbed sediment cores illustrated two types of $\mathrm{Pu}$ occurrence responsible for this distribution. One of these types is composed of Pu particles ( $>70 w t \% \mathrm{PuO}_{2}$ ) added to the disposal site in the same form. This "particulate" type was "filtered out" within the upper 1 meter of the sediment column, accounting for the high concentration of Pu/liter of sediment in this region. The second type of $\mathrm{Pu}\left(0.5 \mathrm{wt} \% \mathrm{PuO}_{2}\right)$ was originally disposed of as soluble Pu(IV). This "nonparticulate" type penetrated deeper within the sediment profile and was deposited in association with silicate hydrolysis of the sediment fragments. (auth)

Proctor, J. F. and I. W. Marine. 1965. Geologic, Hydrologic, and Safety Considerations in the Storage of Radioactive Wastes in a Vault Excavated in Crystalline Rock. Nuclear Science and Engineering 22:350-365.

A recent investigation established the technical feasibility and indicated the high degree of safety that could be afforded by the storage of highlevel radioactive wastes in unlined vaults excavated in crystalline rock 1500 feet beneath the surface of the Savannah River Plant near Aiken, SC. The crystalline rock at the proposed site is covered by 1000 feet of unconsolidated sediments consisting predominantly of sand and clay. A virtually impermeable layer of clay separates the rock from the overlying sediments in which several prolific water-bearing zones occur. The separation of the waters above and below this clay layer is confirmed by their different chemical composition and by the presence of dissolved helium-bearing gas only in the water in the rocks beneath the clay. Based on geologic and hydrologic information obtained in an intense drilling and testing program, upper limits on the rates of water movement through the crystalline rock are calculated to be 1.5 to $7 \mathrm{ft} / \mathrm{yr}$, depending upon the degree of fracturing of the rock. Comparable data on the unconsolidated sediments lead to a calculated maximum rate of water movement of $350 \mathrm{ft} / \mathrm{yr}$. The most significant driving force for the migration of radionuclides from the storage site is derived from the natural water movement coupled with effects due to dispersion and ion exchange. Characteristics of the waste, heat generation, and radiolysis have, by contrast, only small effects on migration. Three barriers prevent migration of the radionuclides: the very low permeability of the rock in which the storage vault is located, the virtually impermeable clay layer separating the rock and sediments, and the ion exchange properties of the sediments. Any one of the se barriers is capable of confining the radionuclides well within the plant boundaries for a time much greater than the 600-year period required to render the wastes innocuous. (auth)

Prout, W. E. 1958. Adsorption of Radinartive Wastes hy Savannah River Plant Soil. Soil Sci. 86:13-17.

The adsorption of radioisotopes on soil was investigated in the laboratory to determine the behavior of low-level radioactive waste solutions 
discharged to the ground. Strontium, cesium, and plutonium distributions between soil and waste solutions were studied. The effects of cation concentration and acidity were determined. The results of the distribution experiments, and material balance considerations, permit prediction of the behavior of activity in beds of soil. Laboratory tests with beds of soil gave results that agreed with these predictions. These results can be applied to the disposal of radioactive solutions to the ground. A typical application is discussed. (auth)

Prout, W. E. 1959. Adsorption of Fission Products by Savannah River Plant Soi1. DP-394.

Data are presented for the equilibrium distrihution of cosium, strontium, piutonium, ruthenium, and zircuritum-niobiull between so11 of the Savannah River plant and various aqueous solutions. Low cation concentration and a $\mathrm{pH}$ range of 7 to 9 were most favorable for absorption of these elements on the soil. (auth)

Prout, W. E. 1962. Studies of the Containment of Radioactive Wastes in the Underground Mined Caverns at the Savannah River Plant. IN: Morgan, J. M., D. K. Jamison, J. D. Stevenson (eds.). Ground Disposal of Radioactive Wastes. Second Conference Pröceedings. TID-7628:380-393.

The DuPont Company is coordinating an exploratory drilling program, to determine the feasibility of mining caverns for the storage of radioactive wastes in the basement rock underlying the Savannah River Plant. 0 ther groups participating in the study include the U.S. Corps of Engineers and the U.S. Geological Survey. At the Savannah River Plant the problem of waste management has been handled satisfactorily by a policy of containment within the environs of the plant proper, Low level wast.e is released to seepage basins at controlled rates. All other liquid wastes are stored in underground steel tanks contained in concrete vaults or in steel-lined concrete tanks. Containment in these vessels has been satisfactory from the standpoint that there has been no loss of stored wastes to the natural environment. However, the tanks have a relatively short life as compared to the radioactive life of the stored materials. Unless a more permanent disposal scheme is developed, new tanks may be required from time to time, and the presently stored liquid may have to be transferred if continuing safe containment is to be assured. Following the drilling of a test hole at the Savannah River Plant in 1952, consisideration was given to the use of caverns mined in bedrock for the ultimate storage of radioactive wastes. Active investigation was postponed, however, since satisfactory interim storage could be obtained in tanks and since the heat generated from the fission products dictated that considerable aging would be required before permanent storage would be practical. It is our current opinion that the bedrock that underlies the plant site has a good potential for containing radioactive wastes. A study of the feasibility of cavern storage is currently underway. A 
total of 10 test holes are to be drilled to a depth of 1000 feet into the basement rock. The rock cores arè to be tested to determine compressive strength, modulus of elasticity, water permeability, coefficient of expansion, specific heat, diffusivity, conductivity, and chemical compatibility of the rock with synthetic and actual wastes. Testing of the rock core from the first hole is complete. Drilling of holes 2, 3, and 4 is more than $75 \%$ complete. (auth)

Purtymun, W. D. 1971. Plutonium in Stream Channel Alluvium in the Los Alamos Area, New Mexico. LA-4561.

A survey of plutonium isotopes plutonium 238 and plutonium 239 in the alluvium of major canyons in the LoS Alamos Area was made to determine concentrations and movement of soil-bound plutonium. Trace concentrations of plutonium were found in alluvium in those canyons which have received or are receiving treated effluents from operations of the Laboratory. The concentrations of plutonium in the alluvium of the remainder of the canyons were no greater than those concentrations attributed to worldwide fallout from atmospheric tests. (auth)

Purtymun, W. D. 1974. Storm Runoff and Transport of Radionuclides in DP Canyon, Los Alamos County, New Mexico. LA-5744, pp. 1-7.

Study determined runoff volume, suspended sediment load and amount of radioactivity carried out of DP Canyon by storm runoff. During summer of 1967,23 runoff events carried $288,000 \mathrm{~kg}$ of suspended sediments in $\sim 36,800 \mathrm{~m}^{3}$ of water. Sediments carried out $\sim 70 \mu \mathrm{Ci}$ of gross alpha, $211,300 \mu \mathrm{Ci}$ gross beta. About 3$], 000 \mu \mathrm{Ci} 90 \mathrm{Sr}$ left canyon in solution as did traces of $238 \mathrm{Pu}, 239 \mathrm{Pu}, 24 \mathrm{i}_{\mathrm{Am}}$. (auth)

Rancon, D. 1973. The Behavior in Underground Environments of Uranium and Thorium Discharged by the Nuclear Industry. IN: Environmental Behavior of Radionuclides Released in the Nuclear Industry. IAEA-SM172/55. pp. 333-346. (in French).

Following various studies on the radioactive contamination of soil by fission products from a variety of effluents, it has been found necessary also to establish in what way long-lived heavy radionuclides could be diffused in underground environments. A proposal is made for the study of the behavior in the soil of uranium and throium originating from outside, as compared with the uranium and thorium existing as natural constituents of the soil. Use was made of various types of soil (acid and alkaline) and of various minerals (argillaceous minerals, calcite and yuartz). Uranium in solution, or uranyl ion to be more precise, has a certain degree of mobility in soils. The coefficient for the distribution of uranyl ion between the solution arid the mineral was measured at various concentrations. The influence of the $\mathrm{pH}$ of the soil-water solution is 
very considerable; the retention of uranium by the soil shows a marked increase within certain narrow $\mathrm{pH}$ ranges. Thorium is subject to high retention by argillaceous and calcareous soils, some of the latter strongly fixing the whole amount. The influence of various parameters ( $\mathrm{pH}$, concentration, soil composition) is also substantial, as retention can be very much reduced under certain extreme conditions. The risk of the spread of thorium in dilute solution over long distances is negligible in most soils. On the other hand, a certain degree of uranium diffusion under the influence of ground-water movements is to be anticipated; diffusion evaluations are presented. (auth)

Reichle, U. E., E. A. Bondietti and R. C. Dahlman. 1974. Plutonium Research and Applied Studie.s. ORNI -4935. pp. 61-65.

This is a new project this year, designed to explore the behavior of plutonium on mesic and humid environments of the eastern United States. Most existing knowledge on the environmental fate of plutonium has been derived from releases in sparsely populated arid environments. However, future uses of plutonium will occur in closer proximity to larger human populations and cultivated land. Intention to locate the first liquid metal fast breeder reactor (LMFBR) in the eastern United States (Tennessee), and locating a waste processing facility (Barnwell, South Carolina) in the Southeast, are examples of the expansion of plutonium facilities into new and different environments. Knowledge on plutonium behavior in these different environments will be needed because new sites of plutonium technology eventually will be located in mesic. subhumid reglons of the eastern United States. Physical characteristics of these environments and related biotic behavior are significantly different from those of arid regions. (auth)

Reisenauer, A. E. 1959. 216-Z-9 Core Sampling Data. HW-61787-RD. 6 p.

Four one-inch diameter core samples taken from the soil beneath the Hanford 216-Z-9 Recuplex waste storage crib at Hanford during 1959 were examined for $\mathrm{Pu}$ content to collect data to permit cvalluation of the life of the crib. Concentrations as high as $1.5 \mathrm{mg} \mathrm{Pu} / \mathrm{cm}^{3}$ of soil were found in une of the cores. Results of the analyses indicated that approximately $8 \mathrm{~kg}$ of the $13 \mathrm{~kg}$ of Pu disposed to this crib might be located within the upper few $\mathrm{cm}$ of soil beneath the crib. (NSA)

Relyea, J. F. and D. A. Brown. 1975. The Diffusion of Pu 238 in Aqueous and Soil Systems. Agronomy Abstracts, p. 124.

Movement of $\mathrm{Pu} 238$ in aqueous salt solutions and soil systems was studied by measuring the diffusion coefficients in both phases and the absorptiondesorption relationship between the phases. Aqueous diffusion coefficients were measured using the capillary tube technique. The diffusion coefficient in soils was determined by the quick-freeze method. Adsorption- 
desorption relations were studied by adding $\mathrm{Pu} 238$ as the nitrate of $5 \mathrm{ml}$ of $\mathrm{H}_{2} \mathrm{O}$ at a $\mathrm{pH}$ of 2.0 and allowing it to equilibrate with one gram of soil. The effectiveness of $\mathrm{Ca}$ and $\mathrm{Ce}$ in replacing $\mathrm{Pu} 238$ from the soil were subsequently studied. Aqueous diffusion coefficients of $\mathrm{Pu} 238$ were several times lower than the values found for exchangeable soil cations (order of $5 \times 10^{-6} \mathrm{~cm}^{2} / \mathrm{sec}$ ). The ratio of $\mathrm{Pu} 238$ adsorbed by the soil to that in the equilibrium solution was greater than 99.1. Diffusion of $\mathrm{Pu} 238$ in four different soils was also found to be much slower than for exchangeable soil cations as would be predicted from aqueous dif-. fusion and adsorption data. (auth)

Rhodes, D. W. 1952. Preliminary Studies of Plutonium Adsorption in Hanford Soi1. HW-24548.

Some preliminary studies of the adsorption of plutonium by soil indicate that at concentrations $<100,000 \mathrm{~d} / \mathrm{m} / \mathrm{ml}$ and a neutral or slightly acid $\mathrm{pH}$, plutonium is adsorbed very effectively (>99\%) from an aqueous solution. The greater portion of the plutonium is adsorbed almost instaneously and seems to be adsorbed just as effectively from a solution containing as much as $82 \mathrm{mg} / 1$ of salts as fróm distilled water. Plutonium is adsorbed must effectively by the soil constituents having a high specific surface and a high cation exchange capacity. The results in general indicate that an exchange reaction is probably the predominate mechanism involved in the removal of plutonium from solution by soil. (auth)

Rhodes, D. W. 1957. The Adsorption of Plutonium by Soil. Soil Science. $84: 465-471$.

The experimental data suggest the definite existence of a polymer or radiocolloid for tracer concentrations of plutonium in sollution at $\mathrm{pH}>2$ with the possible exception of the $\mathrm{pH}$ range 9 to 12. Apparently the polymer formed carries a positive charge that enables it to be taken up rapidly by the soil. The rather complex chemistry of plutonium suggests that the polymer probably has a compusition approximately that of a plutonium hydroxide al though the exact composition of the polymer undoubtedly changes as the conditions of the solution are changed. The desorption of plutonium from soil is difficult to accomplish with aqueous solutions of inorganic salts, but may be accomplished readily by solutions containing organic anions which complex the plutonium. (auth)

Rhodes, D. W. 1957. The Effect of $\mathrm{pH}$ on the Uptake of Radioactive Isotopes From Solution by a Soil. Soll Sctence Soc. of Aril. Proc. 21:389-392.

The reactions with natural earth materials of fission products and plutonium are of current interest in the field of atomic energy waste disposal and soil chemistry. Solutions containing less than $1 \times 10^{-9} \mathrm{mg}$ per 1 iter of selected radioisotopes were equilibrated with samples of a calcareous subsoil. The uptake of these radioactive isotopes by the soil was measured 
as a function of $\mathrm{pH}$. The uptake of $\mathrm{Cs}^{137}$ was not affected appreciably by varying the $\mathrm{pH}$ between 4 and 10 . The maximum uptake of $\mathrm{Sr}^{90}$ occurred at about $\mathrm{pH}$ lo and decreased rapjdly as the $\mathrm{pH}$ was lowered. The radioisotopes $\mathrm{Pu}^{239}, \mathrm{Ce}^{144}, \mathrm{Zr}^{95},-\mathrm{Nb}^{95}, \mathrm{Y}^{91}$ and $\mathrm{Ru}^{\mathrm{T}} 6 \mathrm{6}$ exhibited a maximum uptake between approximately $\mathrm{pH} 4$ and $\mathrm{pH} 8$. Above $\mathrm{pH} 8$ a region of reduced uptake occurred and persisted up to at least $\mathrm{pH} 11$ for most of the polyvalent radioisotopes. The addition of high concentrations of sodium salts to the solution inhibited the uptake of both $\mathrm{Cs}_{\mathrm{s}} 137$ and $\mathrm{Sr}^{90}$ by soil. A relatively small concentration of phosphate $(0.01 \mathrm{M})$ added to the system was found, in effect, to nullify the interference of sodium ion with the uptake of $S r^{90}$, but the phosphate ions had no apparent influence on the uptake of $\mathrm{Cs}$ Y37. (auth)

Reichert, S. 0. 1962. Disposal of Radioactive Wastes to the Ground at the Savanmah River Pldnt. TID-7628. Ground Disposal of Radioactive Wastes, pp. 462-468.

The complex consists of fuel preparation, five reactors, two radiochemical separations plants and a heavy water plant. The soil is sandy with cation exchange capacities of $0.1 \mathrm{meq} / 100 \mathrm{~g}$ soil at $\mathrm{pH} 5 \mathrm{and} 1.2 \mathrm{meq} / 100 \mathrm{~g}$ soil at $\mathrm{pH}$ 10. The high level waste is tanked. The ${ }^{90} \mathrm{Sr}$. the fastest traveling isotope with the exception of tritium and anions, is within 500 feet of seepage basins. (auth)

Richmond, C. R. and E. M. Sullivan. 1974. Annual Report of Biomedical and Environmental Research Program of the LASL Health Division, JanuaryDecember 1973. LA-5633-PR.

Characterization of Los Alamos canyon soils - Eroded soils contained 1-2\% silt and clay in top $2.5 \mathrm{~cm}, 3-4 \%$ silt and clay in remainder of profile with CEC $2-10 \mathrm{meq} / 100 \mathrm{~g}$. Noneroded soils conldined up to $54 \%$ silt and clay with CEC 11-21 meq/100 g. Huney bees call be used as $3 \mathrm{H}$ contamination indicators. Radiation Ecology Studies of Liquid Waste Disposal Sites $137 \mathrm{Cs}, 238,239 \mathrm{Pu}$ - Cs 137 in soils of discharge area-depth sampling-log normal djistribution. Radiation Ecology Studies at Trinity Site - $26 n$ $\mathrm{PCi} / \mathrm{g} 239 \mathrm{Pu}$ at $\mathrm{Gr}$. Zero. Pu has penetrated $7.5 \mathrm{~cm}$ into soil in 20 years. Hydrological Characterization of Soils at the Trinity Site.

Robertson, D. E., W. B. Silker, J. C. Langford, M. R. Petersen, and R. W. Perkins. 1973. Transport and Depletion of Radionuclides in the Columbia River. Part of Radioactive Contamination of the Marine Environment. Proceedings of Symposium held by IAEA., Seattle, WA, July 10-14, 1972. pp. 141-155.

The radionuclide transport and depletion processes in the Columbia River are being characterized following the closure of the last of the Hanford plutonium production reactors in January 1971. Radionuclide concentrations are periodically being measured in river water, sediments and biota between Hanford and Bonneville Dam to determine the rates and mechanisms of the 
processes which govern the distribution and behavior of the radionuclides in the Columbia River system. All the short-lived radionuclides in the river have now decayed, but some residual long-lived radionuclides have remained, being associated mainly with sedimentary deposits in the reservoir behind McNary Dam. . The most abundant radionuclides remaining in the river are Fe 55, Zn 65, Eu 155, Co 60, Eu 152, Eu 154, Mn 54, and Sc 46. Also present in much lower concentrations are Sb 125, Cs 137, Ce 144, and Pu 239. These radionuclides are tightly bound to the sediments and enter the river mainly by resuspension, expecially during the high river flow in the spring and early summer. The depth distributions of radionuclides in sediment cores collected at various locations in the reservoirs behind McNary, The Dalles, and Bonneville Dams are being measured to estimate radionuclide inventories, sediment resuspension and transport, and sedimentation rates in the river system. Because present concentrations of radionuclides in the river water are low, large volume water sampling (up to 1000 liters) is required and is being done at the four dam sites downstream from Hanford to determine radionuclide concentrations, physiochemical forms and transport in the river. Over $95 \%$ of the Columbia River radionuclides of Hanford origin which enter the river from bottom sediments are in particulate forms. The main mechanisms for removing radioactivity from the river system other than by radioactive decay, is by scouring of surface sediment during high river flow, and their subsequent transport into the Pacific Ocean. The dissolution of sediment attached Columbia River radionuclides upon their entry into the marine environment is being studied by leaching Columbia River sediments with seawater. Since the net sediment deposition rate in the reservoir behind McNary Dam has, in the past, been greater than the scouring rate, it appears that eventually the major radioactive sediment deposits in the McNary reservoir will become covered by new, uncontaminated silt deposits. (auth)

Robertson, D. E. 1974. Physiochemical Characterization of N-Reactor Effluent Radionuclides in Soil and Water Systems. BNWL-1950, Pt. 2, pp. 82-85.

The study of the fate of introduced chemical and particulate matter in freshwater ecosystems is fundamental to our understanding of the structure and function of these water bodies. These inputs can be in a variety of forms and need not be solely related to the movement of radioactive materials despite the inherent emphasis in our programs on these isotopes. Intrinsic to investigations of this nature is understanding not only where and in what quantities these materials appear in various ecosystem components, but also knowing what chemical, physical, and biological processes mediate their movement. Our studies in this field have emphasized the Columbia River and its associated ecosystems for several years, and work on the chemical characterization of reactor effluents before and after their passage through the soil before reaching the Columbia is continuing. Emphasis in this program, however, has shifted to more detailed studies of lentic habitats 
receiving low-level radioactive effluents. Our goal is to provide basic data on the cycling of radionuclides within these ponds which will be useful to both ecologists and waste management personnel. (auth)

Robinson, A. V., T. R. Garland, H. Drucker and R. E. Wildung. 1974. Plutonium-Resistant Fungi and Actinomycetes in Soil. II. Alteration of Plutonium Form. BNWL-1950, Pt. 2, pp. 21-30.

After several day incubation exocellular media analyzed by TLC, TLE to see if other than Pu DTPA present. Found a few as yet unidentified Pu compounds, possibly metabolites. (auth)

Rogers, V. C., G. M. Sandquist, J. Byrne. 1975. Leaching of Radioactive Materials at the Salt Lake City Uranium Mill Tailings Site. Transactions of the American Nuclear Society. 1975 Annual Meeting, June 9-13, 1975, New Orleans, LA. p. 94.

Core samples from the old Vitro Mill site at Salt Lake City show ${ }^{226_{R a}}$ and at least one of $i$ ts daughters have leached significantly to a depth of 5 feet. (auth)

Romney, E. M. and J. J. Davis. 1972. Ecological Aspects of Plutonium Dissemination in Terrestrial Environments. Health Physics. 22: 551-557.

The technology of plutonium production and processing is already established, but the realization of $i$ ts peaceful applications depends largely upon the development of methods for preventing its distribution in the environment. Because of safeguards and effective control measures, no accidental plutonium contamination of the public domain has imposed serious risks to a pupulation group. Irace amounts of plutonium from above-ground nuclear detonations are contained in world-wide fallout; however, the levels of plutonium in foodstuffs and other components of the environment are insignificant compared to the amounts known to be hazardous. There has thus been very little interest in the study of ecological aspects of plutonium contamination. The results is a paucity of information on the behavior of plutonium in ecosystems and its radiological effects on natural fauna and flora. The Nevada Applied Ecology Group is embarked upon a program at the Nevada Test Site to investigate the long-range effects of plutonium disseminated into the desert ecosystem. Emphasis has been placed upon standardization of analytical methods, delineation of contailinilled areas, problems of resuspension and redistribution, food chain transport and ecological effects. (auth) 
Romney, E. M., H. M. Mork, and K. H. Larson. 1970. Persistence of Plutonium in Soil, Plants, and Small Mammals. Health Physics 19:487-491.

Periodic surveys during a 10 year period were made of the persistence of residual $\mathrm{Pu} 239$ in soil, plants and small mammals indigenous to fallout areas contaminated with $\mathrm{Pu} 239$ dispersed by high explosive detonations. Downward migration of fallout particles occurred in undisturbed soil profiles, and wind and water erosion accounted for some redistribution of the initial Pu 239 contamination. Long-term cropping experiments showed a relatively low degree of Pu 239 transfer from soil to plants, but there was a consistent increase in its accumulation in plant tissue during a 5 year cropping sequence. Plant uptake of Pu 239 from soil was enhanced by DTPA chelating agent. Qualitative trends from these surveys indicate that the accumulation of residual Pu 239 in kangaroo rats and jackrabbits was highest in bone tissue; considerable amounts also were found in lung tissue. Inhalation is known to be the major pathway for plutonium deposition in lung and bone, but the high levels found in the gastrointestinal tracts indicate that ingestion is also an important route through which these small mammals maintained contact with the residual $\mathrm{Pu} 239$ contamination in the environment. (auth)

Romney, E. M., A. Wallace, R. 0. Gilbert, S. A. Bamberg, J. D. Childress, J. E. Kinnear and T. L. Ackerman. 1973. Some Ecological Attributes and Plutonium Contents of Perennial Vegetation in Area 13. UCLA-12-937. 19 p.

Progress is reported on work conducted at the Nevada Test Site under the auspices of the Nevada Applied Ecology Group, Office of Effects Evaluation, USAEC Nevada Operations Office, Las Vegas, Nevada. Included are data on some ecological attributes of the vegetation within the fenced portion of the Project 57 fallout pattern in Area 13. Also included are some preliminary data on the $239-240 \mathrm{Pu}$ and $241_{\mathrm{Am}}$ in samples of vegetation collected in conjunction with the soil sampling program. Prominent shrub and grass species in the fallout pattern of Area 13 include Artemisia spinescens, Atriplex canescens, Atriplex confertifolia, Eurotia lanata, Grayia spinosa, Kochia americana, Lycium andersonii, and Oryzopsis hymenoides. Individual or codominant species distinguished local association patterns of varied size within the fenced study area. Vegetation cover estimates in sample study plots ranged from 12.8 to 28.3 percent. Shrub densities ranged from $1.2 \times 10^{3}$ to $17.9 \times 10^{3}$ plants per hectare, and the standing shrub biomass ranged from 1592 to $4285 \mathrm{kilograms}$ per hectare $(0.7$ to 1.9 tons per acre). Preliminary results showed rather uniform distributions of 239-240 Pu and $241 \mathrm{Am}$ among individual samples of the same plant species collected within an intensive study plot. However, there was considerable variation in the contamination levels between different species, presumably from superficial entrapment of resuspended particulate material. Concentrations in Eurotia lanata were three to five times higher than in other species sampled from the same study site. The $239-240 \mathrm{Pu}$ and $241 \mathrm{Am}$ generally tended to decrease in samples of vegetation collected at increasing distances from ground zero, but there were poor correlations between vegetation 
and soil 239-240 Pu concentrations in isopleth strata with in the fenced grazing area. Results showed inconsistencies in the Pu/Am ratios for vegetation and soil. Lower ratios found in vegetation samples indicate that preferential uptake and concentration of $241_{A m}$ through plant roots might have occurred in the Project 57 fallout area. (auth)

Romney, E. M., A. Wallace, R. 0. Gilbert and J. E. Kinnear. 1975. 239-240Pu and ${ }^{24}$ Am Contamination of Vegetation in Aged Plutonium Fallout Areas. UCLA-12-986. 52 p.

Data are presented on the ${ }^{239-240} \mathrm{Pu}$ and ${ }^{241}$ Am contents of vegetation samples collected in conjunction with the soil sampling program in aged plutonium fallout areas on the Nevada Test Site (NTS) and the Tonopah Test Range (TTR). Radiochemical analyses indicate definite variations in the contamination levels from sample to sample collected within a given activity stratum. Variations also occur in the contamination levels on different plant species, which can bc attributed to differences in line dilluulls of resuspendable particulate material superficially entrapped upon plant foliage. In spite of these variations, there were some indications of reasonable agreement between the mean activity levels of $239-240 \mathrm{Pu}$ in vegetation and soil samples. (NSA)

Romney, E. M., A. Wallace, R. 0. Gilbert, and J. E. Kinnear. 239-240 Pu and 241 Am Contamination of Vegetation in Aged Fallout Areas. IAEA-SM-199/75.

Vegetation studies in aged plutonium fallout areas showed variations in the 239-240 Pu and 241 Am contamination levels attributable to differences in the amounts of resuspendable particulate material superficially entrapped upon plant foliage. There was reasonable agreement between the mean activity levels in vegetation and soil samples collected across different activity strata defined by FIDLER survey instrument within each fallout area. The ratio of vegetation $\mathrm{Pu}$ to soil $\mathrm{Pu}$ tended to increase moving out from higher to lower activity strata, which might reflect the increasing proportion of finer particulate material initially deposited in fallout debris at greater distance from ground zero. The Pu/Am ratio was reasonably constant for vegetation samples collected from a given fallout area. This ratio, however, varied among separate test event.s primarily as the result of differences in the ingrowth of $24{ }^{9}$ Am within the aged source materials. Inventory estimates indicate that standing vegetation contributes a rather in signiticant portion of the total contaminant remaining in these aged ralluut areas. (auth)

Routson, R. C. 1973. Review of Studies on Soil-Waste Relationships on the Hanford Reservation From 1944-1967. BNWL-1464.

Hanford chemical processing plants have been in operation for more than 20 years, and during this period have disposed large volumes of waste 
liquids to the Hanford sediments. Because the groundwater and sediments at this major nuclear facility have been closely monitored and investigated, a unique opportunity exists to assess the effects of these disposal practices on the Hanford soil environment. The literature regarding effects of the liquid waste disposal operations at Hanford on the soil environment is summarized. This summary is divided into studies pertaining to: the vadose zone below a depth of 20 feet (lower vadose zone); the saturated zone; and the vadose zone above 20 feet (upper vadose zone). The division is based upon the relative desirability of these three zones for nuclear waste disposal (storage). Liquid nuclear wastes have been safely discharged to the lower vadose zone for over 20 years. Migration of these wastes from the lower vadose zone by the mechanisms of diffusion, leaching, and particulate transport is discussed. It is concluded that little movement of sorbed radionuclides by the above mechanisms within ten half-lives of even the long-lived radionuclides occurs; the sorbed radionuclides can only be removed from this zone by a cataclysmic occurrence in which the sediment in the zone and the entrained wastes are both physically removed. Field studies show that essentially all of the long-lived radionuclides disposed to the ground have been sorbed and remain in the upper levels of the lower vadose zone. Radionuclides which normally need to be considered in waste disposal include ${ }^{90} \mathrm{Sr}, 137 \mathrm{Cs}, \mathrm{Pu}, 60 \mathrm{Co}$, $1066_{\mathrm{Ru}}$ transition metals, rare earths, and $3 \mathrm{H}$. In many wastes $90 \mathrm{Sr}$ is the radionuclide which limits ground disposal to Hanford sediments due to its long radioactive and biological half-lives and resulting low MPC. In sediments containing small amounts of mica, ${ }^{137} \mathrm{Cs}$ could become the limjting nuclide; however, $137 \mathrm{Cs}$ has a much shorter biological half-life than $90 \mathrm{Sr}$, and therefore, a higher MPC. Much of the sediment of the Hanford project has a moderate mica content and exhibits high $137 \mathrm{Cs}$ sorption. Due to the likelihood of $90 \mathrm{Sr}$ and $137 \mathrm{Cs}$ limiting the disposal of most wastes, a more detailed review of the sorption of these nuclides is included. (NSA)

Roytson, R. C., G. Jansen and A. V. Robinson. 1975. Sorption of ${ }^{99} \mathrm{TC}$, $23 \mathrm{~Np}$ and $24 \mathrm{Am}_{\mathrm{Am}}$ on Two Subsoils From Differing Weathering Intensity Areas. BNWL-1889. $15 \mathrm{p}$.

Distribution coefficients (Kd values) wereg getermined on subsoils from Washington and South Carolina for ${ }^{24} \mathrm{Am}_{\mathrm{Am}},{ }^{3}{ }_{\mathrm{Np}}$, and ${ }^{99} \mathrm{TC}$ as a function of equilibrium solution concentration of calcium $\left(\mathrm{Ca}^{+2}\right)$ and of sodium $\left(\mathrm{Na}^{+}\right)$. Kd values decreased in all cases with increasing solution concentrations of $\mathrm{Ca}^{+2}$ and $\mathrm{Na}^{+}$. For the South Carolina subsoil Kd values ranged from 1.0 to 67 for $241_{\mathrm{Am}}$ as a function $8 \mathrm{f}_{\mathrm{Ca}}+2,1.6$ to 280 for $241_{\mathrm{Am}}$ as a function of $\mathrm{Na}^{+}, 0.43$ to 0.66 for $237 \mathrm{~Np}$ as a function of $\mathrm{Ca}^{+2}$, and 0.16 to 0.25 for $237_{\mathrm{Np}}$ as a function of $\mathrm{Na}^{-1}$. For the Washington soll kd values were greater than 1200 for $241_{A m}$ and ranged from 0.36 to 2.37 as a function of $\mathrm{Ca}^{+2}$ and from 3.19 to 3.90 for $237 \mathrm{~Np}$ as a function of $\mathrm{Na}^{+}$. Kd values for ${ }^{99} \mathrm{Tc}$ were essentially 0 at all $\mathrm{NaHCO}_{3}$ concentrations on the South Carolina subsoil. (auth) 
Rosse11, T. C. and J. B. Andelman. 1971. Plutonium in the Water Environment. II. Sorption of Aqueous Plutonium on Silica Surfaces. Advances in Chemistry Series 106:280-298.

The sorption and desorption and aqueous plutonium in the range of $10^{-7}$ to $10^{-8} \mathrm{M}$ was studied on quartz and other silica surfaces. Sorption continued typically for 12 to 15 days before apparent equilibrium was reached, and the distribution of plutonium particle sizes sorbed on the silica was different from that in solution. At pH 7, sorption increased with increasing ionic strength, but decreased when bicarbonate was added. The amount of sorption varied at pH 5 and 7 , but differently at high and low ionic strengths, as well as with the age of the solution. Plutonium desorption indicated that there were two basically different sorbed species, and the rate and quantity of desorbed material increased at pH 5 compared with 7 and 9.' (auth)

Rudolph, A. W., T. E. Carrull and R. S. Davidson. Iy/. Plutonium and Its Effects in the Environment. TID-26130.

Approximately 325 references on effects of $\mathrm{Pu}$ on the environment with emphasis on man are given to journals, reports, and conferences for the period 1948 through 1971. Separate author, subject, and report number indexes are included. (NSA)

Saas, A. 1973. Contamination of Soils by Industrial Radioactive Wastes, Mechanisms and Factors of Migration and Evaluation. Sci. Soi1. No. 4: 255-64.

A number of examples are given illustrating the investigations on soil prutecliun carried out by the laboratory of continental radioecolog.y. The techntques of soil and radionuclide migration are first reviewed: the main trends of investigations are then developed: role of the radionuclide vector in the soils, influence of the mode of entry of the radionuclide in the biological cycles, influence of some specific soils compounds, in particular organic matter. The aim of these applied investigations is to demonstrate the main mechanisms involved in the transfer of radionuclides to the soils and their uptake by plants. (NSA)

Sacket, W. M., T. Mo, R. F.Spaling, and M. E. Exner. 1973. A Revaluation of the Marine Geochemistry of Uranium. 1N: Radioactive Contamination of the Marine Environment. IAEA-SM-158/5T

Approximately $10^{15} \mu \mathrm{g} / \mathrm{yr}$ of dissolved uranium are being removed from the ocean by each of the generally accepted significant sinks for uraniumcarbonate deposits and deep anoxic basin sediments. However, these sinks account for only $10 \%$ of the estimated present-day input of uranium. Possible explanations for this discrepancy are: (1) contemporary input values 
are too high owing to a significant contribution from man's effects, such as uranium input via phosphate fertilizers or world-wide cultivation leading to premature leaching of uranium from soils, or (2) there are other important uranium sinks such as the abundant siliceous oozes or continental shelf anoxic sediments. (auth)

Sakanoue, M., M. Nakaura, and T. Imai. 1971. Determination of Plutonium in Envi ronmental Samples. CONF-710705, IAEA-SM-148/54:171-181.

Instead of the time-consuming method using ion-exchange resins separation, a simple solvent extraction method for determing plutonium in environmental samples has been developed and applied for various samples, for example, soil from the Nagasaki area subjected to the first plutonium atomic bomb explosion in 1945, corals from the east Pacific Ocean coast, and seawater from the Pacific Ocean. As yield tracer, the alpha emitter Pu 236 (5.75 $\mathrm{MeV}$ ) was first spiked into the sample, and the sample solution was prepared in $8 M$ nitric solution either by direct leaching of the sample with nitric acid or by dissolving the ferric hydroxide precipitate made from the acidic solution of solid samples or natural water. Solvent extraction with tri-oxtylamine was applied to this aqueous solution and followed by the scrubbing of uranium and thorium with $8 \mathrm{M} \mathrm{HNO}_{3}$ and $10 \mathrm{M} \mathrm{HCl}$, respectively. Finally, plutonium was stripped with $8 \mathrm{M} \mathrm{HCl}+0.2 \mathrm{M} \mathrm{HF}$, and determined by alpha spectrometry using a counting source prepared by electrode position on either a stainless steel plate or nickel foil. In addition to a gross alpha-track counting on cellulose nitrate, the very sensitive fission track method was also examined for determining $\mathrm{Pu} 239$ and the evaluation of the interference from the contaminating uranium was studied. Contamination of the natural environment with plutonium isotopes was found in various samples and the contents of each isotope were determined. (auth)

Sakanoue, M., and T. Tsuji: 1971. Plutonium Content of Soil at Nagasaki. Nature 234:92-93.

Determination of the plutonium content of the soil at Nagasaki, Japan, was made 24 years after the detonation of the atomic bomb. Samples were taken from less disturbed surfaces of the ground, and assays were made for $\mathrm{Pu} 238$, $\mathrm{Pu} 239$, and Sr 90. Powdered dry soil samples were treated with 8M nitric acid after adding Pu 236 tracer. Ferric hydroxide coprecipitation was then indiced from this sample solution in the presence of carbonate ions, and dissolved in $8 \mathrm{M}$ nitric acid and extraction of the solvent with tricylamine. The plutonium content was ten times higher at the Nishiyama location than at other areas tested although the strontium level was comparable. Results indicate that plutonium contaminants in soil are not easily removed naturally. (auth) 
Shel1, W. R. and R. L. Watters. 1974. Plutonium in Aqueous Systems. RLO-2225-T18-11. $26 \mathrm{p}$.

A review was made of the available information concerning Pu in the aquatic environment. The levels are low and the data on the environmental concentrations in lake and marine environments are very limited. of particular relevance to biological accumulation processes is the physical-chemical state of Pu. Limited information is available in natural environmental waters. Indications are that the plankton has the highest concentration factors and that the concentration factors decrease with increasing complexity of the organisms. Results of recent studies of $239 \mathrm{Pu}, 240 \mathrm{Pu}$, and ${ }^{24} 1_{A m}$ concentrations in water, sediment, and biota at Bikini and Eniwetok Atolls are given. The water samples measured indicate that $\mathrm{Pu}$ exists in the particulate, soluble and colloidal physical-chemical states. The plutonium is being injected into the water column from the sediments and has not been removed from the biogeochemical cycle after 16 years. Concentrations of $\mathrm{Pu}$ in vertebrates and invertebrates measured at Eniwetok were low and ranged from 0.001 to $0.2 \mathrm{pCj} / \mathrm{g}$ wet in fish muscle. Additional data are required to better evaluate the potential hazards to man of $\mathrm{Pu}$ in the aquatic environment. A computer program was developed to estimate the final forms of soluble $\mathrm{Pu}$ in natural waters under certain conditions of acidity, oxidation potential, and complexing factors. (NSA)

Schmalz, B. L. 1972. Radionuclide Distribution in Soil Mantle of the Lithosphere as a Consequence of Waste Disposal at the National Reactor Testing Station. ID0-10049, pp. 27-55.

The movement of Pu wastes from Rocky Flats, buried as solids, was monitored via bore holes in the burial grounds. From lab tests, the diffusion coefficient of plutonium was estimated as $4.8 \times 10^{-12} \mathrm{~cm}^{2} / \mathrm{sec}$, resulting in movement of $8.5 \mathrm{~cm}$ in $2.4 \times 10^{5}$ years. However, $\mathrm{Pu}$ and $\mathrm{Am}$ have been leached from the wastes under saturated conditions and deposited in pit soil lining. The study concluded that moisture movement was the principle transport factor and any action inhibiting water entry to the contaminated zone would be desirable. (auth)

Schneider, H. and W. Block. 1968. On the Question of the Capacity of the Rhine for Radioactive Nuclides. Sorption of Radionuclides by Sediments of the Rhine. Gas Wasserfach. 109:1410-15. (in German).

For estimation of the action of decontaminating sediments and suspcinded material in rivers charged with radionuclides, the sorbability of deposits of the Rhine for several nuclides was determined; the sorbability increases in the following order: $I^{-}, \operatorname{Sr}($ II), Pu(IV), $\mathrm{Zn}(\mathrm{II}), \mathrm{Cs}$ (I). Saturation was reached by sediments after 24 hours at the latest for all nuclides. The sediment samples were taken from Oehningen (Upper Rhine), Koblenz (Middle Rhine), and Wesel (Lower Rhine). Data were compared with the organic content for each sample. The sorption of ${ }^{37} \mathrm{Cs}$ is dependent on grain size but not on organic material. A sudden release by living or 
dead organic material of radionuclides is not possible, though desorption from mineral suspended material is more rapid, often occurring within a few hours. Less than $1 \%$ of transported nuclides in the Rhine under any conceivable conditions would be bound to suspended material or sediments. (NSA)

Schneider, P. 1974. Radionuclide Content of Vegetation and Soil on an Integrated Nuclear Complex. DP-MS-75-65. 6 p.

Samples of soil and vegetation collected at the Savannah River Plant in July 1974 were analyzed for plutonium, using different procedures. The method of choice for soil analysis involved a leach procedure followed by separation using an ion exchange column. The elute was finally adjusted to the proper $\mathrm{pH}$ and electroplated to platinum. Counting was done on a solid state alpha spectrometer to resolve $236 \mathrm{Pu}, 238 \mathrm{Pu}$, and $239-240 \mathrm{Pu}$. An internal spike of $236 \mathrm{pu}$ is used to calculate percent recovery. The method of plutonium analysis for vegetation involved dissolution of the ashed plant material and then double separation. The first separation was with TIOA-xylene, and the second used $\mathrm{HCl}$. The organic residue was then destroyed using nitric acid and hydrogen peroxide. Finally, the solution was mounted on a planchet and counted in an alpha spectrometer. Data are included on the content of $137 \mathrm{Cs}$ and $90 \mathrm{Sr}$ in the samples. (NSA)

Schuettelkopf, H. 1974. Environmental Surveillance for Plutonium at the Karlsruhe Nuclear Research Center From 1969 Until 1973. Environmental Surveillance Around Nuclear Installations. Vol. II. Vienna, IAEA. pp. 327-344.

Several nuclear research reactors, a fuel reprocessing plant, an incinerator for radioactive burnable waste and a laboratory for $238 \mathrm{Pu}$ production have been operated on the site of the Karlsruhe Nuclear Research Center, and several institutes there have been concerned with research on transuranium elements. The necessary surveillance of the environment is carried out by analys is for plutonium in plants, precipitation, sediment, plankton and special materials. Nearly 100 samples are collected and arlalyzed each year. The objectives and structure of the surveillance program are described. The analytical results of the last 4 years are reported. The results of environmental surveillance performed with plants and precipitation, and the different annual variations of plutonium concentrations in these sample materials are compared. The effectiveness of the surveillance system is discussed critically, taking as an example some unplanned releases of plutonium to the environment. (auth)

Schulz, R. K., G. A. Tompkins, and K. L. Babcock. 1974. Uptake of Plutonium and Americium by Plants From Soils. UCB-34-P-211-1. 
As part of a research project to study the uptake of plutonium and americium by plants from soils, five California agricultural soils were collected and analyzed as to $\mathrm{pH}$, parent material, and organic matter content. Two soils contaminated with plutonium and americium and two paired control soils were collected from the Nevada Test Site. A method was developed which allowed uniform blending of the nuclide being studied with the experimental soil. Future studies will concentrate on plant uptake from previously contaminated soils and from soils where the nuclide has been added in various chemical forms. Particle analysis of the $\mathrm{Pu} 239$ particles contained in Nevada Test Site soils will also be carried out. (NSA)

Schultz, R. K., G. A. Tompkins and K. L. Babcock. 1974. Uptake nf Plutonium and Americium by Plants From Soils: Uptake by Wheat From Various Soils and Effects of Oxidation State of Plutonium Adrent to S.i1. IAEA-SM-199/92: (UCB-34-P-211-1)

The uptake of $239,240 \mathrm{Pu}$ and ${ }^{241} \mathrm{Am}$ by wheat (Triticum aestivum L.) from three California soils was studied. A forest soil (slightly acid), a fertile alluvial soil (neutral) and a calcareous soil (alkaline) were used. Prior to the uptake studies the Pu was added to the soils in the $\mathrm{Pu}^{3+}$ state in chloride solution and also as the disproprotionate $\mathrm{Pu}^{3+}$, $\mathrm{Pu}^{4+}, \mathrm{Pu}^{5+}, \mathrm{Pu}^{6+}$ in nitrate solution. Americium was added as $\mathrm{AmCl}_{3}$ or $\mathrm{Am}\left(\mathrm{NO}_{3}\right)_{3}$ solutions. The highest concentration of $\mathrm{Pu}$ in the wheat grain was found when Pu was added as nitrate to the alkaline, calcareous soil. The greatest concentration of Am in the grain was found when Am was added as the chloride to a neutral soil. The plutonium distribution ratios (D.R. = $\frac{\text { nuclide concentration in plant, dpm/g of air dry plant material }}{\text { nuclide concentration in soil, } \mathrm{dpm} / \mathrm{g} \text { of air dry soil }}$ for the grain ranged from $4.4 \times 10^{-8}$ to $3.8 \times 10^{-6}$ and the americium D.R.'s ranged from $2.6 \times 10^{-7}$ to $3.0 \times 10^{-5}$. (auth)

Sedlet, J. and F. S. Iwami. 1965. Environmental Radioactivity at Argonne National Laboratory Report for 1962 and 1963. ANI-6945.

This report presents the results of the environmental monitoring program at Argonne National Laboratory during 1962 and 1963. The purposes of the program are to measure the natural radioactive content of the ANL site and its surroundings, and to determine the origin, identity, and magnitude of any radioactivity not naturally present. Of primary interest is the detection of radioactive materials released to the environment as a result of Argonne nperations. (auth)

Sehme1, G. A. and F. D. Lloyd. 1974. Resuspension of Plutonium at Rocky Flats. BNWL-SA-5085 (CONF-740921-11). 39 p.

In a July 1973 field experiment at Rocky Flats, vertical airborne plutonium concentrations were determined as a function of respirable particle size. 
The principal sampling site was a 100-ft meteorological tower which was instrumented at several heights with self-orienting, high volume cascade impactor-cowl systems. Wind speed instrumentation activated selected impactors as a function of wind speed. Airborne plutonium concentrations and concentrations on airborne soil were measured as a function of both height and wind speed. Below $10 \mathrm{~m}$ concentrations decreased with height. Above this height to $30 \mathrm{~m}$, an increase suggested that an elevated upwind source could be contributing. The maximum airborne concentration measured was $3.7 \times 10^{-15} \mathrm{Ci} / \mathrm{m}^{3}$. The maximum concentration per gram of gross airborne soil was $50 \mathrm{pCi} / \mathrm{g}$. Somewhat higher concentration was found on the 2 um airborne soil fraction. All concentrations were significantly less than maximum permissible concentrations. (auth)

Sehme 1, G. A. and F. D. Lloyd. 1974. Resuspension by Wind at Rocky Flats. BNWL-1850 (Pt. 3), pp. 204-211.

A field experiment at Rocky Flats was conducted to initially determine plutonium air concentration dependency on wind speed and sampling height and to determine the respirable particle size distribution and subsequently to determine plutonium resuspension rates from ground source samples concurrently collected by HASL. Radiochemical plutonium analyses for filter samples are awaited from DOW at Rocky Flats. Airborne soil size distributions indicate that airborne concentrations of respirable soil particles increase proportionately with the wind speed to the 4 th to 6 th power. (auth)

Sigler, W. F. 1966. Effects of Uranium Mi11 Wastes on Stream Biota. Agr. Exp. Sta., Bul1. 462, 76.

Waste waters from uranium mills contain radioactive substances. In the Animas river the radium activity was found to be 5 to 9 times above background in the water and up to 25 times the background level in the bottom deposits. Tissues of fish collected from the river contained 10 to 15 times the background levels of radium 226. Studies in the summer of 1958 showed complete absence of bottom tauna below the mill, and this pollution effect extended for 50 miles downstream. The amount of radium in the water and in the biota of the San Miquel and Dolores rivers was even higher than in the Animas river. It is stressed that waste waters from uranium mills should receive adequate treatment before discharge to prevent such pollution. (auth)

Sill, C. W. 1971. The Particle Problem as Related to Sample Inhomogeneity. La-4/56. IN: Fowler, E. B., R. W. Henierson, and M. P. Milligan (cochairmen). Proceedings of Environmental Plutonium Symposium Held at Los Alamos Scientific Laboratory, Los Alamos, New Mexico, August 4-5: 81-83. 
The effect of the specific activity of single particles of various sizes on the comparative homogeneity of plutonium distribution in soil samples is discussed. Information is presented on the relative efficiency of leaching procedures versus total sample decomposition as a function of particle size and origin. (auth)

Sill, J.W. and F. W. Hindman. 1974. Preparation and Testing of Standard Soils Containing known Quantities of Radionuclides. Anal. Chem. 46:1: 113-118.

A general procedure for preparation of standard soils containing a known quantity of any given radionuclide is described. Four separate standards have been prepared from three different soils using plutonium 239 to demonstrate the reproducibility and reliability of the procedure. Extensive analyses using plutonium 236 tracer show that the standards contain the exact concentration calculated to have been added that they are not detectably inhomogeneous on samples as small as 1 gram, and that homogeneous standards of lower concentrations can be prepared exactly by weight dilutions with the unspiked soils. Of a total of 56 determinations made on 1- and 10-gram aliquots of the four individually spiked standards and two others made by dilution, only four determinations showed distinct signs of inhomogeneity with the particular method of preparation and sample size employed. Of the remaining 52 measurements, all agree with the calculated value within three standard deviations of the determination, and 42 were within two standard deviations. The dramatic effect of heat treatment on the leachability of the plutonium is demonstrated. Also, an alternative method for preparation of solid standards for members of the natural uranium and thorium series is suggested. (auth)

S1lver, W. J., C. L. Lindeken, J. W. Meadows, W. H. Hutchin and D. R. McIntyre. 19\%. Environmental Levels of Radioactivity in the Vicinity of the Lawrence Livermore Laboratory. UCRL-51547. 49 p.

The Lawrence Livermore Laboratory continuously monitors the levels of radioactivity within the Livermore Valley and Site 300 . Results of analyses performed during 1973 for gross radioactivity and for specific radionuclides of interest in a variety of environmental samples are presented. In all cases, the levels of activity observed during 1973 were found to be below the appropriate concentration guide values of AEC Manual Chapter 0524. Particulate air filters showed gross beta activities lower than those observed during 1972, reflecting a reduction in global fallout in the atmosphere. Gamma spectral measurements on Laboratory perimeter air filters also showed lower activities of global fallout gamma emitters. These perimeter air samples were analyzed for $239 \mathrm{Pu}, 238 \mathrm{Pu}$, ${ }^{90} \mathrm{Sr}$, ${ }^{335} \mathrm{U}$, and $238 \mathrm{U}$. With the exception of one sampling location, the annual average $239 \mathrm{Pu}$ concentration was $1.3 \times 10^{-17} \mu \mathrm{Ci} / \mathrm{ml}$, typical of global fallout. Air samples taken within Site 300 were analyzed for uranium. These analyses showed a lower than normal ratio of $235 \mathrm{U} / 238 \mathrm{U}$. 
This is due to "depleted" uranium (uranium which is specially processed to lower the ${ }^{235} \mathrm{U}$ content) used at the Site. Airborne uranium concentrations were well below the standards set by the AEC. Soil samples collected in the off-site vicinity of LLL perimeter boundaries and at Site 300 were analyzed for plutonium, uranium, and gamma emitting radionuclides. Traces of plutonium above global background levels were detected in two off-site samples near the east perimeter of the laboratory. Sediment samples collected in surface drainage pathways from LLL showed that the plutonium in these sediments was in the same range observed in soil samples indicate depleted levels of $235 \mathrm{U}$ near firing bunkers, but $235 \mathrm{U} / 238 \mathrm{U}$ ratios approach that of natural uranium at site perimeters. These data indicate no apparent change from that observed in 1972. Water samples collected with in the Livermore Valley exhibited normal background gross beta and tritium activities. Gamma spectral analyses of vegetation samples revealed no gamma-emitting radionuclides other than those present naturally or in global fallout. The vegetation samples collected in areas generally downwind from the Livermore Laboratory revealed tritium activities 10 to 100 times higher than those collected in areas where the Laboratory's contribution should be minimal. However, if the vegetation were a regular part of one's diet, the annual whole body radiation dose from tritium would be less than $1 \mathrm{mrem}$. The off-site radiation exposure rates measured by thermoluminescent dosimeters were in the range to be expected from the naturally occurring radionuclides in the soil and from local cosmic radiation. Assessment of the radiation doses to an individual from the observed environmental activities listed indicates the contribution from artificially produced radionuclides is small in comparison with the approximately 100 $\mathrm{mrem} / \mathrm{y}$ dose received from natural sources. (auth)

Smith, A. E., Compiler. 1973. Nuclear Reactivity Evaluations of 216-Z-9 Enclosed Trench. ARH-2915.

Plutonium accumulation and the nuclear criticality implications were evaluated for a subsurface liquid waste disposal site at Hanford, Washington. Remote plutonium detection by infrared, gamma, and neutron surveys are described. Geological drilling and soil sampling techniques were developed and described. Nuclear criticality safety was evaluated by computer model calculations and by neutron pulsing techniques. This study discusses technologies used to evaluate a waste disposal site for a plutonium recovery operations. (auth)

Smith, A. E., D. J. Brown and R. E. Isaacson. 1974. Chemical Behavior and Ground Movement of Selected Radionuclides. Nuclear Tech. 24:444-446.

Waste management practices at Hanford are based on 30 years of experience and special studies. Aqueous high-level wastes are being converted to salt cakes in underground tanks to reduce the potential for loss of liquid high-level radioactive waste due to tank failure. If wastes enter the ground they are sorbed in the Hanford sediments and become 
fixed in place by natural processes. Water from the equivalent of a thousand years of rainfall in one deluge is not likely to move the radioactive materials such as plutonium, strontium, and cesium to the water table. (auth)

Sotobayaşhj, T., T. Suzuki, and S. Koyama. 1967. Geochemical Fractionation of $239 \mathrm{~Np}$ in Fresh Nuclear Debris Through the Atmosphere. Bull. Chem. Soc. Jap. 40:1555.

Highly fractionated fission products, detected within 36 hours after the third Chinese nuclear test, were enriched with refractory fission products 977r, $99 \mathrm{Mn}$, and $143 \mathrm{Ce}$ and depleted in $132 \mathrm{Te}$ and $133_{\mathrm{I}}$. Most of the particles were depleted in $239 \mathrm{~Np}$, but some were markedly rich in $239 \mathrm{~Np}$ with no detectable amount of $132 \mathrm{Te}$ and $133 \mathrm{I}$. The $239 \mathrm{~Np}$ seemed to behave refractorily in surface bursts. Data suggest that gravitational and meteorological forces and differences in size and density cause particle separation in an atomic cloud. Observations show fractionation behavior of ${ }^{2} 39 \mathrm{~Np}$ to be modified and that particle separation takes place in 1.5 days travel in the cloud. (NSA)

Spalding, R. F. and W. M. Sackett. 1972. Uranium in Runoff From the Gulf of Mexico Distributive Province: Anomalous Concentrations. Science. $175: 629-31$.

Uranium concentrations in North American rivers are higher than those reported 20 years ago. The increase is attributed to applications to agricultural land of larger amounts of phosphate fertilizer containing appreciable concentrations of uranium. Experiments showing a constant phosphorus-uranium ratio for various types of fertilizers and for the easily solubilized fraction of 0-46-0 fertilizers support this view. (auth)

Spitsyn, V. I. and V. D. Balukova. 1972. Study of the Interaction of Wastes With the Geological Material Subsurface Depositories and Development of Methods of Hreparation of Wastes for Disposal. ORNL-tr-2789. 8 p.

The process of liquid radioactive waste disposal into porous water-bearing layers of deep formations is accompanied by a series of physicochemical processes in the geological environment of the storage site. An evaluation of such processes and their consequences should be perfurmed parallel to the hydrogeological studies of the geological depositories. An entire series of studies necessary for a direct characterization of the material of the layer are described. Factors determining the basic conditions of compatibility of the liquid wastes with the geological material are also considered. A series of methodical measures of experimental practice for the determination of the limits of compatibility of the stratal water and the wastes is described. Data on such determinations for a wide range of concentrations of various components of the waste materials are given for 
various levels of mineralization of the stratal water. On the basis of an analysis of the liquid radioactive wastes, as well as an examination of the properties, and behavior of individual components, the development of technological measures for the preparation of the wastes and their disposal into the formation by means of boreholes is presented. For individual conditions, the most advisable and suitable measures of chemical treatment of the operating zones of the boreholes are described from the standpoint of maximum increase of their acceptability. (auth)

Spitsyn, V. I., V. D. Balukova, V. V. Gromov, S. I. Zakharov, B. P. Zhagin and F. M. Spiridonov. 1959. Sorption Regularities in Behavior of FissionProduct Elements During Filtration of Their Solutions Through Ground. IN: Disposal of Radioactive Wastes. Conf. Proc. 2:421-34.

Research on the sorption of radioisotopes under natural conditions employing the controlled filtration process was performed. Radioisotopes were introduced into the solution as soon as filtration had become steady and the process continued for 4 months. Soil samples were taken by drilling at different depths and analyzed to determine their radioisotope content. Diffusion of radioisotopes was observed at depths of $10 \mathrm{~m}$, two distinct boundaries of soil-activity decrease were ascertained: at the surface of the site and at the depth of the solution filtration front. The radiostrontium absorption by natural sorbents, principally pure minerals widely distributed in soils and subsoils, was investigated separately. The presence of calcium ions, even in small quantities, sharply reduces the degree of radiostrontium sorption. Other conditions being equal, strontium may be absorbed to a greater extent than calcium, according to the composition of the sorbent. The field investigations of radiostrontium sorption and migration showed that when filtering radioactive solutions two possible variants have to be considered. In the first case the solutions are discharged into soil unaffected by any flow of ground water. In this situation the radiostrontium is retained by the soil. In the second case, the radioisotopes proceed directly into the water-bearing horizon. The radiostrontium will then migrate with the ground water flow and through the soil and this migration will be further affected by the sorption and desorption processes occurring. The experiments performed demonstrate the ease with which long-lived radioisotopes migrate under natural conditions and call attention to the need for thorough study of ground water problems in connection with various methods of disposing of radioactive waste into ground. (auth)

Swanson, J. L. 1973. Nature of Actinide Species Retained by Sedimerits at Hanford: Interim Progress Report. BNWL-B-296.

A program to develop leach procedures appropriate to characterizing the behavior of different actinide species retained by soils is in progress. Characterization of the $\mathrm{Pu}$ species present in samples taken from the 216-2-9 trench has been made more difficult by the presence in these 
samples of materials which form only sparingly soluble $\mathrm{Pu}$ compounds. Because of the presence of these materials, in some cases the leaching of the $\mathrm{Pu}$ is more a function of the solubility of $\mathrm{Pu}$ in the leach solution than it is a function of the Pu species present in the soil. Pretreatments of the soil samples with alcohol, with hydroxide solutions, and with TBP solutions have been found to give at least partial removal if these $\mathrm{Pu}$ solutility-limiting materials. The percentage of the $\mathrm{Pu}$ that dissolved readily in $5 \mathrm{M} \mathrm{HNO}_{3}$ at room temperature (using repeated solution changes to minimize the effect of the Pu solubility-limiting materials) was found to range from 3 to $90 \%$ depending on sample location and depth. The higher removal percentages were achieved with the deeper portions of the samples. Data on the amounts of actinides, water, and organophosphates present in the 216-Z-9 trench samples used in this work. are included in the Appendix. The $\mathrm{Pu}$ content was found to range from $0.06 \mathrm{mg} \mathrm{Fu} / \mathrm{g}$ soil near the 24-1nch level to $10 \mathrm{mg} \mathrm{Pu} / \mathrm{g}$ soil in the surface portion of one of the samples; the water content was found to range from 4 to $33 \%$ and the organophosphate content ranged up to $1.4 \%$. (auth)

Tamura, T. 1975. Characterization of Plutonium in Surface Soils From Area 13 of the Nevada Test Site. IN: White, M. G. and P. B. Dunaway (eds.). The Radioecology of Plutonium and 0ther Transuranics in Desert Envi ronments. NVO-153 (UC-2):27-41.

Total plutonium was determined in nine surface soil samples $(0-5 \mathrm{~cm})$ from Area 13 in the Nevada Test Site (NTS). Particle size segregation was performed, and each particle size fraction of seven samples was analyzed for plutonium. The coarse silt fraction [53-20 micrometers $(\mu \mathrm{m})$ ] contained the highest percentage of plutonium in the soil (about $65 \%)$. Evidence of erosional translocation of plutonium was observed in one sample and corroborative evidence was noted in describing the soil type. Tests with 8 molar (M) nitric acid showed that about $13 \%$ of the plutonium was leached from the NTS sample, about $70 \%$ from sediments at 0ak Ridge, and about $83 \%$ from sediments at Mound Laboratory. In $0.1 \mathrm{M}$ citric acid, about $1 \%$ of the plutonium was extracted from an NTS sample, $25 \%$ from Oak Ridge samples, and $44 \%$ from Mound. Implicat1ons of these results on transport of plutonium within the NTS are discussed. (auth)

Tamura, T. 1974. Distribution and Characterization of Plutonium in Soils from Nevada Test Site. IN: Dunaway, P. B. and M.G. White (eds.). The Dynamics of Plutonium in Desert Envirummerls. NVO-142 (NVO-AEIC-14-I or Uc-2):29-42.

This study was undertaken to determine the distribution and characterization of plutonium in soil fractions of the Nevada Applied Ecology Group (NAEG) intensive site study ared samples. This report discusses analytical results obtained on three selected surface soil samples from two areas at Nevada Test Site. Analytical methods are described for determination of 
total plutonium content, plutonium distribution in different particle size fractions, and short-time digestion leachability by $\mathrm{HNO}_{3}$ revealed that 65 to $91 \%$ of the plutonium could be leached. The leaching rcsults suggest the possibility of using the acid extraction as a means of predicting the "availability" of plutonium in soils. Preliminary data suggest that plutonium in the coarser size fractions is $\mathrm{PuO}_{2}$, whereas plutonium associated with the finer size particles possibiy is a hydrous $\mathrm{PuO}_{2}$. (auth)

Tamura, T. 1975 Physical and Chemical Characteristics of Plutonium in Existing Contaminated Soils and Sediments. IAEA-SM-199/52.

Plutonium from three sites has been studied to provide information necessary in understanding its behavior and fate under prevailing conditions. Plutonium in soils from the Nevada Test Site (NTS) was predominantly associated $(50-75 \%)$ with the coarse silt $(53-20 \mu \mathrm{m})$ fraction. The coarse silt fraction was further segregated by density gradient zonal centrifugation; the plutonium in the sample from a bare soil range from $60-85 \%$ in the "heavy" mineral fraction $\left(>2.9 \mathrm{~g} / \mathrm{cm}^{3}\right)$ suggesting the presence of oxide forms. The plutonium in a sandy mound taken beneath shrybbery occurred predominantly $(80-95 \%)$ in a lighter fraction $\left(2.5-2.7 \mathrm{~g} / \mathrm{cm}^{3}\right)$ associated with feldspar. Soil extraction of NTS plutonium with $0.1 \mathrm{M}$ citric acid solution showed very low solubility $(\approx l \%)$. The plutonium in samples from Oak Ridge National Laboratory (ORNL) and Mount Laboratory (ML) was predominantly in the clay size $(<2 \mu \mathrm{m})$. The solubility in citric acid was about $20-25 \%$ in the ORNL sample and $40-50 \%$ in the ML sample. Density gradient segregation of the clay size fraction of the ML sample showed the activity distribution to be directly related to the weight of the recovered fraction with enhanced contribution by the very light organic fraction. Approximately $71 \%$ was found in the $2.3-2.4 \mathrm{~g} / \mathrm{cm}^{3}$ fraction which contained $65 \%$ weight percent of the clay and $16 \%$ in the $1.8 \mathrm{~g} / \mathrm{cm}^{3}$ fraction (organic fraction) which contained $6 \%$ of the weight fraction. (auth)

Tamura, T., E. R. Eastwood and 0. M. Sealand. 1972. Applied Soils and Waste Management Studies. IN: Environmental Sciences Division Annual Progress Report Ending September 30, 1972, ORNL-4848. pp. 49-51.

A recovery technique for $\mathrm{Pu}$ is outlined. Total extraction was accomplished from $\mathrm{Pu}$ contaminated soil by use of $\mathrm{HNO}_{3}-\mathrm{HF}-\mathrm{HCl}$, ferric hydroxide and anion exchange purification and electrodeposition. Only about $12 \%$ of the $\mathrm{Pu}$ was extracted by a 2-hour digestion with $8 \mathrm{MHNO}_{3}$. Eventual goal is to characterize the Pu-soil relationship and migration. (auth)

Taylor, C. I. (ed.). 1975. Environmental Sciences Division, Annual Progress Report for Period Ending September 30, 1974. ORNL-5016 (UC-48 Biology and Medicine):1-8. 
Initial adsorption measured after three weeks of addition of $163 \mu \mathrm{g} \mathrm{Pu/1}$ solid, showed that Ca-saturated humic acid was a very effective sorber and did not release $\mathrm{Pu}$ readily upon equilibration with citrate. Camontmorillonite and Ca-kaolinite did not sorb $2-3 \%$ of the $163 \mu \mathrm{g} / \mathrm{g} \mathrm{Pu}$ added. When $\mathrm{Pu}$ was added at the rate of $0.6 \mathrm{\mu g} / \mathrm{g}$ solid, the removal of natural organic matter and/or iron oxide coatings from clay reduced the efficiency of Pu sorption by clay by only 1-5\%. The higher Pu solubility of soils in which $\mathrm{Pu}$ was associated with clay fraction compared to soils in which $\mathrm{Pu}$ was mainly associated with coarser silt sand fractions indicate that the solubility differences may be due to particle size of plutonium particles. (auth)

Templeton, W. L. and A. Preston. 1966. Disposal of Radioactive Waters into Seas, Oceans and Surface Waters. IN: IAEA Publication. pp. 267-289.

Authors reported that various radioactive materials penetrate or redistri-

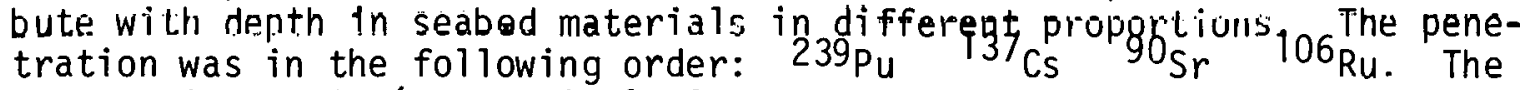
penetration ratio (amount in $15-23 \mathrm{~cm}$ depth divided by amount in $0-5 \mathrm{~cm}$ depth) for plutonium and cesium were 0.17 and 0.08 , respectively. (auth)

Thomas, C. W. and R. W. Perkins. 1975. Transuranium Elements in the Atmosphere. HASL-291. pp. I.80-I. 103.

The main release of transuranium elements to the atmosphere has been a result of nuclear weapons testinq, particularly the high yield fusion bomb tests beginning with the Ivy Mjke test in 1952. It has been estimated that approximately $300 \mathrm{kCi}$ of $239-240 \mathrm{Pu}$ were deposited on the earth's surface through 1972. Approximately $17 \mathrm{kC} j$ of $238 \mathrm{Pu}$ was injected into the atmosphere of the southern hemisphere in April 1964 when a satellite containing a power source failed to achieve a stable orbit. Analysis of the debris of Ivy Mike and subsequent high yield nuclear weapons debris has shown transuranium elements up to mass 257 . The amounts of these heavy radionuclides compared with $239-240 \mathrm{Pu}$ drop off rapidly with mass. However, there are very considerable amounts of $241_{\mathrm{Pu}}$ and $241_{\mathrm{Am}}$ and the $241 \mathrm{Am}$ after total decay of $241 \mathrm{pu}$ will actually exceed the 239-240pu. On comparing the airborne $239-240 \mathrm{Pu}$ to $137 \mathrm{Cs}$, it is found that their ratio has been relatively constant for the last several years, thus one can use the atmospheric models which describe the behavior of the fission product.s in describing the movement of the transuranium elements. Thus, it is possible to predict what the deposition pattern of the transuranium elements has been from past nuclear tests on the surface of the earth. It has been estimated that the nuclear power industry will generate approximately $10^{9}$ curies of transuranium elements during the remainder of this century. While it is highly unlikely that a significant amount of this material can enter the atmosphere, this source needs consideration, particularly in view of the much higher levels of some of the transuranium elements than that of $239 \mathrm{Pu}$. (auth) 
Thomas, H. C. and N. T. Coleman. The Interaction of Radioactive Nuclides and Soils. An Account of Our Present Position With Respect to the Basic Problems Involved. IN: Hearings on Industrial Radioactive Waste Disposal. $3: 1861-1912$.

By assuming that fixation will never be quite complete and disposal never quite final, the problem of the fate of radioactive poisons which have escaped to the environment is discussed. A classification is given of the distribution and different kinds of surface activity exhibited by the soil minerals with empasis on complex mixtures of hydrous oxides and clay minerals. A thermodynamic description of exchange sorption and Donnan invasion is given and thermodynamic functions for various clay systems are graphically shown. (NSA)

Thomas, W. A. änd D. G. Jacobs. 1969. Curium Behavior in Plants and Soil. Soil Science. 108:305-307.

$\mathrm{Cm}^{242}$ was used to measure curium sorption by several clays in equilibrium experiments and in loading and leakage of hydrobiotite columns. Results indicated that above a $\mathrm{pH}$ of about 3, an increasing amount of radiocolloid existed as the $\mathrm{pH}$ was increased. Plants grown on a curium-contaminated soil relocated very little of the curium to foliage. (auth)

Thorburn, R. C. 1950. Absorption on Hanford Soil and Related Soil Properties. NW-15655.

The effects of a solution of $\mathrm{MgCO}_{3}$ and $\mathrm{CaCO}_{3}$ on the retention of $\mathrm{Pu}$ by Hanford soil columns was ascertained. There was no effect on measured effluents as compared to noncarbonate-containing influents. From 55 to $94 \%$ of the water eluted Pu was resorbed by another soil column. Only $24 \%$ of the $\mathrm{Pu}$ was retained on a soil at $\mathrm{pH} 10$ compared to $77 \%$ to $87 \%$ at $\mathrm{pH} 3.8$ to 7.2 . (auth)

Travis, J. R. 1974. Model for Predicting the Redistribution of Particulate Contaminants From Soil Surfaces. LA-UR-74-1340 (CONF-740921-16), P. 59.

A computerized model was developed to describe the redistribution of wind eroding soil-contaminant mixtures. Potentially mobil particulate contaminants can, in the first approximation, be assumed to be indistinguishable from the wind eroding soil in which they are distributed. A grid network characterizes important soil and surface conditions, and mass conserving control volumes are constructed on each cell. Material is transported through the vertical and top surfaces of a control volume by a modified Bagnold-Chepil horizontal flux formulation and modified Gillette vertical flux formulation, respectively. The vertical emissions, considered as puffs from area sources, create at regular time intervals a contaminant cloud which is proportional to the suspendable ground concentration. These puffs diffuse downwind under time dependent wind velocity and 
atmospheric stability conditions, maintaining during the time interval a three-dimensional Gaussian distribution of concentration with cloud volume. Material from each puff is deposited in downwind cells, leading to the possibility of many different flights from these new sources. The usefulness of this predictive tool is demonstrated by calculations involving mixtures of particulate ${ }^{238} \mathrm{PuO}_{2}$ in highly erodable soils under dust storm conditions. Time dependent surface concentration and breathing zone exposure isopleths, evolving from a small contaminated area, show the potential hazard from wind eroding toxic materials. (auth)

Tsutsui, T. and K. Nishimaki. 1972. Movement of Radionuclides Through Saturated Sand Zone. Doboku Gakkai Ronbun Hokokushu, No. 200: 25-29.

The modes of movement of radioactive nuclides through water-bedring formations, when they escape from the radioactive wastes stored underground and mjx into groundwater were studied. The nuclides used in this study arc ${ }^{90} s_{r}$; ${ }^{60} \mathrm{Co}$, and ${ }^{3.37} \mathrm{Cs}$, alld lie dyuifer used is sand. Ihe study was done for the following three cases, in which they move (1) through the ordinary aquifer, (2) through the aquifer affected by some nitric acid wastes, and (3) mixing with nitric acid wastes, such as reprocessing waste-solution. It was known from this study that the movement of these nuclides is relatively slow, and that their speed is some $30 \%$ higher in the aquifer previously affected by the nitric acid waste-solution than in the ordinary aquifer. (NSA)

U.S.A.E.C. Nevada Operations Office, Las Vegas. 1973. Enewetak Radiological Survey. NV0-140. Vol. 1,747 p.

The AEC has conducted a survey in 1973 of the total radiological environment of Enewetak Atoll in order to provide data for judyments as to whether or not all or any part of the Atoll can be safety reinhabited. More than 4500 samples from a 11 parts of the marine, terrestrial, and atmospheric components of the Atoll environment were analyzed by instrumental and radiochemical methods. In addition, an aerial survey for Y radiation levels was conducted over all land areas. Strontium-9n, $137 \mathrm{Cs}, 60 \mathrm{co}$, and $239 \mathrm{pu}$ are the predominant radioactive isotopes now present, but their distribution is far frnm uniform. Islands on the southern half of the Atoll from ALVIN to KEITH have levels of contamination comparable to or less than those due to world-wide fallout in the United States. On the northern half, islands ALICE to IRENE are mnst. heavily.contaminated, KATE to WILMA are least contaminated, and JANET is at an intermediate level. These radiological data were combined with the best information currently available on the expected diet of the Enewetak people to estimate potential whole-body and bone doses to the population for six living patterns at 5-, 10-,30-, and 70-year intervals after return. The main contribution to the population dose comes through the terrestrial food pathway, followed in decreasing order of significance by the external gamma dose, marine, food pathway, and inhalation 
pathways. In the terrestrial food pathway, the main contribution to both whole-body and bone dose is due to the consumption of pandanus and breadfruit. Percentage contributions to the 30-year integral dose for each of the terrestrial food items for a population engaged in agriculture on JANET were calculated. It was concluded that corrective actions to reduce population doses will be most beneficial if they are directed at the primary contributors, i.e., pandanus and breadfruit in the diet and external $\gamma$ dose in the residence areas. (NSA)

Van Dalen, A., F. de Witte and J. Wiskstra. 1975. Distribution Coefficients for Some Radionuclides Between Saline Water and Clays, Sandstones and Other Samples From the Dutch Subsoil. Reactor Centrum Nederland, 75-109.

Distribution coefficients for $\mathrm{Pu}$ and Am were determined on Dutch subsoils of marine origin from $90 \% \mathrm{NaCl}$ saturated solutions at $\mathrm{pH} 7$ to 8 . For samples composed of mainly illite and kaolinite $\mathrm{Kd} \mathrm{Pu}$ is $210^{4}$ and $\mathrm{Kd} \mathrm{Am}$ is $\sim 5 \times 10^{4}$. The $\mathrm{Kd} \mathrm{Pu}$ and $\mathrm{Kd} \mathrm{Am}$ for river sand are respectively 200 and 400. Gypsum-bearing and clay-bearing sandstones were intermediate. The $\mathrm{pH}$ dependence on sorption processes for the elements $\mathrm{Pu}$ and $\mathrm{Am}$ between pH 5-8 was minor. (auth)

Van Haaren, F. W. J. 1964. The Limiting of Radioactive Isotopes in Soil (Underground Water). Foederation Europaeischer Gewa'esser-Schutz, Informationsb1. No. 10:56-61. (in German).

The problem of finding out how ground water is influenced by radioactivity in the soil under normal conditions, by radioactivity in precipitation, and by discharges of concentrated radioactive wastes was considered.

Potassium as a factor in the radioactivity of ground water is discussed. Because the radioactive materials in precipitation are chiefly adsorbed and fixed by a top layer of soil, contamination of ground water by these radioactive materials is not very considerable. Several tests were made of water infiltration through different kinds of soils. It was found that the velocity of flow and the presence of adsorbing material alien to the soil are of great importance. Suil cuntamination by discharge of radioactive wastes is described. (NSA)

Volchok, H. L. 1971. Resuspension of Plutonium 239 in the Vicinity of. Rocky Flats. IN: Fowler, E. B., R. W. Henderson, M. F. Milligan (cochairmen). Proceedings of Environmental Plutonium Symposium, held at LASL, August 4-5. LA-4756 (UC-41):99-103.

Continuous, high-volume airborne particulate sampling has been maintained for over a year, close to, and downwind from the Rocky Flats plant. The sampler is in the vicinity of the highest ground concentrations of $\mathrm{Pu} 239$ as determined in a 1970 inventory. The concentrations have averaged about $2 \mathrm{fCi} / \mathrm{m}^{3}$ of air sampled, 10 to 100 times higher than the expected levels from fallout. In addition a qualitative correlation is demonstratec 
between wind velocity and Pu 239 concentration in the air. The results to date suggest resuspension factors of between $10^{-7}$ and $10^{-9}$ depending upon the assumption taken, for the depth of soil re-entrainment. (auth)

Volchak, H. L. 1974. Transuranic Elements in the Marine Environment. WASH-1359, pp. 155-168.

Transuranic elements have been introduced in dispersed form into the marine environment in: close-in fallout from nuclear explosives testing; world-wide fallout from nuclear explosives testing; atmospheric burn-up of $238 \mathrm{Pu}$ power sources; and liquid wastes from chemical reprocessing plants and reactor operations. The environmental redistributions of Pu have been followed after its introduction by each of these averlues, and a small amount of information exists about Am. Unfortunately the data now at hand do not permit us to distinguish among the distributions of $\mathrm{Pu}$ following its introductjon in different ways. Data are summirion on the conteill or $24 l_{A m}$, $239 u$, and $238 P_{u}$ in samples of seawater and sediments collected at various ocean depths and in samples of plankton, seaweeds, invertebrates, fishes, and mammals collected at various locations. (NSA)

Waldichuk, M. 1961. Sedimentation of Radioactive Wastes in the Sea. NP-9905.

Sedimentation, if it occurs at large distances from shore outside of bottom fishing areas, can be considered a favorable process in effective radioactive waste disposal. Being a concentrating process, however, it can enter into one of the routes of radioactivity from the sea to man through contamination of fish products, edible sea weed, fishing gear, and beaches. Flocculation, sorption, precipitation, and ion exchange rcactions would probably occur freely in Pacific coastal waters, because of the presence of silt-laden water from the Columbia River, Fraser River, and other western streams. While turbid waters from runoff and coastal pollution can be expected to contribute to substantial sedimentation, no quantitative values can be assigned for this effect. Provided that it removes the radioactive wastes from man's environment and deposits them in areas where they can in $n n$ harm, sedimentation can be cullsidered as a satety factor in estimates of maximum permissible release of radioactive wastes. If contamination of marine products by ingcstion and sorptiull of the precipitated waste occurs, the effect. that this would have nn man's uptake ol radiuactivity through utilization of the products must be taken into account in evaluations. A review is given of the investigational results on radioactive waste discharge into the Irish Sea from the Windscale Works, England. A large proportion of the released radioactivity has been found in the sea bed near the outfall. sca waters in this area are almost completely mixed vertically and contain a high concentration of suspended material. There is no reason to believe that liquid radioactive 
wastes discharged off the Pacific Coast of North America would behave in the same way as those released into the Irish Sea, in view of the different oceanographic conditions. A series of studies in the field and laboratory needed to elucidate some of the problems related to sedimentation of fission-product elements is suggested. (auth)

Wahlgren, M. A. and D. M. Nelson. 1973. Residence Times for ${ }^{239} \mathrm{Pu}$ and ${ }_{137} \mathrm{Cs}$ in Lake Michigan Water. ANL-8060 (Pt. 3) pp. 85-89.

Study of the long-term behavior of ${ }^{239} \mathrm{Pu}$ and ${ }^{137} \mathrm{Cs}$ in natural waters is simplified by working on a lake that is essentially a closed system, located where adjacent land fallout measurements are available. Lake Michigan meets both criteria, with an outflow only about $1 \%$ of lake volume each year, and with fallout monitoring stations nearby at Argonne, Illinois, and Green Bay, Wisconsin. The determination of the removal rate of the fallout input from the water column, and of the fraction remaining in the water column, requires knowledge of both the cumulative fallout and the relative annual inputs. The latter is readily obtained from $90 \mathrm{Sr}$ measurements in rainfall pots on land, but the uncertainty in the cumulative total for $90 \mathrm{Sr}$ on land has been estimated as several tens of percents. The relative amounts of rainfall on Lake Michigan and on nearby land differ by less than 10\%. Extensive lake-wide sampling carried out in June 1972 , established the inventory of $239 \mathrm{Pu}, 137 \mathrm{Cs}, 90 \mathrm{Sr}$ and $3 \mathrm{H}$ in the water column of Lake Michigan at a season when it should be well mixed. The results of the analyses confirmed that this was indeed the case. For $90 \mathrm{Sr}$, the mean lake value from our experimental measurements was $0.81 \mathrm{pCi} / 1$. Based on the average of Green Bay and Argonne $90 \mathrm{Sr}$ fallout estimates from precipitation monitoring, the predicted 1973 concentration in Lake Michigan is $0.71 \mathrm{pC} i / 1$, assuming the contribution to the lake from land runoff to be $2 \% /$ year, and loss of outflow and by incorporation to the sediments to equal $2 \%$. The difference between the measured and calculated values may be due to dry deposition; the degree of agreement is encouraging in that an input inventory by direct measurement cannot readily be made for the three lower Great Lakes where residence times are much shorter. The cumulative fallout input of ${ }^{37} \mathrm{Cs}$ to Lake Michigan can now be deduced fairly rigorously, since the ratio of $13 \% \mathrm{Cs}$ to $90 \mathrm{Sr}$ is fixed in the fission processes. (NSA)

Wahlgren, M. A. and D. M. Nelson. 1973. Evidence of an Annual Plutonium Cycle in the Near-Surface Waters of Lake Michigan. ANL-8060 (Pt. 3), pp. 90-92.

The rapid depletion of ${ }^{239} \mathrm{pu}$ frnm the surface waters of Lake Michigan during July and August, the concurrent changes in the season, and the demonstrated preferential sorption of fallout $239 \mathrm{Pu}$ over ${ }^{137} \mathrm{Cs}$ by net plankton all suggest that a biological mechanism is the major removal step in a cycling process involving $\mathrm{Pu}$ and may contribute to the eventual removal of this element to the sediments. (NSA) 
Wahlgren, M. A. and D. W. Nelson. 1973. Plutonium in the Five Great Lakes: Comparison of Surface Waters. ANL-8060 (Pt. 3), pp. 93-98.

Studies of the fallout radionucludes ${ }^{239} \mathrm{Pu},{ }^{137} \mathrm{Cs}$, and ${ }^{90} \mathrm{Sr}$ in Lake Michigan demonstrated that a homogeneous distribution can be found throughout the water column following the winter mixing period, provided that the input of new fallout radioactivity is low as was the case in 1972 and 1973. Assuming that generally similar mixing behavior prevails in all the Great Lakes, surface water and plankton samples were obtained during May and June, 1973, and analyzed for ${ }^{239} \mathrm{Pu}, 137 \mathrm{Cs}, 90_{\mathrm{Sr}}$ and $125_{\mathrm{Sb}}$ as an indicator of recent fallout. The results of the interlake comparison stydy are consistent with the results of more detailed studies on $239 \mathrm{Pu}$ and 137Cs in Lake Michigan, indicating that the major fraction of both of these fallout isotopes has been removed relatively rapidly to the sediment, and suggesting that the average cumulative deposition rate in sediments will approximate that on land for all five Great Lakes. (NSA)

Wahlgren, M. A. and D. M. Nelson. 1974. Studies of Plutonium Cycling and Sedimentation in Lake Michigan. Proc. 17th Conf. Great Lakes Res. $1974: 212-218$.

Estimates of cumulative deposition, together with the results of extensive lakewide sampling in 1972, yielded estimates of mean halftimes for removal from the water column of Lake Michigan of $1.0 \pm 0.3$ years for Pu 239,240 and $1.4 \pm 0.3$ years for Cs 137. However, data from 1971, 1972, and 1973 water samples indicate that the recent halftime is much greater than the 1963-1972 average, present.ly heing on the order of 3 to 4 ycars for both Pu 239 and Cs 137. The longer turnover time is consistent with the Cs 137 turnover time in the water column deduced from analysis of preserved Lake Michigan alewives. Water filtration experiments have demonstrated that $>75 \%$ of the plutunium is nonfilterable and is present as colloid or subcolloidal sized fractions. At an offshore station near Grand Haven, Michigan, the concentration of $\mathrm{Cs} 137$ in the epilimnion underwent a slight but significant decline from June to November, whereas $\mathrm{Pu} 239$ was reduced to a small fraction of its spring value. In net plankton samples doininated by phytoplankton as much lower mean Cs 137: Pu 239 ratio is observed than in water samples, indicating a preferential sorption of $\mathrm{Pu} 239$ over Cs 137 by phytoplankton. The results nf these experiments suggest that sorption by phytoplankton (and the subsequent rapid settling from the epilimnion of phytodetinitus and/or zooplankt.nn fecal pellets) is responsible for the rapid removal of $\mathrm{Pu} 239$ from the epilimnion. (auth)

Wahlgren, M. A., E. M. Yaquchi, D. M. Nelson and J. S. Marshall. 1974. Spatial Distribution of Radionuclides in Lake Michigan Biota Near the Big Rock Point Nuclear Plant. CONF-750593-17. 15p.

A survey was made of four groups of biota in the vicinity of the Bia Rock Point Nuclear Plant near Charlevoix, Michigan, to determine their usefulness 
in locating possible sources of plutonium and other radionuclides to Lake Michigan. This $70 \mathrm{MN}$ boiling-water reactor, located on the Lake Michigan shoreline, was choscn because its fuel contains recycled plutonium, and because it routinely discharges very low-level radioactive wastes into the lake. Samples of crayfish (Orconectes sp.), green algae (Chara sp. and Cladophora sp.), and an aquatic macrophyte (Potamogeton sp.) were collected in Ayqust 1973, at varying distances from the discharge and analyzed for 239-240 $\mathrm{Pu}, 90 \mathrm{Sr}$, and five gamma-emitting radionuclides. Comparison samples of reactor waste solution have also been analyzed for these radionuclides. Comparisons of the spatial distributions of the extremely low radionuclide concentrations in biota clearly indicate that ${ }^{3}{ }^{7} \mathrm{Cs}, 134 \mathrm{Cs}, 65 \mathrm{Zn}$, and $60 \mathrm{Co}$ were released from the reactor; their concentrations decreased exponentially with increasing distance from the discharge. Conversely, concentrations of $239-240 \mathrm{Pu}, 95 \mathrm{Zr}$, and $90 \mathrm{Sr}$ showed no correlation with distance, suggesting any input from Big Rock was insignificant with respect to the atmospheric origin of these isotopes. The significance of these results is discussed, particulariy with respect to current public debate over the possibility of local environmental hazards associated with the use of plutonium as a nuclear fuel. (auth)

Wallace, A., et a1. 1971. Effects of Micronutrient and DTPA Applications on Americium 241 and Micronutrient Contents of PI54619-5-1 Soybeans Grown in Calcareous Hacienda Loam Soil. UCLA-34-p-51-33. IN: Wallace, A., et al. Regulation of the Micronutrient Status of Plants by Chelating Agents and Other Factors. pp. 8-9.

PI54619-5-1 soybeans which are susceptible to lime-induced chlorosis were grown in calcareous Hacienda loam soil with micronutrient and chelate additions. Americium 241 which had been mixed with the soil was greatly increased in plants to which iron DTPA had been added to the soil. Application of high levels of zinc or manganese decreased Americium 241 content of plants only slightly. The FeDTPA was of slight value only in correcting the lime-induced chlorosis. The 4 pounds per acre of iron as DTPA increased zinc contents of leaves as much as did 100 pounds per acre of added zinc. Manganese increased manganese contents of leaves; 200 pounds manganese per acre doubled the manganese content. (auth)

Wallace, A. 1972. Effect of Soil pH and Chelating Agent (DTPA) on Uptake by and Distribution of Americium 241 in Plant Parts of Bush Beans. Radiation Botany. 12:433-15.

Bush Bean (Phaseolus vulgaris L. var. Improved Tendergreen) plants were grown with and without chelating agent diethylenetriaminepentaacetate (DTPA) in Yolo loam soil, which was amended to give a range of soil pH values. A level of $1.68 \mathrm{uCi}$ Am 241 was uniformly mixed with each $500 \mathrm{~g}$ quantity of soil. Highest amounts of Am 241 were found in plant parts at soil pH around 7.7 with the DTPA. The results are interpreted as chelated Am 241 not only being available to the plants especially at pH 7.7 but also the Am 241 being transported through the plants as the metal chelate. (auth) 
Wa1lace, A. 1972. Increased Uptake of $241_{\text {Am }}$ by Plants Caused by' the Chelating Agent DTPA. Health Physics. 22:559-562.

The chelating agent diethylenetriaminepentaacetic acid (DTPA) which has the ability to increase uptake by plants of several metals and is widely used as a practical means of correcting iron deficiency in plants has been shown to greatly increase the uptake from soils of ${ }^{241}$ Am by plants. Application of high levels of zinc or manganese salts decreased 241 Am content of plants gn] s slightly, indicating little, if any, competing effect. Most accumulated 24 Am was transported to leaves of all species studied. The ability of plants to accumulate 241 Am was not related to root temperature. During a subseguent growth period after applications of $241_{\text {Am }}$ to bush beans, some of the $241_{A m}$ was transported from the old leaves to the new leaves and also to new roots. The chelating agent DTPA had no effect on the retranslocation, however. [xtracelois studies whth suil illdicaled lhat DTPA, but not. F.JIJHA, could quantitatively extract ${ }^{24}$ Am from soil. (auth)

Wallace, A., et al. 1971. Retranslocation of Americium 241 in Bush Beans. UCLA-34-p-51-33. IN: Wallace, A. et al. Regulation of the Micronutrient Status of Plants by Chelating Agents and Other Factors. pp. 96-7.

Americium 241 initially after absorption was largely located in leaves of plants. During a subsequent growth period some of the americium 241 was transported from the old leaves to the new leaves and to new roots. The chelating agent DTPA had no effect on the retranslocation. Since the chelating agent DTPA has been shown to increase americium 241 uptake by plants this study was made to determine if DTPA had any effect on retranslocation of americium 241 once it was accumulated in plants. Plants were allowed to accumulate americium 241 and then the americium 241 was removed and plants allowed to grow to maturity with and without DTPA. The results have implications on the absorption of and behavior of chelating agents in plants. (auth)

Wallace, A. and E. M. Romney. 1974. Feasibility and Alternate Procedures for Decontamination and Post Treatment Management of Pu-Contaminated Areas in Nevada. UCLA-12-973, $90 \rho$.

This report was prepared in response to needs for determining the feasibility and environmental impact of cleaning up Pu-contaminated areas in Nevada. Instead of considering all aspects of radioactive decontamination, it deals primarily with findings from pertinent land ared decuntanination and post-management experiences that can be applied to solving $\mathrm{Pu}$ problems at the Nevada Test Site and the Tonopah Test Range. Previous experiences from accidental and planned releases of $\mathrm{Pu}$ in the environment are discussed along with those gained from nuclear fallout decontamination studies. Considerable attention is given to problems concerning revegetation of arid lands. The fragile nature of the desert is such that any drastic alteration will result in a seriously damaged ecosystem. Revegetation by natural means 
is difficult, if not impossible, from a practical point of view. Posttreatment management of disturbed areas is almost always necessary to insure recovery. Correction of the damage may require greater efforts than the decontamination, and may have more far-reaching consequences than those concerned with the present status of the land. Alternate procedures are discussed which may be useful in Nevada, providing the necessary experimental work is done to test the validity of the assumptions made. Many answers to pertinent questions can be obtained from investigations conducted outside of the Pu areas. Recommendations are made for experimental work that should be done to determine the best course of action before cleanup begins. (auth)

Watkins, J.W., F. E. Armstrong, and R. J. Heemstra. 1960. Feasibility of Radioactive Waste Disposal in Shallow Sedimentary Formations. Nuclear Sci. and Eng. 7:133-43.

General considerations pertinent to the disposal of radioactive wastes are reviewed. Suggested methods of disposal, geographical influences, and the factors pertaining to shipping liquid and solid radioactive wastes are discussed. The methods of disposing of oil-field brines are reviewed. The economics of brine injection is compared to costs of storing and estimated costs of disposing of high-level radioactive wastes. A comparison is made of the costs of drilling wells to different depths. The relative economics of drilling exploratory, injection, and monitoring wells to different depths in a disposal or test project is discussed. The geology of comparatively shallow and stratigraphically isolated sandstone lenses and shoestrings common to midcontinental United States is considered. Particular emphasis is given to the geological, engineering, and chemical information available about such formations that have proved to be productive of petroleum and have been repressured with fluids to stimulate oil production.

Laboratory and field research problems pertinent to the disposal of radioactive wastes by injection are outlined. A hypothetical example is given of a pilot plant for secondary treatment and injection of dilute fission products into a shallow, lenticular sandstone formation with well-defined boundary conditions. Monitoring facilities and techniques designed to delerilline hurizontal and vertical migration and differentiation of the migrating radioisotopes are described. A partial cost analys is is made of the pilot system. The advantages and disadvantages of a full-scale system of this type, as compared with other methods of disposal are discussed. (auth)

Welty, C. G. and M. B. Biles. 1973. The U.S. Atomic Energy Commission Program for Monitoring the Behavior of Radionuclide Released to the Environment. IAEA-SM-172/36. Environmental Behavior of Radionuclides Released in the Nuclear Industry. pp. 139-156.

The U.S. Atomic Energy Commission (AEC) conducts major nuclear energy programs at about 30 sites. The environmental monitoring programs at 
these sites are conducted by AEC or its operation contractors and are governed by general requirements set forth in AEC management directives. The objective of these directives is to ensure that environmental monitoring is adequate to determine the extent to which levels of radioactivity released from AEC facilities comply with applicable environmental quality standards and to evaluate the effects, if any, of planned and unplanned releases on the environment. Emphasis has been placed on the monitoring of pathways of human exposure, al though environmental media such as soit and sediment have been monitored to detect significant trends in radioactivity levels. In some instances direct gamma body counts on members of the public and hypothetical dose estimates for selected individuals and population groups have been made to define more accurately the risks of public exposure in the vicinily of AEC facllities. Environmental monitoring programs have generally demnnstrated public exposures in the vicinity of ACC facilities to be less than $1 \%$ of the ICRP recomended standards. Some operations, however, have resulted in potential public exposures representing somewhat larger fractions of the ICRP recommended standards. The levels of exposure that resulted from these and other AEC operations will be discussed. With few exceptions, exposures to individuals and groups in the population have not ranged above a few percent of the ICRP standards. Comprehensive soil and sediment monitoring is being accomplished in the vicinity of a number of AEC facilities and sites to determine the degree of build-up of plutonium in the environment due to routine and accidental releases. There is no evidence that build-up of plutonium in soil and other media present a public health hazard. The quantities of plutonium released and the levels of plutonium detected in the environment will be discussed. (auth)

Whicker, F. W., C. A. Little and T. F. Winsor, 1973. Plutonium Behavinr in the Terrestrial Environs of the Rocky Flats Installation. C00-1156-68. CONF-731117-5, SM-180-45, $15 \mathrm{p}$.

$\mathrm{Pu}$ behavior in the terrestrial environs of the Rocky Flats Plant located between Denver and Boulder, Colorado was investigated by: defining the major components of the terrestrial ecosystem adjacent to Rocky flats; measuring plutonium in such components in order to quantify plutonium "compartments;" determining intercompartmental transport pathways, mechanisms, and rates; and developing a quantitative model which can be used for conceptual and possible predictive purposes. The Rocky Flats environs are described, plutonium data gathered to date are summarized, and methods of plutonium surveillance in terrestrial ecosystems are discussed. From the results obtained, it is concluded that soil constitutes the principal $\mathrm{Pu}$ reservoir in the terrestrial environs of Rocky Flats, and that although $\mathrm{Pu}$ is detectable in all environmental sample material assayed, there is, at present, no evidence of significant biological concentration mechanisms. Further experimental studies are recommended. (NSA) 
Whicker, F. W., C. A. Little and T. F. Winsor. 1973. Plutonium Behavior in the Terrestrial Environs. IN: Environmental Surveillance Around Nuclear Installations. Warsaw Symposium, IAEA, November 5-9, 1973.

Soil represents the principal storage area for $\mathrm{Pu}$ in the Rocky $\mathrm{Flats}$ environs. Pu concentration in the soils and related vegetation and mammals is given, and surveillance for Pu around Rocky Flats is described. (auth)

Whicker, F. W., C. A. Little and T. F. Winsor. 1974. Plutonium Behavior in the Terrestrial Environs of the Rocky Flats Installation. Environmental Surveillance Around Nuclear Installations. Vol. II, Vienna, I.A.E.A. pp. 89-103.

Dow Chemical Corporations's Rocky Flats installation, located between Denver and Boulder, Colorado, processes large quantities of plutonium for the USAEC. Storage barrel leakage was a major incident, which resulted in detectable plutonium contamination of air, soil, and biota within and around the plant boundaries. Commercial and residential land development is rapidly approaching the plant from several directions, and this, coupled with increased public concern over environmental contamination, led to considerable controversy concerning radiation protection guidelines, such as permissible levels of $239 \mathrm{Pu}$ in soil for various classes of land use. Radioecological studies designed to elucidate existing patterns of plutonium concentration in terrestrial ecosystems surrounding the plant and to define transport pathways, mechanisms, and appropriate intercompartmental rate constants are being initiated by the Department of Radiology and Radiation Biology at Colorado State University under support from the Division of Biomedical and Environmental Research, USAEC. Intensive sampling of soil, litter, vegetation, arthropods, small and large wild mammals, reptiles, and amphibians is being conducted for $239,240 \mathrm{Pu}$ assay within an area known to be contaminated, and also within a relatively uncontaminated control area nearby. Ancillary field and laboratory experiments are being planned and conducted to isolate the relative importance of transport pathways and to provide quantitative evaluations of plutonium intake and loss rates by specific biotic and abiotic compartments. From such information, an ecosystem model of plutonium transport will be developed for conceptual and predictive purposes. Such a model will be useful in designing future plutonium surveillance programs to achieve maximum information per unit effor,t. The research approach, findings to date, and methods of plutonium surveillance in terrestrial ecosystems are discussed. (auth)

White, M. G. and P. B. Dunaway. 1974. Nevada Applied Ecology Group Environmental Studies of Plutonium. WASH-1332. 2:9.31-947.

The plutonium program of the Nevada Applied Ecology Group is conducted on the Nevada Test Site (NTS), Tonopah Test Range (TTR), and surrounding areas. Objectives of this relatively comprehensive ecological program are to (1) delineate locations of plutonium contamination, (2) determine 
concentrations in ecosystem components, (3) quantify rates of movement among those components, (4) evaluate radiological hazards of plutonium in organisms, (5) identify areas that need to be cleaned up or treated, and (6) develop techniques for cleanup or treatment. Results indicate that measurable concentrations of plytonium are not being moved now by resuspension of NTS or TTR, but that resuspended plutonium is present in areas close in to "ground zeros." Plutonium concentrations in undisturbed soil decrease with depth, but plutonium is not uniformly distributed in the particle-size fractions within soil samples. At present, and for several hundred years, 241 Am may be of more concern than $239 \mathrm{Pu}$. Relatively uniform concentrations of $239 \mathrm{Pu}$ and $241_{\mathrm{Am}}$ were found for each plant species, but considerable variation in concentrations was found among species. Field populations of micruoryanisms varied cunsiderably from site to site. Plutonium in Aspergillus spores was about onefourth that in a growth medium. Addition of bile and changes in $\mathrm{pH}$ in an artificial digestive tract caused sharp rises in solubility of plutonium nitrate, citrate, and dioxide. Plutonium levels in tissues of small mammals residing on contaminated areas were only two orders of magnitude less than concentrations in their gastrointestinal tracts and pelts. Transfers of plutonium to cattle tissues varied according to form of plutonium and mode of administration. Preliminary results from a comprehensive model indicate that some areas on NTS would have to be cleaned up or treated before constant habitation by people could be permitted. (auth)

Wildung, R. E. and T. R. Garland. 1973. Influence of Soil Microbial Activity on the Uptake and Distribution of Plutonium in the Shoots and Roots of Barley. BNWL-1850, Pt. 2. pp. 22-25.

Barley plants, cultured by a split root technique, showed increased $\mathrm{Pu}$ in barley shoots with decreased soil Pu concentration ( $\mu \mathrm{Ci} \mathrm{Pu} / \mathrm{q}$ of tissue/ $\mu \mathrm{Ci} \mathrm{Pu} / \mathrm{g}$ of soil). Past data on $\mathrm{Pu}$ uptake by plants at high $\mathrm{Pu}$ soil concentrations may not therefore be applicable to low Pu environmental conditions. (auth)

Wildung, R. E. and T. R. Garland. 1974. Relative Solubility of Inorganic and Complexed Forms of Pu 238 and Pu 239 in Soil. BNWL-1950, Pt. 2. pp. 23-25.

Pu was added to the soil as nitrate and DTPA complexes amended with starch, nitrogen and water. Pu nitrates were only 0.05 to $5 \%$ soluble. ${ }_{\text {Pu DTA }}$ complexes were $100 \%$ water soluble for the first 40 days. The $238 \mathrm{Pu}$ DTA complex became somewhat less soluble after 40 days. (auth)

Wildung, R. E., T. R. Garland and H. Drucker. 1973. Potential Role of the Soil Microbiota in the Solubilization of Plutonium in Soil. BNWL1850, Pt. 2. pp. 21-22. 
Sterile and nonsterile soils were inoculated with $10 \mu \mathrm{Ci} / \mathrm{g}$ Pu(IV) nitrate and incubated for 30 days. A liter of water was used to leach a gram of soil for 4 hours with filtration through $5,0.5$ and $0.0 / \mu \mathrm{m}$ millipore filters. The 0.01 and $0.5 \mu \mathrm{m}$ material were considered to be solubilized. Results suggested that the solubility of $\mathrm{Pu}$ in soil is influenced by soil microflora. (auth)

Wilson, D. 0. and J. F. Cline. 1966. Removal of Plutonium-239, Tungsten185 and Lead-210 From Soils. Nature. 209-5026:941-942.

The authors confirmed that only small amounts of ${ }^{239} \mathrm{Pu}$ were translocated from the sediments to plant leaves during plant growth. Leaf to soil ratios of $239 \mathrm{Pu}$ were about 0.001 on the averaqe for barley grown on Milville silt loam, Cinebar silt loam and Ephrata fine sandy loam. (auth)

Wilson, D. W., N. C. Yook, and W. L. Robison. 1975. Evaluation of Plutonium at Enewetak Atol1. Health Physics. 29:599-611.

An extensive survey was carried out in 1972-1973 to assess the current radiological status of Enewetak Atoll. The radionuclides detected in the Atoll environment were studied for their potential contributions to the dose commitment of the returning population according to several pathways of exposure. Plutonium was detected in air and in the terrestrial and aquatic environment at concentrations that varied from background levels due to world-wide fallout to levels several orders-of-magnitude above. The dose commitments from plutonium via the terrestrial food chain and inhalation vary according to the postulated living pattern. The dosages via marine foods can be expected to be insensitive to living pattern and to exceed those via terrestrial foods. Plutonium would contribute nearly all of the dosage via inhalation, but this pathway ranks low in overall importance compared with the food-chain and external-dose pathways. Although the potentjal dose from plutonium via all pathways in low relative to that from ${ }^{60} \mathrm{Co},{ }^{90} \mathrm{Sr}$, and $137 \mathrm{Cs}$, plutonium will still remain in the Atoll environment after the nther major isotopes have decayed away. (auth)

Wong, K. M. 1971. Radiochemical Determination of Plutonium in Seawater, Sediments and Marine Organisms. Anal. Chim. Acta. 56:355-364.

A radiochemical procedure is described for the determination of plutonium in large samples of seawater, sediments and organisms with a sensitivity of $0.004 \mathrm{dpm}$ per 100 liters of seawater (for a 50-liter sample), 0.02 $\mathrm{dpm}$ per $\mathrm{kg}$ of sediments (100-g sample) and $0.002 \mathrm{dpm}$ per $\mathrm{kg}$ of marine organisms (1-kg sample). An iron (II) hydroxide coprecipitation method is used for the concentration of plutonium in seawater. A nitric-hydrochloric acid leaching method is adapted for the treatment of sediments and ashed organisms. Factors influencing the recovery, contamination and blank activity are discussed. (auth) 
Wong, K. M., J. C. Burke, and V. T. Bowen. 1971. Plutonium Concentration in Organisms of the Atlantic Ocean. IN: Proceedings, 5th Annual Health Physics Soc. Midyear Topical Symposium: Health Physics Aspects of Nuclear Facility Siting. 2:529-539.

A series of marine organisms, collected about Cape Cod or in the open north Atlantic 0cean, have been analyzed for plutonium 239 and for other fallout radionuclides. These data are compared with those from analyses of marine aerosols, sediments and seawater. The results show that $\mathrm{Pu}$ 239 has been concentrated in some tissues of each organism so far examined. In fish Pu 239 concentrations range from 0.2 to $140 \mathrm{dpm}$ per $100 \mathrm{~kg}$; fresh weight in benthic invertebrates from 23 to $140 \mathrm{dpm}$ per $100 \mathrm{~kg}$; in plankton from 130 to 340 and, in Sargasso weed, to $1280 \mathrm{dpm}$ per $100 \mathrm{~kg}$. Pu 239 ratios to strontium 90 or ceslum 137 are higher in organisms that in their environment. (auth)

Wong, K. M., V. E. Noshkin, L. Surprenant and V. T. Bowen. 1970. Plutonium 239 in Some Marine Organisms and Sediments. HASL-227, pp. I-25-I-33.

Sediments may show concentration factors over contacting seawater for $\mathrm{Pu}$ of $10^{4}$ or greater. Fish mussels and clams collected from various parts of the world's oceans showed lesser Pu concentration factors with bottom feeders among the higher values. (auth)

Wrenn, M. E. 1974. Environmental Levels of Plutonium and the Transplutonium Elements. WASH-1359, pp. 89-112.

The major transuranic activity in the environment is composed of ${ }^{239} \mathrm{Pu}$, $240 \mathrm{Pu}$, and ${ }^{241} \mathrm{Am}$ from weapons testing, and $238 \mathrm{Pu}$ from the SNAP-9A burnup in 1964. This material is detectable in surface soils around the world, although their presence raises the $\alpha$ background in surfare soils generally less than $1 \%$. The $\mathrm{Pu}$ and Am activity per gram near the surface will decrease slowly with time. Local sources of Pu, al though much smaller in quantity than that from globally distributed weapons testing fallout, can result in concentrations of $\mathrm{Pu}$ in soil exceeding the concentrations of the global level from weapons testing. (auth)

Yaguchi, E. M., B. J. Waller and J. S. Marshall. 1974. Plutonium Distribution in Lake Michigan Biota. CONF-740813-1, 24 p.

Samples of plankton, algae, benthic invertebrates, and eight fish species were collected from Lake Michigan during 1972 and 1973. After ashing, the samples were analyzed by radiochemical methods and gamma ray spectrometry for $239 \mathrm{Pu},{ }^{9} \mathrm{Sr}$, and ${ }^{137} \mathrm{Cs}$, a 71 of which are components of fallout from atmospheric tests of nuclear weapons. Analyses indicated that $239 \mathrm{Pu}$ was scavenged from Lake Michigan water..by phytoplankton and attached algae by a concentration factor of up to 10,000. In each of two food chains 
considered, a progressive discrimination against ${ }^{239} \mathrm{Pu}$ was observed at successive trophic levels: phytoplankton to zooplankton to planktivorous fish to piscivorous fish, and benthic invertebrates to bottom-feeding fish. The benthic invertebrates and fish had somewhat higher $239 \mathrm{pu}$ concentrations than their pelagic counterparts, presumably because of their ingestion of sediments. Ash content was correlated with $239 \mathrm{Pu}$ concentrations in samples of plankton and fish. (auth)

Zillich, J. A. 1974. Biological Impacts of AEC Rocky Flats Plant Waste Discharged to Surface Waters. Vol. I. Proceedings of the Second AEC Environmental Protection Conference, April 15-19, 1974. Albuquerque, NM. WASH-1332-74-V.1, pp. 193-260.

Nutrients discharged from the Rocky Flats Plant site caused algae growth increases as much as 35 times above ambient conditions. Such nutrient discharges if continued could eventually cause taste and odor problems in the water supply for the City of Broomfield. Macroinvertebrate populations in plant site drainages indicated the waste waters were not very toxic. In comparison to other macroinvertebrate populations in other Denver area waters, Rocky Flats drainages were of much better quality. Fish not only live in all plant site drainages but also have been observed reproducing as well. No plant materials showed any significant biomagnification in the aquatic food chain. This includes chlorinated hydrocarbons, plutonium and tritium. The highest yearly average concentration of Plutonium in any offsite plant waters was $16.6 \mathrm{pCi} / 1$. The average yearly concentration in the Great Western Reservoir was less than $0.11 \mathrm{pCi} / 1$. Radiation exposure to Broomfield residents from Rocky Flats products in city drinking water during 1973 was less than 4 millirem. Broomfield residents received more than 500 times that amount from natural sources, therefore, the amount attributed to the Rocky Flats Plant was small in comparison and was not felt to be a public health concern. (auth)

Zlobin, V. S. and 0. V. Mokanu. 1970. Mechanisms of the Accumulation of Plutonium-239 arid Polonium 210 by the Brown Alga Ascophyllam Nodnsum and Marine Phytoplankton.' Radiobiology 10:594-589. (English Translation pp. 160 to 169).

The accumulation of plutonium-239 by Ascophyllum nodosum and marine phytoplankton, as we 11 as that of polonium-210 by macrophytes under the influence of inhibitors of cellular respiration, was investigated. It was established that plutonium and polonium exist in sea water in the form of colloidal particles. Sodjum cyanide induces uniform suppression of the accumulation of $239 \mathrm{Pu}$ and $210 \mathrm{Po}$ in plant cells, while ammonium chloride briefly stimulates accumulation. It is demonstrated that the accumulation of plutonium239 by marine algae is an active process, and it involves an energy expenditure by the cell. (auth). 


\section{THIS PAGE \\ WAS INTENTIONALLY \\ LEFT BLANK}




\section{NATURAL ACTINIDE DISTRIBUTIONS IN SEDIMENTS}

Natural actinide distributions include only those distributions that predate the use of fission or fusion reactions as weapons or energy sources by man. The transuranics are present in nature to either a very small extent, or do not exist in nature as represented by a terrestiral environment. Moreover, certain of the uranium, thorium and vanadium milling and mining operations date from middle of the nineteenth century and have resulted in abnormal distribution patterns of the actinides in the vicinity of these operations. Distribution patterns of the actinides in the vicinity of these mining and milling operations are not considered as natural distributions.

The volume of work done on natural actinide distributions is impressively large, probably due primarily to interest in age dating applications. However, there has been considerable work done, under the impetus of uranium exploration, on the geochemistry of uranium as well. In general, the emphasis in the exploration-related geochemical work has been on migration and depositional mechanisms. The age dating-related work is concerned primarily with actinide distributions rather than mechanisms for deposition or movement.

Despite the fact that there has been relatively little work done on disposal into sediments of uranium-bearing solutions, much of the natural distribution work is directly applicable to uranium-sediment reactions due to waste disposal operations. 


\section{THIS PAGE}

\section{WAS INTENTIONALLY LEFT BLANK}


Adams, J. A. S., J. K. Osmond and J. J. W. Rogers. 1959. The Geochemistry of Thorium and Uranium. IN: Physics and Chemistry of the Earth. 3. L. H. Ahrens, F. Press, K. Rankama and S. K. Runcorn (eds.):298-348.

The natural distribution of uranium and thorium in the crustal rocks is reviewed along with the average abundance in each rock and sediment type. The separation of uranium and thorium during weathering processes is accomplished in three ways: 1) solution processes in which the minerals holding the thorium and uranium are put into true solution; 2) physical movement of resistates containing uranium and thorium; and 3) precipitation with clays, opal and other similar minerals.

The thorium is easily removed by and concentrated in the clays. Uranium, as the uranyl ion, is usually precipitated by a low Eh environment.

Adams, J. A. S. and K. A. Richardson. 1960. Thorium, Uranium, and Zirconium Concentrations in Bauxite. Econ. Geol. 55:1653-75.

Twenty-nine samples of bauxites from different locations were analyzed for thorium and uranium by gamma spectrometric, alpha counting, and wet chemical methods. The thorium concentrations ranged from 5.0 to $131 \mathrm{ppm}$ and averaged $48.9 \mathrm{ppm}$. The uranium concentrations ranged from 2.7 to $26.7 \mathrm{ppm}$ and averaged $11.4 \mathrm{ppm}$. The thorium-to-uranium ratios ranged from 1.5 to 20.9 , with an average value of 5.1 . Zirconium determinations on some of the bauxites gave values ranging from 0.02 to 0.65 percent zirconium, and averaging 0.09 percent zirconium. The thorium, uranium, and zirconium contents of the bauxites derived from nepheline syenites contained more thorium and uranium than bauxites derived from other rock types; bauxites derived from basic igneous rocks had the lowest thorium and uranium concentrations, and bauxites derived from carbonate rocks had the lowest thorium-to-uranium ratios. The greatest concentrations of zirconium were found in bauxites derived from nepheline syenites, and bauxites derived from carbonates contained the lowest concentrations of zirconium. A study of samples from alumina plants treating Surinam and Arkansas bauxites showed that during the process over 70 percent of the thorium and uranium in these two bauxites- is concentrated into the red mud, and the alumina contains very small amounts of these elements. This study also indicated that much of the thorium and uranium in bauxites occurs in either primary or secondary resistate minerals. (auth)

Adams, J. A. S. and C. E. Weaver. 1958. Thorium to Uranium Ratios as Indications of Sedimentary Processes: Example of Concept of Geochemical Facies. Bull. Am. Assoc. Petrol. Geologists. 42:387-430. 
More than 200 new analyses of Th and $U$ made with a $\gamma$-ray spectral technique and an $\alpha$-activity-fluorometric $U$ technique are reported. The over-all error is estimated to be $< \pm 20$ percent if the $T h / U$ ratio is more than 0.5 and there is more than $0.3 \mathrm{ppm} U$ and $T h$, respectively. Ratios in many oxidized continental deposits are above 7 , whereas most marine deposits have ratios below 7; this permits recognition of deposits formed in these environments. $\gamma$-Rays from $U$, Th, and $K$ can be differentiated by a spectral logging device and useful data for interpretation of subsurface rocks are obtained.

Adler, H. H. 1961. Some Possible Geologic Relationships in the Formation of Uranium 235 from Curium247. Econ. Geo1. 56:689-94.

A mechanism for the derivation of $\mathrm{U}^{235}$ from $\mathrm{Cm}^{247}$ is considered as a possible source of $\mathrm{U}^{2.35}$ enrichment in radioactive rare earth minerals. The presence of $\mathrm{Cm}^{247}$ in early earth materials is predictable on the bas is of synthesis through nuclear reactions and from extrapolations of abundances of lighter nuclides. The chemistry of curiuni reflects a geochemical similarity to rare-earth elements and possible incorporation in rare-earth minerals. The amount of enrichment of $U^{235}$ that might be expected from $\mathrm{Cm}^{247}$ decay is calculated for monazite for several geologic ages. Within the limits of the parameters considered, $\mathrm{Cm}^{247}$ would not provide sufficient $\mathrm{U}^{235}$ enrichment to be of economic consequence, but its possible existence in early geologic time may be of interest in geochronology studies. Underestimation of $\mathrm{Cm}^{247}$ abundance may affect significantly the probability for finding interesting variations in $U^{235}: U^{238}$ ratios. (auth)

Agamirov, S. S. 1963. The Geochemical Balance of Radioactive Elements in the Black Sea Basin. Geokhimiya. No. 16:612-14 (in Russian).

By measuring the cross sectional distribution of $U$ and $R a$ in the rivers emptying into the Black Sea $\left(1.15 \times 10^{-6}\right.$ and $2 \times 10^{-13} \mathrm{~g} / 1$, respeclively) whereby the content of the shores of the rivers was estimated, and the known U, Ra, Th values of the Black Sea, the average distributions of the radioactive elements of $U, R a$, and $T h$ in the sea and river water as well as in the deposits of the Black Sea Basin were determined. (CA)

Agamirov, S. S. 1963. Precipitation of $U$ in Black Sea. Geokhimiya. No. 1: 92-3 (in Russian).

Hydrochemical tests of the northeast portion of the Black Sea Basin during July 1961 indicated $2.4 \mathrm{~g} / 1 \mathrm{U}$ in the upper $500-\mathrm{m}$ layer, $1.6 \mathrm{~g} / 1 \mathrm{U}$ between 1000 and $18000 \mathrm{~m}$, and much smaller amounts at greater depths. Further studies showed the feasibility of hexavalent uranium reduction to tetravalent by hydrogen sulfide contamination, followed by a precipitation to a depth of 1700 to $2000 \mathrm{~m}$ where the eH value is 0.15 to $0.20 \mathrm{v}$, resulting in an enrichment of Black Sea sediments. (NSA) 
Alberti, G., C. Bettinali, G. Grassini and F. Silvestro. 1959. Leaching Tests of Uranium of Canale Monterano. IN: Studie Ricerche Della Divisione Geomineraria. 2:129-53.

Short descriptions of the deposit, of the various hypotheses of its origin and of the methods of sampling are given. The results of the radiometric and chemical analyses of samples collected in the various galleries are reported. The conditions of solubilization of the uranium in pure water and in acidic and alkaline solutions were studied, taking in account the concentration of the solutions, the time of leaching, the temperature, the grain size of the crushed material, the presence of oxidizing compounds and of oxygen under pressure. It was found that in the case of leaching by water only, the percentage of uranium going in solution is strictly linked to the acidity of the material. Most of the examined samples shows $\mathrm{pH}-$ values between 2.4 and 3.2, but also extreme values, such as 1.8 and 5.5 were observed. On the average, about 18 percent of the total uranium present goes in solution in pure water, while, in solutions with 20 percent sulfuric acid, maximally 60 percent of the uranium could be leached out. (auth)

Alekseev, F. A. 1972. Use of Radioactive and Stable Isotopes in Geological Research. Yad. Geofiz., Dokl. Uses Nauch. -- Tekh. Konf. 'XX [Dvadtsat] let Proizvod. Primen. lzotop. Islochnikov. Yad. Izluch. Nar. Khoz. SSSR. 177-93 (in Russian).

Distribution of radioactive elements ( $U, K, T h$ ) along the cross section and area of a sedimentation basin indicates the age subdivisions in the deposits, and the stratigraphic boundaries. By establishing the laws governing the distribution of radioactive elements in the basin, it is possible to reconstruct the conditions existing in the sedimentation region (tectonic conditions, climate, physical-chemical situation of the basin), the composition of the rocks, and the size and configuration of the basin, relief of the sea bottom, lithol.-facial zones, etc. There is a large range in the changes of $U$ content within each stratigraphic complex, varition ranges in each age complex, and a relatively regular decrease in the $U$ cuntent upwards in the section. Paleogeographic reconstructions are possible. The maximum $U$ quantities are related to accumulations of humus type organic matter. Increased clayiness of the carbonates is accompanied by increased Th and $K$ content and increased Th/U ratio. (CA)

Alekseev, F. A., L. G. Bondarev, V. L. Zverev and A. 1. Spiridonov. 1973. Effect of the Radioactivity of Atmospheric Precipitation on the Isotopic Composition of Uranium in Lake Issyk-Kul in Relation to Its Age Determination. Geokhimya. No. 5:787-90 (in Russian).

The isotopic composition and $U$ content in the eolian silts in. Lake Issyk-Kul indicate an age of 110-220 thousand years. This was proven by recent geologic and geomorpholic studies of the River Chu which supplies water to the lake. $(\mathrm{CA})$ 
Almdovar, I. 1960. Thorium Isotope Method for Dating Marine Sediments. U. S. Atomic Energy Commission. NY0-8919.

A radiochemical modification of the $I 0\left(T h^{230}\right)$, was developed. A sample of chemical and radiochemical pure $T h$ is isolated from the sediment sample. The $T^{2} 230 / T h 232$ activity ratio is determined from the time dependence of the total $\beta$ activity of the sample. The latter ratio is equal to the U238/Th232 activity ratio. The difference $I=(T h 230 / T h 232)-(T h 234 / T h 228)$ is the Io excess on a Th-normalized basis. It is related to the age $T$ of the sample by $I=I_{0} e^{-\lambda T}$, where $I_{0}$ is the effective value of $I$ at the time of deposition and $\lambda$ is the disintegration constant of Io. (NSA)

Amiel, A. J., D. S. Miller and G. M. Friedman. 1972. Uranfum Distributiun in Carbonate Sediments of a Hypersaltile Puul, Gulr or Elat, Red Sea. ISr. J. Earth-Sci. 21:187-91.

Two kinds of laminites exist interlayered between blue-green algal mat carpets of a hypersaline pool, fibrous aragonite and cryptocrystallirie high magnesian calcite. Cryptocrystalline laminites contain more U (15 ppm) than fibrous laminites $(3.5 \mathrm{ppm})$. Organic $C$ in laminites is 1.1-1.4 weight percent. The organic phase ties up 35 percent of total $U$. Increased $U$ concentration in cryptocrystalline layers is related to organic matter precent in these layers and to fine crystal size and greater specific surface area. In nonorganic matter $U$ occurs in exchangable as well as in absorbed sites from which $U$ can be readily removed by leaching with distilled water. (CA)

Ananyan, V. L. and A. S. Aretisyan. 1971. Contents of Radiunl arid Thorium in the Soils of Armenia Soobshch. Inst. Agrohkum. Probl. Gidroponiki, Akad. Nauk. Arm. SSR. No. 11:5-13 (in Russian).

Studies have shown that the contents of radium and thorium are largely linked with the characteristics of soil-forming rocks. There is no solid link between the humus and calcareousness of radioactive elements. In chernozem soils the contents of radioactive elements increases to some extent. (auth)

Andraschko, J., P. Stipanits and F. Hecht. 1964. The Enrichuieit of Uranium on Peat. Mikrochim. Ichnoanal. Acta. No 1:124-35 (in German).

The exchange and adsorption mechnnisms that are active in the accumulation of trace elements, especially uranium, in peats under natural circumstances were studied. The maximum ion exchange capacity of peat for $\mathrm{Mg}$, Fe, and $U$ were found to be around 0.3 to $0.5 \mathrm{meq} / \mathrm{g}$. (auth)

Andreev, A. G., V. S. Komarov, A. P. Lopatkina and A. N. Sergeev. 1969. Estimation of Age of Uranium-Bearing Hydromorphous Soils on the Basis of Ionium Accumulation. Geokhimiya. No. 6:724-8 (in Russian). 
Conditions for making age determinations on the basis of ionium accumulation for the case of hydromorphous soils with high uranium content were considered. Equilibrium between the solid and liquid phases in places of contact of feeding uranium-bearing waters with organic material is comparatively rapidly set within several years. The concentration of ionium carried into hydromorphous soils together with uranium, may be negligible and not be taken into account when estimating the age. The age of thin bog soils with high uranium content, which was estimated in three regions of Eastern Siberia, varied in the ranges of 1600 to 2800 years. The age of buried soil with a 40 to $50 \mathrm{~cm}$ depth has been estimated as being 4800 years. (auth)

Andreev, A. G., V. S. Komarov, A. P. Lopatkina and A. N. Sergeev. 1969. Evaluation of the Ages of Uranium-Bearing Hydromorphic Soils From the Accumulation of 230 Th. Geochem. Int. No. 6:580-4.

Hydromorphic soils of high uranium content may be dated by the $\mathrm{U} /{ }^{230} \mathrm{Th}$ method if: the age of the uranium accumulation is the same as that of soil formation; allowance can be made for the 230Th content of the soil-forming water; and there is no migration of $U$ or Th beyond the accumulation area. The ages of shallow hydromorphic soils in three areas in East Siberia are between 1600 and 2800 years, in agreement with carbon-14 ages. (auth)

Ananymous. 1968. A Study of Natural Radioactivity in Brazi1. NY0-2577-10.

Studies in two areas of high natural radioactivity in Brazil are reported. The areas include Guarapary, in the monazite sand region, and Moro do Ferro, in an area of volcanic intrusives. Thermoluminescent dosimeters were distributed to selected individuals residing in Guarapary and collected approximately six months later. Uncertainties in the dose rate measurements on the environment made by this method are discussed. Measurements of $\mathrm{Rn}$ and Th decay products in air and respirable dusts were not satisfactory. A whole-body counter was constructed. Plants collected from the Morro do Ferro area were analyzed for $\mathrm{Ra} 224$ and $\mathrm{Ra} 226$. Data on several species of Clethraceae and Melastonataceae are presented. (NSA)

Anonymous. Deposition Rates by the Protactinium Method. TID-21522 (A1-19).

Results are presented of analyses of five deep sea drill cores chosen to represent various sediment types and ocean basins. Core data are tabulated on $231 \mathrm{~Pa}$ leaching, $\mathrm{CaCO}_{3}$ content and age. Date are also included on accumulation rates of $230 \mathrm{Th}$ and $231 \mathrm{~Pa}$ in the specimens. Results of the investigation indicate that the ionium method may be unreliable and that the $\mathrm{Pa}$ method is more dependable. (NAS)

Antal, P. S. 1966. Diagenesis of Thorium Isotopes in Deep Sea Sediments. Limnol. Oceanog, 11:278-92. 
227Th, $230 \mathrm{Th}$, and ${ }^{232} \mathrm{Th}$ were extracted from Caribbean Sea sediment samples of known age using $8 \mathrm{~N} \mathrm{HNO}_{3}$ or concentrated $\mathrm{HCl}$. The yields were compared with the radionuclide content obtained by complete dissolution of the sample and with previously reported data on red clays in Pacific Ocean cores. These comparisons indicated that the internal consistency of dates and sedimentation rates is insufficient to prove the validity of leaching procedures. The nitric acid leaching yields of authigenic $230 \mathrm{Th}$ decreased with depth in the core, that is, with sample age; whereas leaching of 232 Th was independent of depth. It is suggested that the initially soluble precipitate of $230 \mathrm{Th}$ is transformed in the sediment to a more acid-resistant state, with the apparent half life of this transformation as 24,000 years at $3 C$. Therefore, in the solution obtained by partial extraction, the decrease of the ratio $230 \mathrm{Th}: 232$ Th with depth in the core is due not only to radioactive decay but also to the decreased solubility of authigenic $230 \mathrm{Th}$. Thus, sedimentation rates calculated from (230 Th:232Th) solution may be too low by a factor of three. (auth)

Armands, G. and S. Landergren. 1960. Geochemical Prospecting for Uranium in Northern Sweden: the Enrichment of Uranium in Peat. Intern. Geol. Congr., Rept. 21st Session, Copenhagen, Part 15:51-66.

Analyses of peat from Masugnsbyn showed an average content on a dry-matter basis of $600 \mathrm{ppm} \mathrm{U}(=900 \mathrm{ppm}$ in the original component). Analyses of spring waters within the bog showed an average of $0.1 \mathrm{ppm} U$. Profiles across the bog show considerable variation of $\mathrm{pH}$ and $U$ content; similar variations were shown by determinations of $U$ content of plants (betula alba, B. nana, Salix, and Alnus). Twigs contain much more $U$ than do leaves. Leaching experiments on $\mathrm{Fe}$ ore from the region that contained 0.05 percent $U$ showed that 12-26 percent of the $U$ could be leached by $\mathrm{NaHCO}_{3}$ solutions in four days; the $U$ in the bog probably came from leaching the Fe ore by groundwater bicarbonate solutions. (CA)

Baeva, A. I. 1964. Uranium Content in the Black Soil of the Kadabek Region (Caucasus). Izv. Akad. Nauk. Azerb. SSR. Biol. Nauk. 5:89-93 (in Russian).

The content of $U$ is $1.0 \mathrm{ppm}$ in the upper horizon, $2.0 \mathrm{ppm}$ in the next horizon, about 50-80 $\mathrm{cm}$ from the surface. The lower horizon has the same amount of $U$ as the base, which is composed of granite rocks. (CA)

Baeva, A. I. 1967. Uranium and Thorium Levels in Soils in Relation to the Bedrock. Tr. Inst. Pochvoved. Agrokhim., Akad. Nauk. Azerb. SSR 25:151-9 (in Russian).

$U$ content (by the luminescence method with $\mathrm{ZrOCl}_{2}$ as the carrier). Th content (Savvin and Bagreyev, 1960), humus, $\mathrm{CaCO}_{3}^{2}$ and $\mathrm{pH}$ were determined in layers down to the $42-155 \mathrm{~cm}$ deep bedrock in a total of 9 highland and 
steppe chernozem and brown forest and meadow soils from the Malyy Caucasus range in Transcaucasia. The bedrock of individual soils was quartz diorite, hydrothermally modified andesite, quartz and kaolin porphyrites, serpentinite, alunitized rock, and limestone. In the bedrock the $U$ content ( $\mathrm{ppm})$ varied from 0.1 in the quartz diorite to $0.75 \%$ in the sandesite, and the Th content varied from $0.36 \%$ in the serpentinite to $1.2 \%$ in the quartz diorite. The $U$ contents in the soils varied from 0.1 to $5 \mathrm{ppm}$ and the Th from 0.13 to $5.4 \%$, with the Th/U ratio ranging from 2.4 in the $70-93 \mathrm{~cm}$ layer of a highland meadow soil on a quartz-porphyrite rock to 173 in the 35-46 cm layer of a highland-steppe soil on andesite. The $U$ and Th contents tended generally to be higher in the alluvial layers of these soils, while the Th content was generally higher in soils with a light mechanical composition. (CA)

Bain, G. W. 1953. Experimental Simulation of Plateau Type Uranium Deposits. RMO-44.

Experimental simulation of Colorado Plateau type $U$ deposits is divided into seven parts. The first three summarize the essential features of geological occurrence for the ores. The last four parts outline the results of experimental investigation arranged according to each geological group of features influencing mode of occurrence. Both field distribution and laboratory approaches to the problem suggest that the origin for the $U$ and for the $V$ are disconnected problems. The plateau ores occur in or adjacent to fluviatile sediments and generally avoid flood plain and aeolian accumulations. For this reason, a large part of the rocks of the plateau section are not potential host to economic deposits. The principal deposits occur well down towards the bottom of synclines and are there distributed frequently along a near-contour line; this ore axis may transgress several strata although it stays usually on contour in a stratum. Of the several explanations suggested, only the one attributing the ore to slight redistribution by artesian groundwater fails to leave anomalous situations. The structural and physiographic history of the region indicates earliest age for artesian circulation as late cretaceous and the youngest age as the Canyon Cutting cycle of the late Pliocene. The ores came into their present site during this time interval. The red jasperoid pebbles of the Shinarump conglomerate carry a small amount of the primeval uranium of the Plateau deposits. The direction to the source for these pebbles was indicated by field studies. The modification of detritus during transportation was investigated experimentally to estimate how far they had come. Rate of change in size of grain and sphericity of grain was measured under controlled conditions and a source estimated to be along the westward extension of the Uncompahgre axis almost 30 miles northwest from the Dirty Devil claims on the San Rafael Swell. Other source regions are believed to have supplied the primeval uranium as heavy detrital minerals and as uraninite occluded in the jasperoid pebbles. The deposition of heavy minerals in intermittent streams was investigated experimentally and the sites determined. Principal deposition occurred in-channel just below scour pools on meanders. Heavy mineral deposition 
occurred during flood stage and the accumulation was covered by various deposits of the ebb stage. The patterns of the deposits indicated a groundwater flow parallel to structural axes at far below the watertable level in existence when the ores were formed. A simulated aquifer showed that this happens and that the principal groundwater discharge occurs along paths parallel to structures at far below the watertable and near the structural axis of synclines. The effect of rate of recharge and plunge of the structural axis was investigated and the results are presented. Factors influencing precipitation of uranium from uranyl solutions were investigated and it was found that the principal cause for precipitation was reduction in availability of the "vehicle" anion for the uranyl cation. Uranyl sulphate was the principal solution studied. Calcite and $\mathrm{V}_{2} \mathrm{O}_{5}$ abstractcd $\mathrm{SO}_{4}$ ion and caused precipitation of uranium. Precipitation in the case of calcite was proportional to the original uranyl ion concentration and to the thickness of calcite penetrated. Vanadium was very effective in removing $\mathrm{SO}_{4}$ ion and caused precipitation of uranium up to exhaustion of the $\mathrm{V}_{2} \mathrm{O}_{5}$. Many materials, hitherto considered important precipitants, were found to have only minor influence unless accompanied by an $\mathrm{SO}_{4}$ ion "abstractor." (auth)

Baranov, V. I. 1964. Natural Radioactivity of 0ceans. AEC-Tr-6641:7-9.

Contents of naturally-occurring radioisotopes and fission products from fallout in oceans are discussed. Data show that most of the natural radioactivity of sea water is due to $40 \mathrm{~K}$. Uranium-238 contributes the largest part of the alpha activity. In bottom sediments ratios of radioisotopes differ markedly from those in the sea water and the predominating radioisotopes are ${ }^{226} \mathrm{Th}$ and $\mathrm{Ra}$. (NSA)

Baranov, V. I. 1964. Natural Radioactivity of Soils. Izv. Akad. Nauk SSSR. Ser. B101. No. 1:159-63 (in Russian).

The estimation of artificial soil radioactivity from the difference of total radiation assayed radiometrically and radiation of potassium computed from its content in the soil can be regarded as quite valid. However, as a standard of potassium radiation in the soil, use should be made of a soil sample with a definite potassium content rather than of potassium salts. But to assay the soil content in certain radioisotopes, both natural and artificial, use should be made of chemical-analytical or radiochemical methods. The conventional radiometric technic without nuclear spectroscopy cannot substitute a quantitative assay of the major components of soil radioactivity, such as $U$, Th, $K$, and the conclusions based on the readings of radiometric devices might be at variance with the actual pattern and thus devoid of scientific significance. (auth) 
Baranov, V. I. and L. A. Khristianova. 1963. Radioactivity of Ocean Sediments. Khim. Zemnoi Kory, Akad. Nauk SSSR, Tr. Geokhim. Konf. $1: 401-8$.

A radiochemistry study of upper horizons of bottom sea sediments in the northwestern part of the Pacific Ocean was made from samples and cores taken in various parts and formation (terrigenous sediments, diatomaceous sediments, foraminiferal sediments, red deep-sea clays, and volcanic sediments). Maps of $\mathrm{Th}^{230}$ and Th contents and their distribution were plotted. Th232 in the sea sediments is of continental or volcanic origin; most of the $\mathrm{TH}^{230}$ was formed from $U$ in the sea water and only $25 \%$ of the Th230 is of continental origin. The clay fraction in all types of ocean sediments has an Th230: Th ratio increasing from 30 in terrigenous to 50 in pelitic formations. Increase of the Th230: Th ratio from sands, to silts, and to muds indicates that the $\mathrm{Th}^{230}$ in sea water is in a form more easily sorbed than Th. A similar effect was observed with Ra; the clayey fractions are 10 times richer in $\mathrm{Ra}$ than sands. The behavior of $U$ is quite different. Its content in all types of sediments is about the same and does not depend on the granulometric composition of sediment. The Th: $U$ ratio in all types of sediments is $\leqq 1.7-1.8$ in clayey fractions and $\leqq 0.3-0.7$ in sands and silts. The $T^{230}: U$ ratio in all types and all fractions (in silts it is 4 and in clays 7-10) indiçates a distinct radioactive disequilibrium caused by predominance of $T^{230}$ over $U$. The Ra:U ratio has the same character as the $T T^{230}: U$ ratio. (CA)

Baranov, V. I. and L. A. Kuzmina. 1954. Ionium Method for the Determination of the Age of Oceanic Mud Sediments Direct Determination of Ionium. Doklady Akad. Nauk SSSR. 97:483-5.

The radioactive method was used to determine the rate and age of sedimentation of cores from the Okhotsk Sea (I) and of red clay cores from the Pacific Ocean (II). The Ra content was of the order of $2 \times 10^{-12} \mathrm{~g} / \mathrm{g}$ of $I$ and 10 times as great for II. Sea water contains an excess of $U$, owing to soluble carbonate complexes; the sea deposits an excess of insoluble $\mathrm{Ra}$ and Io, as compared to radioactive equilibrium. The Th and In are extended and concentrated by treatment with $\mathrm{Na}_{2} \mathrm{O}_{2}$, solution in $\mathrm{HCl}$, precipitation by $\mathrm{NH} 40 \mathrm{H}$, precipitation as fluoride with La as carrier, the gractional crystallization. (CA)

Baranov, V. I. and L. A. Kuzmina. 1957. Content of Radioactive Elements in the Bottom Deposits of the Pacific Ocean in the Region of the Japanese Islands. Geokhimiya. No. 1:23-32.

The purpose was to elucidate the relationship of the behavior of Io to the $\mathrm{Mn}, \mathrm{Fe}$, and $\mathrm{Si}$ content in 5 columns and 7 samples obtained by bottom dredging. $\mathrm{SiO}_{2}, \mathrm{Fe}_{2} \mathrm{O}_{3}$, and $\mathrm{MnO}$ were determined. The content of Th in the upper layer was approximately 5 to $6 \mathrm{ppm}$, the $U$ concentration amounted to 2-3 ppm, and the Th/U ratio fluctuated from 1.3 to 4.3 . From the studies a great 
constancy was found for the Th content. This indicated absence of migration of isotopes of Th. The absolute concentration of Io more regularly decreased with depth, thus explaining the more complex mechanism of increase of Io on the sea bottom, rather than simple absorption by sesquioxides. (CA)

Baranov, V. I. and L. A. Kuzmina. 1958. Radiochemical Analysis of Deep Sea Sediments in Connection with the Determination of the Rate of Sediment Accumulation. Radioisotropes Sci. Research, Proc. Intern. Conf., Paris, 1957. 2:601-18.

A radiochemical method has been evolved for determining the content of the radioisotopes $\mathrm{U}^{238}$, $\mathrm{Th}^{232}$, $\mathrm{Th}^{230}$, and $\mathrm{Ra}^{226}$ in sea deposits. A general picture has been obtained of their distribution in the sca silt of the Kurile and Japanese Islands. Calculations have been made of the rate of sedimentation of the shifting of radioactive equilibrium in the series of $U$ decay products at various depths of the core. (CA)

Baranov, V. I. and N. G. Morozova. 1973. Behavior of Natural Radionuclides in Soils. Radioecology, Klechkovskii, V.M. (ed.), John Wiley \& Sons, NY, 3-29.

Natural radioactivity of soils is reviewed with emphasis on the geochemical aspects of the radioactivity. Tables are presented to show concentration of naturally radioactive $U, R a$, Th, and $K$ in soils of various countries and in various types of soils in the USSR. The concentration and distribution of natural radionuclides in major soils of some soil-climatic zones of the USSR are discussed. Radiogeological soil maps are considered along with their use in establishment of the general behavior of radionuclides in the planetary soil cover and determination of the role played by the soil-forming process in the geochemistry of natural radionuclides. (NSA)

Baranova, V. I., N. G. Morozova, T. G. Akimova and A. V. Orlova. 1968. Natural Radioelements in Surtace and Soil-Subsoil Waters. Geokhimiya. No. 3:334-41 (in Russian).

Data on the radium, uranium and thorium content in soil-subsoil waters, lake and river waters of the Estonian Soviet Socialist Republic are given. It is shown that the Ra-coptent changes in the ranges of $n \times 10^{-14}$ to $n \times 10^{-13} \mathrm{~g} / 1, \mathrm{U}-\mathrm{n} \times 10^{-9}$ to $n \times 10^{-6} \mathrm{~g} / 1$ and $\mathrm{Th}-\mathrm{n} \times 10^{-8}$ to $\mathrm{n} \times 10^{-7}$ $\mathrm{g} / 1$. In all types of surface waters equilibrium between $U$ and $R a$ is lacking. In soil-subsoil waters, lake and river waters the equilibrium is displaced towards $U$ dominance over $\mathrm{Ra}$. In the same type of waters radium makes up 20 to $50 \%$ of the equilibrium amount with uranium being contained. In lysimetric soil waters and acid waters of low-land bogs $\mathrm{Ra}$ is present in an amount considerably exceeding the equilibrium amount with contained uranium. In surface waters of all types the Th:U ratio $\ll 1$ (with an average value of 0.1 to 0.4 ). (auth) 
Baranov, V. I., N. G. Morozova and K. G. Kunasheva. 1966. Natural Radioactivity of Soddy Carbonate Soil in the Estonian S.S.R. Radioaktiv. Pochv. Metody Fe Opred., Akad. Nauk SSSR. pp. 195-212 (in Russian).

The occurrence of $\mathrm{Ra}$ and Th in peat-carbonate soil of the Estonian S.S.R. has a regional character. Three zones can be observed: the central Estonian zone has a normal $\mathrm{Ra}$ and Th content $(0.7-1.2) \times 10^{-10}$ and $(6-12) \times$ $10^{-4} \%$, respectively, and the southern zone has $(0.3-0.5) \times 10^{-10}$ and (4.7) $x$ $10^{-4} \%$, respectively. The distribution of $\mathrm{Ra}$ and $\mathrm{Th}$ in the soil profile is determined by the type, intensity, and duration of the soil-forming process. Cultivation does not alter the distribution of $\mathrm{Ra}$ and $\mathrm{Th}$ in the soil profile, when the tilling is not lower than the humus horizon. The maximum accumulation of $\mathrm{Ra}$ and $\mathrm{Th}$ in peat carbonate soils in moraine moves from the surface humus horizon $A$ to the depth in the illuvial horizon of well developed zones. Assimilation of radioactive elements in soil horizons takes place simultaneously with soil development. (CA)

Baranov, V. I., N.G. Morozova, K. G. Kunasheva, G. I. Grigorev, and V. I. Vernadskii. 1963. Geochemistry of Some Natural Radioactive Elements in Soil. Soviet Soil Sci. No. 8:733-40.

Studies were made of the average content of natural radioisotopes in soil groups of various climatic zones in the USSR and their distribution by genetic horizons. Soil samples were analyzed for radium and thorium by ordinary radiochemical methods. Data are presented in tables. Preliminary investigations showed that there was no significant deviation in the soil samples from the radioactive equilibrium between uranium and radium. The thorium content of different soils varied 400 -fold and the radium content 100-fold, whereas the content in the underlying rock was within one order of magnitude. Organic matter was found to play an important role in the mirgration of radioelements. Soils rich in organic residues had the lowest $\mathrm{Th}: \mathrm{Ra}$ ratio. (NSA)

Baranov, V. I., A. B. Ronov, and K. G. Kinashova. 1956. On Geochemistry of Dispersed Thorium and Uranium in Clays and Carbonate Rocks of Russian Platform. Geokhimiya No. 3:3-8.

In sedimentation processes $U$ migrates to a considerable extent in the form of soluble compounds, whereas Th migrates in colloidal form. Magnitude of Th: $U$ ratio is twice as large in clays as in carbonate rocks, and in the latter Th is contained in the insoluble portion. Clays of the Russian Platform contain on the average 1.] $\times 10^{-3 \%}$ Th and $4.1 \times 10^{-4} \% \mathrm{U}$; carbonate rocks $2.4 \times 10^{-4} \%$ Th and $2.1 \times 10^{-4 \%} \mathrm{U}$. Maximum content of Th is noted in rocks formed during periods of most intensive erosion of crystalline rocks or shell of weathering. Content of $U$ in rocks of different composition and geological age varies to a considerably lesser extent than than of Th. A certain enrichment in $U$ is observed in rocks having an increased content of organic substances. (NSA) 
Baranov, V. I. and N. I. Titaeva. 1961. Uranium, Thorium, Radium, and Ionium Content in the Quartenary Deposits of the River Lena. Geokhimiya. No. 2:110-14 (in Russian).

Data are given on the content of radioactive elements in young continental sedimentary formations of Siberia. Uranium capture from aqueous environment by sediments with a high content of organic matter is ascertained. The enrichment of the sediments in uranium on the background of low thorium, radium, and ionium contents is indicative of the possibility of using the ionium method to ascertain the time of their formation. (auth)

Barsukưv, V. L., T. M. Sushchevskaya and B. I. Malyshev. 1971. Composition of Solutions Responsible for the Formation of U-Mo Deposits. At. Energ. (USSR). $31: 28-34$ (in Russian).

The composition of hydrothermal solutions, which formed typical U-Mo ore deposits, was evaluated on the basis of gas-liquid inclusions in pilchblende and uraninite-bearing minerals. Aqueous extracts were analyzed for $\mathrm{Na}, \mathrm{K}, \mathrm{Ca}, \mathrm{Mg}, \mathrm{Cl}, \mathrm{SO}_{4}$, and $\mathrm{HCO}_{3}$, and the thermodynamic instability constants of a number of Ca salts at 25 and $150^{\circ} \mathrm{C}$ were calculated as the basis for further discussion of the mechanics of ore formation. (NSA)

Bates, T. F. and W. Spackman. 1965. An Investigation of the Mineralogy, Petrography and Paleobotany of Uranium-Bearing Lignites. Final Research Report. NYO-10361.

A summary is presented of a research program which was conducted to study the uranium complexes in uraniferous lignites, and to develop geological, mineralogical, petrographic, and paleobotanical criteria for locating other sources of uranium. The program covered the following areas: mineralogy of western lignites and related sediments, autoradiography, chemistry and petrography of western lignites and related sediments, palynology of Dakota lignites, and modern phyto-organic sediments and sedimentary environments. (NSA)

Baturin, G. N. 1966. Uranium Content in Caspian Sea Sediments. At. Energ. $21: 515-16$ (in Russian).

The content of $U$ in 34 samples of Caspian Sea sediments, taken across the sea bed, varied 1.0-23 ppm. The maximum content of $U$ was found in sedimenls from the central part of the middle Caspian Sea syncline and the minimum in the sediments from the western shelf of the sea. The data are compared with the $U$ content in the Caspian Sea water $(6.5-10) \times 10^{-6} \mathrm{~g} / 1$, and with $U$ content in waters and sediments from the Black Sea and the Baltic Sea. The experimental data disproved the theory that the accumulation of $U$ in sea sediments is connected with the presence of $\mathrm{H}_{2} \mathrm{~S}$, which is absent in Caspian Sea water. (CA) 
Baturin, G. N. 1968. Geochemistry of Uranium in the Baltic Sea. Geokhimiya. No. 3:377-81 (in Russian).

The content of $U$ in the surface layers of sediments of the Baltic Sea varies from 1 to $4 \times 10^{-4} \%$ in the coastal deposits and from 5 to $20 \times 10-4 \%$ in deeplying clay and silt-clay sediments. The distribution of uranium in the sediments of the Baltic Sea is of the well-regulated type with distinct pelagic maximum. The concentration of uranium in the sediments and its distribution per surface was controlled by the content and distribution of the organic material. The hydrogen sulfide contamination of water near the ground, having a local and sporadic character, is not a basic factor in the concentration of uranium in sediments of this basin. One of the reasons for the low $\mathrm{U} / \mathrm{C}_{\text {org }}$ relation in the sediments of the $\mathrm{Baltic}$ Sea is the low content, in comparison with other seas, of dissolved $U$ in its waters. (auth)

Baturin, G. N. 1969. Uranium in the Surface Layer of Sediments in the Northwestern Part of the Indian Ocean. Okeanologiya. 9:1031-7 (in Russian).

The average content of $U$ in sediments of the northwestern Indian Ocean is the same as that in sedimentary rocks on the continents. Higher $U$ concentrations are reported in two samples with high organic $C$ content, and in fish scales. U concentrations are not related to the quantity of pelitic fractions, but are inversely proportional to $\mathrm{CaCO}_{3}$ concentrations and are correlated with organic $C$ and $P$. Relatively high $U$ concentrations are confined to shelves and the continental slope. The concentrations are minimum in sediments of the abyssal plains.

Baturin, G. N. 1971. Uranium in Solutions of Ooze Deposits in the Southeastern Atlantic. Dok1. Akad. Nauk. SSSR. 198:1186-8 (in Russian).

Determinations of uranium were made in ooze solutions of deposits after separation from the core samples under pressure. A range of 1.3 to 650 $\mu \mathrm{g} \mathrm{U} / 1$ was recorded for the samples under test; in the majority of cases the $U$ content was significantly greater lhan in the ocean waters $(3.2 \mathrm{~g}$ $U / 1)$. A correlation between $\mathrm{pH}$ and $U$ content of samples is shown. (NSA)

Baturin, G. N. 1972. Phosphorites Found in Ocean Depths. Priroda (Moscow). No. 6:86-7 (in Russian).

Numerous fragments of (Lentatively) Tertiary metasomatic phosphorites and phosphatized rocks were taken from the Pacific 0cean bottom. The fragments consist of phosphatized coral-algae and foramiferal limestones in addition to phosphorites containing 20-32\% $\mathrm{P}_{2} \mathrm{O}_{5}$. The $\mathrm{U}$ in the phosphorites ( 80 samples) is 10-100 times lower (1-6 ppm) than the $U$ content in natural phosphorites. The guano from Peru and Fernandino and Christmas Island (Indian Ocean) contain $0.2,0.5$, and $0.4 \mathrm{ppm} U$. This suggests the genetic relation between phosphorites from submarine mountains and guano. The Pacific submarine mountains were islands during Tertiary time and phosphorites found there could be from guano. (CA) 
Baturin, G. N. 1972. Ratio of Average Concentration of Uranium to Organic Matter in Recent Marine and Oceanic Sediments. Dok1. Akad. Nauk SSSR. 207:186-9 (in Russian).

The conçentration of $U$ in recent marine and oceanic sediments is $1 \times 10^{-5}$ to $6 \times 10^{-3} \%$, the content of organic matter $0.1-15 \%$, and the U/organic $C$ ratio $(1-7) \times 10^{-4}$. A high U/organic $C$ ratio is characteristic of zones with a slow sedimentation rate. In submarine oceanic sediments, the calcareous and siliceous oozes have a low average concentration of $U$ with $234 U / 238 U<1$. (CA)

Baturin, G. N. 1973. Uranium During Sedimentation in the Black and Azov Seds. Litol. Polez. Iskop. No. 5:21-32 (in Russian).

In rivers of the Azov-Black Sea basin, U migrates predominantly in a dissoived state. The sediments of the Azov Sea exhibit a uniform distribution of $U$; in the Black Sea sediments, $U$ distribution is controlled by organic matter. The U/organic $i$ ratio in sedtments shows a sleddy illcrease duiling sedimentation. The deposition of $U$ from marine waters occurred, during a lowering of the $E_{H}$, at the interface water-sediment. (CA)

Baturin, G. N. 1973. Uranium in the Contemporaneous Sedimentary Cycle of the Sea.

During rocks weathering and in the river runoff, uranium is divided into the dissolved and the suspended one at an average 1:1 ratio. The average uranium content in the sum of dissolved and suspended matters of river runoff corresponds to its average content in the Earth crust; that determines uranium content in sea and ocean sediments. The share of hydrogenous uranium being concentrated in sediments of sea basins and the peripheric zones of the ocean up to (10 to 60$) \times 10^{-4} \%$ plays in the total balance a secondary role. This concentration is favored by the ericichment of sediments in organic matter and phosphorus, by the heightened uranium content in waters, by the reducing conditions near the boundary of water--bottom divide, by the slackened sedimentation rate, by the renewal of the nearbottom waters. Uranium transition from the soljd phase to interstitial waters, where its concentration reaches $n \times 10^{-4} \mathrm{~g} / 1$, is a precundilion of its redistribution during diagenesis. (auth)

Baturin, G. N. and E. M. Emel'anov. 1973. Distribution of Uranium in the Sediments of the Mediterranean Sea. Okeanologiya. 13:814-20 (in Russian).

Basic types of sea bed sediments were sampled from the $0-5 \mathrm{~cm}$ horizon and analyzed by chemical luminescence. The $U$ concentration was $2-50 \times 10^{-4} \%$, the mean value being $17 \times 10^{-4} \%$. The minimum $U$ concentration was found in coarse silts of the southern part of the basin and the maximum in the fine silty muds of the peripheral parts of the sea. U deposits show correlation with organic $C$. (CA) 
Baturin, G. N., T. D. ITyina, and N. I. Popov. 1971. Soviet Investigations of Natural Radionuclides in Marine and Ocean Sediments. Proc. Roy. Soc. Edinburgh, Section B, 72:183-91.

Investigations of the radioactivity of marine and ocean sediments, begun in the USSR in 1944, helped to reveal the basic traits of marine geochemistry of natural radioelements. Among them $U$ is the most mobile and 232Th the most inert in the marine sedimentary cycle. Considerable work has been done in developing the absolute dating methods based on the use of $\mathrm{Th}$ and $U$ isotopes. It seems that the $230 \mathrm{Th}-23 \mathrm{~T}_{\mathrm{Pa}}$ method is the most reliable for oceanic conditions. The determinations of the total radioactivity and the analysis of the gamma spectrum of marine sediments made in situ and in the laboratory are largely used for revealing tectonic structures as well as the facies composition and content of certain radioelements in sediments. (auth)

Baturin, G. N. and A. V. Kochenov. 1969. Migration of Uranium in Rivers and the Duration of Its Presence in Waters of the World's Oceans, Seas, and Lakes. Geokhimiya. No. 6:715-23 (in Russian).

The average uranium content in the total amount of dissolved and suspended materials of river run-off is similar to its average content in rocks of the Earth's crust. The rivers of the Earth every year supply the World ocean with approximately 20,000 tons of dissolved uranium and with approximately as much suspended uranium at a ratio of $1: 1$. In final run-off basins the prevailing.part of dissolved uranium is precipitated together with terrigenous material on shelfs and continental slopes. The time of dissolved uranium stay in waters of the basins varies from tens of years to hundreds of thousands years and depends on their depth. (auth)

Baturin, G. N. and A. V. Kochenov. 1973. Uranium in Interstitial Waters of Marine and Oceanic Sediments. Geokhimiya. No. 10:1529-36 (in Russian).

Interstitial waters were sampled from the Atlantic and Pacific 0cean and Black Sea diatomaceous and terrigenous shelf oozes, calcareous aleuropelitic continental silts, and eupelagic and miopelagic shales. Location of the sample (latitude and longitude), depth, type of sediment, moisture content, $\mathrm{pH}$, Eh, and organic $\mathrm{C}, \mathrm{CaCO}_{3}$, and amorphous $\mathrm{SiO}_{2}, \mathrm{P}$, and $\mathrm{U}$ contents are tabulated. The $U$ content in the interstitial waters has a wide variation (from $1.3 \times 10^{-6}$ to $650 \times 10^{-6} \mathrm{~g} / 1$ ) caused by the great diagenetic mobility of $U$. The $U$ content is controlled by the $\mathrm{pH}$, Eh, and the content of organic C. (CA) 
Baturin, G. N., A. V. Kochenov, and S. A. Kovaleva. 1966. Some Aspects of the Distribution of Uranium in Black Sea Waters. Dokl. Akad. Nauk SSSR. 166:698-700 (in Russian).

During the 16th voyage of the scientific-research ship "Mikhail Lomonosov" in August-September 1964, 46 samples were taken at various depths of the waters of the Black Sea at 16 different stations, including 15 samples of the bottom layer. According to the determinations, the uranium content of the Black Sea waters (except the bottom layer) ranges from $2 \cdot 10^{-6}$ to $4 \cdot 10^{-6} \mathrm{~g} / 1$, the average being $2.8 \times 10^{-6} \mathrm{~g} / 1$. The uranium content of the bottom layer is much lower, frequently dropping to $n \times 10^{-7} \mathrm{~g} / 1$. This is attributed to the removal of uranium by adsorption on the sediments. One of the major factors in the adsorption of uranium by the sediments is thought to be the presence in the latter of organic matter whose particies can occlude this metal while it is still precipitating in the mass of the water as a result of its reaction with hydorgen sulfide contaminating the water. (NSA)

Baturin, G. N., A. V. Kochenov, and Y. M. Senin. 1971. Uranium Concentration in Recent Oceanic Sediments of Water Uprise Zones. Geokhimiya. No. 4:456-62 (in Russian).

Uranium concentration in recent oceanic sediments in water uprise zones (i.e., of permanent ascending currents) is several times higher near the shores of continents in comparison with deep-sea oceanic sediments. Biogenic and diagentjc phosphates, which are present in these sediments, accumulate up to $10^{-3}$ to $10^{-2}$ \% of uranium. In both cases uranium concentration occurs by the way of extraction from sea water. Uranium precipitation in these regions is connected with the accumulation of organic matter and phosphorus in bottom sediments and with hydrogen sulfide contamination of benthonic waters. The intensive supply of organic matter and phosphorus to sediments of shelf zones is condltioned by their high biological productivity and by periodical mass starvations of the fauna. (auth)

Baturin, G. N., A. V. Kochenov, and K. M. Shimkus. 1967. Uranium and Minor Metals in Columns of Bottom Sediments of the Black and Mediterranean Seas. Geokhimiya. No. 1:41-50 (in Russian).

The similar distribution of metals ( $U$, Mo, Co, $\mathrm{Ni}$, and $V$ ) was observed in sedimentary columns of the Black and Mediterranean Seas. The metal distribution was correlated with that of organic substances. In bottom sediment columns of the Black Sea the correlation with organic $C$ was most typical for $U$ and Mo. The correlation of rare metals and $C_{o r g}$ in the sedimentary columns was contrastingly different from the surface layer of muds. This indicated the diagenetic redistribution of rare metals in the sea sediments. The transformation of organic substances was the main factor affecting mobility of metals in the sedimentary 
formations. Diagenetic redistribution of $\mathrm{Mo}, \mathrm{Co}, \mathrm{Ni}$, and possibly $\mathrm{V}$ was partly related to the formation of pyrite and Fe-Mn microconcretions. The accumulation of $U$ and enrichment of mud in organic substances occurred both during sedimentation and during diagenesis of sediments. The movement of $U$ in the marine sediments was related to the migration of bituminous part of organic substances. The concentration of $U$ in organic components of the Black Sea sediments depended on the rate of sedimentation.

22 references. (CA)

Bel1, K. G. 1960. Deposition of Uranium in Salt-Pan Basins. U.S.G.S. Professional Paper No. 354-G:161-9.

Drainage waters carry minute quantities of uranium into oceans, inland seas, and lakes, and when bodies of water evaporate completely in desiccating salt-pan basins, the uranium must be deposited together with all other dissolved materials. The ratio of uranium to total evaporite sediments is approximately $1: 2 \times 10^{7}$. The distribution of uranium in salt-pan basin sediments is not completely known. Some organic-rich muds, and phosphatic sediments deposited in desiccating basins may contain uranium in amounts as large as $0.0 x$ percent. Uranium may be adsorbed on clays that are deposited with some evaporite sediments. These muds, phosphatic sediments, and clays may remove nearly all of the dissolved uranium from the water of some basins. Anhydrite, gypsum, halite, and potassium-bearing evaporite minerals probably are the lease uraniferous of all rocks in the earth's crust; their uranium contents generally are less than 0.00001 percent. Within salt-pan basins where oxidizing conditions tend to prevail, and no significant amounts of organic-rich muds, clays, and phosphatic sediments are deposited, highly soluble uranium salts remain in solution and are deposited only as the basin finally is completely desiccated. These final highly soluble evaporite sediments are not likely to be preserved because they are subject to removal by wind erosion and leaching. (auth)

Bell, K. G. 1960. Uranium and Other Trace Elements in Petroleums and Rock Asphalts. U.S.G.S. Professional Paper 356-B.

Uranium is a minor trace-element constituent of petroleums and their natural derivatives. The quantity of uranium in crude oils produced by primary-recovery processes generally ranges from none to $5 \mathrm{ppb}$ al though some crude oils may contain as much as a few tens of parts per billion. The average uranium content for all crude oil is estimated to be about $1 \mathrm{ppb}$, or about one-third that of the average content of sea water. Paraffin-base crude oils have the smallest uranium content, less than $1 \mathrm{ppb}$. Mixed-base and asphalt-base crude oils, in general, contain a slightly greater quantity of uranium and show a rough positive correlation between specific gravity and uranium content. There is no correlation between uranium contents of crude oils and geologic ages of reservoir rocks. Crude oils from one region are no more uraniferous than those from any other, except perhaps as a result of local predominance of heavy aromatic and asphaltic constituents. As a group, the crude oil of the 
Colorado Plateau and Rocky Mountain regions, both being uraniferous provinces, contain less-than-average quantities of uranium, a condition that is attributed to predominance of paraffinic constituents. Crude oils produced by secondary-recovery processes utilizing water flooding and detergents apparently contain above-average quantities of uranium, possibly because they contain asphaltic residues that are removed from pore walls of reservoir rocks. The mode of occurrence of uranium in petroliferous materials and the source of the uranium have not been determined. The bituminous constituents of rock asphalts contain as much as a few thousand parts per billion of uranium, the average being about $1000 \mathrm{ppb}$, a concentration that is about a thousand-fold increase over than in crude oils and probabiy a somewhat smaller increase over that in petroleums. It is believed that the bitumens extract uranium from the host rocks. There seems to be a positive correlation between the uranium content of the bitumens and that of the host rocks. There is no evidence that petroleum acts as an ore-forming fluid for uranium. $0 i 1$ field waters containing dissolved organic substances extracted from petroleum, and hydrogen sulfide, may provide a reducing environment in which uranium brought in by ground water or hydrothermal solutions may be precipitated at the interface of the solutions. Crude oil is not a practical source material for uranium; the total uranium content of the crude oil reserves of the United States does not exceed 5 tons. The bitumens of the rock-asphalt deposits of the United States contain several hundred tons of uranium, but, because these bitumens are dispersed in several billion tons of rock, they are not practical source materials for uranium. (auth)

Bender, M., W. Broecker, S. S. Sun, and P. Biscaye. 1971. Geochemistry of Three Cores From the East Pacific Rise. Earth Planet. Sci. Lett. 17.:475- 33.

Sedimentation rates of a core from the crest and two cores frum the flduk of the East Pacjfic Rise were determined from the depth variations of their excess 230 Th content. Composite strip samples from these three cores were analyzed for $\mathrm{Mn}, \mathrm{Fe}, \mathrm{Ni}, \mathrm{SiO}_{2}, \mathrm{Al}_{2} \mathrm{O}_{3}, \mathrm{NaCl}$, and mineralogy, and the rare earth contents and isotopic computation of $\mathrm{Pb}, \mathrm{Sr}$, and $\mathrm{U}$ were determined in the crest core. The Mn accumulation rate of the crest core is 25 times higher than the world average; at least some of the elements in these sediments derive from local volcanism. The relative concentrations of the rare earth elements and the isotopic computation of $\mathrm{U}$ and $\mathrm{Sr}$ in the crest core indicate that these elements derive from sea water. The isotopic computation of $\mathrm{Pb}$ in the crest core indicates that the $\mathrm{Pb}$ is mostly of local volcanic origin. (CA)

Bennett, J. H. and 0. K. Manuel. 1968. Iodine Abundances in Deep-Sea Sediments. J. Geophys. Res. 73:2302-3.

I abundance in 4 samples of deep-sea sediments was $40.3 \pm 3.4,46.4 \pm 2.4$, $49 \pm 10$, and $10.9 \pm 22 \mathrm{ppm}$. $U$ abundance in these samples in the same order was $162 \pm 22,61 \pm 24,250 \pm 100$, and $1500 \pm 400 \mathrm{ppb}$. (CA) 
Bernat, M. and C. Allegre. 1969. Study of the ${ }^{234} \mathrm{U} /{ }^{238} \mathrm{U}$ Ratio in Core Samples of Sediments Near Seashores: Various Effects. Compt. Rend., Ser. D. 268:641-4 (in French).

The variations in the $234 U / 238 U$ observed in the core samples that were studied appear to be due to a variation in the detrital/authigenic ratio for uranium in the sediments. Consideration was given to the possibility that this interpretation is equally valid for the pelagic sediments studied by Teh Lung Ku. If this is true, it is necessary to abandon the idea of transfer into the seawater of $234 \mathrm{U}$ by the sediments. This would have important consequences on the geochemical balance of uranium. (auth) Earth Planet. Sci. Lett., 3:145-50 (November 1967); NSA 22:8233).

Bernat, M., R. H. Bieri, M. Koide, et al. 1970. Uranium, Thorium, Potassium, and Argon in Marine Phillipsites. Geochim. et Cosmochim. Acta. $34: 1053-71$.

Analyses of elements at trace levels in phillipsites from Pacific Ocean deposits indicate the mineral continues to grow within the sedimentary column. The thorium and uranium concentrations decrease while the mineral concentrations increase with depth in the deposit. This observation can be explained by a continuous growth of the phillipsite within the deposits. The varying concentrations of uranium and thorium in phillipsite, fish teeth and clay minerals from given levels of the core indicate. a competition by such substances for the dissolved phases of these elements. Phillipsites from the surface layers (upper $20 \mathrm{~cm}$ ) of widely separated deposits have apparent $\mathrm{K}-\mathrm{Ar}$ ages $>10^{6}$ years. Systematic variations in this ratio occur with depth. At three levels a differentiation of the ${ }^{40} \mathrm{Ar} / 40 \mathrm{~K}$ ratio with respect to size is observed, the larger crystals having smaller ratios and vice versa. Treatment of three samples with $\mathrm{HCl}$, presumably removing about $40 \%$ of the outer layers of the crystals, increased the concentration of radiogenic argon by almost a factor of two. Heating experiments indicate that loss of argon by diffusion is of minor importance. Idealized models of continuous spherical growth of the mineral over long time intervals, and assuming $\mathrm{dr} / \mathrm{dt}=$ constant, indicate the time dependence of the ${ }^{40} \mathrm{Ar} / 40_{\mathrm{K}}$ ratios for a growing crystal. Most of the results can be explained by modified versions of such models. Without additional knowledge about the many parameters involved in marine phillipsite formation, however, these minerals are not suitable for dating by the K-Ar method. (auth)

Bernat, M: and E. D. Goldberg. 1969. Thorium Isotopes in the Marine Environment. Earth Planet. Sci. Lett. 5:308-12.

Analyses of thorium isotopes isolated from fractions of a North Pacific Core, representing authigenic and detrital minerals, indicated that there were movements of $228 \mathrm{Ra}$ with in the sedimentary column, that the thorium comes to the deposit primarily from seawater, that there is no evidence for the migration of thorium isotopes within the sedimentary column, and 
that there is a continued growth of phillipsite at depths in the column. Finally, there appeared to be a preferential accommodation of $231 \mathrm{~Pa}$ and/or $227 \mathrm{Ac}$ in the phillipsite, the authigenic zeolite, relative to the detrital minerals. The high values of the $228 \mathrm{Th} / 232 \mathrm{Th}$ ratios in seawater may be influenced by the contribution of ${ }^{228} \mathrm{Th}$ arising from $228 \mathrm{Ra}$ migration through the water-sediment interface. (auth)

Berzina, I. G., I. B. Berman, M. Y. Gurvich, G. N. Flerov, and Y. S. Shimelevich. 1967. Determination of the Uranium Concentration and Its Spatial Distribution in Different Minerals and Rocks. U.S.A.E.C. JINRP13-3159 (in Russian).

Measurements were made of low concentrations of $U$ and its spatial distribution in different minerals and rocks. Measurements were made in some minerals by spontaneous and induced fission of $U$ nuclei revealed directly in these minerals, and in rocks and other materials by induced fission of $U$ nuclei recorded by special detertors. The comparison of tracks from spontaneous and induced fission of $U$ nuclei shows the migration of $U$ within the time of mineral existence. Recommendations on practical use and selection of detectors and on the integral doses applied are given to determine different concentrations of $U$ in the samples investigated. (NSA)

Bhat, S. G. and S. Krishnaswamy. 1969. Isotopes of Uranium and Radium in Indian Rivers. Proc. Indian Acad. Sci., Section A, No. 1:1-17.

The concentrations of dissolved uranium and radium isotopes have been determined in the waters of several Indian rivers. The concentration of $238 \mathrm{U}$ was found to vary between 0.01 to 7.0 micrograms/liter, depending primarily on the terrain through which the river flows. From the available data on the activity ratios, $234 \mathrm{U} / 238 \mathrm{U}$, concentration of $238 \mathrm{U}$ in rivers and the amount of uranium depositing on the ocean floor, a material balance calculation has been attempted. This showed that, based on above measurements, the supply of $U$ deposited in the sea by rivers was inadequate to explain the observed concentrations of $238 \mathrm{U}$ and $234 \mathrm{U}$ in the oceans. The ${ }^{226} \mathrm{Ra}$ concentration of river waters was found to be of the order of $0.1 \mathrm{dpm} /$ liter (yarying between 0.05 to $0.2 \mathrm{dpm} / 1 \mathrm{iter}$ ). The activity ratios, ${ }^{228} \mathrm{Ra} / 226 \mathrm{Ra}$ range between 1 and 4 . This large variation is clearly related to the fact that the concentrations of the parent nuclides of ${ }^{226} \mathrm{Ra}$ and ${ }^{228} \mathrm{Ra}$ are different. The observed ratios were consistent with those expected from leaching of clays/soils; however, analugous to the situation in the case of $U$ the observed concentrations of $\mathrm{Ra}$ isotopes in the oceans are too large to be explained by their influx by rivers. (auth) 
Bhat, S. G., S. Krishnaswamy, D. Lal Rama, and W. S. Moore. 1969. $234 \mathrm{Th} / 238 \mathrm{U}$ Ratios in the 0cean. Earth Planet. Sci. Lett. 5:483-91.

The activity of the short-lived 234 Th (half-life $=24$ days) is found to be in marked radioactive disequilibrium with respect to the concentration of its parent, $238 \mathrm{U}$, in the top hundred meters of the seawater column; values above and below secular equilibrium exist. The mechanisms responsible for the observed distribution of 234Th are discussed and their rates are evaluated. (auth)

Bhatnagar, A. S. 1969. Radon Measurement in Soil in the Exploration for Uranium in India. STI/PUB-279: CONF-691229: Part of Proceedings of a Panal on Nuclear Techniques and Mineral Resources in Developing Countries held in Krakow, Poland, December 8-12, 1969. pp. 157-162.

Radon distribution in soil is influenced by many factors and present knowledge on these factors is incomplete. Daily variation in the results of radon measurement made at the same station has been noted. This indicates that the measurement is subject to unknown influences and any interpretation based on a single observation can be very misleading. The radon content of the soil is derived not only from the parent material diffused in the soil, but also from the migration of radon from another source containing a higher concentration of the parent. In interpreting a radon anomaly it is necessary to distinguish between the contributions made by these two types of sources. Because of the influence of the unknown factors, the problems of interpretation become very entangled. Since the migration of radon from a distant source with a large concentration of its parent is highly subject to meteorological factors, it is suggested that the unaccounted fluctuations in observed radon values may be themselves taken as an indication of the presence of a distant large source, such as a uranium deposit in the area. (auth)

Bhatnagar, A. S. and P. C. Ghosh. 1954. Using Autoradiography for Quantitative Study of $U$ in Ore. Nucleonics. 12:58-9

A combination of radioassay and autoradiography makes it possible to determine the percentage of $U$ in radioactive minerals without the ir having to be separated from the ore. Radioassay gives the percent $U$ in the ore. Since radioactive particles can be distinguished by an autoradiograph of the sample, a fairly accurate determination of the radioactive mineral in the ore is obtained by counting a large number of particles. The percent $U$ in the radioactive mineral is then calculated. (NSA) 
Boberg, W. W. and D. D. Runnel1s. 1971. Reconnaissance Study of Uranium in the South Platte River, Colorado. Econ. Geol. 66:435-50.

The South Platte River in Colorado drains areas of crystalline and sedimentary rocks. The water is a sodium-calcium-sulfate-chloride type throughout its length of flow in Colorado. The concentration of uranium in the water of the South Platte during the winter of 1969 to 1970 ranged from $5 \mathrm{ppb}$ to $67 \mathrm{ppb}$, making it anomalously rich in uranium in comparison with most other rivers of the world. The concentration of uranium increases downstream, to contrast to the decrease in uranium concentration observed in other rivers that drain areas with known deposits of uranium. The South Platte contains a higher concentration of uranium than either the Colorado or North Platte rivers, despite the fact that the latter two rivers drain ore-producing areas of the United States. It is likely that mos $\tau$ of the uranium in the South Platte is contrihuted hy uraniferous coal seams in the Cretaceous Laramie Formation and by uranium-rich black shales in the Cretaceous Pierre Formation. The possibility that undiscovered deposits of uranium ore are present in the drainage basin of the South Platte cannot be excluded, but no major deposits are known. Use of the parameter "incremental areal uranium-load" permits certain portions of the drainage basin to be recognized as contributors of anomalously large amounts of uranium to the river. In the headwaters of the South, Platte the incremental areal uranium-load is a $10 \mathrm{w} 0.00018 \mathrm{~kg} \mathrm{U} / \mathrm{day} / \mathrm{km}^{2}$, whereas for the increment of drainage between Weldona and Balzac, Colorado, the incremental areal uranium-load is $0.016 \mathrm{~kg} \mathrm{U} /$ day $/ \mathrm{km}^{2}$. This parameter may be useful for hydrogeochemical prospecting for uranium ore in other areas. The concentration of uranium in the interstitial water of the aluvium in cutoff meanders varies seasonally, but there is no clear-cut evidence for precipitation of uranium minerals. Measurements of $\mathrm{Eh}, \mathrm{pH}$, and total vanadium in interstitial waters indicate that neither uraninite, coffinite, nor carnotite is stable. (auth)

Boltneva, L. I., L. I. Buyanova, A. V. Dmitriev, V. A. Ionov, R. M. Kogan, and I. M. Nazarov. 1965. Radioactivity of Sands in Central Asia. Dok1. Adad. Nauk. SSSR 165:183-6 (in Russian).

An airborne $\gamma$-measurements were used to study radioactivity of the main sand massifs in the U.S.S.R. (Kara-Kum, Muyun-Kum, and Balkhash occupying ul million sq $\mathrm{km}$ ) by determining $U$ from $T h$, and $K$ contents. The results were interpreted for 2 groups of sands, separated according to their genesis: (1) sands of various genes is subjected to eolian reworking and eolian sands, and (2) sand of alluvial origin. In the lst group of sands, the displacement of particles during the formation of the sand massif or during secondary migration had no predominant direction. This caused a strong mixing of elastic material and a sufficiently homogenous distribution of particles. This resulted in relatively uniform concentrations of $U$, Th, and $K$ in entire territory of an individual massif. A correlation was found between $U$ and Th. The directed transport of particles, accompanied by gravitational separation, is typical of the alluvial sand massifs. 
Bonatti, E., D. E. Fisher, 0. Joensuu, and H. S. Rydel1. 1971. Postdepositional Mobility of Some Transition Elements, Phosphorus, Uranium, and Thorium in Deep Sea Sediments. Geochim. et Cosmochim. Acta. 35:189-201.

Deep sea hemipelagic sediments from the east Pacific show an oxidized upper zone of variable thickness and a reduced zone below. The geochemistry of a core from this region was studied in detail. The Eh of the upper zone is close to $+100 \mathrm{mV}$, while in the lower zone it reaches about $-400 \mathrm{mV}$. Reducing conditions in the lower section of the core are related to the oxidation of organic matter in the sediment, as indicated by the gradual decrease with depth of the concentration of nitrogen in the upper part of the core. Various elements, such as $\mathrm{Mn}, \mathrm{Ni}, \mathrm{Co}, \mathrm{P}$ and $\mathrm{La}$, are enriched in the upper oxidized zone, while $\mathrm{Cr}, \mathrm{V}$. U and $\mathrm{S}$ are enriched in the lower reduced zone. Postdepositional mobility of the elements in question, mainly by diffusion in the interstitial solutions, can explain their distribution in the core. Redox reactions can account directly for the mobilization of $\mathrm{Mn}, \mathrm{Ni}, \mathrm{Co}, \mathrm{Cr}, \mathrm{V}$ and $\mathrm{U}$, indirectly for that of $\mathrm{P}$ and $\mathrm{La}$. $\mathrm{Fe}$ and $\mathrm{Cu}$ do not migrate significantly, since they are immobilized as sulfides in the reduced zone. Th appears not to be affected by diagenetical mobility. Some of the consequences of the postdepositional mobility of elements in deep sea sediments are: (1) The average elemental content of deep sea sediment, generally estimated from measurements of samples from the upper part of the sediment column, may be affected by errors; namely, an overestimation in the case of. Mn, $\mathrm{Ni}, \mathrm{Co}, \mathrm{P}$ and $\mathrm{La}$; an underestimation in the case of $V, C r$ and $U$. (2) Postdepositional redistribution of $U$ may introduce errors in age determinations of sediments by the 230Th/ $232 \mathrm{Th}$ and $230 \mathrm{Th} / 231 \mathrm{~Pa}$ methods. (3) Some geographical variations in the composition of Fe-Mn nodules can be explained by postdepositional mobility of $\mathrm{Mn}, \mathrm{Ni}$ and $\mathrm{Co}$. (auth)

Borkov, F. P., N. I. Egorov, and E. V. Zaitsev. 1971. Peculiarities of Formation of an Increased Uranium Concentration in Oxidizing Conditions. Izv. Vyssh. Ucheb. Zaved., Geol. Razved. No. 5:51-7 (in Russian).

The peculiarities of the formation of an enhanced $U$ concentration under oxidizing conditions were examined. Similar concentrations are generally adapted to an oxidation zone of $U$ deposits and are scarcely ever encountered in rocks with a Clark content of uranium. The $U$ concentrations in oxidation zones of rocks with normal or somewhat increased $\mathrm{Clark}$ radioactive elements are usually adapted to regions of arid climate, and their formation is considered to be a result of an evaporative concentration of elements in ground waters (insolation). The $U$ concentrations in the ore phenomena under consideration did not agree with these notions, but instead are examples of favorable geological conditions and geochemical circumstances. An epigenetic accumulation of $U$ might occur under conditions of an oxidizing medium through its fixation in the hexavalent state. (auth) 
Borovec, Z. 1973. Uranium in Sedimentary Rocks. Cas. Mineral. Geol. 18:199-208 (in Czech).

A review is presented with 63 references on $U$ contents in rocks, migration during weathering processes, chemical form in natural waters, epigenetic infiltration in sedimentary rocks, and its content in phosphorites, carbonates, evaporites, sands, and sandstones. (CA)

Bostroem, K. and D. E. Fisher. 1971. Volcanogenic Uranium, Vanadium, and Iron in Indian Ocean Sediments. Earth Planet. Sci. Lett. 11:95-8.

About one hundred $U, V$, and Fe analyses of Indian Ocean sedillenls indicate that enrichments of $U$ and $V$ occur in hemipelagic sediments close to the continents, probably associated with biogen constituents. The highest concentration, however, of $U, V$, and Fe occurs in active ridge sediments, suggesting that submarine volcanism is an important source of these elements. (auth)

Breger, I. A. 1955. Radioactive Equilibrium in Ancient Marine Sediments. Geochim. et Cosmochim. Acta 8:63-73.

Radioactive equilibrium in eight marine sedimentary formations has been studied by means of direct determinations of uranium, radium, and thorium. Alpha-particle counting has also been carried out in order to crosscalibrate thick-source counting techniques. The maximum deviation from radioactive equilibrium that has been noted is $11 \%--$ indicating that there is probably equilibrium in all the formations analyzed. Thick-source alpha-particle counting by means of a proportional counter or an ionization chamber leads to high results when the samples contain less than about $10 \mathrm{ppm}$ of uranium. For samples having a higher content of uranium the results are in excellent agreement with each other and with those obtained by direct analytical techniques. The thorium contents that have been obtained correspond well to the average values reported in the literature. The uranium content of marine sediments may be appreciably higher than the average values that have been reported for sedimentary rocks. Data show that there is up to 14 times the percentage of uranium as of thorium in the formations studied, and that the percentage of thorium never exceeds that of uranium. While the proximity of a depositional environment to a land mass may influence the concentration of uranium in a marine sediment, this is not true with thorium. (auth)

Breger, I. A. 1974. The Role of Organic Matter in the Accumulation of Uranium. The Organic Geochemistry of the Coal-Uranium Association. IAEA-SM-183/29. In Formation of Uranium Ore Deposits, pp. 99-124.

Geochemical studies have been carried out on 64 specimens of coalified logs from Triassic and Jurassic uranium-bearing sediments of the Colorado Plateau and from Paleocene and Eocene sediments of Wyoming. These logs 
contain from 0.0005 to $16.5 \%$ uranium. Autoradiographic studies and observations of relative reflectivities of uraniferous and non-uraniferous specimens demonstrate that uranium was introduced into the coal epigenetically in solution along micro-faults and/or shrinkage cracks. Following its introduction, probably as a complex alkali uranyl carbonate, the uranium was reduced by the coal to form uraninite or coffinite. Data indicate that radiation from the uranium and its equilibrium daughter products causes radiochemical dehydrogenation and demethanation of the coal. This transformation results in significantly higher reflectivity and hardness related to cross-linking that produces diamond-like clusters of carbon atoms. Irradiation of the coal does not cause its rank to rise to that of anthracite. Organic sulphur contents up to $13.1 \%$ have been noted for coalified logs of Triassic age from the San Rafael Swell area. Such unusual values have been attributed to the interaction between the coal and hydrogen sulphide from underlying sediments at temperatures of 110 to $120^{\circ} \mathrm{C}$ corresponding to burial under about 3000 th of overburden. If uranium was introduced into the sediments following the interaction between the coal and the hydrogen sulphide, this mineralization could not have occurred before late Cretaceous time. This work, in context with previous studies, has led in a generalization of principles underlying the association of uranium with coal. (auth)

Breger, I. A. and M. Deul. 1956. The Organic Geochemistry of Uranium. U.S.G.S. Professional Paper 300:550-10.

A review with 35 references. The association of $U$ with organic matter such as that of carbonaceous shales and coal is not primary; these materials collect $U$ both by adsorption and by the formation of specific compounds such as humates. (CA)

Breger, I. A., M. Deul, and R. Meyrowitz. 1955. Geochemistry and Mineralogy of a Uraniferous Subbituminous Coal. Econ. Geol. 50:610-24.

A sample of subbituminous uraniferous coal from the Red Desert, Sweetwater County, Wyoming, has been studied mineralogically. The coal contains gypsum (6\%), kaolinite (1\%), quartz (0.3\%), calcite (trace), and limonite (trace). This suite of minerals and the absence of pyrite show that the coal has been subjected to weathering and oxidation. No uranium minerals have been found; mechanical fractionation has indicated that the uranium is associated with the organic constituents of the coal. The minerals that have been isolated contain $0.0006 \%$ uranium, a content that is to be expected for nonuraniferous sedimentary rocks. The organic components of the coal contain approximately $0.002 \%$ uranium. On the basis of materialbalance calculations, the organic components carry $98 \%$ of the uranium in the coal. Batch extraction of the Wyoming coal with $6 \mathrm{~N}$ hydrochloric acid leads to the solution of almost $90 \%$ of its uranium. Recovery of uranium is independent of the particle size of the coal between -4 and -20 mesh, and is accompanied by the solution of approximately $70 \%$ of the inorganic constituents (ash) of the coal. The extract contains, together with uranium, a concentration of several elements such as manganese, cerium, 
and vanadium that are present in the coal. Fischer assays of this weathered coal from the Red Desert indicate a yield of 16.7 gallons of tar per ton. Yields of both tar and char are about 15\% lower if the coal is first treated with $6 \mathrm{~N}$ hydrochloric acid to extract the uranium. It is suggested that uranium was introduced into the coal by means of ground water carrying soluble alkaline or alkaline earth uranyl carbonate complexes. The mineral schroeckingerite--a similar complex--is found near this subbituminous coal in the Red Desert of Wyoming. These complexes, which are unstable in acid medium, release the uranyl ion $\left(\mathrm{UO}_{2}++\right)$, which may then react with organic constituents of the coal to form ionic uranyl-organic compounds that are insoluble above a $\mathrm{pH}$ of about 2.2. Preliminary data indicate that the uranium is associated with various humic components of the coal. The distribution of uranium among the components of the subbituminous coal from Wyoming is similar to the distribution in a lignite from South Dakota. There is no indication that uranium was introduced into or retained by the two coals by appreciably different geochemical processes. (auth)

Breger, I. A., M. DeuT, and S. Rubinstein. 1955. Geochemistry and Mineralogy of a Uraniferous Lignite. Econ. Geol. 50:206-26.

Detailed studies have been carried out on a uraniferous lignite from the Mendenhall strip mine, Harding County, South Dakota. By means of heavyliquid separations, a mineral-free concentrate of the lignite was obtained that contained $13.8 \%$ ash and $0.31 \%$ uranium in the ash. The minera 15 (gypsum $69 \%$, jarosite $10 \%$, quartz $2 \%$, kaolinite and clay minerals $19 \%$, and calcite trace) contain only $7 \%$ of the uranium in the original coal, indicating an association of the uranium with the organic components of the lignite. Batch extractions show that $88.5 \%$ of the uranium can be extracted from the lignite by two consecutive treatments with boiling $1 \mathrm{~N}$ hydrochloric acid. Continuous extraction with hot $6 \mathrm{~N}$ hydrochloric acid, remiuves $98.6 \%$ of the uranium. Columns of coal were treated with water, iN hydrochloric acid, $6 \mathrm{~N}$ hydrochloric acid, and a solution of lanthanum nitrate. The experiment with lanthanum nitrate indicated that only $1.2 \%$ of the uranium in the coal is held by ion exchange. The elutriation experiments showed that the uranium is held in the coal as an organouranium compound or complex that is soluble at a pH of less than 2.18. A geochemical mechanism by which the uranium may have been introduced into and retained by the lignite is discussed. (auth)

Brendakov, V. F., S. V. Iokhel'son, and V. N. Churkin. 1967. Potassium, Radium, and Thorium Contents in Caucasian Soils. Pochvovedenie. No. 1: 41-7 (in Russian).

The distribution of natural radioactive elements in the upper layer of Caucasian soils is discussed. A method of collecting and analyzing soil samples is described. Schematic maps of potassium, radium and thorium distribution in the upper layer of Caucasian soils are presented. (auth) 
Brimha11, W. H., and J. A. S. Adams. 1969. Concentration Changes of Thorium, Uranium, and Other Metals in Hydrothermally Altered Conway Granite, New Hampshire. Geochim. et Cosmochim. Acta. 33:1308-11.

The concentrations of $\mathrm{Th}, \mathrm{U}, \mathrm{K}, \mathrm{Mg}, \mathrm{Ca}, \mathrm{Mn}, \mathrm{Fe}, \mathrm{Zn}, \mathrm{Co}$, and $\mathrm{Cu}$ are significantly different in two sections of a 1000-foot core sample of Conway granite. The differences, attributable to the action of weak hydrothermal fluids, indicate that the fluids, though weak, caused effective redistribution of these elements. (CA)

Broecker, W. S. and A. Kaufman. 1968. Investigations of the $U$ and Th Series Isotope Disequilibria in the Ocean and in Pleistocene Sediments. Annual Report. CU-3139-2.

Research progress is reported in six sections. A separate abstract was prepared for each section. (NSA)

Brown, J. H. and W. D. Keller. 1952. Uranium in the Clay of a Black Radioactive Shale. Science. 116:632-3.

The results of a brief study of a black radioactive shale from $\mathrm{St}$. Genevieve County, Missouri, show that the $U$ contained in it is located predominantly in a relatively fixed condition in the fine clay fraction, and not in the black organic matter. This result is at variance with recent suggestions that the $U$ in black shales is more likely attached to the organic matter. Leaching experiments were conducted to determine the ease of removal of the $\mathrm{U}, \mathrm{HCl}, \mathrm{HNO}_{3}, \mathrm{H}_{2} \mathrm{SO}_{4}$, aqua regia, and dilute $\mathrm{Na}_{2} \mathrm{CO}_{3}$ were effective solvents, but hot and cold $\mathrm{H}_{2} \mathrm{O}$, ethyl alcohol, $\mathrm{CS}_{2}$, and $\mathrm{CCl}_{4}$ did not extract enough $U$ from $2 \mathrm{~g}$ of shale to produce fluorescence. Propyl alcohol dissolved a small amount of $U$. Attempts to exchange the $U$ cationically indicated that the $U$ is held by the clay minerals in a not easile exchangeable condition. (NSA)

Bunker, C. M. and C. A. Bush. 1968. Radioelement Composition of Surface Soil in Adams County, Colorado. U.S.G.S. Professional Paper 600-B:71-5.

Eighty-three samples collected from the Bennett, Manila, Horse Creek, and Sunnydale seven and one-half minute quadrangle areas near Denver, Colorado, were analyzed to determine the radioelement content and distribution. The radioelement concentrations are: 7.7 to $19.0 \mathrm{ppm}$ thorium, 0.7 to 3.3 ppm radium-equivalent uranium, and 2.07 to 3.75 percent potassium. These data provide ground control for a proposed calibration of the U.S. Geological Survey's airborne gamma-radiation detection systems. (auth) 
Burton, J. D., W. B. Guenther, and H. M. Owen. 1964. Profile of Natural Radioactivity in Hartsells Loam. Soil Sci. Soc. Am. Proc. 28:500-1.

During the summer of 1961 bulk samples at 4-in. to 30-in. depth increments were collected at 15 random locations within an apparently uniform single àcre of Hartsells loam in an oak-hickory timber stand on the Cumberland Plateau in Tennessee. Net radioactivity, total potassium content, and mechanical fractions were determined in the laboratory. After samples were stored in sealed containers for 7 days, activity was counted again and found to be increased. Linear regressions of initial activity on silt-plus-clay and on $K, K$ on silt-plus-clay, and 7-day activity on clay, on $\mathrm{K}$, and on 1-day activity were highly significant. Distributions of $K$, and of initial activity in the soil profile were more closely related to the profile of total fines than to the clay curve. Initial activity was believed to be due largely to $40 \mathrm{~K}$, but activity gain during storage was probably due to daughters of $\hat{\imath} 38 \mathrm{j}$ : (auth)

Calvo, M. M. 1974. The Role of Humic Natural Organic Matter in Uranium Concentration. IAEA-SM-183/33. IN: "Formation of Uranium Ore Deposits.

The paper reports a short experiment on the metallogenetic aspects of the uranium-organic matter association in nature. The author carried out several experiments on uranium fixation by organic matter with different degrees of maturity. Although further studies are considered necessary, the results already obtained lead to the following conclusion: when uraniferous solutions come into contact with humic organic matter, the efficiency and nature of the uranium-organic matter association thus established depends on the degree of carhonization attained by the humic material. At the beginning of the development process, the organic matter has high chemical activity and the uranium tends to occur in stable organic phases. As the process continues, a stage is reached from which uranium tends to form its own minerals indeperidently of organic matter. From the coalification stage onwards the tendency towards uranium-organic matter association becomes increasingly less in any form. Petrographically, the humic constituents to which uranium is closely and positively related belong to the huminite maceral group. Last.ly, it is considered that when the organic matter is present as an accessory constituent in other sedimentary rocks and with quite low maturity indices, there is greater favourability for the formation of uranium deposits. (auth)

Cerrai, E., B. Schreiber, and C. Triulzi. 1966. Ra, Io, Th and U in Some Coastal Sediment Samples of the Liqurian Sea. Energ. Nuc1. 13:680-6.

A reversed-phase chromatographic method was used in the separation of $226_{\mathrm{Ra}}$, $230 \mathrm{Th}, 232 \mathrm{Th}$, and ${ }^{238} \mathrm{U}$ found in three coastal sediment cores from the Ligurian Sea. Alpha sources were prepared by electrolytic deposition, and all determinations were made by a spectroscopy. Values are given as grams per gram of sediment and these values are compared with samples from other seas. (NSA) 
Chalov, P. I., K. I. Merkulova, and T. V. Tuzova. 1966. The ${ }^{234} \mathrm{U} /{ }^{238} \mathrm{U}$ Ratio in Waters and Bottom Sediments of the Aral Sea and the Absolute Age of the Basin. Geokhimiya. No. 12:1431-8 (in Russian).

The results of ${ }^{234} \mathrm{U} /{ }^{238} \mathrm{U}$ ratio study in waters and bottom sediments of the Aral Sea are reported. On the basis of $234 \mathrm{U}$ decayed data the absolute age of the Aral Sea (139 \pm 12 thousand years), the upper limits of the date of the Amu Darya bend towards the Aral Sea and the Minor Sea existence (22 thousand years) have been established. (auth)

Chalov, P. I., N. A. Syetlichnnaya, and T. V. Tuzova. 1970. Isotopic Composition of Uranium $(234 \mathrm{U}, 238 \mathrm{U})$ in Waters and Bottom Sediments of the Balkhash Lake and the Time of the Basin Existence. Geokhimiya. No. 7: 848-54 (in Russian).

The results of ${ }^{234} \mathrm{U} / 238 \mathrm{U}$ ratio studies in waters and bottom sediments of the Balkhash Lake are reported. On the basis of the data received according to $234 U$ decay, the absolute age of the Balkhash Lake ( $37 \pm 7$ thousand years) was established. (auth)

Chalov, P. I., N. A. Svetlichnaya, and T. V. Tuzova. 1973. Use of Nonequilibrium Uranium for the Establishment of a Connection Between Inland Bodies of Water in the Past. Geokhimiya. No. 6:897-902 (in Russian).

The nonequilibrium ratio between ${ }^{234} U$ and ${ }^{238} U$ is used for the geochronology of the continental basins and for establjshing a relation between the Balkhash and Ala-Kul lakes in Kasakh SSR. The ${ }^{234} \mathrm{U} / 238 \mathrm{U}$ ratio (R) is determined with an ionization $\alpha$-spectrometer with a resolution of $50-60 \mathrm{keV}$ - The ages of the Bajkhash $(37 \pm 7)$ and Ala-Kul $(49 \pm 7 \times 1000 \mathrm{yr})$ are calculate based on the ${ }^{234} \mathrm{U} / 238 \mathrm{U}$ ratio. However, the $\mathrm{R}$ of the bottom sediments of these two lakes differ from each other suggesting that they had different modes of origin. (CA)

Cherry, R. D. 1964. Alpha Particle Detection Techniques Applicable to the Measurement of Samples From the Natural Radiation Environment. J. A. Adams and W. M. Lowder (eds) Univ. of Chicago Press. Natural Radiation Environment. pp. 407-24.

Detection techniques usefur in measuring $\alpha$ activity in samples from the natural environment are reviewed. Discussions are included concerning total counting with no energy measurements and spectrographic techniques used when a particle energies are measured to identify specific nuclides. (NSA) 
Cherry, R. D., K. A. Richardson, and J. A. S. Adams. 1964. Unidentified Excess Alpha-Activity in the 4.4 Mev Region in Natural Thorium Samples. Nature. 202:639-41.

An unidentified alpha activity with an energy of about 4.4 Mev found in thorite minerals is reported. Positive identity of the source of this activity could not be determined. (NSA)

Cherdyntsev, V. V., U. K. Asylbaev, D. P. Orlov, L. I. Shmonin, E. A. Isabaev, and N. B. Kadyrov. The Uranium Isotopes in the Nature. I. ActiniumRadium Ratio of Minerals. Geokhimiya. No. 8:650-5 (in Russian).

The actinium-radium ratio was investigated in 35 natural minerals by two methods. Considerable deviations of the actinium-radium ratio were observed: in metamorphosed minerals. In some cases it may be shown with certainty that this is caused by the migration removal of radium. At the same time some primary minerals also contain an actinium excess which is especially great for cassiterites and some molybdenites. (auth)

Cherdyntsev, V. V., I. V. Kazachevskii, and E. A. Kuzmina. 1963. Isotopic Composition of Uranium and Thorium in the Zone of Hypergenesis. Investigation of Fossil Bones, Soil and Shells of Mollusks. Geokhimiya. No. 3: 254-65 (in Russian).

The ratio of Th isotopes (Io, $U X_{T}, T h^{232}$, RdTh) and $U$ isotopes $\left(U^{234}\right.$ and $U^{238}$ ) in natural waters, fossil bones, and soils, as well as in shells of freshwater mollusks of the Paleolithic site Molodovo and other areas of the Dniester foreland was investigated. In the waters of Molodovo are djstinguished waters of neogenic limestones with a low value of $y=U^{234},{ }^{238}=$ $10.3 \times 10.5$ and waters of the Paleozoic: $\gamma=1.34$, apparently feeding the quarternary stratum. The mineralization of fossil bones was realized in the Upper Paleolith by waters with low values and in the Middle Paleolith by waters with high $\gamma$-values. Uranium migration was confirmed by the investigation of the radioelement ratios in fossil bones of the sites Molodovo $I$ and Molodovo $V$. This process apparently did not affect the Mousterian layers of the site Molodovo $V$, so that the age of the layers, according to Io/UX ${ }_{1}$ and $\gamma$, equaling 130 thousand years, is near to the truth. The age of the fossil soil of the lower horizon of Molodovo I (end of Riss-Riss-Würm) is more than 260 thousand years. In the shells of fresh-water mollusks an intensive migration of $U$ and $R a$ isotopes occurs. For: example, an exceptional high value RdTh/Th $=12.3 \pm 0.9$ (activity units) was obtained. (auth)

Cherdyntsev, V. V., D. P. Orlov, E. A. Isabaev, and V. I. Ivanov. 1961. Isotopes of Uranium in Natural Conditions. II. Isotopic Composition of Uranium of Minerals. Geokhimiya. No. 10:840-8 (in Russian). 
The deviation of $U^{234} / U^{238}$ from the equilibrium state is in most cases, if not always, connected with the removal of uranium from the mineral, the uranium of solutions and of the minerals precipitated from them proving to be enriched in $\mathrm{U}^{234}$, and the uranium which remained in the mineral being somewhat empoverished in this isotope. An excess of $U^{234}$ is detected in some endogenic minerals. In a number of cases, including such as primary visually preserved minerals, a deficiency in $U^{234}$ is observed. This bears witness of an intensive uranium migration in the zone of epigenesis. A measurable $U^{235}$ excess may accumulate as a result of the decay of some transycanium isotope, being present in the mineral. The surplus content of $U^{235}$ in magnetites of a pegmatite vein by $45 \pm 5$ and $23 \pm 6$ percent is confirmed. The other minerals of this ore body have a normal isotopic composition which indicates the local presence of transuranium emitter in the magnetite. An excess of actinium (and $\mathrm{U}^{234}$ ) is also found in this mineral. An excess of $U^{235}$ of about 40 percent is established in one of the molybdenite samples. A bond between minerals with a surplus of $U^{235}$ and minerals with a surplus actinium is outlined but its character is not found. (auth)

Church, T. M. and M. Bernat. 1972. Thorium and Uranium in Marine Barite. Earth Planet. Sci. Lett. 14:139-44.

Analysis of Th and $U$ from deep-sea barites and their sediments show that (1) marine barites concentrate Th relative to their bulk sediments and appear to be growing near the sediment surface, however, some barites are found associated with ferromanganese deposits, and these barites, like continental varieties, are depleted in Th and may reflect formation or alteration from effects of volcanic processes: (2) while marine barites show ${ }^{230} \mathrm{Th} /{ }^{232}$ Th depositional rates analogous to their sediments, they have distinctly lower isotope ratios which may reflect their formation from deep-sea or pore water; (3) marinebarites, like phillipsites and sea water, contain excess amounts of ${ }^{228} \mathrm{Th}$ and are probably undergoing a continuous exchange chemistry within the Th series as the result of ${ }^{228} \mathrm{Ra}$ mobilization in the sedimentary column. (CA)

Cohen, P. 1961. An Evaluation of Uranium as a Tool for Studying the Hydrogeochemistry of the Truckee Meadows Area, Nevada. J. Geophys. Res. 66:4199-4206.

Forty-seven water samples collected in the Truckee Meadows, an alluviated intermontane basin in western Nevada, were analyzed for uranium and for the principal dissolved constituents. Some of the relationiships between uranium and other chemical constituents described by other writers are verified in the study of the hydrogeochemistry of the Truckee Meadows area; others are not. The following relationships between uranium and bicarbonate-plus-carbonate content, uranium and chloride content, and uranium and sulfate content were observed in the waters of the Truckee Meadows area: uranium content tends to increase as the bicarbonateplus-carbonate content increases; thermal, chloride-rich waters of the 
Steamboat Springs area are relatively deficient in uranium; and some waters high in sulfate content are relatively rich in uranium; others are not. Because of the variability in concentration and the complex interrelationships between the bicarbonate, carbonate, sulfate, and chloride anions, and because uranium content appears to be dependent upon these variables, uranium has little value as a tool for studying the hydrogeochemistry of the area. (auth)

Coppens, R. 1949. On the Radioactivity of the Sand From the Beaches Along the River of Crach (Morbihan). Compt. rend. 229:1319-23 (in French).

The sand of the beaches from Demoiselles to Penestin is romposed largely of heavy elements. A certain amount of radioactivity is, therefore, to be cxpccted in these sands and, in fact; has already been detected (Compt. rend. 228, 1938, 1949). The activity of the sand from various beaches was measured by photographic methods and the results are tabulated. This activity appears to be due, primarily, to thorium and to small inclusions of uranium. The distribution and possible origin of the radioactivity are discussed. (NSA)

Coquema, C., R. Coulomb, M. Goldsztein, and J. C. Schiltz. 1963. Radioactive Disequilibrium and Isotopes of Thorium in Geochronology. In Radioactive Dating. Int. At. Energ. Ag. pp. 133-48 (in French).

Systematic work was going on for a number of years to determjne the main natural radionurlides (1.1238, $\mathrm{Ra}^{226}, \mathrm{Th}^{230}, \mathrm{~Pa}^{231}, \mathrm{Rn}^{222}, \mathrm{Po}^{210}$, and $\mathrm{Th}^{232}$ ) present in a wide variety of geological materials (rocks, soils, ores, river, and marine sediments) with a view to working out the pattern of radioactive equilibrium and the 1 aws of geochemicd dislribution. Although the primary objective of this work is to obtain precise dala un weathering or depusil phemullend, lhe results which were obtalned can be applice directly to geochronological problems. The radiochemical and radiometrical methods which are used routinely are described. These involve the use of multichannel alpha and gamma spectrometers, alpha and beta counting with automatic low-background sets, and the determination of radon by scintillation balloons and of uranium by fluorimetry. Some typical results are given for various geochemical models; on this basis it is possible to make age determinations of secondary mineralization in deposits or to calculate sedimentary deposit rates. Emphasis is laid on the need for subjecting both the sample and the environment to a simultaneous and thorough geochemical study. (auth)

Cullen, T. L. 1967. A Study of Natural Radioactivity in Brazil. NYC 2577-8.

Results of several studies of natural background radiation are reported including thorium activity in a lamp factory and personnel, thorium in Brazilian plants, gamma activity in sugars and in areas with high monazite contents in the sediments. 
Curie, I. 1946. Possibility of Studying the Activity of Rocks by Observation of $\alpha$-Particle Tracks in a Photographic Emulsion. Journal de Physique et le Radium. 7:313-19.

A detailed discussion is presented on the possibility of determining the uranium and thorium content of ordinary rocks by observing $\alpha$-particle tracks in a photographic film applied to the rocks' surface. Such determinations can be made only where radioactive equilibrium can be assumed. For the examination of normal granite, exposures of several months are needed. The same method can be used to study the distribution of radioactive elements within the rock. (NSA)

Dall'Aglio, M. 1971. Study of the Circulation of Uranium in the Supergene Environment in the Italian Alpine Range. Geochim. et Cosmochim. Acta. 35:47-59.

Geochemical prospecting surveys for uranium, carried out in the metamorphic basement of the Italian Alpine Range, detected marked anomalies both in alluvia and waters in the Martello Valley (Trentino Region, Northern Italy). Detailed surveys showed that no uranium occurrences or deposits outcrop in the vicinity of the geochemical anomalies. A detailed study was therefore made in order to determine the causes of these anomalies. Analysis of uranium were made on fresh water, rock, stream sediment and soil samples. The water samples were also analyzed for all the major as well as for some trace elements. Leaching tests on rock samples provided additional information with a view to understanding better the dissolution of uranium with respect to the major elements. The results of these studies emphasize some characteristics of uranium in the supergene environment. Uranium, particularly that contained as uraninite in the pegmatites, is the element which passes most readily into the natural waters, where it may reach anomalous values, even starting from rocks with a normal content. Part of the uranium dissolved in fresh waters is precipitated by the organic matter of soils and stream sediments. The percentage of the uranium precipitated is not high, but it is sufficient to raise the uranium content of the alluvia to significant anomalous values. These processes, in the particular environment of the explored region, explain the anomalous values found in waters and alluvia, starting from rocks whose uranium contents average șlightly more than the clarke value (approximately $5 \mathrm{ppm}$ ). (auth)

Dall'Aglio, M. and E. Casentini. 1970. Distribution of Uranium Between Precipitates and Brines in the Solar Salt Plant of Margherita Di Savoia. Geochemical and Geological Considerations. Boll. Soc. Geol. Ital. $89: 475-84$.

The behavior of uranium during the solar salt production process was studied. The research was conducted at one of the world's largest solar salt plants-located at Margherita di Savoia, Foggia--producing 600,000 tons of sodium chloride per year. The uranium content was determined in the brines, in the gypsum, and the sodium chloride precipitates. The results obtained 
show that uranium is concentrated in the final bitterns, the contents of which exceeds 30 micrograms per liter. The contents of uranium in the gypsum and sodium chloride are very low, i.e., from 0.1 to $0.001 \mathrm{ppm}$. The acid insoluble residues of salts show a higher uranium content, that is in the order of ppm. The geochemical and geological significance of the results obtained is also discussed. (auth)

Dall'Aglio, M., R. Gragnani, and E. Locardi. 1974. Geochemical Factors Controlling the Formation of the Secondary Minerals of Uranium. IAEA-SM183/21. IN: Formation of Uranium Ore Deposits. pp. 33-48.

The formation of secondary uranium minerals directly from natural waters is examined in this paper. There is evidence of some geochemical processes which are capable of creating conditions tavorable for the preclpication of secondary minerals, even when there are no primary uranium (IV) occurrences. Direct experience indicates that at least two hydrogeochemical processes are responsible for the precipitation of secondary uranium minerals; namely (1) the leaching of crystalline rocks, even with a normal content, under particular erosion and weathering conditions in the wet temperate climate zone. This process occurs, for instance, on the Sila Plateau in the Calabria region (Italy), where autunite is still precipitating; and (2) evaporitic processes of inland waters under arid climatic conditions, an example of which is furnished by carnotite deposits in the calcrete area of Western Australia. In the paper the results obtained in the course of hydrogeochemical studies carried out in Sila Plateau and in Western Australia are presented. The secondary mineral precipitation as a step towards the forming of uranium ore bodies in a multistage minerogenetic process is discussed. (auth)

Danchev, V. I., A. M. Kornilov, M. V. Neimyshev, V. V. 01 'kha, B. K. Proshlyakov, N. F. Strelyanov, and M. P. Sytnikov. 1959. Uranium Mineralization in Carbonate Sedimentary Rocks. Geol. Rudn. Mestorozhdenii. No. $6: 26-38$.

Data indicate that the formation of $U$ deposits in carbonate rocks was strongly affected by the country rocks. The $U$ in increased amounts accumulated together with organic matter in carbonate muds and oozes during the deposition of sediments in the sea bottom, as suggested by maps of ore thicknesses (isopachs). During diagenesis, simultaneously with the transformation of carbonate muds, the transition of $U$ compounds into stable mincral associations took place together with the redistribution of ore material (formation of concretions, replacement of faunal remnants, etc.). At a later stage the U-bearing carbonate rocks were subjected to further transforamtion, strongly dependent on the degree of fracturing of the ore body. Small veinlets are characteristic for this stage. The presence of liquid petroleum, usually in domes of anticlines, is a characlerislic feature of $U$ carbonate deposits. The correlation of the petroleum and $U$ indicates that the ore bodies were formed before the oil migrated into them. The oil accumulation in no way affected the distribution of ore 
minerals, and very often the sections most impregnated by oil are practically barren, but the presence of oil (reducing environment) sharply decreases the epigenetic migration of $U$. (CA)

Danchev, V. I. 1963. Conditions of Formation and Classification of Exogenous Uranium Deposits. At. Energ. (USSR) 14:296-308 (in Russian).

In view of the increasing importance of exogenous $U$ deposits, their classification attracted great interest. American and Canadian geologists made a detailed study of the rocks from the Colorado Plateau and Canada, using the surrounding formations as the basis of their classification. Ya.D. Gotman divided the exogenous $U$ deposits into sedimentary rocks of oceanic, lake water, or marsh water origin. V. S. Domarev, who also took the endogenous and metamorphic rocks into consideration, divided the exogenous ones into weathered and sedimentary deposits. Similar classification schemes, developed by V. G. Melkov, L. Ch. Pukhal'skii, A. G. Betekhtin, D. Ya. Surazhckii, V. N. Kotlyar, and A. A. Yakzhin, are given. The following classification is proposed on the basis of the conditions of formation and the composition of the surrounding rocks: weathered, sedimentary-hydrogenous, sedimentary, and sedimentary-metamorphic rocks; each of these groups is further subdivided. The epigenic redistribution is considered as one of the stages of the formation process. This approach is expected to be helpful in the correct evaluation of all exogenous rocks, possibly contributing to the discovery of new deposits. (NSA)

Davidescu, D., G. Pavlovschi, and V. Davidescu. 1969. Uranium in Vine and Wine. Rev. Hort. Viticult. 18:93-100.

In the soils of the Velea Calugareasca and the Dragasani vineyards, mobile uranium ranges between 14 and 163 gamma per $100 \mathrm{~g}$ of soil. The distribution of uranium in various vine organs is not a simple process of suffusion. Higher accumulations are found in the stones. The variable uranium uptake into the different vine species affect this mineral content in wines. The maximum concentration was found in the Royal Peteasca (Maidenty) of the Valea Calugareasca (300 gamma/1000 $\mathrm{ml}$ ). (NSA)

Dementev, V. S. and N. G. Syromyatnikov. 1965. On the Occurrence Form of Thorium Isotopes in Ground Waters. Geokhimiya. No. 2:211-18 (in Russian).

Concentrations and occurrence forms of the thorium isotopes, ${ }^{234} \mathrm{Th},{ }^{228} \mathrm{Th}$, and 232 Th were studied in some types of ground waters of Kazakhstan. The highest thorium concentrations were noted in waters containing a large amount of suspended and culluidal particles and with a high content of organic matters. With the aid of centrifugation and dialysis methods the distribution of thorium isotopes between the particles was established and found to differ by the degree of dispersion, from ionic to coarsely suspended. Differences in the behavior of isotopes with different half- 
lives were noted and found to be apparently connected with different conditions of accumulation in natural waters. With the aid of the ion exchange method a chiefly anionic character of sorption was established. It is suggested that the transportation of thorium isotopes into ground waters is realized both in a colloidal suspension form and as anionic complexes, probably with organic acids of soils. (auth)

Dezsi, Z. 1963. Studies on the Determination of the Radioactive Materials Content of Natural Waters. Fiz. Szemle. 13:298-304 (in Hungarian).

Presence of radioactive materials found in natural waters may be due to natural radioactive substances, contamination by fallout, or to the waste effluents from reactors. Determination of the natural radioactivity is of great economic importance because it may be an indicator of usable $U$ deposits; however, care must be taken in interpretation of the data. The high sensitjxity of the fluorometric method makes it possible to detect $10^{-5}$ to $10^{-10}$ of $U$. Integrating pulsed ionization chambers were used for determining the $\mathrm{Ra}$ and $\mathrm{Rn}$ concentrations in waters. The results of analytical determinations in Rumania and Hungary are reviewed. Although a large body of numerical data is available, no generally valid laws could be developed, although it can be stated that within a given geological formation, the distribution of $U$ and $R a$ follows the logarithmic Gaussian law. There is no equilibrium between the radioactive materials dissolved in the water. $U$ concentrations of the order of $10 \mathrm{r} / 1$ iter could not be correlated with the presence of U-rich ores in the surrounding area.

Dolpoux, M. 1970. Comparison of the Radium and Uranium Contents of Plants Harvested on Uraniferous Land. Conf-690918 (Vol. 2). IN: Proceedings of an International Symposium on Radioecology held in Cadarache, France, September 8-12, 1969. pp. 909-921.

Earlier work established the radium contents of 20 species belonging to the spontaneous flora of uraniferous lands of the Monts d'Ambazac, HauteVienne (France). Later on, the same samples of plant ash were used to determine the uranium content. In both cases, where the ground is highly radioactive, the variation in the concentration of these radioelements is independent of that of their concentrations in the soils. There even seems to be a decrease in the uranium and radium absorption in the most radioactive stations. In addition, the ashes of the most radium-rich plants (for example VACCINIUM MYRTILLUS: $3757 \times 10(E-12)$ Ci per gram of ash) contain on 7 y $13 \mathrm{ppm}$ of uranium whereas DESCHAMPSIA FLEXOUSA (L.) TRIN., that is the richest in uranium amongst the species studied (185 ppm), only contains $440 \times 10 \mathrm{E}-12 \mathrm{Ci}$ of radium per gram of ash. For each species therefore the radium and uranium absorption exhibit a large degree of independence. The main phenomena brought to light are a double absorption selectivity (variation between species towards the same radioelement and different behavior of each species towards uranium and radium). This gives a possible explanation of the wide differences observed between individual support to knowledge of the radioactivity peculiar to plants developing on uraniferous land. (auth) 
Dorta, C. C. and E. Rona. 1971. Geochemistry of Uranium in the Cariaco Trench. Bull. Mar. Sci. 21:754-65.

Four core samples taken during a cruise (P6603) of the R/V Pillsbury from the Cariaco Trench off the coast of Venezuela, were analyzed for major, minor, and trace elements. Special attention was given to $\mathrm{Th}, \mathrm{Pr}$, and $U$. A high concentration of $\mathrm{U}(30 \mathrm{ppm})$ was associated with the organic reducing sediment; with a 5-fold decrease in $U$ in the oxidized clay layer. This change was dated to the last glaciation. No change in Th and Pr concentration was noted. (CA)

Druin, V.A. 1965. Transuranic Elements in Nature. Perspektivy Sinteza Transuranovykh Elementov. pp. 30-3. Izdatel'stvo Znanie (in Russian).

The possibility of finding traces of transuranium elements on Earth is examined. In view of the estimated age of 5 billion years of the Earth, only isotopes with half lives of at least 100 million years may beexpected to be still found. Systematic searches reveal trace amounts of $239 \mathrm{Pu}$ and $237 \mathrm{~Np}$ in uranium minerals, but their half-lives of 24,000 and 2 million years indicate that they could not have been present in the crust at the time of the formation of the Earth, but were probably formed by the interaction of neutrons with the uranium nuclei. Analysis of the A spectrum of New Hampshire thorite revealed the characteristics of the thorium family with small amounts of ad-mixtures of lines originating from decaying members of the uranium family. The spectrum may be explained by ascribing certain lines to $247 \mathrm{Cm}$ and ${ }^{244} \mathrm{Pu}$; Soviet scientists reported similar findings. Other exp?anations of the very high $235 \mathrm{U} / 238 \mathrm{U}$ ratio in these minerals are less plausible. (NSA)

Dwornik, E. and M. Ross. 1955. Application of the Electron Microscope to Mineralogic Studies. Am. Mineralogist. 40:261-74.

A discussion of the use of the electron microscope in mineralogic studies and of sample preparation is followed by a series of electron photomicrographs showing the size, shape, and crystal habit of fine fractions of some uranium-bearing minerals from the Colorado Plateaus, lignite from North and South Dakota, phosphate minerals from Florida, and minerals synthesized in the laboratory. The information obtained from these photographs is useful in establishing paragenetic relations of associated minerals in uranium deposits, in supplementing mineralogic descriptions, and in guiding and checking separation techniques. (auth)

Eckelmann, W. R. and J. L. Kulp. 1956. Uranium-Lead Method of Age Determination. I. Lake Athabasca Problem. Bull. Geol. Soc. Am. 67:35-54.

Specimens of galena, clausthalite, and pitchblende were analyzed chemically and isotopically to obtain apparent ages from the ratios $\mathrm{Pb} 206 / \mathrm{U}^{238}$,

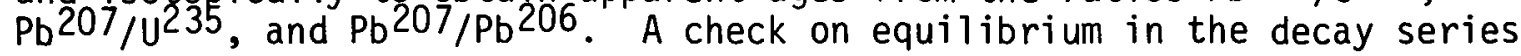


was made by measurement of the $\mathrm{Pb}^{210} / \mathrm{Pb}^{206}$ ratios, and $\mathrm{Rn}$-leakage measurements were also made on the samples. The Rn-leakage correction was found to be very minor, and the $\mathrm{Pb} 210 / \mathrm{Pb} 206$ ratios showed that all samples are presently in radioactive equilibrium. Apparent isotopic ages range from 220 to 1860 million years, and these anomalies cannot be explained by loss of $\mathrm{U}$ or $\mathrm{Rn}$. Partial $\mathrm{Pb}$ removal at some time or times during the geological history of these minerals is the probable cause of the anomaly; the $\mathrm{Pb}^{207 /}$ $\mathrm{Pb}^{206}$ age is thus closest to the true age but is minimal. For the Lake Athabasca district initial deposition of the pitchblende occurred about 1900 million years and recrystallazations accompanied by $\mathrm{Pb}$ removal probably occurred about 1200 million years and 100-200 million years ago. It is considered that agreement among isotopic ages from a given locality is excellent evidence that the true absolute age is known; conversely, anomalous ages owing to $\mathrm{Pb}$ loss prove the occurrence of one or more periods in which the regional temperature has increased. (CA)

El Nadi, A. F. and M. Ammar. 1960. Thorium Content in Nile Water. Proc. Math. Phys. Soc. (U.A.R.) No. 24:11-16.

A study of thorium concentration in Nile water was carried out by the flow method using a cylindrical ionization chamber. The results indicate that the amount before and after flood has an average of $14.7 \pm 0.6 \times 10^{-8} \mathrm{~g} / \mathrm{cc}$, while during flood it decreases to an average of $10.1 \pm 0.7 \times 10^{-8} \mathrm{~g} / \mathrm{cc}$. This decrease may be attributed to the effect of the presence of suspended clays which may absorb Tn gas on its surface and thus decrease the amount of Tn expelled during the process of deemanation. (auth)

El Wakee 1, S. K. and J. P. Riley. 1961. Chemical and Mineralogical Studies of Deep-Sea Sediments. Geochim. et Cosmochim. Acta. 25:110-46.

Chemical and spectrographic analyses are presented for the major and several minor elements in 10 calcareous, 12 argillaceous and 3 siliceous deep-sea sediments from the Altantic, Pacific and Indian Oceans and Mediterranean Sea; a $5 \mathrm{~m}$ core from the Atlantic; 3 deep-sea volcanic sediments; an unuaual calcareous manganiferous ooze, and the $<2 \mu$ fractions from 2 near shore muds. The distribution of the minor elements was very similar to that described by Goldberg and Arrhenies for Pacific sediments. Except for their higher content of ferrous iron and organic carbon the chemical composition of the $<2 \mu$ fraction of the near shore clays closely resembied that of the deep-sea argillaceous sediments. This resemblance and the similarity of the abundances of certain of the minor elements, such as $\mathrm{Ti}, \mathrm{Zr}, \mathrm{Cr}$ and $\mathrm{V}$, in the pelagic to their abundances in igneous rocks, suggests a mainly terrigenous origin for red clay. The argillaceous material of two globigerina oozes from the Mediterranean was very similar in composition to that of the deep ocean sediments. The proportions of all the major elements down the length of the 5-05 m core of red clay from off the Bermuda rise in the Atlantic were very constant. Niggli values have been used to compare the sediments, on a carbonate-free basis, the sediments from the Atlantic are characterized by their higher al and lower 
fin values compared with those from the Pacific and Indian Oceans. Illite and chlorite, with lesser amounts of montmorillonite, are the principal clay minerals in the deep sea sediments. The near shore clays are richest in kaolinite, but illite and montmorillonite are also present. (auth)

Erametsa, 0., K. J. Lounamaa, and M. Haukka. 1969. Vertical Distribution of Uranium in Finnish Peat Bogs. Suom. Kemistilehti B. 42:363-70.

$U$ has a rather high tendency to escape from the $1 \mathrm{ithosphere}$ into the hydrosphere. It is transported mainly in the form of the highly stable uranyl dicarbonate and tricarbonate complexes. Humic acids also form stable complexes with $U$. The capture and the distribution of $U$ from ground waters by solid humic acids was studied in 14 arbitrarily chosen peat bogs scattered in different parts of Finland. The uranium concentration generally peaks to a very sharp maximum at a level beginning $1 / 4$ from the bottom of the bog. In every other bog, at the depth mentioned, the $U$ content exceeded the detection 1 imit of $30 \mathrm{mg} / \mathrm{kg}$ in ash. The method of analysis was by $x$-ray fluorescence, as developed, to detect small amounts of substance. The maximum concentration was $1450 \mathrm{mg} \mathrm{U} / \mathrm{kg}$ in ash. The amount of $U$ was evenly distributed over the total bog area. In 1 bog the distribution of $\mathrm{Pb}$ and $\mathrm{Ni}$ was compared with the distribution of $\mathrm{U}$. (CA)

Erickson, R. L., A. T. Myers, and C. A. Horr. 1952. The Association of Uranium and Other Metals With Crude 0ils, Asphalts and Petroliferous Rocks. TEM-513.

Uranium analyses and semiquantitative spectrographic analyses of the ash of crude oils, natural asphalts, and oils extracted from petroliferous rocks indicate that $\mathrm{U}$ and other metals, including $\mathrm{V}, \mathrm{Ni}, \mathrm{Cu}, \mathrm{Co}, \mathrm{Mo}, \mathrm{Pb}$, $\mathrm{Cr}, \mathrm{Mn}$, and $\mathrm{As}$, are consistently present--sometimes in unusually high concentrations-- in this type of organic matter. The $U$ content of the ash of these samples ranged from less than $0.001 \%$ to more than $10 \%$; the $U$ content of the total 011 or asphalt ranged from less than 0.001 to 32,410 ppm (3.24\%). It seens probable that these metals occur as metalloorganic compounds and are concentrated in the heavy asphaltic portion of petroleum. The high concentration of unusual elements in the ash of the analyzed samples suggests that these elements were concentrated by some agency connected with the actual formation of oil and therefore have a genetic relationship with the origin of oil and the petroleum source beds. The results of this investigation also suggest that natural asphalts and petroliferous rocks may represent the source materials for the $U$ and other metals in some $U$ deposits. (NSA) 
Fieldes, M., G. Bealing, G. G. Claridge, N. Wells, and N. H. Taylor. 1960. Mineralogy and Radioactivity of Niue Island Soils. New Zealand J. Sci. 3:658-75.

Results of $x$-ray-diffraction analysis, differential thermal analysis, magnetic, and radioactivity examinations of Niue Island soils (from samples collected in 1949) are given, and problems of soil origin and agriculture are discussed. The mineralogy of the soils is unusual and shows considerable natural radioactivity. These soils have silicon contents of less than $1 \%$ and average phosphorus content of about $1 \%$. Hakupu soils of the elevated coastal fringe contain up to $40 \%$ of crandallite $\left(\mathrm{CaAl}_{3}\left(\mathrm{PO}_{4}\right)_{2}\left(\mathrm{OH}_{6}\right)\right), 2$ to $5 \%$ magnetite, much geothite, and some gibbsite. Fonuakula and Palai soil types of the inner basin consist mainly of biggsite and qeothite, with up to $8 \%$ crandallite and $1 \%$ magnetite. Crandallite decreases and gibbsite increases in passing from the raised fringe to the central depression. Crandallite contents are limited by contents of phosphorus. The relative contents of magnetite in the soils and in the underlying coral indicate that the soils are not wholly derived from coral and are probably largely derived from pumice and meteoric dust trapped in a former tidal lagoon. Spectrographic evidence supports this. Radioactivity up to thirty times greater than that of average New Zealand soils is due largely to ionium and $\mathrm{Ra}^{226}$ out of equilibrium with parent uranium. The ionium and radium have been trapped from sea water by reef sediments, in the former lagoon. Radioactivity measurements and related data suggest that emergence of the island from the sea occurred less than 200,000 years ago. Further study could aid in establishing the geological ages of terrace levels, thus providing a time scale for Pacific zone fossils, and in assessing effects of radioactivity on plants and animals. (auth)

Fischer, R. P. and J. H. Stewart. 1961. Copper, Vanadium, and Uranium Deposits in Sandstone - Their Distribution and Geochemical Cycles. Econ. Geol. 56:509-20.

Deposits of copper, vanadium, and uranium in nonmarine sandstones are numerous and widespread. Copper deposits, with or without uranium, are mainly resident in first-generation arkosic sandstones derived from granitic rock terrains; deposits rich in vanadium, with or without much uranium, are dominantly in second-generation sandstones derived from sedimentary rocks; and the uranium deposits with little or no vanadium or copper are in either first- or second-generation sandstones, many of which are associated with beds containing volcanic debris. All three metals are dispersed in igneous rocks but not in close association. Copper and uranium enter the hydrothermal environment, but the record of vanadium in hydrothermal solutions and veins is scant. Some of the uranium and most of the copper minerals in igneous rocks and veins oxidize readily and the metals go into surface- and ground-water solutions, but the vanadium in igneous rocks is not so easily mobilized--under normal geologic conditions, conceivably it may require diagenetic reactions and a second period of weathering to solubilize much vanadium. All three 
metals precipitate from solutions in the presence of a reducing agent, such as carbonaceous material or associated sulfide ions, either in sediments as they accumulate or in existing rocks. These geochemical habits permit the concept that copper and uranium are made available by weathering of igneous rock terrains and hence might accumulate in first-generation sediments, whereas vanadium would be commonly available only after a second period of weathering. Perhaps the oxidation or devitrification of volcanic debris may contribute uranium to ground waters as does the weathering of igneous rocks. (auth)

Fisher, D. E. and K. Bostron. 1969. Uranium-Rich Sediments on the East Pacific Rise. Nature. 224:64-5.

The results are reported of $U$ analyses of a series of sediments taken during a traverse across the East Pacific Rise. Most samples were from the depth interval 30 to $70 \mathrm{~cm}$ in the sediment cores, except for a few localities from which surface material could be obtained. Measurements were made by fission track analysis on total sediment samples. The samples were covered with Lexan plastic and reactor irradiated, the $U$ fissions induced providing energetic fragments that impinged on the plastic and left tracks visible after etching in $\mathrm{NaOH}$. Results are tabulated and shown graphically, and indicate a higher than normal $U$ concentration at the ridges. It is considered unlikely that the $U$ is a biogenic constituent in the sediments; the close association between high heat flow, high $U$ content and enrich-. ment in the crest sediments of other probably volcanogenic constituents suggests a similar volcanic origin for U. (NSA)

Flerov, G. N. 1970. Search for Remote Transuranium Elements in IronManganese Nodules. Acta. Phys. Pol. A38:595-601 (in Russian).

Effects of fission of remote transuranium elements were studied in ironmanganese nodules extracted from the bottom of the southern region of the Pacific 0cean. A large number of fission tracks (from 7 to 120 tracks/ $\mathrm{mm}^{2}$ ) were found in the mineral nodules of the feldspar group. The results of analysis showed that spontaneous uranium fission was responsible for only 10 to $20 \%$ of the observed tracks. It was postulated that the rest of the tracks were the result of the spontaneous fission of remote transuranium elements of the earth or cosmic origin, found in the nodules. (NSA)

Frederickson, A. F. 1948. Some Mechanisms for the Fixation of Uranium in Certain Sediments. Science. 108:184-5.

A new theory for the concentration of uranium in the sedimentary crust of the earth is given. It is suggested that large $\mathrm{U}^{+} \hat{2}^{+}$ions are formed and that these, adsorbed between graphite layers of carbonaceous material, may form a strong structure. The uranium may be in the form of adsorbed 
ions and not of discrete minerals, due to base exchange on clays and other layer-lattice minerals. The conclusion is that if the source containing uranium is weathered to clays with a high base exchange capacity, these clays show a high radioactivity. Support for the theory is given by the fact that kaolinite, which has almost no base exchange capacity, has negligible radioactivity. Several samples are compared supporting the theory. (NSA)

Frondel, C. 1956. The mineralogy of Thorium. U.S.G.S. Professional Paper $300,567-79$.

A review with 40 references of the mineralogy and geochemistry of Th, and a comparison with those of $\mathrm{U}$, Ce, and $\mathrm{Zr}-\mathrm{Hf}$. Tables list minerals of these elements and their composition. (CA)

Fronde1; C. 1958. Systematie Mineralogy of Uraniuin aind Thuriunt. U.S.G.s. Bulletin No. 1064.

Uranium and thorium minerals, together with a few rare-earth minerals containing uranium and thorium as nonessential constituents, are systematically and comprehensively described in this volume. The classification of the minerals included here is chemical. It is based on the nature of the anion, giving rise to the following broad categories: oxides, carbonates, sulfates, molybdates, phosphates and arsenates, vanadates, silicates, and the niobatetantalate-titanates or, more properly, multiple oxides. The phosphates and arsenates are described together because in general they are isostructural and form partial or complete solid-solution series. Within each category, minerals of analogous chemical composition and crystal structure are grouped together, such as the torbernite group of minerals within the phosphates in general. No formal distinction is made in the classification between anhydrous species and those containing water or hydroxyl. Almost all of the minerals described are hydrated. Each mineral species is described according to its synonymy, composition, crystallography and crystal habit, physical properties, optical properties, synthesis, identification, natural formation, and occurrence. The descriptive mineralogy is followed by determinative tables in which the mineral species are arranged according to their x-ray powder-diffraction interplanar spacings, chemical composition, optical properties, color, specific gravity, and fluorescence. The work is documented by more than 800 references to the world literature of the past 200 years. (auth)

Frondel, J. W. and M. Fleischer. 1950. A Glossary of Uranium- and Thorium-Bearing Minerals. U.S.G.S. Circular 74.

The glossary is divided into four categories: (1) minerals containing uranium and thorium as major constituents, (2) minerals containing minor 
amounts of uranium and thorium, (3) minerals that, if investigated by modern analytical methods, might show uranium or thorium content, and (4) minerals that are nonuranium- or nonthorium-bearing, but that have been reported to contain impurities or intergrowths of uranium, thorium, or rare-earth minerals. (NSA)

Gabelman, J. W. 1971. Sedimentology and Uranium Prospecting. Sediment. Geol. 6:145-86.

The world's principal economic uranium resources occur in continental sandstones or conglomerates often associated with preferred sedimentary structures. These relations have long been recognized and used empirically in exploration. Although the genesis of the uranium and the controls over its fixation are still debated, the epigenetic nature of deposits in sandstone is now generally accepted, and the argument has shifted to whether it is intrinsic or extrinsic to its present environment. In reducing oxygen-poor magmas and pegmatitic or hypothermal fluids, uranium enters into complex, refractory multiple oxides. It is more easily leached from volcanic glasses, but is not commonly available from any syngenetic source without corrosive alteration. Once liberated, uranium oxidizes readily and is mobile in the surficial environment. Reducing conditions in shallow, cool environments will stabilize uranium. It also may be stabilized in oxidized form by complexing with $P, V$, or As, or by loss of water in arid climates. Upon rock destruction, unaltered refractory minerals commonly remain intact to form placers. Liberated uranium is oxidized and dispersed in the fluid medium. It is extracted chiefly by ionic substitution or absorption in marine phosphates, and by adsorption on organic matter in carbonaceous shales. Both processes prevail everywhere during sedimentation of these uniform rocks, and uranium remains dispersed. It is rarely mobilized from these rocks because the chemical reducing environment remains so widespread. For economic deposits uranium must be concentrated from a mobilized dispersed state or introduced in concentrations. Epigenetic uranium migrates in fluid media through permeability systems that govern the quantity delivered to a precipitation site. Concentrations developed only where permeable rocks offered a precipitation mechanism. Altered rock matrices of most districts suggest that mineralizing fluids pervaded large blocks of ground, but formed deposits only in a few selected stratigraphic units under optimum combinations of permeability, host rock precipitants, and structures with interrupted permeability which allow the precipitants time to act. The most favorable structures are paleostream channels, intraformational unconformities of sandstone lenses in mudstone (or vice versa), and crossbeds. The sedimentary environment of each major productive formation in the United States is discussed, ranging from Triassic to late Tertiary. In each stratum only a small portion of the area of regionally similar sedimentational environment is mineralized. Only a few of the similar widespread sedimentary structures contain uranium, with no apparent differences between productive and barren examples. A common denominator of uranium districts within favorable host units appears to be the similarity in their tectonic position. (auth) 
Gangl off, A.

Uranium Deposits in Sedimentary Basins Studied by the

CEA. AEC- $\operatorname{tr}-7180$.

Uranium deposits in sedimentary deposits of the Agades Basin (Niger), the Franceville Basin (Gabon), Herault Basin (France), and the Bakouma region (Central African Republic) were studied. Data on the geological characteristics and types of sedimentation in each area are presented. Some general characteristics of $U$ deposits in continental clastic sediments, such as the Agades, Franceville, and Herault basins, and the genes is of these deposits are described. The unusual characteristics of the Bakouma uraniferous deposit are discussed. (NSA)

Garrels, R. M. 1955. Some Thermodynamic Relations Among the Uranium Oxides and Their Relation to the Oxidation States of the Uranium Ores of the Colorado Hlateaus. Am. Minéráloğlst 40̈:10̈ü-21.

Fields of stability of uranium (VI) and uranium (IV) hydroxides and oxides in water solution at $25^{\circ} \mathrm{C}$ and one at atmosphere pressure have been calculated as functjons of Eh and $\mathrm{pH}$. Equilibrium values of the activity of $\mathrm{UO}_{2}^{++}$ion and of $\mathrm{U}^{4+}$ ion also have been calculated and are shown as contours on the stability fields. Thermodynamic relations among the uranium (VI) hydroxides and hydrated oxides indicate that the free energy differences among the various species are small. The data are interpreted to mean that a variety of such uranium (VI) compounds may form and even coexist. Similar studies of the uranium (IV) hydroxide indicate that it is unstable relative to the oxide and may well be expected to change to the oxide at a finite rate. Uranium ( $V$ ) compounds probably have a transitory existence because of the instability of the $\mathrm{UO}_{2}^{+}$ion; uranium (III) oxides and hydroxides would not be expected to occur naturally because the uranium (III) ion would decompose water. A comparison of the behavior of the vanadium (III) and (IV) hydroxides with uranium (IV) oxide and uranium (VI) hydroxides indicates that vanadium (III) hydroxide should oxidize to the vanadium (IV) hydroxide at a lower potential that that required for the change from uranium (IV) to uranium (VI). A rather highly speculative diagram showing probable fields of stability of many of the major minerals of the Colorado Plateaus is presented, and the suggestion is made that a consistent picture results if it is assumed that the ores, as viewed today, represent the superimposition of a weathering environment on a mineral assemblage that was formed in a primary reducing environment. It is emphasized that such an interpretation is consistent but not necessarily unique. (auth)

Garrels, R. M. and E. S. Larsen. 1959. Geochemistry and Mineralogy of the Colorado Plateau, Uranium Ores. U.S.G.S. Professional Paper No. 320.

The studies reported are aimed at testing the oxidation concept of $U$ ores, developing a knowledge of the stability relations of $V$ and $U$ minerals under varying conditions of $\mathrm{pH}$ and oxidation-reduction potentials, and defining the nature and equilibrium conditions of the primary (low-valent) ores. 
The first five parts present topical data of general application to the Colorado Plateau; parts 6 through 15 cover the results of theoretical, experimental, or empirical studies relating to the chemical and physical nature of ores and their oxidation; in parts 16 through 19 are described the geological relationships between oxidized and unoxidized ore in several ore deposits on the Plateau; part 20 concerns the broad geochemical relationships of $V$ and $U$ throughout the world. The final part summarizes conclusions and particularly emphasizes the salient problems requiring further study. (NSA)

Geslin, M. 1954. Radioactivity of Water, Rocks, and Natural Sediments. Cahiers Naturalistes. 10, Suppl. 3-8.

This is primarily a review of about 30 papers to compare the relative amounts of radioactivity in the materials mentioned. The unit used for $\mathrm{Ra}$ is $10^{-15} \mathrm{~g}$, and for Th $10^{-5} \mathrm{~g} / \mathrm{g}$ of material. River water contains 2 to 4 units of $\mathrm{Ra}$ as compared to the ocean with 1 to 34 . Igneous and sedimentary rocks contain from 1000 to 3000 units. Marine sediments contain $50,000 \times 10^{-15} \mathrm{~g} / \mathrm{g}$. For all sources reported Th ranges from 0.5 to 2.1 . (CA)

Gibbs, H. S. and G. J. McCallum. 1955. Natural Radioactivity of Soils. New Zealand J. Sci. Tech. B37:354-68.

The radioactivity of principal horizons of a number of soil types was examined for relationships to properties used in the identification and classification of soil profiles. Techniques for measuring the intensity of gamma radiations in the field and of beta radiations in the laboratory are described. After correction for cosmic ray background the measurements showed a range in gamma counts from 410 to $2420 \mathrm{cpm}$ and in beta counts from 21 to $154 \mathrm{cpm}$. Correlation of the data and soil profiles showed that the soil radioactivity depends partly on the rock materials from which the profiles are developed and partly on the extent of weathering and leaching of the profiles. Rock materials determine the initial level of radloactivity in a sol1--high to moderate count rates being general for $C$ horizons from greywacke, sandstone, siltstone, or deposits of rhyolitic ash beds, and low counts being common on $C$ horizons from dolerite or andesitic ash beds. Reduction of the initial level by weathering or leaching is shown by counts of $C$ horizons of soils developed from the same type of rock decreasing with increasing leaching of the profile, and by count rates within the profiles decreasing from $C$ to $B$ horizon and from $B$ to $A$ horizon. The decreasing count rate up the soil profiles indicates an absence of significant accumulation of radioactive substances in $\bar{B}$ horizons and of significant circulation of radioactive substances by the plant and animal life. Radioactivity measurements on A horizons are too variable for comparison of profiles. Measurements on $B$ and $C$ horizons of soils developed from greywacke, sandstone, dolerite, and rhyolitic or andesitic volcanic ash beds are suitable for assisting 
identification of soil types formed from parent materials difficult to distinguish in the field, or for indicating changes of parent materials within a soil profile. As weathering and leaching tend to lessen the differences in count rates between soil types, weakly or moderately weathered and leached soils are recommended for comparisons of natural radioactivity. (auth)

Gindy, A. R. 1961. Radioactivity in Monazite, Zircon, and "Radioactive Black" Grains in Blacksands of Rosetta, Egypt. Econ. Geol. 56:436-41.

More than 50 different heavy minerals are known to occur in the Egyptian $\mathrm{Nile}$ deposits. Small scale concentrations form on the beaches of the Nile delta, the most important occurring near the Rosetta. A variety of techniques employing nuclear emulsions were used to measure the radioactivity of individual grains of monazite, zircon, and black sands from representative Rosetta samples. The specimens are described, and results from measurements of radioactivity are presented graphically. (NSA)

Gof, H. 1968. The Natural Radioactivity of Sediments of the Bay of Banyuls. Cah. Oceanogr. 20:225-35 (in French).

Variations of radioactivity in sediments of the Bay of Banyuls are controlled by equilibrium between the fine clay fraction predominant in the sediments and the proportion of heavy minerals and micas, whose importance is a function of their proximity to the drift zones of the continents. Total activity is in general the result of natural radioactive minerals; but fission products are important. This latter activity is localized in fractions of lamellar minerals (clays, micas), which because of their structure favor fixation 23 artificial radionuc] ides. In all samples the levels are as follows: $232 \mathrm{Th}, 234_{\mathrm{U}}>228 \mathrm{Th}>134 \mathrm{Cs}, 125 \mathrm{Sb} \geq 40_{\mathrm{K}} \geq 67 \mathrm{Zn}$. In various samples (total. clays, sands, heavy minerals, micas) the ratio of fission products to $232 \mathrm{Th}-234 \mathrm{U}$ varied between 0.20 and 0.38 ; that of fission products to $228 \mathrm{Th}$ between 0.44 and 1.07, the latter being a total sample; that of fission products to $40 \mathrm{~K}$ between 0.62 and 1.10 . Analys is was performed by a $400-$ channel analyzer. (NSA)

Goldberg, E. D. 1961. Chemical and Mineralogical Aspects of Deep-Sea Sediments. IN: Physics and Chemistry of the Earth. 4. L. H. Ahrens, F. Prcss, K. Rankama, and S. K. Runcorn (eds.). pp. 281-302.

Keys to phenomena which occurred on the surface of the earth are sought in studies of the chemistry and mineralogy of sediments from the deep-sea floor. Climate, vulcanism, and the paths of ocean water currents are but a few examples of activities that may well be logged in pelagic deposits. Recently, emphasis has been placed on the calcareous deposits with impetus being provided by the isotopic geology of carbon and oxygen. The problems of paleo-temperatures and paleo-productivity in the marine environment have 
been dealt with most successfully (a summary of this work may be found in Arrhenius, 1959). The deep-sea deposits are especially attractive on a number of counts. First of all, the total length of the column of unconsolidated sediments is small; in the Pacific the first major change in travel times of seismic waves occurs at a depth of the order of hundreds of meters (Paitt, 1956). Although up to the present only a surface layer of tens of meters has been cored and but a modest penetration into the Cretaceous has been made, there is every hope that within a few years all levels of the pelagic column will have been explored. Secondly, most of the recovered samples from the deep-sea floor appear to be relatively undisturbed. Some alterations in the depositional record are evident and are apparently due to near-bottom currents, earthquakes, or bottom organisms or combinations of any of the three, but, as will be pointed out in the text, we are now in a position to estimate in many cases the degree of disordering quantitatively. Finally, the various minerals that make up the deposits are small in number, compared to their terrestrial or near-shore counterparts, and can often be unambiguously traced to the geosphere in which they were formed. This circumstance can provide a ready entry into investigations of the mechanisms of formation and modes of transport of individual components of the deposit. Present day researches have for the most part left the descriptive stage; two related areas of work appear quite rewarding--geochronology and the authigenic minerals. The potential radioactive clocks for the pelagic deposits cover essentially the entire span of geologic time. However, their full utilization awaits more information on the chemistry and mineralogy of the solid phases of the deep-sea floor. Also, present laboratory work on the synthesis and analysis of authigenic minerals is already yielding significant information on oceanic conditions in the past accompanying their formation. This paper will attempt to take stock of recently acquired knowledge, and the accompanying problems, emphasizing by way of examples the noncalcareous pelagic sediments of the Pacific 0cean. (auth)

Goldberg, E. D. and M. Koide. 1962. Geochronological Studies of Deep Sea Sediments by the Ionium/Thorium Method. Geochim. et Cosmochim. Acta. $26: 417-50$.

The ionium/thorium method for determining the rates of accumulation of marine sediments was applied to a group of deposits from the Pacific, Atlantic, and Indian 0ceans. The thorium isotopes which were accommodated in authigenic minerals (presumably derived from sea water) were obtained through a hot hydrochloric acid leaching of the sample. A model for the mixing of the upper layers of the sediment, by worm-burrowing or near-bottom currents, is proposed and, if valid, allows the depth of mixing to be ascertained from the ionium/thorium profiles. Sediments in the South Pacific had rather uniform and low rates of deposition $\left(0.3\right.$ to $0.6 \mathrm{~mm} / 10^{3}$ years), while the North Pacific values in general were at least several times higher. These results are in accord with a much greater contribution of sedimentary components from the continents in the northern area. South Atlantic depositional rates were of the same order, millimeters per 
thousand years, as the North Pacific, while two adjacent Indian Ocean cores gave widely contrasting values. Surface values of the ionium/thorium ratio and to a lesser extent the hydrochloric acid leachable thorium concentrations, showed a marked geographical dependence which was attributed to the relative amounts of continental run-off an oceanic area receives. (auth)

Goldberg, E. D., C. Patterson, and T. Chow. 1958. Ionium-Thorium and Lead Isotope Ratios as Indicators of Oceanic Water Masses. A/Conf. 15/P/1980.

The ionium-thorium ratios and isotopic composition of lead in manganese nodules and in deep-sea sediments from the Pacific and Atlantic Oceans have been studied using alpha spectrometric and mass spectrometric techniques, respectively. The manganese nodules are concretionary accumulations of oxides of iron and manganese with appreciable concentrations of such trace metals as cobalt, lead, the rare earths, zinc, copper, nickel, and thorium. These deposits are unique to the deep-sea floor and the ferromanganese phases apparently form from chemical species in solution in oceanic waters. The deep-sea sediments analyzed in this study had as principal constituents clay minerals (mainly illites), detrital quartz and feldspars, biogenous opal, and phillipsite. Both the isotopic composition of the lead and the ionium/thorium ratios in surface samples from the sediments and nodules showed distince variations between oceans and also possessed characteristic values for different localities within the Pacific Ocean. These results can be interpreted on the basis that the deep oceanic water masses, which are in contact with the sediment surfaces, furnish these isotopes to the sediments. The isotopic compositions of lead and thorium in these different circulating water masses probably reflect the previous histories of the waters in the accumulation and loss of products from the major sedimentary cycle. Such isotopic analyses in samples from the deep-sea floor can compliment the classical methods of study of deep-oceanic circulation which are based on the distribution of temperature and the concentrations of dissolved constituents in the water under consideration or on direct measurement of the velocities of the water masses. Further, the possibility of studying the character and behavior of deep oceanic waters in past ages presents itself in the depth distribution of these isotopes in deep-sea cores. Finally, the validity of rates of accumulation of deep-sea sediments based upon ionium/thorium ratios is considered. Two critical assumptions of the method are: the bulk of the ionium and thorium enter the sediments from a dissolved form in ocean waters, and the ionium/thorium ratio in seawater has been constant over the time period that is being studied. Certain aspects of the latter assumption are considered on the bas is of residence times of elements in the oceans and the chemical and mineralogical compositions of deep-sea sediments. (auth) 
Goldsztein, M. and J. Ros. 1963. On the Uranium Content of Sediments of the Western Basin of the Mediterranean. Bull. Inst. Oceanog. $19 \mathrm{p}$. (in French).

The $U$ content of the sediments of the Mediterranean sea was studied. Three hundred samples were analyzed from the French Continental Shelf, from the Balearic Continental Shelf, and from the Abyssal Plain. The average U content is $2.3 \mathrm{ppm}$. In the sediments of the Continental Shelves, $60 \%$ of the $U$ is leachable with $2 \mathrm{~N}$ nitric acid; while this figure is $36 \%$ in the sediments of the Abyssal Plain. (auth)

Gorski, M. and S. Zmyslowska. 1956. Natural Radioactivity of Some Polish Soils. Postepy Nauk Rolniczych 3, No. 6:11-20.

The concentrations of Th and $U$ in two soils was determined by microscopic counts of numbers and measurements of length of $\alpha$-particles tracks in a photographic emulsion. The soil samples, taken at different depths, were compressed into tablets of 18 or $35 \mathrm{~mm}$ diameter; the exposure time of the photographic plates was 26 days (soil I) and 34 days (soil II). The ratio of $T h: U$ concentrations was calculated from the formula: $C_{T h} / C_{U}=3.3$ / $\left(v_{2} / v_{1}-0.8\right)$, where $v_{2}$ is the number of shorter $(32-30-\mu)$, and $v 1$ the number of longer (over $39-\mu)$ tracks. The concentrations were calculated from the relation: $C_{U}=k N /\left[S t\left(7.25+\left(2.23 C_{T h} / C_{U}\right)\right)\right]$, where $N$ is the number of tracks in the measured area. $S$ (corrected for the radioactivity of the photographic emulsion and averaged for areas of high and low depth), $t$ is the exposure time, and $k$ the retardation coefficient of $\alpha$-particles, found for each sample from the equation $k=\Sigma S c / A$, where $c$ expresses the concentrations of nonradioactive soil elements, $A$ their atomic weight, and $S$ their retardation coefficient. Except for few high-depth spots, the distribution of Th and $U$ in all samples was uniform. The concentration of Th was about tenfold that of $U$. Soil I contained $9.2 \times 10^{-7} \mathrm{~g} \mathrm{U} / \mathrm{g}$ and $9.3 \times 10^{-6} \mathrm{~g}$ Th/g at a depth of $10 \mathrm{~cm}$, and $8.6 \times 10^{-7} \mathrm{~g} \mathrm{U} / \mathrm{g}$ and $8.6 \times 10^{-6} \mathrm{~g}$ $\mathrm{Th} / \mathrm{g}$ at a depth of $50 \mathrm{~cm}$. The corresponding values of soil II were: $9.7 \times 10^{-7} \mathrm{~g} U / \mathrm{g}$ and $11 \times 10^{-6} \mathrm{~g} \cdot \mathrm{Th} / \mathrm{g}$ at $5-10 \mathrm{~cm}$, and $8.4 \times 10^{-7} \mathrm{~g} \mathrm{U} / \mathrm{g}$ and $12 \times 10^{-6} \mathrm{~g} \mathrm{Th} / \mathrm{g}$ at $27-33 \mathrm{~cm}$. It is pointed out that natural radioactivity must be taken into consideration when interpreting results of experiments on the effect of nuclear radiations on plant growth. (CA)

Griffiths, J. C., J. A. Cochran, D. W. Groff, and J. S. Kahn. 1954. Petrographical Investigations of the Salt Wash Sediments. RME-3106.

Investigations into the general petrographic background of ore-bearing sediments in the Salt Wash member of the Morrison formation are completed. The first part is an introduction to the problem and a discussion of the physical and chemical characteristics of the ore-bearing sediments. Part II is concerned with the use of bulk density measurements to characterize the ore-bearing sediments. The bulk density variation was investigated to form a quantitative basis for sampling the sediments but the stratification of 
the sediments into units either on the basis of lithology or cementation failed to increase the efficiency of the sampling pattern. Part III describes an investigation into the grain packing of the sediments and establishes that the packing in sediments near an ore-bearing sandstone zone is different from that in a barren sandstone. This analys is serves to confirm the nature of the physical attributes of the ore trap. the emphasis is on textural arrangement which is different in the ore-zone from the barren zone sediments. Part IV describes the results of dye testing the sediments both in the field and the laboratory. This simple test appears to be an effective tool for use in the correlation of mudstone horizons. The results accruing from a field excursion over the Colorado Plateau and the implications of lithological description in the field are described. Part VI is concerned with semiquantitative spectrographic analysis of ore-bearing sediments and mudstones from the well cores of Bull Canyon. The concentration of these elements appears to be somewhat higher than would be expected in average sediments and suggests that the sedimentary rocks on the Colorado Plateau are unusually rich in "trace" elements. It may be concluded that on the hasis uf a very considerable background of petrographic information on the Salt Wash sediments the differences between ore-bearing and barren sediments are differences of degree not kind. The problem of locating ore in the Salt Wash member reduces to the selection of suitable criteria for differentiating the orebearing from barren sediments. These criteria must be capable of being measured by techniques which possess a reasonably high degree of precision and the criteria must be related to the characteristics which are associated with ore in the sediments. (auth)

Grodzinskii, D. M. 1965. Estestvennaya Radioaktivnost' Rastenii I Pochv. Naukova Dumka.

Data on the natural radioactivity of plants and soils and its significance in plant 1 ife and soil fertility are summarized. Methods of studying natural radioactivity and of determining $U$, Ra, Th, Po, and other natural radioelements in plants and soils are discussed. The nature of radioactivity of various types of plants and regional soils and the radiation field produced by this radioactivity in the biosphere are described. New data are included on the blophysical and biochemical processes on which the effects of radioactivity on growth depend. The role of radioactivity in the origin of life on earth and in the evolution of species is shown. The physiological role of natural radioactivity, the significance of the radioactive properties of an element essential to plant nourishment, potassium, and practical uses of naturally radivaclive elements are discussed. (auth)

Gurskii, G. V., V. K. Lukashev, and V. A. Tolkach. 1967. Uranium and Radium in the Zone of Active Water Exchange of the Northeasl Part of the Pripyat Basin. Dok1. Akad. Nauk SSSR. 11:1017-20 (in Russian). 
The results of the determination of the content of uranium and radium in different types of water of the active water-exchange zone were reported. Some regularities of the distribution of these elements, expressed in the increase of the content of uranium in the chloromagnesium waters and the decrease of radium in the water of a sulfate-sodium state, were established. The ratio of radium to uranium was determined and the displacement of the radioactive equilibrium toward some increase of the radium content was noted. The coefficients of water migration for the elements studied were calculated as 1 for uranium and 8 for radium. The character of the distribution of uranium and radium in water and surrounding rocks was examined. (auth)

Gurskii, G. V. and S. A. Tikhonov. 1966. Uranium and Radium Geochemistry in Sod-Podzolic Soils of Belorussia. Dok. Akad. Nauk Beloruss. SSR. 10:763-5 (in Rüsian).

The contents of $U$ and $R a$ in sod-podzolic soils in glacial-lacustrine, loesslike, morainic, and fluvio-glacial loams and in wind-blown sand were studied. The total content and the content in the fractions $<0.001 \mathrm{~mm}$ from the sections $2-22 \mathrm{C} \mathrm{cm}$ were determined. The results are presented in the tables. The content of $U$ is $(0.2-5.0) \times 10^{-4}$, Ra $(0.09-4.83) \times 10^{-10} \mathrm{c} / 0$. The distributions of $U$ and $\mathrm{Ra}$ with respect to particle dimension, depth of sampling, and the type of loam are discussed. (CA)

Habashi, F. 1962. Correlation Between the Uranium Content of Marine Phosphates and 0ther Rock Constituents. Econ. Geol. 57:1081-4.

Sulfate and uranium appear to be genetically related in phosphorites. From the analysis of seven samples of sedimentary phosphates of different origin, it was found that the uranium content increases with decreasing sulfate content. This is attributed to the formation of sulfate complexes of uranium during sedimentation processes. The increase of uranium content with increasing $\mathrm{P}_{2} \mathrm{O}_{5}$ content previously reported in the 1 iterature was verified. A sample of magmatic phosphate was found not to behave in a manner similar to the sedimentary phosphate. (auth)

Haglund, D. S. 1968. The Distribution of Uranium in Recent Carbonate Sediments and Skeletons of Organisms and the Effect of Diagenes is on Uranium Redistribution. Rensselaer Polytechnic Institute. Thesis.

A study of the uranium concentrations of calcium carbonate skeletons from recent molluscs, corals, algae, hydrozoans, and a barnacle and unconsolidated skeletal sands was undertaken to establish relations between environmental, mineralogical, and taxonomic control of uranium uptake. In addition, two suites of carbonate sediments each composed of recent unconsolidated marine beach sands and consolidated Pleistocene limestones were examined to establish the effect of fresh water alteration on the uranium content. 
Analytical work included uranium analyses by the fission track powder method and quantitative mineralogy by $X$-ray diffraction techniques. Environmental designations of the samples are made of the basis of geomorphology.

The mean uranium content of all samples is $1.08 \mathrm{ppm}$, which is approximately half of the uranium clarke of limestones. The difference is due to the influence of low uranium molluscs and the exclusion of non-carbonate held uranium. The uranium concentration ranges of each environmental exhibit broad overlap between the environments. Gross sample uranium content is not judged to be a reliable environmental indicator. Corals contain an average uranium content of $2.96 \mathrm{ppm}$ and aragonitic marine molluscan shells contain an average of $0.15 \mathrm{ppm}$. A taxonomic effect on uranium uptake exists for the corals and the molluscs containing all or some calcite are among those molluscs with the lowest uranium content.

The uranium content of the fresh water samples shows a biomodal distribution. One mode contains pure aragonite molluscs with less than $.02 \mathrm{ppm}$ uranium, the other contains pure calcite samples with greater than $.05 \mathrm{ppm}$ uranium. The Calcite samples include oncolites, algal reef sands, and inorganic precipitates. The distinction between the uranium concentration modes is related to the ability of molluscs to discriminate against uranium incorporation in their shells.

The mean uranium concentration per environment of a 11 recent molluscs appears to be related to the salinity of the environment although broad overlap exists for all environments. The uranium concentration of samples from cores of the marine environment indicate the uranium concentration of the skeletal sands is constant while the samples are in contact with marine water. The uranium content of core samples from fresh water environment decreases with depth in core and is related to increasing crystallinity of the calcite grains.

Uranium concentrations of the recent and Pleistocene carbonate sediments from Bermuda and the Mediterranean Coast of Israel are compared to accepted indicators of fresh water alteration. Aragonite and uranium contents of the beach sands show a trend with high positive correlation, an effect of the coral content of the sands. An inverse relation exists between the uranium and Mg-calcite content of the beach sands. As the fresh water metastable aragonite and $\mathrm{Mg}$-calcite are removed from the sediment system and the sample type changes from unconsolidated beach sand to consolidated 1 imestone there is a concomitant decrease in uranium content. The uranium and calcite concentrations show an inverse relation and indicate the product of fresh water alteration, calcite, rejects uranium. The uranium-stable carbon and oxygen isotope relations for the Bermuda suite are inconclusive, whereas the same plots for the Israeli Coast suite show a direct relation between decreasing uranium content and increasingly negative delta values. The relations of uranium and accepted fresh water alteration indicators provide converging lines of evidence indicating that fresh water dissolution and replacement of marine carbonate sediments causes a reduction, up to 50 percent over the Pleistocene period, in total sample uranium content. (auth) 
Haglund, D. S., G. M. Friedman, and D. S. Miller. 1969. The Effect of Freshwater on the Redistribution of Uranium in Carbonate Sediments. J. Sediment. Petrol. 39:1283-96.

The uranium concentration of two independent carbonate sediment sample suites was studied to establish the effect of fresh water alteration on the redistribution of uranium. Recent carbonate sands and their ancient analogs were studied in Bermuda and along the east coast of the Mediterranean Sea in Israel. The results of the uranium analyses are compared to established indicators of fresh water alteration in carbonate sediments. Interpretation of the data from both areas yields the same conclusions. As the metastable minerals aragonite and Mg-calcite are removed by fresh water from the sediment system and the sample type changes from unconsolidated carbonate sand to consolidated limestone there is a concomitant decrease in uranium content. The uranium and calcite concentrations show an inverse relation and indicate that the product of fresh water alteration, calcite, accepts less uranium than the original aragonite. The relationship between uranium and the stable carbon and oxygen isotopes for the Bermuda suite is inconclusive, whereas the same plots for the Israeli Coast suite show a direct relationship between decreasing uranium content and increasingly negative delta values. The relations between uranium and established indicators of fresh water alteration provide converging 1 ines of evidence indicating that fresh water dissolution and replacement of marine carbonates cause a reduction, up to 50 percent over the Pleistocene samples, in total sample uranium content. (auth)

Hahofer, E. and F. Hecht. 1954. Determination of Uranium in Deep-Sea Samples. Microchim. Acta. pp. 417-34.

A scheme is given for determining $U$ in deep-sea sediments. It provides for fusion with $\mathrm{Na}_{2}-\mathrm{CO}_{3}$, dissolving the melt in dillute $\mathrm{HNO}_{3}$, removal of the $\mathrm{SiO}_{2}$ from $\mathrm{HNO}_{3}$ solution rather than from $\mathrm{HCl}$ solution as usual, extraction of $\mathrm{UO}_{2}\left(\mathrm{NO}_{3}\right)_{2}$ with ether, or separation of $U$ by paper chromatography. The $U$ is finally determined by measuring the intensity of fluorescence of a NaF bead in which the $U$ is concerned. The $U$ content of Pacific Ocean deep borings was approximately $1 \gamma$ per gram of sediment. (CA)

Haji-Vassiliou, A. 1969. The Association of Uranium with Naturally Occurring Organic Materials in the Colorado Plateau and Other Areas. Thesis. Columbia Unviersity.

Urano-organic associations may be divided into various types mainly on the basis of their geological mode of occurrence. In order to understand the nature of these associations more fully, the following problems have been considered: the origin or source of the associated organic matter; the form of occurrence of the associated uranium; and the probable mechanisms responsible for their formation. Most of the types of associations studied here represent occurrences in the Colorado Plateau area. Selected localities include the sandstone-type deposits at Temple Mountain, Utah and 
at Ambrosia Lake, New Mexico; the uraniferous carbonaceous shale near Gallup, New Mexico; and the urano-organic matter in sulfides and altered volcanic rocks at La Bajada, New Mexico. The non-Plateau occurrences are also included: The uraniferous lignite of South Dakota, and the thucholite of the Rand conglomerates of South Africa. The two basically different sources of organic matter in rocks and sediments are terrestrial plant derivatives (or coal) and petroleum derivatives. Geological evidence indicates that both petroleum and plant derivatives have contributed to the formation of the Temple Mountain ore. Similar evidence shows that plant derivatives constitute the most probable source for the organic fractions in the uranoorganic deposits at Ambrosia Lake and Gallup, and, certainly, in the uraniferous lignite. The mode of occurrence of the ore at La Bajada suggests petroleum as the source. The source for the thucholite is not clearly differentiated in terms of geological evidence alone. Physical properties did not decisively relate the origin of the impregnated organic matter to either of the two basic sources, but furnished certain suggestions. These suggestions became definite indications upon consideration of refractive indices and chemical-structural data obtained mainly through organic elemental analysis, infrared spectroscopy, and vacuum differential thermal analysis. A final consideration of both geological and physio-chemical evidence indicates plant derivatives as a major source for the organic components in all but one of the deposits. Petroleum is indicated as the main source for the organic fractions in the La Bajada deposit, as well as a major source (along with coal) for the Temple Mountain ore. Microscopic and X-ray data show the presence of primary uranium minerals (uraninite or coffinite) in the urano-organic ores at Temple Mountain and Ambrosia Lake, and in the thucholite. No uranium minerals were identified in the La Bajada ore or in the uraniferous organic shale. Only secondary uranium minerals have been found in the highly uraniferous lignite. The relationship of the uranium content to the ash content of mechanically fractionated portions of representative samples from each deposit indicates that most of the uranium in the urano-organic materials from Temple Mountain, Ambrosia Lake, and La Bajada is related to the mineral, content of these materials; and most of the uranium content of the lignite and carbonaceous shale is closely associated with the organic components. Several investigators have demonstrated the capacity of organic matter to adsorb or reduce large amounts of uranium from uranium-bearing solutions. In terms of the evidence obtained on the nature of the urano-organic deposits, the accumulation and deposition of most of the uranium in the lignite, the carbonaceous shale, and the ore at Ambrosia Lake and La Bajada may be attributed to such a capacity for the organic components. The major mechanism of formation of the South African Thucholite and the ore at Temple Mountain seems to be the pseudomorphic replacement of pre-existing uraninite by activated organic matter. (NSA) 
Hansen, R. 0. 1965. Isotopic Distribution of Uranium and Thorium in Soils Weathered From Granite and Alluvium. Thesis. University of California.

Chemical techniques and physical instrumentation were developed to measure quantitatively the radioactivities of $\mathrm{U}-234, \mathrm{U}-238$, Th-230, and Th-232 in air-dry powdered samples of soils and rocks. These alpha emitters were measured by alpha-particles spectrometry with ionization chambers and associated electronics constructed for these experiments. In residual soils of the Sierra Nevada, both uranium and thorium were concentrated to a greater degree than in the underlying rocks. Both uranium and thorium were most highly concentrated in clay fractions. Thorium-230 had redistribution patterns different from those of U-238, U-234, or Th-232 and often somewhat between those of isotopes of uranium and those of Th-232, showing the effects of Th-230 having existed as U-234 a significant fraction of the soil-forming period of time. Uranium-234 and U-238 usually had similar radioactivfties. Curie radioactivity levels of individual nuclides ranged from $0.23 \times 10^{-12}$ curies/gram for a fresh rock sample to $3.2 \times 10^{-12}$ curies/gram for a clay formed from the rock in the case of $\mathrm{U}-238$ and $\mathrm{U}-234$. In the residual upland soils studied, uranium was preferentially retained whereas in the alluvial soils thorium was preferentially retained. Lime concretions from Ducor type soils showed enrichment of uranium in excess of thorium. Ages of 40,000 to over 180,000 years were calculated by means of two equations, one based upon the rapid initial accumulation of uranium and the other based upon a constant rate of accumulation of uranium. For an estimate of age for a primary soil (Ahwahnee sandy loam) with a developed "B" horizon, an equation was developed analogous to a branched decay where one branch represented leaching loss and another radioactive decay. An age of 32,000 years was calculated for the topsoil. (NSA)

Hansen, R. 0. and G. L. Huntington. 1969. Throium Movements in Morainal Soils of the High Sierra, California. Soil Science. 108:257-65.

Thorium distributions in a sequence of morainal soils in Bench Valley, California, were determined by gamma spectrometry of profile samples. Concentrations of thorium ranged from $10.8 \mathrm{ppm}$ in a $\mathrm{B} 2 \mathrm{~h}$ horizon, to 24.0 ppm in a B2ir horizon. The data indicated distinct thorium accumulation in horizons immediately underlying horizons of high organic content. A2 or B2ir horizons respectively contained higher thorium concentrations when overlain by $A 1$ or B2h horizons. Soil organic matter apparently complexed with thorium as well as with iron, although the leached iron accumulated visibly in horizons of pH 5.5 or greater, whereas thorium dislributiuns were more diffuse and apparenlity less affected by change in $\mathrm{pH}$. Radium was distributed $(0.85$ to 1.91 picograms $/ \mathrm{g})$ more irregularly than was thorium reflecting the effects of the soil chemistry of $238 \mathrm{U}$, $234_{\mathrm{U}}$, $230 \mathrm{Th}$, as we 11 as $226_{\mathrm{Ra}}$, with the passage of time. Radium distributions are explained in terms of uranium retention by organic matter, mobilization of ${ }^{230}$ Th by organic matter, plant absorption of radium, and time. Potassium concentrations ranged from 1.9 to 4.8 percent, being generally higher in $A 2$ horizons than in $A 1$ horizons. (NSA) 
Hansen, R. 0. and P. R. Stout. 1968. Isotopic Distributions of Uranium and Thorium in Soils. Soil Science. 105:44-50.

Both uranium and thorium tend to concentrate as a result of rock weathering. Uranium and thorium losses from soils occur, but differential leaching favors uranium in one instance and thorium in another. Thorium concentrations are higher than uranium in the B horizons, but in the upper horizons of the upland primary soils uranium concentrations increase. The alluvial soils of the San Joaquin Valley tend to have higher and more evenly distributed concentrations of thorium. There are instances where $U$ and Th become separated as a result of soil-forming processes, such as movement of uranium into lime nodules with calcium, or thorium from topsoils where the organic content is highest. In these instances measurements of decay and of accumulations of $T h-230$ can give clues to the rates of soil-forming processes and for determining the ages of soil fractions. Isotopic analyses of uranium and thorium by alpha particle spectrometry appears to be a useful means of acquiring information about the mechanisms and rates of soil formation. (auth)

Harriss, R. C. and J. A. S. Adams. 1966. Geochemical and Mineralogical Studies on the Weathering of Granite Rocks. Am. J. of Sci. 264:146-73.

Chemical, mineralogical, and autoradiographic techniques have been applied to the study of five weathering profiles developed on granitic rocks. Two profiles from the Tishomingo granite, Oklahoma, two profiles from the Mount Scott granite, Oklahoma, and a single profile from the Elberton granodiorite, Georgia, were investigated. The relative mineral stabilities in the three granites under investigation generally follow the expected sequence: plagioclase feldspar, biotite, potassium feldspar, quartz, from least to most stable respectively. This relative stability sequence is consistently observed regardless of climatic and/or local physiochemical variations. Kaolinite is the predominant clay mineral present in the Elberton profile from Georgia. Illite and Kaolinite are both present as major constituents in the four 0klahoma profiles. The largest physical and chemical changes occur in the transition from the $\mathrm{C}$ horizon (weathered rock) to the $\mathrm{B}$ horizon (soil). Mineralogy is the predominant factor controlling the relative mobility of calcium, sodium, potassium, rubidium, and thorium during weathering. Calcium and sodium are concentrated in the plagioclase feldspars and mafic minerals and are released and mobilized during the early stages of weathering. Potassium and rubidium are concentrated in the relatively stable orthoclase feldspars and thorium in the resistate minerals. These three elements are mobilized only in the intermediate and final stages of weathering. Lithium, copper, manganese, and zinc are generally enriched in the soil portion of the weathered mantle as a result of adsorption and surface exchange with clay minerals. Stability diagrams indicate that the natural surface waters of east-central Georgia are in equilibrium with kaolinite, the major clay mineral present in the soils. In contrast, the surface waters of southern $0 \mathrm{klahoma}$ are in equilibrium with kaolinite and montmorillonite but not illite which is a 
major constituent of the Oklahoma soils. Combined field and theoretical evidence indicates that the Georgia soils have reached maturity and are probably the result of extensive weathering early in the postglacial period. The 0klahoma soils are very immature and are presently undergoing active alteration. (auth)

Haseman, J. D. 1947. Significance of Atomic Energy to Petroleum Problems. Petroleum Engineer. No. 18:70-6.

Explores the theory that there may have been sufficient local concentrations of radioactive minerals in the past sediments to affect the synthesis of petroleum out of plant cellulose. (NSA)

Havlik, B. 1970. Radioactive Pollution of Rivers in Czechoslovakia. Health Physics. 19:617-624.

One of the oldest uranium mining areas in the world is the spa Jachymov in Bohemia. A study of environmental contamination began there when uranium mining was at a maximum, and continued until mining ceased 6 years later. Content of $\mathrm{Ra} 226$ and total beta activity of water, river sediments and water plants were estimated in the streams of this area and from the other uranium ore area, where mining reached its maximum during the study period. Radioactive pollution of the major Czechoslovak rivers during 1964 to 1967 is described. (auth)

Hee, A. 1948. Researches on the Radioactivity of a Vosges Granite by the Photographic Method. Comptes Rendus 277:356-358 (in French).

The radioactivity of a Vosges granite containing pleochroic halos and zircons in close relationshin with uranium and thorium has been studied by the photographic method recently employed by Poole and Bremner (Nature 161, p. 884, 1948). A close contact between a thin slab of the granite and an Ilford plate was maintained for several weeks, after which it was possible to locate the zircons, halos, quartz, and feldspar in the sample. The photographic plate thus obtained was used to study the distribution of alpha particle tracks in the gelatin. A greatly magnified direct photograph was used for reference. Some of the zircons proved to be very active, since many stars and "thickets" of tracks were observed. The complex stars observed seemed to proceed from the zircons having sections perpendicular to the quarternary axis. (The zircons crystallize in the form of a bypyramidal prism having a square base.) However, all of the zircons did not exhibit such activity, some being only slightly active or inactive. It was verified that the pleochroic halos are not associated with the zircons in the granite and are not radioactive. The two important active zircon centers which are found in the surface are made invisible by the halo accompanying each active crystal. Quartz and feldspar were found 
contain only rare isolated tracks. The existence of a white region surrounding an active region in the negative plate is in agreement with Joly's belief that the halos in the rock are due to ionization of the substance by alpha rays, although the halos themselves are not radioactive. More extended work will be published later. (NSA)

Hee, A., M. Jarovoy, and J. Kleiber. 1950. Study by the Photographic Method of Active Deposits of Various Radioactive Substances. Compt. rend. 230:1520-2 (in French).

Several substances rich in uranium and thorium (Colorado carnotite, Tonkin autunite, and Ceylon thorianite) were electrically deposited on metal discs which were then placed in contact with Ilford plates for periods ranging from about 1 hours to about 1 days. The authors then made a statistical study of lengths of the $\alpha$ tracks found in the plates after various exposure times. On the basis of this study they have identified the radioactive elements contained in these minerals. (NSA)

Hecht, F. 1963. Uranium and Thorium Determinations in Austria Waters and Rocks. Fortschr. Geol. Rheinland Westfallen. 10:193-9.

Determinations were made by ion exchange, followed by determinations of $U$ polarographically and of Th with Thoronol. Data are given graphically for several rivers. Concentrations of $U$ above $4 \mathrm{ppm}$ in sediments indicate terrigenous formations rather than marine. (CA)

Hess, V. F. 1918. Distribution of Radioactive Substances in and Over the Sea. Sitzb. Akad. Wiss. Wien. IIa. 127:1297-1313.

The author discusses: Interchange of matter, in general, due to diffusion, heat motion, etc.; movements of radioactive substances in the earth, the atmosphere, and the oceans; $R a$, Th and $U$ content of the seas, oceans, ocean beds, and rivers; and the question of evaporation in this relation. An average of $1.04 \times 10^{-17}$ curie of emanation is given up to the atmosphere by $1 \mathrm{~cm}^{2}$ of sea surface per second. Since $W$. Schmidt and the author previously determined that the land gives off from 2 to 3 times $10^{-17}$ curie, the amounts of emanation escaping from the land surface and the sea surface are approximately equal. (CA)

Heye, D. 1969. Uranium, Thorium and Radium in Ocean Water and Deep-Sea Sediments. Earth Planet. Sci. Lett. 6:112-16.

It was found from the data of 25 deep-sea cores that the U/Th ratio of sediments is nearly constant at a low $\mathrm{CaCO}_{3}$ content. This result and reflections about some other points have led to the assumption that $U$ and Th are being transported into the sediment through the intermediary 
of minerals. During the transport $U$ (preferably ${ }^{234} \mathrm{U}$ ), Ra, and some Th are leached by ocean waters. This model provides for interpretation of the activity ratio $234 \mathrm{U} / 238 \mathrm{U}<1$ in deep-sea sediments with low carbonate content as well as the activity ratio $228 \mathrm{Th} / 232 \mathrm{Th} \sim 15$ in ocean water. Likewise a part of the 226 Ra excess (compared with the Io in solution) may be caused by that leaching. (auth)

Heye, D. 1970. Sedimentation Rate of Deep-Sea Cores of the Indian Ocean With the Ionium/Thorium and the Protactinium/Ionium Method. "Meteor" Forschungsergeb., Reihe C. No. 3:15-22 (in German).

Sediment cores were taken at 5 points in the Indian 0cean and Io, Th, and $\mathrm{Pa}$ determined by measurements of their emanations. The water depths were 2042-4298 $\mathrm{m}$, and in each case cores were taken at sediment depths of from a few $\mathrm{cm}$ to a few $\mathrm{m}$. The rates of sedimentation varied from 0.32 $\mathrm{cm} / 10^{3}$ year at the greatest depth (in the middle) to $2.1-2.6 \mathrm{~cm} / 10^{3}$ year near the coasts. (CA)

Heye, D. 1970. A System for Detection of Ionium, Thorium, and Protactinium to Date Deep-Sea Cores. Geochim. et Cosmochim. Acta. 34:389-97.

A highly sensitive system for detection of small quantities of Ra, Th, and An by delayed coincidences was developed. These isotopes were continually swept from a solution containing their parents into an $\alpha$-proportional gas counter. Some deep-sea cores were dated and no loss of Ra by diffusion could be found. (auth)

Holland, H. D. and J. L. Kulp. 1954. The Mechanism of Removal of Ionium and Radium From the Oceans. Geochim. et Cosmochim. Acta. 5:214-24.

The adsorption and base exchange of Th and $\mathrm{Ra}$ on deep-sea red ctay, globjgerina ooze, and green clay were investigated by use of $T^{228}$ and $\mathrm{Ra} 224$ as tracers. At equilibrium the fraction of radioactivity remaining in the sea-water solution is independent of the told quarilily of tracer added. Extrapolation of the data to actual concentrations of $\mathrm{Th}$ and $\mathrm{Ra}$ in sea water indicates that the concentrations of these elements in sediments is comparable to that of these experiments. It is concluded that base exchange is the method by which Th and $\mathrm{Ra}$ are taken up by the sediments. (CA)

Holland, H. D. and J. L. Kulp. 1954. The Transport and Deposition of Uranium, Ionium, and Radium in Rivers, Oceans, and Ocean Sediments. Geochim. et Cosmochim. Acta. 5:197-213.

Theoretical calculations were made of the factors controlling the concentrations of radioelements in sea water. The influx of $U$ into the 
oceans and its deposition in shelf sediments are nearly equal, and both exceed the rate of radioactive decay and deposition in deep-sea sediments. The production of $\mathrm{Ra}$ by Io decay is greater than river influx, whereas its decay and deposition in deep-sea sediments exceed deposition in shelf sediments. In the case of Io the influx and deep-sea sedimentation rates are nearly equal and much greater than radioactive production from $U$ and deposition in shelf sediments. The Io concentration in sea water is calculated to be $3.1 \pm 1 \times 10^{-15} \mathrm{~g} / \mathrm{ml}$. (CA)

Hoogteijling, P. J. and G. J. Sizoo. 1948. Radioactivity and Grain Size of Soil. Physica. 14:65-72.

By measurements on separated grain size fractions $0-2 \mu, 2-16 \mu, 16-2000 \mu$ of several sedimentary soils, evidence was found for a preference of the radinactive elements for the grain sizes 2-16u. From the variation of the activity with the amount of the material spread each time on the same surface, as well as from the comparison of the radium content with the total activity, it was concluded that the composition of the radiation depends on the fineness of the material. The ratios of the concentrations of the various radioactive elements, therefore, must vary with the grain size. It is suggested that this variation is not only related to the mineral composition of the original material, but also influenced by the combined processes of solution and adsorbtion during the process of sedimentation. (NSA)

Hoogteijling, P. J. and G. J. Sizoo. 1948. Radioactivity and Mineral Composition of Soil. Physica: 14:357.

The data taken on sedimentary sands indicate that the radioactive elements are concentrated in the heavy mineral fraction, being chiefly bound to the zircon mineral. Tabulated activities are recorded for various zircon mineral contents and the zircon activity is compared with that of equivalent weights of the other heavy fractions of sands. Although no relationship between the radioactivity and the zircon content was found for clays, a correlation between radioactivity and potassium content was made. However, the potassium radiation accounted for only a small fraction of the activity of the clays studied. Tabulated data for various clay minerals are shown. No evidence for a concentration of the radioactive elements in any one of the clay minerals was found. It is concluded that during the chemical transformation of the original minerals into the clay minerals the radioactive elements are at least partially free and spread over the whole material by adsorption to the surface of the precipitating particles. (NSA) 
Horr, C. A., A. T. Myers and P. J. Dunton. 1961. Uranium and Other Metals in Crude 0ils. A. Methods of Analysis for Uranium and Other Metals in Crude 0ils, With Data on Reliability. Hyden, H. J. B. Distribution of Uranium and Other Metals in Crude 0ils. U.S.G.S. Bulletin 1100.

A. The content of uranium and other metals in crude oils ranges from a few tenths to several hundred parts per million. To concentrate these metals, crude-oil samples were prepared for analysis and reduced to ash by two methods: a modified ASTM method of dry ignition, and a wet oxidation followed by ashing. Results obtained by the two methods do not differ appreciably. The concentration of copper, vanadium, and nickel in the ash of 37 oils was determined by both the quantitative and semiquantitative spectrochemical procedures. A comparison of the results showed that more than $60 \%$ of the semiquantitative results for these three elements are in the same one-third order of magnitude as the quantitative results. Uranium in the ash was determined fluorimetrically and comparative results on several samples showed satisfactory agreement. B. A total of 120 samples of crude oil and 16 samples of refinery residue were collected from oil fields and refineries located in the western half of the United States. The oil and residue samples were reduced to ash; the uranium content of the ash was determined by fluorometric analysis, and the content of other metals by emission spectrograph. The uranium content in the ash of a majority of the samples is included in the range 0.0002 to $0.001 \%$. The reported average uranium content in the crust of the earth is within this percentage range. In contrast, vanadium and nickel contents in the ash of most of the samples are included in the range of 10 to $50 \%$, which is several orders of magnitude greater than the reported vanadium and nickel contents in the crust of the earth. The amounts of other metals in the ash of oil are similar to those in the crust of the earth; among these latter metals, molybdenum shows the greatest relative enrichment in the ash of crude oil. The ratios of vanadium to nickel of the oil samples tend to increase with increasing age of reservoir rock. Tests indicate that crude oil can leach uranium from sandstone containing uranium minerals such as uraninite and carnotite. The uranium content of crude oils, therefore, can be indicative of the uranium content in sandstone oil reservoirs. (auth)

Horrath, E. 1960. Investigations of Uranium Adsorption to Peat in Natural Waters Containing U-Traces. Magyar Tudományos Akad. Atommag Kutato Intézete, Közlemenyek 2:177-83 (in Hungarian).

Adsorption tests were made with previously standardized peat samples in well waters of the vicinity of Debrecen, Komadi, and the Taktakoz region. The investigations revealed an average value of 2 to $3,5 \times 10^{2}$ for the equilibrium constant, the so-called "enrichment factor" of urantum adsorption by peat. (auth) 
Hosterman, J. W., W. C. Overstreet, and J. J. Warr, Jr. 1964. Thorium and Uranium in Monazite From Spokane County, Washington. "Short Papers in Geology and Hydrology. Articles 122-172." p. 0128-30.

Monazite occurs in residual clay derived from granodrite and related rocks (saprolite) and sedimentary clay deposits of the Latah Formation. In three samples of monazite separates, thorium oxide $\left(\mathrm{ThO}_{2}\right)$ averages 3.67 and uranium oxide $\left(\mathrm{U}_{3} \mathrm{O}_{8}\right)$ averages $0.37 \%$. The tenor of the monazite is not high enough to be considered commercial. (auth)

Ideno, E. and T. Sugimura. 1963. Uranium Content in Recent Sediments in Japan. Nippon Genshiryoku Gakkaishi 5:46-8 (in Japanese).

The $U$ content in some recent sediments in Japan was determined by a colorimetric method (Tutsomoto and Goldberg, CA 54, 20687d). The average content of $U$ was $2.5 \mathrm{ppm}$, in good agreement with the results given by Holland and Kulp. (CA)

I11sley, C. T. 1961. Hydrogeochemical Reconnaissance for Uranium in the Stanley Area, South-Central Idaho. RME-140.

Geochemical data obtained from the analyses of 73 water samples collected in the Stanley area, Idaho, demonstrate the applicability of hydrogeochemical techniques to uranium exploration. Uranium concentrations in surface waters of the area ranged from 0.2 to $22.0 \mathrm{ppb} \mathrm{U}_{3} \mathrm{O}_{8}$. The geometric mean for 27 samples from the Basin Creek mining area was $3.9 \mathrm{ppb} \mathrm{U}_{3} \mathrm{O}_{8}$, and the geometric mean for the remainder of the Stanley area was $1.1 \mathrm{ppb}^{8}$ $\mathrm{U}_{3} \mathrm{O}_{8}$ (39 samples). Samples from seven hot springs averaged $0.3 \mathrm{ppb} \mathrm{U}_{3} \mathrm{O}_{8}$. The conductivity of the surface waters ranged from 45 to 350 micromhos, with the higher conductivities generally found in water from areas underlain by sedimentary rock. The $\mathrm{pH}$ of the surface waters varied only slightly from the average value of 7.4. Twelve of the most highly anomalous uranium concentrations in the Basin Creek district were found from 0.15 to 2 miles downstream from known uranium deposits. (auth)

Imahashi, M. 1970. Uranium and Thorium in Hydrothermally Altered Rocks Under Acid Conditions. As Exempl ified by Silicified Rocks From Tateyama Jigokudani, Toyama. Nippon Kagaku Zasshi. 91:668-9 (in Japanese).

Uranium and thorium content in hydrothermally-altercd rocks from the lateyama Jigokudani hot spring area, Toyama, were determined in order to study the mobility of these elements under acid conditions. The leachabilities of these elements were calculated on the basis of content. It was found that silica is not leachable during the alterations. The calculations demonstrated that $60 \%$ of the thorium as we 11 as $50 \%$ of the uranium could be removed from original rocks. The mobilities of these elements under acid conditions are greater than those during weathering processes under neutral conditions. (auth) 
Isabaev, E. A., U. K. Asylabaev, and V. V. Cherdyntsev. 1960. Determination of Actinium in Minerals. Radiokhimiya. 2:98-103 (in Russian).

Sirlall quantities of $A c$ in the presence of Th were determined by meassuring $A c C$ and ThC with an $\alpha$ analyzer and by determining $\operatorname{Rn}^{219}(A n)$ and $P_{0}^{215}(A C A)$ by counting retarded pulses with a luminescence counter. The existence of primary minerals saturated with actinium was confirmed, and secondary minerals with an increased actinium-radium ratio are discussed. (NSA)

Isabaev, E. A., E. P. Usatov, and V. V. Cherdynstev. 1960. Isotopic Composition of Uranium in Nature. Radiokhimiya. 2:94-7 (in Russian)

The isotopic composition of uranium in natural minerals and waters was analyzed. The ratio of $U$ isotopes in minerals saturated by actinium does not deviate from ordinary. The $U^{238}$ (UI) and $U^{234}$ (UII) varies considerably in secondary metals and natural waters. Tests on 29 water specimens from granites indicated variations from 0.72 to 7.8 , with an average of 3 . (NSA)

Ishihara, S. and T. Mochizuki. 1969. Chemical Characteristics of River Water in the Eastern Part of Shimane Prefecture. With Special Emphasis on Cause of Uranium Anomaly. Chishitsu Chosasho Geppo. 20:435-48 (in Japanese).

River water of tributaries of Hii-gawa and Iinashi-gawa in the eastern part of Shimane prefecture was analyzed for $P$, SO ${ }_{4}^{-}$, and $U$ on 127 samples. The surveyed area is composed mainly of early tertiary granitic rocks, and Miocene andesite and its pyroclastic rocks at north. The Miocene rocks occasionally accompany nonmarine sediments in which a bedded-type uranium deposit can be locally located, as shown as an example near Mitoya. This work was done essentially for geochemical prospecting of the area. Distinct uranium anomalies found in a reconnaissance study were also examined in detail. During the period of this study around the end of August in 1967, there was no accidental condition, e.g., heavy rainfall, that would affert the chemical character of the water. A weak anomaly, $0.18 \mathrm{ppb} \mathrm{U}$, was detected near an edge of the Miocene rocks. Distinct anomalies of uranium along the Ayo river are due to mining operations of uraniferous and pyrite-bearing molybdenite quartz vein deposits, which are the largest source of molybdenum production in Japan. The uranium decreases downward with a rate of $0.07 \mathrm{ppb} / \mathrm{km}$ along the Avo river. Except the mining area, the water of granite region is about ncutral ( $\mathrm{pH}=7.0$ ), higher in $U$ and lower in $\mathrm{SO}_{4}^{2}$ in comparison with that of andesite region. (auth) 
Iskra, A. A., N. V. Kulikov, and U. G. Bakhurov. 1969. Behavior of Natural Radioactive Elements in Non-Rurning Freshwater Basin. A. Energ. (U.S.S.R). 27:134-7 (in Russian).

Experimental data are given on the distribution and accumulation of $238 U$ and ${ }^{226} \mathrm{Ra}$ in model systems of a non-running freshwater basin: water; groundwater; groundwater plants; water plants. It was found that uranium accumulates in the biomass of plants (elodea and water milfoil), thorium-in detritus and ground (and sand), while radium is evenly distributed in the components of the water basin. Accumulation coefficients are given for the major components, which according to their accumulative ability form the following series: detritus > plants > ground. The coefficients reach their highest values (hundreds of thousands and several millions) in detritus. The intensity of accumulation of the elements by plants, detritus and ground may be represented by the series: thorium > radium > uranium. (auth)

Ivanov, I. V. and 0. V. Kolpakov. 1965. Geochemistry of Soils and Overburdens Over the Korobovsk Deposit. Tr. Volgograd. Nauch. - Issled. Inst. Neft. Gaz. Prom. No. 8:214-28 (in Russian).

The complex radiogeochemistry surveys (auto-borne $\gamma$-survey along 7 profiles, B-survey, and rock and soi 1 analyses) were made in 1962 in the territory of the Korobovsk deposit. The chemical characteristics of soils (absence of sulfates, small chloride content, and Mg chloride composition over deposit) were ascertained, together with the decrease of $\mathrm{pH}(6.2)$ in soils over a petroleum deposit in comparison with the soils (pH 6.9) outside of the deposits and an increase in the $\mathrm{pH}$ with increased depths. The geochemistry of radioactive elements was studied. The content of $R a$ in soils somewhat increased from clays to sands but it did not decrease over the petroleum deposits. This was attributed to a weak migration capacity of $\mathrm{Ra}$. The largest amount of $U$ in rocks over deposits was detected in loams. The clay soils, where the sorption compensated for deficiency in $U$-containing minerals, the content of $U$ was only somewhat higher than in sands. The content of $U$ was not the same in various soils because of higher (than for the $R a$ ) coefficient of aquatic migration of $U$. The effect of petroleum deposits was observed in argillaceous soils which contained mobile forms of $U$. The amount of $U$ in clay soils over oil deposits decreased by $22 \%$ in comparison with its content in the soils situated in areas containing no oil deposits. This is attributed to the migration of $U$ from petroliferous areas. It is suggested to investigate the following factors during study of the effects of deposit on behavior of radioactive elements: (1) the actual geochemical environment, (2) the degree of anomaly of the areas in comparison with the normal background determined by a topographic-geochemical method, (3) the anomaly in the section, and (4) migration capacity of elements and effect on it of the mineral composition of soils and rocks. (CA) 
Jayaram, K. M. V., K. K. Dwivedy, M. C. Bhurat, and S. G. Kulshrestha. 1974. A Study of the Influence of Microflora on the Genesis of Uranium Occurrences at Udaisagar, Udaipur District, Rajasthan. IAEA-SM-183/31. IN: Formation of Uranium Ore Deposits, pp. 89-98.

An area of $6 \mathrm{~km}^{2}$ in the vicinity of Udaisagar shaft was investigated to study the role of sulphur and iron-oxidizing bacteria in the mobilization of uranium in the carbonaceous phyllites and its redeposition in breccias and the fault gouge. The Aravalli metasediments consisting of conglomerates, phyllites, impure limestones, carbonaceous phyllites and ferruginousbreccia are intruded by granites and gneisses. The general strike is: $\mathrm{N} 20^{\circ}-30^{\circ} \mathrm{W}-\mathrm{S} 20^{\circ}-30^{\circ} \mathrm{E}$ with an easterly dip of $60-85^{\circ}$. Uranium mineralization is confined to a fault gouge in a $6 \times 200 \mathrm{~m}$ zone, at a depth of $25-45 \mathrm{~m}$ from the surface. The ore contains stringers of uraninite associated with uranyl minerals and some iron and copper sulphides. It analyzes $0.7 \%$ $\mathrm{Fe} 0,2.31 \% \mathrm{Fe}_{2} \mathrm{O}_{3}, 6.3 \% \mathrm{C}, 2.97 \% \mathrm{So}_{4}^{-}, 0.85 \%$ moisture and $0.03-0.06 \% \mathrm{U}_{3} \mathrm{O}_{8}$ and has a bacterial population of $2.3 \times 10^{6} / \mathrm{g}$ of dry solids. It has a pH of 2.2 to 4.5 and a redox potential of -360 to $-480 \mathrm{mV}$. The ore samples show disequilibrium in favor of uranium. Samples of the ore analyzing $0.03 \%$ and $0.06 \% \mathrm{U}_{3} 0_{8}$ yielded a leachability of $43.3 \%$ and. $67.8 \%$ respectively at $60 \%$ P.D. (solids) in 6-h leaching time, using water alone. The carbonaceous phyllites in the immediate vicinity analyze $3.04 \% \mathrm{Fe} 0,2.96 \% \mathrm{Fe}_{2} \mathrm{O}_{3}, 11.2 \% \mathrm{C}$, $0.11 \% \mathrm{SO}_{4}^{2-}, 0.15 \%$ moisture and 0.0005 to $0.0027 \% \mathrm{U}_{3} \mathrm{O}_{8}$ with a $\mathrm{pH}^{2}$ of $7.0-8.5$ and a redox potential of -200 to $-280 \mathrm{mV}$. The occurrence of significantly higher radon values in the vicinity of the shaft $\left(35.5 \mathrm{pCi} / \mathrm{cm}^{3}\right)$, the shallow nature of the deposit, absence of any major. channel for waterborne transportation as indicated by resistivity surveys, the presence of elemental sulphur, soluble sulphates and microflora in the ore samples and the high leachability of uranium in water alone show that uranium is mobilized from the carbonaceous phyllites and redeposited in the fault gouge. (auth)

Josa, J. M., J. L. Merino, and A. Villoria. 1966. Spanish Radioactive Lignites: Uranium Nature and Solubilization. AEC-tr-6851.

The characteristics of some 70 samples of radioactive lignites from different parts of Spain (Huesca, Lerida, Teruel, Galicia and Murcia) with uranium grades ranging from 20 to $1200 \mathrm{ppm}$ are presented. The uranium in these minerals has been recovered by direct treatment and also after elimination of organic matter and enrichment by roasting. The uranium was leached in an acid medium, using agitation as well as static bed techniques. The influence of the following variables was studied: yrain size, anluurt of acid, temperature, time, oxidizing agent and variations in the roasting process. (auth) 
Joshi, L. U. and A. K. Ganguly. 1970. Disequilibrium Studies in ${ }^{232} \mathrm{Th} /{ }^{228} \mathrm{Th}$ Activity Ratio in Some Sediment Samples of India. Proceedings of the Chemistry Symposium, Bombay. Dept. of Atomic Energy II:137-48.

A geochemical study of sediment samples is being carried out by EDTA leaching at $\mathrm{pH} 3.0$ in order to investigate the surface phenomena and distribution of natural thorium in backwater sediments. Unusually high values of $232 \mathrm{Th} /$ 228 Th activity ratios have been found in the deposits of the sediments in the Indian coastal region of Bombay and Kerala Belt. The ratio was approximately 1.75 in the Bombay Harbor region and 1.5 at the coastal region of Kerala. The yariations in the ratio of ${ }^{232} \mathrm{Th} / 238 \mathrm{Th}$ is most likely due to leaching of ${ }^{228} \mathrm{Ra}$ by seawater resulting in depletion of ${ }^{228} \mathrm{Th}$ in the $232 \mathrm{Th}$ decay chain. (auth)

Joshi, L. U. and A. K. Ganguly. 1972. Activity Ratios $234 \mathrm{U} / 238_{\mathrm{U}}$ and $235_{\mathrm{U}}$ $288 \mathrm{U}$ in Coastal Marine Sediments. CONF-721239-P1, Proceedings of the Chemistry Symposium, Vo1. pp. 245-50. Bombay, Dept. of Atomic Energy.

The activities of ${ }^{238} \mathrm{U},{ }^{235} \mathrm{U}$, and ${ }^{234} \mathrm{U}$ in the sediments along the west coast of India were measured and the ${ }^{234} \mathrm{U} / 238 \mathrm{U}$ and ${ }^{235} \mathrm{U} / 238 \mathrm{U}$ ratios were determined. The $U$ isotopes were leached from the sediments with an ammonium carbonate solution, and the $U$ was separated on an anion exchange column. After plating of the $U$ on stainless steel, it was counted in a solid state detector. The results obtained were tabulated for various sites. These results showed that there is disequilibrium between $238 U$ and $234 \dot{U}$, but no disequilibrium was found for the other isotopic ratio. It was shown that the disequilibrium exists only on the surface of the untreated sediment particles The valjdity of the hypothesis that during the transition of $238 \mathrm{U}$ to $234 \mathrm{U}$ the ${ }^{234} \mathrm{U}$ atoms are relocated into crystal defects was doubted. (NSA)

Joshi, L. U. and A. K. Ganguly. 1972. Disequilibrium Studies in ${ }^{234} \mathrm{U} /{ }^{238} \mathrm{U}$ Activity Ratios in Coastal Sediments Along the West Coast of India. Curr. Sci. (India) $41: 762-5$.

Sediment samples were collected from the surface of the sea-beds at different locations along the west coast of India from monozite areas of Kerala to Bombay. Thesse sediment samples were leached by ammonium carbonate solutions for $238 \mathrm{U}, 235_{U}$, and $234 \mathrm{U}$ activities. The reagent was chosen so that it has high efficiency for leaching uranium and does not attack the mineral core of the sediments. Uranium in the leachates was plated on stainless steel planchets and counted using a solid state detector coupled to a 256 channel pulse height analyzer 2311 the sediment samples were found to give 33 ranjum activity ratios, $234 \mathrm{U} / 238 \mathrm{U}$ within a range of 1.129 to 13143 . The $234 \mathrm{U} / 238 \mathrm{U}$ activity ratio in coastal waters was 1.151 . The $235 U / 230 U$ actixity ratios were found to lie in the range of 0.045 to 0.048 Thus, while $234 \mathrm{U} / 238 \mathrm{U}$ ratio indicates existence of disequjlibrium in $238 \mathrm{U}$ radioactive series, there is no fractionation between $235 \mathrm{U}$ and $238 \mathrm{U}$. (auth) 
Jurain, G. 1955. Abnormal Radioactivity in the Upper Triassic of the Vosges. Compt. Rend. 241:975-7.

Lignites from the middle Keuper formation of the upper Triassic exhibit high radioactivity which was shown to be due to the presence of 12.7-18.8 ppm U (compared with an average $4.3 \mathrm{ppm}$ for the lithosphere). The $U$ content is not proportional to the observed radioactivity because the $U$ has been removed at a rate different from that of its radioactive disintegration products (especially Ra). The presence of concentrated $U$ and $V$ in lignite is related to the multiple valence states of both elements. This circumstance permits them to enter into biogeochemical oxidation-reduction reactions with the lignite. (CA)

Kanasiewicz, J. 1966. Geochemical Distribution of Uranium, Selenium, and Rhenium in the Zechstein Layer of Leszczyn Deposits. Kwart. Geol. 10:13 (in Polish).

The highest concentrations of $U$, Se, and Re occur in the layers of low Zechstein, the average content of $U$ being 11.3, of Se 1.31, and Re $1.06 \mathrm{ppm}$. The sorption properties of silt favor retention in deposits all of the elements present in sea water, as testified by a higher $U$ content in marls, $\sim 12.1 \mathrm{ppm}$ as compared to limestone, $\sim 9.4 \mathrm{ppm}$. The layers of new red sandstone and medium and upper Zechstein are markedly lower in the content of these elements. (CA)

Kapkov, Y. N. 1969. Geochemistry of Uranium in Channel Sediments of the Stream Network in a Mountainous Taiga Area. Zap. Leningrad. Gorn. Inst. 56:73-80 (in Russian).

A study of the dispersion processes of uranium in granitoid development showed that the basic mass of transportable material occurs in the form of thin suspensions, true and colloidal solutions, and represents a significant fraction in rock-forming minerals, perhaps as much as 75 to $98 \%$. Uranium is extracted by natural waters relatively easily. It does not play an important role in accessory minerals in the total balance of riverbed deposition. The mobility and the sorption property of uranium in organic material depend on the reaction medium, which in the mountainous Siberian forest region, leads to leaching of the uranium from the upper strata. All this causes a high geochemical background of uranium and the formation of "concentration" flows, and difficulties in separating out the "ore" flows. (auth)

Kaplan, I. R. 1973. Biological Cycling of Elements and Stable Isotopes in Marine Environments. Progress Report, Apri 1 1, 1972-May 1, 1973. UCLA-34-P-134-7. 
Progress is reported in studies on the biological cycling of elements and stable isotopes in marine environments. A neutron activation method for the rapid measurement of total uranium content in marine sediments is described. Other studies reported include the anaerobic degradation of organic matter on the sea floor; an evaluation of the magnitude of ionic diffusion constants in marine sediments; and the development of a rapid monitoring system for dissolved sulfate in seawater and sediments for use in evaluation of the pollution of the ocean floor. A 1ist of papers accepted for publication during the period covered by this report is included. (NSA)

Karkhanavala, M. D. 1958. On Radioactive Uraniferous Iron Oxides. Geochim. et Cosmochim. Acta. 15:229-36.

A study has been made of uranium bearing iron oxides from the shear-zone of Bihar, with particular reference to the nature of the association of uranium with magnetite and hematite. In veins where none or very little hematitization has taken place, the primary magnetite and uraninite coexist. Where hematitization has taken place the uranium is very intimately associated with the hematite, probably as a very limited solid solution. A sample of hematite containing uranium equivalent of $0.15 \% \mathrm{U}_{3} \mathrm{O}_{8}$ was found to be metamict, the reconstitution of which was established by $x$-ray and differential thermal analysis methods. It is believed that a primary oxidizing solution containing uranyl ions caused the oxidation of the ferrous hydrosol to magnetite and the simultaneous precipitation of uraninite. A later stage oxidizing solution or normal agents of weathering converted the magnetite to hematite and the uraninite to probably $\mathrm{U}_{3} \mathrm{O}_{8}$ or $\mathrm{UO}_{3}$, a small amount of which was then somehow taken up in the hematite lattice, and the rest being converted to secondary uranium minerals, the presence of which is known. (auth)

Kashirtseva, M. F. 1969. Effect of Material Composition of Rocks on Formation of Epigenetic Uranium Concentrations. Int. Geol. Rev. 11:530-8.

Analysis of the different forms of physical composition of rocks of different $U$ content showed that accumulations of $U$ are confined to rocks of the pyritic geochemical type. The confinement of epigenetic pyrite and of accumulations of $U$ to the pyritic type of rocks is evidence that the oxidation processes and production of hydrogen sulfide by bacteria are conducive to precipitation of $U$, as they are responsible for the steep Eh threshold at the contact between oxidized and unoxidized rocks. In prospecting for $U$ or deposits of the infiltrational type, the physical composition of the host rocks should be considered, together with other indications, inasmuch as the rocks may be favorable or adverse to the formation of eronomic ores, by virtue of their inherent geochemical characteristics. Accumulations of various elements, particularly U, are favored by the presence of substantial quantities of easily oxidized minerals in the rock, particularly in rocks of the pyritic type in which 
the sulfide forms of iron should at least be about $0.3 \%$. The chloritesideritic type, in which these forms do not exceed $0.1 \%$ of the rock, by weight, and the iron minerals are not easily oxidizable, as a whole, is not as favorable for the accumulations. Rocks in which the iron is mainly clastic and the sulfides are negligible $(0.2$ to $0.3 \%)$ are unfavorable for accumulations of such elements as $\mathrm{U}$, Se, Mo, Pb, Fe, and others. Ore deposits of the type described are rare in nature because only in rare circumstances are all the factors essential for their development simultaneously operative. Among these factors, the physically favorable composition of the host rocks is the indispensable prerequisite. (auth)

Katsurayama, K. 1968. Accumulation of Radioactivity in Rice Fields. Annu. Rep. Res. Reactor Inst., Kyoto University. 1:293-97.

The adsorption capacity of the following radioactive isotopes in the soil is discussed: $\mathrm{Li}, \mathrm{Na}, \mathrm{K}, \mathrm{Rb}, \mathrm{Mg}, \mathrm{Cs}, \mathrm{Ca}, \mathrm{Co}, \mathrm{Ba}, \mathrm{Sr}, \mathrm{H}, \mathrm{La}$, and Th. Equations are given for coefficients of distribution and exchange. Ion exchange capacity of the soil is discussed. Estimation of radioactive concentration in the root zone of rice fields is based on the following phenomena: introduction of water into the rice field; percolation in the superficial soil of the rice field; disintegration of radioactive elements; and accumulation of radioactivity in cultivable soil. A method for estimating the quantity of radioactivity carried by irrigation water into the rice field in the course of a year is described. (NSA)

Kawai, H. and Y. Honda. 1967. Alpha Emitters in Foods. Kinki Daigaku Genshiryoku Kenkyusho Nenpo. 6:15-19.

The alpha-ray activities were determined in foods by a radiochemical method. The successive ion exchange separation of uranium in foods is discussed. The following results were obtained: recovery of uranium by the method was 78.3 plus or minus 3.8 percent on the average; contamination of other nuclides was not. fnund in a separated fraction and separation of uranium was performed almost perfectly; and the uranium content in some vegetation was determined. It was found that the uranium content of vegetables was somewhat greater than the content in cereals, green tea ("Ban-tya"), and potatoes. (NSA)

Kimura, Y., H. Morishima, T. Koga, H. Kawai, and Y. Honda. 1968. Studies on the Behavior and Distribution of Radioactive Substances in Coastal and Estuarine Waters. Kinki Daigaku Genshiryoku Kenkyusho Nenpo. 7:21-31 (in Japanese).

Low-level liquid radioactive wastes are continuously disposed of from fuel processing plants or radioisotope laboratories into coastal waters. For an estimation of the influence of these disposals on our environment, the variation of concentration of thorium and rare earth elements contained 
in coastal and estuarine waters was investigated with the tidal change. It was observed that the concentration of thorium and rare earth elements in coastal water varied widely with the tidal change. This seems to be not only due to simple dilution by the water mass but also to the various physiochemical conditions such as salinity, pH of water, wind, and tidal motion. Since thorium and rare earth elements are apt to be colloidal or particulate in seawater, this character is greatly different from the case of soluble elements. (auth)

Kirchheimer, F. and F. Scheminzky. 1973. Uranium Absorption on Silica Ge1. Oesterr. Akad. W:ss., Math.-Nauturwiss. K1., Sitzungsber., Abt. 2. 180:317-25 (in German).

A gelatinous $\mathrm{SiO}_{2}$ gel deposit from mine water is described, which consists predominantly of small opal botyroidal aggregates. Under a fluorescent microscope, the rock splinters remain dark but the opal aggregates fluoresce an intense green $(254 \mathrm{~nm})$. The fluorescence spectrum of the deposits corresponds to that of the hyalites and Ca-opal-sinters together with a continuum of coalesced bands. Since fluorescence of the opal aggregates depends on $U$ absorption, examination of a fluorescence spectrum can be used for quality and quantity determination of $U$. The $U$-content of most $\mathrm{SiO}_{2}$ gel deposit samples is <1000 ppm solid. (CA)

Klepper, M. R. and D. G. Wyant. 1957. Notes on the Geology of Uranium. U.S.G.S. Bulletin 1046-F.

The report attempts to synthesize this great volume of diverse information and to point out features that may be important in searching for and appraising uranium deposits: The report deals with processes that concentrate uranium; describes types of uranium deposits; and discusses the clustering of uranium deposits within provinces, and provides some clues for prospecting and appraisal. (auth)

Kochenov, A. V. and G. N. Baturin, 1967. The Distribution of Uranium in the Bottom Sediments of the Aral Sea. Okeanologiya. 7:623-7 (in Russian).

Chemical determination of $U$ in 178 sediment cores was made to determine its distribution over the bottom of the Aral Sea. The $U$ content is distinctly controlled by lithologic facial types and the organic matter content of the sediments. The $U$ maximum is found in the central zones of the bays and lagoons rich in organic matter, reaching aboye $10^{-3} \%$ in some regions; most of the lake has a concentration between $10^{-4}$ and $5 \times 10^{-4} \%$. Other higher deposits include argillaceous silts of the central lake and black argillaceous silt of western coastal indentations; only in the central lake does the $\mathrm{C}_{\text {org }}$ fail to reach 3.1 to $3.5 \%$ as in the rest; there it is only $0.7 \%$. The 0 balance of the sea was studied. The two rivers flowing into the lake, the Amu-Dar'ya and the Syr-Dar'ya, carry 387 tons/yr of U; 
the quantity of alluvium is $129 \times 10^{6}$ tons/yr with a $U$ concentration of $2 \times 10^{-4} \%$, so that the flow is 258 tons $\mathrm{U} / \mathrm{yr}$. The total introduction is 645 tons/yr, which also corresponds to the deposited quantity of U. (NSA)

Kochenov, A. V. and G. N. Baturin. 1967. Uranium Distribution in Aral Sea Sediments. Oceanology (U.S.S.R.). 7:484-7.

Sediment samples were taken by bottom grab in the period August-0ctober 1965. Uranium was determined chemically by the pearl-1uminescent method. Great similarity was revealed on comparison of the areal distribution of uranium in the Aral Sea and a bottom sediment chart. The main types of sediment differ clearly in terms of their $U$ content. The least $U(0.0001$ to $0.0002 \%$ ) was noted in the sand and silty ooze of the coastal zone; $U$ content increased in the calcareous and argillaceous sediments of the central areas of the basin to $0.001 \%$. Similar high contents were noted in the argillaceous sediments of the northern bays and the semi-isolated bays of the eastern shore. At the junction between fresh river water and salt seawater, $U$ content was as low as throughout the coastal zone of sandy and silty oozes, between 0.0001 and $0.0005 \%$. There is a distinct correlation between uranium content in Aral Sea sediments and organic matter. It appears that as much $U$ is annually supplied to the bottom sediments as is brought in by the rivers, i.e.., part of the $U$ enters the basin in solution and passes into the sediment, as a result of which the latter is enriched to several times the level of the suspended matter of the river. This explains the increased abundance ratio of uranium in the sediments of the central areas of the Aral Sea. The distribution of $U$ in the water over the area of the sea is uneven and to some extent related to general salinity; $U$ content around the river mouths where the freshening effect of the rivers is felt is $(3$ to 3.5$) \times 10^{-5} \mathrm{~g} / 1 \mathrm{iter}$, whereas in the central areas of the sea it increases to (5 to 6) $\times 10^{-5} \mathrm{~g} / \mathrm{liter}$. The relatively low extraction of $U$ into the sediment from Aral water is apparently to be explained by its high carbonate content and oxygen saturation, and by the low content of the organic component in the sediment. (NSA)

Kochenov, A. V., G. N. Baturin, S. A. Kovaleva, E. M. Emelyanov, and K. M. Shimkus. Uranium and Organic Matter in Sediments of the Black Sea and the Mediterranean. Geokhimiya. No. 3:302-13 (in Russian).

Schemes of organic carbon and uranium distribution in sediments of the Black Sea and the Mediterranean Sea are given. From sediments of the Black Sea a direct correlation between the content of organic matter and uranium was established. Their maximum contents gravitated toward the tehalistatic zones of the Black Sea. The cause of an intensified accumulation of organic matter with bound uranium are the anaerobic conditions in this reservoir. (auth) 
Koczy, F. F. 1949. Thorium in Sea Water and Marine Sediments. Geol. Foren. i Stockholm Forh. 7:238-42.

Experiments are described which show the precipitation of thorium in sea water. The adsorption of isotopes of radium and thorium on red clay, powdered manganous dioxide, and a powdered manganese nodule was determined. Radium adsorbed on all three powders, which is not the case with thorium. The thorium content of a few samples of marine sediments has been measured. They contain about $1 \times 10^{-7} \mathrm{~g} \mathrm{Th} / \mathrm{g}$. One manganese nodule investigated was found to hold as much as $1.3 \times 10^{-6} \mathrm{~g}$ Th/g. The geochemistry of thorium and uranium in sea water is briefly discussed. An attempt is made to estimate the thorium content of sea water with the aid of the ratio Io: Th in the sediments. The thorium content of sea water is calculated to be 1 to $10 \times 10^{-9} \mathrm{~g} \mathrm{Th} / 1$. (NSA)

Koczy, F. F. 1961. Ratio of Thorium-230 to Thorium-232 in Deep Sea Sediments. Science. 134:1978-9.

The ionium-thorium method for age determination in deep-sea sediments is critically reviewed, and its short-comings are discussed. A method that allows an estimate of the rate of sedimentation in the superficial layer of the sediment is presented. A formula for calculating the error in age determination by the method is given for the case when the rate of sedimentation is changing and, with it, the rate of $T^{232}$ sedimentation. (auth)

Koczy, F. F., P. S. Anatal, and 0. Joensuu. 1963. The Natural Radioactive Elements in Sediments. Fortschr. Geol. Rheinland Westfalen. 10:201-14.

A review with 25 references. High contents of $U$ can occur in both marine and non-marine sediments and are not diagnostic; neither is the ratio Th/U. Data are given on $U$ and $Z n$ contents of fractions of a Baltic Sea sediment. (CA)

Koczy, F. F., E. Picciotto, G. Poulaert, and S. Wilgain. 1957. Measurement of Th Isotopes in Sea Water. Geochim. et Cosmochim, Acta. 11:103-29 (in French).

In order to study the geochemistry of thorium isotopes in the hydrosphere, partjicularly in the gsean, a method has been worked out by which $\mathrm{Th}^{232}$, $\mathrm{Th}^{230}$, Th ${ }^{228}$, and $\mathrm{Th}^{227}$ can be determined separately. Eight samples of 20 to 40 liters of sea-water, from $23.0 \%$ to $34.97 \%$ salinity, were collected in November 1953, in the Skagerak and the Gullmarfjord (Sweden). Thorium was isolated by the following procedure: just affer collection, the samples were brought to $\mathrm{pH} 2$ and a given amount of $\mathrm{Th}^{234}$ (UX ${ }_{1}$ ) was added as tracer. Thorium was first precipitated with $\mathrm{Fe}(\mathrm{OH})_{3}$ as carrier. Further purification was obtained by ion-exchange column chromatography 
followed by solvent extraction; the final fraction was obtained as the citric complex, a form suitable to incorporation in the photographic emulsion. The total yield varied from 8 to $23 \%$ according to the sample, as determined by the $\beta$ activity of the tracer. The various $T h$ isotopes were measured through their $\alpha$ activity, using nuclear photographic emulsions, more precisely the double-emulsion technique. RdTh and RdAc both generate five-branched stars; more than $90 \%$ of these originated from RdTh, as indicated by the length of the tracks; while Io and Th only yield single tracks of range $18.8 \mu$ and $15 \mu$ respectively in the emulsion. Most samples showed a much lower activity than expected; this did not make it possible to discriminate between Io and Th through the range distribution of their tracks, thus we could only ascertain upper limits of Io and Th concentrations. (auth)

Koczy, F. F., E. Tomic, and F. Hecht. 1957. Geochemistry of Uranium in the Baltic Sea Basin. Geochim. et Cosmochim. Acta. 11:86-102 (in German).

In order to study the geochemistry of $U$ on typical shelf zones, samples of river water and sea water, as well as samples of sediment from the Baltic Sea region, have been examined. The Baltic Sea region was chosen for the investigation since its hydrography is well known, water transport to and from it can be estimated to a high degree of accuracy, and the region can be well sampled. The $U$ content of river water originating in regions of igneous rocks is $10 \mathrm{w}$, averaging $0.5 \times 10^{-6} \mathrm{~g} \mathrm{U} / 1$. The $U$ content of rivers from sedimentary rock regions seems higher by a factor of two or more, the maximum value found being $12.8 \times 10^{-6} \mathrm{~g} \mathrm{U} / 1$. It may be concluded that the $U$ is more easily leached out from sedimentary regions. While the southern and eastern rivers supplying water to the Baltic Sea have not been investigated, it can be assumed that the ir $U$ content is high, especially since the sea area surrounding the mouths of these rivers exhibit high $U$ values. The Ra content of river water is not in equilibrium with the $U$, amounting to only $10 \%$ of the latter. It is thus concluded that $U$ is more soluble than $\mathrm{Ra}$. The $U$ content of water from the Baltic Sea is also variable ranging from 0.77 to $5.9^{\circ} \times 10^{-6} \mathrm{~g} \mathrm{U} / 1$. High salinity inflowing water shows $1.8 \times 10^{-6} \mathrm{~g} \mathrm{U} / 1$, while that of outflowing water is less, averaging $0.9 \times 10^{-6} \mathrm{~g} \mathrm{U} / 1$. Except for the southeastern regions and deep water areas, a marked correlation of salinity and $U$ content exists. An increase of deep water $U$ content correlates with a surface water increase. Surface water increases can be explained by the high $U$ content of inflowing river waters; high deep water values are correlated with an 0 deficiency. Here is may be assumed that the $U$ (VI) is reduced to $U$ (IV) forming insoluble complex compounds with organic material. This settles slowly to the bottom, and explains the rather high $U$ content of the sediment (values range between 3.2 and $10.3 \times 10^{-6} \mathrm{~g} \mathrm{U} / \mathrm{g}$; the normal content in clays is about $2 \times 10^{-6} \mathrm{~g}$ $\mathrm{U} / \mathrm{g}$ ). By an intense study of the distribution of $U$ in sediments, completed by age determination by aid of $\mathrm{C}^{\top 4}$, it may be possible to follow the changes in the past of the state of ventilation of the deep basins of the Baltic Sea. The attempt to work out a $U$ balance sheet for Baltic Sea $U$ demonstrates precipitation about equals that which is brought in by rivers. Influx 
totals 1100 to 1400 metric tons per year, efflux 700 to 1000 , leaving about 100 to 700 tons of precipitated material. The investigation carried out shows that a considerable quantity of $U$ is precipitated on the Baltic Sea shelf. It appears to be caused by biological activity in the sea which in turn causes an 0 deficiency. The process is slow. Rivers with a high $U$ content can raise the $U$ content of the sea water if they empty under conditions wherein the above factors are not fulfilled. On the other hand, in estuaries and bays into which $U$ bearing rivers do not flow, $U$ can be precipitated from sea water by a high biological activity, which is connected with 0 deficiency. When the minerogenous sedimentation is at the same time very small, the $U$ content of the sediment is enriched, amounting to $200 \times 10^{-6} \mathrm{~g} \mathrm{U} / \mathrm{g}$ and more. (auth)

Koide, M., K. W. Bruland, and E. D. Goldberg. 1973. ${ }^{228} \mathrm{Th} /{ }^{232} \mathrm{Th}$ and $210 \mathrm{~Pb}$ Geochronologies in Marine and Lake Sediments. Geochim. et.Cosmöchim. Acta. $37: 1171-1187$.

Two dating techniques, applicable to coastal marine and lacustrine sediments over periods ranging from years to a century, evolve from the natural radioactive series: Th-228/Th-232 from the Th-232 series and $\mathrm{Pb}-210$ from the $\mathrm{U}-238$ series. There is an excess of Th-228 over and above that supported by the parents Th-232 or Ra-228 in such deposits. The amounts of Th-232 supported and Ra-228 supported Th-228 are similar, indicating that both radium and thorium isotopes are removed from solution in these coastal zones quite rapidly after introduction or formation. The radium isotopes are probably transferred from the overlying waters to the sediments via phytoplankton, where they are reportedly enriched. In the surface levels of the deposits analyzed, there is nearly an order of magnitude more unsupported than supported Th-228. This excess Th-2?8 can be used both for dating purposes over time periods of the order of a decade and as permissive evidence that the uppermost levels of the deposit were obtained during the coring operation. Preliminary results from several lakes indicate the possibility that Th-228/Th-232 geochronologies are held by their sediments. Average rates of accumulation of lake sediments have been obtained from decreases in $\mathrm{Pb}-210$ activity as a function of depth, although surface layers of the deposits may not have been recovered in the coring operation. Finally, $\mathrm{Pb}-210$ geochronologies have been extended from varved to unvarved marine sediments. (auth)

kuidc, M. and E. D. Coldberg. 196s. Uraniuili-234/Urdniuin-238 Rat1os in Sea Water. Progr. Oceanogr. 3:173-7.

The importance of radioactive disequilibrium within the natural uranium238 series in various natural systems has steadily gained importance espectally in geochronological and geochemical studies. Russian workers have shown that the parent member, U-238, and the daughter, U-234, in groundwaters do not exist in radioactive equilibrium concentrations. It has been postulated that while $\mathrm{U}-238$ exists in crustal rocks primarily 
in the +4 state, as a result of the radioactive decays producing the daughter U-234, electrons are lost from the nucleus such that a part. of the U-234 ends up in the +6 state. The latter form is preferentially brought into solution by weathering waters due to the formation of the strong complexes formed between uranyl and carbonate ions. Thus, the activity ratio $A(U-234) / A(U-238)$ of ten exceeds one in surface waters. Experimentally determined values of the activity ratio in surface and deep sea waters from the Atlantic and Pacific Oceans and the Mediterranean Sea are uniform with a value of $1.14 \pm 0.014$. The error arises from the counting statistics in the radioactive assay of the alpha particles emitted by these two isotopes of uranium. This constancy in the ratio is consistent with the long residence time of uranium and relative lack of reactivity in sea waters. (auth)

Koliadin, L. B., D: S. Nikolaev, S. M. Grashchenko, Y. V. Kuznetzov, and K. F. Lazarev. 1960. States of Uranium Detected in Black Sea Waters. Doklady Akad. Nauk S.S.S.R. 132:915-17 (in Russian)

A carbonate complex of hexavalent uranium was found in a Black Sea layer between 0 to $2000 \mathrm{~m}$. The data indicate the physico-chemical impossibility of uranium precipitation by reduction to the tetravalent state in the Black Sea hydrogen sulfide zone. (NSA)

Kolodny, Y. 1969. Studies in Geochemistry of Uranium and Phosphorites. University of California. Thesis.

This dissertation is composed of three almost independent parts; the abstracts are therefore separate. Three experimental studies were performed to determine: the uranium isotopes in sea floor phosphorites; the uranium in an anoxic fjord; and the carbon and oxygen isotopes in apatite $\mathrm{CO}_{2}$. Analyses using $\alpha$-spectroscopy techniques of uranium concentration and $234 \mathrm{U} / 238 \mathrm{U}$ activity ratios were performed on 40 samples of marine phosphorites, almost all of them dredged from the sea floor. In each sample, the concentration and isotopic composition of total uranium and U(IV) were analyzed. Uranium concentrations in the analyzed nodules vary between 6 and $524 \mathrm{ppm}$, tetravalent uranium constituting $38-84 \%$ of the total. Whereas the mean activity ratio for total uranium is 0.97 , the ratio in the U(IV) uranium is 0.71 and the calculated activity ratio for $U(V I)$ uranium is 1.57. This indicates that: all the analyzed nodules arp nld (probably older than $8 \times 10^{5}$ years), and are at the present being eroded rather than deposited and the difference in isotopic. ratios between the two oxidation states of uranium generally confirms previously proposed mechanisms of uranium isotope fractionation. Differential oxidation of $234 \mathrm{U}$ is largely responsible for the measured $234 \mathrm{U} / 238 \mathrm{U}$ disequilibrium ratios. A model for evolution of uranium isotope activity ratios in different oxidation states is presented. A fairly simple chemical fractionation technique was tested for separation of authigenic uranium from its detrital counterpart. $234 \mathrm{U} / 238 \mathrm{U}$ activity 
ratios can serve as an excellent indicator for testing the efficiency of such a technique. Uranium is effectively removed from sea water into anoxic sediments. This process is extremely fast compared to the rate of removal into deep sea sediments. Authigenic uranium is most strongly correlated with organic carbon content of the sediments, probably because of the formation of organo-uranyl complexes. Analysis of interstitial waters can serve as an indicator for the chemical state of uranium in the solid phases. About half of the uranium in sediment from the center of Saanich Inlet is strongly bound (as a chemical complex) to organic matter. The other half is about evenly divided between detrital minerals, authigenic tetravalent uranium, and uranium adsorbed on organic matter. Analysis of stable carbon and oxygen isotopes has been applied to a solution of a Inineralogical problem: elucidation of the relation of the carbonate ion to the apatite structure. Calcite was separated from coexisting apatite in pelletal phosphorites, phosphatized limestones and synthetically prepared apatites by dissolving calcite in triammonium citrate. Both calcite and apatite $\mathrm{CO}_{2}$ were then analyzed for carbon and oxygen isotopes. Carbon and oxygen in the $\mathrm{CO}_{2}$ associated with apatite are enriched in their light isotopes as compared to the coexisting calcites. This indicates that carbonate ion is a structural part of apatite, a conclusion which is in accord with other mineralogical studies. (NSA)

Kolodny, Y. and I. R. Kaplan. 1970. Deposition of Uranium in the Sediment and Interstitial Water of an Anoxic Fjord. CONF-700965-1.

The distribution of uranium in the sediments of Saanich Inlet was determined using chemical fractionation methods to separate authigenic uranium from detrital uranium. $234 \mathrm{U} / 238 \mathrm{U}$ activity ratios were found to be good indicators for determining the efficiency of the separation. Uranium concentration in the sediment. shows a significant enrichment relative to deep sea sediment. Authigenic uranium correlates most strongly with the organic carbon content of the sediment, and is probably bound as organo-uranyl complexes. Approximately half the uranium in the sediment of the central fjord is organically complexed and the remainder is distributed among detrital minerals, authigenic tetravalent uranium and uranium adsorbed on organic matter. Uranium is highly enriched in interstitial water (both oxidizing and reducing waters with an Eh range of $+380 \mathrm{mV}$ to $-140 \mathrm{mV}$ ) relative to its concentration in normal seawater. Its concentration appears to depend on the oxidation state and the organic content of the sediment. Concentration of uranium by the sediments was found to be very efficient in this environment. The residence time of uranium in the water column was found to be 3 or 4 orders of magnitude less than estimated for the open ocean. (auth)

Komarov, A. N. and V. P. Egorov. 1970. Radiographic Study of UraniumContaining Pyrites. Geol. Rud. Mestorozhd. 12:109-12 (in Russian). 
High-sensitivity microradiography based on fragments from induced uranium fission was used for studying hydrothermal uranium sulfide-type uranium deposits in a weakly metamorphic alevrolite agrillite rock. Results of the luminescence analysis showed that the uranium content in pyritic specimens was from $10^{-4}$ to $10^{-5}$ and in the ore bearing rock $m \times 10^{-4} \%$. Radiography in a synthetic miça irradiated in a reactor neutron flux at $3.5 \mathrm{x}$ $1015 \mathrm{n} / \mathrm{cm}^{2}$ revealed that $235 \mathrm{U}$ fissioned into two fragments one of which produced a track in the mica forming a micro-zone of radioinduced disturbances. Two types of pyrite were found in the veins, uranium-bearing pyrite and uranium-free pyrite. In the uranium-bearing pyrite, uranium was distributed uniformly along the mineral. In 20 to $90 \%$ of the minerals, micro-inclusions were found which contained from $10^{7}$ to $10^{9}$ uranium atoms . The rest of the uranium had less than $10^{7}$ atoms. (NSA)

Koppe, E. F., E. S. Erickson, C. L. Trotter, R. S. Good, W. Spackman, and T. F. Bates. 1954. An Investigation of the Mineralogy, Petrography, and Paleobotany of Uranium Bearing Shales and Lignites (Scope B-Lignites). Third Annual Report [for] Period of Apri1 1, 1953 to March 31, 1954. NYO-6061.

Objectives of the program were to learn the location of the uranium relative to the discrete organic and/or inorganic constituents of lignites and to elucidate, in some degree, the environmental conditions conducive to the concentrations of uraniferous materials in lignitic sediments. Collections of suitable lignite and clay for these studies were made. Results of the summer field work indicate the lignite occurrences, record the range of materials encountered, and provide a permanent record of the samples available for study. Intensive study of uranium-bearing lignites and associated clay deposits in this program is focused upon three localities in the Slim Buttes area, Harding County, South Dakota; (1) the Mendenhall stripping site, (2) site "SD-1," and (3) site "BM-1." The clay seams associated with the lignite deposits as the Mendenhall stripping site, site "BM-1" and site "SD-1" were studied with a view toward working out the qualitative mineralogy of these beds. The study centered on the finer-grained fractions of the clay seams, in essence, the clay minerals. The methods of study are described briefly. A discussion of the characteristics of the minerals present and their distribution is included. A general qualitative study of the mineralogy of the lignite seams was also carried out. (auth)

Koppe, E. F., E. S. Erickson, C. L. Trotter, R. S. Good, W. Spackman, and T. F. Bates. 1954. An Investigation of the Mineralogy, Petrography, and Paleobotany of Uranium-Bearing Shales and Lignites. (Scope B-Lignites). Quarterly Progress Report [for] Period of October 1, 1953 to December 31 , 1953. NY0-6059. 
Analyses and sulfur determinations were made upon unweathered, partially weathered, and weathered lignite obtained at site "S.D.-1" in the Slim Buttes area of South Dakota. Changes were noted which can be ascribed to the weathering process. Increased percentages of moisture and volatile matter are recorded upon weathering. Ash content is lower in weathered lignite than it is in unweathered material. The decrease of ash is related to the loss of pyritic sulfur. The first lignite seam at site "S.D.-1" is extremely pyritic in the unweathered portions of the seam. Upon weathering, this form of sulfur is lost. No correlation can be effected between the weathering process and the amount of sulfate sulfur present in the coal. Beta-gamma data demonstrate that the radioactivity is increased twofold in the weathered lignite. This increase is partially attributed to the degree of compaction of the seam upon weathering. An excess of radioactivity is detected which may indicate possible enrichment of the weathered lignite by radioactive substances. Study of clay seam material from the Mendenhall stripping site, site "S.D.-1" and site "B.M.-1", has revealed that the mineral suites found at the three locations were similar in composition but that relative proportions of the component minerals varied. The minerals identified were kaolinite, illite and/or mica, montmorillonite, and quartz. Although the presence of broad groups of clay minerals has been established, the exact nature of the individual minerals present has yet to be established. X-ray data are presented for the mineral identified as kaolinite. Further mineralogical studies on the illite and/or mica mineral and the montmorillonite are discussed. Electron micrographs disclose very small, relatively dense, discrete particles which are found in seams containing major amounts of kaolinite. The relationship between these particles and the kaolinite is being studied. (auth)

Kovalev, A. A. 1962. Uraniferous 0ccurrences Through Evaporation in Arid Regions. CEA-tr-R-1707 (in French).

In arid regions, in zones of eruptive and sedimento-metamorphic rocks, there is a high $U$ occurrence. The great majority of these occurrences, constituted by achrockingerite and uranophane and some secondary U minerals, has a superficial character. Because of the coincidence with zones of fracture and hydrothermal alteration of the encasing rocks, the secondary accumulation can be considered as oxide outcrops of hydrothermal deposits of $U$. The essential geological peculiarities of the secondary $U$ accumulations near the surface allow a differentiation of the oxide outcrops. The essential processes of formation of the secondary accumulations of $U$ is the evaporation of uranifernus waters. The suurce of $U$ in the beds formed by evaporation is essentially from rocks possessing a high $U$ concentration. (NSA)

Kovalev, V. A. 1965. Geochenical Aspects of the Th/U Ratio Investigation in Rocks. Geokhimiya. No. 9:1171-3 (in Russian). 
The Th/U ratio can be used to estimate the intensity of weathering processes. $U$ is more mobile than Th. Black schists and phosphorites show a low Th/U ratio (less than two). Littoral sands and alluvial deposits show a high Th/U ratio (greater than 7 ). Most clay deposits show an intermediate Th/U ratio of 2 to 7 . Leaching experiments with $3 \% \mathrm{HCl}$ on a $0.01 \mathrm{~mm}$ fraction of mineral showed that on $1 y \quad 40 \%$ of the Th could be leached out while $70 \%$ of the $U$ was removed from the mineral. The Th accumulated in the heavier, accessory minerals, and was not leached out readily. (NSA)

Kovalevskii, A. L. 1967. Dependence of the Content of Some Trace Elements on the Clayiness of Soils. Mikroelem. Biosfere Ikh Primen. Sel. Khoz. Med. Sib. Dal'nego Vostoka, Dokl. Sib. Knof., 2nd. 1964. 0. V. Makew. Buryat. Khizhn. Izd.: Ulan-Ude, USSR.

The effect is studied of the clayiness of sod-meadowy noncultivated soils in the west Siberian lowlands (northern and central part) on the amount of total and available trace elements. Samples were taken from a depth of $0.3-3.0 \mathrm{~m}$ : The results show for most of the elements an increase in clayey (fraction $<0.01 \mathrm{~mm}$ ) soil as compared with sandy soils, the ratio being 3.0-6.2 ( $\mathrm{B}, \mathrm{Ni}, \mathrm{Co}, \mathrm{U})$. The greatest difference was noted in the content of $\mathrm{Pm} \mathrm{Co}$, and org. C. Analysis of various fractions according to size showed that the clayey part (0.001-0.01 mm) contains Li, $\mathrm{Zn}$, and $\mathrm{Ni}$ 25-50 times, Mn and $\mathrm{Co} 13-25, \mathrm{Sr}, \mathrm{Mg}, \mathrm{Fe}$ and $\mathrm{Ti} 7-13$, and $\mathrm{Ba}, \mathrm{Sn}, \mathrm{Al}$ and $\mathrm{Cr}$ 3-7 times as much as the sandy fraction $(0.05-0.25 \mathrm{~mm})$. Correlation between $\alpha$-activity and $\mathrm{Co}$ and $\mathrm{Ni}$ is demonstrated. Correlation between radioactivity and trace elements for the mapping of the concentration by aerogram and auto $\gamma$-photos is regarded as promising. (CA)

Koval'skii, V. V. and I. E. Vorotnitskaya. 1966. Regularities in the Biogenic Migration of Uranium. Ukr. Biokhim. Zh., Vol. 38, No. 4:419-424. RFP-TRANS- 141 .

Data are presented on the biogenic migration of uranium in a medium with elevated and normal content of this element. Biogenic migration under dryland conditions was studied in the system: soil-plant-animals. It is shown that uranium concentration by soils depends on: the type of soil and the forms of the uranium compounds. Under conditions of elevated uranium content in the environment, morphological variability was found in some plant species. The diurnal uptake of uranium by farm animals was computed. Biogenic migration of uranium under conditions of an aquatic envi ronment was studied using Lake Ussyk-Kul, the waters of which contain an elevated concentration of this element. It is shown that the uranium content and gradient. of its accumulation in organisms with respect to water diminishes when uranium passes through the chain: algae $\rightarrow$ benthic and planktonic animals $\rightarrow$ fish. (auth) 
Kovalski, V. V., and I. E. Vorotnistskaya. 1965. Biogenic Migration of Uranium in the Lake Issyk-Kul. Geokhimiya. No. 6:724-32 (in Russian).

The role of living organisms in uranium migration in the lake Issyk-Kul and the connection of uranium food chains with the level of its content in fishes inhabiting the lake was studied. Various stages of the biogenic uranium migration were investigated: water silts, benthos algae and higher plants, plankton, benthos animal organisms, and fishes. The uranium content was determined by the extraction-luminescent method. The chief uranium concentrator in the lake was algae of the charophytes family; in this connection an exceptional polymorphism was observed. It was shown that the chief enrichment of silts in uranium was genetically ronnerted with 1 ts accumulation by charophyte algae during their life time, since the greatest uranium amount was contained in silts, underlying the charophyte algae and since uranium was not washed off the algae, which died. The uranium content and its accumulation gradient decreased with the complication of organism structure in the chain: algae $\rightarrow$ animal organisms of the benthos fishes. In uranium passing through the food chain a gradual decrease in uranium concentration was observed. (auth)

Krendelev, F. P. and V. A. Bobrov. 1970. Clarke Contents of Uranium, Thorium, and Potassium in Weathering Profiles Developed on Acidic Igneous and Metamorphic Rocks of the Enisei Ridge. Geokhim. Mineral. Radioaktiv. Elem. Sib. pp. 105-55 (in Russian).

The radioactive elements enter into minerals with different degrees of stability and, therefore, the values of $T h / U$, Th/K, and $U / K$ ratio depend strongly on the conditions of bedrock disintegration and sediment formation. This result is evident from recent sediments where the values of Th/II and $T h / K$ ralius vary sharply. An especially strong increase of the $T h / U$ ratio is observed in redeposited product.s nf weathering profilcs, c.g., oligomictic sandstones and gravelstones. The $U$ and $K$ are removed with the same intensity and redeposited together. A certain accumulation of $U$ was observed only in the soils. The total radioactivity of weathering profile products correlates with the $\mathrm{Fe}_{2} \mathrm{O}_{3} / \mathrm{FeO}$ ratio. (CA)

Krendelev, F. P. and A. A. Kulikov. 1972. Stratigraphic Separation of Cenozoic Formations of the Marker Profile in the Mamontov Mountains Based on Radiometric and Gamma-Spectrometric Data (Southern Yakutia). Tr. Inst. Gẹn1. Geofiz., Akad. Nauk SSSR, Sib. 0tu. Nu. 149:188-96 (in Russiaii).

General rock radioactivity was examined in three complete profiles by determining the $U$, Th, and $K$ contents. A correlation was established between radioactivity and particle size of the material; with increased size of the fragments, radioactivity alld contents of Th and $K$. $U$ did not show this relation, its concentration was minimum in oligomict varieties and maximum in aleurites. $U$ decreases from the floor of each layer towards the roof, whereas that of Th and $K$ increases. This trend is even more clearly reflected in the relation of the pairs $U / K$ and $T h / U$. (CA) 
Krishnamoorthy, T. M., V. N. Sastry and T. P. Sarma. 1971. ${ }^{234} \mathrm{U} /{ }^{238} \mathrm{U}$ as a Tool for Dating Marine Sediments. Curr. Sci. 40:279-81.

A method for dating marine sediments using the decrease of ${ }^{234} \mathrm{U} /{ }^{238} \mathrm{U}$ activity ratio in the calcium carbonate phase was developed. A selective leaching agent $\mathrm{NH}_{4} \mathrm{Ac}$ - HAc buffer was used which attacks only the calcium carbonate phase and very little of the other phases. The rate of sedimentation for the core, M-230 (Lat. $23^{\circ} 10^{\prime} \mathrm{N}$, Long. $67^{\circ} 50^{\prime} \mathrm{E}$ ) from Indian Ocean was found to be $1.16 \mathrm{~mm} / 1000$ years by this method. The calculated ionium value for the particular water column depth and for the typical composition of the top layer of the sediment was $1.58 \mathrm{dpm} / \mathrm{g}$ and agrees-very well with the actual value of $1.28 \mathrm{dpm} / \mathrm{g}$ observed, considering the uncertainties in the parameters used. (auth)

Kröl1, V. S. 1955. The Distribution of Radium in Deep-Sea Cores. Repts. Swedish Deep-Sea Expedition, 1947-1948. 10:1-32.

Determinations of Ra content by the emanation method were made on about 350 samples from 13 Pacific cores and 4 Altantic cores. Determinations of $U$ on 36 samples show that on the whole $U$ and $R a$ are in equilibrium in the deeper layers. The Ra in the upper layers is ionium supported. The distribution of $\mathrm{Ra}$ is compared with those of $\mathrm{Mn}, \mathrm{Fe}, \mathrm{CaCO}_{3}$, and $\mathrm{Ni}$. Rates of sedimentation calculated show considerable variation. (CA)

Kronfeld, J. 1972. Hydrologic Investigations and the Significance of ${ }^{234} \mathrm{U} /{ }^{238} \mathrm{U}$ Disequilibrium in the Ground Waters of Central Texas. Rice University. Thesis.

Forty-six uranium isotopic analyses were made using alpha spectrometry on waters from the deep Trinity aquifer as well as ypgn surface waters in central Texas. Most of the surface waters have ${ }^{234} \mathrm{U} / 238 \mathrm{U}$ alpha-activity ratios clustering between 1.15 and 1.40 . The subsurface waters exhibit extreme isotopic fractionation, being enriched in $234 \mathrm{U}$ between several hundred and twelve hundred percent. The uranium content of the subsurface. water is less than surface water, the majority falling around 0.02 and 0.04 $\mathrm{ppb}$. The most extreme fractionation occurs immediately downdip from the recharge area. From there the activity ratio decreases downdip as a function of the halflife of $234 \mathrm{U}$. There is a corresponding, though nonuniform, decrease in the total uranium content downdip. The Trinity aquifer affords a closed system to an isotope dilution study that utilizes natural $234 \mathrm{U} /$ $238 \mathrm{U}$ disequilibrium as a hydrologic tracer. Rates of water flow so derived, 0.7 to $3.0 \mathrm{ft} / \mathrm{yr}$, are consistent with the transmissibility values of the aquifer rocks, Laboratory leaching of uranium from the soils and aquifer sand yield $234 \mathrm{U} / 238 \mathrm{U}$ activity ratios that are very similar to uranium isotopic compositions of surface waters. No extreme fractionation was found in the solid phases. (NSA) 
Ku, T. 1965. An Evaluation of the $U^{234} / U^{238}$ Method as a Tool for Dating Pelagic Sediments. J. Geophys. Res. 70:3457-74.

The possibility of using the $15 \%$ excess $234 \mathrm{U}$ activity in oceanic uranium for dating pelagic sediments in the age range 100,000 yr to more than 1 Myr was explored. Results from a series of analyses of bulk samples, mechanical separates, and acid leach fractions indicate that separation of authigenic uranium from detrital uranium by either mechanical or chemical means is impractical. Measurements on totally dissolved samples reveal that the sediments do not form a closed system; post-depositional migration of $234 \mathrm{U}$ in the sedimentary column takes place. Based on the experimental data obtained from three red-clay cores with sedimentation rates ranging from 2 to $6 \mathrm{~mm} / 1000 \mathrm{yr}$, a model depicting diffusion of the 234 II generated within the sediments is prupused. The diftusion equation inclydes three parameters: sedimentation rate, diffysion coefficient for ${ }^{234} U$, and fraction of the intermally produced $234 U$ subject to mobility. If the amount of $234 \mathrm{U}$ lost from these cores is typical, a sizeable part of the ${ }^{234} \mathrm{U}$ excess in the sea must be from this source. (auth)

Kuptsov, V. M. 1970. Method for Determination of Smal1 Amounts of Protactinium-231 in Natural Substances. Tr. Konf. Molodykh Issled. Vses. Nach.-Issled. Miner. Syr'ya. Sekts. Anal. Tekhnd., 7th. pp. 41-8 (in Russian).

A method for determining ${ }^{231} \mathrm{~Pa}$ in natural sulistances (rocks, sea sediments, hot spring water deposits, etf.) is proposed. The method is based on $\alpha-$ spectrometric recording of $231 \mathrm{~Pa}$ decay products, (i.e., short-lived emanations of $219_{\mathrm{Rn}}$ ). First, the Th fraction is separated from the sample; it is then held for 19-60 days to achieve equilibrium hetween Ac and $i$ ls decay products; and $\alpha, \alpha$-coincidences are recorded at intervals of $10^{-2} \mathrm{sec}$ frum $219 \mathrm{Rn}$ and $215 \mathrm{Po}^{\mathrm{i}} \mathrm{sotopes}\left(\mathrm{E}_{\mathrm{N}}=7.36 \mathrm{MeV}\right.$ ) by using an $\alpha$-spectrometer with a special attachment. The method assumes equilibrium between $23 \mathrm{~T}_{\mathrm{Pa}}$ and its decay product $227 \mathrm{Ac}$, which approaches 100 years. Otherwise, only the $227 \mathrm{Ac}$ content was determined in the sample. (CA)

Kurokawa, Y. 1971. Data of Natural Radioactivity in Japan. Höken Butsur1. 6:192-3 (in Japanese)

Vata on $U(0.48-2.89)$, Ra $(0.09-1.3)$, Tn $(2.8-20)$, ând $40_{K}(0.6-3.18 \mathrm{ppm})$ is solls of 40 districts and those of $U\left(0.57 \times 10^{-3} \mathrm{ppm}\right.$ average), Th $2.7 \times 10^{-5} \mathrm{ppm}$ average), and $\mathrm{Ra}\left(8.2 \times 10^{-10} \mathrm{ppm}\right.$ average) in 10 river waters in Japan are tabulated. Rates of radiation dose from natural radioisotopes in various districts were 28-95 indoors and 15-134 mR/yr outdoors. A table of natural radioactivities in underground soils is also given. (CA) 
Kurtz, E. B. and R. Y. Anderson. 1956. Uranium Accumulation in Plants as an Indicator of Uranium Deposits in the Soil. Final Report. AECU-3177.

An alpha scintillation method for the analysis of $U$ accumulation in plants as an indicator of $U$ deposits in the soil was developed. (NSA)

Kuznetsov, Y. V. 1969. On Occurrence Forms of Ionium ( ${ }^{230}$ Th) and Thorium (232 Th) in the Ocean. Geokhimiya. No. 2:177-84 (in Russian).

Collected data indicate that ${ }^{230}$ Th and 232 Th are present in different forms not only in oceanic waters but also in other components of the oceanic system, in oceanic sediments and suspensions. It is assumed that most of the ionium in the ocean exists in hydrolytic forms which are sorbed on suspesion particles while thorium is carried into oceans from continents in the composition of residual minerals. Significance of this conclusion in relation to the geochronology of oceanic sediments and the geochemistry of thorium in the ocean is considered. (auth)

Kuznetsov, Y. V. 1969. Rate of Recent Sedimentation in the Ocean. Geokhimiya. No. 2:251-60 (in Russian).

A determination of the rate of recent sedimentation in the Indian and Pacific Oceans was carried out using data on the ${ }^{230} \mathrm{Th}, 231 \mathrm{~Pa}$, and $238 \mathrm{U}$
concentrations in oceanic waters and surface layers of oceanic sediments The obtained results on the rate of recent sedimentation agree well with available publications on this question. The revealed variations in the rate of sedimentation in various regions of oceans are conditioned by the peculiarities of the hydrological regime in these regions. (auth)

Kuznetsov, Y. V. 1971. Possible Variations in the Past Concentration of Uranium in the Oceans. Radiokhimiya. 13:118-25 (in Russian)

Sediments in the bottom of the Pacific Ocean contain an excess of Io (230th) with respect to the concentration calculated on the basis of its concentration in the water; this can be explained in several ways, e.g., it can be assumed that in the past the $U$ concentration in the water was higher than at present, or that the $234 \mathrm{U} / 238 \mathrm{U}$ was higher than at present. (CA)

Kuznetsov, Y. V., E. V. Komarov, A. N. Elizarova, Z. N. Simonyak and A. A. Bochkov. 1973. Simulation of the Forms of Thorium-230 in Seawater to Study its Sedimentation Mechanism. Sov. Radiochem. (Engl. Träris1.), pp. 715-720.

A method is proposed for simulating the forms of existence of ${ }^{234} \mathrm{Th}$ in seawater, based on the introduction into it of uranium in the form of a uranyl carbonate anionic complex with the subsequent formation of ${ }^{234} \mathrm{Th}$ 
from it. It was shown that the kinetics of sorption on quartz glasses of ${ }^{234}$ Th introduced into seawater in the form of a neutral solution differ substantially from the kinetics of sorption of 234 Th formed in the water itself from uranjum. It is suggested that the method proposed for the introduction of 234 Th into seawater simulates the process of the formation of ${ }^{230} \mathrm{Th}$ in it most fully. (auth)

Kuznetsov, Y. V., V. K. Legin, A. P. Lisitsyn, and Z. H. Simonyak. 1964. Radioactive Ocean Suspensions. I. Isotopes of Thorium in Ocean Suspensions. Radiokhimiya. 6:242-54 (in Russian).

Samples of ocean suspensions were taken at numerous places in the Indian ocean. The concentrations of ionium and thorium in the various types of suspensions were determined. The relationships between these elements and the principal other components as well as the granulometric size of the suspension particles were determined. Since the relationships of the two elements were found to be very different, it was concluded that ionium and thorium are in very different forms in the suspensions. A close relationship was established between the ionium content in the suspension and the total phosphorus, iron, organic, and calcium carbonate contents. No relationship was detectable between ionium and amorphous silicon or magnesium carbonate or between thorium and iron, organic, calcium carbonate, or amorphous silicon. The data obtained indicated the possibility of determining the rate of sedimentation from the Io/Th ratio. The ionium and thorium contents in the water of the Caspian and Baltic seas and in muds of the Indian Ocean are shown for comparison. (NSA)

Kuznetsov, Y. V., V. K. Legin, A. P. Lisit.syn, and Z. N. Simonyak. 1967. Radioactivity of Oceanic Suspensions. II. Uranium in Oceanic Suspensions. Radiokhimiya. 9:489-97 (in Russian).

Data are given on the concentration of uranium in oceanic suspensions. The fraction of $U$ in the ocean water, coordinated with the suspensions, was evaluated. The relation between uranium concentration in suspensions and concentration of basic. components of the granulnmetric and chemical states of the suspension was investigated. The direct correlation dependence between $\mathrm{CaCO}_{3}$ concentration and uranium in the suspension was established. (auth)

Kuznetsov, Y. V. and V. N. Shchebetkovskii. 1971. Distribution of Radioactive Isotopes Between Sea Waters and Sedimants. Geokhimiya. No. 12: 1466-72 (in Russian).

Distribution of radioactive isotopes $\left({ }^{137} \mathrm{Cs},{ }^{144} \mathrm{Ce},{ }^{234} \mathrm{Th}\right)$ in the sea water and major types of sediments covering the Pacific Ocean floor are discussed. The foraminiferal, diatomaceous, and iceberg silt and red shallow-water 
clays are favorable locales for the sorption of these isotopes. These sediments show a high content of $137 \mathrm{Cs}$ and $144 \mathrm{Ce}$. Desorption of $137 \mathrm{Cs}$ and ${ }^{144} \mathrm{Ce}$ from the sediments into sea waters was studied. An empirical relation is established between the percentage of desorption and volume of water in the case of ${ }^{137} \mathrm{Cs}$, with $P=V / a+b V$, where $V=$ volume of water, $P=$ desorption percentage, and $a$ and $b$ are empirical constants. The distribution of $137 \mathrm{Cs}$ between sea water and sediments occurs as a homogeneous sorbate. (CA)

Kuznetsov, Y. V., Z,N. Simgnyak, A. P. Lisitsyn, and M. S. Frenklikh. 1968. Thorium Isotopes ( $\left.230 \mathrm{Th},{ }^{232} \mathrm{Th}\right)$ in the Surface Layer of Bottom Sediments From the Indian Ocean. Geokhimiya. No. 2:218-27 (in Russian).

Data on the concentration of thorium isotopes $\left({ }^{230} \mathrm{Th},{ }^{232} \mathrm{Th}\right)$ in the surface layer of various bottom sediments raised in the southern and central ports of the Indian Ocean were obtained. Peculiarities of the distribution of these isotopes on the bottom of the Indian Ocean have been revealed. Investigation of paragenetic associations of $230 \mathrm{Th}$ and ${ }^{232} \mathrm{Th}$ with components of the chemical and granulometric composition of the sediments has shown that the deposition mechanisms of these isotopes substantially differ. (auth)

Kuznetsov, Y. V., Z.jN. Simonyak, A. P. Lisitsyn, and M. S. Frenklikh. 1968. Thorium Isotopes ( $230 \mathrm{Th}, 232 \mathrm{Th})$ in the Surface Layer of the Indian Ocean Sediments. Geochem. Int. 5:169-77.

It has been demonstrated that the content of ionium $\left({ }^{230} \mathrm{Th}\right)$ in the surface layer of oceanic sediments depends on the depth of water, effective surface area of the sedimentary particles, and on the rate of sedimentation. ${ }^{230} \mathrm{Th}$ is co-precipitated with the hydroxides and phosphates of Fe and $\mathrm{Mn}$, while 232Th is contained in the sedimentary detrital particles. (auth)

Kuznetsov, Y. V., Z. N. Simonyak, A. P. Lisitsyn, and M. S. Frenklikh. 1968. Uranium and Radium in the Surface Layer of Oceanic Sediments. Geokhimiya. No. 3:323-33 (in Russian).

Data on uranium and thorium concentration in the surface layer of the Indian Ocean bottom sediments are given. Peculiarities of uranium and radium distribution over the ocean floor were investigated. Paragenetic associations of uranium and thorium with components of the chemical and granulometric composition of bottom sediments were studied. Bonds between uranium and organic carbon and phosphorus were established which provides evidence in favor of the existence of a certain mechanism of uranium withdrawal from ocean water. The presence of radium directly precipitated from oceanic water was proved. (auth) 
Labeyrie, J., C. Lalou, and G. Delibrias. 1967. Study of Marine Transgressions on a Pacific Atoll by Means of Carbon-14 and the Uranium-234/ Thorium-230 Ratio. Radioactive Dating Methods Low-Level Counting, Proc. Symp. Monaco. pp. 349-58 (in French).

The last eustatic maximum of $+3 \mathrm{~m}$ is dated at $-3000 \pm 58$ years, the $0 \mathrm{~m}$ level at $-5000 \pm 500$ years, the $-7 \mathrm{~m}$ level of the eustatic maximum of the last interglacial at $-100,000 \pm 20,000$ years (reexceeded 8000 years ago), and finally another eustatic maximum level, corresponding to a previous interglacial, at $-400,000 \pm 50,000$ years. This level was reexceeded $200,000 \pm 40,000$ years ago. By dating the subadjacent basalt, it was possible to evaluate the minimum average subsidence rate of the atoll. The value obtained can be used to correct the above data. (CA)

Lalou, C.., E. Brichet, and D. Rangue. 1973. Are Some of the Manganese Nodules Found on the Surface of Sediments Contemporary Formations of Sedillentation. C. K. Acad. Sci., Ser. D. 276:1661-4 (in French).

The presence of a considerable excess of ${ }^{230} \mathrm{Th}$ in different parts of $\mathrm{Mn}$ nodules in the Pacific Ocean (980 $\mathrm{m}$ depth) posed a question on the theory of the nodule formation. The results are discussed. (CA)

Lambet, M. S. and D. S. Nikolaev. 1962. The Mode of Uranium Occurrence in the Waters of the Azov Sea and in a Number of Estuaries and Rivers of the Azov-Black Sea Basin. Doklady Akad. Nauk S.S.S.R. 142:681-2 (in Russian).

It had been shown previously that uranium exists in ocean water as a stable carbonate complex. However, there are no data on the state of uranium in river water. Hence, samples of river watcr were filtered d. a pressure of 10 to 12 alm through a cellophane membrane having a pore sizc of about $1 \mathrm{~mL}$. The uranium content was determined by a luminescence method, and the $\mathrm{pH}$ was taken potentiometrically. All measurements were taken immediately after sampling. The results show that uranium passed through the filter and exists in ionic form in the water as a carbonate complex. The possibility of the existence of a uranium organic complex with humic acid in a number of the samples is not excluded. The uranium content of the water increases with an increase in the salt contcnt of the water. (NSA)

Landergren, S. 1964. The Geochemistry of Deep-Sea Sediments. Rep. Swed. Deep-Sea Exped. 10:59-148.

Chemical analyses are given of 480 samples from 15 cores, 8 Pacific, 2 Indian, 5 Atlantic Ocean, along with spectrographic analyses for $T i$, $\mathrm{U}, \mathrm{Cr}, \mathrm{Mn}, \mathrm{Co}, \mathrm{Ni}$, and $\mathrm{B}$. Correlations among the elements are discussed in detail. $\mathrm{Mn}, \mathrm{Co}$, and $\mathrm{Ni}$ are enriched with respect to $\mathrm{Fe}$ in the pelagic clay sediments; Co and $\mathrm{Ni}$ appear to have been adsorbed by $\mathrm{MnO}_{2}$. (CA) 
Landergren, S. and F. T. Manheim. 1963. The Dependence of the Distribution of Heavy Metals on the Facies. Fortschr. Geol. Rheinland Westfalen 10: 173-92.

A summary of data on minor elements in marine and fresh-water sediments with some new data on $\mathrm{Ba}, \mathrm{Sr}, \mathrm{Ga}, \mathrm{Cu}, \mathrm{Zn}, \mathrm{Pb}, \mathrm{Mo}$, Th, and $\mathrm{U}$. None of these elements seems to be a satisfactory indicator of the depositional environment. (CA)

Lange, E. 1956. 0ccurrences of Uranium in Terrestrial Sediments. Z. angew. Geol. 2:3-8.

A review with 17 references. (CA)

Lazarev, K. F., D. S. Nikolaev, and S. M. Grashchenko. 1961. Concentration of Thorium Isotopes in Sea Water. Radiokhimiya. 3:623-35 (in Russian)

A method was developed for concentrating thorium in large volumes of natural water (200 to 5001 ) using iron hydroxide precipitation at low temperature. The contents of thorium and ionium in the Black Sea are $(2.2 \pm 0.2) \times$ $19^{-9}$ and $(2.5 \pm 1.0) \times 10^{-13} \mathrm{~g} / 1$, respectively. The content of thorium decreases from the coastal area to the open sea. Moreover, the thorium content decreases much faster than the ionium because larger quantities of $\mathrm{Th}^{232}$ are found in coarse terrigeneous suspension, while ionium occurs in fine colloidal suspensions that do not settle as easily to the bottom and are carried farther into the open basin. (NSA)

Legin, V. K., Y. V. Kuznetxov, and R. F. Lazarev. 1966. Uranium Occurrences in Marine Sediments. Geokhimiya. No. 5:606-8 (in Russian)

The total $U$ and mobile $U$ contents were determined in samples taken from the $\mathrm{H}_{2} \mathrm{~S}$-contaminated zone of the Black Sea, from the coastal zone of the Black Sea not contaminated with $\mathrm{H}_{2} \mathrm{~S}$, and from the central part of the Azov Sea. The mobility of $U$ was determined by leaching the samples with $0.7 \mathrm{~N} \mathrm{NaHCO}_{3}$ and $3 \mathrm{~N} \mathrm{HCl}+3 \mathrm{~N} \mathrm{H}_{2} \mathrm{SO}_{4}$. The mobility of $\mathrm{U}$ in contemporary sediments from the Black Sea zone contaminated with $\mathrm{H}_{2} \mathrm{~S}$ was much higher than in the sediments of the Azov Sea. Only 4-6\% of the $U$ was extracted from the Azov Sea sediments after twofold leaching with $\mathrm{NaHCO}_{3}$ whereas, under the same conditions, practically all of the $U$ was extracted from the sediments of the Black Sea. This marked difference in the mobility of $U$ suggested different forms of occurrence for the 11 in these sediments. It also suggested the proportion of $U$ from the Black Sea water and the terrigenous form of $U$ occurrence in the sediments of the Azov Sea. '(CA)

Libby, W. F. and G. W. Barton. 1964. Search for Natural Curium 247. J. Geophys. Res. 69:1603-5. 
A sample of rare-earth conceptrate derived from euxenite was analyzed for the long-lived isotope ${ }^{247} \mathrm{Cm}$ by mass spectrometric isotope dilution. Less than $10^{-14} \mathrm{~g}$ of $247 \mathrm{Cm}$ per gram of rare earth was found. It is difficult to reconcile this negative result with the reported discovery of this isotope in nature. (auth)

Lisitsin, A. K. 1960. Uranium Content of 0xidizing 0i1s. Geokhimiya. No. 7:634-9 (in Russian).

Data are given on the uranium distribution in oils and in ashes of oils from paleogene sediments of the Fergana depression, depending on their specific weight and general ash content. Results of uranium extraction from natural waters by oils also are given. The results show that the principal enrichment of oils in uranium occurs during their oxidation under the influence of infiltration sheet waters, the capacity for uranium extraction from underground waters increasing with the increase of the oxidation degree of oils. (auth)

Lisitzin, A. K. 196\%. On the Forms of Uranium Occurrence in Underground Waters and the Conditions of Its Deposition in the Form of $\mathrm{UO}_{2}$. Geokhimiya. Nu. 9:763-9 (in Russian).

For estimating the forms of uranium in underground waters, physiochemical constants of its equilibrium in aqueous solutions were used. It is shown that in weak acid, neutral, and alkalescent underground waters of different mineralization anionic forms of uranium prevail in the form of di- and tricarbonateuranyl. The values Eh of the equilibrium in solution with $\mathrm{UO}_{2 \mathrm{sol}}$ are in accordance with the results of detailed hydrogeochemical observations and analyses. The value Eh of the beginning of precipitation of the tetravalent uranium oxide from underground waters ranges approximately from 0 to -0.2 volt depending on the uranium concentration in solution, the magnitude and character of the total mineralization of water, the $\mathrm{pH}$, and the concentration of $\mathrm{HCO}_{3}^{-}$-ion. (auth)

Lisitsin, A. K. 1969. Deposition Conditions of Molybdenum and Selenium in Exogenetic Epigenetic Uranium Deposits. Litol. Polez. Iskop. No. 5: 27-35 (in Russian).

IJ contents of ground waters are discussed in terms of $\mathrm{E}_{\mathrm{H}^{-}} \mathrm{pH}$ diagrams. Mo migrates under exogenic conditions as $\left[\mathrm{MoO}_{4}\right]^{2-}$ ions. Deposition as $\mathrm{MoS}_{2}$ is conditioned by reducing environment and by $\mathrm{H}_{2} \mathrm{~S}$ produced by sulfatereducing bacteria. $\left[\mathrm{SeO}_{4}\right]^{2-},\left[\mathrm{SeO}_{3}\right]^{2-}$, and $\left[\mathrm{HSeO}_{3}\right]^{-}$are the possible forms of Se transport. By. lowering $E_{H}$ of the ground waters, Se is deposited first, mainly in environments of increased acldity. The deposition of $U$ and Mo is within the fields of $\mathrm{FeO}$ stability. MoS ${ }_{2}$ is deposited under lower $E_{H}$ than $U$ oxides. The lack of Se in the reducing geochemical barriers is explained by low Se in the enclosing rocks and ground waters, the lack of Mo by specific conditions required for $\mathrm{MoS}_{2}$ deposition. (NSA) 
Lisitsin, A. K., I. A. Kondrat'eva, and G. V. Komarova. 1969. Genetic Interpretation of Epigenetic Alterations in Sedimentary Rocks. Litol. Polez. Iskop. No. 3:5-19 (in Russian).

The correlation between compositions of surface waters and authigenous minerals of the last stage of epigenetic alteration was observed in rocks of water-bearing horizons in some ore deposits. A comparison of mineralogicalgeochemical zoning of rocks with hydrogeochemical zoning of waters was used to restore conditons of epigenetic mineralization of several $U$ deposits in the U.S.S.R. The conditions of epigenetic mineralization can be determined directly on complete agreement of epigenetic and hydrogeochemical zoning. A partial agreement of these zonings, observed during study of $U$ deposits, was interpreted by comparison of ore-controlling epigenetic zoning with hydrogeochemical zoning in petroleum-bearing carbonate rocks of the area. It suggested that epigenetic mineral association was formed by intrusion of infiltration waters into petroleum-water horizon. Complete disagreement of recent hydrogeochemical environment with paleohydrogeological conditions of ore formations was observed in the U-Se deposit in continental varicolored stratum. The correlation of hydrogeological and geochemical conditions of deposit formation was then made from lithologic facies and mineralogical geochemical studies. Formation of $U$ and Se concentrations was attributed to groundwaters leaching proluvial formations rich in fragments of acidic effusive rocks. Precipitation of $U$ and Se occurred in the zone of reducing geochemical barrier confined to the boundary of proluvium with river bed deposits rich in plant remnants. The climate during ore deposition was semiarid according to the paleogeographical study, which promoted increase in $U$ and Se concentrations in ground waters by water evaporation. (NSA)

Lopatkina, A. P. 1967. Conditions of Uranium Accumulation by Peats. Geokhimiya. No. 6:708-19 (in Russian).

A substantial part of uranium in waters of humid regions is present in an unstable state and may be precipitated by peats. The peat composition, the uranium content in waters, and the general mineralization of the waters influence the uranium concentration in peat. No more than $20 \times 10^{-4} \%$ of uranium accumulates in peats at the expense of average contents in rocks amounting to 1 to $3 \times 104 \%$. (auth)

Lopatkina, A. P., V. S. Komarov, A. N. Sergeev, and A. G. Andreev. 1970. Concentration of Uranium By Living and Dead Peat-Forming Plants. Geochem. Int. 7:277-82.

Exposed parts of plants, hydromorphic soils, and water from a marshy floodplain of a small stream flowing on mesozoic granites were analyzed for uranium. Water, peat, various mosses, and dead plants from several bogs were also analyzed. It was found that in the humid zone the exposed parts of trees and grasses absorb one tenth to one thousandth of the uranium 
absorbed by the hydromorphic soil in which they grow, regardless of the concentration of uranium in ground waters. It is concluded that these plants cannot be the source of the high concentrations of uranium in peat. The roots of higher plants, plant debris, and the humus of hydromorphic soils absorb much more uranium if they are in direct contact with water. The lower plants, mosses, etc. absorb considerable amounts of uranium, the amount absorbed depending on the concentration of the element in the ground waters and probably, on the area of contact between plant tissues and water. (NSA)

Love, 1. 0. 1964. Uranifcrous Phosphatic Lake of Eocene Äge in Intermontane Basins of Wyoming and IItah. U.S.G.S. Professional Pạpẹp No. 474-E.

The maximum $U$ content is $0.15 \%$ and $\mathrm{P}_{2} \mathrm{O}_{5}$ is $18.2 \%$. The average for the 25 sampled zones, which ranged in thickness from 3 in. to $6 \mathrm{ft}$ is $u n . \Pi n 5 \%$ $\mathrm{U}$ and $2.2 \% \mathrm{~F}_{2} \mathrm{O}_{5} \cdot$ (CA)

McKelvey, V. E., D. L. Everhart, and R. M. Garrels. 1955. Origin of Uranium Deposits. Econ. Geol. 50:464-533.

Uranium is concentrated in certain silicic and silica-alkalic igneous rocks, pegmatites, veins, lenticular sandstones and conglomerates, low-rank highash coals, asphaltic materials, marine black shales, and phosphorites. Its distribution in igneous rocks, pegmatites, and veins shows its tendency to concentrate in late stage differentiates. In the granitic rocks, uranium occurs mainly as a minor constituent of accessory minerals that have cations (such as rare earths, thorium, and calcium) for which uranium can substitute 1somorphously, but it also occurs as an acid-soluble interstitial cunstltuent. In pegmatites, uranium occurs both in uraninite and in olhẹr uranium minerals in combination with niobium, thorium, and rare earths. Uranium is found in both high-temperature veins, where it is mainly in the titanium minerals davidite and brannerite, and low-temperature veins, where it is mainly in pitchblende, the botryoidal variety or uraninite, and coffinite. The low-temperature veins are of several over-lapping types, but all are characterized by sulfides and many contain disseminated iron oxide. Whereas thnrium is associated with uranium in iyneuus rocks and pegmatites, it is rare in the vein deposits of uranium. This separation may be accomplished by oxidation of $\mathrm{U}^{+4}$ at a late magmatic stage to $\left(\mathrm{UO}_{2}\right)^{+2}$ in which form it is carried away from the unoxidizable $\mathrm{Th}^{+4}$. Subsequently $\left(\mathrm{UO}_{2}\right)^{-2}$ is reduced and deposited as pitchblende along with sulfides and other low-valent minerals in veins. The sandstone uranium deposits resemble the pitchblende veins in their mineralogic assemblage except that many of the sandstone deposits also contain vanadium, a metal not abundant in veins. Isotopic studies indicate that the Colorado plateau deposits are epigenetic and suggest that the uranium was derived from a deep-seated source. The uranium in coal and associated carbonaceous shale beds occurs in the form of metallo-organic compounds but secondary uranium minerals like meta-autunite are found in coals that contain more than $0.1 \%$ uranium. The uranium in marine black shales and phosphorites was derived from sea 
water. The precipitation of uranium in the shales probably is brought about by chemical adsorption by living or dead plankton, but reduction evidently plays an important role in its precipitation and stabilization in the shale. Uranium in the phosphorites substitutes for calcium in the apatite structure. Its adsorption by apatite is hindered by abundance of calcium ions, with which it competes for positions in the structure, and by carbonate and hydroxyl ions, which compete with phosphate groups for structure positions and form less stable compounds with uranium. (auth)

McKelvey, V. E. and J. M. Nelson. 1950. Characteristics of Marine UraniumBearing Sedimentary Rocks. Econ. Geol. 45:35-53.

This is a summary, by the U.S. Geological Survey, of general information on the occurrence of uranium in marine shales and phosphorite formations. Such deposits are large but low grade, but inasmuch as other countries, namely Sweden and possibly Russia, are now recovering uranium from them it behooves us to investigate this source. Marine deposition of uranium was favored in certain geological periods and rocks of the appropriate ages occur in most parts of the United States. (NSA)

Magne, R., J. R. Berthelin, and Y. Dommergues: 1974. Solubilization and Insolubilization of Uranium From Granites by Heterotrophic Bacteria. IAEA-SM-183/18. IN: Formation of Uranium Ore Deposits.

Batch cultures and semi-continuous flow perfusions are used as experimental devices to study microbial solubilization and insolubilization of uranium from granites by heterotrophic bacteria. The nutrient media are synthetic (with dextrose or amino acids) or natural (with mine water containing organic compounds). Microbial activity increases 2 to 97 times the solubilization of uranium. The processes are biosyntheses of complexing or chelating compounds. The micro-organisms involved are soil microflora and bacteria of mine water and granites. Some species are identified. Microbial insolubilizations of uranium are described in batch cultures. These processes involve biodegradation of uranium binding organo-compounds. These biodegradations occur after long periods of incubation and promote some neoformations of uranium deposits. Black and yellow deposits are observed and described. These experimental results suggest the model described in the paper. This model seems to apply easily to superficial processes of solubilization and concentration of uranium and in reworking deposits. However, in the case of primary intragranitic uranium deposits it is only an hypothesis correlated by the existence of favorable environmental conditions for bacterial growth and by some geological observations mentioned in the paper. (auth)

Mahdavi, A. 1963. The Thorium, Uranium, and Potassium Contents of Atlantic and Gulf Coast Beach Sands. Thesis. Rice University. 
A field radiometric survey was made of the thorium, uranium, and potassium concentrations in the beach sands along the Gulf and Atlantic Coasts. At 31 localities along these coasts a total of 81 field gamma-ray spectrometric determinations were made. Laboratory gamma-ray spectrometry was done on 91 samples taken at the sites of the field measurements. On the basis of these measurements and general geologic considerations, the data can be conveniently divided into the following four suites: (1) Those beaches to the west of the Mississippi River. (2) Those beaches to the east of the Mississippi River. (3) Those beaches of the south Atlantic Coast from northern Florida to North Carolina. (4) Those beaches of the north Atlantic Coast from Virginia-to Cape Cod, Massachusetts. The highest average was from Suite 3, which consisted of 41 samples, averaging $11 \mathrm{ppm}$ thorium, $4 \mathrm{ppm}$ uranium, and $0.2 \%$ percent chemical potassium. The lowest averages were for the 19 samples from Suite 2, averaging $0.86 \mathrm{ppm}$ thorium, $0.41 \mathrm{ppm}$ uranium, and 0.046 percent chemical potassium. Suites 1 and 2 averaged 2.07 and $2.78 \mathrm{ppm}$ thorium, 0.84 and $0.8 \mathrm{ppm}$ uranium, and 1.17 and 0.31 percent potassium, respectively. A Th/ll ratio of 2.8 is most frequentiy observed and the field and laboratory determinations agreed to within \pm 10 percent of the amount present on the average. The 100-fold larger system measured with the field instrument is considered to be more representative. Thorium above about $2 \mathrm{ppm}$ and uranium above about $0.8 \mathrm{ppm}$ is generally carried in rare resistate minerals such as zircon and monazite, but most samples fell, in the range of 1 to $2 \mathrm{ppm}$ thorium and less than 0.8 ppm uranium. Theoretical arguments suggest that the mean concentration is far above this mode, with considerable percentages (15 to 20\%) of the thorium in sedimentary rocks occurring in thin, dispersed placer concentrations of monazite and zircon sand. (auth)

Mahdavi, A. 1964. The Thorium, Iranium, and Potassium Contents of Atlantic and Gulf Coast Beach Sands. IN: Natural Radiation Environment. pp. 87-114.

Using 81 field stations and 91 laboratory samples, gamma spectrometric measurements were made on the $T h, U$, and $K$ contents in beach sands from the Atlantic and Gulf Coasts. The field measurements showed that the contents could be determined to less than 10\%. The results show that: Th above $1-2 \mathrm{ppm}$ and $U$ above 0.3-0.6 ppm are contained in dense resistate minerals. Most beaches have a Th/U ratio of 2.5 to 3 , with only two beaches (Galveston Island and Cape Cod) having a ratio near the crustal average of 3.8. The contents in several cases can be related to provenance and beach processes. Calculated Th and $U$ contents of sands defined geochemically are ton high compared with the experimental dald. (NSA)

Malyshev, V. I., Y. V. Sharkov, and Z. A. Sokolova. 1971. Use of Isotopic Analys is to Study Weathering and Halo Formation in Various Uranium-Bearing Areas of the Mountaintaiga Zone. Poiski Uranovykh Mestorozhd. Uslovivakh Gorn. Taigi. pp. 39-55 (in Russian). 
The redistribution of radioactive elements occurs in areas of oxidized ores with relatively sufficient amounts of $238 \mathrm{U}$, excess Th, and a high $\mathrm{Ra} / \mathrm{U}$ ratio. The presence of vertical and horizontal zoning in secondary 1ithochemical haloes of placer deposits are detected by isotopicanalysis of natural radigactive elements. $\mathrm{U}$ and $\mathrm{Ra}$ contents and ${ }^{234} \mathrm{U} /{ }^{238} \mathrm{U},{ }^{230} \mathrm{Th} /{ }^{238} \mathrm{U}$, $\mathrm{Ra} / \mathrm{U},{ }^{228} \mathrm{Th} /{ }^{232} \mathrm{Th}$, and ${ }^{228} \mathrm{Th} /{ }^{230} \mathrm{Th}$ ratios of rocks and waters in the mountain-taiga zone are given. (CA)

Manheim, F. 1961. Geochemical Profile in the Baltic Sea. Geochim. et Cosmochim. Acta. 25:52-70.

The relationship between depositional environment and element distribution in central Baltic sediments was investigated by means of chemical computation, $\mathrm{pH}, \mathrm{E}_{\mathrm{H}}$, chlorinity, and temperature determinations. Central Baltic sediments show an unusually short, basinward transition from coarse oxygenated sediment to fine stagnant sediment. This is because of the salinity stratification of the Baltic Sea and the permanent 0 deficit found in deeper layers. Sapropelic sediments with $\mathrm{H}_{2} \mathrm{~S}$ and high organic contents occur in the deeps, where overlying $\mathrm{H}_{2} \mathrm{~S}$-bearing water is stagnant and lacks 0 . Gyttjas (gray-green organic mucks) with or without $\mathrm{H}_{2} \mathrm{~S}$ form in quiet areas, where some 0 renewal takes place in the water. A pH of 7 or less, and lower $\mathrm{pH}$ in the sediment than in the overlying water are characteristic of $10 \mathrm{w}$-carbonate $\left(<0.1 \% \mathrm{CO}_{2}\right)$ sediments, while higher $\mathrm{pH}$ values are found in sediments of higher carbonate contents. Heavy trace metals, such as $\mathrm{Cu}, \mathrm{Ag}, \mathrm{U}$, and Mo are concentrated in the sapropels. Maximum enrichment, Mo possibly excepted, occurs at the peripheries (transition zones) of the stagnant basins. Owing to coprecipitation, Mo follows $\mathrm{Fe}$ sulfides. Maximum $U$ content found in the Baltic is $130 \mathrm{~g} / \mathrm{ton}$, which is not consistent with the hypothes is of Koczy, et a1. (CA51, 7979f). Direct precipitation, coprecipitation, or adsorption from water is indicated, not organic complexing. Mn-Fe nodules occur in a peripheral region of aerated bottom water under moderately reducing sediment conditions. The sediment is apparently the source of the $\mathrm{Mn}$ and $\mathrm{Fe}$, which are soluble in the interstitial, but not in the overlying waters. The concretions differ from deep-sea nodules in their lower trace-element contents. Unusual, Mnenriched (up to $5.2 \% \mathrm{MnO}$ ), sapropelic sediments were found in two.Baltic deeps. A mixed $\mathrm{Mn}^{-\mathrm{CaCO}_{3}}$ mineral, approximately $\left(\mathrm{Mn}_{72} \mathrm{Ca}_{16} \mathrm{Mg}_{12}\right.$ ) carbonate, and structurally suggestive of rhodochrosite, is apparently the carrier. (CA)

Marei, A. N. 1962. Significance of the Bottom Bed as a Regulator of the Specific Radioactivity of Basin Water. Radiats. Gigiena Sb. 2:36:41.

An intense sorption of radioactive substances by the bottom layer and by the hydrobiont occurred, together with contamination of the water, during the delivery of radioactive substances into a basin. Under similar con-. ditions the contamination of the bottom layer depends on its composition. If the layer consists of mud or dense clayey soils, $U$ long-lived decay 
products can penetrate $25-30 \mathrm{~cm}$. Most of the radioactive isotopes are concentrated in the upper $15 \mathrm{~cm}$. Relatively high concentrations of radioactive substances were observed at $1.5 \mathrm{~m}$ depth when the bottom layer was peat. In sand, radioactive substances are present below $1.5 \mathrm{~m}$ depth. The distribution of isotopes in the basin bottom is similar to that in soils. (CA)

Masuda, K. and T. Yamamoto. 1971. Studies on Environmental Contamination by Uranium. II. Adsorption of Uranium on Soil and Its Desorption. $\mathrm{J}$. Radiat. Res. 12:94-9.

Experimental studies on the behavior of uranium on soils were carried out using three kinds of soil; volcanic ash, alluvial, and sandy soils. The results showed that uranium dissolved in water ( 1 to $100 \mu \mathrm{g}$ as $\mathrm{U} / \mathrm{ml}$ ) was almost completely adsorbed on every soil examined. The desorption of uranium from soil with salt solutions was extremely difficult especially from volcanic ash soil. (auth)

Mazor, E. 1963. Notes Concerning the Genchemistry of Phosphorus, Fluorine, Uranium, and Radium in Some Marine Rocks in Israel. Israel J. Earth-Sci. $12: 41-52$.

Phosphorus, F, U, Ra, Th, and $K$ were analyzed in 38 samples of marine sediments ranging in age from Santonian to Eocene and including phosphorite, diagenetically changed phosphoritic rocks, limestone, chalk, and marl. The abundances of the first four mentioned elements were found to be in constant ratios, although the $\mathrm{P}_{2} \mathrm{O}_{5}$ content varied from less than 1 up to $33 \%$. There seems to be essentially one kind of phosphate mineral in all the samples, its $F$ to $P$ ratio being that of a carbonate-fluorapatite. The radioactive equi librium of the $U$ and $R a$ indicates that the apatite has not been disturbed by weathering processes for at least the last 10,000 years. A11 the above geochemical relation agree well with data published on phosphorites in other parts of the world. The carbonate-fluorapatite in the samples of the Senonian Mottled zone formation and in the ferruginous phosphorites, accompanying the Companian-Eocene unconformity in the Ramon area, was not affected by diagenetic processes. (auth)

Menzel, R. G. 1968. Uranium, Radium, and Thorium Content in Phosphate Rocks and Their Possible Radiation Hazard. J. Agr. Food Chem. 16:231-34.

A survey of phosphate rock samples from all major phosphate producing areas of the world showed that phosphate rocks from Florida, the main source of fertilizer phosphates in the United States, ranked relatively high in content of uranium, radium, and thorium. In areas where crops are fertilized with high rates of phosphate from Florida, the addition of uranium and radium may equal the amounts occurring naturally in the plow layer of soils, but the addition of thorium would be less than the amount occurring naturally. The radiation hazard, which might result from uptake of radium into food plants, appears to be negligible. (auth) 
Mihalik, P. 1968. Uranium Compounds in the Dominion Reefs, and Their Association With Phosphorus Compounds. NIM-415.

Nine samples of uranium ore from the Bramley Shaft of the Dominion Reefs Mine were investigated mineralogically and with the electron microprobe to find the cause of the poor leaching characteristics of a fraction of the uranium minerals. The investigation, which is at present still in its preliminary stage, has shown that, in samples that exhibit good leaching characteristics, uranium is generally not intimately associated with phosphorus compounds, whereas the converse is generally true of samples having poor leaching characteristics. The existence of a number of hitherto unknown uranium minerals is also indicated, and it is suggested that they may contribute to the refractory nature of some of these uranium ores. (auth)

Mishra, U. C. and S. Sadasivan. 1971. Natural Radioactivity Levels in Indian Soils. J. Sci. Ind. Res. 30:59-62.

$\gamma$-Spectrometry for ${ }^{232} \mathrm{Th},{ }^{238} \mathrm{U},{ }^{226} \mathrm{Ra}$, and $\mathrm{K}$ in 35 Indian soils agrees with chemical methods. An average dose of $41.7 \mathrm{mR} / \mathrm{yr}$ is distributed: Th 14.0 , $U$ 7.4, and $K$ 20.3. (CA)

Miyake, Y. 1955. Recent Problems in the Chemistry of the Ocean. Kagaku ho Ryoiki. 9:3-8.

A review on the behavior of uranium, ionium, and radium in the ocean, and the measurement of organic production in the sea with $C^{14}$. (CA)

Miyake, H. and M. Michijima. 1972. Nonequilibrium Among Thorium-Series Radionuclides in the Sediments Around a River Mouth. Radioisotopes. 21:74-9 (in Japanese).

The distrubution of ${ }^{228} \mathrm{Th}$ and ${ }^{228} \mathrm{Ra}$ concentrations in the sediments were studied by high-resolution $\gamma$-ray spectrometry with a $G e(L i)$ detector without chemical treatment of the sample. The activities of the nuclides were determined from the activities of their daughters $(212 \mathrm{~Pb}, 208 \mathrm{~T} 1$, and ${ }^{228} \mathrm{Ac}$ ). Samples containing monazite sand of known activity were used as the standards in which the Th-series radionuclides were in equilibrium. The radionuclides were mostly accumulated in a narrow band stretching along the stream from the river. The activity ratios of ${ }^{228} \mathrm{Th}$ to ${ }^{232} \mathrm{Th}$ were also measured by a-ray spectrometry with a double grid ionlzation chamber. The results show the fractionation effect around a river mouth due to the difference of chemical properties between Th and Rd in sea water. (CA) 
Miyake, Y., K. Saruhashi, Y. Katsuragi, T. Kanazawa, and Y. Sugimura. 1964. Uranium, Radium, Thorium, Ionium, Strontium 90 and Cesium 137 in Coastal Waters of Japan. "Recent Research Fields of Hydrosphere, Atmosphere and Nuclear Geochemistry." Maruzen Co. Ltd.

Coastal waters collected in Suruga Bay, Japan in 1960 and 1961 were analyzed for $\mathrm{U}, \mathrm{Ra}$, Th, ${ }^{3} 30 \mathrm{Th},{ }^{90} \mathrm{Sr}$, and $137 \mathrm{Cs}$. The $90 \mathrm{Sr}$ content in the marine organism, Sergetes lucens Hansen, was also measured. Data are presented in tables and graphs values for $90 \mathrm{Sr}$ varied from $0.04 \pm 0.03$ to $0.48 \pm 0.04 \mu \mu \mathrm{C} / 1$ and for $137 \mathrm{Cs}$ from $0.62 \pm 0.12$ to $1.20 \pm 0.36 \mu \mu \mathrm{C} / 1$. The value of $90 \mathrm{Sr}$ in the marine organism was $0.1 \mu \mu \mathrm{C} / \mathrm{g}$ ash. The concentration of uranium in Suruga Bay ranged from 1.6 to $1.8 \mu \mathrm{g} / 1$ at the surface and increased with depth to $5 \mu \mathrm{g} / 1$ near the bottom. The content of radium was 0.3 to $0.6 \times 10^{-13} \mathrm{~g} / 1$ at the surface and $0.5 \times 10^{-13} \mathrm{~g} / 1$ at $1200 \mathrm{~m}$. The content of thorium was 0.6 to $0.9 \times 10^{-7} \mathrm{~g} / 1$ and for 230 Th the values ranged from 2 to $7 \times 10^{-12} \mathrm{~g} / 1$. (NSA)

Miyake, Y. and Y. Sugimura. 1961. Ionium-Thorium Chronology of Deep Sea Sediments of the Western North Pacific Ocean. Science. 133:1823-4.

The rate of deposition of deep-sea deposits collected at depths of 6215 to $8450 \mathrm{~m}$ in the western part of the North Pacific 0cean was estimated by means of the ionium/thorium ratio. The ratio was determinesd by an $\alpha$ spectrometer. Results showed the rate of 0.5 to $0.8 \mathrm{~mm} / 10^{3} \mathrm{yr}$ for the upper 10-cm layer below the sea bottom. (auth)

Miyake, Y., T. Yasujima, and Y Sugimura 1970 , Thorium Concentration and the Activity Ratios $230 \mathrm{Th} / 232 \mathrm{Th}$ and $228 \mathrm{Th} / 232 \mathrm{Th}$ in Sea Water in the Western North Pacific. Nippon Kaiyo Gakkaishi. 2:130-6.

The concentration of thorium isotopes and the activity ratios of $230 \mathrm{Th} /$ ${ }^{232} \mathrm{Th}$ and ${ }^{228} \mathrm{Th} /{ }^{232} \mathrm{Th}$ in seawater collected in the Kuroshio region, the mixing area of Oyashio and Kuroshio, the Japan Sea and the East China Sea in the western North Pacific were determined. Thorium isotopes were analyzed by a-ray spectrometry after separating them with an anion exchange restn. The average content of thorium (232 Th) of $2,2 \times 10^{-9} \mathrm{~g} / 1$ was obtained in the open Pacific waters. The ratio of $230 \mathrm{Th} / 232 \mathrm{Th}$ is in agreement with that of the top layer of the sediment in the same area. The high values of $228 \mathrm{Th} /{ }^{232} \mathrm{Th}$ ratio up to 36 were observed in seawater. The excess $228 \mathrm{Th}$ in seawater may be due to the migration of $228 \mathrm{Ra}$ through the water-sediment interface. Thorium content in suspended matter was 10 to $20 \%$ of the total thorium content in the Pacific water. (auth)

Mizuno, A. and T. Mochizuki. 1970. Distribution of Uranium in the Sediments From San'in Off-Shore, Southwestern Japan. Chishitsu Chosasho Geppo. 21:287-92 (in Japanese). 
The distribution of $U$ in the sediments and its relation to the mud, clay, and $C$ contents were studied. The very fine-grained or muddy sands in the Miho Bay contain on the average $1.8 \mathrm{ppm} U$. An off-shore progressive increase of $U$ contents is observed; in the sand of the shelf area $(0.98$ ppm U), the clayey silt of outer shelf and upper slope (2.2), and the silty clay of slope (3.1). The abundance of $U$ in the sediments agrees with the general tendency in sea area. U contents are in direct proportion to mud or clay contents, but no regular relation is found between $U$ and $C$ contents. $U>5 \mathrm{ppm}$ (maximum $8 \mathrm{ppm}$ ) is found in the horizon $>30$ $\mathrm{cm}$ from the top of core, in which the relation between $U$ and $C$ contents is quite different from that of surface sediments. (CA)

Mizuno, A., S. Sekine, J. Nakazawa, A. Takaku, K. Onodera, and M. Ono. 1969. Uranium Concentration in the Bottoms of the Lakes Shinji-ko and Naka-umi, With Special Reference to Its Genetic Relation With the Sedimentary Environment. Chishitsu Chosasho Hokoku. No. 232:317-52 (in Japanese).

The bottom areas of the lakes Shinji-ko and Naka-umi, along the San'in coast of Japan Sea (mainly oligohaline and polyhaline brackish lakes, respectively), are divided into three sections with respect to the $U$ content. The first contains the lower content of $U(1-3 \mathrm{ppm})$, represented by coastal sandy bottoms of both the lakes and the channels, and of the Ohashi-gawa and Sakai-Suido rivers. The second contains an intermediate content (4-5 ppm U), which is widely developed in the muddy bottoms of both lakes. The last contains the higher content (6-11 ppm U), only occurring in the muddy part of the Yonago Bay of Naka-umi. The tentative conclusions as to $U$ distribution in the bottoms of the lakes are as follows: In the sections of lower and intermediate $U$ content, $U$ probably exists in fine-grained minerals such as zircon, derived from granitic rocks. On the other hand, a portion (1-6 ppm) of the $U$ contained in the section of higher $U$ content was probably derived from the lake water containing $2.8 \gamma \mathrm{U} / 1$ (maximum) by direct precipitation and (or.) coprecipitation with organic and inorganic colloids, controlled mainly by $\mathrm{pH}$ and $\mathrm{E}_{\mathrm{H}}$ conditions. (CA)

Mo, T., A. D. Suttle, and W. M. Sackett. 1973. Uranium Concentrations in Marine Sediments. Geochim. et Cosmochim. Acta. 37:35-51.

A direct proportionality was observed between the percentage of organic $C$ and $U$ in sediments deposited in an anoxic environment in the Pettaquamscutt River in Rhode Island with concentrations of organic C 7-14\% and U 7-30 ppm. A similar relation was found in cores of sediments deposited on the Sigsbee Knolls in the Gulf of Mexico. For Mn nodules a direct relation was found between $\mathrm{U}$ and $\mathrm{Ca}$ concentrations, and both decrease with increasing depth of deposition. For nodules from $4500 \mathrm{~m}$ in the Pacific, concentrations are $3 \mathrm{ppm} U$ and $0.3 \% \mathrm{Ca}$ compared with $14 \mathrm{ppm} U$ and $1.5 \% \mathrm{C}$ at $1000 \mathrm{~m}$. Relatively high $U$ concentrations were observed in carbonates deposited in the deepest parts of the Gulf of Mexico, with the $>88$ ॥ carbonate fraction in Sigsbee Knoll cores having $\leqq 1.20 \mathrm{ppm}$. (CA) 
Moore, G. W. 1953. Extraction of Uranium From Aqueous Solution by Coal and Other Materials. TEI-235.

Since $U$ in nature is commonly associated with carbonaceous material, laboratory studies were conducted to determine the relative ability of various types of carbonaceous material and some other substances to remove $U$ from solution. The results of these experiments indicate that the low rank coals are more effective in extracting $U$ than any of the other materials used. A chemical determination shows that nearly $100 \%$ of the available $U$ in solution is removed by subbituminous coal. The $U$ is apparently retained in the coal by an irreversible process. The notable affinity of $U$ for coalified plant remains suggests that some $U$ deposits may have been. formed nver a long period of time by the extraction of $U$ from dilute groundwater solutions. A possible application of the results of this work may be the extraction of $U$ by coal from natural water or from waste solutions from $U$ processing plants. (auth)

Moore, W. S. 1967. Amazon and Mississippi River Concentrations of Uranium. Thorium, and Radium Isotopes. Earth Planet. Sci. Lett. 2:231-4.

Concentrations of uranium and thorium series isotopes were measured in two large samples of river water and associated sediment. From these data an oceanic residence time for uranium of 4 million years is calculated. The concentration of ${ }^{232} \mathrm{Th}$ in these rivers is an order of magnitude greater than in surface Atlantic waters. The amounts of $230 \mathrm{Th}$ and $226 \mathrm{Ra}$ being supplied to the ocean directly from rivers are less than $4 \%$ of that coming from other sources. (auth)

Murelra, L. and C. Lalou. 1972. Experimentạl Study of the Ration $234 \mathrm{U} / 238 \mathrm{U}$ In Natural Waters Having Passed Through Different Types of Rocks. An. Acad. Brasi1. Cienc. 44:13-18 (in French).

Alpha spectrometry measurements of the ratio $234 \mathrm{U} / 238 \mathrm{U}$ and of uranium-238 content were made in water samples prepared by percolating through various kinds of rocks. Uranium content in the same rocks was measured by gamma spectrometry. The uranium-238 content found in water samples seems to be a function of the soluble uranium fontent in the rock, and for this reason, of its state of weathering. The $234 \mathrm{U} / 238 \mathrm{U}$ ratio in the water samples after percolation is in general greater than one, which proves the greater solubility of uranium-234 in nature. A greater radioactive disequilibrium was found in water samples after percolating igneous rocks than after percolating sedimentary rocks. (auth)

Morozov, V. I., E. N. Nevesskii, S. S. Petrusev, and Y. P. Fedorovskii. 1969. Radiometric and Spectrometric Analyses of Bottom Sediments on Board the Ship. Okeanologiya. 9:522-7 (in Russian). 
The natural radioactivity of bottom sediments from some shelf areas of the Black Sea was measured with low-background radiometric and spectrometric devices. An interrelation between granulometric and material composition of sediments and their total radioactivity was found. Data were obtained on the total radioactivity and the amount of separate isotopes in the nearestuarine zones of some rivers; Kuban, Mzymta, Shakhe, Bryb, as well as in the vicinity of Gelendzhik and Karadag. For the Kuban near-estuarine area, some data are presented showing the predominant westward migration of silty material supplied by the river. (auth)

Morozova, N. G. 1966. Compilation of a Chart Showing the Contents of Natural Long-Life Radioactive Elements in Estonian Soils. Sb. Nauch. Tr. Est. Sel'.-Khoz. Akad. No. 49:165-81 (in Russian).

The $\mathrm{Ra}$ and Th contents were determined radiochemically in 87 of the most typical soils having different textures. Indexes of the contents of these elements in the soils, and charts showing the Ra and Th in the soils depended on the soil-forming rocks. The range of variation of the contents of these elements in Estonian soils was 3 orders from $10^{-12}$ (for peat soils) to $10^{-9} \%$ (for soddy soils on shale eluvia) for $\mathrm{Ra}$, and 2 orders from $1.3 \mathrm{x}$ $10^{-5}$ (in peat soils) to $1.6 x^{i} 10^{-3 \%}$ (in soddy-alluvial soils) for Th. The maximum concentrations of radioactive elements was in the illuvial horizons of the studied soils. (CA)

Moxham, R. M. 1964. Radioelement Dispersion in a Sedimentary Environment and Its Effect on Uranium Exploration. Econ. Geol. 59:309-21.

The radioelement content of the major part of the southeast Texas Coastal Plain sedimentary sequence falls within a range common for sandstones and shales. Exceptions to the normal limit are mainly in small, widely scattered areas. One anomalous area, however, covers several tens of square miles and contains most of the important uranium deposits. Both mechanical and chemical dispersion of radioelements takes place in the immediate vicinity of the ore deposits, though no attempt was made to extend this local dispersion model to the large, regional gamma radiation anomaly. It is suggested that the point-source concept for sedimentary uranium deposits is unrealistic and that conventional aeroradiometric survey grid spacing can be substantially enlarged without seriously reducing efficiency in uranium exploration. (auth)

Murray, E. G. and J. A. S. Adams. 1958. Thorium, Uranium, and Potassium in Some Sandstones. Geochim. et Cosmochim. Acta. 13:260-9.

Nineteen sandstones and sands, including orthoquartzites and placer sands and containing both common and extreme $T h / U$ ratios, were examined by $\gamma$-ray spectrometry (cf. C.A. 52, 11658c), fluorimetric $U$ analys is (C.A. $49,2251 \mathrm{f})$, and $\alpha$-counting. U determinations on the shell fractions of 
the Galveston Island sands showed them to have the same $U$ content as the original samples. The Th and $U$ in many common orthoquartzites are contained almost entirely in the quartz grains. The orthoquartzites have an average and nearly uniform concentration of $0.64 \pm 0.04 \% \mathrm{~K}, 1.7 \pm 0.1 \mathrm{ppm} \mathrm{Th}$, $0.45 \pm 0.005 \mathrm{ppm} U$, giving an average Th/U ratio of $3.8 \pm 0.8$. This ratio may represent an independent determination of the average crystal $\mathrm{Th} / \mathrm{U}$ ratio. It must be concluded that the mean Th content of sandstones can only be estimated as 2-24 ppm. The heavy detrital minerals, zircon and monazite, do not affect concentration ratios except where concentrated in placer sands, when they contain most of the Th and $U$. The modern beach sands studied were in radioactive equilibrium. The data indicate that in many sedimentary basins the near-shore sands are depleted in Th and $U$ relative to deeper-water shales.

$(\mathrm{CA})$

Nascimben, P. 1970. Distribution of Uranium in Some Italian Deposits of Lignite. Ind. Mineraria. 21:1-27 (in Italian).

A survey was conducted on some Italian lignite deposits in order to determine the uranium content and distribution. To this purpose, geological and radiometric field surveys were supplemented by 548 laboratory analyses for $\mathrm{U}_{3} \mathrm{O}_{8}$ in lignite ashes. By means of these analyses, the content of $\mathrm{U}_{3} \mathrm{O}_{8}$ dealing with lignite samples was determined. It was found that about 12,000 tons of $\mathrm{U}_{3} \mathrm{O}_{8}$ are contained in the lignites of some important deposits. About $90 \%$ of this potential is located in the Sulcis area (Sardinia), where the $\mathrm{U}_{3} \mathrm{O}_{8}$ content (in lignites and in ashes) is substantially higher than that found in the other major lignite deposits. Because of the low $\mathrm{U}_{3} \mathrm{O}_{8}$ content found in the examined samples, none of the Italian lignite deposits can be regarded as uranium-bearing formations. Furthermore, at the present state of technological progress, uranium extraction from the ashes, as by-product of lignite burning, is not feasible, because of the high cost of chemical processing and the limited quantities of ashes available for treatment. By means of statistical analyses of the analytical data and geological surveys of the deposits it was possible, moreover, to determine which type of lignite is the most favorable for uranium as well as to advance hypotheses on source and accumulation to explain the occurrence for uranium in Italian lignite deposits. (NSA)

Naumov, G. B. 1961. Some Physico-Chemical Peculiarities of Uranium Behavior in Hydrothermal Solutions. Geokhimiya. No. 2:115-32 (in Russian).

The most typical components of uranium-containing hydrotherms are carbon dioxide, silicic acid, fluorine, and sulphur; the most typical cations are alkaline metals. A study of uranium behavior showed transport in the form of complicated complex ions, among which the carbonate and the fluoride ions are the most probable. Thc processes of complex formation provide a reliable transport of hexavalent uranium under conditions where $\mathrm{UO}^{+}$is reduced to $\mathrm{UO}_{2}$. On the basis of an analysis of the behavior of complex uranium ions; the principle causes of nasturan deposition were traced. (auth) 
Nikiforova, E. M. 1969. Redistributions of Thorium and Radium in Transbaikalia Topologies and Their Significance on Prospecting for Ore Deposits by an Airborne $\gamma$-spectrometric Method. Mikroelem. Landshaftakh Sov. Soyuza. p. 139-57 (in Russian). Ed. M. A. Glazovskaya Izd. Mosk. Univ. MOSCOW, USSR.

The processes of weathering and soil formation promote the removal of Th and $\mathrm{Ra}$ and their accumulation in the topologies. A geochemical relation exists between the content of radioelements in the original rocks and in the local topologies. The accumulation of $R a$ and Th in humus, illuvial, and peaty horizons of soils indicate the presence of their soluble compounds in the corresponding topology and the participation of both Th and $\mathrm{Ra}$ in the biological circulation. Trees contain higher amounts of radioelements when compared with grasses. (CA)

Nikolaev, D. S., V. M. Drozhzhin, K. F. Lazarev, and 0. P. Korn. 1969. The Geochemical Balance of Radioactive Elements in the Basin of the Black and Azov Seas. II. Reserves of Thorium Isotopes. Radiokhimiya. 11:688-98 (in Russian).

The concentrations of thorium and ionium (thorium-230) were determined in the water and suspensions of the main rivers in the basin of the Black and Azov Seas. On the basis of the data obtained, the main elements of balance and the reserves of thorium and ionium in the Black and Azov Seas were determined. The amounts precipitated in deep and shallow water zones in the Black Sea annually are 143 and 691 tons of thorium and 19100 and $10400 \mathrm{~g}$ of ionium. It was calculated that the residence time of thorium in the aqueous phase is 56.5 years for the Black Sea and 160 days in the Azov Sea; for ionium the values are 365 years and 172 days, respectively. (auth)

Nikolaev, D. S., E. I. Efimova, A. I. Il'in, and I. I. Shurko. 1973. Determination of Absolute Age and Sedimentation Rate of Bottom Deposits by an Ionium-Thorium Method. Geokhimiya. No. 2:279-83 (in Russian).

Radiochemical study of bottom deposits (two samples taken from Guinea Bay in the Atlantic Ocean) is described. Distribution of Ra and ${ }^{230} \mathrm{Th}$ as a function of deposit depth does not agree with the element decay. The concentration of ${ }^{232} \mathrm{Th}$ increase irregularly with depth. Abstract age and sedimentation rate of bottom deposits are calculated from the experimentally determined ${ }^{230} \mathrm{Th} /{ }^{232}$ Th ratio, wlitich decreases with the sediment depth. Experimental error in the geochronological study of bottom deposits by the ${ }^{230} \mathrm{Th} /{ }^{232} \mathrm{Th}$ method are discussed. (CA) 
Nikolaev, D. S., K. F. Lazarev, 0. P. Korn, M. I. Yakunin, V. M. Drozhzhin, and A. G. Samartseva. 1965. Isotopic Composition of Uranium in the Waters and Sediments of the Black and Azov Seas. Dok1. Akad. Nauk SSSR. 165: 187-9 (in Russian).

Alpha-spectrometric examinations of uranium separated from the waters and the bottom sediments of the B lack and Azov Seas indicated an enrichment of $234 \mathrm{U}$ in the samples. The ${ }^{234} \mathrm{U} / 238 \mathrm{U}$ values found were 1.10 to 1.28 for the waters and 0.89 to 1.20 for the sediments, in general somewhat higher than the value of 1.15 quoted for the ocean. This may reflect a different age and geochemical history of the waters. The preferential leaching of the daughter $234 \mathrm{U}$ from the rock-forming minerals in comparison with the mother element, $238 \mathrm{U}$, may occur. The degree of enrichment depends on various factors, including the chemical composition of the liquid and solid phases, disintegration of the latter, and time of contact. For the studies the uranium was separated from the waters by precipitation with iron hydroxide from samples of up to 580 liters and from the sediments by acid or bicarbonate leaching. (NSA)

Noakes 3. E., I. R. Supernaw, and L. K. Akers. 1967. Anomalies in the 230 Th/232 Th Activity Ratio in Some Mississippi River Sediments. J. Geophys. Res. 72:2679-82.

Unusually high ${ }^{230} \mathrm{Th} /{ }^{232} \mathrm{Th}$ activity ratios have been found in the fine sediment deposits of the Mississippi River in the Greenville, Mississippi area. The ratio was approximately 4.0 during 1963 in this area, whereas a ratio of 1.0 or less was found in May 1965. The 1.0 value seems to be the natural background value for the entire valley. It is postulated that a natural source for this anomaly is unlikely. (auth)

Osburn. W. S. 1965. Primordial Radionuclides: Their Distribution, Movement, and Possible Effect Within Terrestrial Ecosystems. Health Physics. $11: 1275-1295$.

Volumes of data regarding the static and dynamic distribution of primordial radionuclides and their possible effect on biota are scattered through the literature of a number of disciplines. This paper briefly summarizes the world-wide distribution of these naturally occurring radioactive materials and provides a more detailed account of their occurrence and movement within specific ecosystems. General pathways of nuclide distribution and sites of concentration are pictured by tracing radioactive substances from the long-lived primary material to the inactive end product. This tracing includes major environmental and biological transport mechanisms to which radionuclides are subjected during the course of their life span. Thus, the biology of these naturally occurring nuclides is reviewed. The ecological life history of various plants and animals are outlined and the radiosensitivity of the various stages are considered. Where stages of high radiosensitivity are coincidental with exposure to relatively high levels of background radiation, possible biological effects are discussed. Special attention is given to the interaction of ionizing radiation with other environmental stresses. (auth) 
Osmond, J. K. 1964. The Distribution of the Heavy Radioelements in the Rocks and Waters of Florida. IN: The Natural Radiation Environment. Univ. of Chicago Press. pp. 153-9.

The anomaly of low Th and $U$ contents in sedimentary rocks as compared with igneous rocks is discussed. A program was initiated to study the distribution of the heavy radioelements in the sedimentary rocks and waters of Florida. Alpha pulse-height analys is was used, and some preliminary data are given on the distribution of Th and $U$ in the sedimentary rocks. An attempt was made to calculate the average $T h$ and $U$ contents in Florida rocks; they were found to be very sensitive to the estimated abundance of phgsphorite beds and black sands. Data are also presented on the Th, $U,{ }^{224} \mathrm{Ra}$, and ${ }^{226} \mathrm{Ra}$ contents of several surface and underground waters. (NSA)

Otgonsuren, 0., V. P. Perelygin, and G. N. Flerov. 1969. Search for Transuranium Elements in Iron-Manganese Nodules. Dok1. Akad. Nauk SSSR. 189: 1200-3 (in Russian).

Iron-manganese nodules have a number of advantages compared to other sources in the search for superheavy elements. The nodules are selective absorbents of a number of heayy elements such as $\mathrm{Pb}, \mathrm{Tl}, \mathrm{Hg}$, and $\mathrm{W}$ with enrichment coefficients of $10^{5}$ to $10^{6}$ as compared to ocean water. The age of the nodules varies from a few hundred thousand to millions of years. The heavy element content in the nodule is protected from fission by cosmic rays. Nodule inclusions of organic and mineral origin can serve as fission product detectors in principle. Nodules collected from the bottom of the South Pacific 0cean were examined for fission product tracks under a microscope after etching with hydrofluoric acid. The observed track density was greater than could be accounted for by the uranium content and age of the nodules estimated by various methods. This difference could be due to the absorption of heavy elements, but the evidence is not conclusive. (NSA)

Ovchenkov, V. Y. and D. M. Rubstov. 1972. Content of Radioactive Isotopes of the Uranium and Thorium Series in Soils. Radioekologicheskie Issledovaniya $\vee$ Priodnykh Biogeotsenozakh./Verkhovskaya, I.N. (ed.) Izdatel'stvo Nauka. p. 86-94 (in Russian).

Investigations of the radioisotope composition of soils in region with a high natural radiation background showed that the soils of sites with a high radiation level differ sharply from control sites in regard to their content of radioisotopes of the uranium and thorium series. A feature common to all the soils investigated is the presence of thorium in concentrations exceeding by 1.5 to 3.5 times the mean thorium content in the soils of the Russian plain. On the basis of this character, the region investigated may be recognized as a geochemical province. A high content of radioactive isotopes (with the exception of thorium) is found mainly in 
the 0 to $25 \mathrm{~cm}$ layer. The soils of radium sites contain high (as compared with the state of radioactive equilibrium with Th) amounts of MsTh ${ }_{1}$, RaTh, ThX. Uranium-radium sites have a high uranium, radium, and thorium content in the upper horizons. At a depth of 25 to $125 \mathrm{~cm}$ (radium sites), a radioactive equilibrium is observed in the thorium series up to RaTh. The lower radiation level in radium sites is accounted for not only by the migration of isotopes but also by the decrease of RaTh and MsTh 1 in the process of radioactive decay. (auth)

Pak, A. I. 1974. Epigenetic Zoning and Genesis of Uranium Deposits in Weathering Crusts of Sand-Clay Formations. Metallog. Geokhim. Uzb. P. 48-53 (in Russian).

The weathering crusts formed in the littoral-marine and continental sedimentary rocks have three zones: (a) a surface oxidation zone, (b) a stratal oxidation zone, and (c) a cementation (reduction) zone. Zone(a)has an upper gypsiferous subzone with bypsum $\leq 80 \%$, Mn oxides, and carbonates and silicates of $U$; a middle subzone of fractured rocks with goethite, hydrogoethite, gypsum, $\mathrm{Mn}$ oxides, and $\mathrm{CaCO}_{3}$; and a lower, mottled oxidation subzone with goethite. The rocks in zone (a)were altered by atomic agents and ground waters with positive $E_{H}(250 \mathrm{mV})$, presence of 0 , and content of $U\left(X \times 10^{6}\right)\left(X \times 10^{3}\right) \mathrm{g} / 1$. Zone (b) had three subzones: (1) complete oxidation (of organic matter), with hydrogoethite, hematite, and various supergene minerals including kaolinite, sepiolite, halloysite, and jarosite; (2) reddish brown rock characterized by hydrohematite, goethite-hydrogoethite, and high radioactivity; and (3) mottled nxidation with Fe hydroxides, native $S$, uranophane, etc. Rocks of zone (b) were altered by 0 -containing $(0.2 \mathrm{mg} / 1)$ formation waters containing $U\left(X \times 10^{-5}\right)$, Mo $\left(X \times 10^{-5}\right)$, and $\mathrm{Se}\left(X \times 10^{-4}\right)$ $\mathrm{g} / \mathrm{l}$. Zone $(\mathrm{c})$ has epigene minerals of $U$ oxides; sulfides and carbonates of Fe, Mo, and Sc; quartr, calcile, dolomite, etc. and has subzones, from top to bottom, of $S e, U$, and Mo mineralization. The subzone of $U$ mineralization has pitchblende and sooty uranite associated with Fe disulfides (pyrite, marcacite, and melnikovite).

Pashneva, G. E., T. P. Slavnina, and V. V. Serebrennikov. 1965. Rare Earth and Thorium Content in Soils of Tomsk Region. Izv. Sibirsk. 0td. Akad. Nauk SSSK, No. 4 Ser. Biol.-Med. Nauk. No. 1:48-52 (in Russian).

The concentration of rare earth elements, $Y$, and Th in leached black earth podzolis, turf podzolic, light gray wood, dark gray wood, meta, and river alluvial soils of the tomsk region was determined. The concentration of Th and rare earth elements in the soils depend on the quantity of humus and increases with the increase of the concentration of humus in the soil. The distribution of Th in these soils depends on the development of turf and podzolic processes. The concentration of Th increases in the upper humus-accumulation horizon because of biogenesis and in the alluvial horizon because of the erosion of its eluvial horizon where the concentration of $T h$ is lower than in the $A_{1}, B_{1}$, and $B_{2}$ horizons. The percent 
relation of rare earth elements shows that in the soils studied the rare earth elements of a cerium group predominate, with the exception of turf podzolic and light ray wood soil which have a comparatively high concentration of Er. (auth)

Pashneva, G. E., T. P. Slavnina, and V. V. Serebrennikov. 1965. Rare Earth Elements, $Y$, and Th in Biosphere and Soils. Tr. Tomsk. Gos. Univ., Ser. Khim. 185:44-50 (in Russian).

The rare earth (RE) elements and Th were determined in the principal soils of the Tomsk region. The soil samples were taken from genetic horizons of sections up to a depth of $2 \mathrm{~m}$. A total of 44 samples from 7 sections was studied. The soils were all virgin ones. In leached-out chernozem and meadow soil with high Fe content the greatest amounts of humus were found, namely, 8.43 and $10.31 \%$, respectively. In podzol soil only $1.32 \%$ humus was found. The content of RE elements increases with humus content. An exception is meadow soil with increased Fe content. In those soils where the biogenesis plays a great role, an increased Th content is found in the upper horizons with a gradual decrease with depth. Eluvial soils which are characterized by the loss of the products of soil formation are distinguished by a reduced Th content. In the illuvial soils an accumulation of Th is found. Th accompanies mobile humus. The principal mass of the RE elements in the soils studied is made up of the Ce group. Only in some cases there is an increased $\mathrm{Er}$ content. The $Y$ content in all soils is similar and varies from $2-8 \%$ of the total amount of RE elements. A comparatively high content of $\mathrm{Sm}(23.2 \%)$ is observed in Fe-enriched meadow soil and dark-gray forest soil $(30.4 \%)$. The Ce content in alluvial soil is high $(55 \%)$. The content of $\mathrm{La}$ is 15.2 and of $\mathrm{Nd} 17.1 \%$. Leached-out chernozem is rich in $\mathrm{Pr}$ and $\mathrm{Nd}$ (36.5 and $41 \%$, respectively). RE elements with even numbers prevail over those with odd numbers. The mother soils differ considerably in the content of the various RE elements. (CA)

Penna-Franca, E. 1967. Radiochemical and Radioecological Studies on Brazflian Areas of High Natural Radiation. NYD-3273-9.

Studies of high natural radioactivity areas included a monazite sand region (Guarapary-Meaipe) and two volcanic regions (Araza and Morodo Ferro). Radium and thorium body burdens and somatic chromosome damage were estimated at Araza. (auth)

Pettersson, H. 1943. Red Clay and Its Manganese Concretions. Göteborgs Högskol. Arsskr. 41:1-52 (in Swedish).

The chemical and physical properties, and the biological, mineralogical and petrological composition of red clay and the Mn nodules found in it are presented. The different theories of the mode of formation of red clay are discussed with special reference to submarine volcanic eruptions, which 
result in the formation of $\mathrm{HCl}$ and the solution of $\mathrm{Ca}$ from the bottom sediments as chloride and bicarbonate. The Ra content of red clay, its origin, and its rate of deposition are further discussed. As an explanation of the surprisingly high Ra content in certain samples of red clay the coprecipitation of Io with $\mathrm{Fe}$ from sea water is thought to be most acceptable. The $\mathrm{Ra}$ content and rate of deposition of the Mn nodules are given. The latter varies from 0.5 to $1.3 \mathrm{~mm}$ in 1000 years for Central North Pacific localities. The source of $\mathrm{Ra}$ in the $\mathrm{Mn}$ nodules is found in the concentration of this element, together with $\mathrm{Mn}$, Fe, and others, from surrounding sediments. The $U$ content of red clay is found to be too low to be the source of Ra present in this sediment. The age and thickness of red-clay deposits are discussed and lines for future deep-sea rcsearch are suygested. (CA)

Pettersson, H. 1949. Exploring the Bed of the Ocean. Nature. 164:468-70.

A preliminary report is given of the extensive results obtained during a 15-month Swedish deep-sea expedition. The data taken include a continuous record of the bottom profile along a nautical course of 20,000 nautical miles and 200 long cores taken from depths between 2,000 and more than 4,000 fathoms. In addition there were obtained more than 400 oscillograms from explosions in depths between 300 and 3,500 fathoms and their echoes (taken with a special ultrasonic echograph), and approximately 4,000 samples of sea water from varying depths, some of them large volume, for uranium and radium analyses. Ten thousand temperature records by reversing thermometers or, in the surface layers, by bathythermographs, are included in the oceanographical data, which were mainly concentrated along cross sections through the equatorial current system. Observations were also made on submarine daylight, in different spectral regions, including the ultra-violet, and on the occurrence of light-scattering particles suspended in the deeper water layers. Special attention was given to the very lowest water layers down to about two fathoms from the bottom. Confirming the results previously obtained from more limited samples, it was found that the uranium content of large-volume samples of sea-water from various localities and depths is fairly constant, varying between limits of 1.0 and $1.6 \mu \mathrm{g} / 1$. The radium content is always considerably less than the theoretical value in radioactive equilibrium with the uranium. The radium content also is found to increase with increasing depth. This deficiency in radium supports the hypothesis of a precipitation of the intervening element, ionium, $\left(\mathrm{Th}^{230}\right)$, to the sea bottom; this would also explain the generally high content of radium in the red clay and in radinlarian ooze. (NSA)

Picciotto, E. E. 1960. Geochemistry of the Radioactive Elements in the Ocean and Chronology of Ocean Sediments. Ciel et terre. No. 3-4 (in French).

A review is presented of the state of research on the radioelements in the ocean and the chronology of ocean sediments. The principles of radioactive methods of age measurement are outlined. Tables are given showing 
the half life, concentration, isotopic abundance, and decay rates for natural radioisotopes in the ocean. The geochemical balance of isotopes in the three radioactive families in the ocean is shown. Data on the radioisotope content of recent pelagic sediments covering great ocean depths where sedimentation is slow are presented and discussed. Finally, chronological methods are discussed including those based on decrease of a cosmogenic isotope, decrease of ionium or protactinium, or increase of ionium and protactinium. (NSA)

Picciotto, E. and S. Wilgain. 1954. Thorium Determination in Deep-Sea Sediments. Nature. 173:632-3.

Determination of $\mathrm{Th}^{227}, \mathrm{Th}^{228}, \mathrm{Th}^{230}$, and $\mathrm{Th}^{232}$ in deep-sea sediments by a photographic method is discussed. Concentration of Th was calculated in samples of red clay from the Pacific 0cean ${ }_{7}$ from 5-branched star production, assuming Th to be in equilibrium with $\mathrm{Th}^{227}$ and ascribing all the 5-branched stars to $\mathrm{Th}^{22}$. The chronology of deep-sea sediments by ionium-Th ratios is also discussed. (NSA)

Piggot, C. S. and W. D. Urry. 1942. Radioactivity of Ocean Sediments. IV. The Radium Content of Sediments of the Cayman Trough. Am. J. Sci. 240: $1-12$.

The radioelements are not in equilibrium in the uppermost layers of the sediments at the bottom of the ocean. Of these elements $U$, ionium and Ra have a sufficiently long half life to be of importance. A history of these three elements is reflected in the variation of the Ra content of ocean sediments with the depth below the ocean floor. Measurements of this variation demonstrate that the concentrations of $U$, ionium and $R a$ at any time are established by the usual laws of radioactivity governing the growth and decay of radioelements in a system that is not in radioactive equilibrium. The experimental results must be adjusted to the conditions that pertained to the undisturbed sediments. This requires a knowledge of the history of the specimens between sampling and analysis. The relation between $\mathrm{Ra}$ content and depth in an ocean sediment promises a method of determining the rate of accumulation of the deposit at that place. (CA)

Pliler, R. and J. A. S. Adams. 1962. The Distribution of Thorium and Uranium in a Pennsylvanian Weathering Profile. Geochim. et Cosmochim. Acta. $26: 1137-46$.

Eleven samples representing a pre-Pennsylvanian weathering profile on the Boulder Creek granodiorite near Boulder, Colorado, were analyzed for thorium and uranium by $\gamma$-ray spectrometric and chemical methods. In an effort to determine the possible sites of thorium and uranium in the samples, a study of their leachability in hot $2 \mathrm{~N}$ hydrochloric acid was undertaken. Fresh granodiorite was found to contain $9.3 \mathrm{ppm}$ thorium 
and 2.5 ppm uranium. The first stages of weathering resulted in an apparent removal of $25 \%$ of the thorium and $60 \%$ of the uranium present in the original granodiorite. The leaching study of the fresh granidiorite demonstrated that as much as $90 \%$ of the thorium and $60 \%$ of the uranium could be removed by an acid leach solution. This seems to indicate that most of the thorium and uranium in the fresh rock is situated in acid soluble minerals or in interstitial materials. After the initial drop of the concentration in the lowest part of the weathered mantle, the total uranium and thorium content of the weathered rock increased by a factor of at least 4 in the uppermost, most-weathered rock material. Leaching studies of the weathered rock indicated that uranium is present largely in the primary resistates, such as zircon, xenotime, and apatite, and thorium occurs mainly in or on clays or in the secondary resistates--minerals formed during weathering. (auth)

Pluman, I. I. 1971. Uranium Content in Black Arqillites of the Volga stagc of the Wesl Slberlan Platform as Criterion of Geochemical Conditions of Sedimentation. Geokhimiya. No. 9:1138-43 (in Russian).

A similarity of geochemical peculiarities and in particular of uranium content has been established between recent deposits of seas with hydrosulfuric contamination (Black Sea, and others) and bituminiferous black argilites of the Upper Jurasic Volga stage of the West-Siberian platform. On this basis it was concluded that the geochemical sedimentation medium is identical with that of the Black Sea, i.e., it is hydrosulfuric in the above-bottom part of the sedimentation basin. (auth)

Pokidin, V. K., Y. V. Kuznetov, E. A Prozorovich, and F. A. Asadullaeva. 1972. Radioactivity and Rate of Sediment Formation in the Caspian Sea. Geokhimiya. No. \%:834-43 (in Russian).

On the basis of data on the vertical distribution of ${ }^{226} \mathrm{Ra},{ }^{23}{ }^{2} \mathrm{Th},{ }^{232} \mathrm{Th}$, and $238 \mathrm{U}$ in sediments of the Caspian Sea and with the aid of the radiumionic method the formation rates of deep-sea and shallow water sediments have been determined, which equal respectively: 6.0 to 26.0 and $100 \mathrm{~cm}$ for 1000 years. The difference of vertical sections of $230 \mathrm{Th}$ and ${ }^{232} \mathrm{Th}$ distribution in deep-sea sedimente of the Caspian sea is shown, which confirms the hypothesis about different forms of supply to these isotopes to the sea bottom. A clnse direct connection between the distribution of ${ }^{230}$ Th and calcium carbonate in deep-sea sediments was established, which bears witness of the sorption character of the ${ }^{230}$ Th withdrawal from water by chemogenic calcite. (auth)

Poole, J. H. J. and J. W. Bremner. 1948. Investigation of the Radioactivity of Rocks by the Photographic Method. Nature. 161:884-5. 
The method employed is to place an Ilford Nuclear Research plate at a distance of about $0.1 \mathrm{~mm}$ from a flat surface of the specimen cut with a diamond saw, and expose it for one to three weeks, depending on the probable activity of the specimen. In more recent experiments the plate has been placed in contact with the cut surface, as this makes easier the identification of $\alpha$-rays tracks, which all originate from one nucleus. Theoretically, from the frequencies of two-, three-, four- and five-ray stars, it should be possible to estimate the separate amounts of uranium and thorium present. Enough data have not yet been obtained to determine whether this method will prove possible. The results of some experiments are reviewed briefly. (NSA)

Poole, J. H. H. and J. W. Bremner. 1949. Investigation of the Distribution of the Radioactive Elements in Rocks by the Photographic Method. Nature. $163: 130-1$.

A method is described for the microscopic study of the distribution of radioactive elements in rocks. A standard microscope slide of the rock to be examined is made, but the cover glass is omitted, so that the $\alpha-$ rays from the rock can affect a nuclear plate placed in contact with the slide. Both slide and plate are placed in a specially constructed brass frame, in which they are held against three definite contacts, so that either slide or plate can be removed from the frame and replaced in the same position. The distribution of the tracks on the developed plate can be correlated with the rock minerals by replacing the rock slide on top of the plate. Polarized light can be used for the identification of the minerals in the usual manner. A composite photomicrograph of a Finland granite is given, showing numerous $\alpha$-ray tracks originating from some of the crystals. The nuclear plate was exposed to the rock slide for about 10 days. The absolute radioactivity of a crystal may be roughly estimated from the number of $\alpha$-particles emitted. (NSA)

Poulaert, G. and S. Zmyslowska: 1958. Application of $\gamma$-Spectrometry for the Measurement of Natural Soil Radioactivity. Roczniki Nauk. Rolniczych. Ser. A. 78:539-51.

The average yalues for the soils investigated are $10^{-6} \mathrm{~g} \mathrm{U}$ and $10^{-5} \mathrm{~g} \mathrm{Th} / \mathrm{g}$ of soil. $\mathrm{K}^{40}, U$, and Th were determined by using an MBLE $\gamma$ spectrometer of the type PN 2.4.3/A, which contains a NaI(T1) crystal. $K$ is present in soils and rocks in average concentrations of $10^{-1} \mathrm{~g} / \mathrm{g}$; the average error of the determinations for $U$ and Th is of the order of $10 \%$, for $K, 20 \%$. This rather large error does not preclude the use of the method for scanning and prospecting purposes, as the results are obtained so rapidly. (CA) 
Prister, B. S. 1970. Behavior of Uranium in the Biologic Chain. A-AC82/G/L-1298: AEC-tr-7128. pp. 194-27.

Field experiments on the accumulation of uranium in basic crops were carried out for three years on a large tract of land. Crops included grains, legumes, root crops, and vegetables. Measurements of the uranium content of the soil were made by extracting uranium with nitric solutions. A formula is presented for determining the coefficient of accumulations, or relative capacity of plants to accumulate uranium. Values for these coefficients are tabulated for grains, legumes, root plants, and vegetables. Data on accumulation of uranium in tissues of chickens and swine are tabulated. Studies on concentration of uranium in dairy products showed that the content of butter and cheese was eight times as great as that of milk. Data on uranium content of the human diet showed that morc than half the uranium reached man through products of vegetable orlgin. rood products of animal origin contributed 28 percent of uranium to man. (NSA)

Prister, B. S. and S. S. Prister. 1970. Effects of Uranium on the Growth and Development of Plants and Its Accumulation as a Function of the Content in the Germination Medium. Radiobiologiya. 10:138-40.

It was found in greenhouse experiments that $U$ at a dose of $200 \mathrm{mg} / \mathrm{kg}$ of sand was nontoxic for plants. For a water culture a $50 \mathrm{mg} / 1 \mathrm{iter}$ dose of $U$ results in death of corn plants on the fourth day. The relation between the accumulation of $U$ by the plants and $i$ ts content in the medium was a decreasing exponential function. With increasing $U$ concentration in the roots, intake into the aboveground portion of the plants decreased. (auth)

Rackley, R. I. 1971. Environment of Wyoming Tertiary Uranium Meposits. Americáll Assn. Petroleum Geologists Bul1. 56:755-74.

Four major uranium districts in Tertiary rocks of central Wyoming are in fluvial sandstones derived from the granitic rock of the ancestral Sweetwater arch and deposited in adjacent intermountain basins. Sediments transported southward into the Great Divide basin was deposited on an apron of alluvial fans. Sedimentation in the Gas Hills area of the Wind River basin was on the alluvial fan in which ridges of older rock disrupled the normai development of the fan. Sediment in west Shirley basin was deposited on an alluvial fan, but in east Shirley basin and in the Powder River bas in sedimentation was channel and flood-basin deposits of a meandering stream. The sandstones are subarkosic to arkosic, medium grained to conglomeratic, angular and poorly sorted. Sandstones intertongue with green or carbonaceous shales. Sedimentation was in a warm, humid climate with abundant vegetation. Decay of the organic material created reducing conditions in the sediment which caused partial carbonization of some of the plant debris, formation of pyrite, and precipitation of uranium minerals. Following burial, upliftinduced changes in the hydrodynamic system caused an invasion of the reduced sediment by oxygenated water far below the static water table. This caused 
destruction of carbonaceous material, oxidation of pyrite, and accumulation of uranium and other susceptible metals in a wave or front just ahead of the invading oxidizing environment. The invading oxidation was a dynamic, expanding process which moved through the permeable zones of the fluvial sequence until its dimensions measured miles in areal extent and hundreds of feet in thickness. This geochemical cell had a sharply defined boundary produced by biochemically controlled changes in physical and chemical conditions. Oxygenated waters, aided by Thiebacillus ferrooxidans, oxidized pyrite to produce sulfuric acid and ferric sulfate, a strong oxidizer, which leached uranium and other susceptible elements. In the reducing part of the cell, anaerobic bacteria, including the sulfate reducer Desulfovibrio, consumed the organic material in the sediments and the sulfide, and a mildly alkaline, strongly reducing environment which precipitated pyrite, uranium, and other metals on the front. Migration of the cell was controlled by the permeability of the sandstone and by availability of carbon and pyrite. The cell advanced faster in the more permeabile zones and was retarded in zones of reduced permeability and areas of greater pyrite and carbon content. The position of the mineral front was a function of the initial sedimentary pattern. Sedimentation, alteration, and mineralization in the Gas Hills and Shirley basin districts illustrated these conditions and processes. (auth)

Rafal'skii, R. P. 1963. Physico-chemical Investigation of Conditions Conducive to Formation of Uranium Ores. Gosatomizdat. (in Russian)

Physicochemical studies were made of the primary mineralization of uraniumbearing deposits. The crystallization of amorphous silica and the mechanism of hydrothermal transformation of silica glass to quartz under isothermal conditions are analyzed. The solubility of U(IV) and U(VI) compounds in aqueous solutions and the reduction of $U(I V)$ and $U(V I)$ by divalent iron, sulfur, sulfur compounds, and other reducing agents are discussed as well as the reduction and precipitation of uranium by minerals. The hydrothermal transport and deposition of uranium are also discussed. (NSA)

Rafal'skii, R. P. and K. F. Kudinova. 1959. Conditions for the Reduction and Precipitation of Uranium by Minerals. Atomnaya Energ. 7:333-7 (in Russian).

It is postulated that primary uranium minerals were precipitated by iron, sulfur, and arsenic reduction of $U(V I)$ present in hydrothermal solutions. Experiments produced crystalline pitchblende, collomorphic uranium powder, and sooty uranium black formed by reduction of $U(V I)$ to $U(I V)$ by acid solutions at 100 to $135^{\circ} \mathrm{C}$. The character of the formation depends upon the precipitator mineral, interaction temperature, and in some cases on the concentration of uranium in solution. (NSA) 
Ragland, P. G. 1964. Autoradiographic Investigations of Naturally 0ccurring Materials. J. A. Adams and W. M. Lowder (eds.) University of Chicago Press. Natural Radiation Environment. pp. 129-51.

An analysis of information obtained by autoradiography of rocks is presented. Suggestions concerning applications of radiographic methods are included. Discussions of distribution of $\alpha$ emitters in constituent minerals are also included along with data on a activity in various rocks. (NSA)

Raikov, L. 1965. Natural Radioactivity of Bulgarian Soils. Rast. Nauki. $2: 31-36$.

Total Bela-padiudctivity ot various soil types and paternal rocks was measured by means. of STS-6 counter. Measurements were made with two cylinders, an outside and inside one. A tritiated soil sample of $150 \mathrm{~g}$ shifted through an $1 \mathrm{~mm}$ mesh sieve, was put in the outside cylinder and in the inside cylinder, the wall of which is a thin paper, and placed in the cylindrical counter. Radioactivity of various soils is expressed in impulses per minute and it varies greatly. Cinnamon forest soils, developed over calcareous rocks, have a radioactivity of about ten impulses per minute, while the radioactivity of brown forest soils, underlain with rhyolites and alluvial and diluvial soils developed over materials originating in acid eruptive rocks attains ten times higher values. Chernozem soils, grey forest, chernosem-smolnitza and podzolic cinnamon soils take a medium position within the extremes pointed out. The radioactivity of nearly all soils investigated was due (in two thirds of the cases) to radioactive potassium. Uranium, thorium and other element groups have a greater participation in the peat-bog and solonetz soils in the region of Plovdiv. Considerably increased radioactivity ( 2 to 3 times) of the 0 to $6 \mathrm{~cm}$ top soil layer was observed in virgin soils of certain mountain areas due to radioactive elements deposited by precipitation. (auth)

Raikov, L. and S. Sapundzhiev. 1966. Natural Radioactivity and Chemical Composition of Iron-Manganese Concretions in Saline and Podzolized Soils. Pochvozn. Agrokhim. 1:327-30 (in Bulgarin).

Concretions in saline soils have a much higher radioactivity than concretions in podzolic, 6-8 times higher than in zonal soils. The radioactivity is due mainly to $U$; its contents are determined in $0-20 \mathrm{~cm}$ meadow-solonchak-snlonets soils with $5.9 \mathrm{ppm}$, in its concretions $>3 \mathrm{~mm} 62 \mathrm{ppm}$ and $<3 \mathrm{~mm} 46 \mathrm{ppm}$ the contents in cinnamon-podzolic soil are in concretions $>3 \mathrm{~mm} 9.2,<3 \mathrm{~mm}$ 6.7 , in such of light-gray mountain soil $4.7 \mathrm{ppm}$. The concretions in solonets contain 10.28-12.59 percent Mn0 vs 0.15-0.16 percent in soil; moreover, 3-4 times more $\mathrm{Fe}_{2} \mathrm{O}_{3}$, and much less $\mathrm{SiO}_{3}$. (CA) 
Rekharskdya, V. M. 1971. Uranium Distribution in Clay Minerals in an Oxidation Zone. Atomic Energy (USSR) 31:61-3 (in Russian).

Argillaceous minerals with an increased $U$ content in the zone of oxidation were examined chemically and physically. The data show that kaolinite and similar minerals collected $U$ in the oxidation zone, and in such zones the most favored areas are those in which iron sulfide has been retained.

Richardson, K. A. 1963. The Radioactivity, Sites of Alpha Emitters, and Radioactive Disequilibrium in the Conway Granite of New Hampshire. Rice University. Thesis.

The radioactivity of the Conway grainite of New Hampshire was studied by $\gamma$-ray spectrometry, autoradiography, and $\alpha$-particle pulse-height analysis, as part of an investigation of the possibility of recovering Th from common rocks. It was concluded that the Conway granite is homogeneous with respect to Th, and the mean Th concentration in the Conway granite of the White Mountain batholith is $56 \pm 6 \mathrm{ppm}$. On this basis, the Conway granite in the White Mountain batholith is considered a low-grade Th resource containing three million tons of Th per hundred feed of depth. Conparison of Th and $U$ concentrations in drill-core samples and in samples taken from outcrops indicates an average $U$ loss of 35 percent from surface samples of Conway granite. Autoradiographic results show that $\sim 2 / 3$ of the $\alpha$ emitters in the Conway granite are concentrated in accessory mineral grains identified as thorite, huttonite, allanite, and zircon. The wide ranges of a activity and the estimated Th concentrations in zircon, thorite, and huttonite suggests that extensive isomorphism exists between zircon and thorite, and that the mineral identified as huttonite is isomorphous between monazite and huttonite. Radioactive disequilibrium in the U-238 series was found in extremely weathered rock, with a U-234 deficiency of about 50 percent. 0ther samples taken from deeper in the drill core and from other outcrops showed an equilibrium ratio between $\mathrm{U}-238$ and $\mathrm{U}-234$. (NSA)

Richardson, K. A. drid J. A. S. Adams. 1963. Fffect of Weathering on Radioactive Elements in the Conway Granite of New Hampshire. (CONF-498-3).

Studies were made on the effects of weathering on thorium and uranium in the Conway granite of New Hampshire. The results showed that weathering processes have leached and isotopically fractionated uranium to a depth of 30 to 40 feet below the surface, and leaching of uranium has occurred at greater depths in the vicinity of joints. This chemical alteration has occurred in rock that does not optically show evidence of weathering. (NSA)

Ritchie, J. C., P. H. Hawks and J. R. McHenry. 1972. Thorium, Uranium, and Potassiuril in Upper Cretaceous, Pateocene, and Eocene Sediments of the Little Tallahatchie River Watershed in Northern Mississippi. Southeast. Geol. $14: 221-31$. 
Size analyses and $\gamma$-ray spectrometric analyses were made of 129 outcrop samples that contained: Th 0.9-29.9, average 8.4 ppm; U 0.3-10.9 average $2.2 \mathrm{ppm} ; \mathrm{K} \mathrm{0}-2.43$, average 0.86 percent; Th/U average 3.8 . The contents of $U$, Th, and $K$ in the sediments increase with decreasing particle size. (CA)

Ritchie, J. C. and G. L. Plummer. 1969. Natural Gamma Radiation in Northeast and East-Central Georgia. Bul1. Ga. Acad. Sci. 27:173-194.

Thorium, uranium and potassium (al1 naturaliy occurring), and beryllium 7 , cesium 137, ruthenium 106, cerium 144, antimony 125, zirconium-niobium-95 and manganese 54 (all from fallout) were found in suil samples collected in northeastern and east-central Georgia. Thorium concentrations ranged from 3 to $70 \mathrm{ppm}$ with an average concentration of $15.8 \mathrm{ppm}$. Uranium concentrations varied from 1 to $10 \mathrm{ppm}$ with an average of $3.7 \mathrm{ppm}$. The average thorium to uranium ratio was $4,3: 1$. Total potassium ranged from nondetertable levels to 4.8 percent with an average of 1.08 percent. Concentrations of thorium and uranium in granitic outcrop soils were the same as non-outcrop soils. Potassium concentrations in granitic outcrop soils were three times that of non-outcrop soils. Cesium 137 concentrations in outcrop soils were ten times greater than that in non-outcrop soils. Although concentrations given in this report cannot be considered as absolute values, they are good estimates of the thorium, uranium and potassium at the particular locations samples and are probably representative of concentrations elsewhere in northeastern and east-central Georgia. Average concentrations of thorium and uranium were higher in the study area than those reportedly found in the worldwide lithosphere and soil. One probable cause for higher concentrations is the occurrence of monozite in the Georgia Piedmont. Commercially mineable uranium ores are usually at least 100 times more concentrated thall dny concentrations found in the study area. Neither uranium nor thorium is dll active metabolite in plants or animals. Although uranium is more ilubile than thorium in soils, neither uranium nor thorium concentrations are high in plant or animal tissues, therefore, they cannot be considered of great importance in ecological food chains. Potassium, on the other hand, is mobile in the soil, and is an active metabolic. Total gamma radiation $(0-2.70 \mathrm{MeV})$ ranged from 560 to $8900 \mathrm{CPM} / \mathrm{Kg} \mathrm{cr}$ a 18 -fold range in activity. Calculated dose rates ranged from 2.25 to $38.30 \mathrm{UR} / \mathrm{hr}$ or a 17-fold range. The average dose rate for the $13230 \mathrm{ils}$ was $10.65 \mathrm{uR} / \mathrm{hr}$. Distribution of thorium, uranium and potassium followed broad geologic patterns. Concentrations of these elements were lowest in the sandy materials of the Coastal Plain and highest in the basic igneous-metamorphic material of the Piedinulit. Otstribution of thorium, uranium and potassium in four soil series was best related to geologic parent material. The Piedmont soils, Appling, Madison and Cecil, had higher concentrations than sandy Norfolk soils of the Coastal Plain. A high correlation $(r=0.88)$ was found between aerial gamma radioactivity and dose rates indicating that gamma aeroradioactiivity maps can be used to delineate areas with different background radiation. (Auth) 
Robinson, C. S. and J. N. Rosholt. 1961. Uranium Migration and Geochemistry of Uranium Deposits in Sandstone Above, At, and Below the Water Table. Part II. Relationship of Uranium Migration Dates, Geology, and Chemistry of the Uranium Deposits. Econ. Geol. 56:1404-20.

Data were obtained from uranium ore samples representing deposits above the water table, deposits just above and below perched water tables, and deposits at least 250 feet below the water table in the Hulett Creek area, Wyoming. The first uranium deposition occurred more than 250,000 years ago for the deposits now at or above the water table. Approximately 60,000 to 80,000 years ago these deposits were oxidized, leached, and locally enriched. Accumulation of uranium in the deposits below the water table probably did not start before 180,000 years ago and has continued to the present. (auth)

Robinson, S. C. 1952. Autoradiographs as a Means of Studying Distribution of Radioactive Minerals in Thin Section. Am. Manual. 37:544-7.

A simple method is described of recognizing those grains in a thin section of rock that contribute to its radioactivity. Thin sections are made without a cover glass and the surface is placed against the emulsion and held there under light pressure for exposure. The specimen and emulsion are then remounted back-to-back to interpose the glass slide between them. The mount is studied under a medium power objective such that the tracks are out of focus when the microscope is focused on the rock slice and vice versa. When the centers of tracks are found, it is only necessary to focus down to the rock slice to identify the mineral that has caused them. (NSA)

Romney, E. M., V. Q. Hale, A. Wallace, 0. R. Lunt, J. D. Childress, H. Kaaz, G. V. Alexander, J. E. Kinnear and T. L. Ackerman. 1973. UCLA-12-916. Some Characteristics of Soil and Perennial Vegetation in Northern Mojave Desert Areas of the Nevada Test Site.

Data were compiled from several interrelated projects conducted at the Nevada Test site as part of a team effort to obtain more information on suil and plant relationships in the desert ecosystem in order to better understand the impact of nuclear testing on the environment. It ties together the masses of acquired data into one convenient volume for use by the funding agency and also to serve as a basis for the continuing systems analysis work involved with these projects. Included are results from the chemical and physical characterization of soil profiles at 79 study sites located in some northern Mojave Desert areas of the Nevada Test Site. These profiles were characterized under clumps of perennial vegetation and under bare desert pavement in order to determine the modifying influence of shrubs on desert soli. Ecological attributes of perennial vegetation determined by nondestructive, dimensional analysis are reported in terms of density, area, volume, and biomass according to the existence of shrubs as solitary plants or as members of a shrub clump. Mineral element compositions of leaves and stems are reported for the 
most common plant species at each study site. Also included are the concentrations of $137 \mathrm{Cs}$, and the natural $40_{K}$ (as total $\mathrm{K}$ ), uranium, and thorium found in the surface fractions of the soil profile. Abiotic data compiled during a five year period from nine sampling stations are reported for rainfall, air temperature, soil temperature and soil moisture. (auth)

Rona, E. 1967. Natural Radioactive Elements in Marine Environment. Final Report. 0RO-2411-8.

A resume of research carried out at the Institute of Marine Sciences from 1960 to 1967 is presented. Before this project started, work on the problem of natural radioactive elements in marine environments was pursued in a somewhat haphazard fashion; it was not until the past decade that concentrated efforts were made to thoroughly study all aspects of the problem. Among the problems given particular emphasis were: chemical balance in the sea; inflow from rivers and deposition into sediments; mechanisms for the removal of the radioactive nuclides and stable trace elements; and determination of sedimentation rates of large areas. The study of the radium distribution in the oceans led to the conclusion that the sediments must be its principal source; emphasizing the importance of the sediment-water to oceanographic problems. One of the foremost interests was the dating of the Pleistocene epoch; theoretical considerations and critical discussions open the way for the successful dating of Caribbean cores to 200,000 years. The enclosed list of papers gives a more comprehensive understanding of the work carried out during this period. (auth)

Rona, E. 1970. Absolute Dating of Ocean Sediments by Use of $230 \mathrm{Th} / 321 \mathrm{~Pa}$ Ratio and Geochemical Studies of Limiting Boundary Conditions with Special Attention to Exotic Environments. Annual Progress Report. 0R0-3622-9.

One deep sea core from the central Caribbean was dated by ${ }^{14} \mathrm{C}$ and $231 \mathrm{~Pa} / 230 \mathrm{Th}$ methods. The ages obtained were in good agreement with the ages previously obtained for other cores. Sediment cores from the Cariaco Trench were analyzed, and a high $U$ concentration was found. Fossil marine carbonates from the Afar depression between Ethiopia and the Red Sea were studied to develop a geochronology of the region. Tenative ages of the deposits are qiven. (NSA)

Rona, E., L. Muse and B. L. Brandau. 1966. Protactinium in Deep Sea Sediments. IN: Physico-Chemie du Protactinium. Centre National de la Recherche Scientifique, pp. 333-8.

A method is presented utilizing protactinium to determine absolute ages of marine sediments. This method necessitates the separation of submicrogram quantities of protactinium in pure form from other elements which are present in the sediments in much higher quantities. The method is given and ages, calculated for a sediment core taken from the Gulf of Mexico, are presented as an example. (auth) 
Rosholt, J. N. 1961. Late Pleistocene and Recent Accumulation of Uranium in Groundwater Saturated Sandstone Deposits. Econ. Geol. 56:423-30.

Protactinium-231 and thorium-230 relations in several groundwater saturated sandstoned containing uranium ore indicate that much of the uranium has been accumulating in very recent times. Samples from the Hauber mine, Crook County, Wyoming, were selected to illustrate the concept of recent accumulation and the methods of calculation of the estimated minimum and maximum dates of the start of the uranium accumulation. The radiochemical results of eight samples from this mine show extremely consistent radioactive daughter product distribution, and a close correlation between the estimated dates of the start of uranium accumulation and the uranium content of the ore. The results for mill pulp samples, representing large tonnages of ore, indicate that the major part of uranium deposition started between 40,000 and 130,000 years ago and the rate of deposition has increased approaching the present time. (auth)

Rosholt, J. N. 1961. Uranium Migration and Geochemistry of Uranium Deposits in Sandstone Above, At, and Below the Water Table. Part I. Calculation of Apparent Dates of Uranium Migration in Deposits Above and At the Water Table. Econ. Geol. 56:1392-1403.

The distribution of the daughter products is determined by radiochemical analyses of samples from ore deposits in sandstone, and the apparent minimum and maximum dates of uranium introduction or redistribution may be calculated from the $\mathrm{Pa}^{231} / \mathrm{Th}^{230}$ ratio. The primary assumption required is that the protactinium and thorium do not migrate in measurable quantities from the place where they were produced by the decay of the parent uranium isotopes. The upper limit of age determination is about 250,000 years, based on the half lives of $\mathrm{Pa}_{2} 231$ and $\mathrm{Th}^{230}$. The difference in the half iives of these isotopes is reflected in their differential rates of growth and decay corresponding to migrations of the parent uranium during the time range considered. The growth and decay patterns, analyzed mathematically, are used to determine the apparent date of uranium migration. Calculations based on analyses of samples from the Hulett Creek area, Wyoming, illustrate the results for typical sandstone ore deposits that are above and at the water table. (auth)

Rosholt, J. N. 1963. Uranium in Sediments. Thesis. University of Miami.

An oceanographic approach is used to study the distribution of abmurinal nc.currences of uranium in sediments. These occurrences predominate in marine phosphorites, black marine shales, and deposils in terrestiralfluvial sandstones and ancient conglomerites. In early Paleozoic times, marine shales accounted for th majority of uranium deposition. By the beginning of tertiary time, the balance had shifted to predominant deposition in marine phosphorites, which continued to the present. Much smaller total quantities of uranium are associated with terrestrial sandstones and ancient conglomerates, although its concerilration is greater and its economic. 
recovery is more feasible. All the abnormal occurrences fit into a unique niche in the hydrologic cycle, and emplacement was largely controlled by cycles of organic substances in water. Radiochemical analyses of $231 \mathrm{~Pa}$, $230 \mathrm{Th}$, and $226 \mathrm{Ra}$ were made on a few hundred samples from sandstone-type uranium deposits. These results, in comparison to the uranium content of samples, indicate that much of the uranium in terrestrial sediments is presently in a slow, continual state of migration toward to ocean. (NSA)

Rosholt, J. N. 1970. Nuclear Methods Applied to Uranium Geochemistry. Trans. Nucl. Sci. NS-17. 1:173-6.

Stable and radioactive daughter products produced from nuclear disintegrations of uranium have proved useful in fundamental studies of the geochemistry of uranium in igncous rock and sedillentary environments and in ore deposits. Information gained from geochemical studies or uranium migration has been used to develop models for attempts to date archeological, geological, and oceanographic environments represented by samples of bone, wood, charcoal, continental and marine carbonates, marine sediments, and glacially derived soils. Recent improvements of nuclear instrumentation and techniques allowed accurate measurements of natural radioactive isotopes, and it is now believed that radioactive equilibrium between the long-lived isotopes of the two uranium decay series is more the exception than the rule in nature. It was assumed that the $234 \mathrm{U}$ and $238 \mathrm{U}$ isotopes were in equilibrium until Thurber confirmed that considerable separation between $234 \mathrm{U}$ daughter and $238 \mathrm{U}$ parent exists in nature. It now has been documented that the $234 \mathrm{U}$ content may range from 60 percent deficient to 500 percent in excess relative to $238 \mathrm{U}$. An excess of 15 percent of $234 \mathrm{U}$ isotope in seawater is well documented. A summary of previous work has shown that geochemical fractionation of the radioactive nuclides in $238 \mathrm{U}$ and $235 \mathrm{U}$ decay series takes place in the hydrologic environment, resulting in depletion of $230 \mathrm{Th}$ and $231 \mathrm{~Pa}$ with rospect to their parents, $238 \mathrm{U}, 234 \mathrm{U}$, and $235 \mathrm{U}$, in water and a compleminlury enrtehment of these daughter nuclides in some sediments. Subsequent assimilation of uranium, essentially free of radioactive daughters, occurs in some specific types of deposits such as carbonates and phosphates. In the study of the geochemical processes involved in the migration of uranium and $i$ ts isotopes $(234 \mathrm{U}, 235 \mathrm{U}, 238 \mathrm{U})$ in the hydrologic cycle, radioactive tracers produced by nuclear processes in nature $(230 \mathrm{Th}$ as tracer of $234 \mathrm{U}$ and $231 \mathrm{~Pa}$ as tracer of $235 \mathrm{U}$ and $238 \mathrm{U}$ ) have proved useful in studies of the Pleistocene. This tracer technique is a powerful tool when applied to pleistocene chronology, and possibly to the correlation of glacial deposits in their respective stages of glacial deposition. Natural tracer sludies have been initiated to investigate the process of uranium removal from Precambrian granitic rocks by comparison of the concentrations of radiogenic lead isotopes $(206 \mathrm{~Pb}, 207 \mathrm{~Pb}, 208 \mathrm{~Pb})$ to the concentrations of uranium and thorium in total rock samples. Initial results indicate the large volumes of uranium have been removed from the Granite Mountaills in Wyoming and may have provided a major source for the uranium deposits in the central Wyoming basins. (auth) 
Rosholt, J. N., E. L. Garner and W. R. Shields. 1964. Fractionation of Uranium Isotopes and Daughter Products in Weathered Granite and UraniumBearing Sandstone, Wind River Basin Region, Wyoming. U.S.G.S. Professional Paper. No.501, B84-7.

Isotopic ratios of $235 \mathrm{U} / 234 \mathrm{U}$ for three samples representing different stages of weathering of granite show 7 to 23 percent deficjent ${ }^{234} \mathrm{U}$. The slightly weathered rock is most deficient, suggesting major $234 \mathrm{U}$ leaching at an early stage in the decomposition. Isotopic ratios in samples from a uranium deposit in sandstone showed slight excess $234 \mathrm{U}$ in parts of the adjoining oxidized sandstone characterized by relatively high uranium content. $230 \mathrm{Th} /$ $234 \mathrm{U}$ ratios indicate relatively recent deposition of redistributed uranium in parts of the oxidized sandstone where the $234 \mathrm{U} / 235 \mathrm{U}$ ratio is high. The low $234 \mathrm{U} / 235 \mathrm{U}$ ratios prevailing in uranium-poor parts of the oxidized sandstone are believed to have resulted from preferential leaching of $234 \mathrm{U}$ in these places and over a considerable time. (auth)

Rozhkova, E. V., E. G. Razumnaya, et a1. Sorption in Concentration of Uranium in Sedimentary Rocks. A/CONF 15/P/2059 (in Russian).

The results of a study of the role of sorption processes in accumulating uranium in sedimentary deposits are discussed. A number of uranium-bearing sedimentary rocks were investigated. It was found that uranium is connected only with certain components of these rocks which proved to contain no uranium minerals. Assumptions were made as to the possibility of accumulation of uranium in these components as a result of sorption processes. At the second stage of investigation experiments were carried out with the sorption of uranium from the solutions of its saits. Experiments were made with the rock components under conditions which made is possible to determine the sorption capacity of these components and to establish the basic regularities of the sorption process. The comparison of the results of the first and second stages of the investigation indicates the possibility of uranium being accumulated in sedimentary rocks by sorption at various periods of their formation as well as in the process of epigenetic ore formation in sedimentary deposits. (auth)

Rubtsov, D. M. 1966. Distribution of Thorium in Various Soils. Pochvovedenie. No. 3:55-67 (in Russian).

Different concentrations of thorium and its decay products in soils cause different levels of $\gamma$ radiation output above the surface of the soil mantle. The concentration of thorium in fine grain soil, that is, products of weathering and soil formation, is higher than in basement rock-schists with layers of quartzite. Increased concentration of thorium in the fine grain soil is related to processes of weathering and soil formation. The fluctuating concentration of thorium in the soil determines basically the concentration of thorium in the air near the ground. The presence of thorium in vegetable objects indicates that it is in the biological cycle in nature. The uptake of thorium in vegetative objects is determined not only by the concentration 
of thorium in the fine grained soil but is also regulated by the species of vegetative association and by the trend in the soil-making process. The processes of soil formation, characteristic of a bioclimatic zone, appear as the basic source of the transdistribution of thorium in the soil profile. (auth)

Rubtsov, D. M. 1971. Soils of Separate Biogeocoenoses Containing Increased Amounts of Natural Radioactive Elements. Metody Radioekol. Issled. pp. 24-34 (in Russian).

A technique is described of the study of the effect of increased nalural soll radioactivity on the content and elemental composition of radioactive isotopes in soil. Increased content. of $U, R$, and $T h$ is cxpressed as absent amount in soil or in arbitrary units. An important part of the accumulation of radioactive isotopes is played by soil oraanic matter and by colloidal soil fractions. In the latter, particle dimensions have considerable influence. In fine-dispersion fractions of mountain forest soil, there is a direct correlation between the content of Th and the amount of organic matter. (CA)

Rubtsov, D. M. 1972. Thorium and Radium Content in the Silt Fraction of the Podzolic Mountain Soils of Thin Forests. Radioekologicheskie.

Issledavaniya V Prirodnykh Biogeotsenozakh. IN: Verkhovskaya (ed.) Izdatel'stov Nauka, pp. 42-53.

Investigations have shown that in zones of ore manifestation, thorium is associated with the coarse dispersed nart of aleuritc. In the zone uf lhe halo of dispersion and the zone of hackground areas, thorium represented by the fine dispersed fraction is prevailing. The distribution of the silty thorium fraction in different soil profiles is determined by the nature of soil forming processes and the thorium content of aleurite and correlates in a certain measure with the composition of the plant association. The presence of thorium in separate fractions of organic matter was ascerclained. The amount of uranium in the soils considered varies with the range of the geochemical background of uranium content in the soils of the Russian plain. Uranium is confined mainly to the fraction $>n .001 \mathrm{~mm}$. The distribution of the uranium of the silty fraction along soil profiles is determined, like that of thorium, by the nature and trend of the process of soil formation. Uranium enters the vegetative objects of forest litters far more intensely than thoriull. (auth)

Rubtsov, D. M. 1972. Thorium and Uranium Content in the Clay Fraction of Podzolic Mountain Soils of Thin Forests. Radioekol. Issled. Prir. Biogeutsenozakh, pp. 53-66 (in Russian). 
Th and $U$ were quantities determined in clay fractions of individual genetic horizons of thin forest podzolid mountain soils from localities with significantly different levels of $\gamma$-radiation above the soil surface. Th in the $<0.001 \mathrm{~mm}$ fraction appears to be the primary source of Th accumulation in soil. This fraction can be involved in the soil-plant biological cycle and it is capable of forming organo-mineral complexes. The maximum content of Th was in the $A_{2}$ and $B C$ horizons. The soil fractions $>0.001 \mathrm{~mm}$ contained 57-96 percent of total $U$ in the soil; this is explained by the high minerizing capacity of $U$ compounds. A relatively high level of $U$ was found in the $>0.001 \mathrm{~mm}$ fractions of the podzolic $A_{2}$ horizon. Th was found in some organic matter fractions. Forest litter contained more $U$ than Th. (CA)

Rubtsov, D. M. 1972. Distribution of Uranium and Radium in the Podzolic Mountain Soils of Thin Forests. Radioekologicheskie Issledovaniya $v$ Prirodnykh Biogeotsenozakh. pp. 42-53. Izdatel'strvo Nauka./Verkhovskaya, I. N. (ed.) (in Russian).

The content and distribution of uranium and radium in the profiles of podzolic mountain soils of thin forests were determined. A tendency was discovered to a preferential accumulation of uranium and radium in the products of soil formation (aleurite as compared with base rocks) by sericitic shists with quartzite intercalations. The presence of uranium and radium in the vegetative objects of forest litters confirms the already established fact that uranium and radium are involved in the biological cycle of matter exchange in nature. The distribution of radium and uranium in soil profiles reflects the zonal features inherent in the given bioclimatic zone. In base rocks and soils, the equilibrium between radium and uranium is disturbed in favor of radium. In the order of decreasing energy of their absorption by vegetative objects radioactive elements form the series: radium > uranium > thorium. (auth)

Rubstov, D. M. and E. J. Pravdina. 1972. Content and Distribution of Uranium, Radium, and Thorium in Mountain Tundra Soils. Radioekologicheskie Issledovaniya v. Prirodnykh Blogeutsenozakh. I. N. Verkhovskaga (ed.) pp. 67-86. Izdatel'stvo Nauka (in Russian).

Investigations of the content and distribution of thorium, uranium, and radium in mountain tundra soils showed a differentiation of their content according to genetic soil horizons, determined by the nature of the processes of formation. The absolute biological accumulation of thorium and uranium was found to be lower in the soils of mountain tundras as compared with the more southern mountain tundra soils of thin forests. Against a background of a reduced absolute biological accumulation of thorium and uranium in mountain tundra soils, an increase is observed of the relative coefficient of the participation of thorium and uranium in the biological cycle of matter exchangc. (auth) 
Ryde11, H. S. 1971. U, Th, and Pa Isotopes as Indicators of Geologic Processes in Marine Environments. ORO-3622-12.

From August 1970 to August 1971 several geochemical studies were initiated using Th and $U$ isotopes as indicators of geological processes in the marine environment. Summaries are presented of the following investigations: the postdepositional mobility of some transition elements, $P, U$, and $T h$ in deep-sea sediments; the final desiccation of the Afar Rift, Ethiopia; $U$ content of Caribbean cores; mineralogy of Afar Rift, Ethiopia; Pa, Th, and $U$ content in atmospheric dust; mineralogy and petrology of rock samples from fractured zones of the Equatorial Mid-Atlantic Ridge; and the Th and $U$ isotope content.s in marine ferromanganese deposils. (NSA)

Ryde11, H. S. and J. M. Prospero. 1972. Uranium and Thorium Concentrations in Wind-Borne Saharan Dust Over the Western Equatorial North Atlantic Ocean. Earth Planct. Sci. Lett. 14:397-402.

The average uranium and thorium concentration in 15 samples of wind-borne Saharan dust collected at Barbados, West Indies, is 3.6 and $12.4 \mathrm{ppm}$, respectively; these values are approximately one-third greater than that of average crustal material. The thorium-uranium weight rat10 of the dust is 3.5 , about the same as that of the crust; the $234 \mathrm{U} / 238 \mathrm{U}$ activity ratio is 1.08 and the $230 \mathrm{Th} / 234 \mathrm{U}$ activity ratio, 0.97 . It is concluded that the presence of large amounts of African dust in Atlantic sediments would not significantly affect the validity of the assumptions inherent in the $231 \mathrm{~Pa} /$ $230 \mathrm{Th}$ and $230 \mathrm{Th} / 232 \mathrm{Th}$ dating methods. (auth)

Ryde11, H. S. and E. Bonatti, 1973. Uranium in Sub-Marine Melalliferous Deposits. Geochtm, et Cosmochim. Acta. 37:2557-65.

Hydrothermal submarine metalliterous deposits, common in areas of the ocean floor with a high heat flow containing $\sim 10 \mathrm{ppm} U$. The ratio is close to that of seawater. These data are explained by a model where thermal water (essentially heated seawater) in its sub bottom circulation often is unable to leach $U$ from the basaltic oceanic crust; in fact, these thermal waters may in some cases lose 11 . When leaching of $U$ from the basalt dues lake place, probably during shallow stages of the sub bottom circulation, the resulting anomalous $234 \mathrm{U} / 238 \mathrm{U}$ ratio can be preserved in the hydrothermal deposit only if mixing with "seawater" $U$ is prevented. (CA)

Sackett, W. M. 1960. Protactinium-231 Content of Ocean Water and Sediments. Science. 132:1761-2. 
By means of a direct method for determining $\mathrm{Pa}^{231}$, a deficiency in ocean water was found to be accompanied by unsupported $\mathrm{Pa}_{2} 231$ in ocean sediments. Protactinium-ionium ratios obtained for a surface and a deep section in the same equatorial core yielded apparent ages which were in agreement with predicted ages. (auth)

Sackett, W. M. 1963. Evaluation of the $\mathrm{Pa}_{2} 231 / \mathrm{Th} 230$ Method as a Geochronological Tool for the Study of Pelagic Sediments. TID-19555.

An evaluation of the $\mathrm{Pa}^{231} / \mathrm{Th}^{230}$ method is being made. Preliminary data indicate that absolute ages for various levels of pelagic sediments are obtained only in rare instances. However, accumulation rates based on the slope of the curve of the exponential change in $\mathrm{Th}^{230} / \mathrm{Pa}^{231}$ ratio with depth apparently agree with radiocarbon based accumulation rates. Various assumptions of the method are being tested. Eleven samples of seawater are being processed for their protactinium and isotopic thorium composition. (auth)

Sackett, W. M. 1972. Geochemical Behavior of Uranium and Thorium Series Nuclides. Annual Progress Report. 1971-1972. ORO-385?-7.

Developments are reported for studies on: removal of Th from seawater and contemporary geochemistry of uranium. Previous studies on Th in seawater are reviewed, particularly in regard to depth. A new geochemical balance for $U$ in the Gulf of Mexico (GOM) is in the process of the final stages of computation. Input from over 22 rivers entering the GOM was analyzed. The results indicated that the GOM receives some of the highest $U$ input concentration of any known basin. (NSA)

Sackett, W. M. 1974. Geochemical Behavior of Uranium and Thorium Series Nuclides. OR0-3852-15, 11 p., Annual Progress Report 1973-1974.

Samples were collected to measure ${ }^{228} \mathrm{Ra}$ and 220 Th distributions in the Gulf of Mexico. Summary profiles of the ${ }^{228} \mathrm{Ra} / 226 \mathrm{Ra}$ activity ratio, salinity, temperature, and dissolved oxygen are given for three stations to study mixing dynamics in the Gulf. Studies are also being made of radium and uranium in livestock feed additives. (NSA)

Sackett, W. M., W. S. Broecker and D. L. Thurber. 1965. The Geochemistry of Protactinium-237 and the Dating of Pelagic Sediments. Annual Report. TID-21522. 
Papers are included on sediment deposition rate determination by the protactinium method and on measured rates of marine sediment deposition and implications for accumulation rates of extra-terrestrial dust. Separate abstracts were prepared for these papers. A paper on $U$ and Th series nonequilibrium in seawater was previously abstracted in NSA; see 19:9380. (NSA)

Sackett, W. M. and G. B. Cook. 1969. Uranium Geochemistry of the Gulf of Mexico. Trans., Gulf Coast Ass. Geol. Soc. 19:233-8.

$U$ concentrations $\left(10^{-6} \mathrm{~g} 1\right)$ and the ratio $234 \mathrm{U} / 238 \mathrm{U}$ were determined: Gulf of Mexirn, 3.4-3.6, 1.14.1.18, estudries and bays along the Gulf, 2.1-17.3, $1.12-1.54$; rivers in Texas and Oklahoma, 0.6-3.0, 1.01-1.44. The high U concentrations in $U$. S. rivers are considered to be due to the dissolution $8 f \cup$ from phosphate fertilizers. Determinations of $U$, Th, and the ratio $234 \mathrm{U} / 238 \mathrm{U}$ are given for sediments of the Gulf and of rivers. (CA)

Sackett, W. M., T. Mo, R. F. Spalding and M. E. Exner. 1973. A Revaluation of the Marine Geochemistry of Uranium. IN: Radioactive Contamination of the Marine Environment. IAEA Symposium, Seattle, Washington, July 10-14, 1972, pp. 757-769.

Approximately $1015 \mu \mathrm{g} / \mathrm{yr}$ of dissolved uranium are being removed from the ocean by each of the generally accepted significant sinks for uraniumcarbonate deposits and deep anoxic basin sediments. However, these sinks account for only 10 percent of the estimated present-day input of uranium. Possible explanations for this discrepancy are: 1) contemporary input values are too high owing to a significant contribution from man's effects, or 2) lihere are other important uranium sinks such as the abundant siliceous oozes ur continental shelf anoxic sediment.s. (auth)

Sakancue, M. 1960. Geochemical Studies on the Radioactive Sediments. II. Uranium Content of Natural Waters from the Ningyo-Pass Mining Area. Nippon Kagaku Zasshi 81:896-8.

In order to find the amounts of $U$ leached from the U-bearing sedimentary bed by the action of natural waters, $U$ was determined paper chromatographically in water samples collected inside the drift of thc Ningyo-Pass mine and from the rivulets and streams near the mine. Waters that have passed through the urluxidized zone ternd to contain higher concentrations of $U$ ( 80 and 250 $\gamma / 1)$ than that passed through the oxidized zone $(21-33 \mathrm{r} / 1)$. This tendency was confirmed by a model except; two ore samples obtained from the two zones were treated with water of different $\mathrm{pH}$ values, and the supernatant liquids were analyzed for $U$. (CA)

Sakanoue, M. 1960. Geochemical Studies on the Radioactive Sediments. III. Uranium, Phosphorus, and Arsenic in the Sedimentary Bed at Ningyo Pass. Nippon Kagaku Zasshi 81:898-902. 
$U, P$, and As were determined in core samples taken from the unoxidized zone where ningyoite occurred, oxidized zone where autunite occurred, mixed zone, and shale beds containing fairly large amounts of $U$. Arsenic was determined by a modified Gutzeit method, and $P$ by the molybdenum blue method after evolution of arsine. In the unoxidized zone correlation is highly possitive between $U$ and $P$, suggesting that the $U$ in these sediments was deposited mainly as a compound whose composition corresponds to that of ningyoite, a $\mathrm{Ca}^{7+} U^{4+}$ phosphate mineral. In the unoxidized zone $U$ also shows a positive correlation with As, and the presence of As-bearing pyrite (as high as 0.76 percent As) was confirmed. It is pointed out that pyrite is related to the deposition of $U$. (CA)

Sakanoue, M. and K. Komura. 1971. Anomalously High $234 \mathrm{U} / 238 \mathrm{U}$ Ratio in a Natura 1 Sample. Phys. Sci. 233:80-1.

Following the discovery of the radioactive disequilibrium of the $234 \mathrm{U} / 238 \mathrm{U}$ anomaly has been shown to occur commonly in nature. This ratio is available for dating quaternary samples back to about one million years, because of the relatively long half 1 ife of $234 \mathrm{U}(2.48 \times 105 \mathrm{yr})$. The dating aspects and the geochemistry of the $U$ and Ac series disequilibrium were studied, and some data are given for a maghemite sample collected in northeast Japan. The chemical and radiometric procedures are described in detail; an abnormally high $234 \mathrm{U} / 238 \mathrm{U}$ ratio of about 15 was found. An abnormality was also found in the 230Th activity, which was about nine times larger than the equilibrium value with the parent $234 \mathrm{U}$. The bistory of the sample is discussed and mechanisms are are suggested for the ${ }^{234} \mathrm{U}$ enrichment. (NSA)

Sakanoue, M., S. Yoneda, K. Onishi, K. Koyama, K. Komura and T. Nakanishi. 1968. $\alpha$-Radioactive Nuclides of Uranium, Protactinium, and Thorium in Uranium Deposits. Geochim. J. (Nagoya). 2:71-86.

Radiochemistry separations were made on many samples and determinations hy $\alpha$-spectrometry were made of $238 \mathrm{U}, 234 \mathrm{U}, 231 \mathrm{~Pa}, 232 \mathrm{Th}$, and $230 \mathrm{Th}$. Analyses of ore samples from the Ningyo-Toge Mine, Ukayama, had isutupic ratios indicating extensive preferential leaching of U. A Mu nodule (Min 20.1 percent) from a montmorillonite bed, Katama district, was enriched in both $\mathrm{Ra}$ and $\mathrm{Pa}$. Secondary $\mathrm{U}$ minerals from the Tono district, Gifu, gave ages of about 5000 and 34,000 years. U in phosphorite from Oyaemondani, Noto district, was apparently not syngenetic with the phosphate, but was introduced into it later. (CA)

Sarma, T. P. 1964. Dating of Marine Sediments by Ioniun arid Protatinum Methods. Thesis. NY0-8925.

It is the objective of this investigation to find reliable methods for dating marine sediments based on non-equilibrium secondary natural radioactivity, and to apply these dating methods to determine the times at 
which geologically significant events in the past have taken place. Radiochemical procedures are developed to isolate thorium, protactinium and uranium from sedimentary materials following complete decomposition of the samples with $\mathrm{HF}$ plus $\mathrm{H}_{2} \mathrm{SO}_{4} \cdot{ }^{23} \mathrm{U},{ }^{228} \mathrm{Th}$, and $233 \mathrm{pa}$ are used as tracers for the chemical yields of uranium, thorium, and protactinium, respectively. The thorium and uranium samples were counted by surface-barrier solid-state alpha detectors. The $231 \mathrm{~Pa}$ activities were measured in a Frisch-grid ionization chamber. Multichannel pulse analyzer is used with both detectors. The absolute specific activities of $238 \mathrm{U}, 234 \mathrm{U}, 232 \mathrm{Th}, 230 \mathrm{Th}$, and $23 \mathrm{~Pa}$ were determined in various sections of four different areas from the Pacific, Atlantic, and Indian 0ceans. The $230 \mathrm{U}$ and $234 \mathrm{U}$ specific activities observed ranged from 0.6 to $2.3 \mathrm{dpm} \mathrm{g}^{-1}$, whereas the $232 \mathrm{Th}$ specific activities showed greater variations, of the order of 0.08 to $4 \mathrm{dpm} \mathrm{g}^{-1}$. The $236 \mathrm{U} / 238 \mathrm{U}$ activity ratios are close to unity within the experimental uncertainly of about 5-10 percent. The variations in the 230 Th specific activities are considerable and they fluctuate between 0.6 and $55 \mathrm{dpm} \mathrm{g}^{-1}$, depending on the location of the core and the depth at which the sample was taken. The 231 pa specific activities are lower than those of $232 \mathrm{~Pa}$ by a factor of about 10 in the top layers of the sediments, and by a factor of about 20 in the deep sections of the core. The excess 230 Th specific activities are calculated by subtracting the $234 \mathrm{U}$ specific activities from the total $230 \mathrm{Th}$ specific activities in the same sections of the core. Similarly, the excess $231 \mathrm{~Pa}$ specific activities are gained by subtracting the $235 \mathrm{U}$ specific activities ( 0.046 times the $238 \mathrm{U}$ specific activities) from the $231 \mathrm{~Pa}$ specific activities. In three of the cores analyzed, the excess $230 \mathrm{Th}$ and $231 \mathrm{~Pa}$ specific activities decreased fairly steadily and nearly exponentially, especially below about 20 to $30 \mathrm{~cm}$. From the slope of the semi-log plot of specific activity vs depth, the mean sedimentation rate at each location was calculated. In the Pacific core (Scripps $M S N-2 G$ ), an average age sedimentation rate of $0.86 \times 10^{-4} \mathrm{~cm}$ year- 1 was obtained, whereas in the Indian Ocean core (Goteborg SDSE-137) the value of $3.3 \times 10^{-4} \mathrm{cmll}$ year ${ }^{-1}$ was obtained. In the Mid-Atlantic core (Lamont V16-21), the average rate was about $3.7 \times 10^{-4} \mathrm{~cm}$ year-1 which is unexpectedly small for an Atlantic core. In the North Atlantic core (Lamont A179-15), a deficiency of $230 \mathrm{Th}$ and 234 (: is present in some sections of the column. A geochemical model is constructed to calculate the $230 \mathrm{Th}$ and $23 \mathrm{~Pa}$ specific activities in freshly deposited sediments, and thereby ascertain under what circumstances one can expect excesses and deficiencies of $230 \mathrm{Th}$ with respect to $234 \mathrm{U}$ and of $231 \mathrm{~Pa}$ with respect to $235 \mathrm{~J}$. The $230 \mathrm{Th}$ and $2.31 \mathrm{~Pa}$ deficiencies can be explained by high sedimentation rates of biogenic clacite, exceeding about $8 \times 10^{-3} \mathrm{~cm}$ year-1. Because of the complications due to several components always present in sediments, it is evident that complete dissolution rather chan partial leaching is necessary to obtain meaningful specific activities of the various radionuclides. Theoretical calculations were made to account for the diffusion-like mixing by sub-surface organisms, underwater currents, or both. The effect of this pseudo-diffusion on the depth distribution has been calculated for ${ }^{14} \mathrm{C}, 231 \mathrm{~Pa}$, and $230 \mathrm{Th}$ activities, and for the $231 \mathrm{~Pa} / 230 \mathrm{Th}$ ratio. Of the four indices which might be used for dating sediments, 1) excess 230 Th specific activity, 2) 232 Th-normal ized excess 230 activity, 3 )excess $231 \mathrm{~Pa}$ specific activity, 4) excess $231 \mathrm{~Pa} /$ excess $230 \mathrm{Th}$ activity 
ratio, the first seems to be of greatest utility for determining ages and sedimentation rates. The second quantity fluctuates as a result of rather large 232Th variations. The last two indices are less precise and their applicability is limited to about 200,000 years; besides, they are more affected by pseudo-diffusion. ${ }^{14} \mathrm{C}$ is affected even more by pseudodiffusion, leading to erroneously high previous estimates of sedimentation rates. For reliable $14 \mathrm{C}$ dating, one must determine the activity of many points and also correct for pseudodiffusion. The $230 \mathrm{Th}$ measurements are good for this. The $231 \mathrm{~Pa}$ excess and $231 \mathrm{~Pa} / 230 \mathrm{Th}$ ratio can also help to indicate the conditions of deposition. The core V16-21 is one of eight cores in which the Pliocene-Pleistocene boundary is believed to be present, according to Ericson, Ewing and Wollin (1963). The boundary is at a depth of close to $165 \mathrm{~cm}$ in this locality. According to the ionium measurements made on this core, the apparent age of the boundary is close to $(503 \pm 20) \times 10^{3}$ year. A more probable age, $(525 \pm 20) \times 10^{3}$ year, results from making a correction for assumed and indicated mixing in the top layers. The ages of the uppermost sections of the core V16-2l calculated from the decay of excess $231 \mathrm{~Pa}$ and the excess $231 \mathrm{~Pa}$ /excess $230 \mathrm{Th}$ ratio are in good agreement with the excess $230 \mathrm{Th}$ ages. The dating of the Ericson-Ewing-Wollin boundary is the first time a geologically significant event has been dated by the 230 Th dating method, although it cannot be considered definitely established on the basis of this single core that this event is actually the beginning of the Pleistocene epoch. 500,000 years is about the practical dating limit of the 230Th method for such sediments, but in favorable cases (such as deep Pacific cores), this might be extended to 600,000 or 700,000 years. For longer times a method based on the growth of the spontaneous fission product 129 I might be useful. (auth)

Schmidt-Collerus, J. J. 1969. Research in Uranium Geochemistry. Investigation of the Relationship between Organic Matter and Uranium Deposits. Part II. Experimental Investigations. Final Report. GJ0-933-2.

The feasiblity of the micropyrolysis-gas chromatography-mass spectrometry (MPGM) method for the characterization of the organic matter associated with uranium in fluviatile ore deposits was investigated. The role of biogenically generated hydrogen sulfide in the reduction and precipitation of uranium in particular in the roll-type deposits was also investigated. It was found that the MPGM method, applied successfully to the characterization ("fingerprinting") of various intractable natural biolths, can equally well be applied to the characterization of the organic matter in uranium ore deposits and to the study of the nature of this association. The enrichment of uranium in the roll-type deposits appears to be associated principally with the organic matter present and caused by specific ligating moieties in it, the role of hydrogen sulfide is probably of a secondary nature. Nonetheless, if hydrogen sulfide was synergistically involved in the reduction and precipitation of uranium together with the organic matter it is more likely that its origin was mainly biogenic in nature because of the facile availability of organic matter as energy source for the $\mathrm{H}_{2} \mathrm{~S}$ producing microorganisms. This mechanism for the $\mathrm{H}_{2} \mathrm{~S}$ production appears also the 
less complicated one than that assumed for the inorganic mechanisms, involving oxidation of sulfides to sulfites and disproportionation of the latter to form $\mathrm{H}_{2} \mathrm{~S}$ and sulfates -- although the possible simultaneous partial formation by the latter reaction mechanism cannot be excluded.

Schofield, J. C. 1967. Origin of Radioactivity at Niue Island. N. Z. J. Geol. Geophys. 10:1362-1371.

Origin of the high soil radioactivity on Niue, an isolated island in the South Pacific, is discussed. The high radioactivity of the Niuean soils is similar to that found in deep sea sediments. Ionium and Ra 226 are the source of the bulk of the radioactivity on Niue. Because of the greater solubility of $U$, separation from the daughter products occurs in seawater, the high radioactive content in deep sea sediments being due to a slow rate of clastic deposition compared with the deposition of shelf sediments. The rate of sedimentation in deep sea areas is unlikely to have been as rapid as in the now dry lagoon at Niue; hence, a seawater origin for the abnormally high radioactivity at Niue is unlikely. A separation from $U$ of the daughter products also takes place in hydrothermal solutions which could have come from the volcanic substructure at Niue, possibly phonolite, one of the most radioactive ignenus rocks. The anomalous distribution of radioactive soil values at Niue favors a volcanic origin rather than a seawater origin. Evidence is also presented that radioactivity in the limestone was derived from groundwater and not percolating rainwater. Groundwater is the main source of freshwater at Niue and if hydrothermal activity is still present, the groundwater may be injurious to health and should be tesled for radioactivity. (NSA)

Schopf, J. M. and R. J. Gray. 1954. Microscopic Studies of Uranifernus Coal Deposits. U.S.G.S. Circular 343.

Quantitative coal petrologic studies have been completed on 4 beds of uranium-bearing lignite from the S1im Buttes area of Harding County, South Dakota. Comparison of analyses of these deposits with analyșes of lignite from commercial deposits suggests that the Slim Buttes coal deposits are highly diverse in composition. Relative to most coal deposits, however, all of the Slim Buttes coal that was studied has an unusually high uranium content. The studies shaw that no quantitative correlation exists between uranium content and the coal petrologic constituents that are normally determined for coal-type classification and for prediction of coal behavior in utilization. As the coal constituents normally determined are to some extent heterogeneous, a further study was made of subordinate components. The components of translucent attritus were studied particularly, not only for selected layers of Slim Buttes lignite, but also for layers of coal from the Goose Creek field in southern Idaho. These data are presented for 11 layers of relatively high uranium content and for 8 associated layers that are much less radioactive and approach values that are about normal for coal. The results of this comparison cast doubt on direct correlation of uranium content with 
the amount of any single microscopic component of coal. A more complex control of uranium occurrence in coal is indicated. It may be significant that the samples richest in uranium contain relatively large amounts of humic attrital matter resulting from decomposition and microbial decay. One may tentatively conclude that this type of organic material is most favorable to uranium emplacement. (auth)

Schroeder, J. H., D. S. Miller and G. M. Friedman. 1970. Uranium Distributions in Recent Skeletal Carbonates. J. Sediment Petrology. 40:672-81.

Fission track analysis which was used to map $U$ distributions in sections at the ppb to ppm level, showed considerable intraskeletal heterogeneities in coral and mollusks. In the corals, a zone next to the internal surface of the corallite $U$ is enriched with respect to the inner portions of the skeleton; configuration and the factor of relative enrichment of this zone vary between coral species. The branching coral 0culina diffusa, exhibits alternating bands of relatively high and low $U$ contents arranged subparallel to the external surface. In the mollusk shells studied, $U$ concentrations vary between different layers of a given shell; further variations exist within a given layer perpendicular to the direction of accretion. Trace element distribution in carbonate skeletons is determined primarily by biological processes and can be expected to change when affected by physiochemical diagenetic influences. The patterns of $U$ distribution presented are potential indicators of $U$ mobility during diagenesis and potential checks on the closed system requirement for $U$ series dating of biogenic carbonates. (CA).

Schulz, R. K. 1965. Soil Chemistry of Radionuclides. Health Physics. $11: 1317-24$.

The naturally occurring radionuclides found in the soil in significant amounts include ${ }^{14} \mathrm{C}, 40_{\mathrm{K}}, 87_{\mathrm{Rb}}$, and members of the $U$, Ac, and $T h$ series. More than 300 radioisotopes will be undetectable, because of their short half-lives. $\mathrm{Y}, \mathrm{Pr}, \mathrm{Pm}, \mathrm{Th}, \mathrm{Pa}, \mathrm{Zr}$, and $\mathrm{Nh}$ ncccur in soils, but are either very strongly adsorbed by the clay particles or are present as insoluble oxides or hydroxides. In either of these states, these elements will be immobile in the soil and largely unavailable to plants. The elements which have a greater degree of mobility include $\mathrm{Sr}, \mathrm{Ba}, \mathrm{U}, \mathrm{Ra}, \mathrm{Pb}, \mathrm{Mn}, \mathrm{Co}, \mathrm{Zn}$, $\mathrm{Fe}, \mathrm{Ru}, \mathrm{Cr}, \mathrm{K}, \mathrm{Rb}, \mathrm{Ca}$, and $\mathrm{C}$. In considering the mobility of any ion, all others have to be taken into account. The amount and species of the complementary lons will have a strong influence on the redistribution of these isotopes in the soil profile and will affect plant uptake. (CA)

Scott, M. R. 1968. Thorium and Uranium Concentrations and Isotope Ratios in River Sediments. Earth Planet Sci. Lett. 4:245-52. 
Sediments from five rivers in the eastern and southern United States have been divided into several size fractions and analyzed for thorium and uranium isotope concentrations. The $238 \mathrm{U}$ decay series exhibits disequilibrium as a result of weathering. The $234 \mathrm{U} / 238 \mathrm{U}$ activity ratio is less than unity in sediment derived from well-leached soils and greater than unity in sediment containing relatively large amounts of organic material from organic-rich surface layers of soil profiles. 230 Th exists in excess of equilibrium amounts relative to its parent $234 \mathrm{U}$ in the fine fraction of most of the sediments analyzed. The thorium concentration and $230 \mathrm{Th}$ excess are significantly higher in the 2 to $0.2 \mu$ and less than $0.2 \mu$ size fractions than in the 2 to $20 \mu$ fractions, indicating adsorption by clays, complexing with sesquioxides, or possiblc concentration in resistates. Unsupported $230 \mathrm{Th}$ is being added to deep-sea sediments at a maximum rate of $0.5 \mathrm{dpm} / \mathrm{cm}^{2} / 1000$ years; therefore, detrital material is not a significant source of excess $230 \mathrm{Th}$ in deep-sea sediments. (auth)

Shalmina, G. G., F. P. Krendelev, G. F. Zaripora and V. A. Bobrov. 1972. Radioactive Elements in the Weathering Crusts of Central Urals Granites. Tr. Inst. Geol. Geofiz., Akad. Nauk SSSR, Sib. Otd. No. 149:139-51 (in Russian).

The contents of $\mathrm{SiO}_{2}, \mathrm{Al}_{2} \mathrm{O}_{3}, \mathrm{TiO}_{2}, \mathrm{Fe}_{2} \mathrm{O}_{3}, \mathrm{FeO}, \mathrm{CaO}, \mathrm{MgO}, \mathrm{K}_{2} \mathrm{O}, \mathrm{Na}_{2} \mathrm{O}, \mathrm{U}, \mathrm{Ra}$, Th, and radioactive $K$ in Paleozoic granites of the central Urals and their eluvial Lower Jurassic and Upper Cretaceous weathering products were determined. Samples were taken from bore holes at the Magnitnaya Mountains and from the Krasnaya Gorka deposit. The distribution curves of U, Rd, and Th coincided with those of relative amounts of feldspars and quartz, muscovite and hydromicas, and zircon, respectively, in the silt fractions of the crusts indicating that $U, R a$, and $K$ are present in feldspars, muscovite, and hydromicas; Ra lidilly in hydromicas and muscovite; and Th in zircon. (C.A)

Shcherbina, V. V. Geochemistry of Uranium in Oxidation Zurle of Ore Deposits According to Experimental Data. A/CONF 15/P/2066. (in Russian).

Investigations of geochemical processes in the oxidation zone of ore deposits and reproduction of these processes by experiment made it possible to reveal the nature of chemical reactions which account for the formation of uranium illinerals in the oxidation zone of ore deposits. Superposition of later geochemical prucesses on the products of earlier processes, their stage of development, and the resulting mineralogical zonality are observed. The reactions proceeding in the oxidation zone of uranium ore deposits are as follows: hydroloysis; ionic exchange resulting in hardly soluble compounds; oxidation-reduction reactions; formation and destruction of complex compounds; and sorption processes. The nature of these reactions depends on humid or arid types of weathering. Examples of reactions that account for paragenesis of exogenous uranium minerals and their connection with endog̣enous mineralization are given. (auth) 
Skocek, V. 1962. Patches Enriched in Vanadium in Permian Sediments. Vestn. Ustredniho Ustavu Geol. 37:347-52 (in Czechoslovakian).

In Lower Permian sediments of the Plzen and Manetin basins (Czechoslovakia), light-green patches, 0.5 up to $1.5 \mathrm{~cm}$, occur. Their amount in sandy rocks is greater than in the clay ones. According to the form of the center, the patches were divided into five groups. The chemical analyses gave $V$ up to 8.20, $\mathrm{U} 0.062, \mathrm{MnO} 0.02$, and $\mathrm{Cu} 0.70$ percent in the centers. Spectrochemically, $\mathrm{Ni}, \mathrm{Zn}$, and $\mathrm{Sr}$ were detected in subordinate amounts and $\mathrm{Ag}, \mathrm{Co}, \mathrm{Cr}$, and $\mathrm{Pb}$ in traces. The origin of the patches was favored by suitable conditiops in the course of diagenesis during which $V$ could migrate in the form of $V^{5+}$ anionic complexes. Small fragments of dark minerals (especially mica), crystals of calcite, and accumulations of organic substance served as the centers of precipitation. The centers enriched in $V, U$, etc., reduced $\mathrm{Fe}^{+++}$ to $\mathrm{Fe}^{++}$and conditioned its transport from the immediate vicinity of the center. This was the principal cause of the bleaching of red sediments. The patches described occur in sediments possessing a special association of authigenic minerals (calcite, oxides of $\mathrm{Fe}$ ) which originated under special climatic conditions. The patches may serve in parallelizing of stratigraphic profiles. (CA)

Smith, A. R. and H. A. Wollenberg. 1972. Geology and Natural Terrestiral Dose Rates. Report. HASL-269:8-11.

The natural component of environmental $\gamma$-ray radioactivity determined on $l$ and depends mainly of the $U$, Th, and $K$ contents of the rock and soil. Detailed studies of the distribution and abundance of $U$, Th, and $K$ and associated $\gamma$-dose rates in rocks encompassed are summarized. (CA)

Smith, R. F. and J. M. Jackson. 1969. Variations in $234 \mathrm{U}$ Concentrations of Natural Uranium. KY-581.

Uranium ore concentrates from sixteen world sources were analyzed to determine variations in the $234 \mathrm{~V}$ content of natural uranium. A spread of approximately 7.5 percent of the $234 \mathrm{U}$ content was apparent among the various sources. The lowest concentration, $0.00500 \pm 0.00002 \mathrm{wt}$ percent $234 \mathrm{U}$, was obtained on ore concentrate from Mines Develofment in Edgemont, South Dakota. The highest concentration, $0.00539 \pm 0.00002$ wt percent $234 \mathrm{U}$, was obtained on Belgian Congo pitchblende. (auth)

Smith, W. L. and F. J. Flanagan. 1956. Use of Statistical Methods to Detect Radioactivity Change Due to Weathering of a Granite. Am. J. Sci. 254:31624. 
Fourty-four samples of the Conway granite were collected from the red and green phases of the rock at the Redstone, New Hampshire quarries. A large variation in radioactivity as measured by $\beta$-counting is shown between individual samples. Inspection of the data shows that the red phase is higher in radioactivity than the green. An analysis of variance with a single variable of classification shows that the means of the fresh and weathered red phases are not significantly different, whereas a " $t$ " test using differences between pairs of the fresh and weathered green samples shows that the means of these two sets differ significantly. From these tests and a comparison of the variances of the respective sets, it is inferred that weathering has had a significant effect on the green phase only. It has been shown, by comparing the variances of the subsets of data with the known variance of the method of measurement, that some external factor such as variations in mineralogic composition or differential leaching or adsorption may be responsible for the variations in radioactivity. (auth)

Somayajulu, B. L. K. and T. M. Church. 1973. Radium, Thorium, and Uranium Isotopes in the Interstitial Water from the Pacific Ocean Sediment. $J$. Geophy. Res. 78:4529-31.

The $\mathrm{Ra}$, Th, and $U$ isotopic concentrations were determined in the interstitial water expressed from a deep sea core of the eastern equatorial Pacific. The isotopes $226 \mathrm{Ra}, 228 \mathrm{Ra}, 230 \mathrm{Th}$, and $228 \mathrm{Th}$ are higher by 1 to 3 orders of magnitude than their concentrations in seawater. Ra release from sedimentary phases with migration into the water column is indicated. The results are also compatible with the excess $228 \mathrm{Th}$ (relative to $232 \mathrm{Th}$ ) found in authigenic deep sea minerals. (CA)

Somayajulu, B. L. K. and E. D. Goldberg. 1966. Thorium and Uranium Isotopes in Seawater and Sediments. Earth Planet. Sci. Lett. 1:102-6.

Thorium concentrations in three open Pacific 0cean water samples had values of $n \times 10^{-10}$ grams/liter, concentrations similar to those previously measured in the Atlanntic. Radioactive disequilibrium exists between the dissolved forms of 231 Th and $232 \mathrm{Th}$ and the dissolved, excess unsupported $228 \mathrm{Th}$ apparently is introduced by the input of ${ }^{228} \mathrm{Ra}$ from the particulate phases containing $232 \mathrm{Th}$. The $230 \mathrm{Th} / 232 \mathrm{Th}$ ratios in seawater are similar to those taken from the surface sediments in the same area. Differences in the $230 \mathrm{Th} / 232 \mathrm{Th}$ ratios in barite and foraminifera extracted from the same levels in sediments are suggestive of differences in the ratio between surface and deep ocean waters. (auth)

Starik, I. E., A. N. Elizareva, Y. V. Kuznetsov. 1963. Determination of the Age of Ocean Sediments by the Ionium-Protactinium Method. Radiokhimiya $5: 154-7$. 
Sediment samples taken from the bottom of the Indian 0cean (depth $4461 \mathrm{~m}$ ) were decomposed by sintering with $\mathrm{NH}_{4} \mathrm{~F}$ and the excess fluoride removed by treating the residue with $(\mathrm{COOH})_{2}$. Pa and Th were then precipitated with $\mathrm{Ca}$ oxalate; $\mathrm{Pa}$ was separated from Th by extraction with iso-Bu2CO. The $\mathrm{Pa}$ and $\operatorname{Th} 230$ concentrations were then measured by counting their $\alpha$-activity and the concentration of $\mathrm{Th}^{232}$ was measured by a colorimetric method (with Arsenazo III). The age of the sediments was then calculated by means of the Rosholt equation (R., et al., C.4 55, 13215b) giving values of 19,900 for the top of the sedimentation bed and 500,000 years for samples taken $\sim 100 \mathrm{~cm}$ below the top. The experiments revealed an analogy in the vertical distribution of $\mathrm{Pa}$ and $\mathrm{Th}^{230}$ which indicates an analogous mechanism of sedimentation. No such relation was found in the case of $T^{230}$ and $T^{232}$. The average rate of sedimentation was $2.5 \mathrm{~mm} / 1000$ years; the rate of sedimentation at present $(3-3.5 \mathrm{~mm})$ is higher than in the geologic past $(1.6$ $\mathrm{mm} / 1000$ years 500,000 years ago). These results agree with data obtained by the radiocarbon dating method. (CA)

Starik, I. E., Y. V. Kuznetsev, S. M. Grashchenko and M. S. Frenklikh. 1958. The Ionium Method of Determination of the Age of Marine Sediments. Geokhimiya. pp. 3-13.

A study of the distribution of $\mathrm{Ra}$, Io and $\mathrm{U}$ in deep-water marine sediments and sediments of the coastal zone of the Pacific and Indian 0ceans. Before making determinations of Io in the sediments, blank experiments were made in order to check reagents and vessels for contamination with Th isotopes. For the determinations themselves, $5 \mathrm{~g}$ of mud, calcined at $800^{\circ}$, was placed in a Pt dish, the UX ${ }_{1}$ indicator added, and the mixture treated with a mixture of $\mathrm{HF}$ and $\mathrm{H}_{2} \mathrm{SO}_{4}$. The sulfates which formed were washed with five percent $\mathrm{HNO}_{3}$, dissolved by heating, and a $\mathrm{CO}_{3}$-free solution of $\mathrm{NH}_{3}$ was added to the solution. The sesquioxides which formed were filtered off and washed with hot water. The precipitate was dissolved in a five percent solution of $\mathrm{HNO}_{3}$, the solution was evaporated to a small volume, and the acidity of the solution was brought to $0.1 \mathrm{~N}$ by dilution with water. Fifty $\mathrm{mg}$ of $\mathrm{CaCl}_{2}$ and an equal volume of oxalic acid were added to the hot solution. The Ca oxalate precipitate was filtered off, washed with a one percent solution of oxalic acid, calcined to $\mathrm{CaCO}_{3}$ in a muffle furnace, and dissolved in a solution of five percent $\mathrm{HNO3}_{3}$. An equal volume of a solution of $\mathrm{NH}_{3}$ and several drops of $\mathrm{H}_{2} \mathrm{O}_{2}$ (three percent) were added, and the resulting small precipitate of hydroxides was filtered off through two schott filters connected in series. The precipitate was washed with a solution of $\mathrm{NH}_{3}$ and dissolved in five percent $\mathrm{HNO}_{3}$ solution. In the resulting solution coprecipitation of Th isotopes was carried out twice with $10 \mathrm{mg}$ of Ca oxalate. After complete separation of Io from $\mathrm{Ca}$, by passage of the solution through a Schott filter, the active precipitate on the filter was dissolved in IN $\mathrm{HNO}_{3}$, and in order to separate Po the solution was subjected to electrolysis in a Pt dish which served as anode. A Pt plate with an area of 7.5 $\mathrm{sq} . \mathrm{cm}$ served as cathode. The current strength was $100 \mathrm{ma}$, and the voltage was $2.1 \mathrm{v}$. The time required for electrolys is was 10 hours. After separation of $\mathrm{Po}$, the solution was evaporated to dryness and the $\mathrm{NH}_{4}$ salts were removed by heating. The active precipitate was dissulved in HNO3 solution and the 
solution evaporated to a volume of $0.5 \mathrm{ml}$. Then after evaporation of this solution by heating under a lamp $\alpha$-measurements of $T h$ isotopes were made. Then the precipitate was dissolved in 1:1 $\mathrm{HNO}_{3}$ and measurements of the yield were made by $\beta$-counting. The yield according to the UX 7 indicator varied within limits of 80 to 95 percent. Accuracy of the measurements was determined by the Io content in the sample, and in the present experiments it varied within limits of 8-15 percent. The vertical distribution of Ra, $U$, Th isotopes, $\mathrm{Fe}, \mathrm{Mn}$, and $\mathrm{Ca}$ was determined in 7 core samples of the marine sediments. The Io content in coastal sediments changed greatly along the length of the core sample. Io and $\mathrm{Ra}$ were not found to be in radioactive equilibrium. In all the core samples and in all the experimental points of deep-water sediments, Io and $\mathrm{Ra}$ were in radioactive equilibrium. Thus, it. was concluded that there is mu migration of $\mathrm{Ra}$ in the sediments. The forms of occurrence of In and Th in decp-water marilie sediments were apparnntly different. Rall of sedinienlalion in areas of the ocean bottom changed little with time. In all the core samples studied the concentrations of $U$ and Th remained constant along the length of the core. In a number of core samples a distinct relationship between the vertical distribution of $\mathrm{Ra}$ and Io and that of $\mathrm{Ca}$ was observed. (CA)

Starik, I. E., Y. V. Kuznetsov and V. K. Legin. 1959. On the Origin of Uranium and Thorium in Ground Deposits of Antarctic. Radiokhimiya. 1:3214 (in Russian).

Studies of uranium and thorium distribution in various fractions of the Antarctic shelf show the main depositions are found in the brecciated ccntinental rock. (NSA)

Startk, I. E., Y. V. Kuznetsov, V. K. I.egin and Z. N. Simonyak. 1961. On Some Properties of the Ionium Method of Age Determination. Radioktimina. 3:490-\% (in Russian).

A radiochemical analysis was made of marine sedimentation containing radium, uranium, ionium, and thorium. The absence of radioactive equilibrium was established in the lower parts of columns where equilibrium is ordinarily accepted on the basis of ionium vertical distribution. The saturation of radium (in relation to ionium) found in upper levels of deep-water red clays indicate the feasibility of direct radium precipitation. Some data were obtained on sedimentation in the central region of the Indian 0cean that are in good agreement with published data. (NSA)

Starik, I. E., Y. V. Kuznetsov, E. P. Petryaev and V. K. Legin. 1963. Geochemistry of Radioactive Elements. Khim. Zemnoi Kory, Akad. Nauk SSSR Tr. Geokhim. Konf. 1:374-83. 
A study of the geochemistry of radioactive elements in ocean water and sediments revealed several facts which cannot be explained only by the leaching of radioactive elements from minerals. This difference is most distinctly observed in a comparison of the $\mathrm{Ra}$ : U ratio, obtained during experiments in mineral leaching, with data on the $U$ and $R a$ contents in natural waters (formation waters of oil deposits and mineral springs) and with their contents in ocean water. The leaching of $\mathrm{Ra}$ and $U$ from minerals suggests that the content of $\mathrm{Ra}$ in ocean water should be hijgher than that of $U$. Experimental data show the opposite. However, when the form of occurrence of these isotopes is considered, this disagreement disappears. In fact, more $\mathrm{Ra}$ than $U$ is delivered into water during rock leaching. But $U$ forms in seawater stable, easily soluble, complexes which migrate in aquatic medium. The $\mathrm{Ra}$ under conditions of natural waters $(\mathrm{pH}>6)$ was sorbed by suspended and colloidal particles and, together with them, precipitated into sediments. This results in relative enrichment (in comparison with $\mathrm{Ra}$ ) of ocean waters with U. (CA)

Starik, I. E., D. S. Nikolaev, S. M. Grashchenko, Y. V. Kuznetsov, K. F. Lazarev and V. R. Legin. Natural Radioactivity of the Waters and Sediments in the Black Sea and the Sea of Azov. AEC-tr-6641. pp. 10-13.

Radioactivity was measured in water and bottom sediments from the Black Sea and the Sea of Azov during 1958 and 1959. Uranium concentrations varied from 1.5 to $2.8 \times 10^{-6} \mathrm{~g} / 7$ with no apparent regularity of variation in either horizontal or vertical traverses. The constancy of the $U$ concentration in both seas was shown to be related to the presence of the carbonate complex of uranium. Although the uranium contents in the waters of both seas were similar, the concentrations in the upper portion of the bottom sediments were different, a difference explained by variation of hydrochemical conditions. Thorium-232, ${ }^{226} \mathrm{Th}$, and Ra were also determined. (NSA)

Starik, I. E., D. S. Nikolaev, Y. V. Kuznetsov and V. K. Legin. 1961. Radioactivily of Black Sea Deposits. Doklady Akad. Nạuk. SSSR. 139:1456-9 (in Russian).

The content of radium in ocean deposits varies from 4 to $50 \times 10^{-12} \mathrm{~g} / \mathrm{g}$, while the radium content in Black Sea deposits is relatively constant at 5 to $9 \times 10^{-13} \mathrm{~g} / \mathrm{g}$ (substantially lower than in ocean deposits). The radium content does not vary with the height of the core sample. The absolute content of lonfuin varies from 0.8 to $5.8 \times 10^{-10} \mathrm{~g} / \mathrm{g}$ (approximately that found in ocean deposits) with the higher ionium values being found in the surface layers. Since the Black Sea deposits are relatively young in age, the amount of ionium is almost always greater than the amount of radium, and the ionium and radium are not in equilibrium with each other. The uranium content in Black Sea deposits is 10 to $12 \times 10^{-6} \mathrm{~g} / \mathrm{g}$ (5 to 7 times greater than the uranium content in typical ocean deposits). The surface layers of the core sample have a higher uranium content than the lower 
layers. The precipiation of uranium is favored by the reducing conditions prevalent in the Black Sea. The ratio of thorium to uranium is low in the upper layers of the core sample, but rises to a value that is more typical of ocean deposits in the lower layers of the core sample $(\mathrm{Th} / U>3)$. For the last 1500 years the rate of deposition in the Black Sea is estimated at 36 to $60 \mathrm{~cm}$ per 1000 years. This high rate of deposition accounts for the deficiency of radium in the Black Sea deposits.

Starik, J. E., D. S. Nikolaev, Y. V. Kuznetsov and V. K. Legin. 1961. The Ratio of Radioactivities in Deposits of the Azov Sea and of the Black Sea. Doklady Akad. Nauk SSSR. 139:456-9 (in Russian).

The distributions of Th, Io and Ra contents as a function of depth in 5.0meter core samples from three stations in the Azov Sea were investigated in the summer of 1959. The absolute contents of $U$, Th, Io and $R a$ in sediments of the Azov Sea are approximatcly the same as lhose in littoral ocean deposits. The average uranium concentration in sediments of the Azov Sea was $1.3 \times 10^{-6}$ grams per gram of sludge, while the uranium in the upper layers of the Black Sea sediments was $5.7 \times 10^{-6} \mathrm{~g} / \mathrm{g}$. The average concentration of thorium is greater in deposits of the Azov Sea than it is in deposits of the Black Sea, but the concentration of ionium is somewhat greater in deposits of the Black Sea than it is in deposits of the Azov Sea. Apparently, the main part of the ionium precipitates from solution after being. formed from the uranium in solution. The concentration of $\mathrm{Ra}$ was found to be $7.2 \times 10^{-13} \mathrm{~g} / \mathrm{g}$ of sludge in the Azov Sea. The Ra is continuously carried down by sediments which act as carriers. Hence, the amount of Ra is almust twice the equilibrium amount based on the amount of $U$ present in solution. The ratio of Th to $U$ is variable, but is always greater than three. (NSA)

Sugimura, T. and T. Sugimura. 1962. Uranium in Recent Japanese Sediments. Nature. 194:568-9.

Samples of sediments, of which two were marine, three from inlets, four sections of a core from a brackish lake, one from an oilfield, and one from a gasfield, were analyzed for their $U$ content. The $U$ contents ranged from 1.3 to $18.1 \mu \mathrm{g} \mathrm{U} / \mathrm{g}$, and the high $\mathrm{U}$ contents of Lake Hamana and Kagoshilma Bay are probably due to reducing conditions. The average $U$ content, excluding the unusually high contents, is $2.5 \mathrm{ppm}$. (NSA)

Sugimura, Y. 1964. Natural Radioactive Elements in the Ocean. Kagaku No Ryoiki. 18:89-101 (in Japanese).

A review is given of the distribution of natural radioactive elements and isotopes in seawaters and sediments. The $U$ contents in seawaters are tabulated; the average is $3.3 \times 10^{-6} \mathrm{~g} \mathrm{U} / 1$. The $234 \mathrm{U} / 238 \mathrm{U}$ ratio is discussed. The $U$ contents in sea sediments are from 0.1 to $80 \mathrm{ppm}$. Attempts were made to determine $231 \mathrm{~Pa}$ in seawaters and sediments. Seawaters contain $2 \times 10^{-9}$. 
$1 \times 10^{-7} \mathrm{~g} \mathrm{Th} / 1$ and $n \times 10^{-11}-\mathrm{n} \times 10^{-14} \mathrm{~g} 230 \mathrm{Th} / 1$. Sea sediments contain 6-13 ppm Th; 60-70 percent of the Th is leached with cold HCl. Studies were made to determine the sedimentation rate of sediment from the contents of $232 \mathrm{Th}$ and $230 \mathrm{Th}$ (Io). Many data are available on the $226 \mathrm{Ra}$ contents in seawaters, and the table is given. These contents are less than those in eguilibrium with $U$. Pelagic sediments contain an average of $10 \times 10^{-12} \mathrm{~g}$ $226 \mathrm{Ra} / \mathrm{g}$. Distributions of $210 \mathrm{~Pb}, 210 \mathrm{Po}, 227 \mathrm{Ac}$, etc., are discussed. The surface seawaters off California contain $0.2 \times 10^{-6} \mathrm{~Pb} / 1$. The sea sediments contain an average of $30 \mathrm{ppm} \mathrm{Pb}$. (NSA)

Sugimura, Y. 1969. Study of the Chronology of Deep Sea Sediment with Radioisotopes. Nippon Kaiyo Gakkaishi. 25:261-8 (in Japanese).

The sedimentation rate and other characteristics of the ocean floors in the western North Pacific, Indian Ocean, and Japan Sea were studied by the $230 \mathrm{Th} /$ Th method first proposed by Picciotto, et al. The samples of 1 to 2 gram from each horizon of deep sea cores were processed with an anion exchange resin to separate the Th isotopes. These isotopes were fixed to an electroplating unit made of platinum, and the a intensity was measured by $\alpha-$ spectrometry. The distribution of surface $230 \mathrm{Th} / \mathrm{Th}$ ratio in the Pacific Ocean showed a remarkable regional difference, and the sedimentation rate in the world oceans was below $10 \mathrm{~mm}$ per thousand years. The surface sedimentation rate in the western North Pacifjc ranges from 0.5 to $7.3 \mathrm{~mm} / 10^{3}$ year, but the ratio changes sharply at $10^{5}$ year. B.P., suggesting that the rate was greater before turning point of $10^{5}$ year. The average rate of $15 \mathrm{~mm} / 10^{3}$ year was obtained in the equatorial region of the Indian Ocean. The sedimentation rate in the Japan Sea was found to be about ten times as large as the Pacific Ocean, and the distribution of uranium shows a remarkable increase from $10^{4}$ year B.P. on. The cause of this change was probably due to the glacial custacy which might control the water exchange in the Japan Sea, and it shows that at the time some oxygen-free conditions were brought about at the bottom of the sea. (NSA)

Szabo, A. and A. Soo. 1957. Radioactivity of Waters and Muds from Salt Lakes and Mineral Springs in Sovata and Praid Baths. Acad. Rep. Populare Romine Inst. Fiz. Atom. IFA/R/12.

In the salt lakes and mineral springs in this area, the radon content ranged from 0 to $1.17 \mathrm{millimicrocuries}$ and the Ra from 0 to $31.5 \times 10^{-12} \mathrm{~g} / \mathrm{g}$. The saltwater contains either traces or detectable amounts of $\mathrm{Rn}$ or $\mathrm{Ra}$. Thermal water contained the highest amount.s. (CA)

Szabo, B. J. 1972. Uranium-Series Systematics in Natural Materials from the Newport Area, Oregon. U.S.G.S. Professional Paper No. 880-C:199-201. 
Analyses of $U$, Th, and $\mathrm{Pa}$ isotopes in recent and fossil wood and kelp samples from this region indicate that migration of these radioelements was extensive. Thus, this type of material at chis location is unsuitable for U-series dating. The analytical data from a shell sample from the same area showed evidence of recent $U$ assimilation, which contributed to a minimum age estimate only. (CA)

Szalay, A. 1954. The Enrichment of Uranium in Some Brown Coals in Hungary. Acta Geol. Acad. Sci. Hungary. 2:299-311.

Geochemical enrichment of uranium is ascertained in some brown coal strata in Hungary. These strata are situated near to the detritus zone of the two existing granitic mountains of Hungary. The uranium content of these coal strata is about the same (about 0.01 percent) as the $U$ content of bioliths (oil shales, carbonate rocks, etc.) used to be. It seems highly probable that the same unknown general geochemical law is responsible for all such enrichments in bioliths. The granitic rocks are the primary sources of uranium, the $U$ migrated into the sea or moor water during the age of chemical decomposition of the rocks. Uranium became adsorbed by the decumposing organic substance of the sediments. Laboratory experiments revealed that decomposing plant debris, peat, lignite, and brown coal have a very high adsorption power and capacity for uranium, which is in fact sufficiently high to explain geochemical enrichment. Subsequent experiments revealed and control experiments verified that the humic acid colloid particles are responsible for the adsorption, which is a cation exchange prucess. The adsorption equilibrium ronstant of humic acid substance is much higher for uranium than for cations of lower valence and lower atomic weight. It seems, that the hitherto unknown law of geochemical enrichment of uranium in bioliths is herewith explained. This law may be formulated in the following manur: the geochemical erırichment of uranium in carbonate rocks (bioliths) is caused by the adsorption of dissolved uranium by the humic acid content of the sediments. The adsorption is a cation exchange process. (auth)

Szalay, A. 1957. The Role of Humus in the Geochemical Enrichment of $U$ in Coal and Other Bioliths. Acta Phys. Acad. Sci. Hungary. 8:25-35.

Investigations established that the enrichment of $U$ in peats, coals, and other bioliths is caused by adsorption on the humic acid. Adsorption isotherms have been measured and numerically evaluated. The adsorption itself is actually a catiun exchange process. The enrichment factor of $i: 10,000$ agrees well with the quotient of the concentration of $U$ in bioliths and natural waters. (auth)

Tatsumoto, M. and E. D. Goldberg. 1959. Some Aspects of the Marine Geochemistry of Uranium. Geochim. et Cosmochim. Act. 17:201-8. 
The $U$ concentrations in marine calcareous material of a biological origin varied between $0.0 X$ and $0 \cdot X \mathrm{ppm}$, with the exception of corals which had concentrations of several ppm. The aragonitic oolites and aragonite precipitated from seawater had values similar to those of the corals. A geochronology based on the growth of ionium ( $T h^{230}$ ) from $U$ is applicable not only to corals, as previous investigators have pointed out, but also to oolites. Several examples of "oolite ages". are given. The $U$ content of ferromanganese minerals from pelagic deposits is of the order of from 4 to $5 \mathrm{ppm}$. (auth)

Telfair, D., R. Garrison and C. Smith. 1960. Natural Radioactivity of Miami Soils. Science. 131:727-8.

The relation between gross $\gamma$ activity and soil depth for a particular soil (Miami silt loam) is presented, together with a discussion of the contribution of $K 40$ and the $U$ and Th series and of the effects of fallout from bomb tests in increasing the radioactivity of a thin layer of surface soil. The increased count rate in the $B$ horizon is caused partly by $k^{40}$ in the lower soil horizons and partly by a similar trend for Ra. The greater accumulation of $\mathrm{Rn}$ in the $\mathrm{B}$ horizon must be accompanied by a higher $\mathrm{Ra}$ concentration. This was not expected, since $R a$ is known to behave chemically somewhat as $\mathrm{Ca}$ does, and $\mathrm{Ca}$ (in these soils) has been leached from the $\mathrm{B}$ horizon but occurs at higher concentrations in the underlying glacial till ( $C$ horizon). It is possible that the leaching of $U$ from the $A$ horizon and its adsorption on clay surfaces in the $B$ horizon are important here. (CA)

Thomson, J. and A. Walton. 1971. Natural Radioactive Decay Series Elements in the Oceans and Sediments. Proc. Roy. Soc. Edinburgh, Sect. B. 72: 167-82.

A literature reivew is presented of studies on radioisotopes in oceans and sediments. Studies of radium in oceans and sediments are reviewed with regard to the origin of high radium concentrations in sediments and the migration of radium in sediments. Studies on thorium and protactinium in oceans and sediments are discussed under the following headings: analytical advances; direct measurements of uranium, tiroium, and protactinium isotopes; thorium isotope ratio $(230 \mathrm{Th} / 23<\mathrm{Th}$ ) approach; thorium/protactinium (230 Th/ $231 \mathrm{~Pa}$ ) approach; uranium isotope ratio $(234 \mathrm{U} / 238 \mathrm{U})$ deviation; leaching vs solution of sediments; and comparisons of age determination methods.

Thurber, D. L. 196?. Natural Variations in the Ratio of $U^{234}$ to $U^{238}$. Radioactive Dating. Proc. Symp., Athens. pp. 113-20.

Anomalous $\mathrm{U}^{234} / \mathrm{U}^{238}$ activity ratios in integrating basins, such as the ocean and playa lakes, provide a promising new geological dating method for the period $10^{5}-10^{6}$ years in both continental and marine systems. The $0^{234 / 1238}$ 
activity ratios of $\mathrm{CO}_{3}$-- deposits from 2 glacial lake basins and a few selected marine samples, were measured by a-spectrometry after a chemical separation of $U$ from Th. Core samples from an Eniwetok drill-hole gave ages based on $U^{234} / U^{238}$ ratios in agreement with other methods. Six samples from the Lake Lahontan Basin gave a ratio $\sim 1.5$, and 6 from Lake Bonneville were $\sim 2.0$, indicating that these samples are $<1.5 \times 10^{6}$ years old. (CA)

Tiratsco, E. N. 1949. The Radioactivity of Sediments. IV. Radioactivity and Petroleum. Petroleum. 12:313-15.

Previous workers have reported unusually high radon activities in crude oils and in oilfield waters (Bohn, J. Franklin Institute 210, 461 (1930); Bern, Kali 30, 41(1936)). Activity measurements were made on crude oil samples from Germany, Holland, Iraq, and Trinidad. Alpha-ray activities were found which indicated high radon concentrations, but no $\gamma$ radiation was detected. These results tend to confirm previous reports, and to indicate that radon is absorbed by crude oil from the surrounding rocks. No radioactivity was detected in the oilfield waters. However, high activities were noted in several samples of oil shales. The activities of the oil shale and crude oil samples are tabulated. The author considers the possible influence of this radioactivity on the formation of oil deposits. (NSA)

Titaeva, N. A. 1967. On the Character of Radium and Uranium Bond in Peat. Geokhimiya. 12:1493-99.

In little-mineralized hydrocarbonate-calcic surface waters uranium is considerably more mobile than radium. Radium is well sorbed not only by clay sediments but also by peat. In peat uranium is bound to the fraction of hurric acids and fluvoacids being soluble in alkalis, and radiunl to the insoluble residue. The bond of elements under oxidizing conditions has an exchange character. In the presence of great calcium amounts in water the radium bound in peat and in the insoluble residue becomes poorly exchangeable. In humic acid the exchange character of the radium bond is preserved. (auth)

Titaeva, N. A. and T. I. Veksler. 1969. Uranium and Thorium During Weathering of Yakutia Rocke. Gcokhimiya. Nö. 6:740-4 (in Kussian).

The behavior of $U$ and Th was studied during weathering of bedrock under specific conditions of the sharply continental climale of Yakutia and widely distributed permafrost, $i . e$. , under conditions inducive to intense physical weathering. Cold waters over the permafrost layer are rich in organic substances and have elevated $\mathrm{O}_{2}$ and $\mathrm{CO}_{2}$ concentrations favorable for chemical weathering of upper thawing layers of rocks. The study was made in two areas in the upper reaches of the Vilyui River and in the Aldan-Timpton interfluve. 
Ine tirst region was within the large differentiated trap intrusion and the second consisted of an Archean metamorphic gneiss and crystalline schist complex. Noticeably high removal of Th, accumulating in alluvium, was observed in both areas. The $U$ was also removed from all rocks. The removal of $U$ somewhat lagged behind that of other metal components in rocks which were relatively easily chemical weathered (carbonate rocks, tuffs, and dolerites), the $U$ concentration increasing somewhat in the eluvium from these rocks. This was not observed in crystalline metamorphosed and acidic igneous rocks where the eluvium had a somewhat low concentration of $U$. The mobile $U$ was removed first. The $T h / U$ ratio increased in the weathering products of all rocks. The Th/ $U$ ratio can be used as an indicator of chemical weathering of rocks. (CA)

Tolstoi, M. I. 1961. Relation of the Radioactivity of Clays to Their Mineralogical Composition. Izv. Vysshikh Uchebn. Zavedermi, Geol. i Razveaka. $4: 66-71$.

A study was made of 55 clay samples taken from wells in Carpathia. Studied were: 1) the total radioactivity of the samples; 2) the $U$ and Th contents; and 3 ) the content of organic material. A total of 500 samples of clays and clay fractions was studied. The total radioactivity increases with increasing contents of $K$ salts and organic residues in the clay material.

Tugarinov, A. I. and I. B. D'yachkova. 1967. Some Common Geochemical Characteristics of Selenium and Uranium. Vop. Prik1. Radiogel. No. 2: 380-6 (in Russian).

The Se geochemistry in earth crust is controlled above all by analogy of $i$ ts properties with those of $S$. The highest Se/S ratio, typical of sedimentary rocks in which the Se is present mostly in the form of native Se or selenides is accompanied, as a rule, by $U$ mineralization. The mobility of Se and $U$ under oxidizing conditions and their almost complete inert behavior in reducing medium are the main geochemistry properties controlling Se and $U$ in exogenic processes. Extraction of Se and $U$ from rocks is possible by solutions, having sufficiently high $E_{H}$, through oxidation. The alkaline medium is the most favorable for simultaneous transfer of Se and $U$ into the mobile state. The Se and $U$, migrating in surface waters, are concentrated in rocks having high reducing capacity. If, under favorable conditions (short distance from the denudation area, oxidation character of the solution, etc.). the Se reaches the sea, then, similarly to $U$, it is precipitated immediately and is accumulated in the continental shelf region. Absorption phenomena promote the separation of Se andS in addition to oxidation-reduction factors. Organic substances played a large part in the concentration of $\mathrm{Se}$ and $U$. " Under hypogene conditions, the oxidationreduction factor controlled to a large degree the formation of sediments of elements having changed valency in a definite sequence. (CA) 
Turekian, K. K. and K. K. Bertine. 1971. Deposition of Molybdenum and Uranium Along the Major Ocean Ridge Systems. Nature. 229:250-1.

In order to investigate the time varying pattern of the deposition of $U$ and Mo along a ridge site the distribution of these elements with depth in a core raised from the Mid-Atlantic ridge Lamont-Doherty core A 180-74 was studied. The two elements are shown to vary sympathetically with a pronounced enrichment at the depth interval between 40 and $70 \mathrm{~cm}$. It is proposed that most of the sediments with high concentrations of molybdenum and uranium found on seismically active and relatively inactive ocean rises reflect the formation of anaerobic sediments, in part the result of the high rate of supply of organic material to the relatively shallow ocean bnt.t.ms along the ridgc area. (NJA)

Turekian, K. K., J. P. Riley and G. Skirrow (eds). 1964. Geochemistry of Marine Sediments. TID-21074.

A discussion of the major features of deep-sea sediment geochemistry is presented. The information is presented in sections on components of deep-sea sediments, radioactive dating and rates of accumulation, traceelement geochemistry in the oceans, and geographical variations. (NSA)

Tyuryukanova, E. B. and V. A. Kalugina. 1971. The Behavior of Thorium in Soils. Soviet Journal of Ecology. 2:467-469.

An investigation of thorium distribution in soil profiles showed that it accumulated in the ferruginous humus horizon or in the humus horizon of meadow soils. The latter accumulation may be indicative of biological cycling. Ihorium contents were lowest in peaty horizons indicating limited uptake of thorium by bog plants.

Umemoto, S. and M. Sakanoue. 1958. Geochemical Studies on the Radioactive Sediments. I. Uranium and Radium in the Sedimentary Beds at the Ningyo Pass, Tottori Prefecture. Nippon Kayaku Zasshi. 79:27-32.

The sedimentary beds consist (in downward order) of ash-colored shale, silts, ash-colored shale (I), brown shale (II), black shale (III), silt and clay, limonite (IV), and conglomerate (V). The bed rock is granile. The $U$ content of I, II, III, and IV are $0.11,0.08,0.13$, and 0.03 prercent, respectively. A slrung radioactivity of III containing large amounts of $\mathrm{MnO}_{2}$ (7-8 percent) is mainiy due to the activity of $\mathrm{Ra}\left(5.4 \times 10^{-9} \mathrm{~g} \mathrm{Ra} / \mathrm{g}\right)$. Differential thermal analysis curves for I, II, and III show the presence of halloysite. There is a relation between the $U$ content and the estimated content of halloysite. Analysis of autunite found in the layer of $V$ gave 49.0 percent $U$ and $3.53 \times$ $10^{-8} \mathrm{~g} \mathrm{Ra} / \mathrm{g}$. By assuming that the mineral originally contained no $\mathrm{Ra}$, and that the present $R a$ has been derived from $U$, its age is calcualted to be about 30,000 years. (CA) 
Urry, W. D. 1948. Radioactivity of Ocean Sediments. VII. Rate of Deposition of Deep-Sea Sediments. J. of Marine Research. 7:618-34.

The rate of sedimentation can be determined from Ra content of the sediments, since variations in $\mathrm{Ra}$ content occurred during the establishment of radioactive equilibrium in deep-sea deposits. Rates of deposition as a function of time (for the past half million years) are reported for red clay, globigerina ooze, foraminiferal marl, glacial marine deposits, and calcareous blue mud. The results agree well with those of other methods. (NSA)

Urry, W. D. 1948. The Radium Content of Varved Clay and a Possible Age of the Hartford, Connecticut, Deposits. American Journal of Science. 246: $689-700$.

The radium content of the summer and winter portions of the varves in the clay deposits at Hartford, Connecticut, vary rhythmically. When the radium contents of the summer and of the winter portions are plotted against time as measured by the varve count, the curves exhibit slopes of opposite sign . The total radium content of any varve, however, is practially constant. These phenomena may be due to a disturbance of the radioactive equilibrium but this hypothesis, while plausible, is far from proved. A greater concentration of the uranium. relative to ionium in the winter clay than in the summer clay would explain these phenomena. Such a disturbance of the equilibrium provides a means of determining the age of the deposits. On this basis, one derives a tentative figure for the age of the Hartford clay (varve 3700 ) of 18,000 years. The hypothesis of a disturbance of radioactive equilibrium is supported by the fact that the analyses of the summer and winter curves which are completely independent give very nearly the same age. (NSA)

Urry, W. D. 1949. Radioactivity of Ocean Sediments. VI. Concentration of the Radioelements in Marine Sediments of the Southern Hemisphere. American Journal of Science. 247:257-275.

In the previous publications of this series [American Journal of Science 55 229(1933); J. Wash Acad Sci 29 405(1939); Amer J. Sci 239 81(1941); $2401(1942) ; 24093(1942)]$ the use of measurements of the radium concentration in the sediments beneath the ocean as a means of determining the age of the sediments has been described. Since the previous data were taken in the northern hemisphere, further determinations have been made using cores obtained from the southern hemisphere. Seventy such determinations of the uranium content of ocean sediments have been made for a number of depths in each of six cores obtained from various areas. The curves thus obtained of the radium content as a function of depth below the ocean bottom are similar in all qualitative respects to the curves previously obtained for cores from the North Atlantic and Caribbean Sea. (NSA) 
Urry, W. D. and C. S. Piggot. 1942. Radioactivity of Ocean Sediments. V. Concentrations of the Radioelements and Their Significance in Red Clay. American Journal of Science. 240:93-103.

The relationship among $U$, ionium and $R a$ in deep-sea red clays is similar to that in calcareous ocean sediments. The red clay, represented by a core $246 \mathrm{~cm}$ long, is distinguished from the calcareous sediments by a very rapid decrease in Ra just below the surface of the ocean bottom and the attainment of equilibrium between $U$, ionium and $R a$ in the bottom $1 / 4$ of the core, which signifies a very slow deposition compared with that of calcareous deposits. The $\mathrm{Ra}$ content at equilibrium with the $U$ is only 7 percent of that near the surface of this deposit. The high surface concentrations of Ra and ionium, particularly in red clay, are transient phenomena, produced by some unknown mechanism, which concentrates these elements, relatively to the $U$ content, during the deposition of the sediment. (CA)

Veeh, H. H. 1967. Deposition of Uranium from the Ocean. Earth Planet. Sci. Lett. 3:145-50.

Anaerobic sediments from the upper continental slope in the eastern Pacific, the Gulf of California, and a Norwegian Fjord have been analyzed for their total uranium content and $234 \mathrm{U} / 238 \mathrm{U}$ ratios by alpha-spectrometry. The uranium concentrations range from 4.8 to $39 \mathrm{ppm}$ and are thus significantly higher than the average uranium content of three ppm in deep sea clays, stream sediments and soils. The $234 \mathrm{U} / 238 \mathrm{U}$ ratios approach the seawater value of 1.15 in samples with high uranium content. These results indicate that uranium is being removed from seawater in near shore areas under certain conditions. If such conditions prevail in only 0.4 percent of the total area covered by the ocean, an amount of uranium equal to that supplied by streams (assuming $0.04 \mu \mathrm{g} / 1$ ) can be removed from the ocean, on the basis of measured accumulation rates in the Gulf of California, off southern California, and in other areas. The effect of Pleistocene sea level fluctuations as a controlling factor in determining the concentration of uranium in seawater is diminished by the occurrence of extensive areas of uranium deposition below $200 \mathrm{~m}$ and by the very long residence time of uranium in the ocean. (auth)

Venkataramian, K. 1966. Uranium in Carbonaceous Clays in Neyveli, South Arcot, Madras State. Journal of Geological Society India. 7:129-33.

Lignite seams are low in $U\left(0.004\right.$ percent $U_{3} 0_{8}$ in the ash), but a thin seam of carbonaceous clay overlying the lignite showed in 19 analyses $0.005-$ 0.086 percent $U_{3} 0_{8}$. The clay is also high in $V(90-1300)$, Mo $(5-23)$, Se $(3-180)$, and $A s(3-40 \mathrm{ppm})$. The material shows radioactive disequilibrium. (CA). 
Vinogradov, A. P. 1959. The Geochemistry of Rare and Dispersed Chemical Elements in Soils. Second Edition. New York, Consultants Bureau, Inc.

This volume consists of nineteen chapters which cover the following subjects: methods of determining rare and dispersed elements in soils; some general geochemical regularities in the distribution of rare elements; soil-forming rocks and soils of the eastern European plain; boron in soils, fluorine, bromine, and iodine in soils; arsenic and selenium (tellurium) in soils; lithium, rubidium, and cesium in soils; strontium and barium in soils; rare earth metals and yttrium, titanium and zirconium (hafnium) in soils; vanadium, chromium, manganese, cobalt, and nickel in soils; copper, zinc, and cadmium in soils; lead and tin in soils; molybdenum and tungsten, radioactive elements in soils; other dispersed elements in soils; and geochemical regularities in the distribution of rare elements in soils. (NSA)

Voitekhovskaya, Y. V., G. V. Gurskii and S. A. Tikhonov. 1965. Content of Uranium in Soddy Podsolic Soils of the Belorussian SSR. Mater. Nouc. Konf. Molodykh Geol. Beloruss., First Minsh. pp. 98-9 (in Russian).

$U$. in the Belorussian soddy podsolic soils, developed on various soil-forming rocks, varies 0.2-5.0 with an average content of $1.8 \mathrm{ppm}$. The soils, developed on the glacial loams, and soils in depressed parts of the topography had the highest content of $U(\leqq 3.5-5 \mathrm{ppm})$. The smallest content of $U$ was observed in soils developed on colian sands and loess loams. (CA)

Von Backstroem, J. W. 1973. Uranium Amongst the Fossils. Nucl. Active. p. 31-4.

$A U$ and $U$ occurrences are related in the sediments of the Witwatersrand Supergroup. The two were deposited together as an integral part of sediments transported by water. $U$ is found with reptile fish and flora fossils embedded in line clastic sediments in the Karoo basin. This geological formation is similar to that of the Colorado Plateau where $U$ deposits are being exploited. An aerial radiometric survey of the Karoo deposits will be undertaken. (CA)

VonGunten, H. R., W. Buser and F. G. Houtermans. Determination of Extreme Th/U-Ratios in Minerals. A Radiochemical Method for Determination of Thorium. A/CONF $15 / P / 250$.

For age determination of $U$ and Th minerals an accurate measurement of the Th/U ratio is needed, especially when accessory lead is present. The correction of accessory lead may be made on the basis of the isotope $\mathrm{Pb}^{208}$. It is therefore necessary to determine very low contents of Th in $U$ minerals very exactly to have a measure for radiogenic $\mathrm{Pb}^{208}$. The quantitative determination of thorfum in minerals by chemical methods is rather laborious. The proposed radiochemical method reduced the chemical separations to a 
minimum. The principle of the method consists of an analysis of the decay curve of the lead fraction. After dissolution of the mineral all lead is extracted by the dithizone method. The extracted lead is measured in liquid counter tubes. After decay of short-lived RaB, AcB, and daughter products the radioactivity increases, until equilibrium of ThC and ThB is attained. Then the radioactivity is determined during 3 to 48 hours by ThB $+C+C^{\prime \prime}$. In case of very $10 \mathrm{w} \mathrm{Th} / \mathrm{U}$ ratios $\left(<10^{-3}\right)$ the solution was extracted twice with inactive lead as carrier. The second extraction of the same solution, after growth of ThB, allows an accurate measurement of ThB, allows an accurate measurement of ThB and therefore of the Th content in the solution. The disturbing effect of $\mathrm{RaE}$ is in this way reduced by the ratio of 0.5 days to 30 years. Th can be determined down to a ratio $\mathrm{Th} / \mathrm{U} \sim 10^{-4}$. The method is also practicable for high Th/U ratios. It is evident that the method is restricted to Th and $U$ minerals in complete radioactive equilibrium. (auth)

Weeks, A. D. Mineralogy and Oxidation of the Colorado Plateau Uranium Ores. U.S.G.S. Professional Paper. 300:187-93.

The $V$-rich ores contain mainly roscoente and montroseite. Primary ores with $V / U 15: 1$ to $1: 1$ contain the $U$ as uraninite and coffinite, the $V$ as montroseite. Ores lacking $V$ contain chiefly uraninite with pyrite, Cu sulfides, and galena. On oxidation, trivalent $V$ yields quadrivalent and quinquevalent $V$ minerals such as rauvite, melanovanadite, and corvusite. Further oxidation yields minerals containing $U(V I)$ and $V(V)$, such as carnotite, tyuyamunite, hewettite, pascoite, and others. Oxidation on nonvanadiferous $U$ ores yields a wide variety of U(VI) oxides, carbonates, sulfates, phosphates, arsenates, and silicates. Oxidation of the ores is much slower in ore below the water table. (CA)

Whitehead, N. L., R. R. Brooks and G. E. Coote. 1971. Gamma Radiation of Some Plants and Soils from a Uraniferous Area in New Zealand, N. Z. J. Sci. 14:66-76.

The amounts of several $\gamma$-emitters in plants (Weinmannia racemosa, kamahi; Nothofagus fusca, red beech; Coprosma australis; Quintinia acul ifolia; Blechnum procerum, fern; Marchania berteroana, liverwort; Unicinia leptostachya, sedge; Fissidens rigidulus and Bryum blandum, aquatic bryophytes; and Stereocaulon ramulosum, a lichen) growing on a uraninite vein and associated soils from a uraniferous area were determined by $\gamma$-spectrometry with the use of a Ge detector operating in the low energy region. The following isotopes were absorbed by plants: $210 \mathrm{~Pb}, 227 \mathrm{Ac}, 238 \mathrm{U}, 235 \mathrm{U}$, and $226 \mathrm{Ra}$. The average plant/soil ratios (dry weight) were $0.092,0.170$, 0.197 , and 0.815 , respectively. The contribution of each radionuclide and $i$ ts daughters to the activity of the plant samples were $2.2,3.3,81.5,33$, and 10.4 percent, respectively. The remainder, 0.7 percent, was due to $228 \mathrm{Th}$ and its daughters. Th isotopes were absorbed by a fern and a liverwort. ${ }^{141} \mathrm{Ce}$ and ${ }^{444} \mathrm{Ce}$ from fallout were found in leaf tissue. (CA) 
Whitehead, N. E., R. R. Brooks and P. J. Peterson. 1971. Nature of Uranium Occurrence in the Leaves of Coprosma Australis (A Rich.) Robinson. Aust. J. Biol. Science. 24:67-73.

The distribution and chemical form of uranium was investigated in leaves collected from plants of $C$. australis (Rutiacace) growing in a mineralized soil in the fuller Gorge, New Zealand. Only small amounts of uranium (< 10 percent) were found in a low molecular weight form. The predominant occurrence of uranium (65 percent) was as a uranium - RNA complex, which was isolated by high-voltage electrophoresis from an aqueous extract of the freezedried leaves. Uranium (25 percent) was released from the solvent extracted leaf residue by pepsin, thus revealing the presence of a uranium-protein complex. However, in view of the known dissociation constants for these two complexes, and other tests, it is clear that the majority of the uranium in vivo is in the form of a uranium-protein complex. This finding is confirmed by a differential centrigufation experiment, in which it was shown that at least 50 percent of the total uranium was bound to cell was proteins. (auth)

Wildung, R. E., R. C. Routson, T. R. Garland and A. V. Robinson. 1974. Sampling and Characterization of Surface Soils for Pu Studies. BNWL-1850, Part 2, UC48, pp. 23.

Ecosystems has 35 soils on which they will measure particle size; primary and secondary minerals vs size; $\mathrm{CEC}, \mathrm{CaCO}_{3}$; Percent $\mathrm{OC}$, ash; $\mathrm{FeAl}$ amorphous; and water-holding capacity.

Williams, C. and G. Brown. 1971. Uranium Content of Peaty Soils Rich in Molybdenum and Selemum from Co. Limerick, Eire. Geoderma. 6:223-5.

Peaty soils from Kilcolman, Co. Limerick previously shown to contain anomalously large amounts of selenium and molybdenum contain up to $550 \mathrm{ppm}$ uranium and $150 \mathrm{ppm}$ bromine. The uranium probably derives from the Clare Shales and is likely to have been connsentrated on the peat from drainage waters. (auth)

Wiseman, J. D. H. 1949. Geology on the Deep-Sea Floor. Nature. 164: $682-4$.

The six papers given before the geological section on problems concerning the deep-sea floor at a recent meeting of the British Association at Newcastle upon Tyne are discussed and some relevant information and comments added. The papers discussed included "The Chronology of the Ocean Floor" by $H$. Pettersson (Nature 164, 468(1949)) and one by the author on manganese nodules found on the surface of the deep-sea floor of the Arabian basin. These nodules are associated with red clay and are largely composed of manganese, iron, and water and contain, in addition, unusual amounts of nickel, copper, cobalt, barium, and radium. Definite confirmation about the fragmentation of spherical nodules and the deposition at a later date 
of a secondary manganese layer is given by the distribution of radium in tetrahedral nodules. The radium content of the secondary peripheral layer is practically constant $\left(11 \times 10^{-12} \mathrm{~g} / \mathrm{g}\right)$, while immediately below this layer the content is much lower $\left(0.9 \times 10^{-12} \mathrm{~g} / \mathrm{g}\right)$, and toward the center no radium could be detected. It is clear from these determinations that the original nodule was spherical and increasing radium content toward the periphery, and that it afterwards broke into tetrahedral masses, around which a secondary layer of manganese material was deposited. The Pettersson paper dealt with the methods used for correlation in deep-sea cores; first the radioactive method, second the mineralogical method, third the pollen analysis method, and fourth the biological method. The significance of the high content of radium in seawater, which has been noted in his article in Nature, is discussed. (NSA)

Wollenburg, H. 1972. Fission Track Radiography of Uranium and Thorium in Radioactive Minerals. Report. RSO-228.

The fission track method is a quick, relatively simple, and inexpensive technique to determine the location and abundance of $U$, and in some cases $T h$, in thin or polished sections of rocks. Thermal $n$ induce fission in $235 \mathrm{U}$, while $232 \mathrm{Th}$ and $238 \mathrm{U}$ fission with fast-n bombardment. Therefore, sections with appropriate track detectors are exposed first to thermal $n$ to induce only $U$, then to fast $\mathrm{n}$ for $\mathrm{U}$ plus Th. The detectors are etched to reveal the tracks caused by passage of massively charged fission fragments. High quality muscovite mica is the preferable track detector for minerals with $U$ concentrations > 10 to 15 ppm, mainly because tracks in mica are easy to recognize. Polycarbonate plastic (Lexan or Makrofol) is preferred as a track detector for low concentrations of $U$ and $T h$ because this material contains essentially no inherent $U$, therefore, it has no background tracked. Th is determined successfuliy if the Th/U ratio of the mineral is sufficiently large. Relative errors (from counting statistics) in Th are $<25$ percent if $\mathrm{Th} / \mathrm{U}$ is $>3$, for ratios $<3$ the errors increase rapidly and exceed 40-50 percent if $\mathrm{Th} / \mathrm{U}$ is $<1$. (CA)

Yabuki, H. and M. Shima. 1973. Uranium and Other Heavy Elements in DeepSea Sediments Coexisting with Manganese Nodules. Sci. Pap. Inst. Phys. Chem. Ris. (in Japanese). 67:155-6.

$\mathrm{Mn}, \mathrm{Fe}, \mathrm{Cu}, \mathrm{Ni}$, and $\mathrm{Co}$ were analyzed by atomic absorption spectrometry and $U$ was determined by the induced fission track method by applying internal standard addition. The samples were deep-sea sediments, a kind of foraminiferous ooze which consists mainly of $\mathrm{CaCO}_{3}$ found in the area with the $\mathrm{Mn}$ nodules. The analyses were compared with similar data obtained previously for the $\mathrm{Mn}$ nodules. The nodules were richer by a factor of $\sim 5$ for $U$ and by a factor of $>100$ for the other elements. This tendency of $U$ is also seen in the relation between seawater and nodules or sediments. This may mean that $\mathrm{UO}^{2+}$ ion in seawater rarely coprecipitates with $\mathrm{Mn}$ or Fe by scavenging effect, but forms complex ions with carbonate and is adsorbed on the surface 
of sediments or nodules. Data suggest that $\mathrm{Mn}, \mathrm{Ni}$, and $\mathrm{Co}$ are accumulated in both nodules and sediments at about the same rate. Results imply that $\mathrm{Cu}$ coprecipitates with $\mathrm{Fe}$, rather than $\mathrm{Mn}$. (CA)

Yakobenchuk, V. F. 1968. Radioactivity and Chemical Properties of Sod-Podzolic Soils in the Ukrainian Western Polesie. Visn. Sil's' Kogosped. Nauki. $11: 45-50$ (in Ukranian).

The level of $\alpha$-radioactivity of sod-podzolic soils of the area is dependent on the content of $\mathrm{Al}$ sesquioxide $\mathrm{Al}_{2} \mathrm{O}_{3}$. The level of $\mathrm{B}$-radioactivity is correlated with the amount of sandy and muddy particles of mechanical composition of the soil, and with the amount of $K, U$, and sesquioxides of $A 1$ and $\mathrm{Fe}$. The concentration of $U$ is correlated with the amounts of oxides of $\mathrm{Si}, \mathrm{Fe}, \mathrm{Al}$, Th, and $\mathrm{Ra}$. The amount of $\mathrm{Th}$ is dependent on the reaction of soil solution and on the amount of $\mathrm{CaO}$. The amount of $\mathrm{Ra}$ is correlated with the amount of organic substances in the soil. Chemical analyses are tabulated. (CA)

Yamamoto, T., E. Yunoki, M. Yamakawa and M. Shimizu. 1973. Environmental Contamination by Uranium. III. Effects of Carbonate Ion on Uranium Adsorption to and Desorption from Soil. Journal of Radiat. Res. 14: 219-224.

Adsorption of uranium on soils and its desorption from uranium-adsorbed soils in the presence of carbonate ion were examined by using three kinds of soils: alluvial soil, sandy soil and volcanic ash soil. The absorption ratio of uranium for each soil was approximately 100 percent for the mixtures of uranyl ( 1 to $50 \mu \mathrm{gU} / \mathrm{ml}$ ) and carbonate solutions $\left(4.3\right.$ to $109 \mu \mathrm{gCO} 3^{2-} / \mathrm{ml}$ ). In the uranium adsorbed soil $(7.1$ to $500 \mu \mathrm{gU} / \mathrm{g}$ air-dried soil) with carbonate ion $(4.3,43.4 \mu \mathrm{g} / \mathrm{ml})$, the desorption ratio of uranium for each soil was low ( 0.09 to 1.2 percent). The adsorption of uranium on soils and the desorption from uranium adsorbed soils with stream water were probably similar to those with carbonate solution. (auth)

Yamamoto, T., K. Masuda and N. Onishi. 1968. Studies on Environmental Contamination by Uranium. I. Environmental Survey of Uranium in Kamisaibara Village. Okayama Prefecture. J. Radiat. Res. 9:92-9.

In order to investigate situations of uranium contamination in Kamisaibara village where uranium mines are being developed, measurements have been made on the amounts of uranium contents in soil and in farm produce since 1965 by counting system and fluorimetric method. As a result, it. has been found that the mean amounts of uranium flow in the streams in each year is higher at the sampling spots where drainages of gallarium and the pilot refinery were disposed, and the amounts were between 5.39 and $204.5 \mathrm{mg}$ per minute. At sampling spots about 2,000 $\mathrm{m}$ lower than gallery and pilot refinery drainages, the detectable amounts were 0 to about 30 percent more 
than detected amounts in each preceding year. In general, the spots where the element can be detected gradually move downward year by year. The uranium contents in soil sampled in the village were 1.9 to $4.0 \mathrm{ug}$ per $\mathrm{g}$ of air-dried soil. Uranium was detected in all vegetables sampled in the village, and the contents were between 0.1 and $0.67 \mathrm{ug}$ per $\mathrm{g}$ of ash, while it could not be detected in all the vegetables sampled in Okayama City. on uranium contents in soils and vegetables, however, no remarkable variation with time could be observed. (auth)

Yastrebov, M. T. 1971. Natural Radioactivity of Some B1ack-Earths in the European fireas of the USSR. Biol. Pochvoved. 26:93-97 (in Russian).

The radionuclides ${ }^{238} \mathrm{U}, 226 \mathrm{Ra},{ }^{242} \mathrm{Th}$, and $40 \mathrm{~K}$ in black earth were determined by gamma spectrometry, with a maximum error of 11 percent. The order $8 f$ absorption of these heavy nuclides by plant roots is $226 \mathrm{Ra}>238 \mathrm{U}>242 \mathrm{Th}$. In the southern chernozems the $238 \mathrm{U}$ content in the humus-accumulating layers was a factor of 1.3 to 1.8 lower than in rock because of the loss of this isotope by being taken up in plant roots. The $226 \mathrm{Ra}, 232 \mathrm{Th}$, and $40 \mathrm{~K}$ contents of the southern chernozem layer is 1.3 to 1.5 times that in rock, apparently because of less intense removal by plants. In distinction from the leached soils, the $238 \mathrm{U}$ accumulation in carbonate illuvial layers of the southern chernozems is sma11. Analytical data are tabulated. (NSA)

Yastrebov, M. T. 1971. Natural Radioactivity of Some Soils Formed in Various Landscapes of the Sod-Podzol Zone. Izv. Akad. Nauk SSSR Ser. Biol. No. 3: 408-14 (in Russian).

$\gamma$-Ray spectrometric investigations of soil samples showed that ${ }^{238} \mathrm{U}, 226_{\mathrm{Ra}}$, $232 \mathrm{Th}$, and $40 \mathrm{~K}$ migrated from the sod-podzol soils of eluvial and transeluvial landscapes of the Valdai llills into the silt-gley soils of the hydromornhous landscape in the Prijlmensk lowland. This will increase the exposure of plants and microorganisms of this area to radioecological influences.

Yastrebov, M. I., 1973. Natural Radioactivity of Some Soils in Landscapes of the Tamov Forest Steppe. Vestn. Mosk. Univ., Biol., Pochuved. 28:91-6 (in Russian).

Behavior of $238 \mathrm{U}, 226 \mathrm{Ra}, 232 \mathrm{Th}$ and $40 \mathrm{~K}$ in meadow soils in wcll watered $\mathrm{Ca}-\mathrm{Na}$ forest-meadow 1 andscape and in typical paleohydromorphic rhernozems was described. Data on ion mobllities of these isotopes were tabulated and the level of natural isotopes determined at various depths. The contents of the four isotopes in such soils was determined mainly by their content in the horizons and mineral structures, by land profiles, by the action of surface and soil waters, and by bigaccumulation. In $A_{1}$ horizons of the chernozems and meadow soils the $226 \mathrm{Ra}$ predominated over $238 \mathrm{U}$ owing to greater bioaccumulation of the former. In chernozem-meadow and chernozemoid bottom soils, $238 \mathrm{U}$ predominated over $226 \mathrm{Ra}$ owing to greater inflow in the water supplies. (CA) 
Zeschke, G. 1959. Uraninite Occurrence in Heavy Mineral Sands in the Indus Valley. Minera 1. Abhand1. 93:240-56 (in German).

In the gold-rich sands of the Indus River, especially in the northern part of West Pakistan, uraninite, monazite, scheelite, zircon, ilmenite, and previously unknown minerals were discovered. Uraninite exhibits an abnormally high radioactivity would could be traced back to the decay products of the radium series. The type of radiation was investigated and discussed. Chemical and physical separations were made to detect the radiation source. Uraninite is especially enriched in the smallest grains, generally in idiomorphic form. The occurrence was compared with other known occurrences. It was shown that a weathering of uraninite can follow different patterns and that a liquid transport of several $50 \mathrm{~km}$ as well as an enrichment in alluvial ores results. The economic possibilities were mentioned. (auth) 
THIS PAGE

\section{WAS INTENTIONALIY LEFT BLANK}




\section{SELECTED BIBLIOGRAPHIES AND ANNUAL REPORTS}

Several bibliographies already have been published that have included actinide-sediment reactions in their report abstracts. These bibliographies have been listed in the following section for the convenience of persons working in sediment-related areas such as plant ecology. The recent annotated bibliography by $C$. W. Francis (ORNL-EIS-75-77) would be of primary interest to those researchers. Much of the literature pertaining to radioisotopes other than the actinides and their sediment or clay reactions were reviewed by Brownel1, Kindle and The is (ARH-2731).

Recent annual or semi-annual reports also were included in some instances as a means of becoming current on actinide-sediment work. 
THIS PAGE

\section{WAS INTENTIONALLY}

LEFT BLANK 
Anonymous: 1973. Radioactive Waste Management. A Bibliography of Publicils Available Literature Pertaining to the USAEC's Hanford, Washington Productior Site. TID-3340.

This bibliography contains abstracts of 1098 technical reports and journal articles which have appeared in Nuclear Science Abstracts from January 1951 through July 1973 pertaining to radioactive waste management at the Hanford site.

The abstracts are grouped into ten categories as indicated by the table of contents. Within the categories, they are arranged by the Nuclear Science Abstracts volume and abstract number.

Anonymous. 1974. Proceedings of the Second AEC Environmental Protection Conference, held at Albuquerque, New Mexico, April 16-19, 1974. Vol: 1, WASH-1332-74-V-1.

The Division of Operational Safety of the Atomic Energy Commission sponsored the environmental protection meeting. Attendees from most of the Atomic Energy Commission installations gave papers on a diversity of subjects including plutonium in the soil, wastewater treatment to remove plutonium and plutonium transport by groundwater.

Bensen, D. W. 1960. Review of Soil Chemistry Research at Hanford. $\mathrm{HW}-67201$.

Soil adsorption of cesium, strontium, plutonium, zirconium, ruthenium and the rare earth series isotopes from water and from simulated and actual waste in the laboratory and under field conditions is discussed.

Ion exchange, precipitation and in some cases mineral replacement reactions are responsible for radionuclide uptake by soil. The completeness with which an ion is taken up by ion exchange on the soil is dependent upon the concentration of the radionuclide and upon the concentration of accompanying ions. The concentration of the radionuclide and of accompanying cation species are of minor importance in precipitation and in mineral. replacement reactions.

Cesium is taken up by an ion exchange reaction. In some cases a portion of the cesium is "fixed" in the soil. Strontium is also largely taken up by ion exchange. In calcareous soil strontium can be removed from alkaline solutions by a mineral replacement reaction with calcite $\left(\mathrm{CaCO}_{3}\right)$. Above $\mathrm{pH} 2$ plutonium and zirconium are laregly taken up by precipitation on the soil. The rare earth nuclides and yttrium are similarly precipitated at $\mathrm{pH}$ above 6 . Below the $\mathrm{pH}$ necessary for complete precipitation, soil uptake of these nuclides presumably occurs by a combination of ion exchange and precipitation. The uptake of trivalent rulheriium is similar to that of the rare earths. 
Soil uptake of plutonium, zirconium, rare earths and ruthenium is adversely affected by anions which form complex anionic species with the nuclides.

Strontium is usually taken up from alkaline wastes more completely than cesium. However, from an acid waste, cesium uptake is better than that of strontium. The general order of radionuclide uptake from waste is:

$$
\mathrm{Pu}>\mathrm{R} \text {. E. }>\mathrm{Sr}>\mathrm{Cs}>\mathrm{Ru} \text { (auth) }
$$

Brownel1, L. E., C. H. Kindle and T. L. Theis. 1973. Review of Literature Pertinent to the Aqueous Conversion of Radionuclides to Insoluble Silicates with Selerted References and Bibliography. ARH-2731.

Radioartive waste fission products and residual actinides in chemical processing plant wastes need to be isolated from biological processes until the radionuclides decay to innocuous levels. A promising method for effecting isolation is to convert the wastes to a highly insoluble material for final storage. The product should be inert for maximum immobility regardless of storage mode during long-term and any interim storage. Naturally-occurring systems that may yield suitable product forms are the aluminosilicate mineral groups which form much of the earth's crust.

Methods being investigated convert nuclear waste into crystalline aluminosilicate minerals wherein each of the nuclide cations are contained within individual molecular cages that constitute the crystal lattices. In the course of the investigation, the literature pertinent to immobilization of cations by silicates, with emphasis on aqueous systems, was reviewed. This report summarizes the literature and includes a bibliography to assist other investigators. (auth)

Christ1, R. J. 1964. Storage of Radioactive Wastes in Basement Rock Beneath the Savannah River Plant. DP-844(TID-4500, 28th Ed.):C14-C17.

The ground beneath a three-square-mile area of the Savannah River Plant was explored to determine the attitude, continuity, types, and character of the basement rock; the hydrology of the basement rock; and the hydrology and character of the overburden. These studies show that radioactive waste solutions can be stored safely in the basement rock beneath the Savannah River Plant. A conceptual design has heen developed for construcling a $20,000,000-g a l i o n$, or larger, storage facility 1300 to 1700 feet beneath the ground. (auth) 
Dunaway, P. B. and M. G. White, (eds.). 1974. The Dynamics of Plutonium in Desert Environments. Nevada Applied Ecology Group Progress Report as of January 1974. NVO-142, Nevada Operations Office, Las Vegas, Nevada. (NVO-AEIC-74-1).

A progress review of the applied ecology group that includes reports under the headings of soils, statistics, vegetation, microorganisms, animals, resuspension, distribution and inventory, information support and modelling.

Environmental Plutonium Data Base Group. 1972. Environmental Aspects of Plutonium. A selected, Annotated Bibliography. ORNL-EIS-72-21.

This bibliography is the first publication of the Environmental Plutonium Data Base, which is being assembled for computer storage and retrieval. Work at the Oak Ridge National Laboratory was supported by the Nevada Applied Ecology Group of the USAEC Nevada Operations Office, Las Vegas, Nevada. Although the literature was selected and abstracted specifically to meet the needs of the Nevada Applied Ecology Group, other people involved in similar or related research should find this publication useful. The abstracts report observations and measurement methods about or applicable to plutonium in the environment. The subjects of central concern were the movement of plutonium through the environment, particularly that of the Nevada Test Site with emphasis on its availability to man. Related material, such as biological effects of plutonium, interaction of plutonium with various ecosystems, dispersion of fallout from nuclear explosions, was also included. (auth)

Environmental Plutonium Data Base Group. 1973. Environmental Aspects of Plutonium and other Elements, A Selected, Annotated Bibliography. ORNL-EIS-73-21 (Supp 1. 1).

This supplement to the bibliography (ORNL-EIS-72-21) published by the Environmental Plutonium Data Base Group contains an additional 884 references that have been prepared for computer storage and retricval. The literature was selected to meet the needs of the Nevada Operations Office, Las Vegas, Nevada, but should be of interest to others in related fields. The deposition and movement of plutonium, americium, and uranium and their pathway through terrestrial and aquatic ecosystems to man are emphasized. An effort is made to include numerical data in the abstracts and to refer to relevant tables (in the comment field). Indexes are given for authors, permuted titles, subject categorles, key words, publication description, geographic location, and taxonomy. (auth) 
Fowler, E. B., R. W. Henderson, and M. F. Milligan (Co-chairmen). 1971. Proceedings of Enviornmental Plutonium Symposium, held at LASL, August 4-5. LA-4756 (UC-41).

The purpose of this symposium was to discuss the distribution and measurement of plutonium in the environment. To this end, the subject matter has been divided into three broad categories, the first dealing with distribution or how plutonium has entered the environment, the second dealing with methodology or the means by which one obtains environmental samples and analyzes them, and the third with the results obtained from such measurements and the interpretation which can be inferred from them. (auth)

Francis, C. W., S. S. Talmage and B. B. McMullin. 1975. Radionuclide Movement in Soils and Uptake by Plants. A Selected, Annotated Bibliography. ORNL-EIS-75-77.

This selected annotated bibliography was originally assembled as an information retrieval data base for the purpose of writing a comprehensive literature review by $c$. W. Francis on the movement of radionuclides in soil and uptake by plants. The data base was started when it became apparent that only through such a retrieval system could the voluminous amount of literature be critically surveyed. The data base is a result of literature searches from 1948 to 1975. It contains information on how various chemical, physical, and biological factors influence the movement of radionuclides in soils and uptake in plants. As a result of public concern about radioactive fallout prior to the moratorium on nuclear testing in the atmosphere, much of the data is related to the major fission products in radioactive fallout, strnntium-90 and cesium-137. A concentrated effort was made to select the literature that dcalt with processes affecting the movement and biological availability of radionuclides. Consequently literature in which the major purpose was to report concentrations of radionuclides in soils and plants such as monitoring type reports, was not included. The data base includes references to nearly all fission products, a large number of biologically important activation products and various naturally occurring radioactive nuclides such as uranium and thorium. The Russian literature has been carefully surveyed, and the dat.a hase probably rcpresents the llust complete bibliography on research efforts in Russia related to radionuclide transport in soil-plant systems. (auth)

International Atomic Energy Agency, Vienna. 1974. Activities of the International Laboratory of Marine Radioactivity, 1974 Report. IAEA-163, pp 90-103.

The analytical determination of radionuclides in sea water depends upon their physicochemical forms. Studies are continuing which deal with 
the identification of these different forms. In addition, the techniques developed for studying trace metal behavior at fresh water/saline water interfaces relating to sorption/desorption reactions on sediments have been extended to the study of plutonium and americium. The plutogium experiments were performed using a specially prepared isotope, $23 \mathrm{Pu}_{\mathrm{u}}$, which decays by electron capture thereby greatly facilitating the radiochemical measurements. The results of these studies and recent data from the intercalibration program are presented.

Iyer, R. H. and M. V. Ramaniah, (eds.). 1972. Radiochemistry Division Annual Progress Report for 1971. Bhabha Atomic Research Centre, Bombay, India. BARC-628.

The major highlights of the activities of the Radiochemistry Division during the year 1971 were research and development work on the actinides and other radioelements and services like chemical, mass spectrometric, $X$-ray and optical spectrographic analys is of plutonium and other radioactive materials and supply of special radioactive sources to various institutions inside and outside Bhabha Atomic Research Centre. As in previous years, research on the actinide elements centered around solution and radiation chemistry of plutonium, study of various complexes using $X$-ray, electro paramagnetic resonance, thermogravimetric, Mossbauer and optical spectrographic techniques and investigations of neutron induced fission. The development work on actinides included process chemistry of neptunium, preliminary studies on transplutonium elements, setting up and operation of gamma-ray and neutron monitoring assemblies for the in-line analysis of fission products and plutonium respectively in fuel reprocessing streams and the accurate analysis of plutonium in plutonium oxide samples and sintered $\mathrm{PuO}_{2}$ pellets. (auth)

Kaufman, W. J., (ed.). 1961. Ground Disposal of Radioactive Wastes Conference Proceedings Berkeley, California, August 25-27, 1959. TID-7621 Published by Sanitary Engineering Research Laboratory, University of Califorria at Berkeley.

These proceedings were compiled from papers submitted by those attending an unclassified conference on ground disposal of radioactive waste, and from tape recordings of discussions at the conference. The conference was sponsored by the Division of Reactor Development, U. S. Atomic Energy Commission, and was held at the University of California, Berkeley, California.

The purpose of the meeting was to review the progress made in research and development studies related to ground disposal of low and intermediate activity wastes over the past few years, both in the United States and abroad. 
Major subjects of discussion included: (1) operating practices, experiences, and problems at Hanford, Oak Ridge, National Reactor Testing Station, the Savannah River Plant, Chalk River, Ontario, Canada, Saclay, France, and Mol, Belgium; (2) research on ion exchange and adsorption in natural media; and (3) current investigations of hydrodynamic problems in flow through porous media.

Martin, F. M., C. T. Sanders and S. S. Talmage, (eds.). 1974. Environmental Aspects of the Transuranics. A Selected, Annotated Bibliography. ORNL-EIS-74-21 (Supplement 3).

This fourth published bibliography of 528 references is from the computer information file built to provide support to the Nevada Applied Ecology Group of the Atomic Energy Commission Nevada Operations Office. The general scope is environmental aspects of uranium and the transuranic elements, with a prepondcrance of material on plutonium. In addition, there are supporting materials involving basic ecology or general reviews on other nuclides that are entered at the request of the Nevada Applied Ecology Group. References provide findings-oriented ab3tracts. Numerical data is referred to in the comment field. Indexes are given for author, subject category, key words, geographic location, permuted title, taxons, and publication description. (auth)

Panel on Radioactivity in the Marine Environment. 1971. Radioactivity in the Marine Environment, Committee on Oceanography, National Acaderny of Sciences, National Research Council.

This is a summary of what has been learned about radionuclides in the marine environment since publication of NAS-NRC Publication No. 551, The Effects of Atomic Radiation on Oceanography and Fisheries, in 1957.

Routson, R. C. 1973. Review of Studies on Soil-Waste Relationships on the Hanford Reservation from 1944-1967. BNWL-1464.

Hanford chemical processing plants have heen in operation for more than twenty years, and during this period have disposed large volumes of waste liquids to the Hanford sediments. Because the groundwater and sediments at this major nuclear facility have been closely monitorer and investigatod a unique uppurtunity exisls tu assess the effects of these disposal operations at Hanford on the soil environment. The literature regarding effects of the liquid waste disposal operations at Hanford on the soil environment is summarized. This summary is divided into studies pertaining to: the vadose zone below a depth of twenty feet (lower vadosc zone); the saturated zone; and the vadose zone above twenty feet (upper vadose zone). . The division is based upon the relative desirability of these three zones for nuclear waste disposal (storage). Liquid nuclear wastes 
have been safely discharged to the lower vadose zone for over twenty years. Migration of these wastes from the lower vadose zone by the mechanisms of diffusion, leaching, and particulate transport is discussed. It is concluded that little movement of sorbed radionuclides by the above mechanisms within ten half-lives of even the long-lived radionuclides occurs; the sorbed radionuclides can only be removed from this zone by a cataclysmic occurrence in which the sediment in the zone and the entrained wastes are both physically removed. Field studies show that essentially all of the long-lived radionuclides disposed to the ground have been sorbed and remain in the upper levels of the lower vadose zone. Radionuclides which normally need to be considered in waste disposal include strontium-90, cesium-137, plutonium, cobalt-60, ruthenium-106 transition metals, rare earths, and hydrogen-3. In many wastes strontium-90 is the radionuclide which limits ground disposal to Hanford sediments due to its long radioactive and biological half-lives and resulting low maximum permissible concentrations. In sediments containing small amounts of mica, cesium-137 could become the limiting nuclide; however, cesium-137 has a much shorter biological half-life than strontium-90, and therefore, a higher maximum permissible concentration. Much of the sediment of the Hanford project has a moderate mica content and exhibits high cesium-137 sorption. Due to the likelihood of strontium-90 and cesium-137 limiting the disposal of most wastes, a more detailed review of the sorption of these nuclides is included. (NSA)

Schmalz, B. L. 1972. Radionuclide Distribution in Soil Mantle of the Lithosphere as a Consequence of Waste Disposal at the National Reactor Testing Station. ID0-10049, pp 27-55.

This report is a study of the distribution of radionuclides in the soil resulting from disposal of liquid and solid waste at the National Reactor Testing Station (NRTS). The situation involving liquid waste is appraised by: (a) mathematical models using parameter determined in the laboratory; (b) physical models using soil samples and simulated waste solution; and (c) sampling of soil and water where waste is being discharged.

In case of strontium-90, the data obtained indicate that the sorption capacity of the alluvial deposits between the disposal pond bottoms and the basalt bedrock has been reached. The data for cesium were erratic but the most pessimistic interpretation indicates that the capacity of the alluvium has not been reached. The amount of cobalt-60 estimated . to be in the alluvium is greater than that reported to have been discharged. The discharge estimates do nut take into account the more frequent usage of unsheathed cobalt wires for neutron flux measurements during the early history of the reactors. Cobalt- 60 retention in the soil is attributed to reactions other than ion exchange.

A theoretical appraisal of the migration of radionuclides at the burial ground indicates that the potential hazard is small under well-drained circumstances. Leaching of waste and the migration of some fission 
products as well as plutonium isotopes and daughter products is shown to have occurred to a very limited extent. This is inferred to have resulted from inundation of waste as a result of poor drainage of snowmelt runoff. The concentrations and distances are small and are not interpreted as a cause for concern in regard to insulting the regional aquifer system.

A hypothetical evaluation is included of the environmental problems remaining after active operation of a disposal site has been discontinued. It is concluded that disposal sites can be used for other purposes with certain restrictions. (auth)

Smith, A. E., Compiler. 1973. Nuclear Reactivity Evaluations of 216-Z-9 Enclosed Trench. ARH-2915.

Plulunium accumulation and the nuclear crlticality implications were evaluated for a subsurface liquid waste disposal site at Hanford, Washington. Remote plutonium detection by infrared, gamma, and neutron surveys are described. Geological drilling and soil sampling techniques were developed and described. Nuclear criticality safety was evaluated by computer model calculations and by neutron pulsing lechniques. This study discusses technologies used to evaluate a waste disposal site for a plutonium recovery operation. (auth)

Stuber, C. E. 1975. Transplutonium Elements - A Bitliography. TID-3317-56.

This bibliography, prepared especially for distribution at the International Atomic Energy Agency/Energy Research and Development Administration International Symijustum on the Iransuranium Nuclides in the Environment, San Tranciscu, November $1 \%-21,1975$, comprises 589 references on the transplutonium elements compiled through the period January 1 to October 15, 1975. The references were retrieved from the Nuclear Science Abstracts data base using a computerized information retrieval system and were formatted for publication with indexes by computer. In each group, references were arranged in order by the original Nuclear Science Abstract number, which p?aces them in approximatc chronological order. Sequence numbers appear beside each reference, and the indexes refer to these sequence numbers.

Part I includes 565 references dealing with the production and chemical, nuclear, physical, and biological properties and health, safety, and environmental aspects of elements with $Z>95$. References treating more than one element are grouped with the element having the lowest atomic number; therefore the subject index must be consulted for a complete sel of references on an element. The Actinides group includes references dealing with the actinide elements in general or treating the actinides collectively. References dealing with $Z \geq 104$ elements are included in the Transactinide group. 
Part II includes 24 references dealing with the natural occurrence of the transplutonium elements. This collection of references is concerned with attempts to locate or prove the existence of the transplutonium elements in nature.

Part III, a feature added to enhance the usefulness of this bibliography to the participants at this symposium, contains 772 references on the environmental aspects of neptunium and plutonium retrieved from Nuclear Science Abstracts through the period June 1, 1973 through October 15, 1975. Author, report number, and subject indexes are included. (auth)

Taylor, C. I., (ed.). 1975. Environmental Sciences Division, Annual Progress Report for Period Ending September 30, 1974. ORNL-5016:1-8.

Initial adsorption measured after three weeks of addition of $163 \mu \mathrm{g} \mathrm{Pu} / 1$ solid, showed that Ca-saturated humic acid was a very effective sorber and did not release plutonium readily upon equilibration with citrate. Ca-montmorillonite and Ca-kaolinite did not sorb $2-3 \%$ of the $163 \mathrm{\mu g} / \mathrm{g}$ $\mathrm{Pu}$ added. When $\mathrm{Pu}$ was added at the rate of $0.6 \mu \mathrm{g} / \mathrm{g}$ solid, the removal of natural organic matter and/or iron oxide coatings from clay reduced the efficiency of $\mathrm{Pu}$ sorption by clay by only $1-5 \%$.

The higher $\mathrm{Pu}$ solubility for soils in which the $\mathrm{Pu}$ was associated with clay fraction compared to soils in which Pu was mainly associated with coarser silt sand fractions indicate that the solubility differences may be due to particle size of plutonium particles.

Thompson, M. A., (ed.). 1972. Research and Ecology Semi-Annual Progress Report, January-June, 1972. F. J. Miner and H. W. Miller. Plutonium Behavior in the Soil/Water Environment. RFP-1921-A, pp 1-3.

A program has been undertaken to obtain information about the behavior of plutonium in a soil/water environment. The work to date has been concerned with the investigation of the parameters effecting the movement of plutonium in the soil. (auth)

Vaughan, B. E. and Environmental and Life Sciences Division Staff, Ecosystems Department. 1974. Pacific Northwest Laboratory Annual Report for 1973 to the U. S. Atomic Energy Commission, Division of Biomedical and Environmental Research, Part 2, Ecological Sciences. BNWL-1850, Pt. 2, pp 19-24.

Previous studies have indicated that plutonium is largely insoluble in soil over the short-term and is not accumulated by plants. However, it is possible that naturally occurring ligands in soil arising from organic matter decomposition processes may form complexes with plutonium increasing plutonium solubility in soil and uptake by plants. Furthermore, 
the possibility exists that the chemical form of plutonium may be directly altered by the soil microflora as has been demonstrated for other metals.

The present studies were undertaken to determine (1) the effects of plutonium on the soil microbial population and on soil microbial processes, (2) the potential for formation of plutonium complexes in soil and the role of the soil microflora in this process, (3) the extent of plant uptake and translocation of plutonium or its complexes, and (4) the bond types and chemical forms of plutonium or its metabolites in microbial and plant tissues and soils. The progress of these investigations is summarized. (auth)

Vaughan, B. E. and Environmental and Life Sciences Division Staff, Ecosystems Department. 1974. Pacific Northwest Laboratory Annual Report for 1974 to the U. S. Atomic Energy Commission Division of Biomedical and Environmental Research, Part 2, Ecological Sciences. BNWL-1950 Pt 2, pp 21-62.

Previous studies have indicated that plutonium is largely insoluble in soil over the short-term and is not accumulated by plants. However, it is possible that naturally-occurring ligands in soil arising from organic matter decomposition processes may form complexes with plutonium increasing plutonium solubility in soil and uptake by plants. Furthermore, the possibility exists that the chemical form of plutonium may be directly altered by the soil microflora as has been demonstrated for other metals.

The present program was undertaken to determine (1) the effects of plutonium on the soil microbial population and on soil microbial processes, (2) the potential for formation of plutonium complexes in soil and the role of the soil microflora in these processes, (3) the extent of plant uptake and translocation of plutonium or its complexes, and (4) lhe bond lypes and chemical forms of plutonium or its metabolites in microbial and plant tissues and soils. Previous studies in this program involved measurement of (1) the influence of plutonium on the soil microflora and soil microfloral processes and demonstration of the role of the soil microbiota in influencing plutonium solubility in soil, (2) the subseyuent availability of solubilized plutonium to plants and (3) the distribution of plutonium in plant shoots and roots. The progress of subsequent investigations to develop an understanding of the mechanisms of the microbial effects and to further elucidate the fate of different plutonium isotopes and chemical forms in soils and mature plants is summartzed. (auth)

White, M. G. and P. B. Dunaway, (eds.). 1975. The Radioecology of Plutonium and Other Transuranics in Desert Environments. Nevada Applied Ecology Group Progress Report as of January 1975. NV0-153, Nevada Operations Office, Las Vegas, Nevada. 
A progress review of the applied ecology group that includes reports of results since 1974 (NVO-142) under the headings of soils, vegetation, large vertebrates, small vertebrates, microorganisms, resuspension, distribution and inventory, decontamination procedures, statistics and support activities. Nevada Applied Ecology Group is currently preparing a handbook of methods. 


\section{THIS PAGE}

\section{WAS INTENTIONALLY LEFT BLANK}




\section{SUBJECT INDEX}

Actinium

Chemistry and Geochemistry of Actinides, 5, 6, 8, 34, 60,81, 85, 86, 93 . Migration and Accumulation of Actinides in Sediments, 101.

Natural Actinide Distributions in Sediments, 436, 490, 491.

Americium

Chemistry and Geochemistry of Actinides, 6, 8, 22, 23, 48, 51, 54, 60, $61,68,85,86,98$.

Cultural Actinide Distributions in Sediments, 230, 231, 241, 242, 247 , $248,250,251,254-258,261,263,269-271,279,284,286,288-290$, $298,299,301,306,309,311,312,315,322,323,326-328,336$, $340,343,344 ; 347,348$.

Migration and Accumulation of Actinides in Sediments, 127-130, 144, 145, $150,151,155-160,162,167,168,170,173,178,194,196,197$, $201,202,204,208,220,221$.

Selected Bibliographies and Annual Reports, 511, 516, 517.

Berkelium

Chemistry and Geochemistry of Actinides, 6, 8, 60, 61, 85, 86 .

Migration and Accumulation of Actinides in Sediments, 130 .

Selected Bibliographies and Annual Reports, 516, 517.

Californium

Chemistry and Geochemistry of Actinides, 6, 8, 60, 61, 85, 86 .

Migration and Accumulation of Actinides in Sediments, 130 .

Selected Bibliographies and Annual Report, 516, 517.

Curium

Chemistry and Geochemistry of Actinides, 5, 6, 8, 48, 60, 61, 85, 86 .

Cultural Actinide Distributions in Sediments, $311,312,337$.

Migration and Accumulation of Actinides in Sediments, 130, 201, 202, 216, 288-290.

Natural Actinide Distributions in Sediments, 356, 391, 441,442.

Selected Bibliographies and Annual Reports, 516, 517.

Einsteinium

Chemistry and Geochemistry of Actinides, 6, 8, 60, 61 .

Migration and Accumulation of Actinides in Sediments, 130.

Selected Bibliographies and Annual Reports, 516, 517. 
SUBJECT INDEX (CONT'D.)

Fermi um

Chemistry and Geochemistry of Actinides, 6, 8 .

Migration and Accumulation of Actinides in Sediments, 130 .

Selected Bibliographies and Annual Reports, 516, 517.

Lawrenci um

Chemistry and Gcochemistry of Aclinides, 6, 8, 61 .

Migration and Accumulation of Artinires in Sediments, 130.

Mendelevium

Chemistiy dul Geochemistry of Actinides, 6,8 .

Migration and Accumulation of Actinides in Sediments, 130 .

Selected Bibliographies and Annual Reports, 516, 517.

Neptuni um

Chemistry and Geochemistry of Actinides, 5, 6, 8, 16-18,44, 55, 60, $61,68,72,76,85,86,89-91,98$.

Cultural Actinide Distributions in. Sediments, 259, 260, 290, 306, 311 , $312,323,332$.

Migratinn and Accumulation of Actinides in Sediments, 111, 202, 208.

Natural Actinide Distributions in Sediments, 391.

Selected Bibliographies and Annual Reports, 51.3, 516, 517.

Nöbe 1 i um

Chemistry and Geochemistry of Actinides, 6, 8, 60, 61 .

Migration and Accumulation of Actinides in Sediments, 130 .

Selected Bibliographies and Annual Reports, 516, 517.

Plutonium

Chemistry and Geochemistry of Actinides, 5, 6, 8, 19-21, 24-26, 30-33, $38,39,41,42,46-48,50,51,53-55,60,61,65,67,68,72,73$, $76-79,82,84-92,94-96,98$.

Culturd 1 Actlnide Uistributions in Sediments, 227-234, 236-244, 246-351.

Migration and Accumulation of Actinides in Sediments, 111-127, 137-134,

$139-146,149-151,153-164,167-175,177,178,183,184,188-209$, $211-222$.

Natural Actinide Distributions in Sediments, 391.

Selected Bibliographies and Annual Reports, 509-519.

Protactinium

Chemistry and Geochemistry of Actinides, 5, 6, 8, 33, 44, 45,60,61, $77,83,85,86$. 
SUBJECT INDEX (CONT'D.)

Migration and Accumulation of Actinides in Sediments, 103, 104, 137, 152. Natural Actinide Distributions in Sediments, 359, 369, 413, 460, 461, $470,471,476-481,486,487,490 ; 491$.

Thorium

Chemistry and Geochemistry of Actinides, 5-8, 10, 11, 29-31, 33, 40, 41, $50,54,56,57,60-62,65-67,80-82,85,86,99$.

Cultural Actinide Distributions in Sediments, 239, 240, 252, 282, 315, 316.

Migration and Accumulation of Actinides in Sediments, 101-103, 131, 134, $135,137,141-143,152,153,165,170,171,173,174,177,179$, $183-187,190,195,197,198,200,201,205,207,209,210,212$, $213,217,218,223,224$.

Natural Actinide Distributions in Sediments, 353, 355-366, 369, 372-377, $380-382,384-389,392,396,397,399,400403,404,409,410,412$, $413,416,420,426-428,432-434,437-441,444-446,448-450,452-$ $458,460-463,466-481, .483-496,499,500, .502,504$.

Selected Bibliographies and Annual Reports, 512.

Uranium

Chemistry and Geochemistry of Actinides, 5-8, 12-15, 29-44, 47, 49, 50, 52-77, 79-86, 89-99.

Cultural Actinide Distributions in Sediments, 228, 241, 242, 252, 258, $259,264,267,271-273,280-281,290,297,308,315,316,320$, $324,325,329-332$.

Migration and Accumulation of Actinides in Sediments, 104-111, 131 , $132,134-140,142-144,146-148,151-153,158-161,163-169,174-$

$194,198-201,204,205,207,209,210,212-214,217-219,222-224$.

Natural Actinide Distributions in Sediments, 353, 355-387, 389-391, 393$410,412-454,456-459,461-505$.

Selected Bibliographies and Annual Reports, 511, 51?, 514. 


\section{THIS PAGE \\ WAS INTENTIONALLY \\ LEFT BLANK}


OFFSITE

1

ERDA Chicago Patent Group Chicago Operations Office 9800 South Cass Avenue

Argonne, Illinois 60439

A. A. Churm

1

ERDA Division of Waste Management and Transportation

ERDA Technical Information Center

UC-11 Environmental Control Technology and Earth Sciences

UC-70 Nuclear Waste Management

ONSITE

ERDA, Richland Operations office

B. J. Melton/P. F. X. Dunigan, Jr.
M. C. Alford
H. Babad
G. E. Backman
D. E. Braden
L. I. Brecke
D. J. Brown
I. E. Bruns
J. S. Buckingham
R. D. Carter
D. T. Crawley
D. A. Dodd
F. R. Dornheim
D. T. Dukelow
J. D. Fecht
K. R. Fecht
R. E. Felt
R. D. Fox
D. R. Gustavson
G. I. Hanson
K. M. Harmon
W. M. Harty, Jr.

H. H. Hopkins, Jr.

R. E. Isaacson

M. J. Kupfer

M. Legatski

C. A. Lorenzen

C. W. Malody

H. L. Maxfield

T. R. McKenzie

B. J. McMurray

S. M. Price

W. H. Price

N. C. Rodewald

L. W. Roddy

V. L. Schuclein

H. P. Shaw

R. M. Smithers

J. A. Teal

R. H. Wilson

W. I. Winters

D. D. Wodrich

W. H. Zimmer

ARHCO Document Services 
L. L. Ames (10)

J. W. Bartlett

H. C. Burkholder

D. B. Cearlock

J. P. Corley

G. W. Dawson

J. R. Eliason

D. E. Olesen

A. M. Platt

D. Rai (15)

J. R. Wildung
J. K. Soldat

C. M. Unruh

R. C. Routson

R. J. Serne (10)

J. I. Swanson

R. W. Wallace

R. E. Wildung

Technical Information Files (3)

Technical Publications (1) 